\title{
Prediction of Corrosion of Advanced Materials and Fabricated Components
}

DOE Award Number: DE-FC36-04GO14043

Project Period: 11/2003 - 06/2007

Principal Investigators:

Andre Anderko

973-539-4996 ext. 25; aanderko@,olisystems.com

Marta A. Jakab

210-522-5240; Marta.Jakab@swri.edu

Recipient Organizations:

OLI Systems, Inc.

108 American Road, Morris Plains, NJ 07950

Southwest Research Institute

6220 Culebra Road, San Antonio, TX 78228

Team Member Organizations:

Haynes International

Bechtel Bettis Inc.

ChevronTexaco Exploration and Production Company

DuPont Engineering Technology

Shell Global Solutions

Mitsubishi Chemical

Toyo Engineering Corporation

September 29, 2007 


\section{Acknowledgement}

This report is based upon work supported by the U.S. Department of Energy under Award no. DE-FC36-04GO14043.

\section{Disclaimer}

All findings, opinions, and conclusions or recommendations expressed in this report are those of the authors and do not necessarily reflect the views of the Department of Energy. 


\section{Contents}

Executive summary $\quad 5$

$\begin{array}{ll}\text { Project objective } & 6\end{array}$

$\begin{array}{ll}\text { Background } & 6\end{array}$

Selection of alloys, treatment methods, and representative process environments 7 $\begin{array}{ll}\text { Introduction } & 7\end{array}$

$\begin{array}{lr}\text { Alloy selection } & 9\end{array}$

$\begin{array}{ll}\text { Thermal instabilities of Fe-Ni-Cr alloys } & 9\end{array}$

Thermal instabilities of duplex stainless steels 11

Effect of composition, microstructure and the environment on the corrosion $\begin{array}{ll}\text { behavior of } \mathrm{Cu}-\mathrm{Ni} \text { alloys } & 13\end{array}$

$\begin{array}{lr}\text { Experimental procedures } & 16\end{array}$

$\begin{array}{ll}\text { Materials and sample preparation } & 16\end{array}$

$\begin{array}{lr}\text { Microchemistry measurements } & 19\end{array}$

$\begin{array}{ll}\text { Electrochemical tests } & 19\end{array}$

Experimental database development - results 26

$\begin{array}{ll}\text { Development of microchemistry data } & 26\end{array}$

$\begin{array}{ll}\text { Measurement of electrochemical parameters } & 31\end{array}$

$\mathrm{E}_{\text {corr }}$ and $\mathrm{E}_{\mathrm{rp}}$ of base alloys 31

Corrosion potential measurements 31

Crevice repassivation potential measurements 38

Effect of inhibitors on $\mathrm{E}_{\mathrm{rp}}$ of base alloys $\quad 50$

$\mathrm{E}_{\mathrm{rp}}$ of heat-treated alloys to simulate weldments $\quad 57$

$\mathrm{E}_{\mathrm{rp}}$ of weldments 69

Development of experimental data on damage growth and distribution $\quad 72$

Development of a model for predicting the occurrence of localized corrosion $\quad 78$

$\begin{array}{ll}\text { Development of a general corrosion model } & 79\end{array}$

Development of a model for the repassivation potential 87

Application of the model to individual alloys in chloride oxyanion environments 91

Generalization of the model as a function of alloy composition $\quad 110$

Predicting the repassivation potential of heat-treated materials $\quad 116$

Predicting depletion profiles at grain boundaries $\quad 117$

Relating the repassivation potential to depletion profiles 123

Repassivation potential of weldments 128

$\begin{array}{ll}\text { Prediction of corrosion damage } & 131\end{array}$

$\begin{array}{ll}\text { Rate of pit nucleation } & 133\end{array}$

$\begin{array}{lr}\text { Rate of pit propagation } & 133\end{array}$

$\begin{array}{ll}\text { Rate of pit repassivation } & 139\end{array}$ 
$\begin{array}{ll}\text { Transition of a pit into crack } & 139\end{array}$

$\begin{array}{lr}\text { Rate of crack propagation } & 140\end{array}$

$\begin{array}{ll}\text { Rate of corrosion fatigue propagation } & 147\end{array}$

$\begin{array}{ll}\text { Statistical properties of the damage function } & 153\end{array}$

Example of application of DFA. Transition of pits into cracks 157

Example of application of DFA. Extrapolation of corrosion damage in space and time $\quad 160$

Application of DFA to the $r$ largest order statistics 167

$\begin{array}{ll}\text { Monte Carlo simulation of pit propagation } & 169\end{array}$

Analytical method for estimating chloride concentration inside the crevice 174 $\begin{array}{ll}\text { Example of application of DFA to pitting } & 178\end{array}$

$\begin{array}{ll}\text { Encapsulation of models in software } & 179\end{array}$

$\begin{array}{ll}\text { Summary } & 180\end{array}$

$\begin{array}{ll}\text { Awards } & 183\end{array}$

$\begin{array}{ll}\text { Publications and presentations } & 184\end{array}$

$\begin{array}{ll}\text { References } & 186\end{array}$ 


\section{Executive Summary}

The goal of this project is to provide materials engineers, chemical engineers and plant operators with a software tool that will enable them to predict localized corrosion of process equipment including fabricated components as well as base alloys. For design and revamp purposes, the software predicts the occurrence of localized corrosion as a function of environment chemistry and assists the user in selecting the optimum alloy for a given environment. For the operation of existing plants, the software enables the users to predict the remaining life of equipment and help in scheduling maintenance activities.

This project combined fundamental understanding of mechanisms of corrosion with focused experimental results to predict the corrosion of advanced, base or fabricated, alloys in real-world environments encountered in the chemical industry. At the heart of this approach is the development of models that predict the fundamental parameters that control the occurrence of localized corrosion as a function of environmental conditions and alloy composition. The fundamental parameters that dictate the occurrence of localized corrosion are the corrosion and repassivation potentials. The program team, OLI Systems and Southwest Research Institute, has developed theoretical models for these parameters. These theoretical models have been applied to predict the occurrence of localized corrosion of base materials and heat-treated components in a variety of environments containing aggressive and non-aggressive species.

As a result of this project, a comprehensive model has been established and extensively verified for predicting the occurrence of localized corrosion as a function of environment chemistry and temperature by calculating the corrosion and repassivation potentials. To support and calibrate the model, an experimental database has been developed to elucidate (1) the effects of various inhibiting species as well as aggressive species on localized corrosion of nickel-base alloys, stainless steels and copper-nickel alloys and (2) the effects of heat treatment on localized corrosion. Excellent agreement with experimental data has been obtained for alloys in various environments, including acids, bases, oxidizing species, inorganic inhibitors, etc. Further, a probabilistic model has been established for predicting the long-term damage due to localized corrosion on the basis of short-term inspection results. This methodology is applicable to pitting, crevice corrosion, stress corrosion cracking and corrosion fatigue. Finally, a comprehensive model has been developed for predicting sensitization of Fe-Ni-Cr-Mo-W-N alloys and its effect on localized corrosion.

As a vehicle for the commercialization of this technology, OLI Systems has developed the Corrosion Analyzer, a software tool that is already used by many companies in the chemical process industry. In process design, the Corrosion Analyzer provides the industry with (1) reliable prediction of the tendency of base alloys for localized corrosion as a function of environmental conditions and (2) understanding of how to select alloys for corrosive environments. In process operations, the software will help to predict the remaining useful life of equipment based on limited input data. Thus, users will also be able to identify process changes, corrosion inhibition strategies, and other control options before costly shutdowns, energy waste, and environmental releases occur. With the Corrosion Analyzer, various corrosion mitigation measures can be realistically tested in a virtual laboratory. 


\section{Project Objective}

The goal of this project is to provide materials engineers, chemical engineers and plant operators with a software tool that will enable them to predict localized corrosion of process equipment including fabricated components as well as base alloys. For design and revamp purposes, the software will predict the occurrence of localized corrosion and guide the user to select the optimum alloy for a given environment. For the operation of existing plants, the software will enable the users to predict the remaining life of equipment and help in scheduling maintenance activities.

The results of this project will reduce the barriers to the use of advanced materials in industry by allowing process designers and operators to evaluate these materials under realistic conditions of fabrication and in-service chemical environments. Users will also be able to identify process changes, corrosion inhibition strategies, and other control options before costly shutdowns, energy waste, and environmental releases occur. These capabilities translate into benefits of at least $\$ 0.7$ to $\$ 1.0$ billion annual cost savings, annual energy savings of 88 trillion Btu/year, and significantly reduced environmental impact.

\section{Background}

Over the last two decades, many advanced metallic materials have been developed for withstanding severe corrosion and erosion that are encountered in industrial processes. However, the application of these materials by industry has fallen far short of initial expectations because (i) their performance has been limited by fabrication processes, which are not considered in materials development and (ii) there has been a lack of tools to evaluate their performance in a given application prior to placing them in service. This project combines fundamental understanding of mechanisms of corrosion with focused experimental results to predict the corrosion of advanced, base or fabricated, alloys in "real-world" environments encountered in the chemical industry. The results of this project will reduce the barriers to the use of advanced materials in industry by allowing process designers and operators to evaluate these materials under realistic conditions of fabrication and in-service chemical environments. Users will also be able to identify process changes, corrosion inhibition strategies, and other control options before costly shutdowns, energy waste, and environmental releases occur. These innovative corrosion mitigation measures can be tested in a virtual laboratory without risking the plant. The "useful remaining life" can be predicted based on operating experience and projected operating conditions so that catastrophic failures can be avoided and well-planned corrosion control and maintenance actions can be proactively scheduled.

The program aims to develop a tool that will make it possible to predict the corrosion performance of base alloys and fabricated components in any environment utilizing a minimum data set. At the heart of this approach is the development of correlations between local compositions in the alloy with fundamental parameters that dictate the occurrence of localized corrosion. The fundamental parameters that dictate the occurrence of localized corrosion are the corrosion and repassivation potentials. The 
program team, OLI Systems and Southwest Research Institute, has developed theoretical models for these parameters. In this project, these theoretical models are extended to predict the occurrence of localized corrosion of base materials and heat-treated components in a variety of environments containing aggressive and non-aggressive species.

The project was divided into four main tasks, i.e., (1) Selection of alloys, treatment methods, and representative process environments; (2) Development of an experimental database of alloy microchemistry in relation to fabrication process parameters, electrochemical parameters that govern localized corrosion and damage growth and distribution; (3) Extension of OLI's methodology for predicting the occurrence and propagation of localized corrosion to handle base metals and fabricated components of critical importance in chemical process industry and (4) Encapsulation of the models in engineering software.

\section{Selection of alloys, treatment methods, and representative process environments}

\section{Introduction}

Southwest Research Institute ${ }^{\circledR}$ performed the electrochemical testing to provide experimental parameters to the model developed by OLI Systems. The fabrication processes considered in this work included welding and heat treatments. In addition, several base alloys were measured in different environments in order to extend the coverage of metal/environment combinations in the simulation software. The corrosion resistance of several advanced materials was measured in different solution chemistries. In many cases, known corrosion inhibitor species were added in the solution to establish an experimental framework for the modeling of potential inhibitor effects in process environments.

Welding is a very important and often applied fabrication technique and can significantly alter the corrosion behavior of the alloys. The following factors are believed to affect the corrosion resistance of welded components:

1. Segregation of alloying elements and precipitation of intermetallic phases, carbides or nitrides in the solidified weld.

2. Segregation of alloying elements and precipitation of phases in the unmixed zones bordering the weld and the base metal. Such unmixed zones are the weakest links in welds made by over-alloyed filler metals.

3. Precipitation of carbides, nitrides or intermetallic phases in the heat affected zone (HAZ) adjacent to the weld.

The localized corrosion resistance of metals is mainly controlled by the microchemical distributions of alloying elements, for example, $\mathrm{Cr}$ and $\mathrm{Mo}$. If a high $\mathrm{Cr} / \mathrm{Mo}$ zone forms due to the thermal exposure during the welding process, the area adjacent to this zone 
becomes depleted in these alloying elements. Since $\mathrm{Cr}$ and $\mathrm{Mo}$ are responsible for the corrosion resistance of the alloys, the depleted area is more susceptible to localized corrosion. Even if no $\mathrm{Cr} / \mathrm{Mo}$ depletion occurs, galvanic coupling between the enriched zone (more noble) and adjacent sites can cause significant localized corrosion. These features are controlled by alloy and weld filler selection as well as fabrication parameters.

The overall approach applied in this project that combined experiments and modeling is outlined in Figure 1.

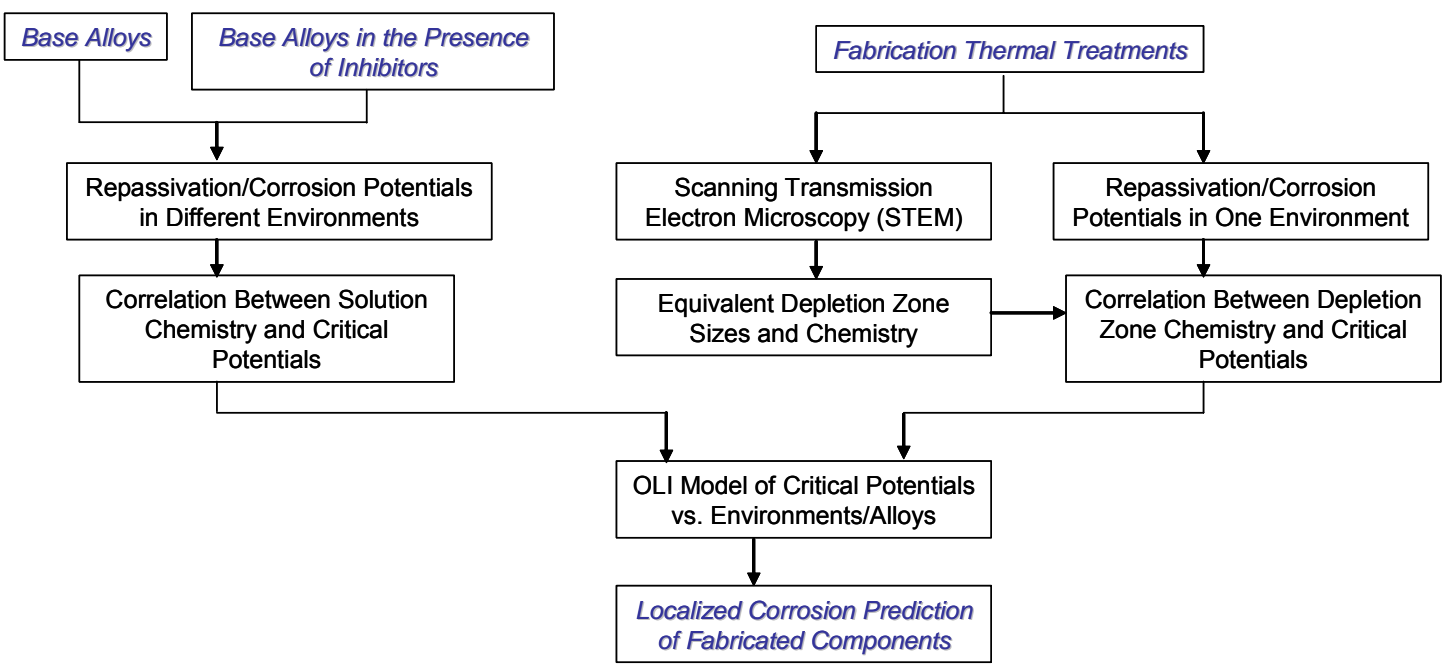

Figure 1. Overall approach for predicting corrosion of advanced materials and fabricated components.

In order to predict the in-service localized corrosion susceptibility of alloys subjected to fabrication processes, thermal aging-dependent localized corrosion parameters need to be generated in the laboratory. Crevice repassivation potential $\left(\mathrm{E}_{\text {rcrev }}\right)$ was selected as the corrosion parameter, based upon previous work showing its sensitivity to microstructure and applicability for predicting the lifetime expectancy of candidate high-level nuclear waste container materials. Previous work at the Southwest Research Institute has shown that the repassivation potential generated for a limited set of environments could be used to predict the values for a much wider set of environments containing aggressive, inhibitive, and diluent species (Anderko et al., 2004; Brossia et al., 2004). To study the effect of heat-treatment on localized corrosion, the following methodology was used:

1. Measure $\mathrm{E}_{\mathrm{rcrev}}$ in aqueous chloride environments solely as a function of metallurgical differences (microstructural evolution due to thermal aging), and correlate the results with degree of sensitization (DOS) derived from electrochemical potentiodynamic reactiovation (EPR) tests.

2. Derive parameters for modeling the effect of metallurgy and alloying content on $\mathrm{E}_{\text {rcrev. }}$.

3. Measure the effects of inhibitors on $\mathrm{E}_{\mathrm{rcrev}}$ independent of metallurgical variations (solution annealed condition only). 
4. Derive parameters to model the effect of inhibitors as a function of alloy composition.

5. Integrate these parameters in order to predict the effect of inhibitors and microstructure on $\mathrm{E}_{\text {rcrev}}$.

6. Test the resulting model by comparing measured $\mathrm{E}_{\mathrm{rcrev}}$ with predicted values for aged specimens in the presence of inhibitor ions.

The resulting model will provide the process industry a powerful tool to predict the structural integrity or "useful remaining life" of existing infrastructure, as well as aid in materials selection for construction of new industrial processes in any process stream, as the derived parameters may be extended to other inhibitors and alloys.

The methodology described above enables the prediction whether or not localized corrosion will occur. While this approach is very valuable in case of the design of new processes, the prediction of the lifetime of already existing process equipment requires a different approach. For this purpose, Damage Function Analysis (DFA) was used to simulate the nucleation and growth of localized corrosion events. In order to calculate the Damage Function, pit depth distribution was measured on materials exposed to corrosive solutions.

\section{Alloy Selection}

The alloys studied in this project were chosen to represent a broad range of systems typically used in the industry as fabricated components. The first phase focused on Fe-NiCr-Mo alloys. These alloys can be classified into four categories:

Category 1: Austenitic alloys that precipitate Cr carbides, e.g., 304L, 316L, 600, 690, 800 and 825

Category 2: Austenitic alloys that precipitate complex Cr, Mo, W carbides, e.g., C-4

Category 3: Austenitic alloys that precipitate carbides and/or intermetallic phases, e.g., C276, C-22, G-35, 625, 718 and 254SMO

Category 4: Duplex stainless steels that precipitate carbides, nitrides and intermetallics, e.g., 2205 and 2304

The testing focused on alloys from categories 1, 3 and 4, where significant gaps in the available literature data were identified. The chosen materials were: 316L, 600, 690, 825, C-276, C-22, 254SMO, 2205 and 2304.

Phase II focused on $\mathrm{Cu}-\mathrm{Ni}$ alloys, which are widely used in marine applications as well as in the process industry. Alloys investigated in this phase were: Monel 400 (Cu-Ni 35-65), CDA 706 (Cu-Ni 90-10) and CDA 715 (Cu-Ni 70-30).

\section{Thermal Instabilities of Fe-Ni-Cr Alloys}

Fe-Ni-Cr alloys, e.g., 600 and 690, undergo precipitation of chromium carbides at grain boundaries when subjected to elevated temperatures $\left(500-900^{\circ} \mathrm{C}\right)$. The precipitation is initially accompanied by a chromium depleted grain boundary layer (GBCD) due to the 
different diffusivities of carbon and chromium in the austenite matrix. The chromium depletion broadens spatially with time at temperatures in the precipitation regime until the carbon activity in the carbides is equal to that in the surrounding matrix. The time required to achieve this depends on the carbon content of the material, but typically occurs within a day at $700^{\circ} \mathrm{C}$. Continued thermal exposure results in the "healing" of the chromium depleted layer, which returns the chromium concentration of the chromium depleted layer to that of the bulk matrix. The chromium concentration in the depleted region has been found to drop to 3\% (Was et al., 1981), which is well below the threshold 9.8-11.7\% criterion for establishing passivity in these alloys (Airey et al., 1981). The loss of local passivity, termed sensitization, has been shown to adversely impact the corrosion and stress corrosion cracking resistance of these alloys. Since the chromium content of alloy 690 is much higher, sensitization recovery times and severity are expected to be reduced.

Grain boundary carbide precipitation occurs when a mill- or solution-annealed alloy is heated or cooled slowly through a temperature range of 500 to $900^{\circ} \mathrm{C}$. The carbon solubility limit in alloy 600 approximately scales with temperature as shown in Equation 1 (Scarberry et al., 1976)

$\%$ Carbon $=e^{\frac{T-1445}{128}}$

At $1150^{\circ} \mathrm{C}$, the solubility is approximately $0.1 \%$, while at $650^{\circ} \mathrm{C}$, it drops to approximately $0.002 \%$. Carbon is invariably present as an impurity in commercially produced alloys. The commercially produced alloy is typically thermomechanically processed and mill-annealed at $1000^{\circ} \mathrm{C}$. This treatment results in relatively precipitatefree grain-boundaries, but some matrix carbides remain. A high temperature solution annealing (at $1100^{\circ} \mathrm{C}$ ) is sometimes carried out in the laboratory to ensure complete dissolution of all carbides prior to controlled aging studies. The composition of carbides in alloy 600 is $\mathrm{Cr}_{7} \mathrm{C}_{3}$ (Scarberry et al., 1976), and $\mathrm{Cr}_{23} \mathrm{C}_{6}$ in 690 (Was, 1990). Sensitization occurs because the carbide is in equilibrium with the carbon and chromium in the grain boundary as shown in Equation 2 for $\mathrm{Cr}_{7} \mathrm{C}_{3}$.

$$
7 C r+3 C=C r_{7} C_{3} \quad K=\frac{a_{C_{7} C_{3}}}{\left(a_{C r}\right)^{7} \times\left(a_{C}\right)^{3}}
$$

The activity of the carbide can be assumed to be unity, thus the activity of the carbon at the grain boundary is inversely proportional to the activity of chromium. At initial stages of precipitation, the carbon activity is high and the chromium activity is low. Because carbon is a relatively small atom that is located in and diffuses through interstitial spaces, the carbon activity will attain rapid equilibrium with the carbide in the bulk of the grain. However, the chromium atom is less mobile and therefore its diffusion from the interior of the grain lags that of the carbon. This results in a chromium depleted layer near the precipitated carbide/grain boundary. Since the corrosion resistance of alloy 600 is largely due to its chromium content, the chromium depleted layer is susceptible to corrosion, and the location of GBCD in the microstructure gives rise to susceptibility to intergranular attack (IGA). 
The first direct evidence of grain boundary chromium depletion in alloy 600 was reported by Was et al. (1981) who found that the depth of depletion (i.e., the difference between the lowest chromium content in the depleted zone and the bulk/matrix chromium content) increased for aging times up to 10 hours at $700^{\circ} \mathrm{C}$. Continued aging at $700^{\circ} \mathrm{C}$ resulted in healing of the GBCD, although complete recovery was not evident before 100 hours of aging. Other studies on alloy 600 examined the kinetics for "full" sensitization (minimum $\mathrm{Cr}$ concentration in GBCD). It was found that heat to heat variations in the carbon content can dramatically alter the sensitization kinetics for alloy 600 (Was et al., 1981; Yukitoshi et al., 1979; Hall and Briant, 1985; Duffaut et al., 1966). The hours needed at $700^{\circ} \mathrm{C}$ to achieve the minimum $\mathrm{Cr}$ concentration in GBCD significantly decrease with increasing $\mathrm{C}$ content. For example, at $0.023 \% \mathrm{C}$ content, the time needed at $700^{\circ} \mathrm{C}$ to achieve the minimum $\mathrm{Cr}$ concentration is 17 hours (Yukitoshi et al., 1979), while at $0.093 \%$ C content, the time needed drops to 2 hours (Duffaut et al., 1966). Quantitative modeling of the sensitization process has been well understood for simple alloy systems such as alloy 600 (Was, 1990; McIlree and Michels, 1977; Was and Kruger, 1985; Kruger et al., 1988; Wilson and Aspden, 1976). A substantial body of work exists regarding the effects of grain-boundary precipitation on stress corrosion cracking (SCC) of alloy 600 (McIlree and Michels, 1977; Wilson and Aspden, 1976; Weeks, 1974; Theus, 1977; Brown, 1969; Airey, 1979; Airey and Pement, 1983; Bandy and Van Rooyen, 1984), since cracking of nuclear steam generator piping accounts for a significant portion of all material failures for these systems (Weeks, 1974).

For alloy 690, Kay et al. (1989)demonstrated the minimum $\mathrm{Cr}$ at the grain boundary was observed after 5 hours of aging at $700^{\circ} \mathrm{C}$, and recovered after approximately 100 hours. Casales et al. (2002) reported the minimum $\mathrm{Cr}$ concentration to occur after 48 hours a $\mathrm{t}$ $700^{\circ} \mathrm{C}$. However, the minimum $\mathrm{Cr}$ levels reported were 20.5 and 25, respectively, well above the minimum levels required for "stainless" behavior.

Work performed to understand the effect of sensitization on the occurrence of intergranular corrosion has focused on accelerated test techniques (Airey et al., 1981; Scarberry et al. 1976; Hall and Briant, 1985; Theus, 1977; Brown, 1969; Airey, 1979; Airey and Pement, 1983; Bandy and Van Rooyen, 1984) that directly exploit the effect of microchemical segregations of the alloy on corrosion in severely oxidizing, acidic environments or on the electrochemical polarization behavior. In the latter case, electrochemical potentiodynamic reactivation (EPR) test has been used to characterize the degree of passive film stability in an acidic environment that exhibits active-passive behavior. While these accelerated tests allow the identification of improvements in alloying and heat treatment, and serve as good quality control tools, the generated data do not necessarily makes it possible to predict the performance lifetime of these materials in real-world environments. Furthermore, these tests do not address localized corrosion susceptibility of the alloy. The oxidizing acid environments do not cause pitting or crevice corrosion. The EPR test is typically performed in dilute sulfuric acid and accesses the potentials in the active-passive regime. Nevertheless, the EPR test results could be used as a simple measure of the Degree of Sensitization (DOS) to correlate localized corrosion susceptibility determined in environments that cause localized corrosion. Unlike the case of general corrosion, where the alloy is passive without the chromium depletion, under localized corrosion conditions, the passive film can be destabilized even 
without Cr-depletion. Therefore, the presence of Cr-depleted grain boundaries adds another layer of complexity to the local destabilization of the passive film in a localized corrosion environment.

\section{Thermal Instabilities of Duplex Stainless Steels}

Duplex stainless steels (DSS) contain approximately 50 volume\% austenite in a ferrite matrix. The combination of these two phases gives rise to optimum qualities of both superior pitting and hydrogen stress corrosion cracking (HSCC) resistance of austenite coupled with the resistance to chloride stress corrosion cracking seen with ferrite. Duplex stainless steels, however, are subject to thermally induced phase evolution when subjected to temperatures in the range of $500-900^{\circ} \mathrm{C}$. Precipitation of these phases results in loss of mechanical integrity (Nilsson and Liu, 1991; Kordatos et al., 2001; Chen et al., 2002; Kacar and Acarer, 2003; El Koussy et al., 2004; Calliari et al., 2006; Badji et al., 2007) as well as corrosion resistance (Devine, 1979; Devine, 1980; Devine 1988; Ravindranath and Malhotra, 1994; Hoffmeister and Lothongkum, 1994; Amadou et al., 2004; Park et al., 2005). Chi and sigma phases, nitrides and austenite have all been observed to precipitate in this temperature regime and partition chromium, molybdenum and nitrogen from the matrix. This alloy, like other Fe-Ni-Cr alloys, relies heavily on these elements for their corrosion resistance, thus partitioning of these elements into specific phases and away from others induces susceptibility to corrosion. The duplex microstructure is obtained by controlling the $\mathrm{Ni}, \mathrm{N}, \mathrm{Mo}$ and $\mathrm{Cr}$ content in the stainless steel. Ni and N stabilize the austenite phase, while $\mathrm{Cr}$ and Mo act as ferrite stabilizers. The ratio of the duplex phases is controlled through the post solidification cooling rate. Addition of alloying elements gives rise to desirable annealed properties, however, it also increases the number of possible phases. The precipitated phases found in the $\mathrm{Fe}-\mathrm{Ni}-\mathrm{Cr}-$ Mo-N duplex stainless steel system subjected to temperatures in the range of $500-1000^{\circ} \mathrm{C}$ are shown in Table 1 (Herbsleb and Schwaab, 1991; Calliari et al., 2006; Park et al., 2005; Kim and Kwon, 1999; Chen et al., 2002; Michalska and Sozanska, 2006; Sieurin and Sandstrom, 2007; Nilsson and Liu, 1991; Badji et al., 2007).

All phases present are enriched in $\mathrm{Cr}$ compared to the parent matrix phases, which contain 22-24 wt\% Cr. Therefore, the precipitation of the phases listed in Table 1 is always accompanied by a $\mathrm{Cr}$ depleted area in the surrounding matrix either in the form of depleted grain boundaries or a complementary phase that is uniformly $\mathrm{Cr}$-depleted.

A substantial body of work exists that deals with the corrosion behavior of duplex steels as a function of thermal exposure. Much of this work has been performed for simulated weld material (Nilsson and Liu, 1991; Kacar and Acarer, 2003; El Koussy et al., 2004; Badji et al., 2007; Hoffmeister and Lothongkum, 1994; Chen and Yang, 2002; Liou et al., 2002; Palmer et al., 2004; Sieurin and Sandstrom, 2006) or focuses on cooling rate dependent microstructures (Kordatos et al., 2001; Hoffmeister and Lothongkum, 1994; Elmer et al., 2007; Chen and Yang, 2001; Josefsson et al., 1991), making it difficult to translate the data to isothermal heat treatments. In addition, as this material is intended for use in environments where SCC is the primary design constraint, much of the literature deals with susceptibility to SCC, corrosion fatigue or intergranular attack 
(Devine, 1979; Devine, 1980; Devine, 1988; Amadou et al., 2004; Liou et al., 2002; Merino et al., 1993; Bernard et al., 2005; Lo and Tsai, 2007).

Table 1. Precipitate phases and their compositions in Fe-Ni-Cr-Mo-N duplex stainless steels. The compositions are given in wt\%.

\begin{tabular}{|c|c|c|c|c|c|}
\hline Phase & Temperature $\left({ }^{\circ} \mathrm{C}\right)$ & $\mathrm{Cr}$ & $\mathbf{N i}$ & Mo & Reference \\
\hline $\mathrm{Cr}_{2} \mathrm{~N}$ & 825 & & & & (Herbsleb and Schwaab 1991) \\
\hline $\mathrm{M}_{23} \mathrm{C}_{6}$ & 325 & & & & \\
\hline \multirow{8}{*}{ Sigma } & 900 & 28.8 & 3.3 & 7.5 & \\
\hline & 850 & 27 & 3.4 & 7.8 & (Calliari et al., 2006) \\
\hline & 850 & 30.3 & 4.1 & 8.12 & (Park et al., 2005) \\
\hline & 850 & 30.82 & 3.03 & 9.72 & (Kim and Kwon 1999) \\
\hline & 900 & 28.6 & 2.8 & 7.5 & (Chen et al., 2002) \\
\hline & 700 & 30.89 & 2.87 & 6.24 & $\begin{array}{c}\text { (Michalska and Sozanska } \\
\text { 2006) }\end{array}$ \\
\hline & 850 & 32.71 & 1.72 & 9.31 & (Sieurin and Sandstrom 2007) \\
\hline & 850 & 28.97 & 4.76 & 8.36 & (Badji et al. 2007) \\
\hline \multirow{4}{*}{ Chi } & 825 & 24.4 & 3.6 & 12.2 & (Herbsleb and Schwaab 1991) \\
\hline & 850 & 24.5 & 3.3 & 11.6 & (Calliari et al. 2006) \\
\hline & 900 & 25.7 & 2.6 & 14.6 & (Chen et al. 2002) \\
\hline & 700 & 28.18 & 2.74 & 10.48 & $\begin{array}{l}\text { (Michalska and Sozanska } \\
\text { 2006) }\end{array}$ \\
\hline $\mathrm{R}$ & $550-650$ & & & & (Nilsson and Liu 1991) \\
\hline
\end{tabular}

\section{Effect of Composition, Microstructure and the Environment on the Corrosion Behavior of Cu-Ni Alloys}

The general electrochemical characteristics of the copper-nickel alloys are given by the potential-pH diagram. Several authors measured the $\mathrm{pH}$ dependence of the corrosion rates and critical potentials (e.g., corrosion potential $\left(\mathrm{E}_{\text {corr }}\right)$ and pitting potential $\left(\mathrm{E}_{\mathrm{pit}}\right)$ in seawater (Verink and Pourbaix, 1971; Efird, 1975). Both the 90-10 and 70-30 Cu-Ni alloys were found to be passive under alkaline conditions. The passive-active transition occurred at a slightly lower $\mathrm{pH}$ in case of the 70-30 $\mathrm{Cu}-\mathrm{Ni}$ alloy $(\mathrm{pH} 7.8)$ than in case of the 90-10 alloy ( $\mathrm{pH} 8.5$ ) (Efird, 1975). Under acidic conditions, the $\mathrm{Cu}-\mathrm{Ni}$ alloys show active dissolution behavior (Ismail et al., 2006; Singh and Gupta, 2001). While their corrosion rate is low under fairly mild conditions, it is accelerated when they are exposed to acidic chloride solutions (Ismail et al., 2006) due to the formation of a highly soluble dichloro cuprous ion complex (Kato et al., 1980):

$$
\mathrm{Cu}+2 \mathrm{Cl}^{-}=\mathrm{CuCl}_{2}^{-}+e^{-}
$$


In general, the corrosion resistance of the $\mathrm{Cu}-\mathrm{Ni}$ alloys increases with increasing $\mathrm{Ni}$ content up to approx. $30 \%$, then it remains constant (North and Pryor, 1970) or slightly decreases (Ismail et al., 2006). It was suggested that the nickel additions have a beneficial effect to the passivation reaction. Nickel was found to be incorporated in the oxide layer. The formation of Ni-doped oxide consumes mobile cation vacancies, therefore decreases the ionic and electronic conductivity (Ismail et al., 2006; Kato et al., 1980; North and Pryor, 1970; Zaky and Assaf, 2002; Kato et al., 1980). The Ni enrichment of the oxide layer is higher when the Ni content of the alloy is higher (Zaky and Assaf, 2002). In case of the 70-30 Cu-Ni alloy, approximately $70 \%$ of the oxide film is nickel oxide (McGuire et al., 1978). The 90-10 Cu-Ni alloy forms a Ni-rich layer in the oxide at the interface of the inner $\mathrm{Cu}_{2} \mathrm{O}$ and outer $\mathrm{Cu}(\mathrm{OH})_{2}$ layers (Kato et al., 1980a; Kato et al., 1980b).

Addition of small amount of iron as an alloying element was found to significantly increase the immunity potential and decrease the corrosion rate, but it did not affect the passivation pH (Verink and Pourbaix, 1971; Efird, 1977; Bailey, 1951; LaQue and Mason, 1950).

Heat treatments and heat exposure that often occurs, for example, during welding has been shown to affect the corrosion resistance of copper-nickel alloys (Beccaria et al., 1994; Lee et al., 1991). Annealing treatments at high temperatures $\left(450-1000^{\circ} \mathrm{C}\right)$ that increase the grain size and cause the precipitation of intermetallic particles significantly increase both the general corrosion rate and susceptibility to pitting corrosion (Beccaria et al., 1994). Welded structures contain $\mathrm{Cu}$ - and Ni-enriched areas with microstructural variations that are prone to accelerated corrosion (Lee et al., 1991). Moreover, the compositional variations in the weld structure lead to significant potential differences and galvanic corrosion between the heat affected and unaffected zones (Lee et al., 1991). Copper-nickel alloys are known for their excellent corrosion resistance and good resistance to biofouling (Parvizi et al., 1988). The environment (e.g., oxygen content, solution composition, flowrate), however, significantly affects their corrosion rate.

The oxygen content of the solution was found to have a significant effect on the corrosion resistance of $\mathrm{Cu}-\mathrm{Ni}$ alloys (MacDonald et al., 1978). At low to moderate oxygen concentrations $\left(\left[\mathrm{O}_{2}\right] \leq 6.6 \mathrm{mg} / \mathrm{L}\right)$, the $70-30$ alloy is more corrosion resistant than the 90 10 alloy, as expected (MacDonald et al., 1978). In oxygen saturated seawater, however, the 70-30 alloy does not exhibit superior behavior due to the shift of its open circuit potential to a value more noble than the pitting potential (MacDonald et al., 1978). In seawater, two different pit morphologies of Monel 400 (M400) have been observed depending on the oxygen content of the solution (Ali, 1994; Ali and Ambrose, 1992). Some pits have shallow and trenched structure, while others penetrate deeply.

Sulfide ions have been shown to significantly increase the corrosion rate of $\mathrm{Cu}-\mathrm{Ni}$ alloys (Valilappan et al., 1990; Woods et al., 1990; Syrett, 1981; Beccaria et al., 1991). In sulfide containing environments, porous copper sulfide layer forms on the surface of the alloys, which does not protect against corrosion (Syrett 1981). This layer also prevents the formation of the protective copper oxide layer (Syrett 1981). During the enhanced corrosion in sulfide containing environments, preferential copper dissolution was observed (Woods et al., 1990; Beccaria et al., 1991). In flowing seawater, a critical velocity was found at which localized corrosion occurs (Syrett and Wing, 1980). 
Chloride ions cause the breakdown of the passive film on the $\mathrm{Cu}-\mathrm{Ni}$ alloys leading to localized corrosion (Milosev and Metikos-Hukovic, 1991; Metikos-Hukovic and Milosev, 1992). The structure, composition and thickness of the passive film influence the extent of localized corrosion (Milosev and Metikos-Hukovic, 1992). Several stages of the localized corrosion were identified (Milosev and Metikos-Hukovic, 1992). First, the chloride ions adsorb inside the pores of the outer oxide layer. This time period is known as the pit incubation period. During pit nucleation, the $\mathrm{Cl}^{-}$ions are incorporated into the outer oxide layer and penetrate to the inner oxide layer. This chloride ion incorporation is thought to modify the oxide lattice. The $\mathrm{Cl}^{-}$ions replace the $\mathrm{O}^{2-}$ ions in the lattice and enhance cation diffusion through the oxide layer (Milosev and Metikos-Hukovic, 1991). The charge imbalance caused by the ion substitution is neutralized by ejection of a $\mathrm{Cu}^{+}$ ion into the solution creating a cation vacancy (Milosev and Metikos-Hukovic, 1991):

$\mathrm{Cu}_{\text {metal }}^{+}+\mathrm{O}_{\text {oxide }}^{2-}+\mathrm{Cl}_{\text {electrolyte }}^{-}+2 \mathrm{H}_{\text {electrolyte }}^{+}=\mathrm{Cu}_{\text {electrolyte }}^{+}+\mathrm{Cl}_{\text {oxide }}^{-}+\mathrm{H}_{2} \mathrm{O}$

The copper ion dissolution causes the formation of a porous film over the dissolution site (Hettiarachchi and Hoar, 1979). At the pit induction time, the $\mathrm{Cl}^{-}$ions completely perforate the inner oxide layer. This stage is followed by steady pit growth. The critical potentials characteristic of localized corrosion, i.e., pitting potential and repassivation potential, were found to be linearly dependent on the logarithm of the chloride ion concentration (Metikos-Hukovic and Milosev, 1992).

Addition of other anions either inhibits or accelerates the localized corrosion of coppernickel alloys (Gouda et al., 2000). As discussed above, sulfide ions accelerate the corrosion of $\mathrm{Cu}-\mathrm{Ni}$ alloys. The pitting potential $\left(\mathrm{E}_{\mathrm{pit}}\right)$ has been shown to decrease with increasing dissolved sulfide ion concentration (Gouda et al., 2000). Thiosulfate ions, on the other hand, were found to raise $\mathrm{E}_{\mathrm{pit}}$, thus inhibit the localized corrosion via a competitive adsorption mechanism. Sulfate and sulfite ions were also found to act as inhibitors, although $\mathrm{SO}_{3}{ }^{2-}$ is oxidized in solution to $\mathrm{SO}_{4}{ }^{2-}$ ion. Interestingly, sulfate ions exhibit a synergistic effect when added to chloride ions increasing the corrosion rate in case of pure copper (Mankowski et al., 1997; Duthil et al., 1996). Their accelerating effect is a consequence of their large degree of mobility and interaction with the oxide film (Milosev et al., 1992). Bicarbonate ions, on the other hand, promote the formation of the passive layer on $\mathrm{Cu}$ (Milosev et al., 1992; Thomas and Tiller, 1972a; Thomas and Tiller, 1972b). If the bicarbonate to sulfate ion ratio is equal to or larger than 1, localized corrosion of copper can be avoided (Milosev et al., 1992). Hypochlorite ions that form during chlorination have also been found to increase the pitting potential. The hypochloride ions are converted to chlorite ions that accumulate in the pores and inhibit pitting corrosion (Gouda et al., 2000).

The flowrate of the electrolyte also affects the corrosion behavior of $\mathrm{Cu}-\mathrm{Ni}$ alloys. In the presence of high turbulence, a unique corrosion morphology, the so-called horse-shoe corrosion develops (Bianchi et al., 1978). This morphology is caused by the impingement corrosion of the alloy, in which the alloy actively dissolves in a small area of high turbulence, while the remaining surface is in a passive state (Bianchi et al., 1978). 
The crevice corrosion of $90 \mathrm{Cu}-10 \mathrm{Ni}$ alloys was investigated in simulated crevice experiments (Efird and Verink, 1977). The steady state potential of the crevice samples significantly decreased with increasing $\mathrm{pH}$. Between $\mathrm{pH} 6$ and 10, a discontinuity was observed at a certain potential, called the crevice protection potential (Efird and Verink, 1977). No extensive literature database exists on the localized, especially crevice, corrosion of $\mathrm{Cu}-\mathrm{Ni}$ alloys.

\section{Experimental Procedures}

\section{Materials and Sample Preparation}

\section{Materials}

The compositions of alloys used in the Phase I electrochemical tests are summarized in Table 2. Their main alloying elements are iron, nickel, chromium and molybdenum. Four of these eight alloys are Fe-based (316L, 254SMO, 2205 and 2304 duplex SS), while the others are Ni-based superalloys $(600,690, \mathrm{C}-276,825, \mathrm{C}-22)$. The $316 \mathrm{~L}$ stainless steel contains high concentrations of $\mathrm{Ni}$ and $\mathrm{Cr}$. The superaustenitic 254SMO stainless steel contains even more $\mathrm{Ni}$ and $\mathrm{Cr}$, as well as $\mathrm{N}$ for superior corrosion resistance. It also contains a fairly significant amount of $\mathrm{Cu}$ to improve its resistance to acidic environments. The 2304 and 2205 duplex stainless steels have high $\mathrm{Cr}$ and relatively low Mo concentration. Two Ni-based alloys, the 600 and 690, do not contain Mo. The Cr concentration is higher in the 690 alloy. Alloy 825 contains a high concentration of $\mathrm{Fe}$ and low concentration of Mo. C-276, on the other hand, has high Mo concentration. C-22 has both high $\mathrm{Cr}$ and Mo content.

In Phase II, Cu-Ni alloys were investigated. The compositions of these alloys are shown in Table 3.

\section{Heat Treatment Schedules}

Several Fe-Ni-Cr-Mo alloys were subjected to heat treatments in order to simulate the microstructure of weldments. Alloys 600 and 690 were subjected to heat treatments at $700^{\circ} \mathrm{C}$ for up to 160 hours ( $>6$ days). All initial heat treatments were performed from the mill-annealed condition, which is not a reproducible initial condition due to the presence of variable amounts of matrix and grain boundary carbides. In order to obtain more reproducible results, the samples were solution annealed at $1100{ }^{\circ} \mathrm{C}$ for 30 minutes prior to the heat treatments. Heat treatments at higher temperatures (up to $1200^{\circ} \mathrm{C}$ ) for shorter time periods were also performed. Upon reaching the specified thermal aging or solution annealing time, the specimens were immediately quenched to room temperature in an agitated water bath.

Specimens of DSS 2205 and 2304 were subjected to isothermal heat treatments at 475 , 700 or $870^{\circ} \mathrm{C}$ for times up to 480 hours. Upon reaching the specified heat treatment time, the specimens were immediately quenched to room temperature in an agitated water bath. 
These alloys were not solution annealed prior to heat treatment, the heat treatments were carried out from mill annealed condition.

Table 2. Compositions of alloys used in Phase I of the experiments. The compositions are given in wt \% and were provided by the test coupon manufacturer.

\begin{tabular}{|c|c|c|c|c|c|c|c|c|c|}
\hline Alloy & \multicolumn{9}{|c|}{ Alloying Element/Amount } \\
\hline \multirow[b]{2}{*}{$316 L$} & $\begin{array}{c}C \\
0.021 \\
\end{array}$ & $\begin{array}{c}C r \\
16.791 \\
\end{array}$ & $\begin{array}{c}C u \\
0.349\end{array}$ & $\begin{array}{l}F e \\
\text { bal. }\end{array}$ & $\begin{array}{c}M n \\
1.341 \\
\end{array}$ & $\begin{array}{c}M o \\
2.086\end{array}$ & $\begin{array}{c}N \\
0.041\end{array}$ & $\begin{array}{c}N i \\
10.260\end{array}$ & $\begin{array}{c}P \\
0.030\end{array}$ \\
\hline & $\begin{array}{c}S \\
0.002\end{array}$ & $\begin{array}{c}S i \\
0.469\end{array}$ & & & & & & & \\
\hline \multirow[b]{2}{*}{600} & $\begin{array}{c}A l \\
<0.172\end{array}$ & $\begin{array}{c}C \\
0.020\end{array}$ & $\begin{array}{c}\text { Co } \\
<0.059\end{array}$ & $\begin{array}{c}C r \\
14.660\end{array}$ & $\begin{array}{c}C u \\
0.200\end{array}$ & $\begin{array}{c}F e \\
9.690\end{array}$ & $\begin{array}{c}M n \\
0.280\end{array}$ & $\begin{array}{c}N b \\
0.020\end{array}$ & $\begin{array}{c}N i \\
75.090\end{array}$ \\
\hline & $\begin{array}{c}P \\
<0.009\end{array}$ & $\begin{array}{c}S \\
<0.001\end{array}$ & $\begin{array}{c}S i \\
0.040\end{array}$ & $\begin{array}{c}T a \\
<0.010\end{array}$ & $\begin{array}{c}T i \\
<0.310\end{array}$ & & & & \\
\hline \multirow[b]{2}{*}{690} & $\begin{array}{c}A l \\
0.210\end{array}$ & $\begin{array}{c}C \\
0.029\end{array}$ & $\begin{array}{c}C r \\
29.600\end{array}$ & $\begin{array}{c}C u \\
<0.010\end{array}$ & $\begin{array}{c}F e \\
10.130\end{array}$ & $\begin{array}{c}M n \\
0.150\end{array}$ & $\begin{array}{c}N i \\
59.520\end{array}$ & $\begin{array}{c}P \\
0.003\end{array}$ & $\begin{array}{c}S \\
0.001\end{array}$ \\
\hline & $\begin{array}{c}S i \\
0.020\end{array}$ & $\begin{array}{c}T i \\
0.340\end{array}$ & & & & & & & \\
\hline \multirow[b]{2}{*}{ C276 } & $\begin{array}{c}C \\
0.002\end{array}$ & $\begin{array}{c}C o \\
0.560\end{array}$ & $\begin{array}{c}C r \\
15.900\end{array}$ & $\begin{array}{c}C u \\
0.090\end{array}$ & $\begin{array}{c}F e \\
6.000\end{array}$ & $\begin{array}{c}M n \\
0.260\end{array}$ & $\begin{array}{c}M o \\
16.050\end{array}$ & $\begin{array}{c}N i \\
57.300\end{array}$ & $\begin{array}{c}P \\
0.003\end{array}$ \\
\hline & $\begin{array}{c}S \\
0.002\end{array}$ & $\begin{array}{c}S i \\
0.030\end{array}$ & $\begin{array}{c}V \\
0.160\end{array}$ & $\begin{array}{c}W \\
3.290\end{array}$ & & & & & \\
\hline \multirow[b]{2}{*}{825} & $\begin{array}{c}A l \\
0.100\end{array}$ & $\begin{array}{c}C \\
<0.010\end{array}$ & $\begin{array}{c}C r \\
22.720\end{array}$ & $\begin{array}{c}C u \\
1.700\end{array}$ & $\begin{array}{c}F e \\
29.910\end{array}$ & $\begin{array}{c}M n \\
0.340\end{array}$ & $\begin{array}{c}M o \\
3.330\end{array}$ & $\begin{array}{c}N i \\
40.630\end{array}$ & $\begin{array}{c}S \\
<0.001\end{array}$ \\
\hline & $\begin{array}{c}S i \\
0.320\end{array}$ & $\begin{array}{c}T i \\
0.950\end{array}$ & & & & & & & \\
\hline \multirow[b]{2}{*}{ C22 } & $\begin{array}{c}C \\
0.003\end{array}$ & $\begin{array}{c}C o \\
0.480\end{array}$ & $\begin{array}{c}C r \\
21.240\end{array}$ & $\begin{array}{c}F e \\
3.820\end{array}$ & $\begin{array}{c}M n \\
0.300\end{array}$ & $\begin{array}{c}M o \\
13.430\end{array}$ & $\begin{array}{c}N i \\
\text { bal. }\end{array}$ & $\begin{array}{c}P \\
0.006\end{array}$ & $\begin{array}{c}S \\
0.001\end{array}$ \\
\hline & $\begin{array}{c}V \\
0.170 \\
\end{array}$ & $\begin{array}{c}W \\
2.850 \\
\end{array}$ & $\begin{array}{c}S i \\
0.035 \\
\end{array}$ & & & & & & \\
\hline $\begin{array}{c}254 \\
\text { SMO }\end{array}$ & $\begin{array}{c}C u \\
0.750\end{array}$ & $\begin{array}{c}C \\
<0.020\end{array}$ & $\begin{array}{c}C r \\
20.000\end{array}$ & $\begin{array}{l}F e \\
\text { bal. }\end{array}$ & $\begin{array}{c}N i \\
18.000\end{array}$ & $\begin{array}{c}M o \\
6.250\end{array}$ & $\begin{array}{c}N \\
0.200\end{array}$ & $\begin{array}{c}M n \\
<1.000\end{array}$ & $\begin{array}{c}\mathrm{Si} \\
<1.000\end{array}$ \\
\hline \multirow[b]{2}{*}{2205} & $\begin{array}{c}C \\
0.017\end{array}$ & $\begin{array}{c}C r \\
22.500\end{array}$ & $\begin{array}{l}F e \\
\text { bal. }\end{array}$ & $\begin{array}{c}M n \\
1.550\end{array}$ & $\begin{array}{c}M o \\
3.200\end{array}$ & $\begin{array}{c}N \\
0.164\end{array}$ & $\begin{array}{c}N i \\
5.800\end{array}$ & $\begin{array}{c}P \\
0.020\end{array}$ & $\begin{array}{c}S \\
0.001\end{array}$ \\
\hline & $\begin{array}{c}S i \\
0.410 \\
\end{array}$ & & & & & & & & \\
\hline 2304 & $\begin{array}{c}C \\
0.021\end{array}$ & $\begin{array}{c}C r \\
22.650\end{array}$ & $\begin{array}{l}F e \\
\text { bal. }\end{array}$ & $\begin{array}{c}M n \\
1.440\end{array}$ & $\begin{array}{c}M o \\
0.280\end{array}$ & $\begin{array}{c}N \\
0.100\end{array}$ & $\begin{array}{c}N i \\
4.900\end{array}$ & $\begin{array}{c}S i \\
0.350\end{array}$ & \\
\hline
\end{tabular}


Table 3. Compositions of alloys used in Phase II of the experiments provided by the test coupon manufacturer (wt \%).

\begin{tabular}{|c|c|c|c|c|c|c|c|c|c|}
\hline Alloy & \multicolumn{10}{|c|}{ Alloying Element/Amount } \\
\hline & $A l$ & $C$ & $C o$ & $C u$ & $F e$ & $M n$ & $N i$ & $P$ & $P b$ \\
& 0.030 & 0.125 & 0.020 & 32.850 & 2.030 & 0.800 & 63.920 & 0.002 & 0.002 \\
\cline { 2 - 12 } M400 & $S$ & $S i$ & $S n$ & $Z n$ & \multicolumn{7}{|c|}{} \\
& 0.004 & 0.080 & 0.002 & 0.010 & & & & \\
\hline & $C$ & $C u+A g$ & $F e$ & $M n$ & $N i+C O$ & $P$ & $P b$ & $S$ & $Z n$ \\
CDA & $0.006 /$ & 88.750 & $1.270 /$ & $0.440 /$ & 9.900 & $<0.010$ & 0.014 & 0.004 & $0.050 /$ \\
706 & 0.007 & & 1.310 & 0.450 & & & & & 0.040 \\
\hline CDA & $C$ & $C u$ & $F e$ & $M n$ & $N i$ & $P$ & $S$ & $Z n$ & \\
715 & 0.014 & 67.890 & 0.660 & 0.490 & 30.850 & 0.005 & 0.006 & 0.020 & \\
\hline
\end{tabular}

\section{Sample Preparation for Microchemistry Measurements}

The microchemistry measurements were carried out on 2205 duplex stainless steel. The specimens were polished on a grinding wheel using 600 grit $\mathrm{SiC}$ paper to a thickness of approximately 10-15 mils. $3 \mathrm{~mm}$ diameter disks were punched from the resulting foil using a $3 \mathrm{~mm}$ TEM disk punch. The disks were then polished to sub-10 mil thicknesses on both sides and degreased in an ultrasonic acetone bath. Finally, the samples were electropolished in a 5\% perchloric acid $\left(\mathrm{HClO}_{4}\right), 20 \%$ acetic acid $\left(\mathrm{CH}_{3} \mathrm{COOH}\right)$ and $75 \%$ methanol $\left(\mathrm{CH}_{3} \mathrm{OH}\right)$ solution at $0^{\circ} \mathrm{C}$.

\section{Sample Preparation for Crevice Repassivation Potential Measurements}

For crevice corrosion testing, all samples were polished to 600-grit finish, rinsed and degreased in isopropyl alcohol (Cu-Ni alloys) or acetone (all other alloys) in ultrasonic bath for 10 minutes. The specimens were then air-dried and weighed. The crevices were created on 3-5 mm (0.125-0.2 in.) thin sheet samples by attaching serrated polytetrafluoroethylene (PTFE) washers (12 teeth per side) using C-276 bolts isolated through PTFE sleeves and an initial torque of $0.14-8 \mathrm{Nm}$ (20 inoz-70 inlb). The specimens were attached to a sample holder machined out of C-276 in order to establish the electrical connection outside the cell. The geometry of the specimen is illustrated in Figure 2.

For corrosion potential measurements, the crevice specimens were used without the application of crevice washers (open specimens). The samples in this case, too, were polished to 600-grit, rinsed and degreased with isopropanol or acetone depending on the type of the alloy. The specimens were attached to C-276 sample holders for electrical connection.

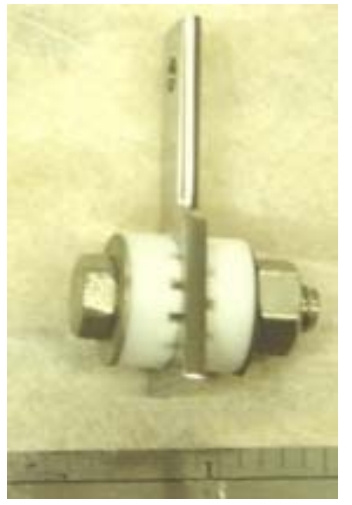

Figure 2. Geometry of specimen used in crevice corrosion tests. 
The damage growth assessment tests were initially performed on sheet materials polished to 600-grit and hung vertically in a glass tank as shown in Figure 3a. However, due to preferential corrosion observed at the edges and slow pit initiation, flat specimens with rounded edges and a pipe material were later used in as-received condition to eliminate the edge effects and promote pit initiation. The ends of the pipe sections were masked using MicroStop lacquer to avoid crevice corrosion. The pipe sections were then connected to a cartridge pump to circulate to corrosive solution as shown in Figure $3 \mathrm{~b}$.

(a)

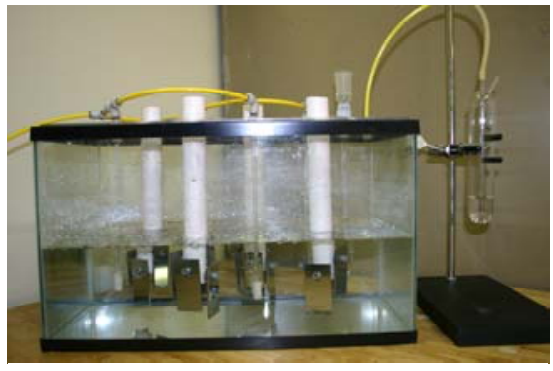

(b)

Figure 3. (a) Glass tank with vertically hung sheet specimens and (b) pipe specimens used to determine damage growth rates and distribution.

\section{Microchemistry Measurements}

A JEOL 4000 FEX microscope was used in both TEM and STEM mode for imaging, diffraction and energy dispersive spectrometry data collection. The $\mathrm{k}$ factors were determined using a mill annealed sample as a standard in which the ferrite and austenite grain compositions had been measured via microprobe.

\section{Electrochemical Tests}

\section{Corrosion Potential Measurements}

The corrosion potentials were measured in $0.5 \mathrm{M}$ sodium sulfate solution in an electrochemical cell shown schematically in Figure 4a. The environment was kept chloride ion free in order to avoid any localized corrosion.

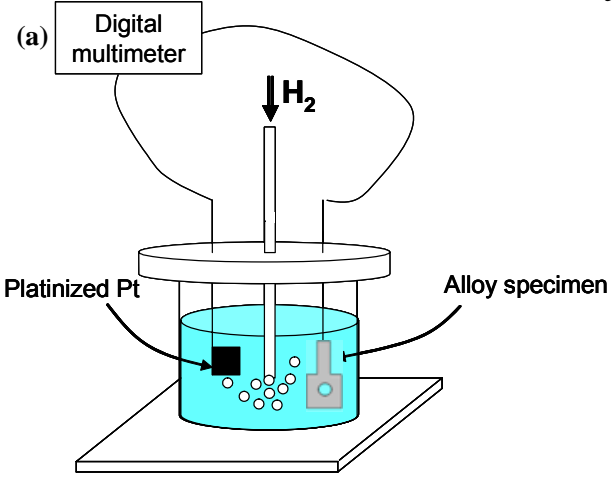

(b)

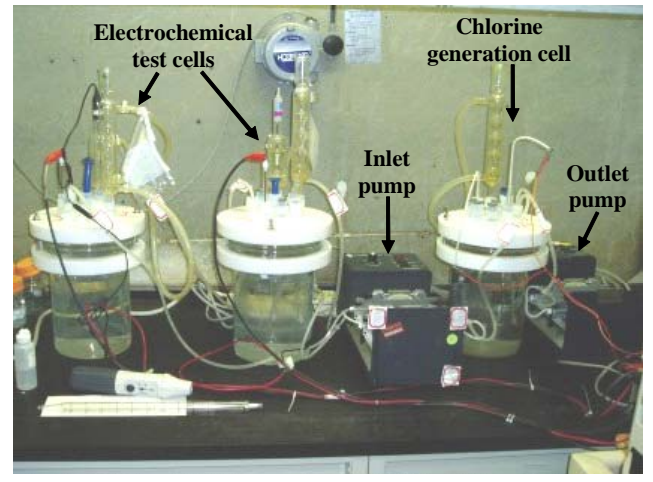

Figure 4. Electrochemical cells used to measure corrosion potential of alloys; (a) sodium sulfate environments, (b) synthetic seawater and chlorinated synthetic seawater environments. 
The solution was deaerated by purging with 1 atm of high purity hydrogen. Standard hydrogen electrodes consisting of an acid solution, platinized platinum wire and hydrogen gas purged at 1 atm were used as reference electrodes. Platinized platinum electrodes were used in the cells to check for traces of oxygen and other contaminants, such as nitrates. The redox potential of platinized Pt electrode was equal to that of the standard hydrogen electrode in the absence of contaminants. The effect of nitrate ions at different $\mathrm{pH}$ values was also measured in solutions containing sodium sulfate, sodium nitrate, nitric acid and sulfuric acid at constant total nitrate ion concentration in case of C22. The working electrodes were connected to a digital multimeter and the corrosion potentials were monitored as a function of time for 3 days.

The corrosion potential of $\mathrm{Cu}-\mathrm{Ni}$ alloys was measured in synthetic seawater prepared according to the ASTM D-1141 standard (2003). The solution contained $24.53 \mathrm{~g} / \mathrm{L} \mathrm{NaCl}$, $5.20 \mathrm{~g} / \mathrm{L} \mathrm{MgCl}_{2}, 4.09 \mathrm{~g} / \mathrm{L} \mathrm{Na}_{2} \mathrm{SO}_{4}, 1.16 \mathrm{~g} / \mathrm{L} \mathrm{CaCl}_{2}, 0.695 \mathrm{~g} / \mathrm{L} \mathrm{KCl}, 0.201 \mathrm{~g} / \mathrm{L} \mathrm{NaHCO}_{3}$, $0.101 \mathrm{~g} / \mathrm{L} \mathrm{KBr}, 0.027 \mathrm{~g} / \mathrm{L} \mathrm{H}_{3} \mathrm{BO}_{3}, 0.025 \mathrm{~g} / \mathrm{L} \mathrm{SrCl}_{2}$ and $0.003 \mathrm{~g} / \mathrm{L} \mathrm{NaF}$. This solution was not deaerated, the oxygen concentration was monitored during the exposure using a handheld $\mathrm{DO}_{2}$ meter. The working electrode was connected to a specimen holder rod made out of C-276. The corrosion potential was measured against a saturated calomel reference electrode using a potentiostat.

The effect of free chlorine $\left(\mathrm{Cl}_{2}\right)$ concentration on the corrosion potential was also measured for the $\mathrm{Cu}-\mathrm{Ni}$ alloys. Free chlorine was generated in situ to avoid the decomposition of hypochlorites and provide a constant free $\mathrm{Cl}_{2}$ level. $\mathrm{The}^{\mathrm{Cl}} \mathrm{Cl}_{2}$ was generated in an electrochemical cell from synthetic seawater by applying $3 \mathrm{~V}$ direct voltage through two platinized niobium mesh electrodes for 3-10 seconds. This solution was then pumped into the test cells as shown in Figure $4 \mathrm{~b}$. The free $\mathrm{Cl}_{2}$ levels in both the generation and test cells were monitored using a colorimetric chlorine test kit.

\section{Cyclic Potentiodynamic Polarization of Crevice Specimens}

Cyclic potentiodynamic polarization tests of crevice specimens were carried out to determine the crevice stabilization and repassivation potentials of $\mathrm{Cu}-\mathrm{Ni}$ alloys under different environmental conditions.

Some of the measurements were performed in alkaline (pH 9 and 11) sodium chloride or sodium chloride + borate buffer solutions at three different temperatures $(23,60$ and $95^{\circ} \mathrm{C}$ ). The chloride ion concentration was varied from $5 \times 10^{-4} \mathrm{M}$ to $5 \times 10^{-2} \mathrm{M}$. The borate buffer solution contained $2 \times 10^{-3} \mathrm{M}$ sodium hydroxide and $1.06 \times 10^{-2} \mathrm{M}$ sodium tetraborate $(\mathrm{pH} \sim 9)$. The solutions were deaerated by purging with nitrogen gas before and during the tests.

The cyclic potentiodynamic polarization scans were carried out in three-electrode electrochemical cells equipped with platinized niobium mesh counter electrodes and saturated calomel reference electrodes (SCE; $\mathrm{Hg}_{(1)} \mathrm{Hg}_{2} \mathrm{Cl}_{2(\mathrm{~s})}, \mathrm{KCl}_{(\mathrm{aq})}(4.56 \mathrm{M})$ ). Several cells were connected to a multichannel potentiostat, which allowed the simultaneous testing of up to eight specimens as illustrated in Figure 5. 


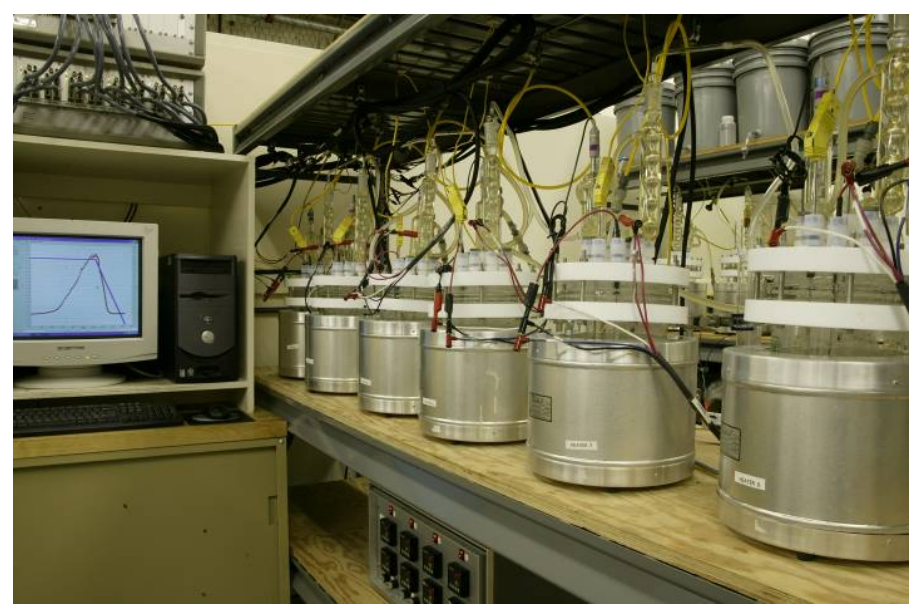

Figure 5. Electrochemical cells used to measure crevice corrosion parameters in different environments.

The corrosion potential $\left(\mathrm{E}_{\text {corr }}\right)$ was monitored for $1 \mathrm{hr}$ prior to the scan. The polarization curve was measured from $-0.1 \mathrm{~V}$ vs. $E_{\text {corr }}$ to a vertex current of $1 \mathrm{~mA} / \mathrm{cm}^{2}$ and then back to $-0.1 \mathrm{~V}$ vs. $E_{\text {corr }}$ at a scan rate of $0.1 \mathrm{mV} / \mathrm{sec}$. The crevice stabilization potential was defined as the inflection point on the anodic scan, while the repassivation potential was determined as the potential at which the measured current density decreased to $10^{-6}$ $\mathrm{A} / \mathrm{cm}^{2}$.

The same cells were used to measure the pitting and repassivation potentials of $\mathrm{Cu}-\mathrm{Ni}$ alloys without the presence of crevice washers in $\mathrm{Cl}_{2}$-free and $\mathrm{Cl}_{2}$-containing synthetic seawater. The polarization curves were measured using the same parameters as in case of the crevice specimens. Cathodic potentiodynamic polarization scans were also carried out in case of the seawater environments (open specimens). In these tests, $\mathrm{E}_{\text {corr }}$ was monitored for 14 days, followed by a cathodic potentiodynamic polarization scan from $0.1 \mathrm{~V}$ vs. $\mathrm{E}_{\text {corr }}$ to $-1.5 \mathrm{~V}$ vs. SCE using a scan rate of $0.1 \mathrm{mV} / \mathrm{sec}$.

\section{Potential Staircase (PS) Method to Determine the Crevice Repassivation Potentials}

In a number of cases, the crevice repassivation potentials were determined using the "potential staircase" (PS) method, which is a combination of potentiostatic hold (controlled crevice growth) and potentiodynamic scan (crevice repassivation). A flowchart and schematic of the measurement sequence is shown in Figure 6 . The specimen was subjected to a potentiostatic hold at 0.4 or $0.6 \mathrm{~V}$ vs. SCE for up to 4 days or until the charge density reached $65 \mathrm{~mA} . \mathrm{hr}$. During this time, crevice corrosion initiated and grew in susceptible alloys. After the potentiostatic hold, the potential was gradually decreased from the potentiostatic hold potential to $-0.4--0.6 \mathrm{~V}$ vs. SCE at a scan rate of -0.0167 or $-0.167 \mathrm{mV} / \mathrm{sec}$. The repassivation potential was determined as the potential at which the measured current density decreased to $10^{-5}, 10^{-6}$ or $2 \times 10^{-6} \mathrm{~A} / \mathrm{cm}^{2}$. In some cases, crevice corrosion did not initiate during the potentiostatic holds. In those cases, the repassivation potential was determined to be equal to or higher than the potentiostatic hold potential. 

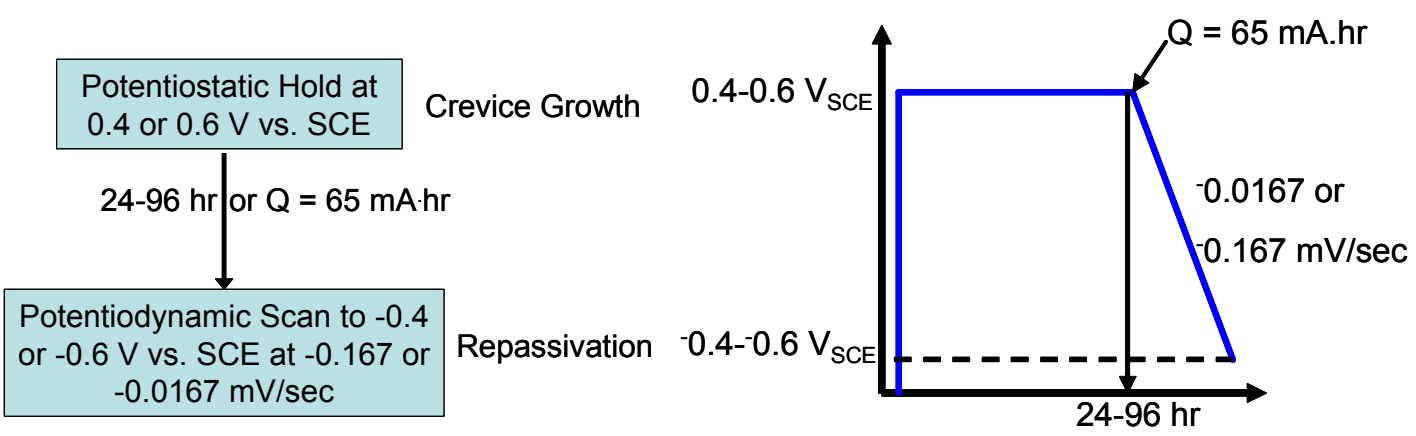

Figure 6. Flowchart and schematic of electrochemical sequence used to measure crevice repassivation potentials in case of the $\mathrm{C}-276$ specimens. Note that the experimental parameters changed depending on the alloy and solution chemistry.

The PS tests were carried out in case of a variety of alloys at several chloride ion concentrations and temperatures. In many cases, known inhibitor species, such as $\mathrm{OH}^{-}$, $\mathrm{SO}_{4}{ }^{2-}, \mathrm{MoO}_{4}{ }^{2-}, \mathrm{NO}_{2}{ }^{-}$and $\mathrm{VO}_{3}{ }^{2-}$, were added to the solution at different concentrations to determine the effect of inhibitors on $\mathrm{E}_{\text {rcrev }}$.

\section{Electrochemical Potentiodynamic Reactivation Tests}

The Electrochemical Potentiodynamic Reactivation (EPR) test was used to measure the degree of sensitization (DOS) of Fe-Ni-Cr-Mo alloys. The technique is based on the preferential breakdown of the passive film on the sensitized grain boundaries, where chromium is depleted (Mignone et al., 1982; Fang et al., 1998). This preferential breakdown is detected during a controlled potential sweep from the passive to active regions. Breakdown of the passive film over the sensitized grain boundaries causes an increase in current density (ASTM, 2004). It is assumed that only sensitized grain boundaries become active, while grain bodies and unsensitized grain boundaries remain passive. The higher the degree of sensitization of the material, the greater increase it shows in current density. The test solution used in EPR tests (e.g., dilute $\mathrm{H}_{2} \mathrm{SO}_{4}$ ) encourages uniform dissolution and contains an activator or depassivator (typically $\mathrm{KSCN}$ ). In our tests, douple-loop EPR (DL-EPR) technique was used. In a single loop test (SL-EPR), only a reactivation scan is carried out and any measured reactivation charge is considered to be due to sensitization. In the DL-EPR technique, however, an anodic scan is performed from the corrosion potential before the reactivation scan. The initial anodic scan has a cleaning effect on the surface making the test independent of surface finish and the presence of random pits and metallic inclusions. This technique is fundamentally different from the repassivation potential measurement, which relies on the cessation of localized corrosion. These two techniques are compared in Figure 7. 


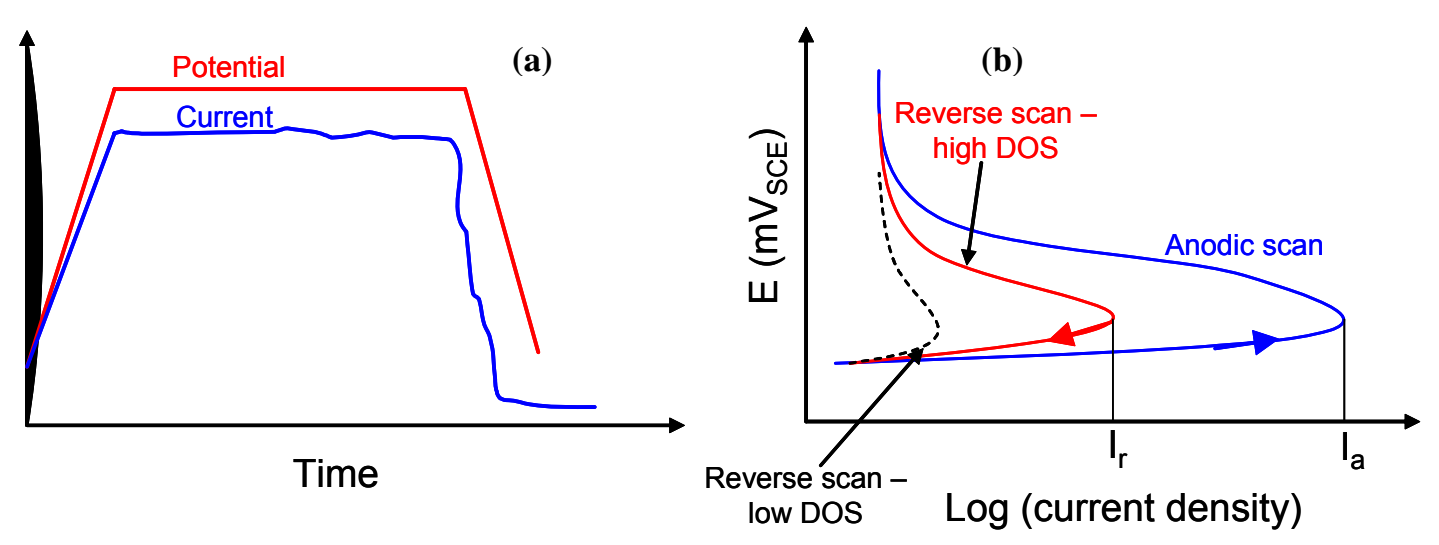

Figure 7. Schematics of (a) repassivation potential measurement and (b) DL-EPR test.

The degree of sensitization (DOS) can be calculated from the ratio of current measured during the anodic and reverse scans:

$$
D O S=\frac{I_{r}}{I_{a}}
$$

The DL-EPR tests were carried out at $30^{\circ} \mathrm{C}$ in solutions containing $0.05-0.5 \mathrm{M} \mathrm{H}_{2} \mathrm{SO}_{4}$ and $5 \times 10^{-5} \mathrm{KSCN}$. The potential was scanned from $-0.15 \mathrm{~V}$ vs. $\mathrm{E}_{\text {corr }}$ to $0.4 \mathrm{~V}$ vs. SCE and back to $-0.15 \mathrm{~V}$ vs. $\mathrm{E}_{\text {corr }}$ at a scan rate of $0.167 \mathrm{mV} / \mathrm{s}$.

\section{Tsujikawa-Hisamatsu Electrochemical (THE) Method}

The Tsujikawa-Hisamatsu electrochemical method was used to determine the crevice repassivation potentials of C-22 and 825 . This method is particularly useful in case of highly corrosion resistant materials, where a cyclic potentiodynamic polarization can lead to transpassive dissolution or crevice corrosion outside the washers. During the THE test, only small amount of current flows through the sample to ensure that crevice nucleation and propagation processes take place instead of transpassive dissolution. The THE method involves two phases, the stimulation and repassivation phases. The stimulation phase is a potentiodynamic polarization scan in the anodic direction until the current reaches a threshold value indicating the initiation of crevice corrosion. The scan is followed by a galvanostatic hold at the threshold current density for two hours. At the end of the galvanostatic hold the potential is measured, the electrochemical cell is returned to potentiostatic control, the potential is stepped down towards $\mathrm{E}_{\text {corr }}$ in $10 \mathrm{mV}$ increments and the potential is held constant for $2 \mathrm{hrs}$, while the current is monitored. If the current increases as a function of time, it indicates that the crevice corrosion continues. If the current does not increase during the $2 \mathrm{hr}$ potentiostatic hold, the repassivation potential has been reached. A flowchart of the experimental sequence and a representative potential/current vs. time plot is shown in Figure 8.

In our tests, prism crevice assembly (PCA) electrodes were used. The prismatic specimens were equipped with ceramic crevice washers pre-coated with PTFE tape. The securing bolts were made out of C-276 alloy and were tightened using torque between 
$0.35 \mathrm{Nm}$ (50 inoz) and 7.91 Nm (70 inlb). The specimen was placed in a three-electrode electrochemical cell that was held at $90^{\circ} \mathrm{C}$ and contained $1 \mathrm{M} \mathrm{NaCl}$ solution.

The corrosion potential of the specimen was monitored for $24 \mathrm{hrs}$, while the solution was purged with high purity nitrogen gas to remove any dissolved oxygen. The potentiodynamic scan was performed from $-0.1 \mathrm{~V}$ vs. $\mathrm{E}_{\text {corr }}$ until the target current density was reached.
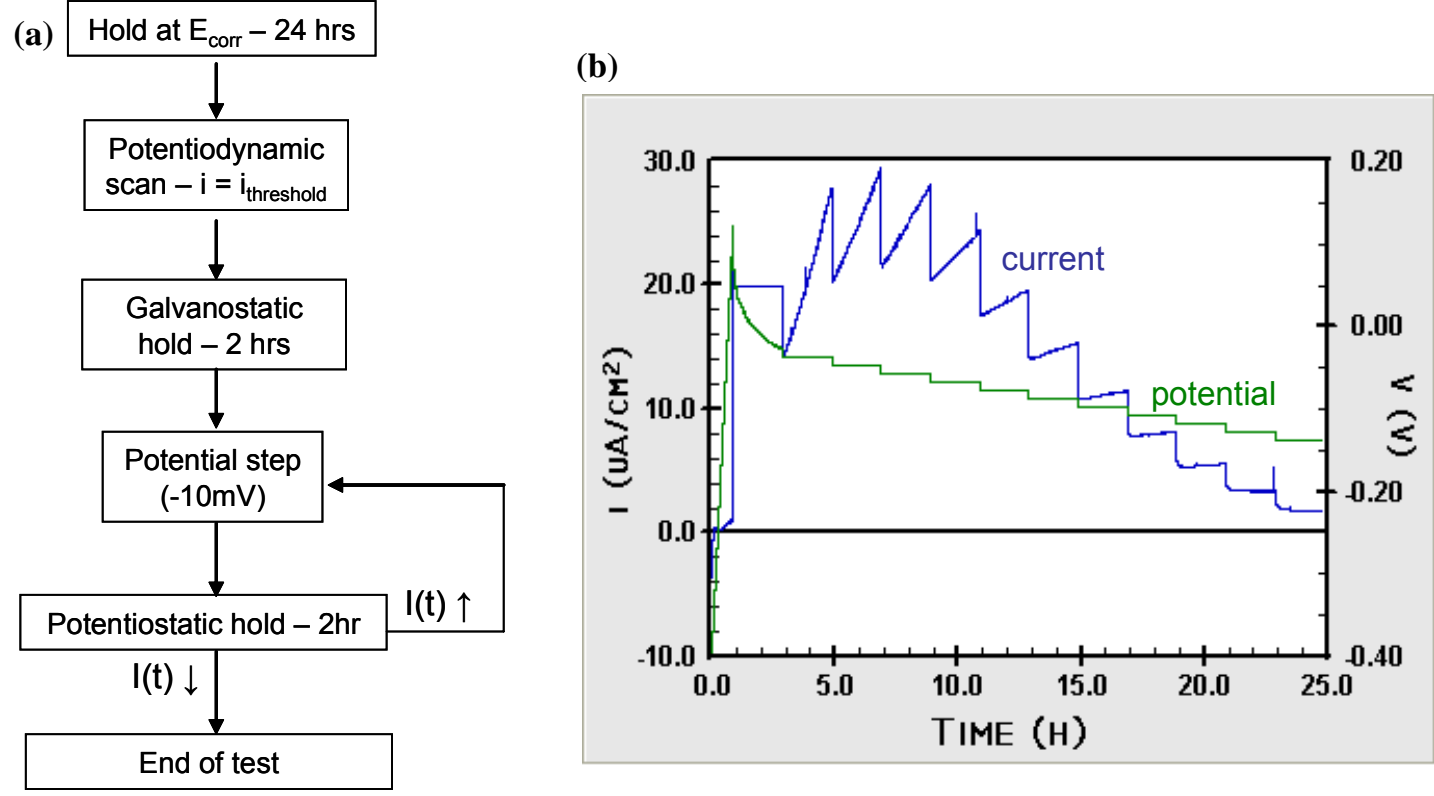

Figure 8. Flowchart and representative experimental output of THE method.

The different target current densities (i) and torque values (T) used in this work are summarized in Table 4.

Table 4. Target current and charge density values ( $i$ and $q$, respectively) as well as torques (T) used in the THE measurements.

\begin{tabular}{|c|c|c|c|}
\hline Alloy & $\mathrm{i}\left(\mathrm{A} / \mathrm{cm}^{2}\right)$ & $q\left(\mathrm{C} / \mathrm{cm}^{2}\right)$ & $T$ (in lb) \\
\hline \multirow{3}{*}{$\mathrm{C}-22$} & \multirow{3}{*}{$2.133 \times 10^{-6}$} & \multirow{3}{*}{0.015} & 6.5 \\
\hline & & & 50 \\
\hline & & & 70 \\
\hline \multirow{7}{*}{825} & \multirow{4}{*}{$2.133 \times 10^{-6}$} & \multirow{4}{*}{0.015} & 3.125 \\
\hline & & & 6.25 \\
\hline & & & 20 \\
\hline & & & 50 \\
\hline & $1.389 \times 10^{-4}$ & 1.000 & 20 \\
\hline & \multirow[t]{2}{*}{$2.083 \times 10^{-3}$} & \multirow[t]{2}{*}{15.000} & 20 \\
\hline & & & 50 \\
\hline
\end{tabular}




\section{Damage Growth and Distribution Tests}

The distribution of pit sizes as a function of time was measured on two alloys in two different geometric arrangements: 825 flat specimens and 316L stainless steel cylindrical specimens (pipe sections). Since polished surfaces have significantly lower pit initiation times, the specimens were used in the mill-annealed finish.

The edges of the flat specimens were rounded to eliminate edge effects and were hung in an Erlenmeyer flask from the vapor phase such that only their lower parts were exposed to the solution to avoid crevice corrosion at the specimen - holder contact point. The exposures were carried out in three different solutions containing ferric ions. Their compositions are shown in Table 5. The ferric ions contributed to a stable redox potential in solution that was significantly higher than the repassivation potential enabling localized corrosion of the specimens.

Table 5. Composition of solutions used for the flat specimen exposures in the damage growth and distribution tests.

\begin{tabular}{|c|c|}
\hline Solution ID & Solution Composition \\
\hline Solution \#1 & $60 \mathrm{~g} / \mathrm{L} \mathrm{FeCl}_{3} \cdot 6 \mathrm{H}_{2} \mathrm{O}+40 \mathrm{~g} / \mathrm{L} \mathrm{NaCl}$ \\
\hline Solution \#2 & $30 \mathrm{~g} / \mathrm{L} \mathrm{FeCl}_{3} \cdot 6 \mathrm{H}_{2} \mathrm{O}+40 \mathrm{~g} / \mathrm{L} \mathrm{NaCl}$ \\
\hline modified "yellow death" solution & $1 \mathrm{~g} / \mathrm{L} \mathrm{Fe}_{2}\left(\mathrm{SO}_{4}\right)_{3}+40 \mathrm{~g} / \mathrm{L} \mathrm{NaCl}+0.1 \mathrm{M} \mathrm{HCl}$ \\
\hline
\end{tabular}

The flasks were placed in a water bath and maintained at temperatures between 40 and $80^{\circ} \mathrm{C}$. A schematic and a photograph of the experimental setup are shown in Figure 9.
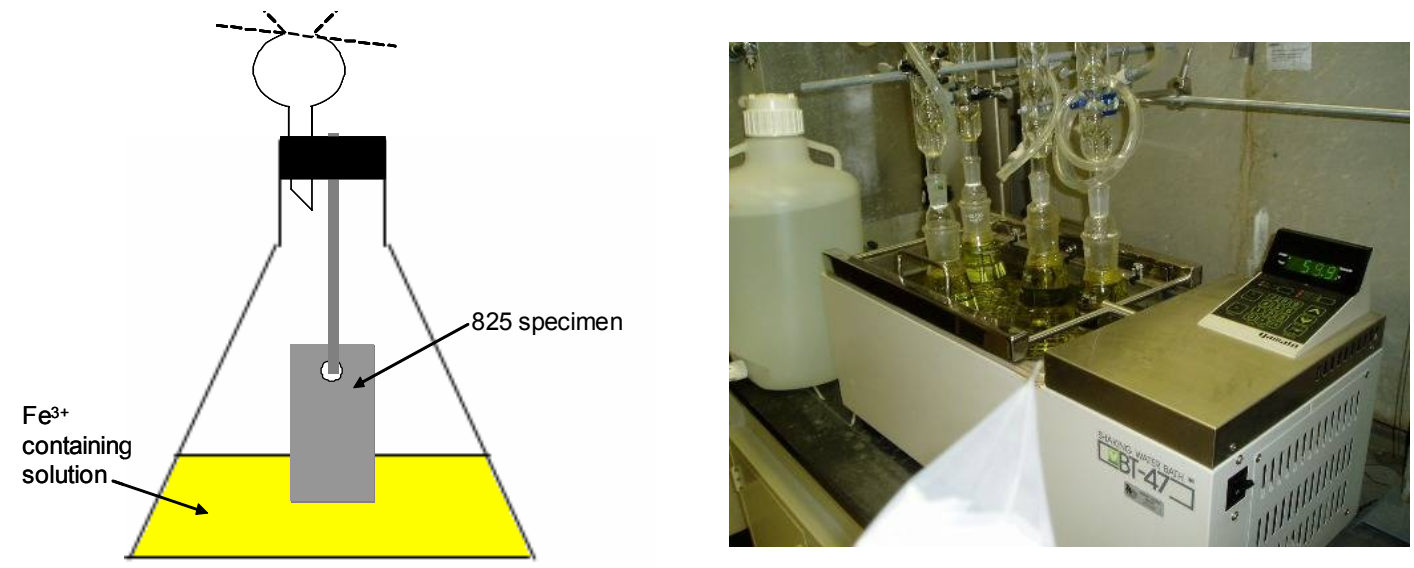

Figure 9. Schematic and photograph of experimental setup used for flat specimen in damage growth and distribution tests.

Independent specimens were removed from the solutions at different time periods and pit depths were measured using a digital microscope. The microscope was focused at the top and bottom of each pit and the turn of a calibrated, fine-focusing knob indicated the pit depth. 
Cylindrical specimens were also used to eliminate the edge effects that were experienced in the tests described above. 316L stainless steel pipes of $3 / 8$ in. diameter were cut into 2 in. sections. Both ends of each section were masked using MicroStop lacquer to avoid crevice corrosion. The sections were then individually connected to PTFE tubing and they were filled with a solution containing $0.868 \mathrm{M} \mathrm{NaCl}, 0.184 \mathrm{M} \mathrm{FeCl}_{2}$ and $0.184 \mathrm{M}$ $\mathrm{FeCl}_{3}(\mathrm{pH}=1.84)$. The PTFE tubing was connected to a cartridge pump and the solution was circulated in the pipe section at a very low flowrate. The exposures were carried out at room temperature and $40^{\circ} \mathrm{C}$. In case of the higher temperature exposure, the setup was placed into an oven to maintain $40^{\circ} \mathrm{C}$. The specimens were disconnected, rinsed and airdried after different exposure times. They were then cut in half lengthwise to reveal the pits inside. The pit depths were measured using a digital microscope as described above.

\section{Experimental Database Development - Results}

\section{Development of Microchemistry Data}

Microchemistry data was developed for 2205 duplex stainless steel as a function of isothermal aging treatment at 700 and $870^{\circ} \mathrm{C}$.

Microstructural evolution with aging time at both 700 and $870^{\circ} \mathrm{C}$ for 2205 is shown in Figure 10. Precipitation progressed with aging time at both temperatures. At $700^{\circ} \mathrm{C}$, the precipitation had a finer morphology, and was restricted to the ferrite-ferrite $(\alpha / \alpha)$ and ferrite-austenite $(\alpha / \gamma)$ grain boundaries. At $870^{\circ} \mathrm{C}$, the precipitation appeared coarser and more globular, eventually becoming a major constituent of the microstructure.

A closer examination of the precipitated regions was performed in order to determine if chemical segregation of $\mathrm{Cr}$ or Mo had occurred. At $700^{\circ} \mathrm{C}$, precipitation was observed at both the $\alpha / \alpha$ and $\alpha / \gamma$ grain boundaries after as little as 0.5 hours of aging. Figure 11 shows these boundaries as well as the Energy Dispersive X-ray Spectroscopy (EDS) composition profiles. The composition profiles were measured along the white arrows shown in the images. The $\alpha / \alpha$ precipitates had a sawtooth morphology, while the $\alpha / \gamma$ precipitates were more cellular. According to the EDS profiles, the $\alpha / \alpha$ precipitates were significantly enriched in Mo, and slightly depleted in $\mathrm{Cr}$ at the grain boundary. The $\alpha / \gamma$ precipitates showed no $\mathrm{Cr}$ depletion and a slight Mo enrichment at the grain boundary in the matrix. At ferrite-ferrite boundaries, the decomposing matrix was showed a $\mathrm{Cr} / \mathrm{Fe}$ peak intensity ratio of 0.33 for primary austenite and 0.38 for primary ferrite indicating that it was depleted in $\mathrm{Cr}$ when compared to the mill annealed condition. Similar depletion has been shown by Park et al.(2005).

As the heat treatment progressed, increased precipitation was observed. A metallographic image of the precipitated region in the $\alpha / \alpha$ interface after 5 hours of aging at $700^{\circ} \mathrm{C}$ is shown in Figure 12. It shows that the ferrite had decomposed to form a region of Cr-rich precipitates and a depleted matrix phase. The depleted matrix contained approximately half the chromium concentration of that found in the mill-annealed ferrite phase. The precipitates at this heat treatment showed slight $\mathrm{Cr}$ enrichment and substantial Mo 
enrichment. These phases are likely the eutectoid transformation of $\alpha \rightarrow \sigma+\gamma_{2}$ (secondary austenite formation). In essence, the abstraction of $\mathrm{Cr}$ and $\mathrm{Mo}$ from the precipitate destabilizes the ferrite phase, which transforms to a secondary austenite phase. Due to its formation mechanism, the secondary austenite is depleted in $\mathrm{Cr}$ and $\mathrm{Mo}$ compared to the primary austenite, and is believed to cause increased susceptibility to localized corrosion.

Outside the precipitated region, the non-transformed ferrite matrix showed some grainboundary $\mathrm{Cr}$ depletion, as shown in Figure 13, although the levels of $\mathrm{Cr}$ depletion were not as severe as those observed in the secondary austenite.
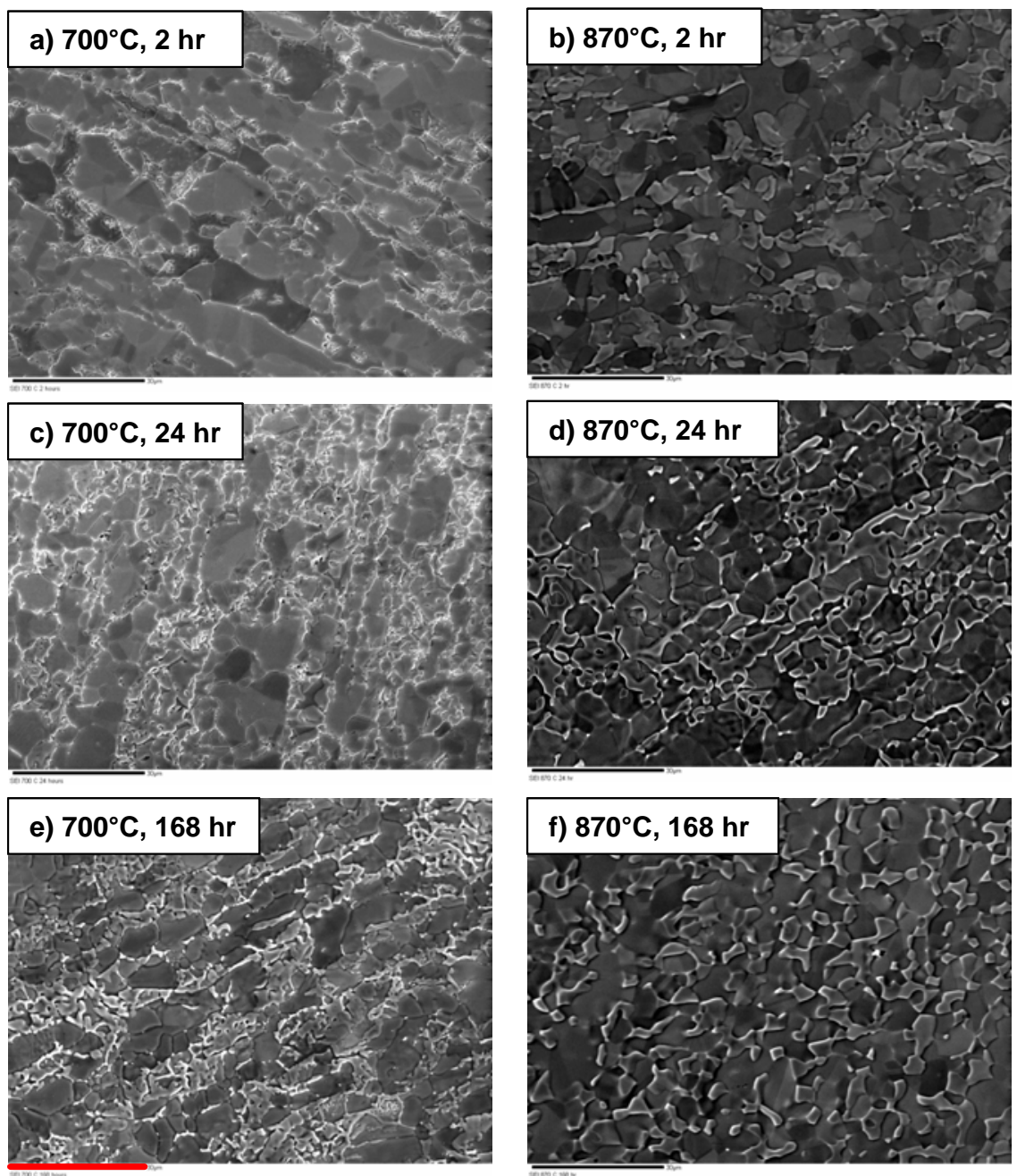

$30 \mu \mathrm{m}$

Figure 10. Microstructural evolution of 2205 duplex stainless steel as a function of aging time and temperature. 

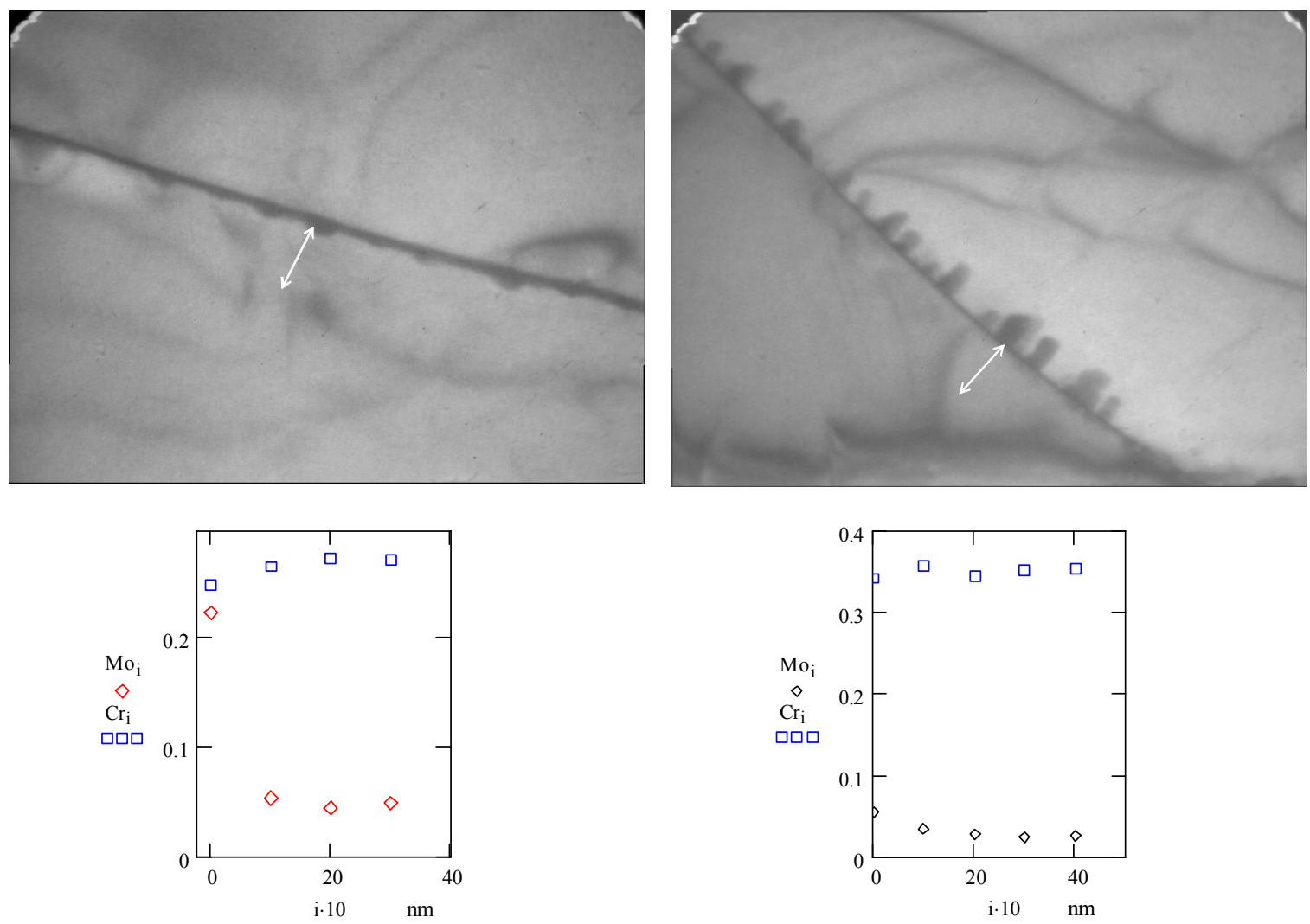

Figure 11. $\alpha / \alpha$ (ferrite/ferrite) and $\alpha / \gamma$ (ferrite/austenite) grain boundary precipitates observed in 2205 duplex stainless steel after $0.5 \mathrm{hr}$ aging at $700^{\circ} \mathrm{C}$. In the EDS composition maps, the ratios of elemental peak intensities are shown on the vertical axes.
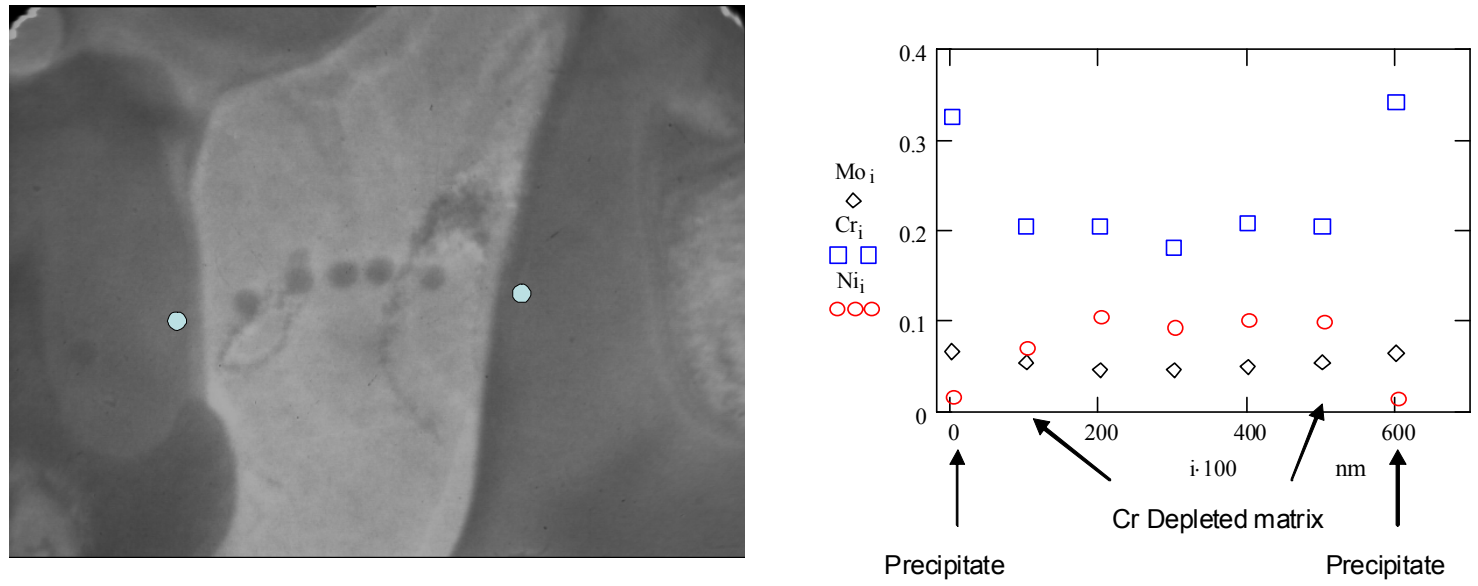

Figure 12. Cr-rich precipitates and secondary austenite in alloy 2205 observed after 5 hrs of aging at $700^{\circ} \mathrm{C}$. The EDS profile was measured at the locations represented by blue dots in the image. The ordinate shows the ratios of $\mathrm{Mo}, \mathrm{Cr}$ and $\mathrm{Ni}$ to $\mathrm{Fe}$. 

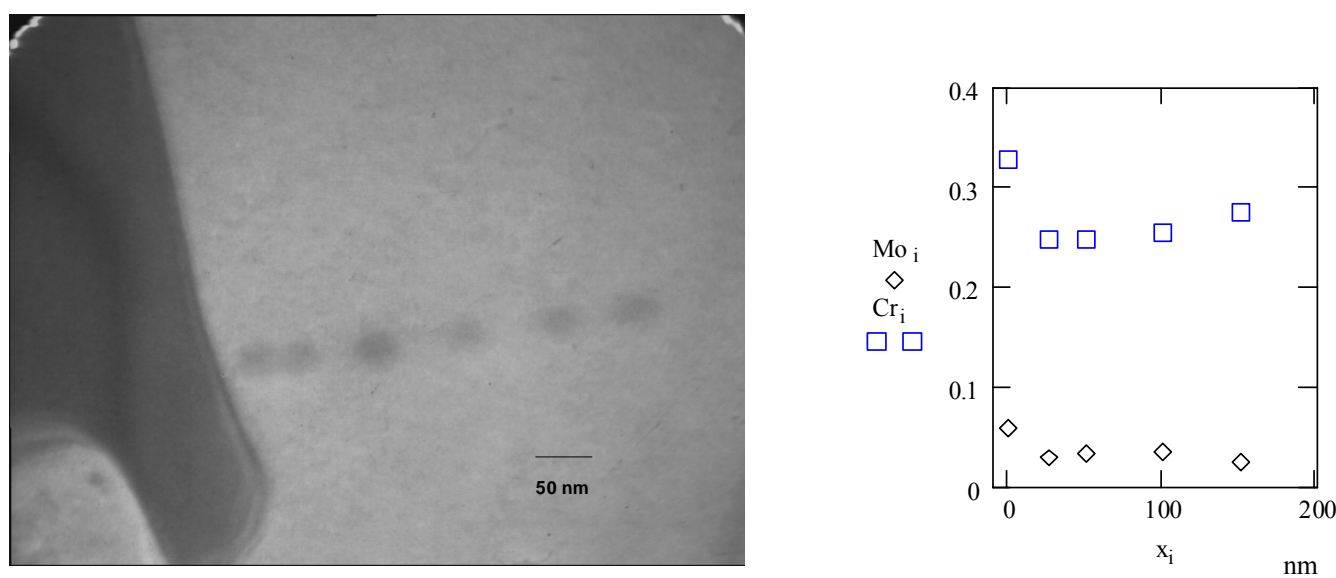

Figure 13. Non-transformed ferrite matrix observed outside of the precipitated region of alloy 2205 after aging for $5 \mathrm{hrs}$ at $700^{\circ} \mathrm{C}$ indicating GBCD at the precipitate - ferrite interface. The EDS profile was measured at the locations represented by blue dots in the image. The ordinate shows the ratios of Mo and Cr to Fe.

This finding is further verified in Figure 14, which shows the micrograph and composition profile across a primary austenite-secondary austenite boundary. The transition from the primary phase to the secondary phase is denoted on the EDS profile. A sharp increase in $\mathrm{Cr}$ concentration can be observed at the secondary austenite primary austenite boundary.
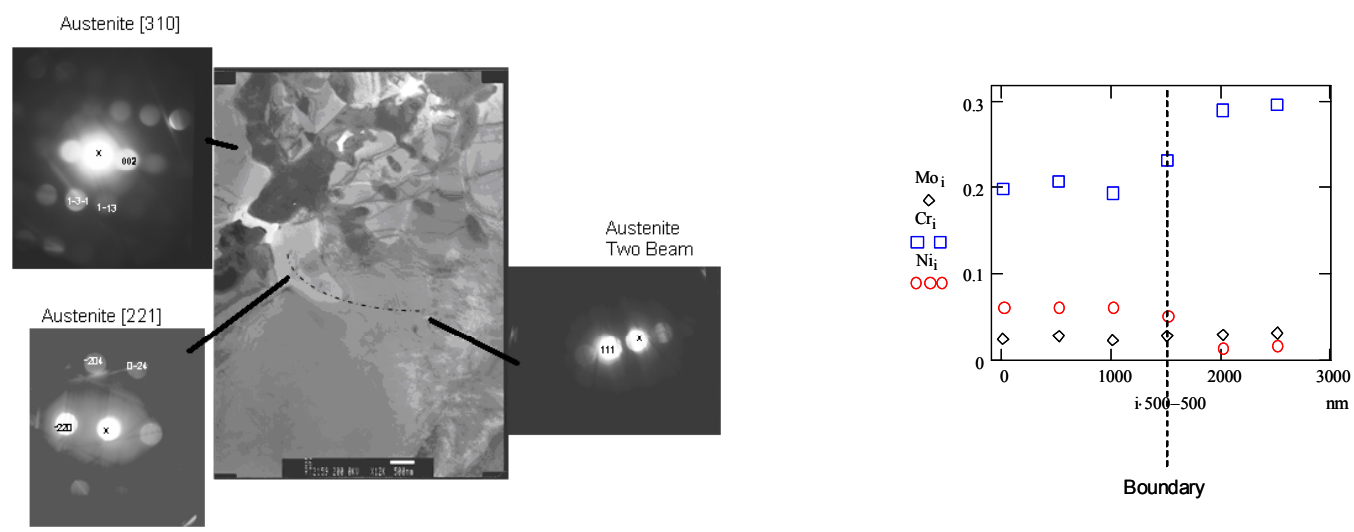

Figure 14. Grain boundary between the primary and secondary austenite phases observed after $\mathbf{5 ~ h r}$ aging at $700^{\circ} \mathrm{C}$. The EDS profile was measured along the dotted line shown in the micrograph. The boundary between the two phases is shown as a vertical line in the composition profile.

Following 24 hours of thermal treatment at $700^{\circ} \mathrm{C}$, the STEM imaging revealed even more severe GBCD, evident as more heavily etched regions of the TEM specimen during electropolishing, as illustrated in Figure 15, left. Corresponding EDS profile taken from the grain boundary extending into the matrix phased also indicated GBCD (Figure 15, 
right, top). EDS profiles were also measured at the different spots of the phases present in the precipitated region and are shown in Figure 15 (right, bottom), as well.
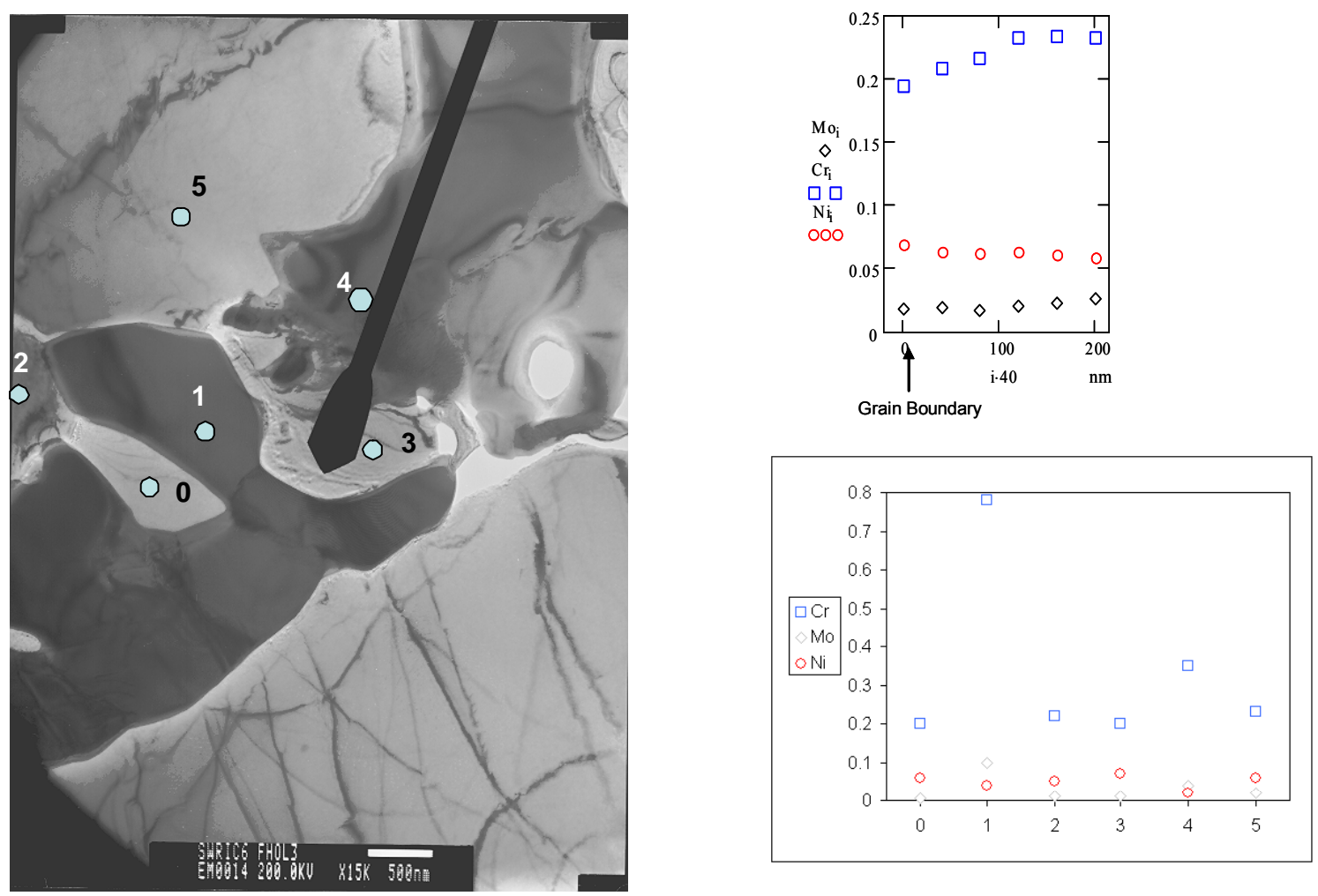

Figure 15. STEM image (left) and corresponding EDS profiles (right) of various phases in the precipitated region of alloy 2205 after $24 \mathrm{hr}$ aging at $700^{\circ} \mathrm{C}$. Sensitization at this heat treatment was evidenced by preferentially thinned grain boundaries in the micrograph as well as by $\mathrm{Cr}$ enrichment away from the grain boundary in the EDS line profile (right, top).

The Cr depletion at the grain boundaries dropped below the $\mathrm{Cr}$ level of the secondary austenite (phases marked as 0, 2, 3 and 5). The precipitate in spot 1 showed enormous $\mathrm{Cr}$ enrichment, while the precipitate in spot 4 showed little $\mathrm{Cr}$ enrichment and only slight Mo enrichment. These findings were different from the profiles seen at 0.5 and $5 \mathrm{hrs}$ of aging. It is evident that as the isothermal aging time increases, the Cr-depleted secondary austenite phase continues to grow, composing an increasing volume fraction of the microstructure. This phase is estimated to contain approximately $12.5 \% \mathrm{Cr}$ based on the $\mathrm{Cr} / \mathrm{Fe}$ intensity ratios from EDS profiles taken from the secondary austenite and parent ferrite phase from which it precipitated. The primary ferrite is estimated to contain roughly $24 \% \mathrm{Cr}$.

STEM imaging was also performed on specimens aged at $870^{\circ} \mathrm{C}$ for $0.5-2 \mathrm{hrs}$. Figure 16 shows a micrograph of the precipitated region observed after $0.5 \mathrm{hr}$ aging time along 
with selected areas X-ray diffraction (SAD) and EDS profile results. Precipitates appeared larger at this temperature than for comparable treatments at $700^{\circ} \mathrm{C}$.
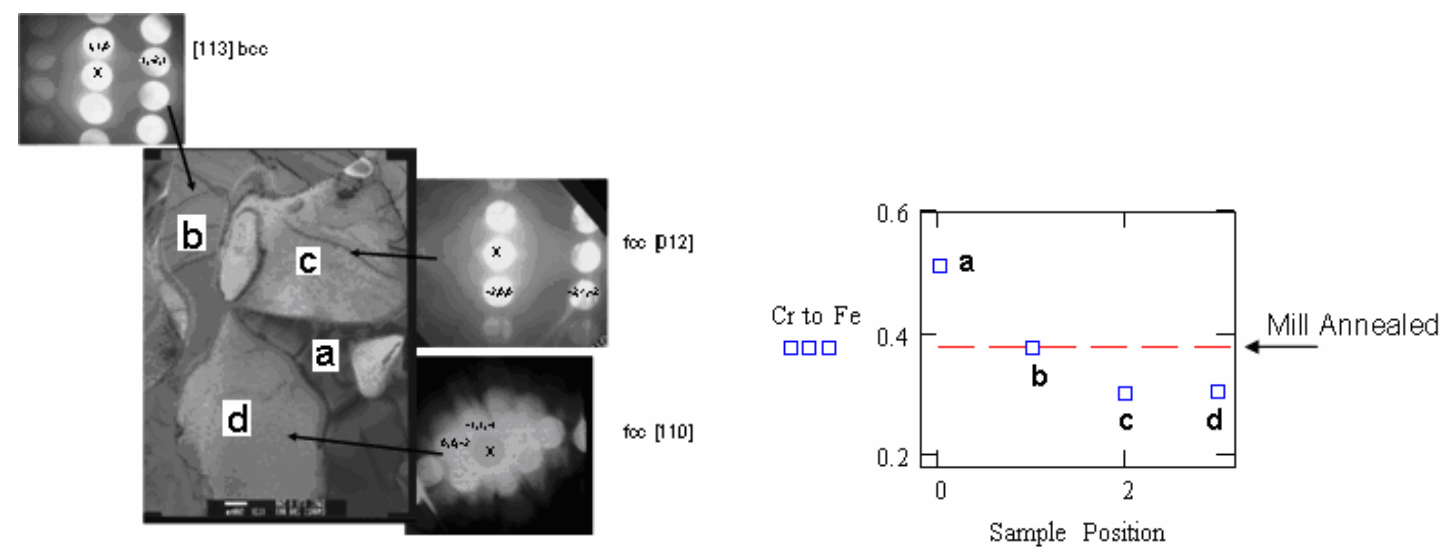

Figure 16. Micrograph, SAD images and $\mathrm{Cr} / \mathrm{Fe}$ ratio measured by EDS of alloy 2205 exposed to $870^{\circ} \mathrm{C}$ for $0.5 \mathrm{hr}$. The locations from which the EDS profiles were collected are labeled in the micrograph.

The precipitate (a) is shown as the dark spike in the image, which is surrounded by two austenite phases (c and d) that appear to be consuming a ferrite grain (b). The precipitate is highly enriched in $\mathrm{Cr}$, while the two secondary austenite grains are $\mathrm{Cr}$-depleted, though not to the extent seen at $700^{\circ} \mathrm{C}$. The intact ferrite grain showed no compositional deviation from the mill-annealed ferrite. After two hours at $870^{\circ} \mathrm{C}$, however, the specimen did not show any ferrite or austenite grains with compositions similar to that observed for the mill annealed sample. Figure 17 displays the $\mathrm{Cr}$ to $\mathrm{Fe}$ ratio determined at the center of 9 different grains and that at a precipitate phase.

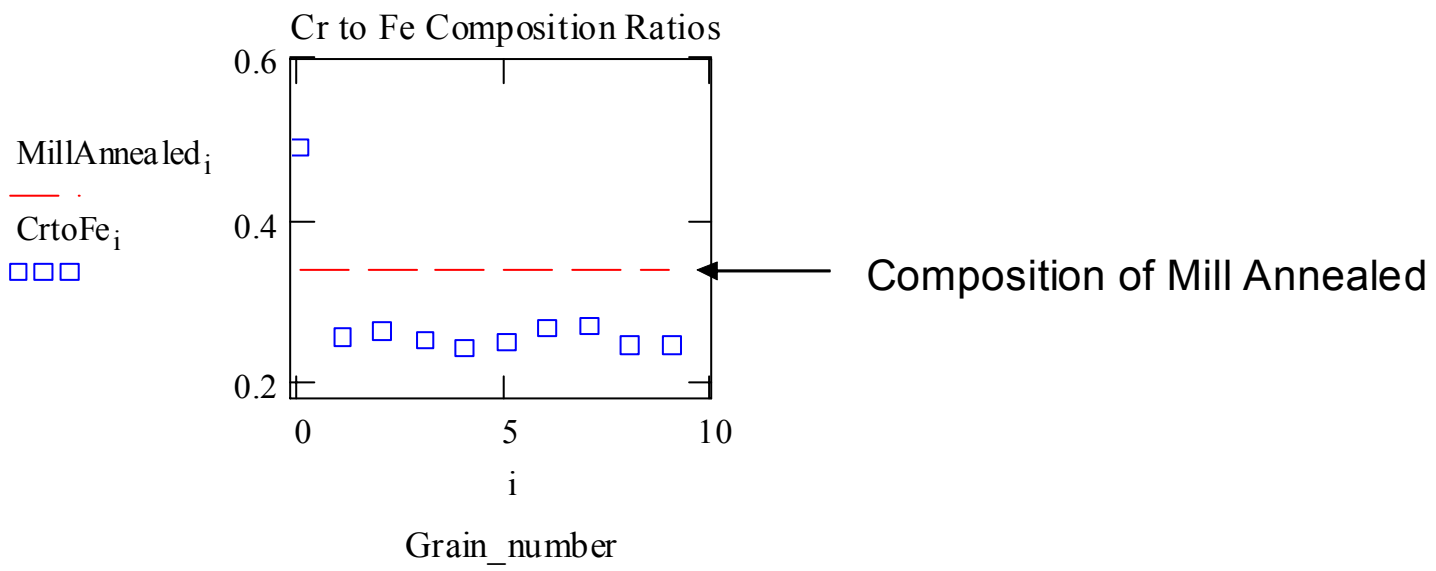

Figure 17. EDS profiles of various selected phases of alloy 2205 after isothermal heat treatment at $8^{\circ}{ }^{\circ} \mathrm{C}$ for 2 hours. 
All of the grains examined were depleted in $\mathrm{Cr}$ with respect to the mill-annealed composition. While the secondary austenite phase observed at this isothermal heat treatment temperature was not as severely depleted as that found in case of the material aged at $700^{\circ} \mathrm{C}$, it appeared sooner at $870^{\circ} \mathrm{C}$ and was more abundant after longer aging times than at $700^{\circ} \mathrm{C}$ (Figure 10$)$.

\section{Measurement of Electrochemical Parameters}

$E_{c o r r}$ and $E_{r p}$ of Base Alloys

\section{Corrosion Potential Measurements}

Effect of Oxidizing Species and pH on $E_{\text {corr }}$ of Selected Alloys. The corrosion potentials of 316L, 2205 and C-22 were measured in $0.5 \mathrm{M} \mathrm{Na}_{2} \mathrm{SO}_{4}$ in a hydrogen atmosphere $(\mathrm{p}=1$ atm) as described in Section 2.3.1. The measurements were carried out in a chloride-free environment in order to avoid any localized corrosion. The corrosion potentials were measured against standard hydrogen electrode. The redox potential of a platinized platinum electrode was also measured in the same cell to determine the presence or absence of trace amounts of oxidizing agents (oxygen, nitrate etc. contaminants). The measured corrosion potentials as a function of time are summarized in Table 6.

Table 6. Corrosion potentials measured on three alloys in hydrogen de-aerated solutions of $0.5 \mathrm{M} \mathrm{Na}_{2} \mathrm{SO}_{4}$ at ambient temperature.

\begin{tabular}{|c|c|c|c|c|c|c|}
\hline \multirow{3}{*}{$\begin{array}{l}\text { Exposure } \\
\text { Time (hr) }\end{array}$} & \multicolumn{6}{|c|}{ Measured Potential (V) } \\
\hline & \multicolumn{2}{|c|}{ Cell\#1, pH = 6.45} & \multicolumn{2}{|c|}{ Cell \#2, pH = 8.23 } & \multicolumn{2}{|c|}{ Cell \#3 } \\
\hline & $316 \mathrm{~L}$ & Platinized Pt & 2205 & Platinized Pt & C-22 & Platinized Pt \\
\hline 0 & -0.018 & -0.668 & -0.098 & -0.652 & -0.092 & -0.626 \\
\hline 0.5 & -0.030 & -0.670 & -0.099 & -0.653 & -0.098 & -0.667 \\
\hline 1.0 & -0.041 & -0.671 & -0.112 & -0.654 & -0.103 & -0.688 \\
\hline 1.5 & -0.047 & -0.671 & -0.117 & -0.655 & -0.106 & -0.692 \\
\hline 2.0 & -0.055 & -0.671 & -0.122 & -0.656 & -0.114 & -0.693 \\
\hline 2.5 & -0.063 & -0.671 & -0.125 & -0.659 & -0.127 & -0.693 \\
\hline 3.0 & -0.069 & -.672 & -0.129 & -0.660 & -0.132 & -0.692 \\
\hline 3.5 & -0.080 & -0.673 & -0.137 & -0.663 & -0.142 & -0.690 \\
\hline 19.25 & -0.166 & -0.685 & -0.217 & -0.685 & -0.340 & -0.696 \\
\hline 20.5 & -0.168 & -0.684 & -0.219 & -0.673 & -0.356 & -0.695 \\
\hline 21.5 & -0.173 & -0.681 & -0.220 & -0.663 & -0.363 & -0.694 \\
\hline 22.5 & -0.174 & -0.681 & -0.223 & -0.656 & -0.367 & -0.694 \\
\hline 24.0 & -0.176 & -0.684 & -0.227 & -0.649 & -0.373 & -0.698 \\
\hline 26.0 & -0.178 & -0.682 & -0.232 & -0.644 & -0.373 & -0.700 \\
\hline 27.0 & -0.181 & -0.682 & -0.232 & -0.642 & -0.378 & -0.700 \\
\hline 43.75 & -0.192 & -0.682 & -0.255 & -0.632 & -0.414 & -0.701 \\
\hline 46.5 & -0.196 & -0.683 & -0.259 & -0.629 & -0.422 & -0.702 \\
\hline 48.33 & -0.197 & -0.684 & -0.259 & -0.629 & -0.426 & -0.701 \\
\hline 51.5 & -0.197 & -0.683 & -0.265 & -0.627 & -0.432 & -0.703 \\
\hline & & $\begin{array}{l}\text { Calculated: } \\
-0.623\end{array}$ & & $\begin{array}{c}\text { Calculated: } \\
-0.728\end{array}$ & & $\begin{array}{c}\text { Calculated: } \\
-0.749\end{array}$ \\
\hline
\end{tabular}


The potentials on Pt for $316 \mathrm{~L}$ and $\mathrm{C}-22$ were found to be comparable to the values calculated for $25^{\circ} \mathrm{C}$ from the measured $\mathrm{pH}$ using the equation below:

$$
E_{P t}=-\frac{2.303 R T}{F} p H-\frac{R T}{2 F} \ln \left(\frac{p_{H_{2}}}{p_{0}}\right)
$$

The slight differences between the measured and calculated values $(-60 \mathrm{mV}$ for $316 \mathrm{~L} \mathrm{SS}$ and $+46 \mathrm{mV}$ for C-22) reflect a combination of factors including liquid junction potentials, surface contamination and ambient temperature. The potential of Pt in the duplex SS 2205 cell was significantly higher than the calculated value $(\Delta \mathrm{E}=+100 \mathrm{mV})$, which was probably due to the presence of oxidizing contaminants in the solution (nitrate ions, oxygen). The corrosion potential of all three alloys was found to be significantly different from each other. This may reflect differences in hydrogen ion reduction exchange current densities on the three surfaces.

After determining the corrosion potential of the base alloys in a neutral solution, the effect of $\mathrm{pH}$ in the presence of constant concentration of oxidizing species $\left(\mathrm{NO}_{3}{ }^{-}\right.$ions $)$ was investigated. Mixtures of sodium sulfate + sodium nitrate + nitric acid + sulfuric acid were used to obtain different $\mathrm{pH}$ values at a constant total nitrate ion concentration $(0.5$ M). The effect of $\mathrm{pH}$ on the corrosion potential of platinized platinum is shown in Figure 18a. The potentials of platinized $\mathrm{Pt}$ in $\mathrm{NaCl}$ and $\mathrm{Na}_{2} \mathrm{SO}_{4}$ solutions were close to the theoretical slope of hydrogen electrodes $(-0.59 \mathrm{pH})$ at room temperature suggesting that oxygen was not a significant contributor to the cathodic current density. Figure 18a indicates that above $\mathrm{pH} 2.5$, the nitrates had no effect on the corrosion potential. At $\mathrm{pH}$ values below 2.5 , the corrosion potentials measured in the presence of nitrates were significantly higher than those measured without $\mathrm{NO}_{3}{ }^{-}$ions, even though there was significant scatter in the data.

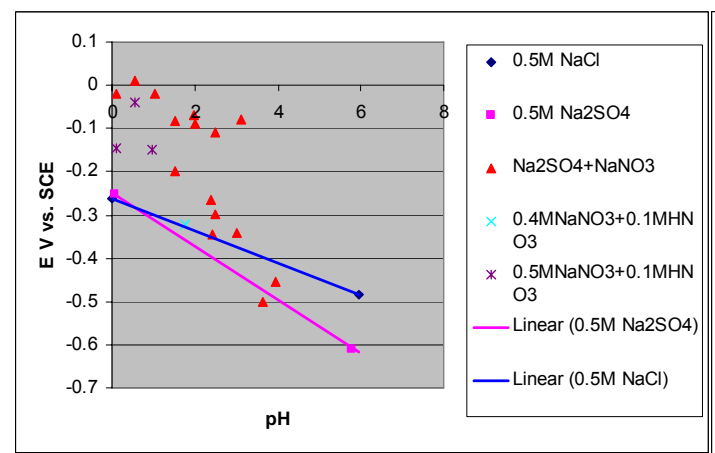

(a)

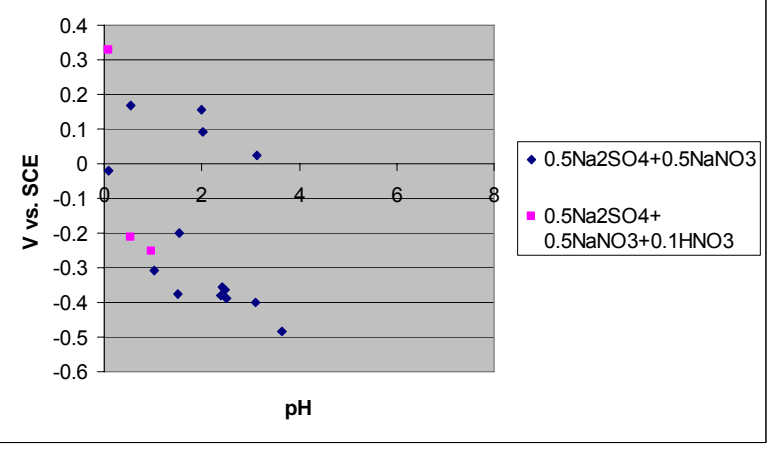

(b)

Figure 18. Corrosion potential of platinized $\mathrm{Pt}$ in $\mathrm{Na}_{2} \mathrm{SO}_{4}$ solutions. The trendlines show the potentials in $0.5 \mathrm{M} \mathrm{NaCl}$ and $0.5 \mathrm{M} \mathrm{Na}_{2} \mathrm{SO}_{4}$ solutions. The slopes of these lines are -0.44 and -0.57 , respectively.

The corrosion potentials of $\mathrm{C}-22$ measured in the same $\mathrm{NO}_{3}{ }^{-}-\mathrm{SO}_{4}{ }^{2-}$ solution mixtures are shown in Figure 18b. As in case of Pt, the corrosion potentials at $\mathrm{pH}$ values above 2.5 did not show any effect of the nitrate ions. At lower $\mathrm{pH}$ values, however, the potentials 
measured in the presence of nitrates were higher than those without nitrates indicating the possibility of cathodic reactions arising from the $\mathrm{NO}_{3}{ }^{-}$ions.

Effect of Free Chlorine Concentration on $E_{\text {corr }}$ of $\mathrm{Cu}$-Ni Alloys. The corrosion potentials of $\mathrm{Cu}-\mathrm{Ni}$ alloys (M400, CDA706 and CDA715) were measured in synthetic seawater with and without the presence of free chlorine. The solutions were not deaerated in this case. The dissolved oxygen concentrations $\left(\mathrm{DO}_{2}\right)$ were monitored and they were found to be very similar for all three alloys $(\sim 6.8 \mathrm{ppm})$ and they did not change significantly with time. The corrosion potentials as a function of time at different chlorine concentrations are shown in Figures 19a-c.

(a)

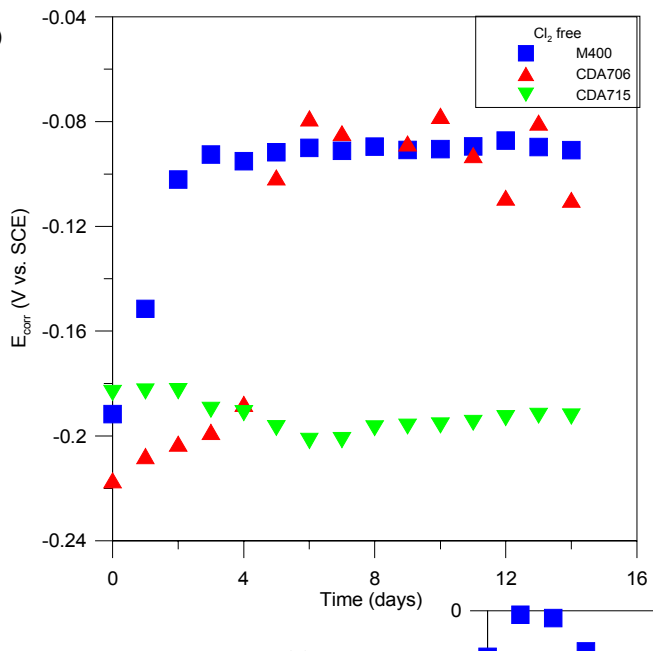

(b)

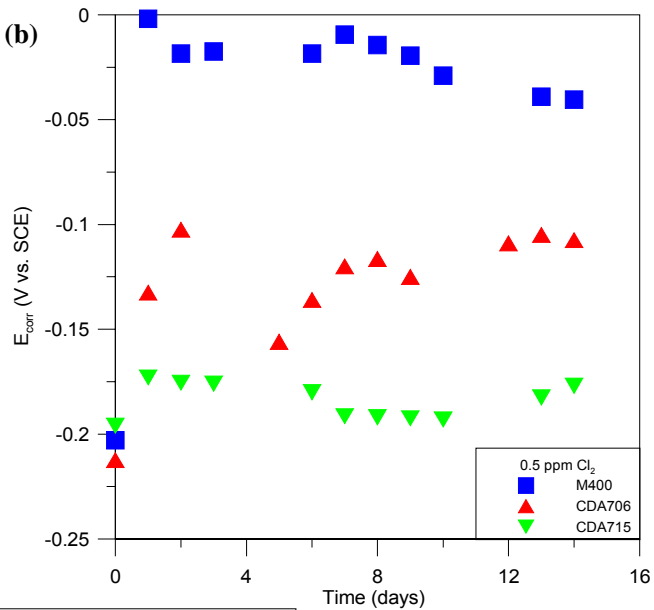

(c)

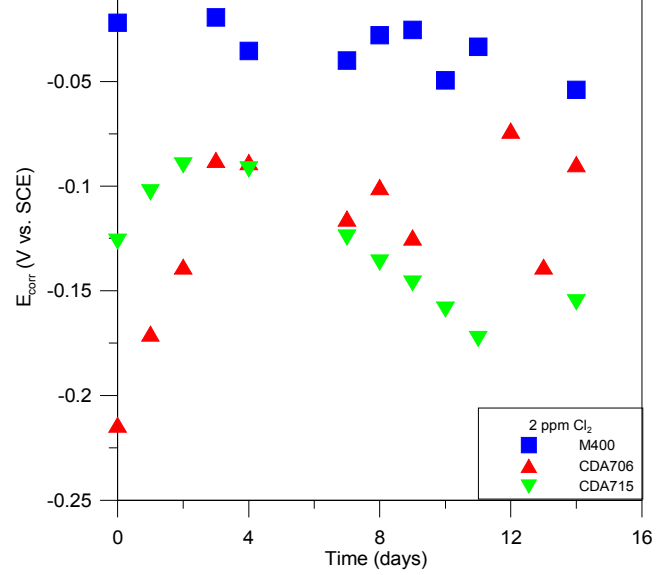

Figure 19. Corrosion potential of M400, CDA706 and CDA715 in synthetic seawater containing (a) 0 ppm, (b) 0.5 ppm and (c) 2 ppm free chlorine.

The corrosion potential of CDA715 was lower than that of M400 and CDA706 at all chlorine levels. This might have been due to the difference in Ni enrichment of the surface. The corrosion potential was expected to be higher at higher surface $\mathrm{Ni}$ concentrations. Figures 20a-c summarize the corrosion potentials for the individual alloys at different chlorine levels. 

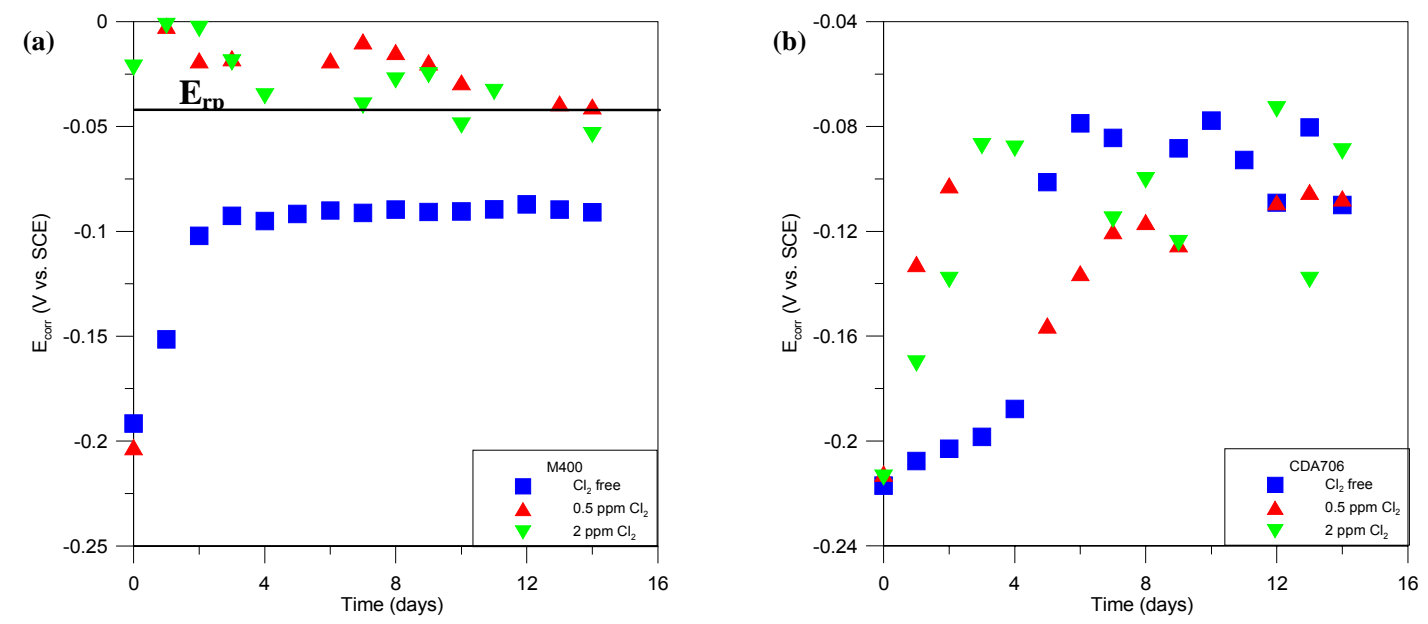

(c)

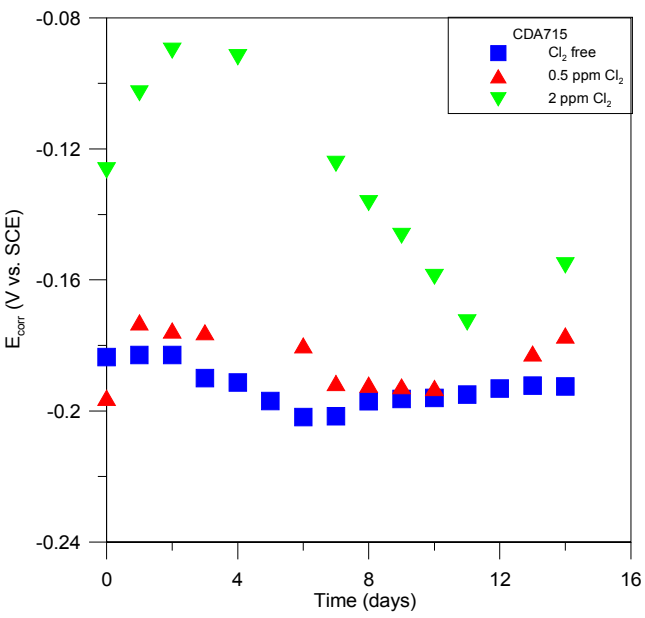

Figure 20. Corrosion potential of (a) M400, (b) CDA706 and (c) CDA715 at different chlorine levels (0, 0.5 and 2 ppm).

$\mathrm{E}_{\text {corr }}$ of M400 was found to be higher in solutions containing free chlorine than in $\mathrm{Cl}_{2}$-free environments, however, it is independent of the chlorine concentration in the investigated concentration range. $\mathrm{E}_{\text {corr }}$ of CDA706 did not depend on the chlorine level, while that of CDA715 increased at $2 \mathrm{ppm}$ free $\mathrm{Cl}_{2}$ level. In order to further investigate the effect of free chlorine concentration on the corrosion potential of $\mathrm{Cu}-\mathrm{Ni}$ alloys, the anodic and cathodic potentiodynamic polarization curves were measured. Figures $21 \mathrm{a}-\mathrm{c}$ show the anodic cyclic potentiodynamic polarization curves of the three alloys at different chlorine levels. M400 showed passivity at 0 and $0.5 \mathrm{ppm} \mathrm{Cl}_{2}$ concentrations, while it was actively corroding at $2 \mathrm{ppm} \mathrm{Cl}_{2}$ level. The passive range, however, was very narrow at $0.5 \mathrm{ppm}$. 

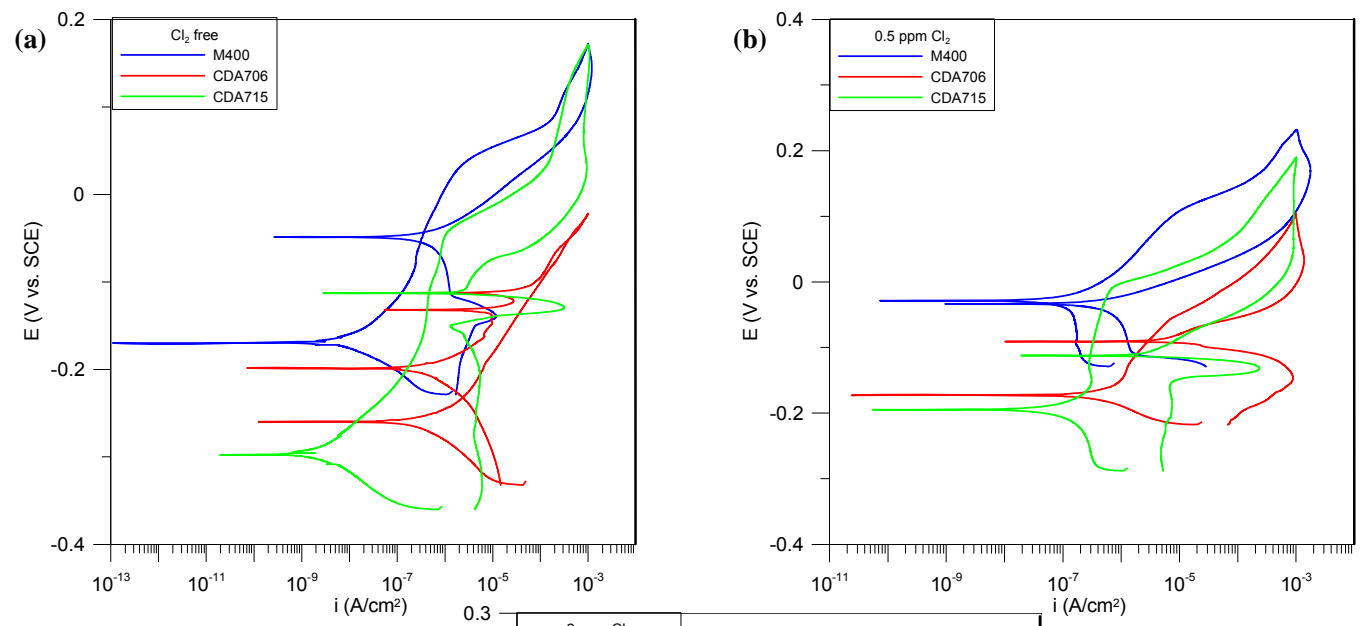

(c)

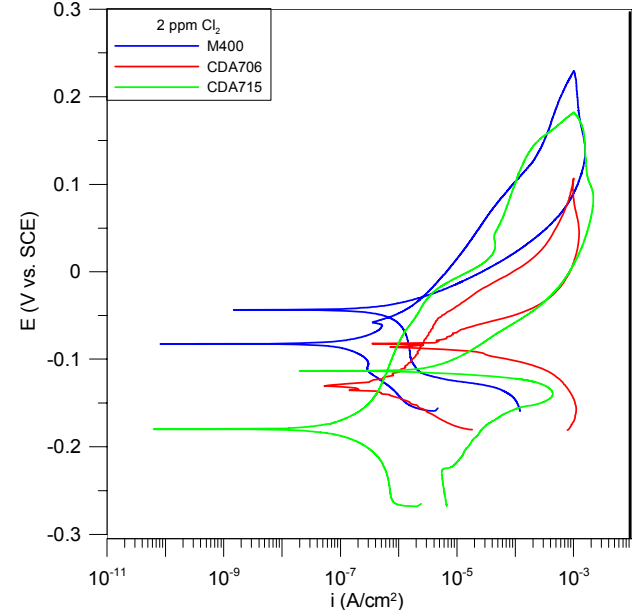

Figure 21. Cyclic potentiodynamic polarization curves of M400, CDA706 and CDA715 at (a) 0 ppm, (b) 0.5 ppm and (c) 2 ppm $\mathrm{Cl}_{2}$ levels.

This finding was in agreement with the $\mathrm{E}_{\text {corr }}$ values observed at different $\mathrm{Cl}_{2}$ levels. The corrosion potential remained below the repassivation potential $\left(\mathrm{E}_{\mathrm{rp}}\right)$ of the alloy when no free chlorine was present as shown in Figure 20a. When the solution contained at least $0.5 \mathrm{ppm}$ free chlorine, the corrosion potential exceeded $\mathrm{E}_{\mathrm{rp}}$ for some period of time. Visual examination of the specimens revealed the presence of significant localized corrosion damage on the surface at $2 \mathrm{ppm}$ free chlorine concentration, while the least amount of pitting was observed in case of chlorine free exposures (Figure 22). CDA 706, which contains the least amount of $\mathrm{Ni}$ as alloying element, actively corroded at all chlorine levels. CDA 715, however, was only active at $2 \mathrm{ppm} \mathrm{Cl}_{2}$ concentration. 
no $\mathrm{Cl}_{2}$

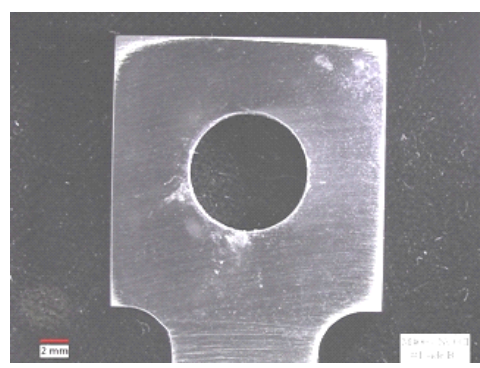

$0.5 \mathrm{ppm} \mathrm{Cl}_{2}$

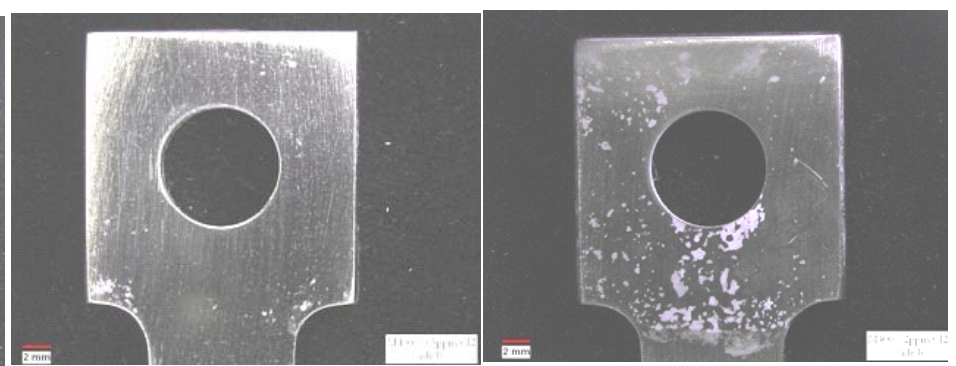

Figure 22. Low magnification optical microscope images of M400 exposed to synthetic seawater containing different free chlorine concentrations for 14 days.

The cathodic potentiodynamic polarization scans of M400, CDA706 and CDA715 at different chlorine levels are shown in Figures 23a-d.
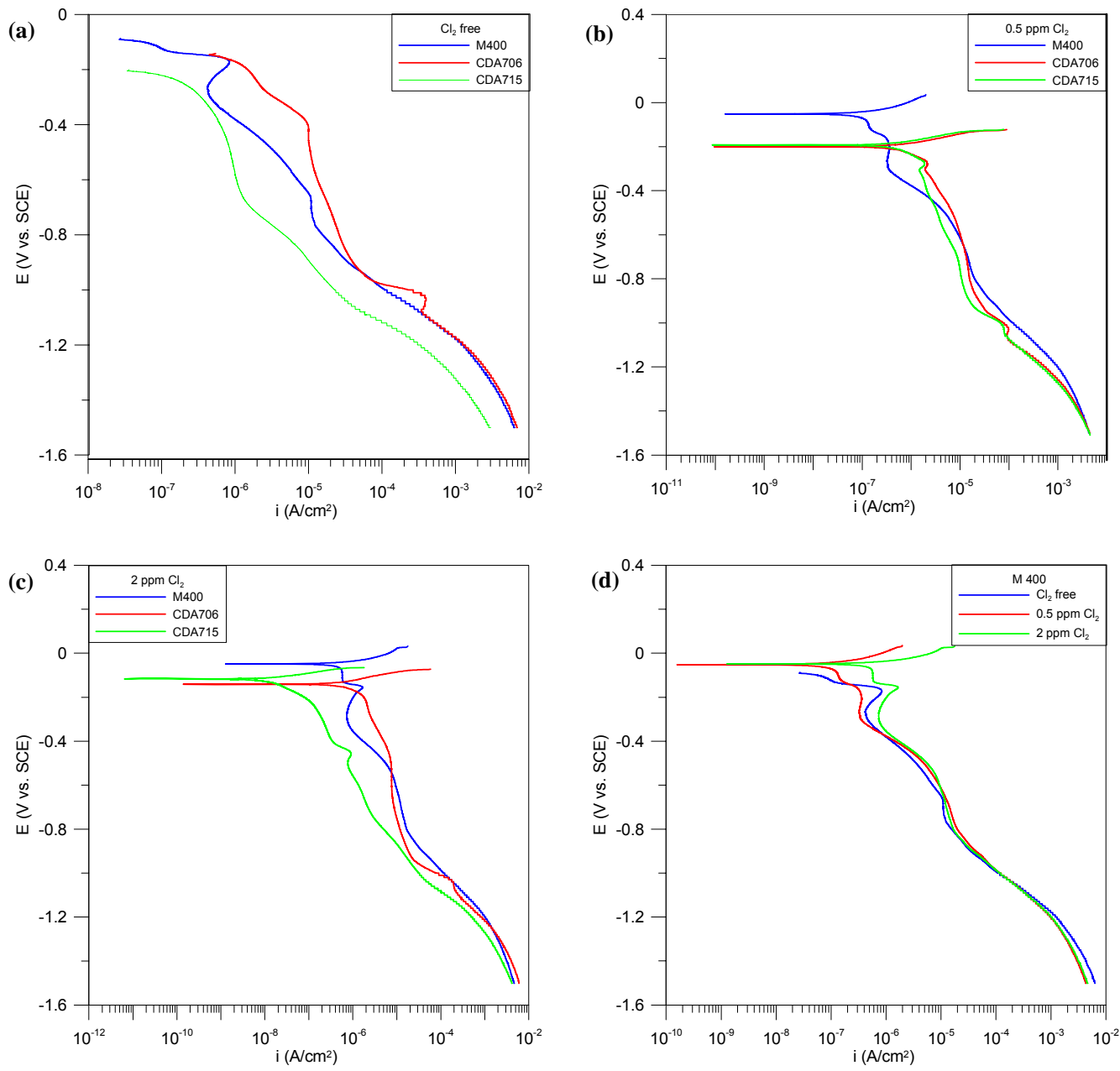

Figure 23. Cathodic potentiodynamic polarization curves of M400, CDA706 and CDA715 at (a) 0 ppm $\mathrm{Cl}_{2}$, (b) $0.5 \mathrm{ppm} \mathrm{Cl}_{2}$ and (c) $2 \mathrm{ppm} \mathrm{Cl}_{2}$ as well as (d) those of M400 at different chlorine levels. 
Figures 23a-c compare the different alloys at constant chlorine levels, while Figure 22d compares M400 at different chlorine levels. In $\mathrm{Cl}_{2}$ free environment, CDA715 showed the lowest cathodic current density, which indicates low ORR rate, while CDA706 had the highest cathodic current density indicating high ORR rate. These findings are consistent with the low $\mathrm{E}_{\text {corr }}$ found in case of CDA715 and high $\mathrm{E}_{\text {corr }}$ in case of CDA706 in chlorine-free environment. CDA706 has high $\mathrm{Cu}$ concentration in the bulk, which most likely results in a high surface $\mathrm{Cu}$ concentration, which leads to high ORR rates. The CDA715 surface might be enriched in $\mathrm{Ni}$, which explains the low ORR rates. The high $\mathrm{E}_{\text {corr }}$ of M400 might be due to high ORR caused by $\mathrm{Cu}$ enrichment on the outside surface layer. No significant differences were found in case of individual alloys at different free chlorine concentrations, as the example of M400 indicates in Figure 22d.

\section{Crevice Repassivation Potential Measurements}

$\mathrm{Cu}$-Ni Alloys. The crevice corrosion properties of $\mathrm{Cu}-\mathrm{Ni}$ alloys (M400, CDA706 and CDA715) were determined as a function of several environmental variables in order to provide input parameters for the OLI model. The environmental variables investigated were: chloride ion concentration, presence or absence of $\mathrm{pH}$ buffer, temperature and bulk solution $\mathrm{pH}$. Cyclic potentiodynamic polarization scans were performed on crevice specimens in deaerated solutions to determine the corrosion potential $\left(\mathrm{E}_{\text {corr }}\right)$, crevice stabilization potential $\left(\mathrm{E}_{\mathrm{crev}}\right)$ and crevice repassivation potential $\left(\mathrm{E}_{\mathrm{rcrev}}\right)$. The details of the experimental procedure are given in sections 2.1 and 2.3.2 above. The cyclic potentiodynamic polarization curves of M400 crevice specimens at different chloride levels under alkaline conditions are shown in Figure 24. The alloy exhibited passivity in this $\mathrm{Cl}^{-}$concentration range due to oxide growth by migration under a high electric field (Zaky and Assaf, 2002). The breakdown of this film is believed to occur when the chemisorbed chloride ions on the surface react with $\mathrm{Cu}$, promoting its dissolution according to the following equations (Milosev and Metikos-Hukovic, 1991):

$$
\begin{aligned}
& \mathrm{Cu}+\mathrm{Cl}^{-}=\mathrm{CuCl}+e^{-} \\
& \mathrm{CuCl}+\mathrm{Cl}^{-}=\mathrm{CuCl} l_{2}^{-}
\end{aligned}
$$

Under alkaline conditions, the cuprous chloride complex reacts with $\mathrm{OH}^{-}$ions to form porous $\mathrm{Cu}(\mathrm{OH})_{\mathrm{x}} \mathrm{Cl}_{\mathrm{y}}$ precipitates on the surface that do not exhibit barrier properties.

Visual examination of the specimens revealed that the corrosion damage mainly occurred in areas just outside the crevice exposed to the bulk solution. This was due to the ennoblement of the potential in the crevice caused by accumulation of cuprous ions that occurs during the acidification of the crevice environment (Schleich, 2005). According to thermodynamic calculations, $\mathrm{Cu}^{+}$ion is highly soluble under acidic conditions $(\mathrm{pH} \leq 5)$. As the crevice environment becomes more acidic, the dissolution of $\mathrm{Cu}$ is facilitated by the solubility of $\mathrm{Cu}^{+}$ions, leading to $\mathrm{Cu}^{+}$accumulation in the crevice. The crevice stabilization (i.e., passivity breakdown) and repassivation potentials decrease with increasing $\mathrm{Cl}^{-}$concentration (Figure 24). The higher bulk $\mathrm{Cl}^{-}$concentration promotes the complex formation reactions (Equations 7 and 8), therefore facilitates the $\mathrm{Cu}$ dissolution reaction. Addition of a $\mathrm{pH}$ buffer, e.g., borate, is expected to shift $\mathrm{E}_{\text {crev }}$ to more noble potentials thereby inhibiting the localized corrosion reaction. This effect is shown in 
Figure $25 . \mathrm{E}_{\text {rcrev }}$, however, is not affected by the presence of the $\mathrm{pH}$ buffer, since the $\mathrm{H}^{+}$ concentration in an active crevice is significantly higher than the buffer capacity of the borate solution in the environment established after the growth of the crevice.

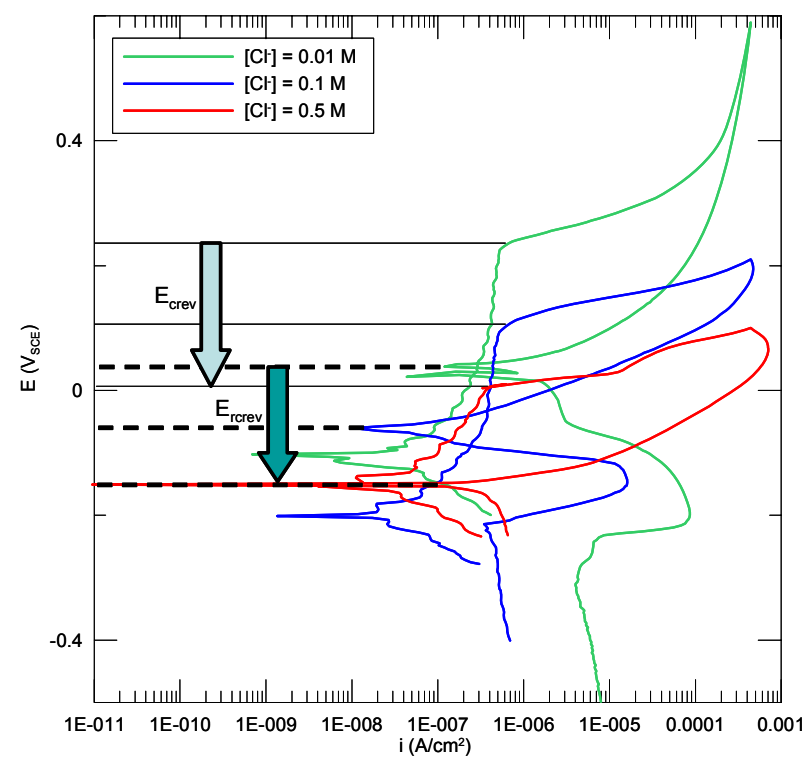

Figure 24. Cyclic potentiodynamic polarization curves of $\mathrm{M400}$ as a function of chloride ion concentration at room temperature under alkaline conditions (pH 11).

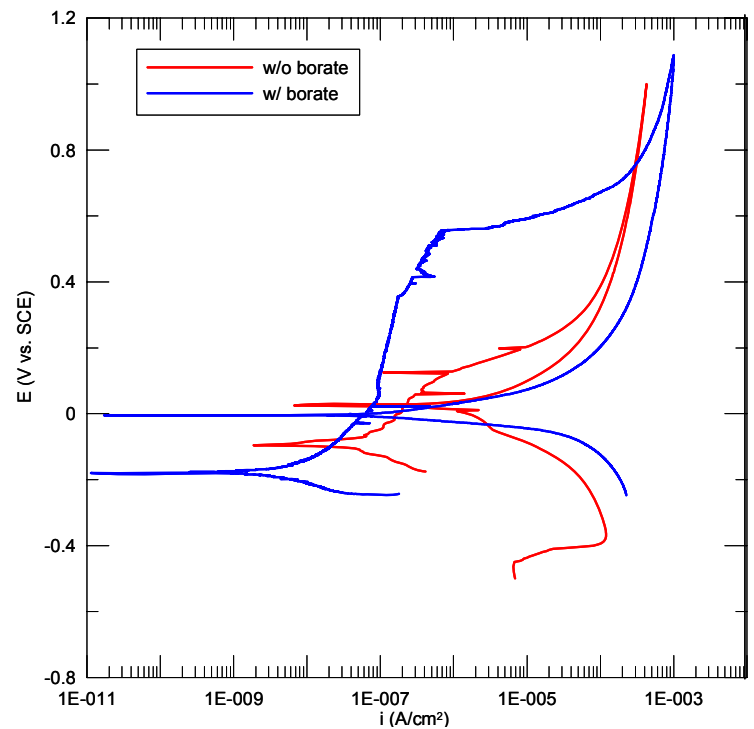

Figure 25. Cyclic potentiodynamic polarization curves of M400 in pH 9, $0.005 \mathrm{M}$ chloride solution with and without the presence of borate buffer.

In case of the high $\mathrm{Cu}$ containing alloys (CDA706 and CDA715), passivity could only be achieved by the addition of borate buffer at $\mathrm{pH} 9$, while they exhibited passivity without the presence of borate buffer at $\mathrm{pH} 11$. The borate buffer in this case acted as a corrosion inhibitor as indicated by Table 7, which compares the crevice stabilization and repassivation potentials in case of low chloride concentrations with and without the presence of borate buffer $(0.0106 \mathrm{M}$ sodium tetraborate $+0.002 \mathrm{M} \mathrm{NaOH})$. 
Table 7. Crevice stabilization and repassivation potentials of CDA715 alloy at room temperature with and without the presence of borate buffer.

\begin{tabular}{|c||cc||cc|}
\hline \multirow{2}{*}{$\left.\mathbf{c}\left(\mathbf{C l}^{-}\right) \mathbf{M}\right)$} & \multicolumn{2}{c||}{$\mathbf{E}_{\text {crev }}\left(\mathbf{V}_{\text {SCE }}\right)$} & \multicolumn{2}{c|}{$\mathbf{E}_{\text {rcrev }}\left(\mathbf{V}_{\text {SCE }}\right)$} \\
0.0005 & w/ borate & w/o borate & w/ borate & w/o borate \\
0.005 & 0.715 & 0.640 & 0.618 & 0.142 \\
& 0.750 & 0.583 & 0.678 & -0.009 \\
\hline
\end{tabular}

The corrosion, crevice stabilization and crevice repassivation potentials $\left(\mathrm{E}_{\mathrm{corr}}, \mathrm{E}_{\mathrm{crev}}\right.$ and $\mathrm{E}_{\mathrm{rcrev}}$, respectively) of M400 measured at different chloride levels and temperatures are summarized in Table 8 . These solutions did not contain borate buffer.

Table 8. $E_{\text {corr, }} E_{\text {crev }}$ and $E_{\text {rcrev }}$ of $M 400$ at different chloride levels and temperatures measured at pH 9.

\begin{tabular}{|c|c|c|c|c|}
\hline & $\mathbf{c}\left(\mathrm{Cl}^{-}\right)(\mathrm{M})$ & $E_{\text {corr }}\left(V_{\text {SCE }}\right)$ & $E_{\text {crev }}\left(V_{\text {SCE }}\right)$ & $E_{\text {rcrev }}\left(V_{\text {SCE }}\right)$ \\
\hline $\begin{array}{c}\text { Temperature: } \\
23^{\circ} \mathrm{C}\end{array}$ & $\begin{array}{c}0.0005 \\
0.005 \\
0.010 \\
0.050 \\
0.100 \\
0.250 \\
0.500\end{array}$ & $\begin{array}{l}-0.127 \\
-0.101 \\
-0.160 \\
-0.197 \\
-0.214\end{array}$ & $\begin{array}{c}0.258 \\
0.139 \\
0.079 \\
0.041 \\
0.014\end{array}$ & $\begin{array}{c}0.071 \\
0.025 \\
0.016 \\
0.015 \\
-0.069\end{array}$ \\
\hline $\begin{array}{c}\text { Temperature: } \\
60^{\circ} \mathrm{C}\end{array}$ & $\begin{array}{c}0.0005 \\
0.005 \\
0.01-0.5\end{array}$ & -0.233 & $\begin{array}{c}\mathrm{N} / \mathrm{D}^{\dagger} \\
-0.026 \\
\text { no passivity }\end{array}$ & -0.057 \\
\hline $\begin{array}{c}\text { Temperature: } \\
95^{\circ} \mathrm{C}\end{array}$ & $0.0005-0.5$ & & no passivity & \\
\hline
\end{tabular}

not determined

At higher temperatures, M400 exhibited no passivity at this $\mathrm{pH}$ level. At room temperature, the crevice stabilization and repassivation potentials decreased with increasing aggressive ion $\left(\mathrm{Cl}^{-}\right)$concentration, while the corrosion potential did not change significantly with temperature.

Table 9 summarizes the $\mathrm{E}_{\text {corr }}, \mathrm{E}_{\text {crev }}$ and $\mathrm{E}_{\text {rcrev }}$ of M400 at different chloride levels and temperatures in $\mathrm{pH} 11$ environment. In this case, M400 was passive at all investigated temperatures. The corrosion potential of M400 was not found to be dependent on $\mathrm{Cl}^{-}$ion concentration $\left(\mathrm{c}_{\mathrm{Cl}}\right.$ ) and/or temperature $(\mathrm{T})$. The crevice stabilization and repassivation potentials, on the other hand, consistently decreased with both increasing chloride ion concentration and temperature. At this higher $\mathrm{pH}$ level, the M400 was found to be passive throughout the measured concentration and temperature range. 
Table 9. $E_{\text {corr, }} E_{\text {crev }}$ and $E_{\text {rcrev }}$ of $M 400$ at different chloride levels and temperatures measured at pH 11.

\begin{tabular}{|c|cccc|}
\hline & $\left.\mathbf{c}\left(\mathbf{C l}^{-}\right) \mathbf{( M}\right)$ & $\mathbf{E}_{\text {corr }}\left(\mathbf{V}_{\mathbf{S C E}}\right)$ & $\mathbf{E}_{\text {crev }}\left(\mathbf{V}_{\mathbf{S C E}}\right)$ & $\mathbf{E}_{\mathbf{r c r e v}}\left(\mathbf{V}_{\mathbf{S C E}}\right)$ \\
\hline & 0.0005 & -0.197 & 0.384 & 0.052 \\
Temperature: & 0.005 & -0.141 & 0.228 & 0.015 \\
$23^{\circ} \mathrm{C}$ & 0.010 & -0.121 & 0.239 & 0.200 \\
& 0.050 & -0.154 & 0.151 & -0.037 \\
& 0.100 & .0 .168 & 0.115 & -0.05 \\
& 0.250 & -0.145 & 0.101 & -0.106 \\
& 0.500 & -0.148 & 0.042 & -0.142 \\
\hline & 0.0005 & -0.045 & 0.559 & 0.056 \\
Temperature: & 0.005 & -0.139 & 0.207 & 0.018 \\
$60^{\circ} \mathrm{C}$ & 0.010 & -0.168 & 0.168 & -0.035 \\
& 0.050 & -0.169 & 0.121 & -0.04 \\
& 0.100 & -0.181 & 0.035 & -0.158 \\
& 0.500 & -0.171 & -0.116 & -0.172 \\
\hline & 0.0005 & -0.371 & 0.264 & -0.149 \\
Temperature: & 0.005 & -0.180 & 0.098 & -0.177 \\
$95^{\circ} \mathrm{C}$ & 0.010 & -0.185 & 0.045 & -0.233 \\
& 0.050 & -0.169 & 0.076 & -0.251 \\
& 0.100 & -0.179 & -0.041 & -0.257 \\
& 0.500 & -0.199 & -0.053 & -0.223 \\
\hline
\end{tabular}

The corrosion, crevice stabilization and repassivation potentials of CDA706 measured at pH 9 are shown in Table 10. These solutions contained borate buffer in order to passivate the CDA 706 alloy. The corrosion potential values were found to be independent of the environmental parameters $\left(\mathrm{Cl}^{-}\right.$ion concentration, temperature). The crevice stabilization and repassivation potentials, on the other hand, decreased with increasing $\mathrm{Cl}^{-}$ concentration and temperature.

Table 10. $E_{\text {corr }}, E_{\text {crev }}$ and $E_{\text {rcrev }}$ of CDA706 at different chloride levels and temperatures measured at pH 9.

\begin{tabular}{|c|c|c|c|c|}
\hline & $\mathrm{c}\left(\mathrm{Cl}^{-}\right)(\mathrm{M})$ & $E_{\text {corr }}\left(V_{\text {SCE }}\right)$ & $E_{\text {crev }}\left(V_{\text {SCE }}\right)$ & $E_{\text {rcrev }}\left(V_{\text {SCE }}\right)$ \\
\hline \multirow{5}{*}{$\begin{array}{c}\text { Temperature: } \\
23^{\circ} \mathrm{C}\end{array}$} & 0.0005 & -0.069 & 0.809 & 0.672 \\
\hline & 0.005 & -0.133 & 0.773 & 0.005 \\
\hline & 0.010 & -0.062 & 0.533 & 0.010 \\
\hline & 0.050 & -0.182 & 0.207 & -0.032 \\
\hline & 0.500 & -0.232 & -0.066 & -0.077 \\
\hline \multirow{4}{*}{$\begin{array}{c}\text { Temperature: } \\
60^{\circ} \mathrm{C}\end{array}$} & 0.0005 & -0.088 & 0.300 & 0.196 \\
\hline & 0.005 & -0.275 & -0.002 & -0.020 \\
\hline & 0.050 & -0.179 & -0.013 & -0.258 \\
\hline & 0.500 & -0.298 & -0.120 & -0.292 \\
\hline $\begin{array}{c}\text { Temperature: } \\
95^{\circ} \mathrm{C}\end{array}$ & $0.0005-0.500$ & & no passivity & \\
\hline
\end{tabular}


The same electrochemical parameters for CDA706 at pH 11 are summarized in Table 11.

Table 11. $E_{\text {corr }}, E_{\text {crev }}$ and $E_{\text {rcrev }}$ of CDA706 at different chloride levels and temperatures measured at pH 11.

\begin{tabular}{|c|cccc|}
\hline & $\left.\mathbf{c}\left(\mathbf{C l}^{-}\right) \mathbf{( M}\right)$ & $\mathbf{E}_{\mathbf{c o r r}}\left(\mathbf{V}_{\mathbf{S C E}}\right)$ & $\mathbf{E}_{\text {crev }}\left(\mathbf{V}_{\text {SCE }}\right)$ & $\mathbf{E}_{\text {rcrev }}\left(\mathbf{V}_{\text {SCE }}\right)$ \\
\hline Temperature: & 0.005 & -0.399 & 0.612 & 0.035 \\
$23^{\circ} \mathrm{C}$ & 0.050 & -0.401 & 0.003 & -0.037 \\
& 0.500 & -0.428 & -0.066 & -0.267 \\
\hline \multirow{3}{*}{ Temperature: } & 0.005 & -0.477 & 0.330 & 0.087 \\
$60^{\circ} \mathrm{C}$ & 0.010 & -0.230 & 0.025 & 0.002 \\
& 0.050 & -0.439 & -0.070 & -0.059 \\
& 0.500 & & no passivity & \\
Temperature: & 0.005 & -0.486 & 0.058 & -0.037 \\
$95^{\circ} \mathrm{C}$ & 0.010 & -0.382 & 0.011 & -0.276 \\
& 0.050 & -0.497 & -0.050 & -0.270 \\
& 0.500 & & no passivity & \\
\hline
\end{tabular}

Due to the higher $\mathrm{OH}^{-}$concentration, the alloy exhibited passivity without the presence of an inhibitor, therefore, these solutions did not contain borate buffer. Similarly to the previous cases, the corrosion potential did not depend on $\mathrm{c}_{\mathrm{Cl}}$ and $\mathrm{T}$, while $\mathrm{E}_{\text {crev }}$ and $\mathrm{E}_{\mathrm{rcrev}}$ was found to be dependent on $\mathrm{c}\left(\mathrm{Cl}^{-}\right)$and $\mathrm{T}$.

Tables 12 and 13 show $\mathrm{E}_{\text {corr }}, \mathrm{E}_{\text {crev }}$ and $\mathrm{E}_{\text {rcrev }}$ of CDA715 as a function of temperature and chloride ion concentration at $\mathrm{pH} 9$ and 11, respectively. The $\mathrm{pH} 9$ solutions contained borate buffer in order to passivate the alloy, while the $\mathrm{pH} 11$ solutions did not contain any inhibitor species.

Table 12. $E_{\text {corr, }}, E_{\text {crev }}$ and $E_{\text {rcrev }}$ of CDA715 at different chloride levels and temperatures measured at pH 9.

\begin{tabular}{|c|c|c|c|c|}
\hline & $\left.\mathbf{C}\left(\mathbf{C l}^{-}\right) \mathbf{( M}\right)$ & $\mathbf{E}_{\text {corr }}\left(\mathbf{V}_{\mathbf{S C E}}\right)$ & $\mathbf{E}_{\text {crev }}\left(\mathbf{V}_{\mathbf{S C E}}\right)$ & $\mathbf{E}_{\text {rcrev }}\left(\mathbf{V}_{\mathbf{S C E}}\right)$ \\
\hline \multirow{3}{*}{$\begin{array}{c}\text { Temperature: } \\
23^{\circ} \mathrm{C}\end{array}$} & 0.0005 & -0.311 & 0.86 & 0.838 \\
\cline { 2 - 5 } & 0.005 & -0.251 & 0.866 & 0.584 \\
\cline { 2 - 5 } & 0.010 & -0.134 & 0.745 & 0.003 \\
\cline { 2 - 5 } & 0.050 & -0.309 & 0.202 & -0.016 \\
\hline \multirow{3}{*}{$\begin{array}{c}\text { Temperature: } \\
60{ }^{\circ} \mathrm{C}\end{array}$} & 0.500 & -0.387 & 0.020 & -0.097 \\
\cline { 2 - 5 } & 0.0005 & -0.284 & 0.784 & 0.730 \\
\cline { 2 - 5 } & 0.005 & -0.174 & 0.503 & -0.030 \\
\cline { 2 - 5 } & 0.010 & -0.035 & 0.181 & -0.025 \\
\hline \multirow{3}{*}{ Temperature: } & 0.050 & -0.312 & 0.018 & -0.194 \\
\hline $95^{\circ} \mathrm{C}$ & 0.500 & -0.280 & -0.057 & -0.109 \\
\cline { 2 - 5 } & 0.0005 & -0.344 & 0.648 & -0.130 \\
\cline { 2 - 5 } & 0.050 & -0.245 & 0.122 & -0.219 \\
\hline
\end{tabular}


Table 13. $E_{\text {corr, }}, E_{\text {crev }}$ and $E_{\text {rcrev }}$ of CDA715 at different chloride levels and temperatures measured at pH 11.

\begin{tabular}{|c|c|c|c|c|}
\hline & $\left.\mathbf{c}\left(\mathbf{C l}^{-}\right) \mathbf{( M}\right)$ & $\mathbf{E}_{\text {corr }}\left(\mathbf{V}_{\mathbf{S C E}}\right)$ & $\mathbf{E}_{\text {crev }}\left(\mathbf{V}_{\mathbf{S C E}}\right)$ & $\mathbf{E}_{\text {rcrev }}\left(\mathbf{V}_{\mathbf{S C E}}\right)$ \\
\hline \multirow{3}{*}{$\begin{array}{c}\text { Temperature: } \\
23^{\circ} \mathrm{C}\end{array}$} & 0.0005 & -0.139 & 0.640 & 0.142 \\
\cline { 2 - 5 } & 0.005 & -0.207 & 0.583 & -0.009 \\
\cline { 2 - 5 } & 0.050 & -0.162 & 0.099 & -0.061 \\
\hline \multirow{3}{*}{$\begin{array}{c}\text { Temperature: } \\
60{ }^{\circ} \mathrm{C}\end{array}$} & 0.500 & -0.140 & 0.011 & -0.117 \\
\cline { 2 - 5 } & 0.0005 & -0.136 & 0.644 & -0.004 \\
\cline { 2 - 5 } & 0.005 & -0.130 & 0.198 & -0.152 \\
\hline \multirow{3}{*}{$\begin{array}{c}\text { Temperature: } \\
95^{\circ} \mathrm{C}\end{array}$} & 0.050 & -0.140 & 0.043 & -0.202 \\
\cline { 2 - 5 } & 0.0005 & -0.161 & -0.073 & -0.228 \\
\cline { 2 - 5 } & 0.005 & -0.296 & 0.272 & -0.091 \\
\hline
\end{tabular}

The corrosion potential of CDA 715 was not found to be dependent on the investigated parameters, i.e., chloride ion concentration and temperature, while the crevice stabilization and repassivation potentials decreased with increasing $\mathrm{c}_{\mathrm{Cl}}$ and $\mathrm{T}$.

Correlations between $\mathrm{E}_{\text {crev }}, \mathrm{E}_{\mathrm{rcrev}}$ and $\mathrm{c}_{\mathrm{Cl}}$ and $\mathrm{T}$ were established. Examples are shown in Figures 26 and 27. Figures 26a and b show the crevice repassivation potentials of the $\mathrm{Cu}-$ $\mathrm{Ni}$ alloys as a function of chloride ion concentration at $\mathrm{pH} 9$ and 11 , respectively, measured at $23^{\circ} \mathrm{C}$. The crevice repassivation of $\mathrm{M} 400$ at two different $\mathrm{pH}$ values as a function of $\mathrm{c}_{\mathrm{Cl}}$ - is shown in Figure 27a. Figure 27b summarizes the temperature dependence of M400 at different chloride levels under highly alkaline conditions ( $\mathrm{pH}$ 11).

A linear relationship was found between the critical potentials $\left(E_{\text {crev }}, E_{\text {rcrev }}\right)$ and the logarithm of bulk chloride ion concentration, which can be described by the following general equation:

$$
E_{\text {crev }, \text { rcrev }}=a \cdot \log c_{C^{-}}+b
$$

where $a$ and $b$ are constants. This is in agreement with findings by Milosev and coworkers for the case of pitting and repassivation potentials of $\mathrm{Cu}-\mathrm{Ni}$ alloys (Milosev and Metikos-Hukovic, 1991; Metikos-Hukovic and Milosev, 1992).

The constants and $\mathrm{R}^{2}$ values (i.e., ratios of regression variance and total variance) determined from Equation 9 are summarized in Tables 14 and 15 for $\mathrm{pH} 9$ and 11, respectively.

It is interesting to note that the crevice repassivation potential exhibited different behaviors characterized by different constants at high and low chloride levels under 
mildly alkaline conditions ( $\mathrm{pH} 9$ ). This is probably due to the difference in the amount of surface damage that occurs in the vicinity of the crevice as a function of chloride levels. At high $\mathrm{c}\left(\mathrm{Cl}^{-}\right)$, the damage of the oxide film is more severe, thus it is harder to repassivate the surface leading to a significantly more negative $\mathrm{E}_{\text {rcrev. }}$. Alternatively, at low chloride ion concentrations, the water or $\mathrm{OH}^{-}$ions can participate in the formation of the oxide layer, which is necessary for the repassivation to occur.
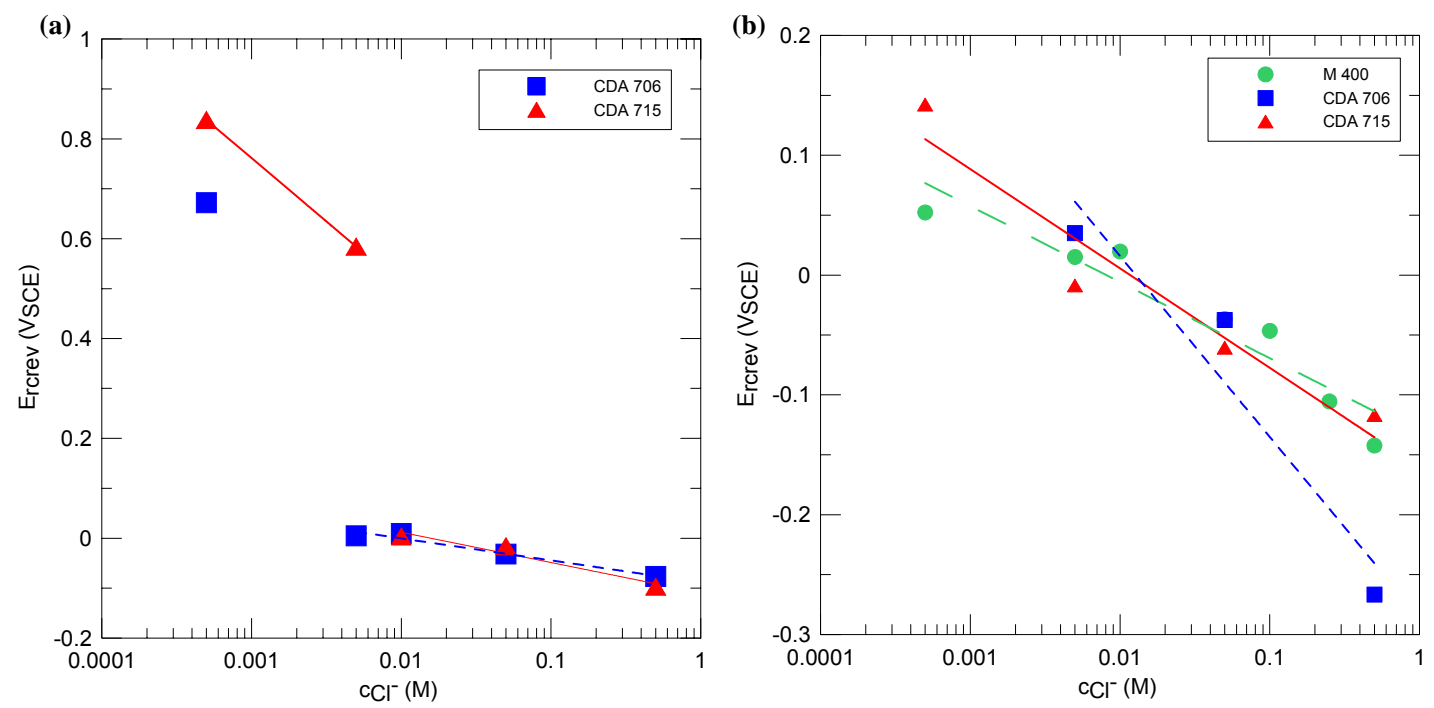

Figure 26. Crevice repassivation potential of $\mathrm{Cu}-\mathrm{Ni}$ alloys as a function of chloride ion concentration measured at $23^{\circ} \mathrm{C}$ in (a) $\mathrm{pH} 9$ solution containing borate buffer, (b) pH 11 solution without the presence of borate buffer.

(a)

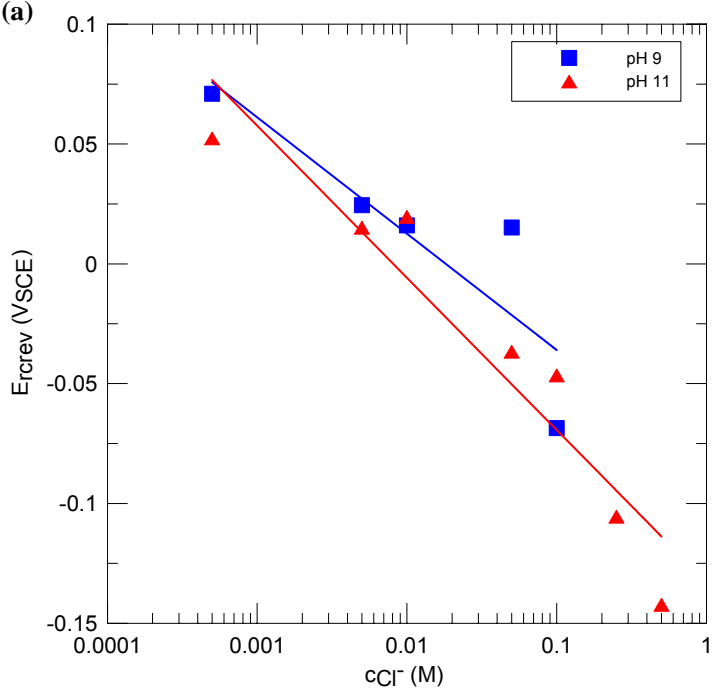

(b)

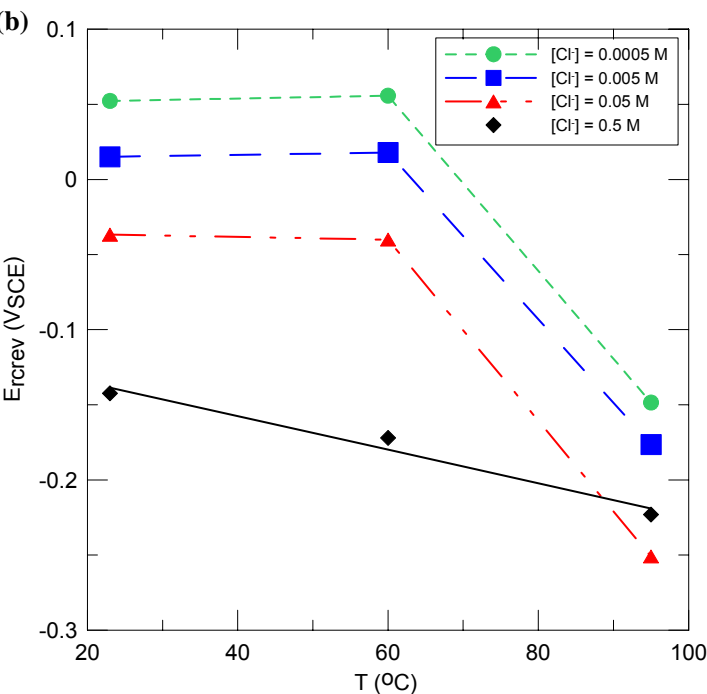

Figure 27. Crevice repassivation potential of M400 (a) as a function of chloride ion concentration at different $\mathrm{pH}$ values measured at $23^{\circ} \mathrm{C}$, (b) as a function of temperature at different chloride levels measured at pH 11.

The explanation for the critical $\mathrm{Cl}^{-}$concentration value where the breaking point occurs is not clear at this time. At $\mathrm{pH} 11$, there was no difference between the behavior of $\mathrm{E}_{\text {crev }}$ and $\mathrm{E}_{\text {rcrev }}$ at different chloride levels. The higher $\mathrm{OH}^{-}$concentrations give rise to easier oxide 
formation, thus easier repassivation, which is no longer affected by the chloride ion concentration.

As shown in Figure 27a, the bulk solution $\mathrm{pH}$ did not have a significant effect on $\mathrm{E}_{\text {rcrev }}$. This result was expected, since it is well known that repassivation process depends on the solution chemistry developed in the crevice region during the growth of the crevice and not on the bulk solution chemistry (Jones 1996). The difference between $\mathrm{E}_{\text {crev }}$ and $\mathrm{E}_{\text {rcrev }}$, however, is $\mathrm{pH}$ dependent due to the $\mathrm{pH}$ dependence of $\mathrm{E}_{\text {crev }}$ (not shown). $\Delta \mathrm{E}=\mathrm{E}_{\text {crev }^{-}}$ $\mathrm{E}_{\text {rcrev }}$ significantly increases with increasing $\mathrm{pH}$.

Table 14. Coefficients and $\mathrm{R}^{2}$ values of $E_{\text {crev }}$ and $E_{r c r e v}$ vs. $\log \left[\mathrm{Cl}^{-}\right]$equations (Equation 9) for CDA706 and CDA715 at pH 9.

\begin{tabular}{|c|c|c|c|c|}
\hline Parameter, Temp. & Alloy & $a$ & $b$ & $\mathbf{R}^{2}$ \\
\hline \multirow{2}{*}{$\begin{array}{l}\mathrm{E}_{\text {crev }} \\
23^{\circ} \mathrm{C}\end{array}$} & CDA706 & -0.0604 & -0.138 & 0.913 \\
\hline & CDA715 & -0.0612 & -0.059 & 0.834 \\
\hline \multirow{4}{*}{$\begin{array}{l}\mathrm{E}_{\text {rcrev }} \\
23^{\circ} \mathrm{C}\end{array}$} & CDA 706, low $\left[\mathrm{Cl}^{-}\right]$ & $\mathrm{N} / \mathrm{A}$ & $\mathrm{N} / \mathrm{A}$ & $\mathrm{N} / \mathrm{A}$ \\
\hline & $\mathrm{CDA} 706$, high $\left[\mathrm{Cl}^{-}\right]$ & -0.0083 & -0.089 & 0.966 \\
\hline & CDA 715, low $\left[\mathrm{Cl}^{-}\right]$ & -0.0479 & -0.0005 & $\mathrm{~N} / \mathrm{A}$ \\
\hline & $\mathrm{CDA} 715$, high $\left[\mathrm{Cl}^{-}\right]$ & -0.0114 & -0.109 & 0.945 \\
\hline \multirow{2}{*}{$\begin{array}{l}\mathrm{E}_{\text {crev }} \\
60^{\circ} \mathrm{C}\end{array}$} & CDA706 & -0.0239 & -0.190 & 0.824 \\
\hline & CDA715 & -0.0555 & -0.256 & 0.882 \\
\hline \multirow{4}{*}{$\begin{array}{l}\mathrm{E}_{\text {rcrev }} \\
60^{\circ} \mathrm{C}\end{array}$} & CDA 706, low $\left[\mathrm{Cl}^{-}\right]$ & -0.0359 & -0.438 & 0.979 \\
\hline & $\mathrm{CDA} 706$, high $\left[\mathrm{Cl}^{-}\right]$ & -0.0064 & -0.302 & $\mathrm{~N} / \mathrm{A}$ \\
\hline & CDA 715, low $\left[\mathrm{Cl}^{-}\right]$ & $\mathrm{N} / \mathrm{A}$ & $\mathrm{N} / \mathrm{A}$ & $\mathrm{N} / \mathrm{A}$ \\
\hline & $\mathrm{CDA} 715$, high $\left[\mathrm{Cl}^{-}\right]$ & -0.0181 & -0.253 & 0.771 \\
\hline
\end{tabular}

Table 15. Coefficients and $\mathrm{R}^{2}$ values of $E_{\text {crev }}$ and $E_{r c r e v}$ vs. $\log \left[\mathrm{Cl}^{-}\right]$equations (Equation 9) for M400, CDA706 and CDA715 at pH 11.

\begin{tabular}{|c|c|ccc|}
\hline Parameter, Temp. & Alloy & $\boldsymbol{a}$ & $\boldsymbol{b}$ & $\mathbf{R}^{2}$ \\
\hline $\mathrm{E}_{\text {crev }}$, & M400 & -0.0201 & 0.0015 & 0.974 \\
\cline { 2 - 5 } $23^{\circ} \mathrm{C}$ & $\mathrm{CDA706}$ & -0.0284 & -0.286 & 0.917 \\
\cline { 2 - 5 } & $\mathrm{CDA715}$ & -0.0156 & -0.160 & 0.925 \\
\hline $\mathrm{E}_{\text {rcrev }}$ & $\mathrm{M} 400$ & -0.0120 & -0.133 & 0.903 \\
$23^{\circ} \mathrm{C}$ & $\mathrm{CDA706}$ & -0.0284 & -0.286 & 0.917 \\
& $\mathrm{CDA715}$ & -0.0156 & -0.160 & 0.925 \\
\hline $\mathrm{E}_{\text {crev }}$, & M400 & -0.0389 & -0.188 & 0.938 \\
\hline $60^{\circ} \mathrm{C}$ & $\mathrm{CDA706}$ & -0.0667 & -0.565 & 0.753 \\
\cline { 2 - 5 } & $\mathrm{CDA715}$ & -0.0435 & -0.212 & 0.897 \\
\hline $\mathrm{E}_{\text {rcrev }}$, & M400 & -0.0153 & -0.194 & 0.874 \\
$60^{\circ} \mathrm{C}$ & $\mathrm{CDA706}$ & -0.056 & -0.243 & 0.899 \\
& $\mathrm{CDA715}$ & -0.0135 & -0.276 & 0.866 \\
\hline
\end{tabular}


The temperature dependence of the crevice repassivation potential was found to be dependent on the chloride level (Figure 27b). At low $\mathrm{c}\left(\mathrm{Cl}^{-}\right)$, i.e., in the range of 0.0005 $0.05 \mathrm{M}, \mathrm{E}_{\mathrm{rcrev}}$ did not depend on the temperature at moderate $\mathrm{T}$. It then dropped significantly at $95^{\circ} \mathrm{C}$. At high $\mathrm{c}\left(\mathrm{Cl}^{-}\right)$, the crevice repassivation potential was linearly dependent on the temperature, according to the following equation:

$$
E_{\text {rcrev }}=-0.00111 \cdot T-0.113 \quad R^{2}=0.973
$$

As expected, the crevice repassivation potential decreased with increasing temperature since the corrosion process is accelerated at higher temperatures.

C-22 and Alloy 825 . The crevice repassivation potential of highly corrosion resistant alloys, such as C-22 and 825 was measured using the Tsujikawa-Hisamatsu Electrochemical (THE) method. Several measurements on C-22 were carried out at 70 inlb torque in order to test the reproducibility of the method, since it is being recommended as a new ASTM standard test. Measurements at lower torques were also performed to determine the effect of torque (i.e., crevice gap geometry) on $\mathrm{E}_{\text {rcrev }}$. The measured crevice repassivation potentials in case of C-22 are summarized in Table 16.

Table 16. Crevice repassivation potential values and observed corrosion morphologies of $\mathrm{C}-22$ measured in $1 \mathrm{M}$ NaCl solution using the THE method. The applied charge density was $0.0154 \mathrm{C} / \mathrm{cm}^{2}$.

\begin{tabular}{|ccc|}
\hline Torque (inlb) & $\mathrm{E}_{\text {rcrev }}(\mathrm{V}$ vs. SCE $)$ & Observed morphology \\
\hline 6.5 & 0.0259 & shallow attack, 6/24 sites attacked \\
50 & -0.1847 & shallow attack, 23/24 sites attacked \\
& -0.1566 & shallow attack, 23/24 sites attacked \\
70 & -0.1532 & shallow attack, 24/24 sites attacked \\
& -0.1554 & shallow attack, 24/24 sites attacked \\
\hline
\end{tabular}

The average crevice repassivation potential at 70 inlb was $-0.1551 \mathrm{~V}$ vs. SCE, with a standard deviation of 0.0017 indicating a very good reproducibility of the technique. Figure 28 shows the low magnification image of a specimen following testing to illustrate the damage morphology along with the dependence of $\mathrm{E}_{\mathrm{rcrev}}$ on the applied torque.

The crevice repassivation potential was found to decrease with increasing torque until a plateau was reached. There are two plausible explanations for this trend. At higher torque, a tighter crevice forms, which allows for the generation of a more aggressive solution chemistry. $\mathrm{E}_{\mathrm{rcrev}}$ is expected to be lower in more aggressive environments, where the repassivation process is more difficult. The application of a higher torque can also lead to surface damage during the assembly of the specimen lowering $\mathrm{E}_{\text {rcrev }}$. This surface damage was observed on numerous occasions in this work, especially at 70 inlb torque. 


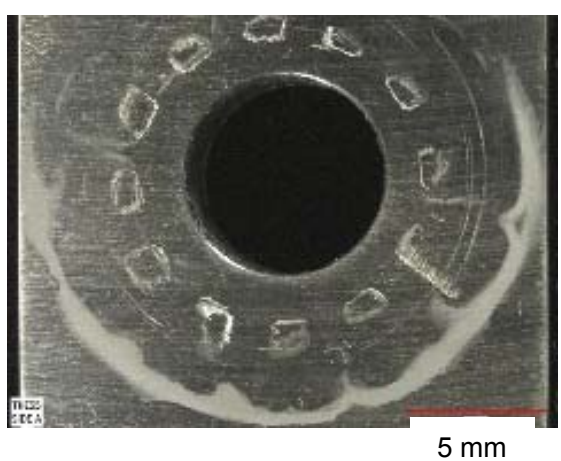

(a)

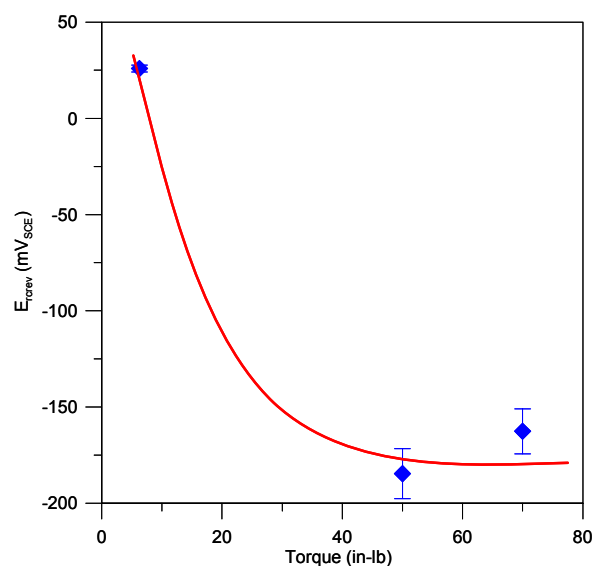

(b)

Figure 28. (a) Low magnification (20X) microscope image of a C-22 PCA specimen after testing. (b) Crevice repassivation potential of $\mathrm{C}-22$ as a function of applied torque.

In case of alloy 825 , the effect of both the torque and applied charge density was investigated. The measured average crevice repassivation potentials at different parameters (charge density/torque combinations) as well as the type of attack are summarized in Table 17.

Table 17. Crevice repassivation potential ( $\left.E_{\mathrm{rcrev}}\right)$ of alloy 825 and type of attack observed as a function of torque and applied charge density.

\begin{tabular}{|cccc|}
\hline $\begin{array}{c}\text { Charge Density } \\
\left(\mathbf{C} / \mathbf{c m}^{2}\right)\end{array}$ & Torque (inlb) & $\mathbf{E}_{\text {rcrev }}(\mathbf{V}$ vs. SCE) & Type of attack \\
\hline \multirow{3}{*}{0.0154} & 3.125 & -0.235 & \\
& 6.25 & -0.233 & localized, crevice \\
& 20 & -0.227 & \\
1 & 50 & -0.211 & \\
& 20 & -0.195 & localized, crevice \\
15 & 3.125 & no damage at crevice & transpassive \\
& 20 & -0.131 & dissolution \\
50 & 50 & -0.097 & transpassive \\
& 20 & no damage at crevice & dissolution \\
\hline
\end{tabular}

The crevice repassivation potential as a function of torque and charge density are shown in Figure 29. No statistically significant dependence was found between $E_{\text {rcrev }}$ and the torque. This finding can be due to the lower corrosion resistance of alloy 825 compared to that of $\mathrm{C}-22$. The lower corrosion resistance implies that the critical chemistry needed to sustain crevice corrosion is not as severe as in case of C-22. This lower critical chemistry is attained easily even for larger gaps. The crevice repassivation potential was found to be independent of the charge density at lower charge densities. However, at 15 $\mathrm{C} / \mathrm{cm}^{2}$ applied charge density, $\mathrm{E}_{\mathrm{rcrev}}$ seemed to increase with increasing charge density when it was determined by the THE method. This result was not expected for crevice 
corrosion. According to Galvele's model, $E_{\text {rcrev }}$ decreases with charge density until it reaches a plateau. At lower charge densities, $\mathrm{E}_{\mathrm{rcrev}}$ is inversely proportional to the crevice depth due to the lengthening transport path, while at large charge density values, i.e., deep crevices, $\mathrm{E}_{\text {rcrev }}$ does not depend on the crevice depth as a result of the competing effects of the lengthening transport path and increasing ohmic resistance (Dunn et al., 2000).

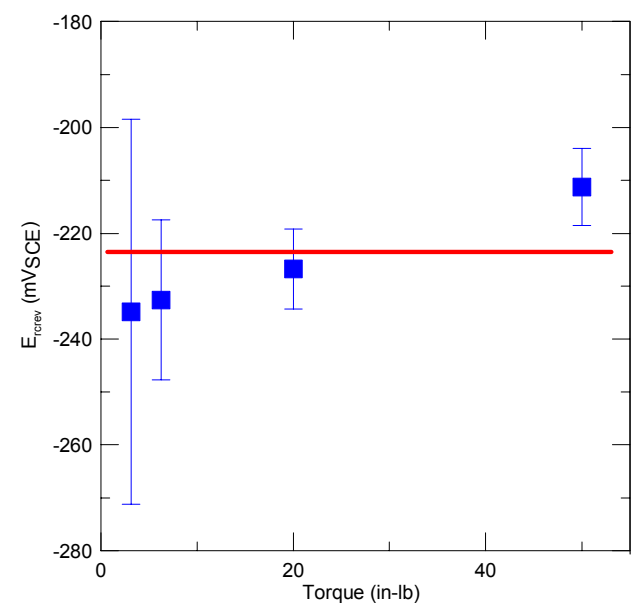

(a)

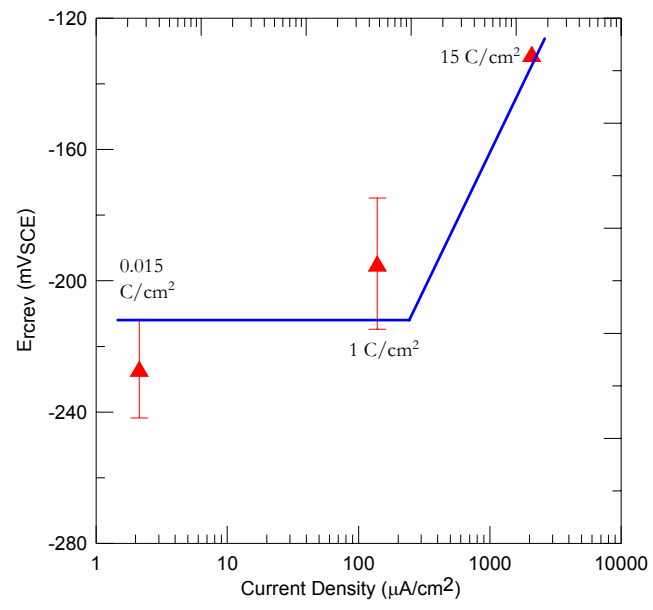

(b)

Figure 29. Crevice repassivation potential of alloy 825 measured in $1 \mathrm{M} \mathrm{NaCl}$ at $90^{\circ} \mathrm{C}$ using the THE method as a function of (a) applied torque and (b) applied charge density (current density).

Since the charge density dependence tests provided unexpected results, they were further investigated. The anodic scans of low and high charge density measurements were compared to cyclic potentiodynamic polarization scan collected under the same conditions. The results are summarized in Figure 30.

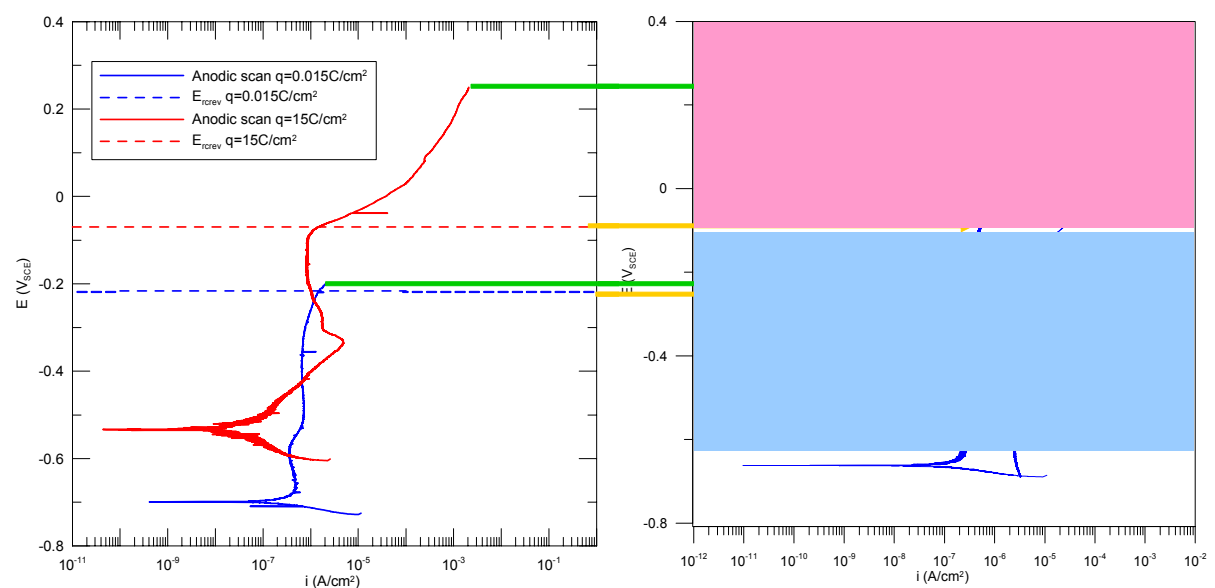

Figure 30. Anodic scans and cyclic potentiodynamic polarization curve of alloy 825 indicating the regions of passivity and transpassive dissolution.

The crevice stabilization potential determined from the CPP was $-0.0853 \mathrm{~V}$ vs. SCE. This potential is lower than the potential reached during the anodic scan at $15 \mathrm{C} / \mathrm{cm}^{2}$. This 
indicates that the specimen underwent transpassive dissolution during the galvanostatic hold. The potential determined as $\mathrm{E}_{\mathrm{rcrev}}$ is the potential at which the current density decreases as the transpassive dissolution slows down. The potential reached during the anodic scan at $0.015 \mathrm{C} / \mathrm{cm}^{2}$ is just slightly higher than the crevice repassivation potential determined from the CPP indicating that it is possible to sustain stable crevice growth under these conditions without transpassive dissolution of the alloy. Damage depth profiles measured at low and high applied charge densities further prove the above theory. At low charge densities $\left(1 \mathrm{C} / \mathrm{cm}^{2}\right)$, the maximum crevice depth measured was 78 $\mu \mathrm{m}$, which is typical of crevice damages. At high charge densities $\left(15 \mathrm{C} / \mathrm{cm}^{2}\right)$, however, the deepest damage depth was $836 \mu \mathrm{m}$, which is indicative of transpassive dissolution of the alloy. Examples of depth profiles are shown in Figure 31.

(a)
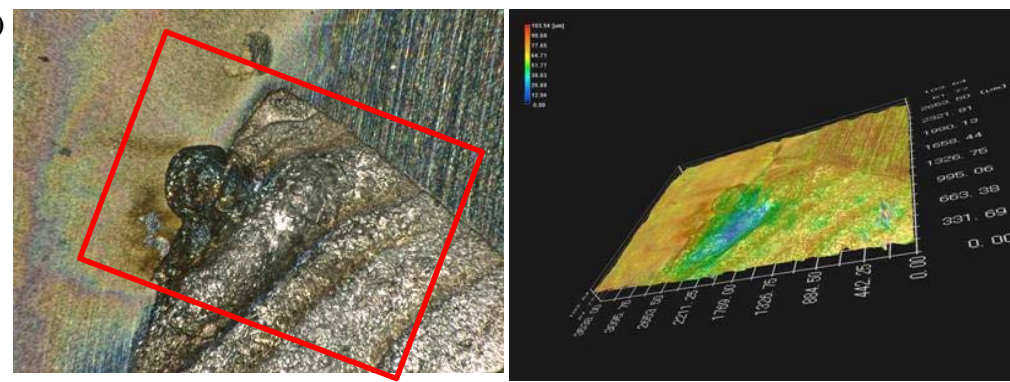

(b)
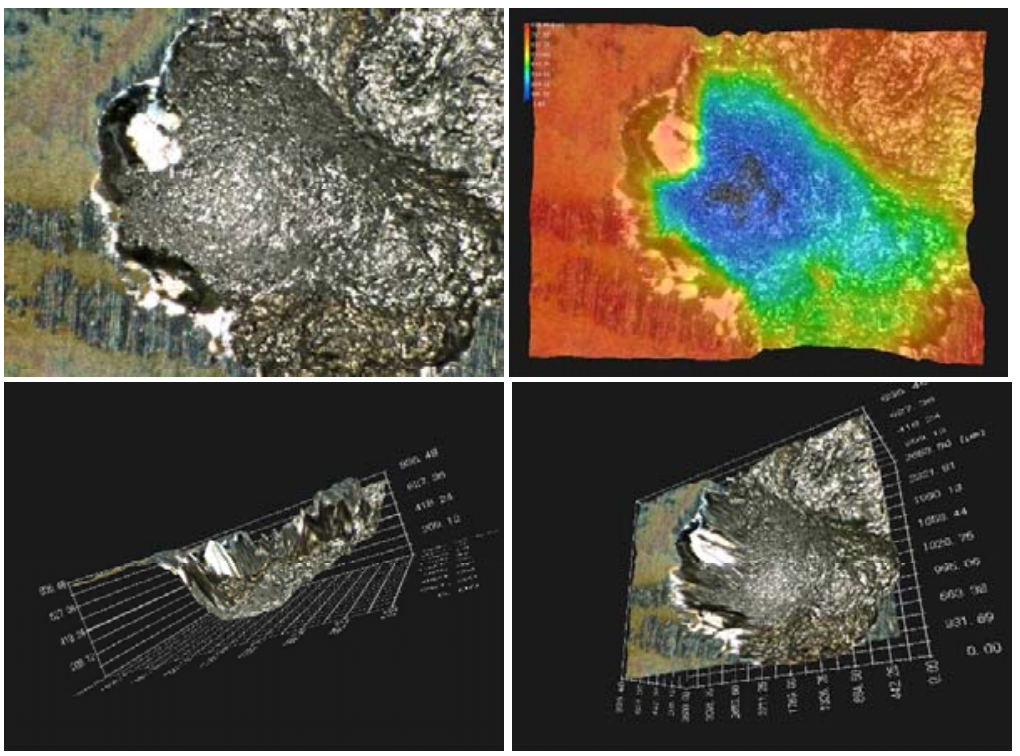

Figure 31. Crevice depth profiles of alloy 825. (a) Crevice grown at low applied charge density (1 $\left.\mathrm{C} / \mathrm{cm}^{2}\right)$. (b) Crevice grown at high applied charge density $\left(15 \mathrm{C} / \mathrm{cm}^{2}\right)$.

Therefore, it can be concluded from these auxiliary tests that the crevice repassivation potential determined using the THE method at high applied charge densities is not a "true" crevice repassivation potential, but it is the potential at which the transpassive dissolution significantly slows down or stops.

The THE method was found to be a very valuable, highly reproducible electrochemical method to determine the crevice repassivation potential of corrosion resistant alloys, however, caution must be exercised when determining the experimental parameters. 
Cyclic potentiodynamic polarization scan can be used as a guideline in determining the applied charge density and current density associated with it. If the application of high charge densities is required, it is advised that the time interval of the galvanostatic hold is increased instead of the applied current density to avoid transpassive dissolution.

\section{Effect of Inhibitors on $E_{r p}$ of Base Alloys}

The crevice repassivation potential of selected base alloys was measured in solutions containing different combinations of inhibitor and aggressive species at various concentrations. The effect of inhibitors on $\mathrm{E}_{\mathrm{rcrev}}$ was measured using the "potential staircase" (PS) method at 23 and $60^{\circ} \mathrm{C}$. The base alloys investigated were $316 \mathrm{~L}$ stainless steel (SS), 254SMO, 2205 duplex SS, alloy 600 and alloy 690.

316L Stainless Steel. $316 \mathrm{~L}$ stainless steel did not show any corrosion damage at $23^{\circ} \mathrm{C}$ in 0.004-0.04 M sodium chloride solutions even without the presence of inhibitors. At this temperature, the lowest $\mathrm{Cl}^{-}$concentration where corrosion was observed was $0.42 \mathrm{M}$, therefore this $\mathrm{Cl}^{-}$ion concentration was used in subsequent inhibitor studies. The crevice repassivation potentials as a function of inhibitor concentrations for different inhibitors measured at $23^{\circ} \mathrm{C}$ in $0.42 \mathrm{M} \mathrm{NaCl}$ solution are summarized in Table 18. Sulfate ions $\left(\mathrm{SO}_{4}{ }^{2-}\right)$ were found to decrease the crevice repassivation potential of $316 \mathrm{~L}$ SS, thus they act as aggressive ions facilitating the corrosion of the alloy. Molybdate, vanadate and nitrite ions $\left(\mathrm{MoO}_{4}{ }^{2-}, \mathrm{VO}_{3}{ }^{-}\right.$and $\mathrm{NO}_{2}{ }^{-}$, respectively) significantly increased the crevice repassivation potential when present above a critical concentration, and in some cases, no crevice corrosion was observed at potentials up to $0.4 \mathrm{~V}$ vs. SCE at higher inhibitor levels. The critical concentration above which the inhibitor was effective in raising $\mathrm{E}_{\text {rcrev }}$ was the lowest in case of the nitrite ions indicating that these ions were the most effective in inhibiting crevice corrosion of 316L SS.

Table 18. Crevice repassivation potential of $316 \mathrm{~L}$ SS as a function of inhibitor concentration for different inhibitors measured at $23^{\circ} \mathrm{C}$ in $0.42 \mathrm{M} \mathrm{NaCl}$ solution.

\begin{tabular}{|c|c|c|}
\hline Inhibitor & Concentration (M) & $E_{\text {rcrev }}$ (V vs. SCE) \\
\hline None & $\mathrm{N} / \mathrm{A}$ & -0.067 \\
\hline \multirow{3}{*}{$\mathrm{SO}_{4}{ }^{2-}$} & 0.04 & -0.058 \\
\hline & 0.4 & -0.167 \\
\hline & 1.0 & -0.083 \\
\hline \multirow{3}{*}{$\mathrm{MoO}_{4}{ }^{2-}$} & 0.04 & -0.119 \\
\hline & 0.4 & 0.390 \\
\hline & 1.5 & no crevice corrosion \\
\hline \multirow{4}{*}{$\mathrm{NO}_{2}^{-}$} & 0.004 & -0.123 \\
\hline & 0.01 & 0.042 \\
\hline & 0.04 & no crevice corrosion \\
\hline & 0.4 & no crevice corrosion \\
\hline \multirow{4}{*}{$\mathrm{VO}_{3}^{-}$} & 0.04 & -0.129 \\
\hline & 0.2 & 0.390 \\
\hline & 0.4 & 0.014 \\
\hline & 1.4 & no crevice corrosion \\
\hline
\end{tabular}


The measured crevice repassivation potentials as a function of inhibitor concentration are shown in Figure 32a. When no crevice corrosion was observed, the $\mathrm{E}_{\text {rcrev }}$ value was taken as $0.4 \mathrm{~V}$ vs. SCE, which was the potential used during the potentiostatic hold (crevice growth period). The $\mathrm{E}_{\text {rcrev }}$ of the base alloy without the presence of inhibitors is illustrated by a straight line in the graph. The nitrite ions were found to be much more effective than all the other species investigated in this study. $E_{\text {rcrev }}$ increased very rapidly with increasing inhibitor concentration in case of both $\mathrm{MoO}_{4}{ }^{2-}$ and $\mathrm{NO}_{2}{ }^{-}$ions. However, higher concentration of $\mathrm{MoO}_{4}{ }^{2-}$ was required to achieve the same inhibiting effect as the $\mathrm{NO}_{2}^{-}$ ions.

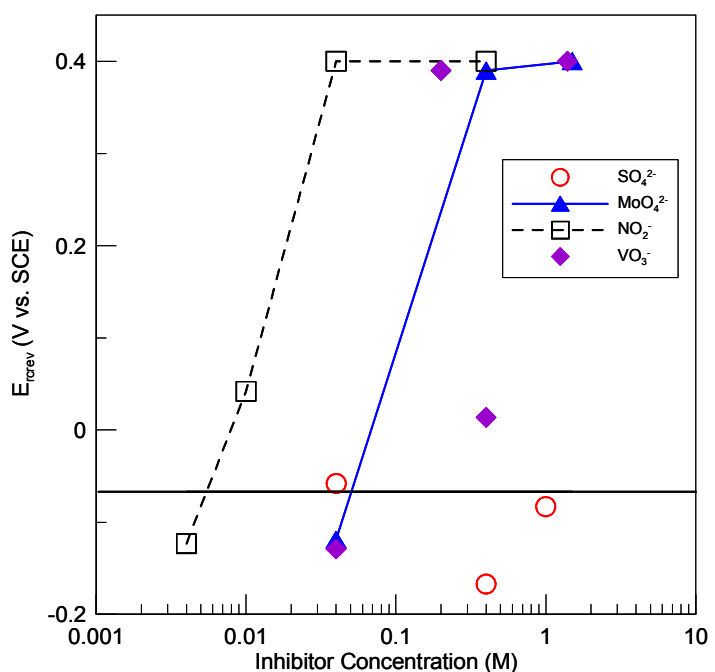

(a)

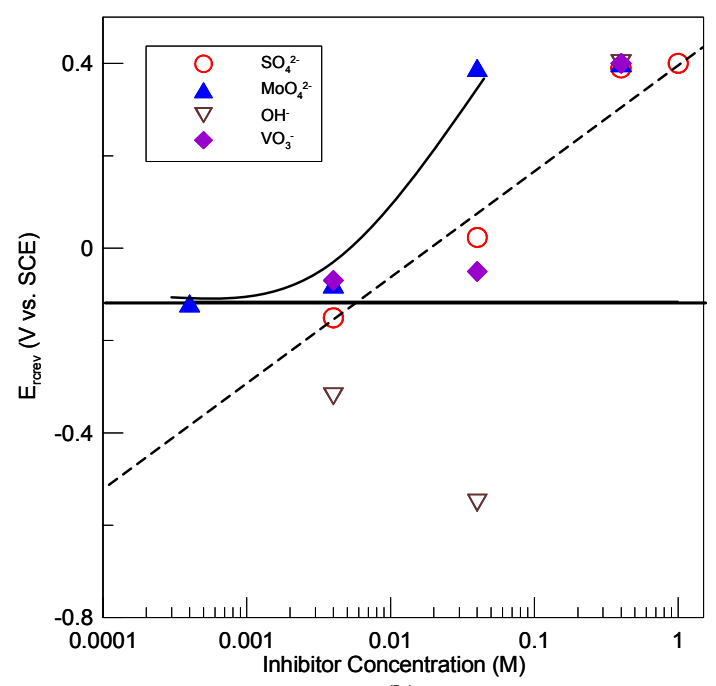

(b)

Figure 32. Crevice repassivation potential of $316 \mathrm{~L}$ stainless steel as a function of inhibitor concentration measured (a) in $0.42 \mathrm{M} \mathrm{NaCl}$ solution at $23^{\circ} \mathrm{C}$ and (b) in $0.04 \mathrm{M} \mathrm{NaCl}$ solution at $60^{\circ} \mathrm{C}$.

The effect of inhibitors on $\mathrm{E}_{\mathrm{rcrev}}$ was also evaluated in $4 \mathrm{M} \mathrm{NaCl}$ solution in case of $\mathrm{MoO}_{4}{ }^{2-}$ and $\mathrm{NO}_{2}{ }^{-}$. The results are summarized in Table 19.

Table 19. Crevice repassivation potential of $316 \mathrm{~L}$ SS as a function of inhibitor concentration for different inhibitors measured at $23^{\circ} \mathrm{C}$ in $4 \mathrm{M} \mathrm{NaCl}$ solution.

\begin{tabular}{|c|c|c|}
\hline Inhibitor & Concentration (M) & E $_{\text {rcrev }}$ (V vs. SCE) \\
\hline None & $\mathrm{N} / \mathrm{A}$ & -0.408 \\
\hline \multirow{2}{*}{$\mathrm{MoO}_{4}{ }^{2-}$} & 0.4 & -0.210 \\
& 1.5 & -0.228 \\
\cline { 2 - 3 } & 0.4 & -0.164 \\
\hline \multirow{2}{*}{$\mathrm{NO}_{2}^{-}$} & 2.0 & 0.015 \\
\cline { 2 - 3 } & &
\end{tabular}

Both the $\mathrm{MoO}_{4}{ }^{2-}$ and $\mathrm{NO}_{2}{ }^{-}$ions raised $\mathrm{E}_{\text {rcrev, }}$, thus provided corrosion inhibition for $316 \mathrm{~L}$ $\mathrm{SS}$ in $4 \mathrm{M} \mathrm{NaCl}$ solution, however, the $\mathrm{NO}_{2}{ }^{-}$ions were found to be significantly more 
effective, especially at higher inhibitor concentrations. Interestingly, $\mathrm{E}_{\mathrm{rcrev}}$ was not affected by increasing $\mathrm{MoO}_{4}{ }^{2-}$ concentration.

At $60^{\circ} \mathrm{C}$, two different chloride levels were investigated, $0.04 \mathrm{M}$ and $0.42 \mathrm{M}$. At this elevated temperature, crevice corrosion initiated at lower aggressive ion concentration than at room temperature. The crevice repassivation potentials obtained in $0.04 \mathrm{M} \mathrm{NaCl}$ solution containing different inhibitors are summarized in Table 19.

Table 20. Crevice repassivation potential of $316 \mathrm{~L}$ SS as a function of inhibitor concentration for different inhibitors measured at $60^{\circ} \mathrm{C}$ in $0.04 \mathrm{M} \mathrm{NaCl}$ solution.

\begin{tabular}{|c|c|c|}
\hline Inhibitor & Concentration (M) & $E_{\text {rcrev }}$ (V vs. SCE) \\
\hline None & $\mathrm{N} / \mathrm{A}$ & -0.115 \\
\hline \multirow{4}{*}{$\mathrm{SO}_{4}{ }^{2-}$} & 0.004 & -0.151 \\
\hline & 0.04 & 0.023 \\
\hline & 0.4 & 0.390 \\
\hline & 1.0 & no crevice corrosion \\
\hline \multirow{3}{*}{$\mathrm{VO}_{3}^{-}$} & 0.004 & -0.070 \\
\hline & 0.04 & -0.051 \\
\hline & 0.4 & no crevice corrosion \\
\hline \multirow{3}{*}{$\mathrm{OH}^{-}$} & 0.004 & -0.321 \\
\hline & 0.04 & -0.552 \\
\hline & 0.4 & no crevice corrosion \\
\hline \multirow{4}{*}{$\mathrm{MoO}_{4}{ }^{2-}$} & 0.0004 & -0.120 \\
\hline & 0.004 & -0.078 \\
\hline & 0.04 & 0.390 \\
\hline & 0.4 & no crevice corrosion \\
\hline
\end{tabular}

Vanadate and molybdate ions were found to be very potent inhibitors of the crevice corrosion of $316 \mathrm{~L}$ stainless steel similarly to the room temperature case. They significantly raised the crevice repassivation potentials even at relatively low inhibitor concentrations. In this case, sulfate ions were found to act as inhibitors. In previous tests, they were found to be aggressive ions lowering $E_{\text {rcrev }}$ at room temperature in $0.42 \mathrm{M}$ $\mathrm{NaCl}$ solution. It is possible that the sulfate ions are not very effective inhibitors, thus, they only have an effect at low chloride levels. Alternatively, the inhibiting mechanism, e.g., adsorption properties, might be different at different temperatures. Hydroxyl ions were also investigated in this set of tests, they were found to lower $E_{\text {rcrev }}$, thus, they acted as aggressive species. $\mathrm{E}_{\text {rcrev }}$ values as a function of inhibitor concentration are summarized in Figure $32 \mathrm{~b}$. A linear relationship was found between $\mathrm{E}_{\mathrm{rcrev}}$ and the inhibitor concentration in case of the molybdate ions:

$$
E_{\text {rcrev }}=12.928 \cdot c_{\mathrm{MoO}_{4}^{2-}}-0.127 \quad R^{2}=0.999
$$

In case of the sulfate ions, linear relationship was found between $\mathrm{E}_{\mathrm{rcrev}}$ and the logarithm of inhibitor concentration in the form of: 


$$
E_{\text {rcrev }}=0.117 \cdot \log c_{S O_{4}^{2-}}+0.465 \quad R^{2}=0.959
$$

The trendlines are shown in Figure 32b.

254 SMO. The crevice repassivation potential of alloy $254 \mathrm{SMO}$ was determined at $60^{\circ} \mathrm{C}$ at two chloride levels. Table 21 summarizes the measured $\mathrm{E}_{\text {crev }}$ values at different $\mathrm{Cl}^{-}$and inhibitor concentrations.

Table 21. Crevice repassivation potentials of $254 \mathrm{SMO}$ at $60^{\circ} \mathrm{C}$.

\begin{tabular}{|c|c|c|c|}
\hline Chloride level (M) & Inhibitor & Concentration (M) & $\mathbf{E}_{\text {rcrev }}$ (V vs. SCE) \\
\hline \multirow{4}{*}{0.4} & none & $\mathrm{N} / \mathrm{A}$ & -0.028 \\
\cline { 2 - 4 } & \multirow{3}{*}{$\mathrm{MoO}_{4}{ }^{2-}$} & 0.004 & -0.083 \\
\cline { 3 - 4 } & & 0.010 & -0.081 \\
\cline { 3 - 4 } & & 0.040 & 0.038 \\
\cline { 3 - 4 } & & 0.100 & -0.067 \\
\hline \multirow{4}{*}{4.0} & none & $\mathrm{N} / \mathrm{A}$ & not measured \\
\cline { 2 - 4 } & $\mathrm{OH}^{-}$ & 0.4 & 0.390 \\
\cline { 2 - 4 } & & 2.0 & -0.238 \\
\cline { 2 - 4 } & $\mathrm{SO}_{4}{ }^{2-}$ & 0.4 & -0.190 \\
\cline { 2 - 4 } & & 2.0 & -0.198 \\
\cline { 2 - 4 } & $\mathrm{MoO}_{4}{ }^{2-}$ & 0.4 & no crevice corrosion \\
\cline { 3 - 4 } & & 1.5 & \\
\cline { 3 - 4 } & & & \\
\cline { 3 - 4 }
\end{tabular}

All inhibitors increased the crevice repassivation potential at both chloride levels, especially at higher concentrations. At $4 \mathrm{M} \mathrm{NaCl}$ concentration, the sulfate and molybdate inhibitors were not as effective as the hydroxide, which significantly increased the crevice repassivation at relatively low level. At higher $\mathrm{OH}^{-}$concentrations, no crevice corrosion was observed.

2205 Duplex Stainless Steel. E $_{\text {rcrev }}$ of 2205 duplex stainless steel was measured at $60^{\circ} \mathrm{C}$ in solutions containing $0.04,0.4$ and $4.0 \mathrm{M}$ chloride ions. In $0.04 \mathrm{M} \mathrm{NaCl}$, the crevice repassivation potential measured without the presence of inhibitors was $0.390 \mathrm{~V}$ vs. SCE, a value very close to the potentiostatic hold potential. Upon the introduction of inhibitors, no crevice corrosion was observed. Subsequent tests therefore focused on 0.4 and $4 \mathrm{M} \mathrm{Cl}^{-}$ levels. Table 22 summarizes the measured $\mathrm{E}_{\text {rcrev }}$ values.

Molybdate increased $\mathrm{E}_{\text {rcrev }}$ even at low concentrations in $0.4 \mathrm{M} \mathrm{NaCl}$ solution, while sulfate was only effective at higher levels. In case of $4 \mathrm{M} \mathrm{NaCl}$ solution, no effect of $\mathrm{MoO}_{4}{ }^{2-}$ and $\mathrm{SO}_{4}{ }^{2-}$ inhibitor addition was seen. The effect of hydroxide ions was found to be puzzling; at low and high $\mathrm{OH}^{-}$concentrations, the crevice repassivation potential decreased compared to that of the uninhibited case, while at intermediate $\mathrm{OH}^{-}$ concentration, there was a significant increase in $\mathrm{E}_{\text {rcrev }}$. 
Table 22. Crevice repassivation potentials of 2205 duplex stainless steel at $60^{\circ} \mathrm{C}$.

\begin{tabular}{|c|c|c|c|}
\hline Chloride level (M) & Inhibitor & Concentration (M) & $E_{\text {rcrev }}$ (V vs. SCE) \\
\hline \multirow{5}{*}{0.4} & none & $\mathrm{N} / \mathrm{A}$ & -0.185 \\
\hline & \multirow[t]{2}{*}{$\mathrm{MoO}_{4}{ }^{2-}$} & 0.004 & -0.119 \\
\hline & & 0.01 & -0.100 \\
\hline & \multirow[t]{2}{*}{$\mathrm{SO}_{4}{ }^{2-}$} & 0.004 & -0.197 \\
\hline & & 0.01 & -0.051 \\
\hline \multirow{8}{*}{4.0} & none & $\mathrm{N} / \mathrm{A}$ & -0.331 \\
\hline & \multirow{3}{*}{$\mathrm{OH}^{-}$} & 0.4 & -0.586 \\
\hline & & 1.0 & 0.0003 \\
\hline & & 2.0 & -0.567 \\
\hline & \multirow[t]{2}{*}{$\mathrm{SO}_{4}{ }^{2-}$} & 0.4 & -0.288 \\
\hline & & 2.0 & -0.302 \\
\hline & \multirow[t]{2}{*}{$\mathrm{MoO}_{4}{ }^{2-}$} & 0.4 & -0.216 \\
\hline & & 1.5 & -0.259 \\
\hline
\end{tabular}

Alloys 600 and 690. The effect of inhibitors on the crevice corrosion of alloy 600 was measured at two different chloride ion concentrations $(0.04$ and $4 \mathrm{M})$ and two temperatures $\left(23\right.$ and $\left.60^{\circ} \mathrm{C}\right)$. At the lower chloride level, the tests were carried out at $60^{\circ} \mathrm{C}$, because crevice corrosion was not observed at room temperature. At the higher chloride level $(4 \mathrm{M})$, however, the tests were all carried out at room temperature $\left(23^{\circ} \mathrm{C}\right)$ due to the severity of crevice corrosion at elevated temperature. The results are summarized in Tables $23\left(23^{\circ} \mathrm{C}, 4 \mathrm{M} \mathrm{NaCl}\right)$ and $24\left(60^{\circ} \mathrm{C}, 0.04 \mathrm{M} \mathrm{NaCl}\right)$.

All inhibitors were found to increase the crevice repassivation potential of alloy 600 to some extent. They were more effective at higher temperature and lower chloride level. Interestingly, the molybdate and sulfate ions were better inhibitors than the hydroxide ions at a given concentration.

Table 23. Crevice repassivation potential of alloy 600 measured in $4.0 \mathrm{M} \mathrm{NaCl}$ solution at $23^{\circ} \mathrm{C}$.

\begin{tabular}{|c|c|c|}
\hline Inhibitor & Concentration (M) & E $_{\text {rcrev }}$ (V vs. SCE) \\
\hline none & $\mathrm{N} / \mathrm{A}$ & -0.319 \\
\hline \multirow{2}{*}{$\mathrm{MoO}_{4}{ }^{2-}$} & 0.4 & -0.153 \\
\cline { 2 - 3 } & 1.5 & -0.169 \\
\hline $\mathrm{SO}_{4}{ }^{2-}$ & 2 & -0.284 \\
\hline \multirow{2}{*}{$\mathrm{OH}^{-}$} & 0.4 & -0.254 \\
& 2 & -0.194 \\
\cline { 2 - 3 } & 4 & -0.155 \\
\cline { 2 - 3 } & & \\
\hline
\end{tabular}


Table 24. Crevice repassivation potential of alloy 600 measured in $0.04 \mathrm{M} \mathrm{NaCl}$ solution at $60^{\circ} \mathrm{C}$.

\begin{tabular}{|c|c|c|}
\hline Inhibitor & Concentration (M) & $E_{\text {rcrev }}$ (V vs. SCE) \\
\hline none & $\mathrm{N} / \mathrm{A}$ & -0.282 \\
\hline \multirow{5}{*}{$\mathrm{MoO}_{4}{ }^{2-}$} & 0.01 & -0.097 \\
\hline & 0.04 & -0.086 \\
\hline & 0.2 & \multirow{3}{*}{ no crevice corrosion } \\
\hline & 0.32 & \\
\hline & 0.4 & \\
\hline \multirow{6}{*}{$\mathrm{SO}_{4}^{2-}$} & 0.004 & -0.112 \\
\hline & 0.04 & -0.112 \\
\hline & 0.1 & -0.048 \\
\hline & 0.2 & \multirow{3}{*}{ no crevice corrosion } \\
\hline & 0.32 & \\
\hline & 0.4 & \\
\hline \multirow[t]{2}{*}{$\mathrm{OH}^{-}$} & 0.04 & -0.208 \\
\hline & 0.4 & -0.096 \\
\hline
\end{tabular}

The effect of inhibitors on the crevice corrosion of alloy 690 was measured under similar conditions as the alloy 600 , i.e., at 23 and $60^{\circ} \mathrm{C}$, in 0.04 and $4 \mathrm{M} \mathrm{NaCl}$ solutions. In this case, both chloride levels were tested at $60^{\circ} \mathrm{C}$ in order to study the effect of aggressive ion concentration on $\mathrm{E}_{\mathrm{rcrev}}$ in the presence of inhibitors. The results are summarized in Tables $25\left(4 \mathrm{M} \mathrm{NaCl}, 23^{\circ} \mathrm{C}\right)$ and $26\left(0.04\right.$ and $\left.4 \mathrm{M} \mathrm{NaCl}, 60^{\circ} \mathrm{C}\right)$.

In $4 \mathrm{M} \mathrm{NaCl}$ solution, none of the inhibitors were found to be effective even at high concentrations at either temperatures. In $0.04 \mathrm{M} \mathrm{NaCl}$ solution at $60^{\circ} \mathrm{C}$, however, hydroxide and molybdate ions were found to inhibit the crevice corrosion of alloy 690 . $\mathrm{MoO}_{4}{ }^{2-}$ ions were significantly more effective than $\mathrm{OH}^{-}$ions.

Table 25. Crevice repassivation potential of alloy 690 measured in $4.0 \mathrm{M} \mathrm{NaCl}$ solution at $23^{\circ} \mathrm{C}$.

\begin{tabular}{|c|c|c|}
\hline Inhibitor & Concentration (M) & $E_{\text {rcrev }}$ (V vs. SCE) \\
\hline None & $\mathrm{N} / \mathrm{A}$ & -0.169 \\
\hline \multirow{3}{*}{$\mathrm{OH}^{-}$} & 0.4 & -0.189 \\
\hline & 1.0 & -0.234 \\
\hline & 1.5 & -0.236 \\
\hline \multirow[t]{2}{*}{$\mathrm{MoO}_{4}{ }^{2-}$} & 0.4 & -0.165 \\
\hline & 1.5 & -0.113 \\
\hline \multirow[t]{2}{*}{$\mathrm{SO}_{4}^{2-}$} & 0.4 & -0.278 \\
\hline & 1.5 & -0.207 \\
\hline
\end{tabular}


Table 26. Crevice repassivation potential of alloy 690 measured in 0.04 and $4.0 \mathrm{M}$ $\mathrm{NaCl}$ solution at $60^{\circ} \mathrm{C}$.

\begin{tabular}{|c|c|c|c|}
\hline Chloride level (M) & Inhibitor & Concentration (M) & $E_{\text {rcrev }}$ (V vs. SCE) \\
\hline \multirow{8}{*}{0.04} & none & $\mathrm{N} / \mathrm{A}$ & -0.221 \\
\hline & \multirow[t]{2}{*}{$\mathrm{OH}^{-}$} & 0.04 & -0.146 \\
\hline & & 2.0 & -0.153 \\
\hline & \multirow{3}{*}{$\mathrm{MoO}_{4}^{2-}$} & 0.004 & -0.212 \\
\hline & & 0.01 & -0.087 \\
\hline & & 0.04 & 0.043 \\
\hline & $\mathrm{SO}_{4}{ }^{2-}$ & 0.04 & -0.276 \\
\hline & $\mathrm{VO}_{3}^{-}$ & 0.04 & -0.276 \\
\hline \multirow{6}{*}{4.0} & none & $\mathrm{N} / \mathrm{A}$ & -0.291 \\
\hline & \multirow{3}{*}{$\mathrm{OH}^{-}$} & 0.4 & -0.376 \\
\hline & & 1.0 & -0.387 \\
\hline & & 2.0 & -0.363 \\
\hline & \multirow[t]{2}{*}{$\mathrm{MoO}_{4}{ }^{2-}$} & 0.4 & -0.300 \\
\hline & & 1.5 & -0.324 \\
\hline
\end{tabular}

The crevice repassivation potential of alloys 600 and 690, as a function of inhibitor concentration is shown in Figures $33 \mathrm{a}\left(4 \mathrm{M} \mathrm{NaCl}, 23^{\circ} \mathrm{C}\right)$ and $33 \mathrm{~b}\left(0.04 \mathrm{M} \mathrm{NaCl}, 60^{\circ} \mathrm{C}\right)$. The crevice repassivation potential of alloy 690 was higher in both environments without the presence of inhibitors, as expected. The higher Cr content of alloy 690 gives rise to a higher resistance to crevice corrosion. In general, a greater effect of the inhibitors was observed in case of alloy 600 . In $4 \mathrm{M} \mathrm{NaCl}$ solution at $23^{\circ} \mathrm{C}$, sulfate and hydroxide ions were found to increase $\mathrm{E}_{\text {rcrev }}$ of alloy 600 , while they lowered $\mathrm{E}_{\text {rcrev }}$ of alloy 690. Molybdate ions increased $\mathrm{E}_{\mathrm{rcrev}}$ of both alloys. In $0.04 \mathrm{M} \mathrm{NaCl}$ solution at $60^{\circ} \mathrm{C}$, both molybdate and hydroxide ions showed inhibiting effect on the crevice corrosion of alloys 600 and 690 . Sulfate ions, on the other hand, only raised the crevice repassivation potential of alloy 600 . In case of alloy 690 , they acted as aggressive ions, lowering $\mathrm{E}_{\text {rcrev. }}$.
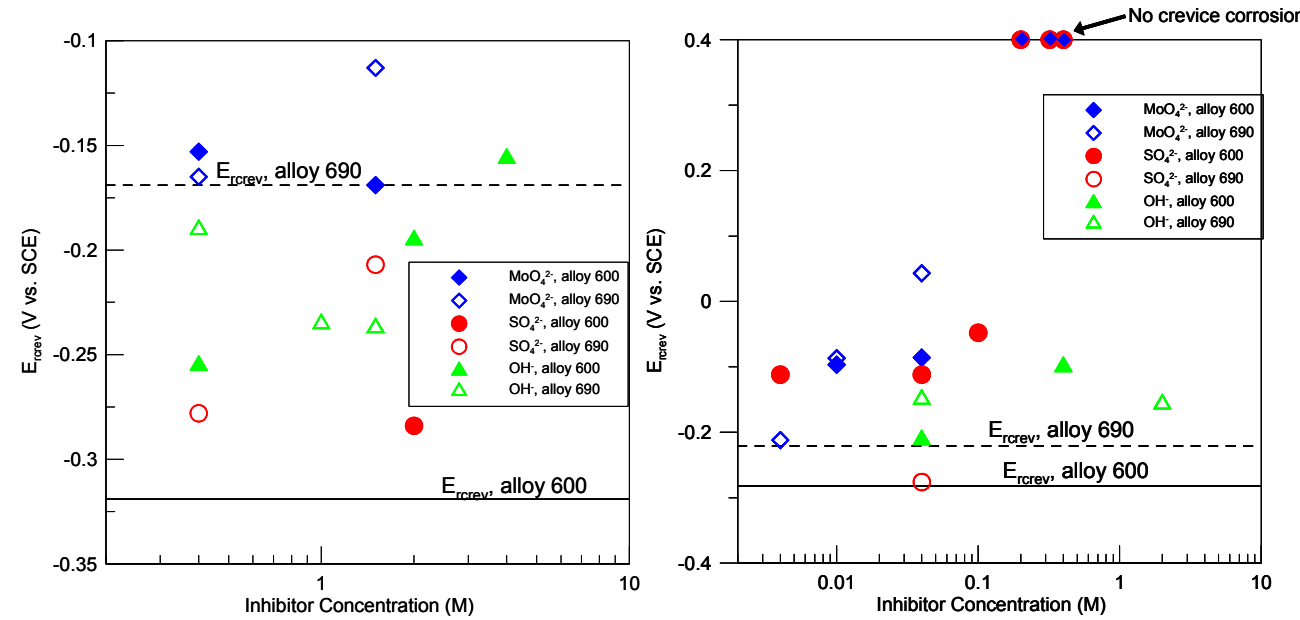

Figure 33. Crevice repassivation potential of alloys 600 and 690 as a function of inhibitor concentration (a) in $4 \mathrm{M} \mathrm{NaCl}$ solution at $23^{\circ} \mathrm{C}$ and (b) in $0.04 \mathrm{M} \mathrm{NaCl}$ solution at $60^{\circ} \mathrm{C}$. The straight lines indicate the $\mathrm{E}_{\text {rcrev }}$ values without the presence of inhibitors. $\mathrm{E}_{\mathrm{rcrev}}$ is shown as $0.4 \mathrm{~V}$ vs. SCE where no crevice corrosion was observed. 


\section{$E_{r p}$ of Heat Treated Alloys to Simulate Weldments}

Alloy 600. The crevice repassivation potentials of thermally aged alloy 600 were determined by cyclic potentiodynamic polarization (CPP) and potential staircase (PS) methods. In these tests, alloy 600 was obtained from two different heats, arbitrarily referred to as lot 1 and lot 2 , with the following compositions (wt $\%$ ):

lot 1 - Fe: 9.69, Ni: 75.09, Cr: 14.66, Mn: 0.28, Ti: <0.310, C: 0.02, Al: <0.172, Cu: 0.2 lot 2 - Fe: 9.19, Ni: 74.41, Cr: 15.56, Mn: 0.21, Ti: 0.23, C: 0.04, Al: 0.252, Cu: 0.04 .

The crevice repassivation potential of alloy 600 determined from CPP at different chloride ion concentrations for lot 1 as a function of aging time at $700^{\circ} \mathrm{C}$ is summarized in Figure 34. The specimens were solution annealed prior to aging at $1100^{\circ} \mathrm{C}$ for 30 minutes in order to solutionize the alloy. The resulting microstructure is shown in Figure 35 . According to the results, the specimens were sufficiently solutionized after heating to $1100^{\circ} \mathrm{C}$ for 30 minutes followed by a water-quench.

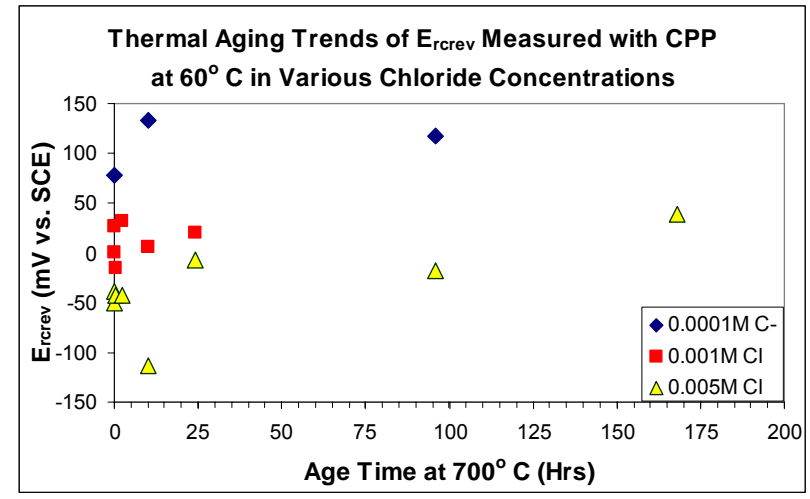

Figure 34. $\mathrm{E}_{\text {rcrev }}$ as a function of $\mathrm{c}_{\mathrm{Cl}}$ and aging time measured with CPP.

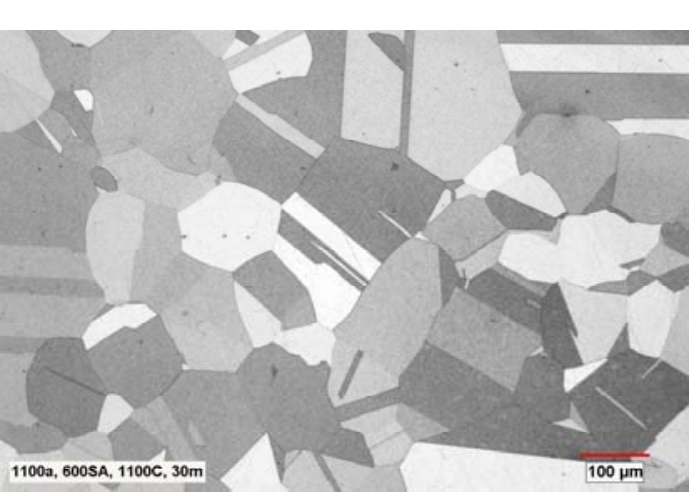

Figure 35. Micrograph of alloy 600 after solution-anneal treatment at $1100^{\circ} \mathrm{C}$ for 30 min.

An inverse relationship was observed between the repassivation potential and chloride ion concentration, as expected, since increasing $\mathrm{Cl}^{-}$ion concentrations are more corrosive to "stainless" alloys, such as alloy 600 due to the more severe localized corrosion. Conflicting trends of $\mathrm{E}_{\text {rcrev }}$ with thermal aging treatments were observed at varying concentrations. At $0.0001 \mathrm{M} \mathrm{Cl}^{-}$level, the $\mathrm{E}_{\text {rcrev }}$ increased with thermal aging time, which suggests that the alloy became more resistant to localized corrosion with sensitization. At $0.001 \mathrm{M} \mathrm{Cl}^{-}$level, no observable trend was found with aging time, while at $0.005 \mathrm{M} \mathrm{Cl}^{-}$, an initial drop on $E_{\text {rcrev }}$ was found up to 10 hours of aging, followed by a recovery of $\mathrm{E}_{\mathrm{rcrev}}$ to the levels seen in the solution annealed condition. These unusual and unexpected trends warranted further studies. The charge density passed during the repassivation scan was calculated for each specimen, because previous tests showed that for shallow pits, $E_{\text {rcrev }}$ depends on the charge density obtained during test (Sridhar and Cragnolino, 1993). Figure 36 shows the measured crevice repassivation potential as a function of calculated charge density. At 0.0001 and $0.001 \mathrm{M}$ chloride levels, a strong inverse dependence of the measured $\mathrm{E}_{\text {rcrev }}$ on charge density was observed. This suggests that the trends seen for $E_{\text {rcrev }}$ as a function of thermal aging time (Figure 36) were confounded by the effect of 
charge density, thus they are not representative of sensitization. However, at $0.005 \mathrm{M}$ chloride level, the measured crevice repassivation potential is independent of the charge passed, thus the trend illustrated in Figure 36 may be attributed solely to sensitization.

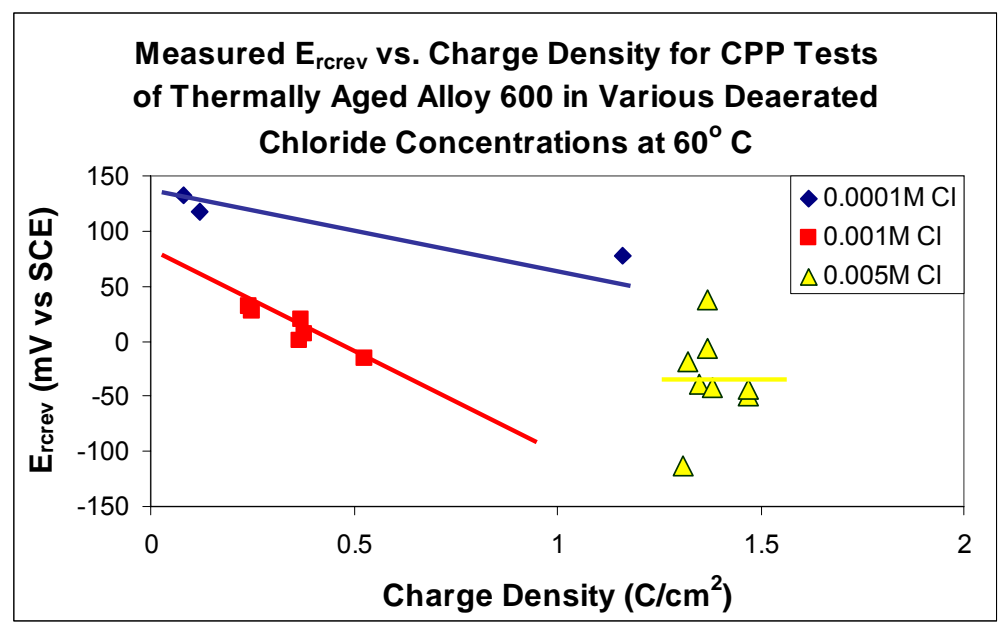

Figure 36. Dependence of the measured $E_{\text {rcrev }}$ on the charge density passed during CPP scans at different chloride levels.

The crevice repassivation potential as a function of aging time at different chloride levels was also measured using the PS method. Figure 37 summarizes the results obtained for both lots of alloy 600 at different $\mathrm{Cl}^{-}$concentrations.

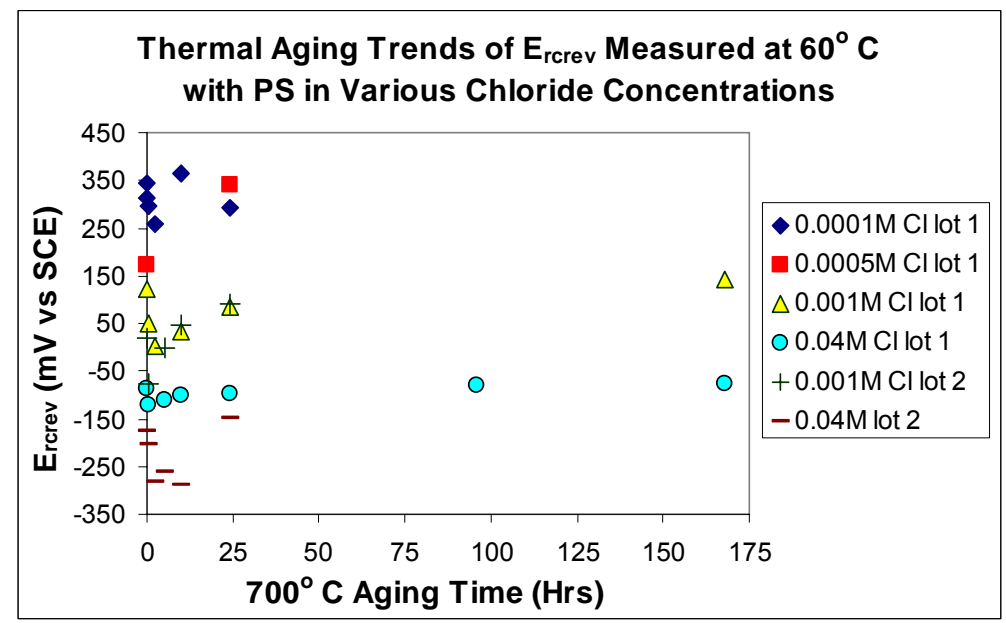

Figure 37. Crevice repassivation potential as a function of aging time measured at different chloride concentrations using the PS method.

At low chloride levels, i.e., $10^{-4}$ and $5 \times 10^{-4} \mathrm{M}$, no trends were observed, while at 0.001 and $0.04 \mathrm{M} \mathrm{Cl}^{-}$concentrations, trends similar to those found in case of CPP were measured. In order to test whether these trends are due solely to sensitization or are confounded by charge density effect, $\mathrm{E}_{\text {rcrev }}$ as a function of charge density was determined as shown in Figure 38. 


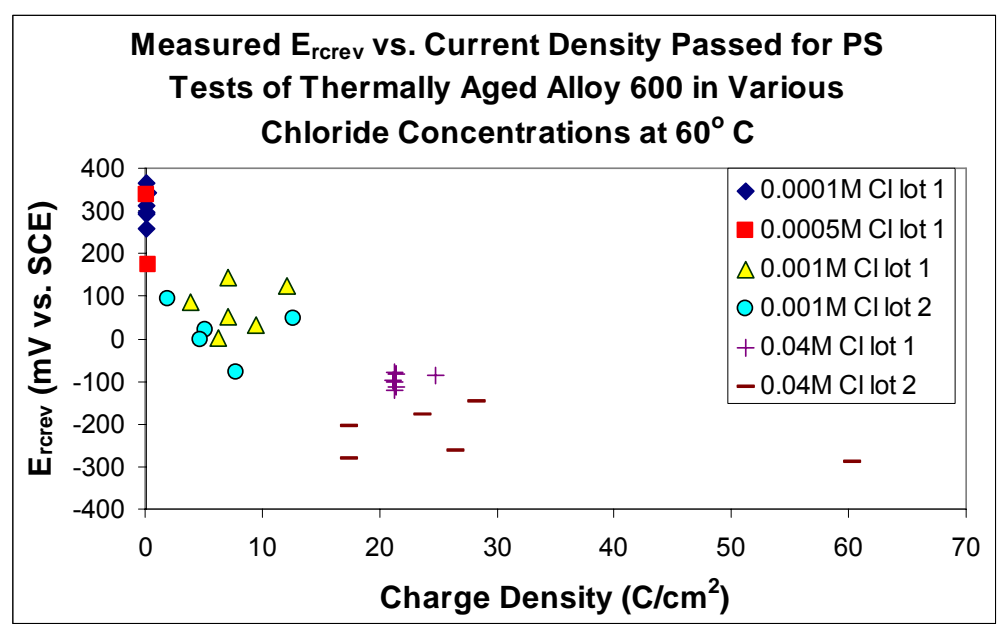

Figure 38. Crevice repassivation potential of alloy 600 as a function of charge density determined by PS scans at different chloride levels.

A strong dependence of the repassivation potential on the charge density can be seen for charge densities $<2.5 \mathrm{C} / \mathrm{cm}^{2}$, especially at the lower chloride levels $\left(10^{-4}\right.$ and $\left.5 \times 10^{-4} \mathrm{M}\right)$, where it is more difficult to initiate crevice corrosion. Thus, it can be concluded that the PS tests performed in $10^{-4}$ and $5 \times 10^{-4} \mathrm{M} \mathrm{Cl}^{-}$did not promote enough localized corrosion to yield $\mathrm{E}_{\text {rcrev }}$ measurements independent of charge density generated during the test. At 0.001 and $0.04 \mathrm{M} \mathrm{Cl}^{-}$concentrations, no dependence of $\mathrm{E}_{\mathrm{rcrev}}$ on the charge density was observed, thus the trends observed in Figure 37 for these higher chloride levels were probably due to metallurgical effects. Similarly to the CPP results, the crevice repassivation potential initially decreased with aging time, then it recovered to the level seen in the solution annealed condition. The specimens from the different lots showed very similar behaviors, especially in $0.001 \mathrm{M} \mathrm{NaCl}$ solution. The crevice repassivation potentials as a function of aging time that are independent of the charge density are summarized in Figure 39. According to the observed trend, the initial aging of the material is accompanied by a drop in the repassivation potential, but then it recovers within $24 \mathrm{hrs}$ of thermal aging for most specimens. Lot 1 material in $0.04 \mathrm{M} \mathrm{Cl}^{-}$showed an initial $\mathrm{E}_{\mathrm{rcrev}}$ drop that was sustained for the entire 24 hours without evidence of recovery.

In order to understand the metallurgical changes that occur during the aging process, EPR tests were performed to determine the degree of sensitization (DOS) as a function of aging time. Initially, the tests were performed using the "standard" $0.5 \mathrm{M} \mathrm{H}_{2} \mathrm{SO}_{4}$ solution, however, it was found to be too aggressive to discern the DOS for different thermal treatments. Thus, the sulfuric acid concentration was lowered in subsequent experiments and a test solution of $0.05 \mathrm{M} \mathrm{H}_{2} \mathrm{SO}_{4}+5 \times 10^{-5} \mathrm{M} \mathrm{KSCN}$ was used. This new test solution was able to adequately distinguish between different DOS values corresponding to the mill annealed and solution annealed conditions, therefore it was implemented for the thermally aged specimens. A representative EPR curve is shown in Figure 40. 


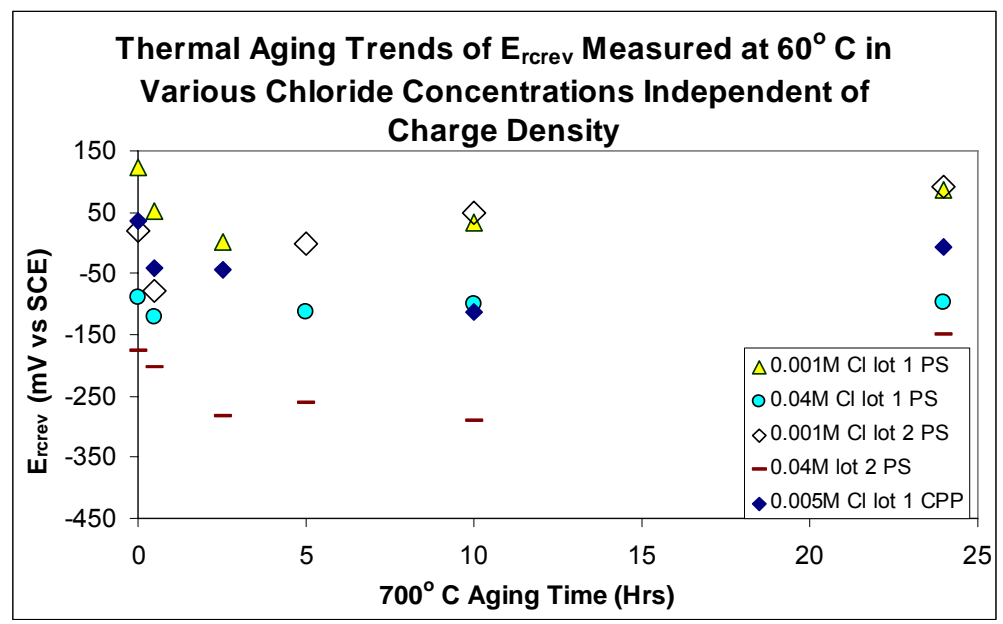

Figure 39. Crevice repassivation potential as a function of aging time in case of conditions that were independent of charge density.

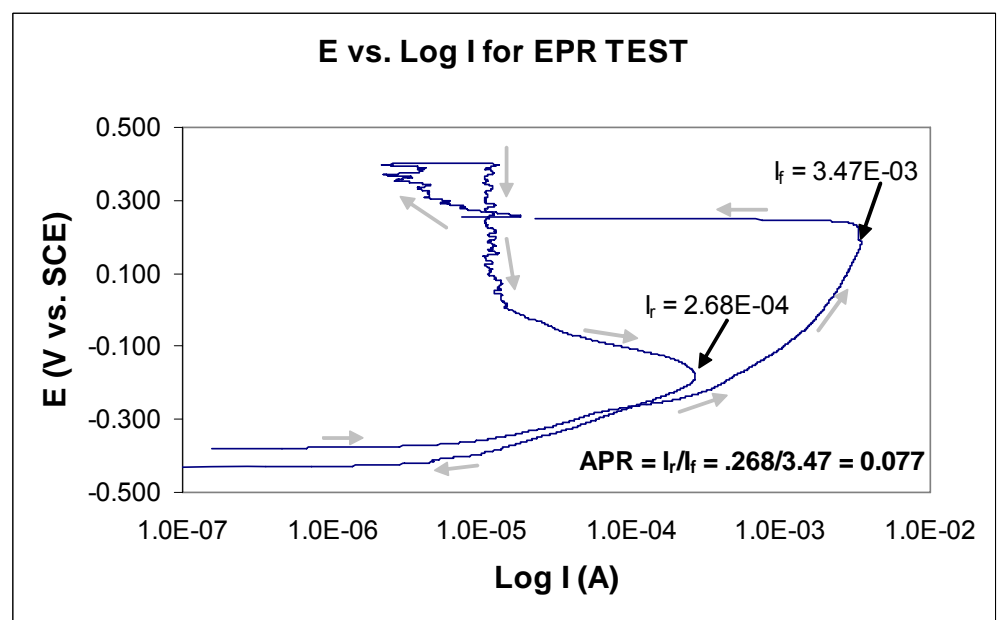

Figure 40. Representative EPR curve measured in $0.05 \mathrm{M} \mathrm{H}_{2} \mathrm{SO}_{4}+5 \times 10^{-4} \mathrm{M} \mathrm{KSCN}$ solution at $23^{\circ} \mathrm{C}$. Specimen: alloy 600 .

The ratio of forward and reverse current values ( $\mathrm{I}_{\mathrm{f}}$ and $\mathrm{I}_{\mathrm{r}}$, respectively), or anodic peak ratio (APR) was used as a measure of the degree of sensitization. The anodic peak ratios (APRs) as a function of aging time for the different heats are shown in Figure 41.

The EPR results show that the DOS increased with aging time up to between 10 and 24 hours in case of lot (heat) 1 and up to 5 hours for lot (heat) 2. Healing, manifested by the return of APR values to solution annealed levels, was observed after 96 hours for lot (heat) 1. The different carbon contents of the two lots might have been responsible for their different sensitization behaviors. In order to further understand the effect of carbon content of the alloy on DOS, the time required to reach the minimum chromium concentration for sensitization in the GBCD was plotted as a function of carbon content based on data found in the literature (Was et al., 1981; Yukitoshi, et al., 1979; Hall and Briant, 1985; Duffaut et al., 1966) and it is shown in Figure 42. 


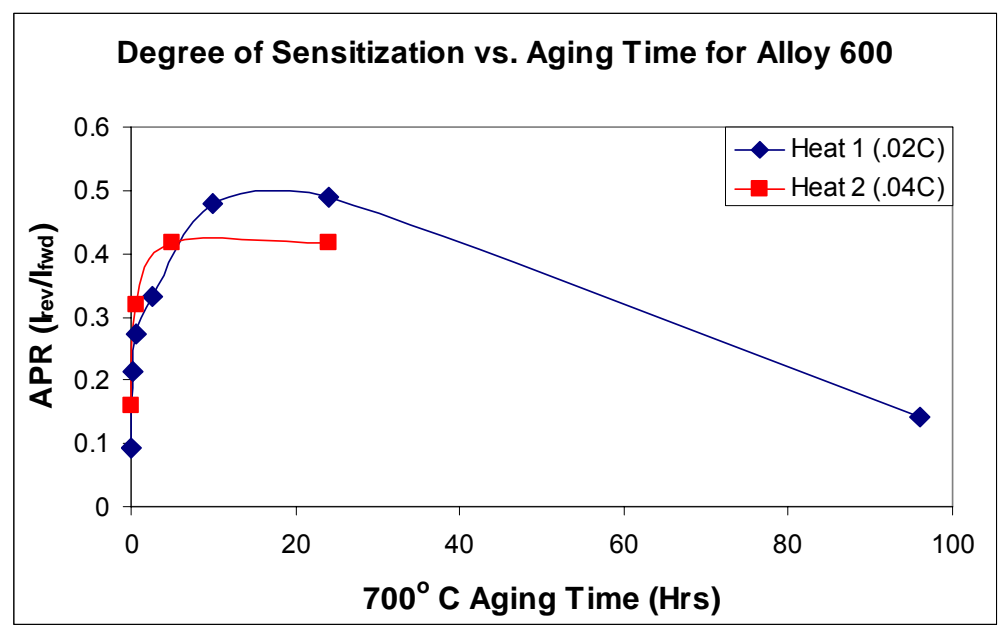

Figure 41. APRs recorded in $0.05 \mathrm{M} \mathrm{H}_{2} \mathrm{SO}_{4}+5 \times 10^{-5} \mathrm{M}$ KSCN solution for alloy 600 heats that were solution annealed and subsequently subjected to thermal aging treatments at $700^{\circ} \mathrm{C}$ for different time intervals.

A trendline was fitted to the experimental data points to determine the mathematical relationship between the hours required to reach the minimum $\mathrm{Cr}$ concentration in the GBCD and the carbon content of the alloy. The following relationship was found between the two parameters:

$$
\text { Time }_{\min C r}=0.0561 \cdot \% C^{-1.5164}
$$

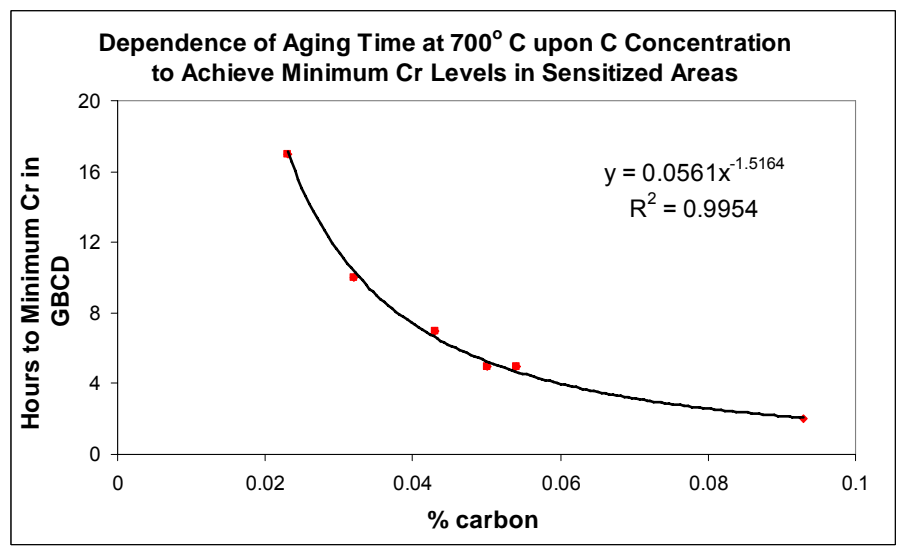

Figure 42. Hours required to achieve minimum $\mathrm{Cr}$ level in the GBCD as a function of carbon content of the alloy.

Based on Equation 13, the time to reach the minimum $\mathrm{Cr}$ content, i.e., maximum sensitization is 20 hours for lot 1 specimens $(\mathrm{C}=0.02 \%)$, while lot 2 specimens $(\mathrm{C}=$ $0.04 \%$ ) should be fully sensitized within 7 hours. These predicted values are consistent with the observed APR trends (Figure 41). Metallographic data were also taken to further verify the sensitization levels. The exposed surface of the materials was examined following the EPR test. Sensitized areas along the grain boundaries and, eventually, within the grains were found to be preferentially corroded during the test and visually evident as furrows, also referred to as troughs and ditches. Figure 43 shows the 
microstructure of aged specimens from lot 1 following EPR testing. The micrographs indicate increasing furrowing along the grain boundaries from 2.5 to $24 \mathrm{hrs}$, which is drastically reduced after $96 \mathrm{hrs}$ of aging. The microscopy results are consistent with the electrochemical findings.
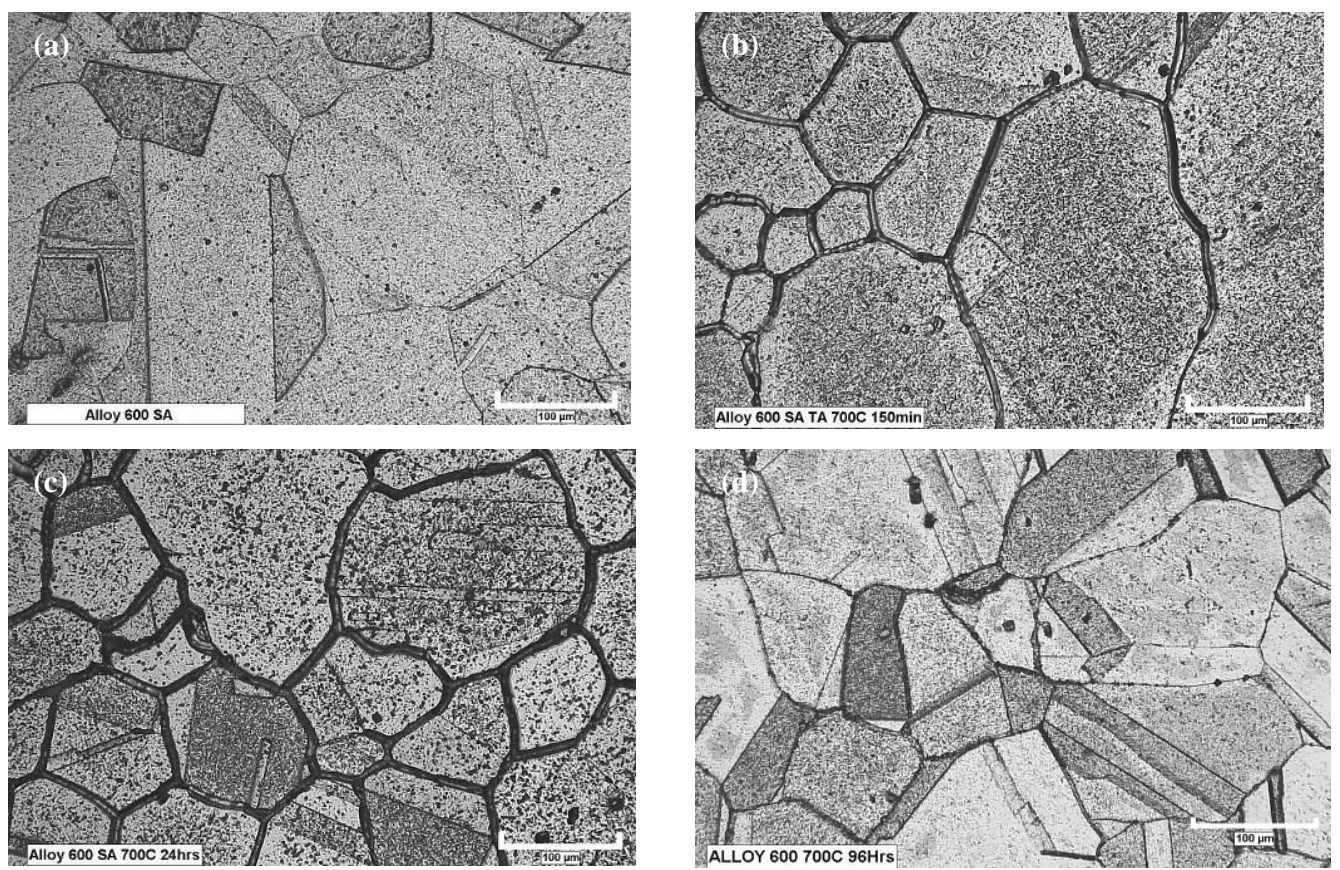

Figure 43. Micrographs of EPR tested specimens: (a) solution annealed, (b) solution annealed, then thermally aged for 2.5 hrs, (c) solution annealed, then aged for 24 hrs and (d) solution annealed, then aged for 96 hrs. The thermal aging treatments were carried out at $700^{\circ} \mathrm{C}$.

The sensitization kinetics measured by EPR and crevice repassivation potential tests is compared in Figure 44.

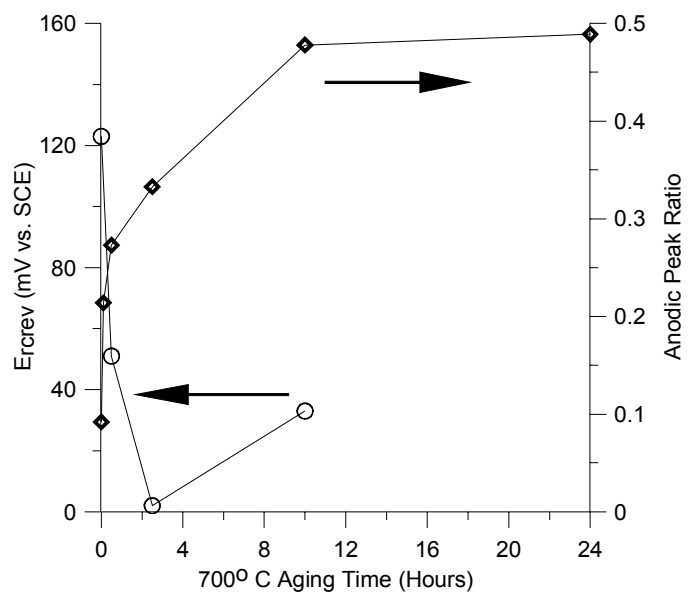

Figure 44. Comparison of sensitization kinetics measured by EPR and $E_{\text {rcrev }}$ tests. 
While $\mathrm{E}_{\text {rcrev }}$ values show healing after approximately $2.5 \mathrm{hrs}$ of aging, the EPR results continue showing increased degree of sensitization up to 24 hours. Several factors can provide an explanation for this finding. It is well known from the literature that EPR tests are relatively accurate in determining degree of sensitization. However, the effect of the degree of sensitization on $\mathrm{E}_{\text {rcrev }}$ is not known. Thus, additional localized corrosion parameters were investigated as a function of aging time (Figure 45).

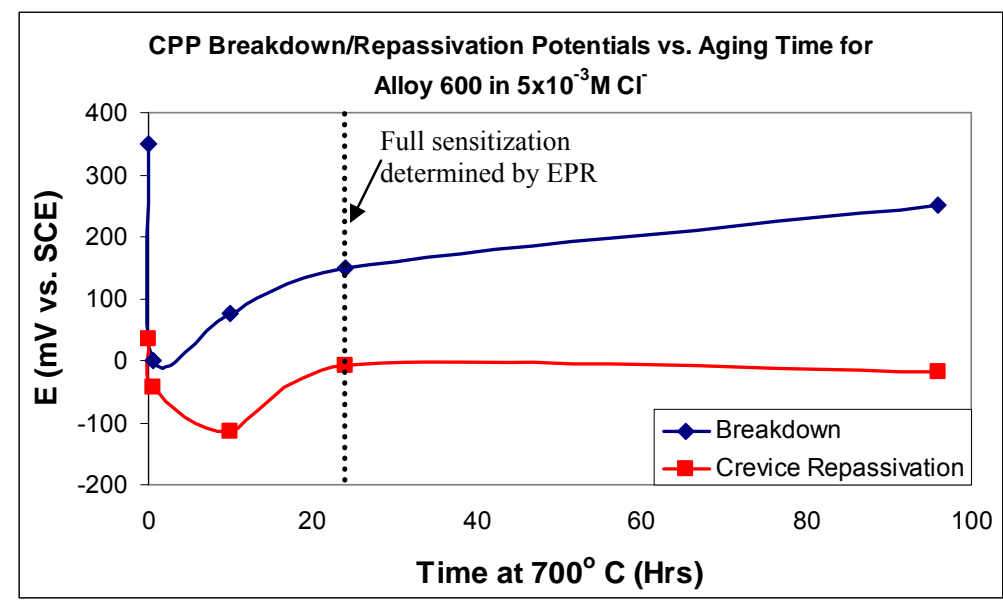

Figure 45. Breakdown and crevice repassivation potential of alloy 600 measured in $0.005 \mathrm{M} \mathrm{NaCl}$ solution at $60^{\circ} \mathrm{C}$. The aging time required to reach full sensitization as determined by the EPR technique is shown as a vertical line.

The breakdown potentials show an initial drop and partial recovery prior to the time required for full sensitization determined from EPR. In Figure 36, the breakdown and crevice repassivation potentials indicate an increased susceptibility to localized corrosion prior to reaching the maximum $\mathrm{Cr}$ depletion (full sensitization). In order to analyze the source of this discrepancy, it is important to understand what these test methods aim to show. EPR is designed to determine the volume of material that has undergone chromium depletion under a certain threshold value and therefore, in sensitized alloys, it is relevant exclusively to the grain boundaries. The threshold value depends on the corrosivity of the test solution. In our tests, the threshold chromium level was not determined, however, it was shown that the solution used in the experiments $\left(0.05 \mathrm{M} \mathrm{H}_{2} \mathrm{SO}_{4}+5 \times 10^{-5} \mathrm{M} \mathrm{KSCN}\right)$ clearly detected different levels of sensitization as thermal aging progressed. The localized corrosion tests (CPP and PS) measure the susceptibility to localized corrosion. For example, $E_{\text {rcrev }}$ tests show the potential at which stable crevices cease to grow. Since local passivity breakdown may occur for creviced areas where $\mathrm{Cr}$ depletion has not occurred, the CPP and PS tests do not necessarily indicate the volume of material that is depleted in $\mathrm{Cr}$ as the EPR test does, nor is it exclusive to the grain boundaries. Upon examining a post-test specimen, it can be seen that the corrosion that occurs in $\mathrm{E}_{\text {rcrev }}$ measurements extends well outside the grain boundary region (Figure 46). While the localized damage may initiate in the GBCD, the growth of the damage extends beyond the GBCD region and into the bulk material where chromium depletion has not occurred. 


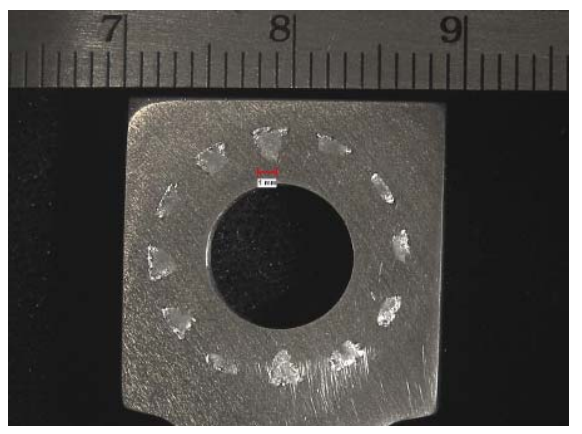

Figure 46. Low magnification image of a crevice specimen following CPP test.

Schematics shown in Figure 47 provide further illustration of the difference between the $\mathrm{EPR}$ and CPP/PS test methods.

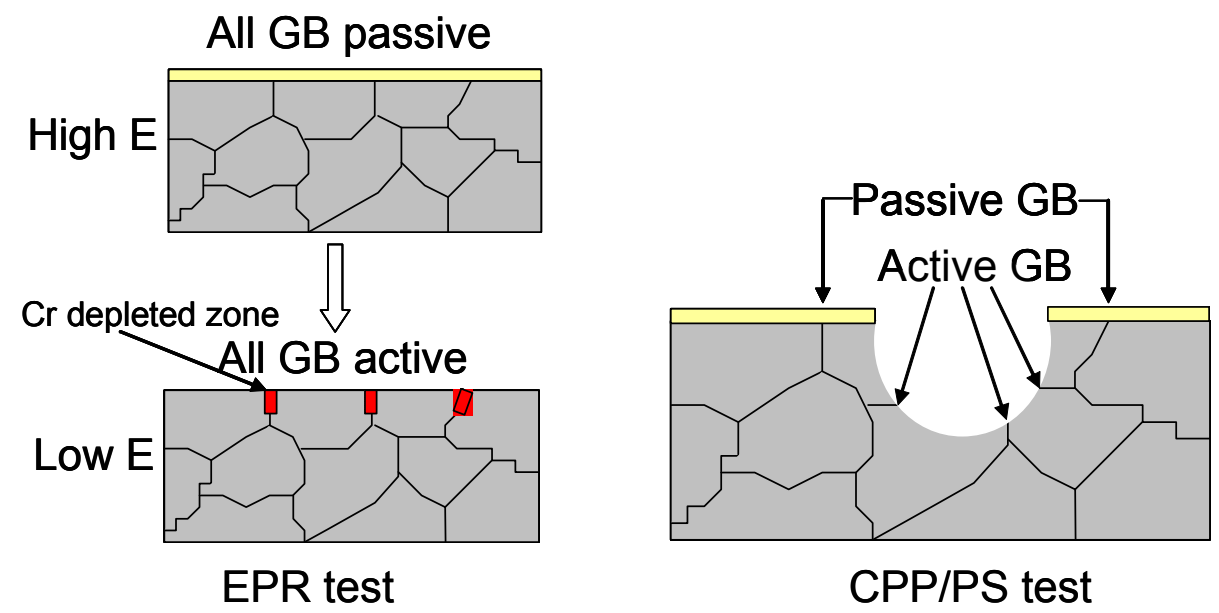

Figure 47. Schematic diagrams of EPR and CPP/PS ( $\left.E_{\text {rcrev }}\right)$ test methods to illustrate the differences in the grain boundary effects.

Microchemical changes in the alloy microstructure stemming from thermal exposure add another factor that can play a roll in the development of local loss of passivity. The susceptibility of an alloy to loss of passivity and subsequent localized corrosion depends on several internal and external factors including temperature, concentration of oxidizing species, alloy composition, geometry of crevices and pits, etc. While a compositionally uniform material may be subject to localized corrosion and/or crevice corrosion in certain environments, a sensitized material is expected to undergo localized corrosion in comparatively less corrosive environments, because loss of passivity may occur more readily in materials that are depleted in chromium. The exact reason for this increased susceptibility is not well understood at this time, however, the geometry of the chromium depleted region, the grain size, crevice or pit geometry, composition of environment and alloy are all likely to play a role.

During tests performed at different chloride concentrations, it was observed that the corrosivity of the test solution influenced the apparent sensitization kinetics when determined from $\mathrm{E}_{\mathrm{rcrev}}$ measurements. Figure 48 shows the crevice repassivation 
potentials as a function of aging time at different chloride levels. The aging time required to reach the lowest value of $E_{\text {rcrev }}$, i.e., greatest level of susceptibility, depends on the $\mathrm{Cl}^{-}$

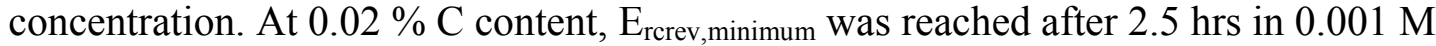
$\mathrm{NaCl}$ solution and after $10 \mathrm{hrs}$ in $0.005 \mathrm{M} \mathrm{NaCl}$. At $0.04 \% \mathrm{C}$ content, it was reached after $0.5 \mathrm{hrs}$ in $0.001 \mathrm{M} \mathrm{NaCl}$ and after $5 \mathrm{hrs}$ in $0.04 \mathrm{M} \mathrm{NaCl}$. Thus, the apparent rate of sensitization decreases with increasing solution corrosivity.

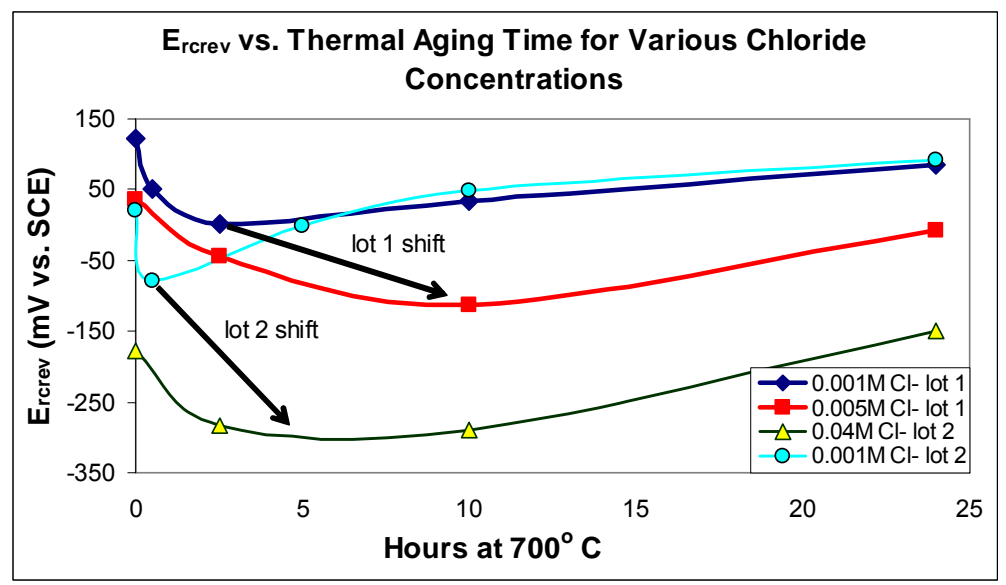

Figure 48. Crevice repassivation potentials as a function of thermal aging time at different chloride ion concentrations for different heats of alloy 600 .

It is expected that as the corrosivity of the solution increases, the chromium threshold for susceptible material increases decreasing the aging time required to achieve $\mathrm{E}_{\text {rcrev,minimum. }}$ However, there are several additional factors influencing the sensitization kinetics. For example, as the size of the threshold material volume changes, the formation kinetics varies, resulting in different apparent sensitization kinetics. Other potential factors to be taken into account are the severity of $\mathrm{Cr}$ depletion, depletion location, geometry and number of depleted areas etc.

The dependence of $\mathrm{E}_{\text {rcrev }}$ on chloride ion concentration was also determined in the solution annealed state. The results are summarized in Figure 49.

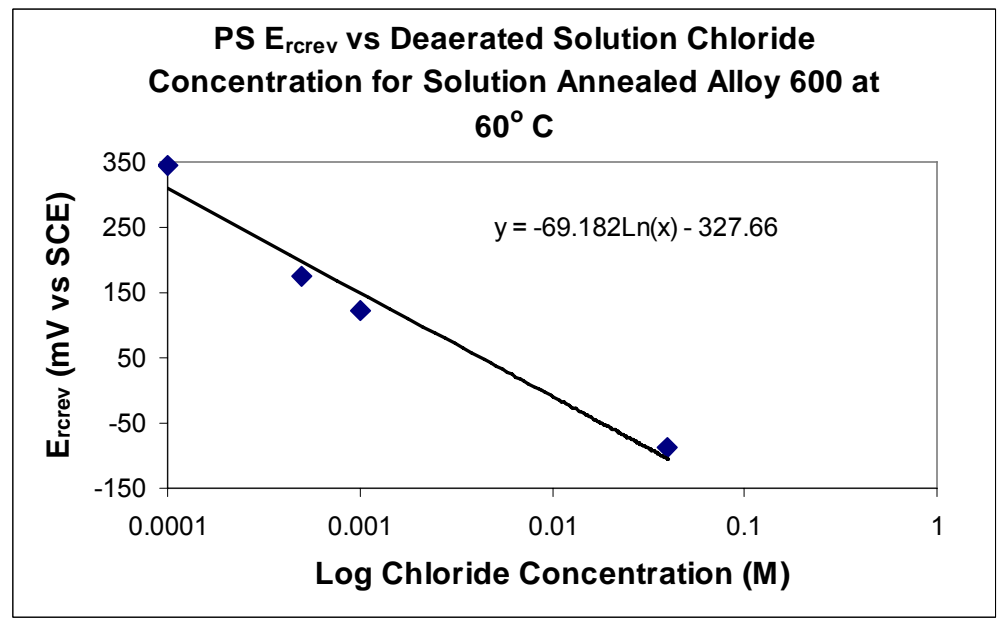

Figure 49. $E_{\text {rcrev }}$ of solution annealed alloy 600 as a function of chloride ion concentration. 
$E_{\text {rcrev }}$ decreases with increasing chloride ion concentration, as expected, due to the increased corrosivity of the environment.

Alloy 690. The crevice repassivation potential of alloy 690 as a function of aging treatments was measured using the $\mathrm{E}_{\mathrm{rcrev}}$ tests. The aging treatments were performed on both mill annealed and solution annealed materials at $700^{\circ} \mathrm{C}$ and $870^{\circ} \mathrm{C}$. The crevice repassivation potentials measured in $0.04 \mathrm{M} \mathrm{NaCl}$ solution are shown in Figure 50.

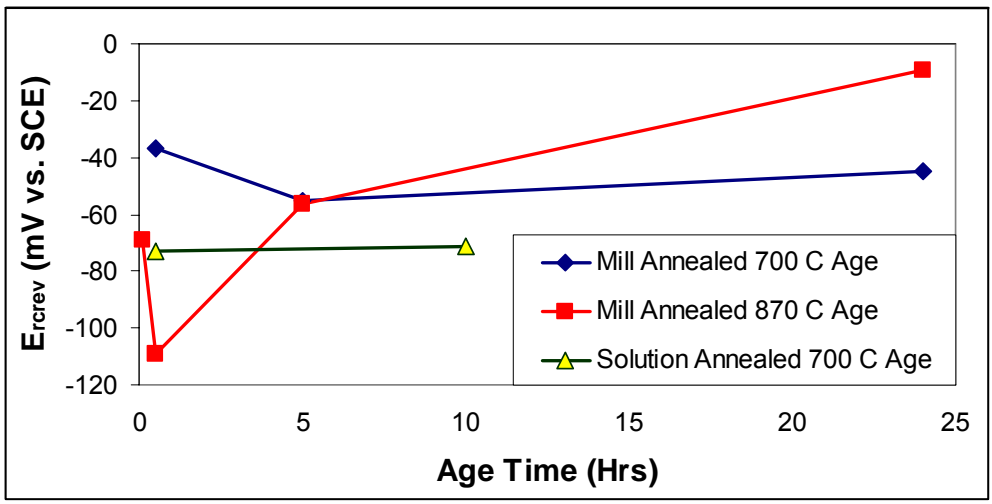

Figure 50. $\mathrm{E}_{\text {rcrev }}$ of alloy 690 determined by $\mathrm{PS}$ method at $60^{\circ} \mathrm{C}$ in $0.04 \mathrm{M} \mathrm{NaCl}$ solution.

No trend outside the uncertainty range $( \pm 50 \mathrm{mV})$ was found between the $\mathrm{E}_{\mathrm{rcrev}}$ and the aging time. Due to the high chromium content of this alloy, the $\mathrm{Cr}$ concentration in the GBCD layer likely did not drop below the critical value needed for passivation in chloride environments. Thus, no evidence of sensitization was observed in alloy 690 under the tested conditions.

2205 and 2304 Duplex Stainless Steels. The crevice repassivation potentials of isothermally aged duplex stainless steels 2205 and 2304 were determined using the potential staircase method. In these tests, two different heats of alloy 2205 were used with the following compositions:

Lot: AB130 - Fe: Bal., Ni: 5.8, Cr: 22.5, Mo: 3.2, Mn: 1.55, C: 0.017, N: 0.164, Si: 0.41 Lot: AA260 - Fe: Bal., Ni: 5.7, Cr: 22.5, Mo: 3.22, Mn: 1.42, C: 0.018, N: 0.172, Si: 0.35

The measured $E_{\text {rcrev }}$ values for alloy 2205 in solutions containing $0.04 \mathrm{M}$ and $0.4 \mathrm{M} \mathrm{Cl}^{-}$ are shown in Figure 51.

Short-term isothermal aging treatments at $700^{\circ} \mathrm{C}$ resulted in a significant drop of $\mathrm{E}_{\text {rcrev }}$. The $\mathrm{E}_{\mathrm{rcrev}}$ drop was larger than that found in other alloys that undergo precipitation and subsequent sensitization at the precipitation boundaries, e.g., 600. Interestingly, in case of alloy 2205, no recovery of the crevice repassivation potential was observed. Unlike alloy 600 which showed healing of the $\mathrm{Cr}$ depletion after a few hours of aging, no such healing and subsequent $E_{\text {rcrev }}$ recovery was observed in alloy 2205 even after 480 hrs of aging at $700^{\circ} \mathrm{C}$ (not shown). The crevice repassivation potential, however, reached a plateau after approximately $24 \mathrm{hrs}$ of aging. 


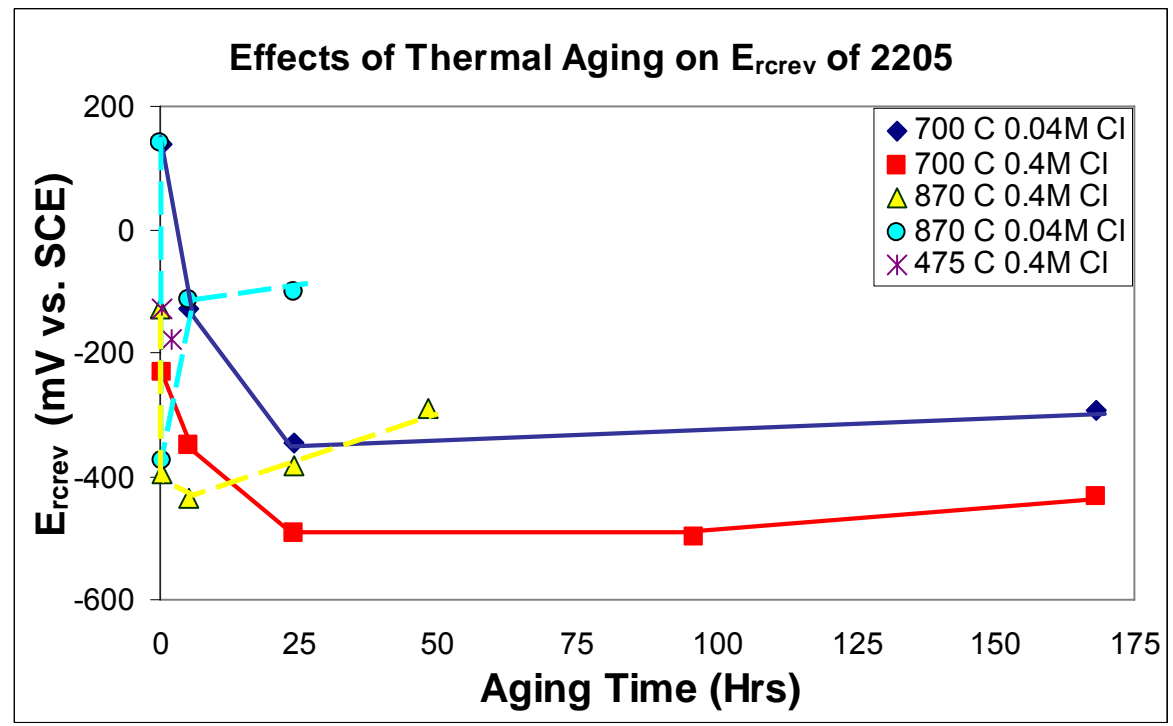

Figure 51. Crevice repassivation potential of isothermally aged alloy 2205 as a function of aging time measured at different chloride levels. The $\mathrm{E}_{\mathrm{rcrev}}$ measurements were carried out at $60^{\circ} \mathrm{C}$.

Isothermal heat treatments at $870^{\circ} \mathrm{C}$ were accompanied by an initial drop in $\mathrm{E}_{\text {rcrev, }}$ as well, but partial recovery of the crevice repassivation potential was observed with subsequent aging. The recovery time was found to be affected by chloride ion concentration. In $0.04 \mathrm{M} \mathrm{NaCl}$ solution, the recovery was evident after $0.5 \mathrm{hr}$ aging, while in $0.4 \mathrm{M} \mathrm{NaCl}$ solution, a slower healing process started after $5 \mathrm{hrs}$ of aging. Full recovery of $\mathrm{E}_{\text {rcrev }}$ to the value measured under mill-annealed conditions was not observed for the thermal treatments tested in this work.

Thermal aging at lower temperature, i.e., $475^{\circ} \mathrm{C}$, resulted in an $\mathrm{E}_{\mathrm{rcrev}}$ drop, as well, however, this decrease in repassivation potential was not as severe as in case of comparable aging times at 700 and $870^{\circ} \mathrm{C}$.

In order to understand the behavior of $\mathrm{E}_{\mathrm{rcrev}}$ as a function of aging time at different heat treatment temperatures, the microstructural and microchemical analyses (see Section 3.1) results were compared with the electrochemical findings. STEM analyses indicated that both heterogeneously depleted GBCD areas and homogeneously depleted precipitates of secondary austenite phase were present in alloy 2205 after isothermal heat treatment at 700 and $870^{\circ} \mathrm{C}$. The severity of $\mathrm{Cr}$ depletion and the volume fraction of the depleted material varied with temperature (Figure 10). The secondary austenite phases were found to be stable in the tested temperature regime, therefore no "healing" of the depleted $\mathrm{Cr}$ originating from the austenite phase was expected, the drop in $\mathrm{E}_{\mathrm{rcrev}}$ associated with $\mathrm{Cr}$ depleted secondary austenite formation is a non-recoverable loss of passivity for alloy 2205. As indicated in Figures 13 and 19 in Section 3.1, grain boundary Cr depletion (GBCD) was also observed after isothermal heat treatment at $700^{\circ} \mathrm{C}$. This depletion was found to be more severe than the precipitation of the secondary austenite phase after 24 hrs of heat treatment at $700^{\circ} \mathrm{C}$. In case of alloys, where only GBCD was observed, e.g., alloy 600 , recovery of $E_{\text {rcrev }}$ occurred after a certain amount of aging time. In case of 
alloy 2205 , no recovery was found at $700^{\circ} \mathrm{C}$, while partial recovery was noted at $870^{\circ} \mathrm{C}$. In order to understand this difference between the recovery behaviors, the relative levels of $\mathrm{Cr}$ depletion at the grain boundaries and in the secondary austenite phase need to be examined. At $700^{\circ} \mathrm{C}$, the $\mathrm{Cr}$ level of the secondary austenite was found to be comparable to the GBCD level. Thus, in this case, if healing were to occur at the grain boundaries, the secondary austenite phase remains or increases in volume, therefore, the alloy is still susceptible to localized corrosion. However, at $870^{\circ} \mathrm{C}$, the secondary austenite phase is less severely depleted than the grain boundaries, thus some recovery in $\mathrm{E}_{\text {rcrev }}$ is observed as the healing of the GBCD occurs. The precipitated secondary austenite phase, which is more susceptible to localized corrosion attack than the primary austenite, is still present and therefore, the $\mathrm{E}_{\text {rcrev }}$ never returns to the mill annealed level.

The crevice repassivation potentials of alloy 2304 as a function of aging time determined in $0.04 \mathrm{M} \mathrm{NaCl}$ solution are shown in Figure 52 .

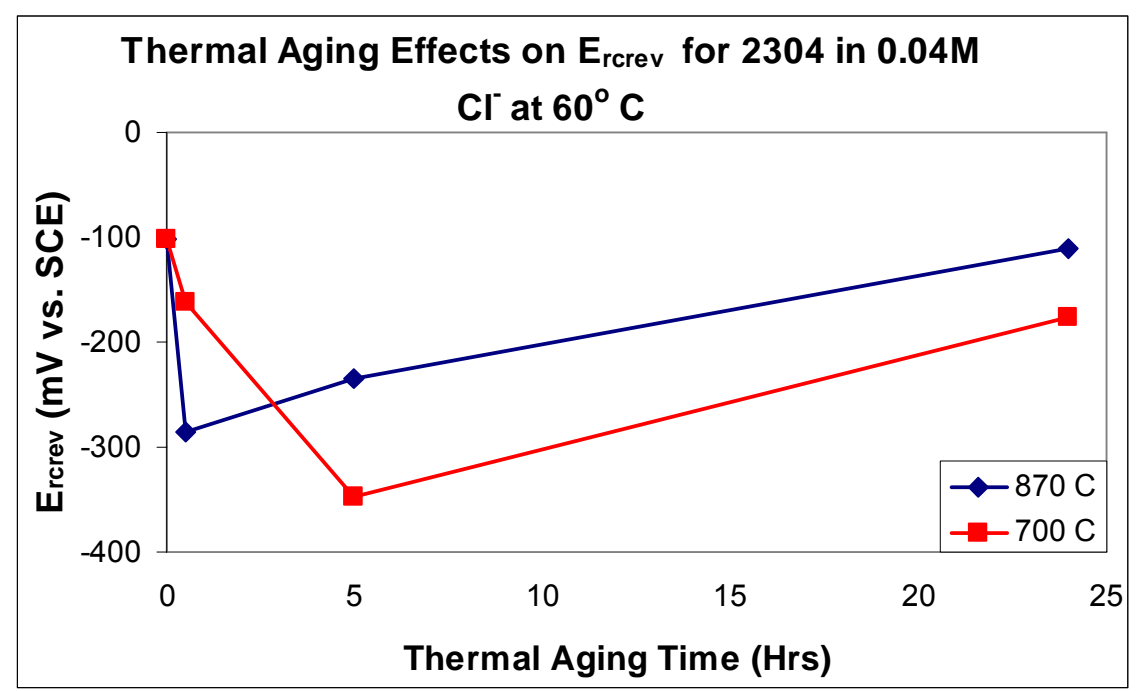

Figure 52. Crevice repassivation potential of alloy 2304 as a function of aging time at 700 and $870^{\circ} \mathrm{C}$ measured in $0.04 \mathrm{M} \mathrm{NaCl}$ solution. The $E_{\text {rcrev }}$ measurements were carried out at $60^{\circ} \mathrm{C}$.

Similarly to alloy 2205, alloy 2304 also showed a decrease in $\mathrm{E}_{\text {rcrev }}$ at short times upon isothermal treatment at both 700 and $870^{\circ} \mathrm{C}$. However, a recovery of $\mathrm{E}_{\text {rcrev }}$ was observed within $24 \mathrm{hrs}$ of aging at both temperatures. Furthermore, at $870^{\circ} \mathrm{C}$ heat treatment temperature, the magnitude of the $\mathrm{E}_{\text {rcrev }}$ drop was not as large as in case of alloy 2205. The time required for $\mathrm{E}_{\text {rcrev }}$ recovery was found to be dependent on the aging temperature, however, while the recovery time of alloy 2205 was directly proportional to the temperature, an inverse relationship was found between the recovery time of alloy 2304 and the heat treatment temperature (i.e., $\mathrm{t}_{\text {recovery }}=5 \mathrm{hrs}$ for $700^{\circ} \mathrm{C}$ and $\mathrm{t}_{\text {recovery }}=0.5 \mathrm{hrs}$ for $\left.870^{\circ} \mathrm{C}\right)$.

In case of alloy 2304 , the $\mathrm{E}_{\text {rcrev }}$ drop was fully recovered with aging time. This alloy contains essentially no Mo $(\sim 0.28 \mathrm{wt} \%)$, thus the Mo containing precipitate phases (sigma and chi) are destabilized and their growth is suppressed. While $\mathrm{Cr}$ rich precipitates may still form and partition $\mathrm{Cr}$ from the matrix, the complementary $\mathrm{Cr}$-rich precipitate 
phases are less depleted and any GBCD is recoverable with prolonged thermal exposure. In the annealed condition, the $\mathrm{E}_{\text {rcrev }}$ of 2304 was found to be lower than that of 2205 in $0.04 \mathrm{M} \mathrm{NaCl}$ solution (- $0.1 \mathrm{~V}$ vs. SCE and $+0.15 \mathrm{~V}$ vs. SCE, respectively), therefore alloy 2304 was more susceptible to localized corrosion attack. However, it experienced a smaller $\mathrm{E}_{\mathrm{rcrev}}$ drop with aging and this drop was fully recoverable, thus, when subjected to temperatures in the precipitation regime $\left(700-870^{\circ} \mathrm{C}\right)$, alloy 2304 was found to be less susceptible to localized corrosion overall.

$E_{r p}$ of Weldments

The corrosion resistance of an alloy often changes during fabrication processes due to microstructural and microchemical effects. In a welded material, the local chemical and microstructural changes lead to different electrochemical behaviors of the base metal, weld metal and heat affected zone (HAZ). However, previous study by Dunn et al showed that for alloy $\mathrm{C}-22$, welding did not have a significant effect on the repassivation potential as illustrated in Figure 53 (Dunn et al., 2003). In this study, the repassivation potentials of alloy $\mathrm{C}-276$ weldments were measured. $\mathrm{E}_{\text {rcrev }}$ of the base metal, weld metal and HAZ was determined and correlated to microchemistry data reported in the literature. Previous studies by Sridhar (1990) indicated that the critical pitting temperature of alloy $\mathrm{C}-276$ base metal in a solution of $12 \mathrm{wt} \% \mathrm{H}_{2} \mathrm{SO}_{4}+1.2 \mathrm{wt} \% \mathrm{HCl}+1 \mathrm{wt} \% \mathrm{FeCl}_{3}+1 \mathrm{wt} \%$ $\mathrm{CuCl}_{2}$ was $110^{\circ} \mathrm{C}$, whereas that for the weldment ranged from 80 to $95^{\circ} \mathrm{C}$. The critical pitting temperature of the weldment was relatively insensitive to weld heat input ranging from 4 to $16 \mathrm{~kJ} / \mathrm{cm}$. These results suggest that the effect of welding on the localized corrosion resistance of alloy $\mathrm{C}-276$ is relatively minor.

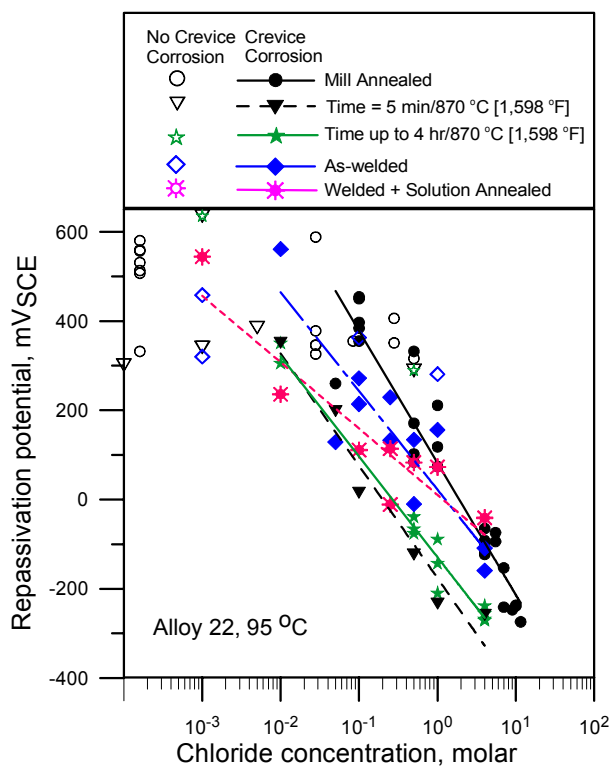

Figure 53. Repassivation potential of alloy C-22 as a function of chloride concentration after different heat treatment and welding processes (Dunn, 2003).

The welding procedure of the alloy C-276 specimens was performed by Haynes International and it is described below. 


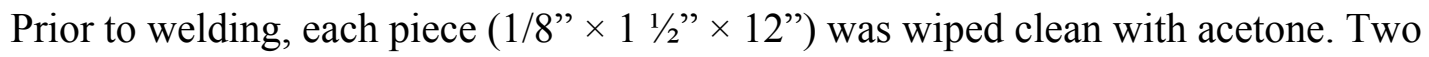
pieces were then manually gas tungsten arc tack welded (GTAW) together to form one piece, $1 / 8 " \times 3 " \times 12 "$ ( 4 total weldments). The tacked weldments were then placed in an airline unit and an autogenous GTAW root pass was performed. Upon completion, the weldment was removed from the airline, brushed with stainless steel wire and cooled to room temperature. The autogenous root welds were made at 250-265 amps and 9 volts. After cooling, the weldments were placed back in the airline unit and a cover pass was placed on the top side of the root pass using matching weld filler wire. The cover pass was run at 195 amps and 12.5 volts. The travel speeds were in the $10-12 \mathrm{inch} / \mathrm{minute}$ range. This resulted in a calculated average heat input of $5 \mathrm{~kJ} / \mathrm{cm}$ for the root pass and 5.2 $\mathrm{kJ} / \mathrm{cm}$ for the cover pass. One hundred percent welding grade argon was used for both weld torch and back side purge gas $\left(35 \mathrm{ft}^{3} \mathrm{hr}(\mathrm{CFH})\right.$ torch/8 $\mathrm{CFH}$ backing). These weld coupons were prepared on an automatic "Airline" welding machine which utilizes a copper backup bar and copper hold downs. This type of fixturing offered a large heat sink, therefore the parameters described above would only be appropriate for welding on the same or similar unit. After the weldments were received, the samples were cut such that the crevice area overlapped with the center of the weld (mid-weld), the weld and the heat affected zone (HAZ) (end-weld) or the base metal away from the weld (base metal). The locations of the different specimens are shown in Figure 54.

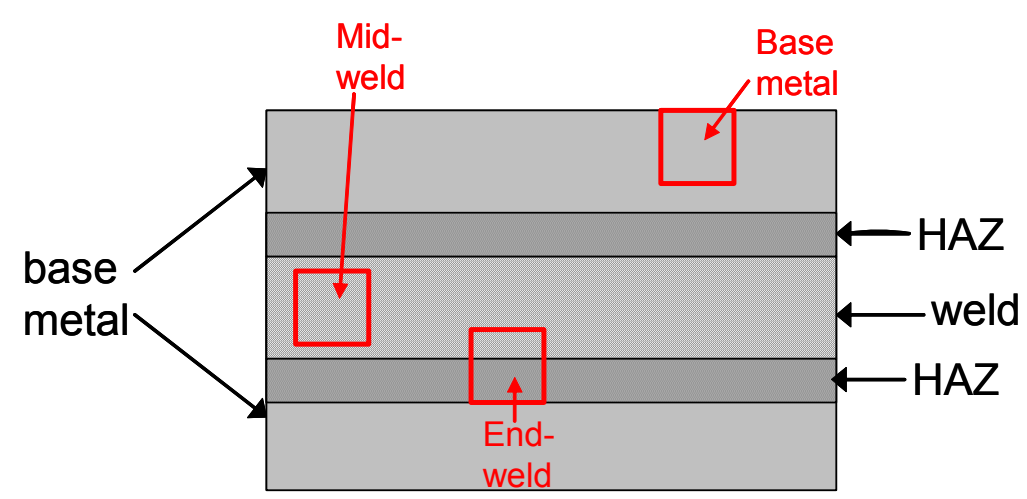

Figure 54. Schematic of locations from where the C-276 specimens were cut out relative to the weld location.

The crevice repassivation potentials were measured in solutions containing different concentrations of $\mathrm{NaCl}$ at 60 and $95^{\circ} \mathrm{C}$. $\mathrm{E}_{\text {rcrev }}$ was determined at three different current density threshold ( $\mathrm{i}_{\text {th }}$ ) values: $10^{-5}, 2 \times 10^{-6}$ and $10^{-6} \mathrm{~A} / \mathrm{cm}^{2}$. The results are summarized in Table 27 . At $60^{\circ} \mathrm{C}$, no crevice corrosion was observed in many specimens, especially in case of the welds. This would imply that the welded areas have higher corrosion resistance than the base metal. However, since a considerable scatter was observed in the experimental data, it is more likely that the $\mathrm{E}_{\text {rcrev }}$ values are comparable, thus there is no significant difference between the base and welded materials. 
Table 27. Crevice repassivation potential of alloy C-276 weldments measured in $\mathrm{NaCl}$ solutions at 60 and $95^{\circ} \mathrm{C}$. $\mathrm{E}_{\mathrm{rcrev}}$ is given in V vs. SCE.

\begin{tabular}{|c|c|c|c|c|c|c|}
\hline \multicolumn{7}{|c|}{$i_{\text {th }}=10^{-5} \mathrm{~A} / \mathrm{cm}^{2}$} \\
\hline $\mathrm{C}_{\mathrm{Cl}-}(\mathrm{M})$ & $\mathbf{E}_{\text {rcrev,base }}$ & E $_{\text {rcrev,midweld }}$ & E $_{\text {rcrev,endweld }}$ & $\mathbf{E}_{\text {rcrev,base }}$ & E $_{\text {rcrev,midweld }}$ & $\mathbf{E}_{\text {rcrev,endweld }}$ \\
\hline 0.1 & n.c.c. ${ }^{\dagger}$ & n.c.c. & n.c.c. & 0.358 & 0.319 & 0.359 \\
\hline 0.5 & 0.575 & n.c.c. & n.c.c. & 0.231 & 0.205 & 0.498 \\
\hline 1.0 & n.c.c. & n.c.c. & n.c.c. & 0.128 & 0.031 & 0.317 \\
\hline 4.0 & 0.095 & n.c.c. & n.c.c. & -0.078 & -0.123 & -0.110 \\
\hline 6.0 & 0.068 & n.c.c. & n.c.c. & -0.168 & -0.156 & -0.189 \\
\hline \multicolumn{7}{|c|}{$i_{t h}=2 \times 10^{-6} \mathrm{~A} / \mathrm{cm}^{2}$} \\
\hline & & $\mathrm{T}=6^{\circ} \mathrm{C}$ & & & $\mathrm{T}=95^{\circ} \mathrm{C}$ & \\
\hline $\mathrm{C}_{\mathrm{Cl}-}(\mathrm{M})$ & $\mathbf{E}_{\text {rcrev,base }}$ & $\mathbf{E}_{\text {rcrev,midweld }}$ & E $_{\text {rcrev,endweld }}$ & $\mathbf{E}_{\text {rcrev,base }}$ & $\mathbf{E}_{\text {rcrev,midweld }}$ & $\mathbf{E}_{\text {rcrev,endweld }}$ \\
\hline 0.1 & 0.488 & n.c.c. & n.c.c. & 0.233 & 0.168 & 0.326 \\
\hline 0.5 & 0.182 & 0.534 & n.c.c. & 0.177 & 0.053 & 0.108 \\
\hline 1 & n.c.c. & 0.489 & n.c.c. & 0.117 & -0.023 & 0.209 \\
\hline 4 & 0.028 & n.c.c. & n.c.c. & -0.153 & -0.174 & -0.142 \\
\hline 6 & -0.019 & 0.509 & n.c.c. & -0.229 & -0.183 & -0.222 \\
\hline \multicolumn{7}{|c|}{$i_{t h}=10^{-6} \mathrm{~A} / \mathrm{cm}^{2}$} \\
\hline & & $\mathrm{T}=6^{\circ} \mathrm{C}$ & & & $\mathrm{T}=95^{\circ} \mathrm{C}$ & \\
\hline $\mathrm{C}_{\mathrm{Cl}-}(\mathrm{M})$ & E $_{\text {rcrev,base }}$ & E $_{\text {rcrev,midweld }}$ & E $_{\text {rcrev,endweld }}$ & E $_{\text {rcrev,base }}$ & Ercrev,midweld $_{\text {reld }}$ & E rcrev,endweld \\
\hline 0.1 & 0.283 & n.c.c. & n.c.c. & 0.205 & 0.153 & 0.300 \\
\hline 0.5 & 0.128 & 0.469 & 0.526 & 0.121 & 0.023 & 0.027 \\
\hline 1 & n.c.c. & 0.313 & n.c.c. & 0.109 & -0.039 & 0.091 \\
\hline 4 & 0.015 & 0.549 & n.c.c. & -0.181 & -0.196 & -0.156 \\
\hline 6 & -0.055 & 0.454 & n.c.c. & -0.262 & -0.208 & -0.241 \\
\hline
\end{tabular}

At $95^{\circ} \mathrm{C}$, all specimens underwent crevice corrosion. The crevice repassivation potential of both the base and welded materials decreased with increasing chloride ion concentration for each current threshold. $\mathrm{E}_{\mathrm{rcrev}}$ as a function of $\mathrm{c}_{\mathrm{Cl}^{-}}$is shown in Figure 55 for $i_{\text {th }}=10^{-6} \mathrm{~A} / \mathrm{cm}^{2}$. The crevice repassivation potential of the weldments is very similar to that of the base metal confirming the findings of previous investigators (Sridhar, 1990). As expected, the crevice repassivation potential decreased with increasing aggressive (chloride) ion concentration. A linear relationship was found between $\mathrm{E}_{\mathrm{rcrev}}$ and $\mathrm{c}_{\mathrm{Cl}^{-}}$for all three cases that can be described by the following equations

$$
\begin{array}{ll}
E_{\text {rcrev }}=-0.117 \cdot \log c_{C l^{-}}+0.0027 & \mathrm{R}^{2}=0.88 \\
E_{\text {rcrev }}=-0.0918 \cdot \log c_{C l^{-}}-0.005 & \mathrm{R}^{2}=0.99 \\
E_{\text {rcrev }}=-0.125 \cdot \log c_{C l^{-}}+0.009 & \mathrm{R}^{2}=0.93
\end{array}
$$




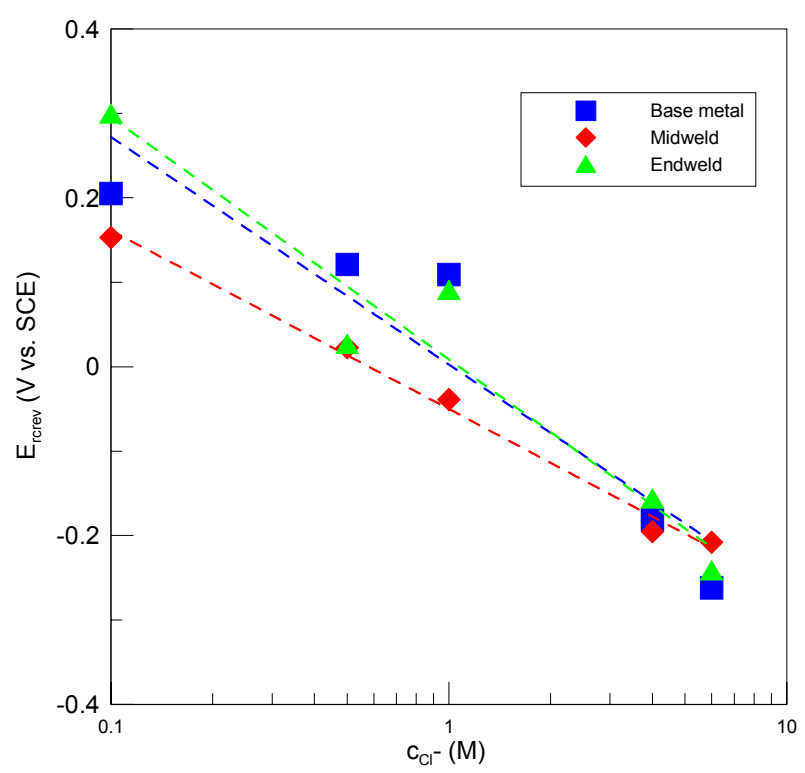

Figure 55. Crevice repassivation potential of $\mathrm{C}-276$ base metal and weldments as a function of chloride level measured at $95^{\circ} \mathrm{C}$.

The data obtained in this work was correlated with microchemistry data from the literature in order to gain further insight into the effect of welding on the localized corrosion of Ni-based alloys. Cieslak and coworkers investigated the welding metallurgy of several Ni-base alloys (C-4, C-22 and C-276) (Cieslak et al., 1986). Upon cooling these alloys from $1250^{\circ} \mathrm{C}$ to $850^{\circ} \mathrm{C}$, the solidification process occurs according to the following equations:

C-4:

$$
\begin{gathered}
L \rightarrow L+\gamma \rightarrow L+\gamma+T i C \rightarrow \gamma+T i C \\
L \rightarrow L+\gamma \rightarrow L+\gamma+P \rightarrow \gamma+P \rightarrow \gamma+P+\mu \\
L \rightarrow L+\gamma \rightarrow L+\gamma+\sigma \rightarrow \gamma+\sigma \rightarrow \gamma+\sigma+P \rightarrow \gamma+\sigma+P+\mu
\end{gathered}
$$$$
\text { C-276: }
$$$$
\text { C-22: }
$$

where $\gamma$ is the matrix and $\sigma, P$ and $\mu$ are topologically close-packed (TCP) intermetallic phases. The solidification of alloy $\mathrm{C}-4$ leads to the formation of a single phase matrix $(\gamma)$ and widely dispersed $\mathrm{TiC}$ particles. The $\mathrm{TiC}$ particles originate from the segregation of $\mathrm{Ti}$ to interdendritic regions (Cieslak, et al., 1986). In case of alloy C-276, the $\gamma$ phase crystallizes first, followed by the $P$ phase. Then, as the cooling metal enters the region of $\gamma+\mu$ stability of the ternary phase diagram, partial transformation of $P$ to $\mu$ occurs since there is no sufficient time available at temperature to complete the $P \rightarrow \mu$ reaction. Thus, the weld metal contains a mixture of intermediate $(P)$ and final $(\mu)$ transformation products in the matrix $(\gamma)$. In $\mathrm{C}-22$, the solidification process starts with the formation of $\gamma$-phase and ends with the crystallization of $\sigma$-phase. Subsequently, the $\sigma$-phase undergoes partial solid state transformation into $P$ and $\mu$ phases resulting in a weld microstructure containing a mixture of $\gamma$ matrix and $\sigma, P$ and $\mu$ TCP phases. Microprobe profiles obtained during scanning electron microscope studies of the welded alloys indicate $\mathrm{Ni}$ enrichment and Mo depletion in the dendrite cores of the welded zone for all three alloys. However, no $\mathrm{Cr}$ segregation was observed after the solidification process. 
Analytical electron microscopy of the TCP phases further confirmed this finding, i.e., the TCP phases were found to be enriched in Mo and $\mathrm{W}$ and depleted in $\mathrm{Ni}$ and Fe relative to the $\gamma$ matrix and the $\mathrm{Cr}$ content of the TPC phases was similar to that of the matrix. Since the corrosion resistance of these alloys mainly depends on their $\mathrm{Cr}$ content, their crevice repassivation potential is not significantly affected by welding, which is in agreement with our findings in case of C-276 and findings by Dunn et al. (2003) in case of C-22.

\section{Development of Experimental Data on Damage Growth and Distribution}

Prediction of the remaining lifetime of process equipment that already exists and is subject to corrosion is very important to the chemical process industry. This task can be achieved by Damage Function Analysis (DFA) method, which includes both the mechanistic treatment of corrosion damage nucleation and growth and the empirical treatment of their repassivation. It provides a way to calculate the number of corrosion damage sites (pits or cracks) per surface area that develop after a given amount of time and are characterized by a given penetration depth. In order to develop the damage functions, kinetic parameters for pit nucleation, growth and repassivation are required. In this work, the Integral Damage Function method was used, in which the experimentally measured corrosion damage can be extrapolated into the future.

The objective of this part of the experimental work was to measure the kinetics of the pit nucleation and growth. However, due to the stochastic nature of the pitting process, there is a distribution of pit sizes at any given time. Furthermore, the growth and coalescence of pits change this distribution with time. Previous studies on type 304L stainless steel used a potentiostatic method for growing pits. However, this method, when used on flat specimens, results in an uneven potential distribution. Therefore, the pit growth was measured under open-circuit conditions in this work. The selection of solution chemistry is very important in these types of measurements. If the solution used for exposures is very corrosive, high frequency of pit coalescence prevents the accurate measurement of damage size distribution. If, on the other hand, the solution is not corrosive enough, no pit nucleation occurs within the exposure time. The required solution chemistry depends on the alloy. In this work alloy 825 flat specimens and 316L SS pipe sections were used.

In case of the alloy 825 flat specimens, the modified "yellow death" solution $(1 \mathrm{~g} / \mathrm{L}$ $\left.\mathrm{Fe}_{2}\left(\mathrm{SO}_{4}\right)_{3}+40 \mathrm{~g} / \mathrm{L} \mathrm{NaCl}+0.1 \mathrm{M} \mathrm{HCl}\right)$ and the ferric chloride solution containing $30 \mathrm{~g} / \mathrm{L}$ $\mathrm{FeCl}_{3} \cdot 6 \mathrm{H}_{2} \mathrm{O}+40 \mathrm{~g} / \mathrm{L} \mathrm{NaCl}$ were found to be too mild, no significant number of pits were initiated on the surface of the specimens away from the edges. After much experimentation, a solution containing $60 \mathrm{~g} / \mathrm{L} \mathrm{FeCl}{ }_{3} \cdot 6 \mathrm{H}_{2} \mathrm{O}+40 \mathrm{~g} / \mathrm{L} \mathrm{NaCl}$ was chosen to carry out the exposures. In this solution, the corrosion potential of alloy 825 is significantly higher than the repassivation potential, therefore, sufficient amount of pitting damage occurred during the exposure. The specimen edges were rounded to avoid edge effects. Only the lower parts of the specimens were immersed in the solution in order to avoid crevice corrosion at the specimen - holder contact area. However, preferential corrosion was still observed, the pits were concentrated in the meniscus area. The depths of pits measured on specimens exposed for different lengths of time at $80^{\circ} \mathrm{C}$ are summarized in Table 28. The average pit depths and standard deviation for each time interval are also shown. 
Table 28. Depths of ten deepest pits measured on alloy 825 flat specimens exposed to $60 \mathrm{~g} / \mathrm{L} \mathrm{FeCl} 3.6 \mathrm{H}_{2} \mathrm{O}+40 \mathrm{~g} / \mathrm{L} \mathrm{NaCl}$ solution at $80^{\circ} \mathrm{C}$ for different lengths of time.

\begin{tabular}{|c|c|c|c|}
\hline & $\mathbf{t}_{\text {exposure }}=\mathbf{4} \mathbf{h r}$ & $\mathbf{t}_{\text {exposure }}=\mathbf{5} \mathbf{h r}$ & $\mathbf{t}_{\text {exposure }}=\mathbf{2 1} \mathbf{h r}$ \\
\hline Pit \#1 & $4 \mu \mathrm{m}$ & $8 \mu \mathrm{m}$ & $8 \mu \mathrm{m}$ \\
\hline Pit \#2 & $6 \mu \mathrm{m}$ & $8 \mu \mathrm{m}$ & $10 \mu \mathrm{m}$ \\
\hline Pit \#3 & $10 \mu \mathrm{m}$ & $10 \mu \mathrm{m}$ & $10 \mu \mathrm{m}$ \\
\hline Pit \#4 & $12 \mu \mathrm{m}$ & $10 \mu \mathrm{m}$ & $10 \mu \mathrm{m}$ \\
\hline Pit \#5 & $12 \mu \mathrm{m}$ & $12 \mu \mathrm{m}$ & $12 \mu \mathrm{m}$ \\
\hline Pit \#6 & $14 \mu \mathrm{m}$ & $14 \mu \mathrm{m}$ & $12 \mu \mathrm{m}$ \\
\hline Pit \#7 & $14 \mu \mathrm{m}$ & $16 \mu \mathrm{m}$ & $12 \mu \mathrm{m}$ \\
\hline Pit \#8 & $16 \mu \mathrm{m}$ & $18 \mu \mathrm{m}$ & $12 \mu \mathrm{m}$ \\
\hline Pit \#9 & $20 \mu \mathrm{m}$ & $20 \mu \mathrm{m}$ & $16 \mu \mathrm{m}$ \\
\hline Pit \#10 & $22 \mu \mathrm{m}$ & $20 \mu \mathrm{m}$ & $18 \mu \mathrm{m}$ \\
\hline Average \& St. dev. & $13.0 \pm 5.6 \mu \mathrm{m}$ & $13.6 \pm 4.7 \mu \mathrm{m}$ & $12.0 \pm 3.0 \mu \mathrm{m}$ \\
\hline
\end{tabular}

No time dependence of the pit depths was observed at this higher temperature. It is possible that the corrosion was severe enough after $4 \mathrm{hr}$ exposure to mask any potential effect. Alternatively, the dominance of lateral pit growth and pit coalescence might have been responsible for the lack of observed trend.

Table 29 summarizes the depths of the deepest pits measured at $40^{\circ} \mathrm{C}$ exposed for different lengths of time. In this case, the exposure was carried out for a significantly longer time period due to the lower corrosivity of the environment. At shorter exposure times, only a total of ten pits were observed on the duplicate specimens, while after 2 to 7 days of exposure, 20 or more pits were observed. In these cases, pit depths were recorded for the 20 deepest pits.

No trend as a function of time was observed at this lower temperature either. When comparing the two different exposure temperatures, no temperature dependence was found. Figure 56 shows photographs of the specimens after exposure for different time intervals at $40^{\circ} \mathrm{C}$. It can be seen from these images that preferential pitting occurred at the meniscus as mentioned earlier.

Moreover, the photographs clearly show severe pit coalescence even after only $24 \mathrm{hrs}$ of exposure probably due to the high corrosivity of the solution. In order to eliminate the undesirable experimental features discussed above, i.e., preferential pitting at the meniscus and pit coalescence, new experiments were designed. 
Table 29. Depths of ten to twenty deepest pits measured on alloy 825 flat specimens exposed to $60 \mathrm{~g} / \mathrm{L} \mathrm{FeCl}_{3} \cdot 6 \mathrm{H}_{2} \mathrm{O}+40 \mathrm{~g} / \mathrm{L} \mathrm{NaCl}$ solution at $40^{\circ} \mathrm{C}$ for different lengths of time.

\begin{tabular}{|c|c|c|c|c|c|c|}
\hline & $t_{\text {exp }}=4 \mathrm{hr}$ & $t_{\text {exp }}=24 \mathrm{hr}$ & $t_{\text {exp }}=48 \mathrm{hr}$ & $t_{\text {exp }}=72 \mathrm{hr}$ & $t_{\text {exp }}=96 \mathrm{hr}$ & $\begin{array}{c}t_{\text {exp }}=168 \\
h r\end{array}$ \\
\hline Pit \#1 & $10 \mu \mathrm{m}$ & $8 \mu \mathrm{m}$ & $8 \mu \mathrm{m}$ & $10 \mu \mathrm{m}$ & $8 \mu \mathrm{m}$ & $8 \mu \mathrm{m}$ \\
\hline Pit \#2 & $10 \mu \mathrm{m}$ & $8 \mu \mathrm{m}$ & $8 \mu \mathrm{m}$ & $10 \mu \mathrm{m}$ & $8 \mu \mathrm{m}$ & $8 \mu \mathrm{m}$ \\
\hline Pit \#3 & $10 \mu \mathrm{m}$ & $8 \mu \mathrm{m}$ & $10 \mu \mathrm{m}$ & $10 \mu \mathrm{m}$ & $8 \mu \mathrm{m}$ & $8 \mu \mathrm{m}$ \\
\hline Pit \#4 & $12 \mu \mathrm{m}$ & $10 \mu \mathrm{m}$ & $10 \mu \mathrm{m}$ & $12 \mu \mathrm{m}$ & $8 \mu \mathrm{m}$ & $8 \mu \mathrm{m}$ \\
\hline Pit \#5 & $12 \mu \mathrm{m}$ & $10 \mu \mathrm{m}$ & $10 \mu \mathrm{m}$ & $10 \mu \mathrm{m}$ & $10 \mu \mathrm{m}$ & $10 \mu \mathrm{m}$ \\
\hline Pit \#6 & $14 \mu \mathrm{m}$ & $12 \mu \mathrm{m}$ & $12 \mu \mathrm{m}$ & $10 \mu \mathrm{m}$ & $10 \mu \mathrm{m}$ & $10 \mu \mathrm{m}$ \\
\hline Pit \#7 & $14 \mu \mathrm{m}$ & $12 \mu \mathrm{m}$ & $12 \mu \mathrm{m}$ & $10 \mu \mathrm{m}$ & $10 \mu \mathrm{m}$ & $10 \mu \mathrm{m}$ \\
\hline Pit $\# 8$ & $18 \mu \mathrm{m}$ & $12 \mu \mathrm{m}$ & $12 \mu \mathrm{m}$ & $10 \mu \mathrm{m}$ & $12 \mu \mathrm{m}$ & $10 \mu \mathrm{m}$ \\
\hline Pit \#9 & $18 \mu \mathrm{m}$ & $14 \mu \mathrm{m}$ & $12 \mu \mathrm{m}$ & $10 \mu \mathrm{m}$ & $12 \mu \mathrm{m}$ & $10 \mu \mathrm{m}$ \\
\hline Pit \#10 & $20 \mu \mathrm{m}$ & $14 \mu \mathrm{m}$ & $12 \mu \mathrm{m}$ & $10 \mu \mathrm{m}$ & $12 \mu \mathrm{m}$ & $12 \mu \mathrm{m}$ \\
\hline Pit \#11 & 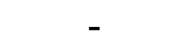 & - & $12 \mu \mathrm{m}$ & $10 \mu \mathrm{m}$ & $12 \mu \mathrm{m}$ & $12 \mu \mathrm{m}$ \\
\hline Pit \#12 & - & - & $14 \mu \mathrm{m}$ & $10 \mu \mathrm{m}$ & $14 \mu \mathrm{m}$ & $12 \mu \mathrm{m}$ \\
\hline Pit \#13 & - & - & $14 \mu \mathrm{m}$ & $10 \mu \mathrm{m}$ & $14 \mu \mathrm{m}$ & $12 \mu \mathrm{m}$ \\
\hline Pit \#14 & - & - & $14 \mu \mathrm{m}$ & $10 \mu \mathrm{m}$ & $14 \mu \mathrm{m}$ & $12 \mu \mathrm{m}$ \\
\hline Pit \#15 & - & - & $14 \mu \mathrm{m}$ & $10 \mu \mathrm{m}$ & $16 \mu \mathrm{m}$ & $12 \mu \mathrm{m}$ \\
\hline Pit \#16 & - & - & $16 \mu \mathrm{m}$ & $10 \mu \mathrm{m}$ & $16 \mu \mathrm{m}$ & $14 \mu \mathrm{m}$ \\
\hline Pit \#17 & - & - & $18 \mu \mathrm{m}$ & $10 \mu \mathrm{m}$ & $16 \mu \mathrm{m}$ & $14 \mu \mathrm{m}$ \\
\hline Pit \#18 & - & - & $18 \mu \mathrm{m}$ & $10 \mu \mathrm{m}$ & $16 \mu \mathrm{m}$ & $14 \mu \mathrm{m}$ \\
\hline Pit \#19 & - & - & $20 \mu \mathrm{m}$ & $10 \mu \mathrm{m}$ & $20 \mu \mathrm{m}$ & $16 \mu \mathrm{m}$ \\
\hline Pit \#20 & - & - & $32 \mu \mathrm{m}$ & $10 \mu \mathrm{m}$ & $20 \mu \mathrm{m}$ & $16 \mu \mathrm{m}$ \\
\hline $\begin{array}{l}\text { Average } \\
\& \text { St. dev. }\end{array}$ & $\begin{array}{c}13.8 \pm 3.7 \\
\mu \mathrm{m}\end{array}$ & $\begin{array}{c}10.8 \pm 2.3 \\
\mu m\end{array}$ & $\begin{array}{c}13.9 \pm 5.3 \\
\mu m\end{array}$ & $\begin{array}{c}13.0 \pm 3.6 \\
\mu \mathrm{m}\end{array}$ & $\begin{array}{c}12.8 \pm 3.8 \\
\mu m\end{array}$ & $\begin{array}{c}11.4 \pm 2.5 \\
\mu m\end{array}$ \\
\hline
\end{tabular}

Alloy $316 \mathrm{~L}$ stainless steel pipe segments were exposed to a solution containing $0.868 \mathrm{M}$ $\mathrm{NaCl}, 0.184 \mathrm{M} \mathrm{FeCl}_{3}$ and $0.184 \mathrm{M} \mathrm{FeCl}_{2}(\mathrm{pH} 1.84$ ). The use of cylindrical pipe sections eliminated the potential edge effects and preferential pitting at the meniscus observed in case of the flat specimens. The solution was circulated inside the pipe using a peristaltic pump in order to provide a constant supply of fresh solution, because, in preliminary tests, the oxidation of ferrous ions to ferric ions significantly affected the corrosivity of the solution. The exposures were carried out at $23^{\circ} \mathrm{C}$ and $40^{\circ} \mathrm{C}$ for 4 and $8 \mathrm{hrs}$, and for 2 , 4 and $6 \mathrm{hrs}$, respectively. After the prescribed exposure times, the specimens were cut longitudinally in half and examined using an optical microscope. The pit depths were measured using a calibrated digital microscope. Examples of pits observed after exposure are shown in Figure 57.

Most pits were round or elliptical in shape and no pit coalescence was observed. In some cases, crevice corrosion was observed on the ends of the pipe sections under the Microstop lacquer. Table 30 summarizes the depths of pits found on the room temperature specimens after different exposure times. 


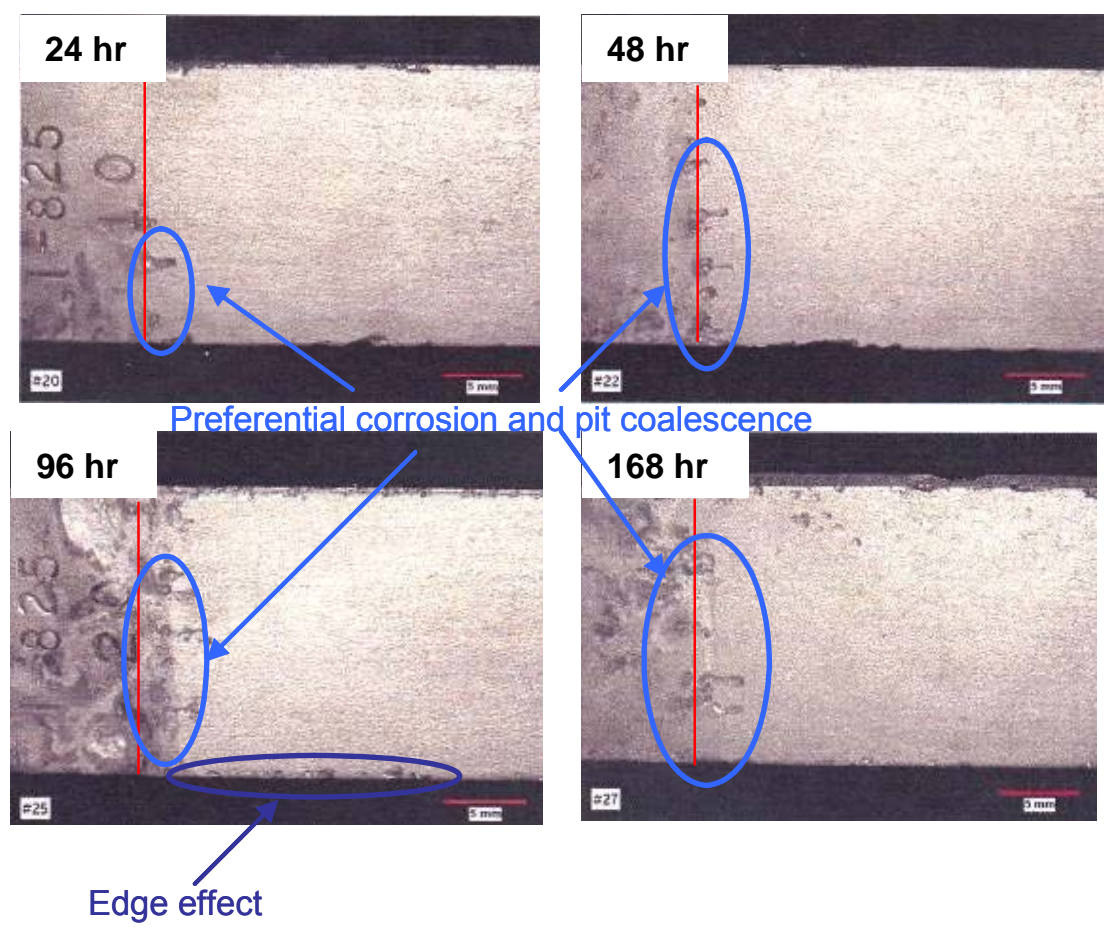

Figure 56. Photographs of pitted alloy 825 specimens exposed to ferric chloride containing solution at $40^{\circ} \mathrm{C}$.
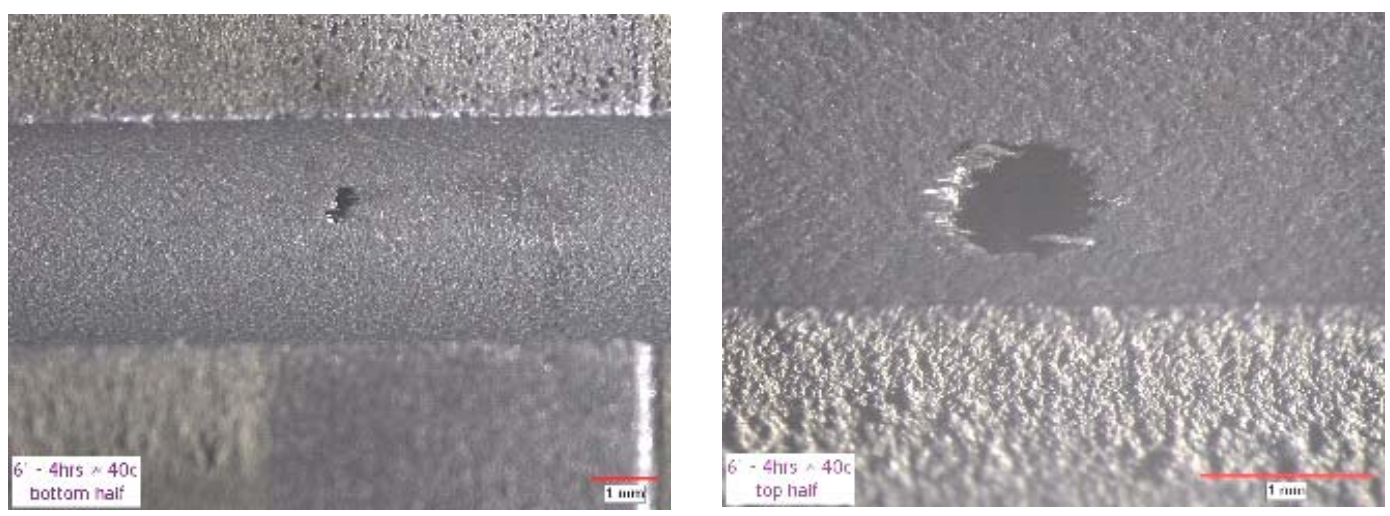

Figure 57. Examples of pits found inside a 316L SS pipe section after exposure to $\mathrm{NaCl} / \mathrm{FeCl}_{2} / \mathrm{FeCl}_{3}$ solution at $40^{\circ} \mathrm{C}$ for $4 \mathrm{hrs}$.

The average pit depth increased with time, as expected. The number of pits found on the specimen surfaces (top and bottom) also increased significantly. The pit depths measured after exposures at $40^{\circ} \mathrm{C}$ are shown in Table 31. 
Table 30. Depths of pits found on the inside of 316L SS pipe sections exposed to $\mathrm{NaCl} / \mathrm{FeCl}_{3} / \mathrm{FeCl}_{2}$ solution at $23^{\circ} \mathrm{C}$. The averages and standard deviations are also indicated.

\begin{tabular}{|c|cc|}
\hline & $\mathrm{t}_{\text {exposure }}=4 \mathrm{hr}$ & $\mathrm{t}_{\text {exposure }}=8 \mathrm{hr}$ \\
\hline Pit \#1 & $10 \mu \mathrm{m}$ & $80 \mu \mathrm{m}$ \\
Pit \#2 & $5 \mu \mathrm{m}$ & $45 \mu \mathrm{m}$ \\
Pit \#3 & $30 \mu \mathrm{m}$ & $50 \mu \mathrm{m}$ \\
Pit \#4 & $20 \mu \mathrm{m}$ & $50 \mu \mathrm{m}$ \\
Pit \#5 & $10 \mu \mathrm{m}$ & $40 \mu \mathrm{m}$ \\
Pit \#6 & $30 \mu \mathrm{m}$ & $40 \mu \mathrm{m}$ \\
Pit \#7 & - & $85 \mu \mathrm{m}$ \\
Pit \#8 & - & $35 \mu \mathrm{m}$ \\
Pit \#9 & - & $35 \mu \mathrm{m}$ \\
\hline Pit \#10 & - & $25 \mu \mathrm{m}$ \\
\hline Average \& St. Deviation & $18.0 \pm 11.0 \mu \mathrm{m}$ & $48.5 \pm 19.0 \mu \mathrm{m}$ \\
\hline
\end{tabular}

Table 31. Depths of pits found on the inside of 316L SS pipe segments exposed to $\mathrm{NaCl} / \mathrm{FeCl}_{3} / \mathrm{FeCl}_{2}$ solution at $40^{\circ} \mathrm{C}$. The averages and standard deviations are also indicated.

\begin{tabular}{|c|ccc|}
\hline & $\mathbf{t}_{\text {exposure }}=\mathbf{2} \mathbf{h r}$ & $\mathbf{t}_{\text {exposure }}=\mathbf{4} \mathbf{h r}$ & $\mathbf{t}_{\text {exposure }}=\mathbf{8} \mathbf{h r}$ \\
\hline Pit \#1 & $30 \mu \mathrm{m}$ & $40 \mu \mathrm{m}$ & $125 \mu \mathrm{m}$ \\
Pit \#2 & $70 \mu \mathrm{m}$ & $150 \mu \mathrm{m}$ & $210 \mu \mathrm{m}$ \\
Pit \#3 & $45 \mu \mathrm{m}$ & $75 \mu \mathrm{m}$ & $145 \mu \mathrm{m}$ \\
Pit \#4 & $20 \mu \mathrm{m}$ & $60 \mu \mathrm{m}$ & $85 \mu \mathrm{m}$ \\
Pit \#5 & $45 \mu \mathrm{m}$ & $105 \mu \mathrm{m}$ & $95 \mu \mathrm{m}$ \\
Pit \#6 & $30 \mu \mathrm{m}$ & $50 \mu \mathrm{m}$ & $50 \mu \mathrm{m}$ \\
Pit \#7 & $15 \mu \mathrm{m}$ & $70 \mu \mathrm{m}$ & $85 \mu \mathrm{m}$ \\
Pit \#8 & $75 \mu \mathrm{m}$ & $215 \mu \mathrm{m}$ & $155 \mu \mathrm{m}$ \\
Pit \#9 & $5 \mu \mathrm{m}$ & $50 \mu \mathrm{m}$ & $55 \mu \mathrm{m}$ \\
\hline Pit \#10 & - & $175 \mu \mathrm{m}$ & $155 \mu \mathrm{m}$ \\
\hline \hline Average \& St. dev. & $37.0 \pm 24.0 \mu \mathrm{m}$ & $99.0 \pm 61.0 \mu \mathrm{m}$ & $116.0 \pm 51.0 \mu \mathrm{m}$ \\
\hline
\end{tabular}

The average pit depth increases with increasing exposure time. The results obtained at different temperatures are compared in Figure 58.

Although the standard deviations associated with the measurements are very large, clear trends of increasing pit depths with increasing exposure time and temperature are seen in Figure 58. The corrosion rate is faster at higher temperatures contributing to larger pit depth. The pit depths were found to reach a plateau at $40^{\circ} \mathrm{C}$ after approximately 6 hours of exposure. The maximum pit depth might be associated with mass transport limitations towards the bottom of the pit where the electrochemical reaction occurs. 


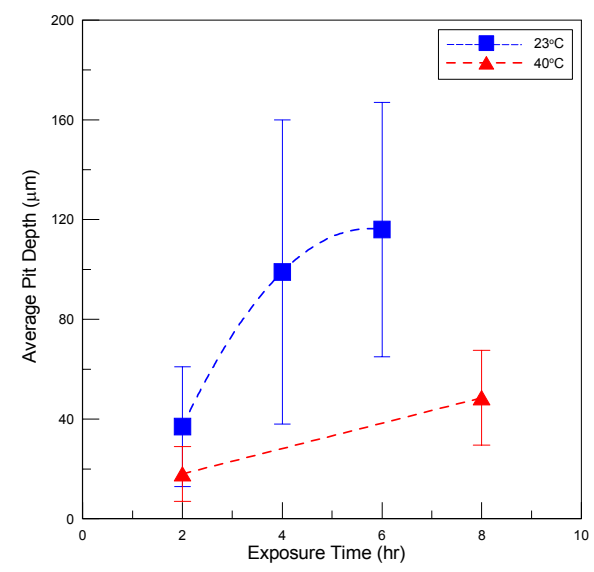

Figure 58. Pit depths measured on the inside of $316 \mathrm{~L}$ SS pipe sections exposed to $\mathrm{NaCl} / \mathrm{FeCl}_{2} / \mathrm{FeCl}_{3}$ solution at different temperatures.

\section{Development of a model for predicting the occurrence of localized corrosion}

Predictive modeling of localized corrosion is very challenging because of the large number of factors that influence the nucleation, growth and repassivation of pits or crevices. Among the key factors, properties of chemical species in an aqueous environment, concentrations of components, alloy composition, and temperature are of particular importance. In the last four decades, considerable progress was made in understanding the mechanisms of localized corrosion of various metallic materials (Staehle et al., 1974, Szklarska-Smialowska, 1986, Isaacs et al., 1990, Natishan et al., 1996, 1998, Seo et al., 1999). At the same time, various modeling methodologies have been developed by considering atomic or molecular processes, microstructural features, and transport processes in macroscopic cavities.

In our previous studies (Anderko et al., 2004, Sridhar et al., 2004), a comprehensive computational model has been proposed to predict the tendency of metals to undergo localized corrosion as a function of environmental conditions. To predict the occurrence of localized corrosion, this approach relies on calculating two characteristic parameters as functions of solution chemistry, i.e., (1) the corrosion potential and (2) the repassivation potential, also called the protection potential. The repassivation potential ( $\mathrm{E}_{\mathrm{rp}}$, or $\mathrm{E}_{\mathrm{rcrev}}$, depending on whether one measures the potential of an open or creviced specimen) is a measure of the tendency of an alloy to undergo localized corrosion in a given environment. In this paper, the two repassivation potentials are referred to by the common notation of $\mathrm{E}_{\mathrm{rp}}$, because the two potentials coincide at high pit depths. It has been shown in previous papers (Dunn et al., 1996, 2000, Anderko et al., 2004) that $E_{\mathrm{rp}}$ is the potential below which stable pitting or crevice corrosion does not occur. Also, $\mathrm{E}_{\mathrm{rp}}$ is relatively insensitive to surface finish and prior pit depth as long as it exceeds a certain minimum value. The predicted repassivation potential is then compared to the corrosion 
potential $\left(E_{\text {corr }}\right)$ in the same environment to determine an alloy's susceptibility to localized corrosion. The separation of localized corrosion modeling into two steps is valid as long as the initiation of stable localized corrosion is considered because the corrosion potential is not affected at this stage by the localized corrosion processes and the interaction between pits can be ignored. Such a separation remains valid as long as significant pit or crevice corrosion growth does not occur and the area of an actively corroding pit does not become significant compared to the overall area.

The corrosion potential is calculated from a general corrosion model by considering all relevant partial electrochemical processes that are operative on the surface of the metal. The repassivation potential is computed from a separate model that accounts for the physical phenomena in occluded corrosion environments. In this chapter, we describe how these two models work for engineering alloys in various chemical environments.

The concept is illustrated schematically in Figure 1. For a given alloy, the repassivation potential decreases with an increase in chloride concentration (cf. Figure 1a). In the general case, the main regions of the $\mathrm{E}_{\mathrm{rp}}$ versus chloride concentration plot are a lowslope portion at high chloride concentrations and a high-slope portion at low concentrations. On the other hand, the corrosion potential is not a strong function of chloride concentration unless significant localized corrosion occurs. The critical chloride concentration for localized corrosion is observed when $\mathrm{E}_{\text {corr }}$ exceeds $\mathrm{E}_{\mathrm{rp}}$ (Fig. 1a). Similarly, for a given chloride concentration, a critical temperature exists (Figure 1b). The repassivation potential is also strongly affected by the presence of inhibitors. As shown in Figure 1c, this gives rise to a critical inhibitor concentration. In many environments, the presence of oxidants may increase $\mathrm{E}_{\text {corr }}$ so that localized corrosion may occur beyond a critical concentration of redox species (Figure 1d). The actual conditions in a system may be a combination of the idealized cases shown in Figure 1a-d.

\section{Development of a general corrosion model}

The corrosion potential is calculated using a previously developed general corrosion model (Anderko and Young, 2000, Anderko et al., 2001 and Sridhar et al., 2004). At the same time, the model provides the uniform corrosion rate as a function of environment chemistry and temperature. The model was described in previous papers and, therefore, we do not provide its details here.

The model consists of a thermophysical module and an electrochemical module. The thermophysical module predicts the speciation of the aqueous environment and the activities and transport properties of solution species that participate in interfacial reactions. The electrochemical model utilizes this information to simulate electrochemical reactions at the metal-solution interface. The electrochemical model of general corrosion takes into account various partial reactions on the surface of the metal and transport processes for the species that participate in the reactions. The model includes passivation phenomena, which may be influenced by $\mathrm{pH}$ and the presence of aggressive or inhibitive species in the solution. Further, it combines the partial processes to compute corrosion rates in the framework of the mixed potential theory. 
In this project, we developed the parameters of this model to reproduce the corrosion rates and corrosion potentials of nickel-base alloys, i.e., alloys 600, 690, 825, 625, 276, 22, and nickel. In addition, OLI Systems' Corrosion Analyzer software contains parameters for carbon steel, aluminum (1100), alloy 254SMO, and type 304, 316, and $13 \% \mathrm{Cr}$ stainless steels, which were developed previously.

It should be noted that the general corrosion model has been developed on the basis of a very large body of experimental data. Therefore, a comprehensive comparison of calculated results with experimental data would be too voluminous to be included in this report. Instead, OLI Systems maintains comprehensive spreadsheets with this information. These spreadsheets are available on request to project team members. In this report, we only provide a small number of representative results to illustrate the performance of the model.

a.

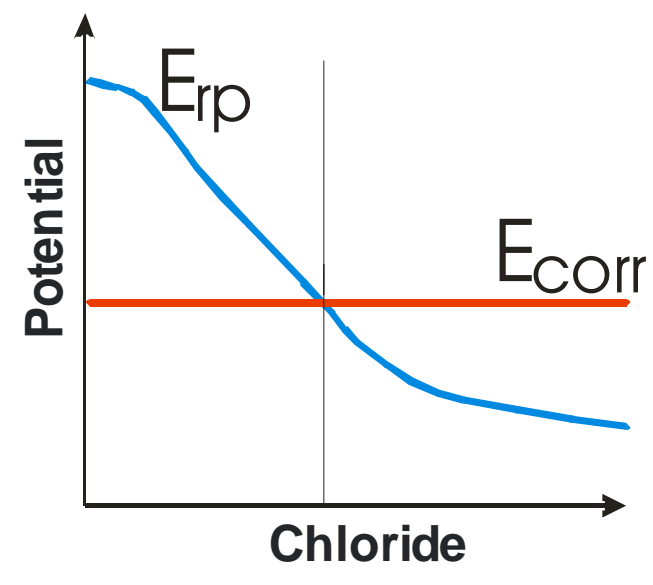

c.

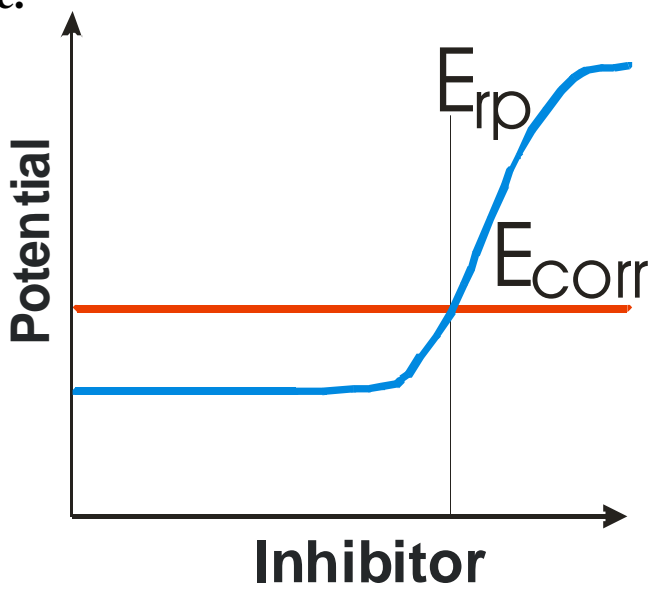

b.

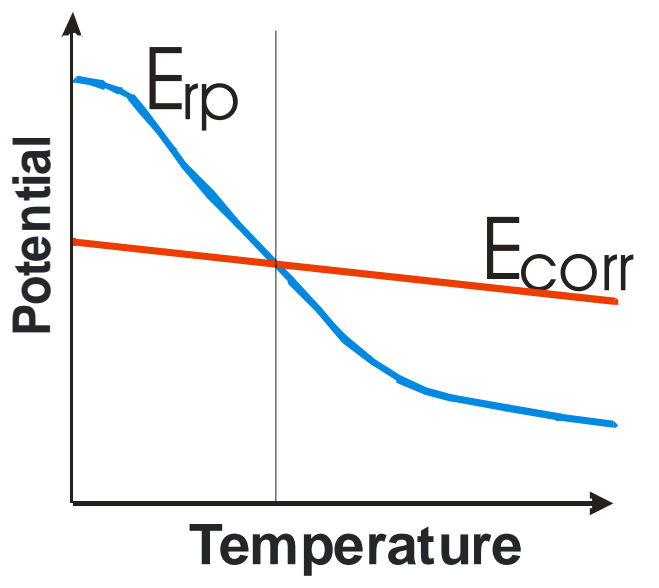

d.

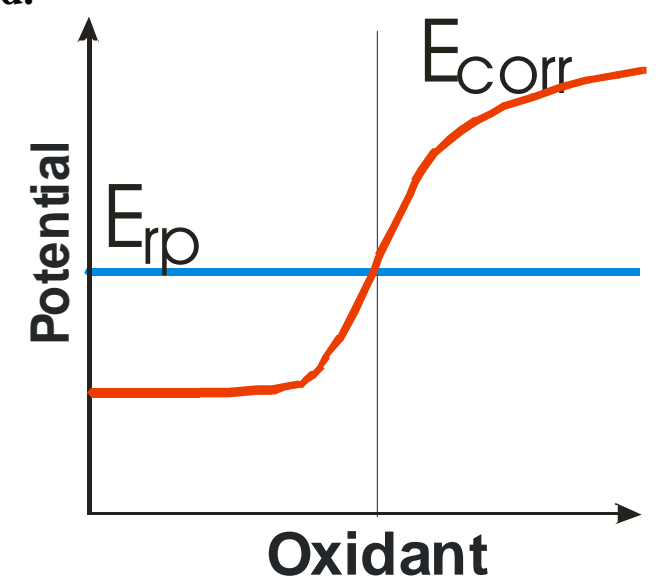

Figure 1. Schematic illustration of the relative behavior of the corrosion potential $\left(\mathrm{E}_{\text {corr }}\right)$ and repassivation potential $\left(\mathrm{E}_{\mathrm{rp}}\right)$ as functions of different environmental variables. 
Figures 2-7 illustrate the performance of the general corrosion model for alloy 600 . In the case of this alloy, parameters have been developed to reproduce simultaneously corrosion rates and corrosion potentials in various environments including:

(1) Aqueous acids: $\mathrm{H}_{2} \mathrm{SO}_{4}, \mathrm{HCl}, \mathrm{H}_{3} \mathrm{PO}_{4}, \mathrm{HNO}_{3}, \mathrm{H}_{3} \mathrm{BO}_{3}$, formic, acetic, propionic, lactic and citric acids;

(2) Acid gases: $\mathrm{SO}_{2}, \mathrm{CO}_{2}$

(3) Bases: $\mathrm{NaOH}, \mathrm{KOH}, \mathrm{LiOH}$

(4) Salts: $\mathrm{NaCl}, \mathrm{CaCl}_{2}, \mathrm{Na}_{2} \mathrm{~S}, \mathrm{Na}_{3} \mathrm{PO}_{4}, \mathrm{Na}_{2} \mathrm{SiO}_{3}$

(5) Oxidizing species: $\mathrm{O}_{2}, \mathrm{FeCl}_{3}, \mathrm{NaOCl}, \mathrm{CuSO}_{4}, \mathrm{Na}_{2} \mathrm{Cr}_{2} \mathrm{O}_{7}$

Figures 2 and 3 show the representation of corrosion rates in sulfuric and formic acids, respectively, at elevated temperatures. In both cases, the model accurately represents experimental data at concentrations up to ca. 30 molal.

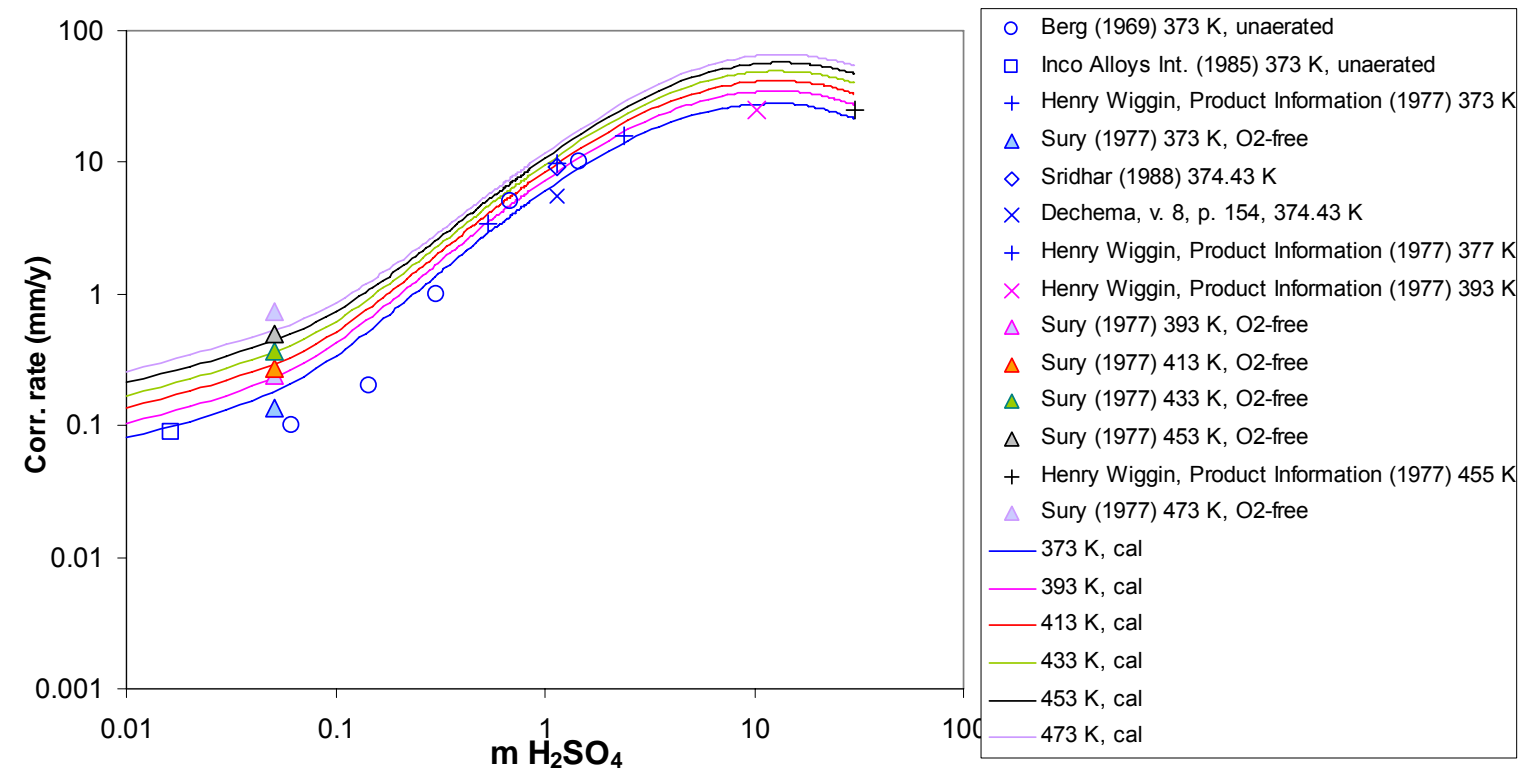

Figure 2. Calculated and experimental corrosion rates of alloy 600 in $\mathrm{H}_{2} \mathrm{SO}_{4}$ at elevated temperatures.

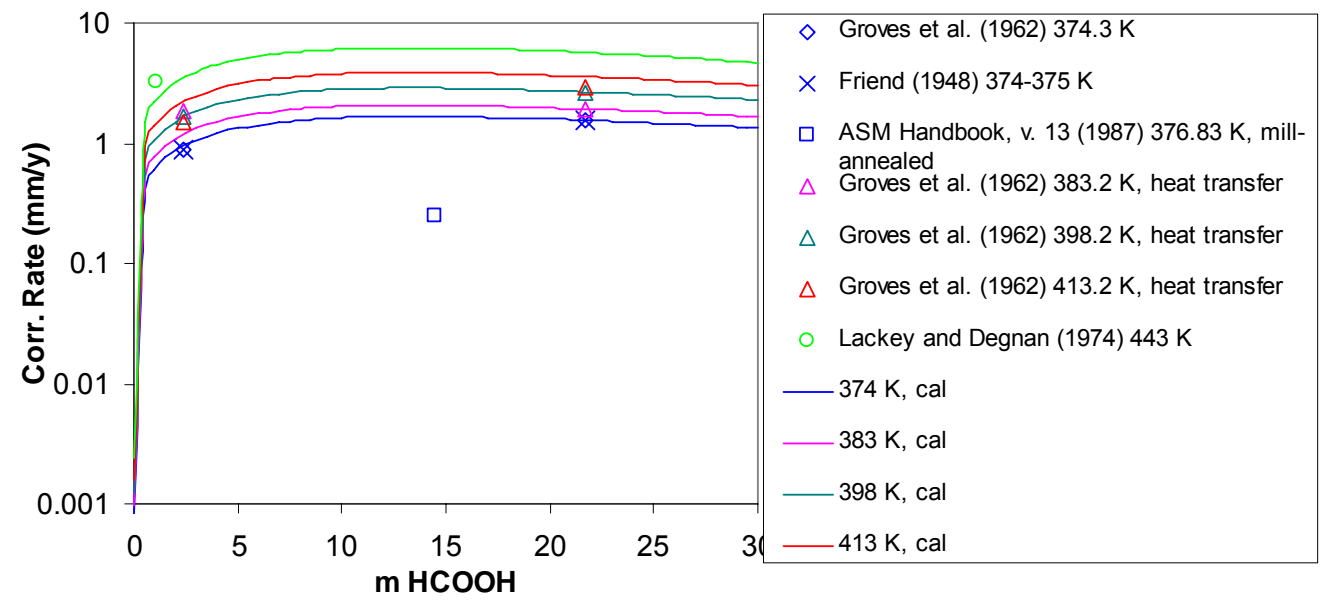

Figure 3. Calculated and experimental corrosion rates of alloy 600 in aqueous formic acid. 


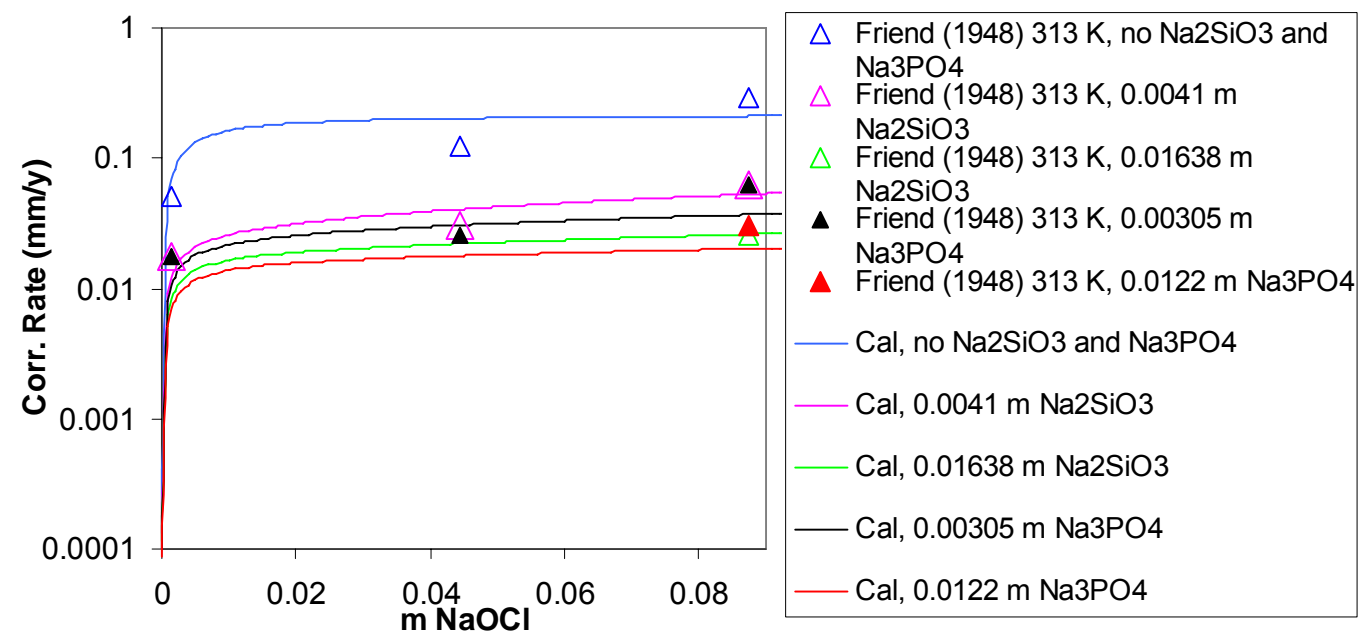

Figure 4. Calculated and experimental corrosion rates of alloy 600 in $\mathrm{NaOCl}$ solutions with and without $\mathrm{Na}_{3} \mathrm{PO}_{4}$ and $\mathrm{Na}_{2} \mathrm{SiO}_{3}$ additions.

Figure 4 shows the effect of sodium hypochlorite, a strongly oxidizing component, on the corrosion rates of alloy 600 . An inhibitive effect of sodium phosphate and sodium silicate is also reproduced by the model.

The effect of dissolved oxygen on corrosion potential is of particular importance for predicting localized corrosion. Figure 5 shows the corrosion potential in aerated solutions containing 6 ppm $\mathrm{O}_{2}$ in which $\mathrm{pH}$ was varied by adding various concentrations of $\mathrm{LiOH}$ or $\mathrm{H}_{3} \mathrm{PO}_{3}$. Figure 6 shows the dependence of the corrosion potential in dilute $\mathrm{LiOH}$ solutions on the concentration of dissolved oxygen. As shown in the figures, the effects of temperature, $\mathrm{pH}$ and dissolved oxygen are correctly reproduced by the model.

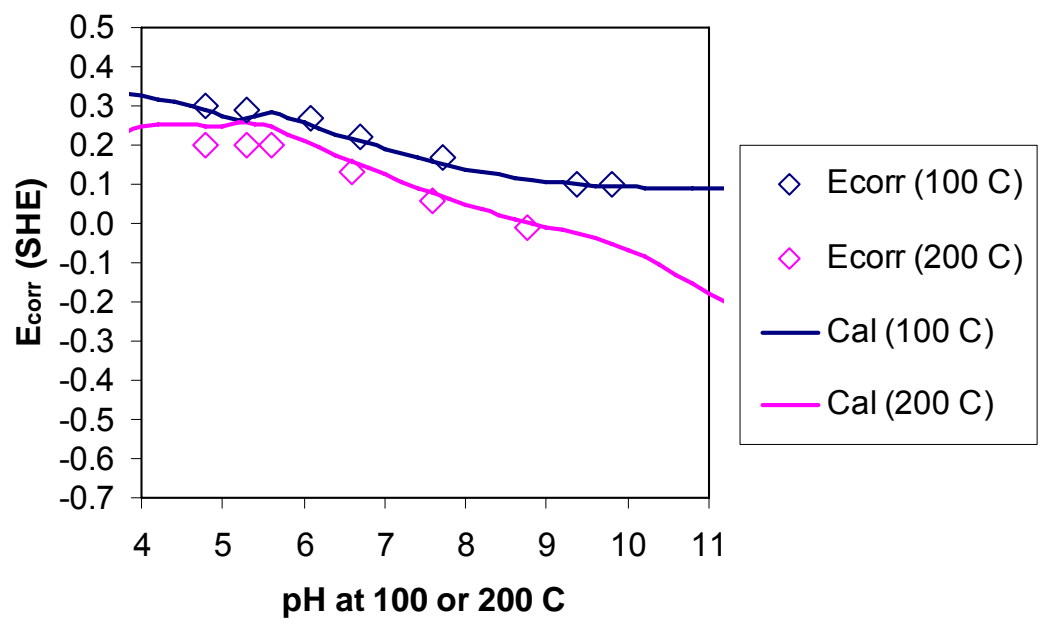

Figure 5. Calculated and experimental corrosion potentials of alloy 600 as a function of $\mathrm{pH}$ and temperature. The $\mathrm{pH}$ was varied by adding $\mathrm{LiOH}$ and $\mathrm{H}_{3} \mathrm{BO}_{3}$ 


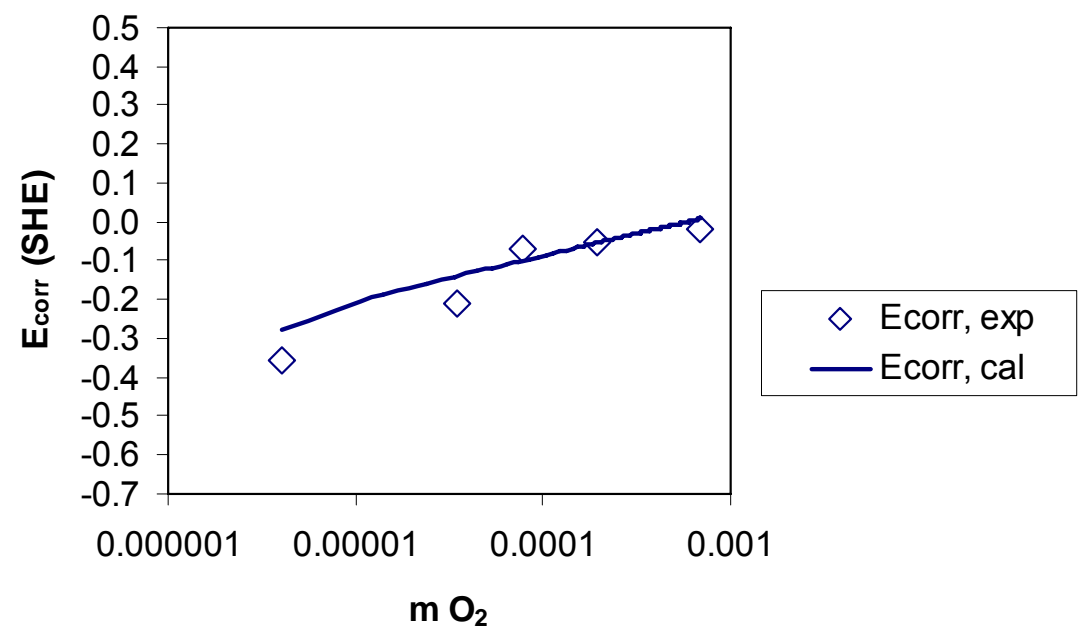

Figure 6. Calculated and experimental corrosion potentials of alloy 600 in $0.1 \mathrm{~m} \mathrm{LiOH}$ at $200{ }^{\circ} \mathrm{C}$ as a function of dissolved oxygen concentration.

The model predicts the corrosion potential in a wide range of $\mathrm{pH}$ of the solution. For example, Figure 7 shows the corrosion potential of alloy 600 in sulfuric acid solutions. In this case, the effect of aeration is much smaller than in the case of neutral or weakly acidic or alkaline solutions. This is due to the fact that the predominant cathodic reaction is the reduction of hydrogen ions. Thus, the model correctly represents the effects of various cathodic processes on the corrosion potential.

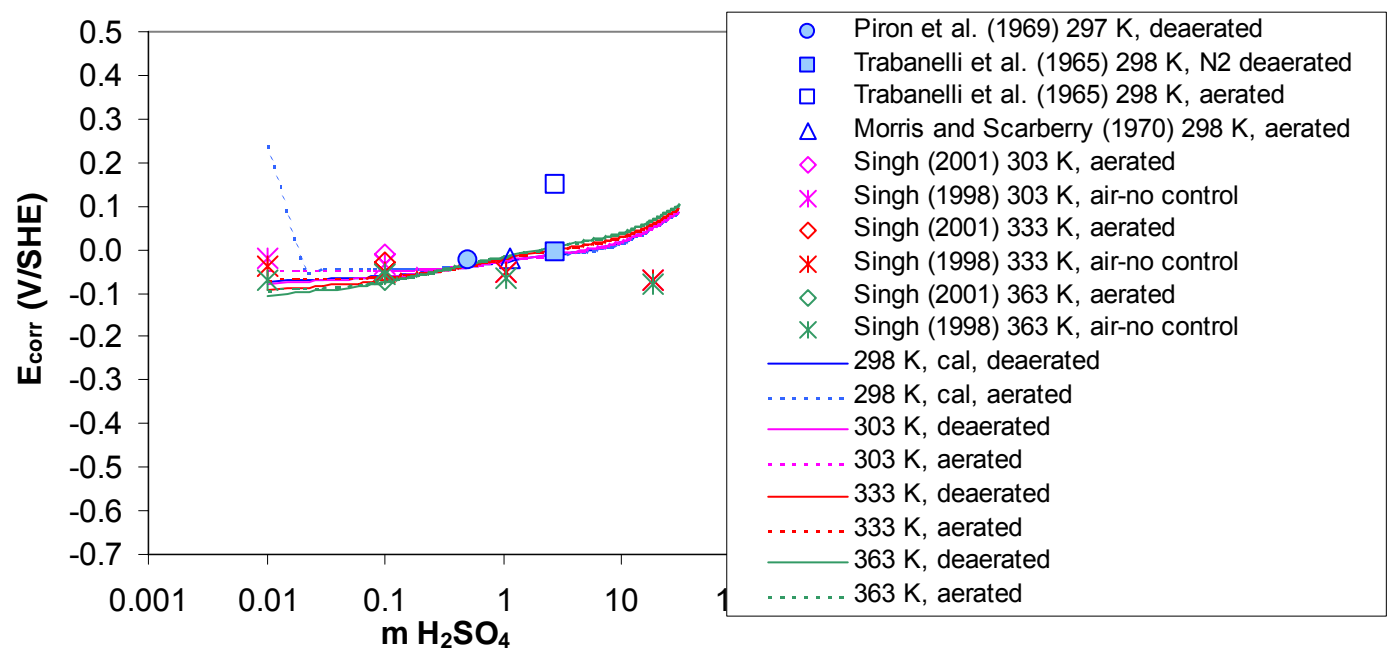

Figure 11. Calculated and experimental corrosion potential of alloy 600 in $\mathrm{H}_{2} \mathrm{SO}_{4}$ solutions at various temperatures.

The general corrosion model is particularly useful for studying the effect of solution chemistry on corrosion. Here, we describe the effect of fluoride ions as an example. Fluoride ions in acidic environments have a substantial effect on passivity. This effect is in many ways different from that of chlorides and other ions. While the fluoride ion is not 
as active in promoting localized corrosion as the chloride ion, it increases the passive current density and affects the active-passive transition. The effect of fluoride ions on passive dissolution can be accurately taken into account using the previously developed model of passive film dissolution (Anderko et al., 2001, Sridhar et al., 2004). This specific $\mathrm{F}^{-}$effect is due to the formation of fluoride surface complexes, which are typically more important than the simple $\mathrm{pH}$ effect in a relatively weak acid like HF. The calculated corrosion rates in HF-containing systems are compared with experimental data in Figures $12-15$.

Figure 12 shows the corrosion rates of alloy 22 as a function of HF concentration for several temperatures. The substantial increase in the corrosion rate with HF concentration is consistent with the dissolution of the passive film and general corrosion in the active state.

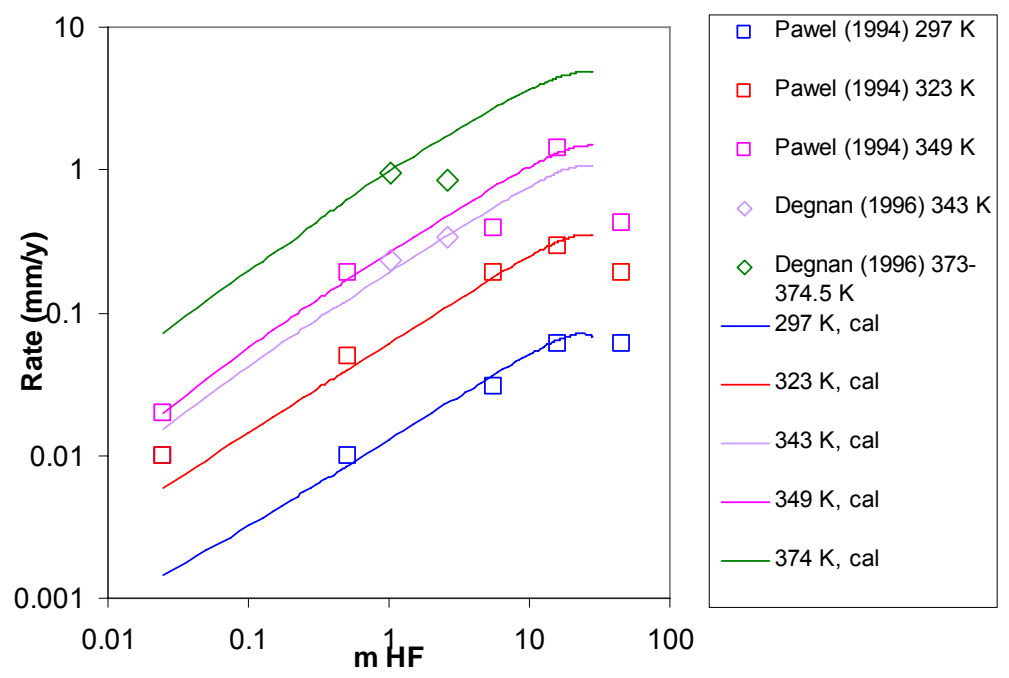

Figure 12. Calculated and experimental corrosion rate of alloy 22 as a function of $\mathrm{HF}$ concentration at various temperatures.

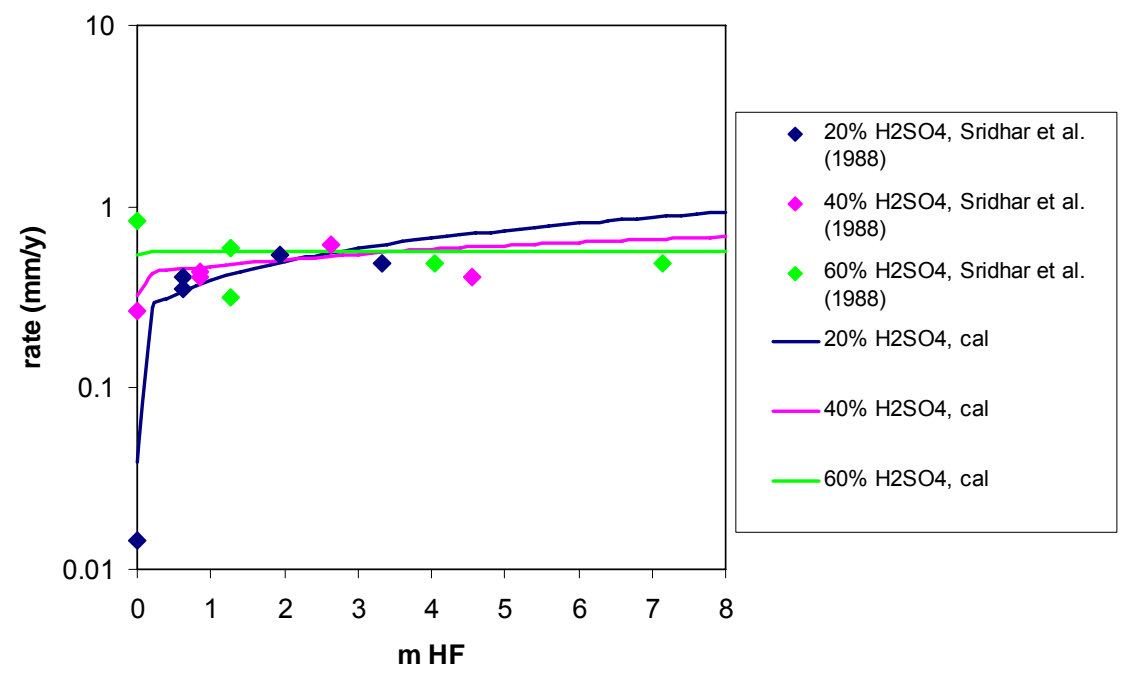

Figure 13. Calculated and experimental corrosion rates of alloy 22 in mixed $\mathrm{HF}+\mathrm{H}_{2} \mathrm{SO}_{4}$ solutions as a function of $\mathrm{HF}$ content for fixed $\mathrm{H}_{2} \mathrm{SO}_{4}$ concentrations. 
Figure 13 shows the corrosion rates of alloy 22 in mixed $\mathrm{HF}+\mathrm{H}_{2} \mathrm{SO}_{4}$ solutions. It is noteworthy that $\mathrm{HF}$ accelerates corrosion at lower concentrations of $\mathrm{H}_{2} \mathrm{SO}_{4}$ whereas only a small effect is observed for $40 \%$ and $60 \% \mathrm{H}_{2} \mathrm{SO}_{4}$. This is due to the fact that $\mathrm{HF}$ destroys passivity in relatively dilute $\mathrm{H}_{2} \mathrm{SO}_{4}$ solutions, which increases the corrosion rate. In $40 \%$ and $60 \% \mathrm{H}_{2} \mathrm{SO}_{4}$ solutions, the alloy dissolution proceeds in the active state. Thus, the addition of a weak acid such as HF does not substantially influence the corrosion rate.

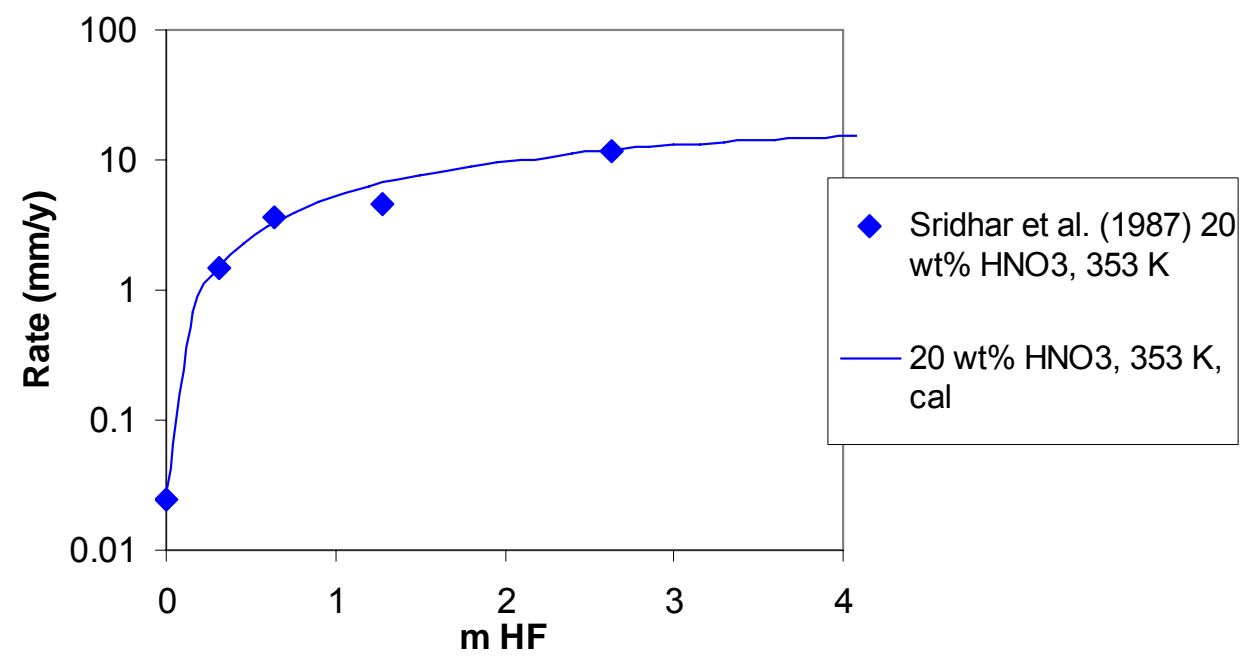

Figure 14. Calculated and experimental corrosion rate of alloy 22 in mixed $\mathrm{HNO}_{3}+\mathrm{HF}$ solutions.

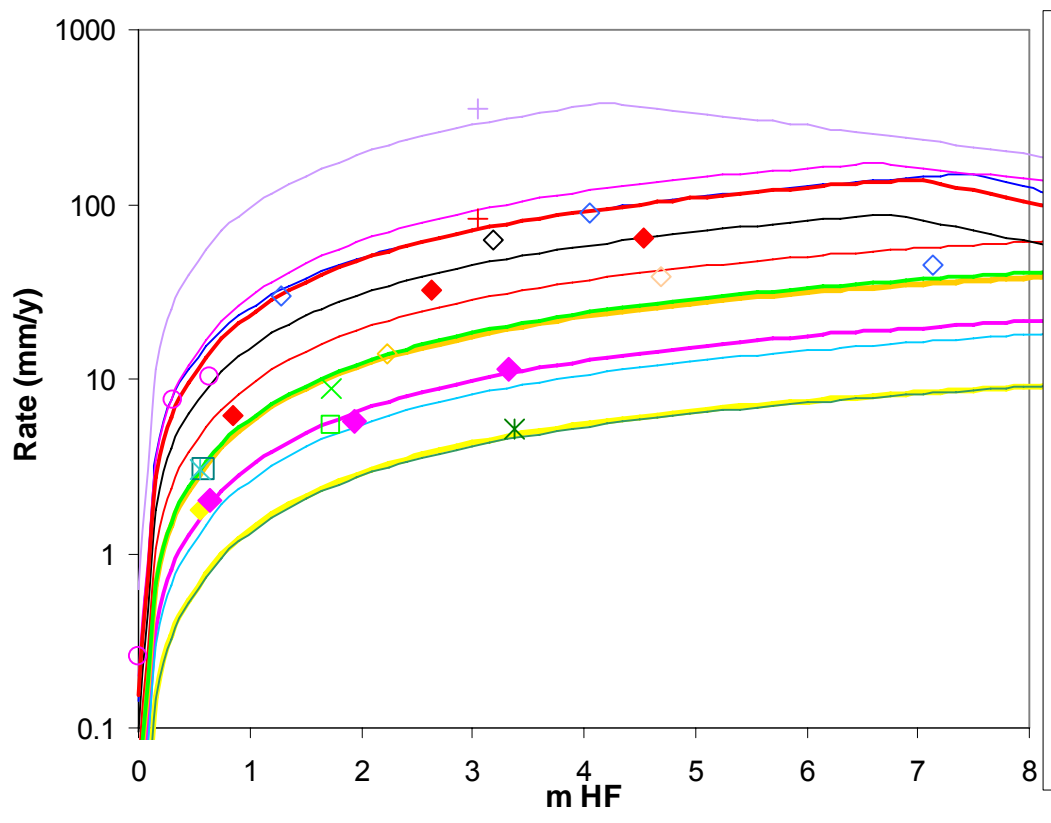

\begin{tabular}{|c|c|}
\hline & Sridhar (2003) $324.8 \mathrm{~K}, 10 \mathrm{w}$ t\% HNO3 \\
\hline$\bullet$ & Sridhar (2003) $324.8 \mathrm{~K}, 20 \mathrm{w} \mathrm{t} \% \mathrm{HNO}$ \\
\hline$\diamond$ & Sridhar (2003) $324.8 \mathrm{~K}, 30 \mathrm{wt} \% \mathrm{HNO}$ \\
\hline - & Sridhar (2003) $324.8 \mathrm{~K}, 40 \mathrm{wt} \% \mathrm{HNO}$ \\
\hline$\diamond$ & Sridhar (2003) $324.8 \mathrm{~K}, 50 \mathrm{wt} \% \mathrm{HNO}$ \\
\hline$\diamond$ & Sridhar (2003) $324.8 \mathrm{~K}, 60 \mathrm{w}$ t\% HNO3 \\
\hline$\diamond$ & Sridhar (2003) $324.8 \mathrm{~K}, 65 \mathrm{w} \mathrm{t} \% \mathrm{HNO}$ \\
\hline$\circ$ & Sridhar et al. (1987) $353 \mathrm{~K}, 20 \mathrm{w}$ t\% HNO3 \\
\hline$\square$ & Corbett and Morrison (1989) $343 \mathrm{~K}, 10 \mathrm{w}$ t\% HNO3 \\
\hline$\square$ & Corbett and Morrison (1989) $377 \mathrm{~K}, 15 \mathrm{w} \mathrm{t} \% \mathrm{HNO} 3$ \\
\hline * & Manning et al. (1988) $333 \mathrm{~K}, 5 \mathrm{wt} \% \mathrm{HNO}$ \\
\hline * & Manning et al. (1988) $333 \mathrm{~K}, 10 \mathrm{w}$ t\% HNO3, w elded \\
\hline & Stellite Div. (1973) $343 \mathrm{~K}, 10 \mathrm{w}$ t\% HNO3 \\
\hline & Int. Nickel Co., 283-305 K, 50 w t\% HNO3 \\
\hline & Int. Nickel Co., 336 K, 39 w t\% HNO3 \\
\hline & Int. Nickel Co., 354 K, 39 w t\% HNO3 \\
\hline & Cal, $324.8 \mathrm{~K}, 10 \% \mathrm{HNO} 3$ \\
\hline & Cal, $324.8 \mathrm{~K}, 20 \% \mathrm{HNO} 3$ \\
\hline & Cal, $324.8 \mathrm{~K}, 30 \% \mathrm{HNO} 3$ \\
\hline & Cal, $324.8 \mathrm{~K}, 40 \% \mathrm{HNO}$ \\
\hline & Cal, $324.8 \mathrm{~K}, 50 \% \mathrm{HNO}$ \\
\hline & Cal, $324.8 \mathrm{~K}, 60 \% \mathrm{HNO} 3$ \\
\hline & Cal, $353 \mathrm{~K}, 20 \% \mathrm{HNO}$ \\
\hline & $\mathrm{Cal}, 343 \mathrm{~K}, 10 \% \mathrm{HNO} 3$ \\
\hline & Cal, $333 \mathrm{~K}, 5 \% \mathrm{HNO} 3$ \\
\hline & Cal, $333 \mathrm{~K}, 10 \% \mathrm{HNO} 3$ \\
\hline & Cal, $336 \mathrm{~K}, 39 \% \mathrm{HNO}$ \\
\hline & Cal, $354 \mathrm{~K}, 39 \%$ HNO3 \\
\hline
\end{tabular}

Figure 15. Calculated and experimental corrosion rates of alloy 276 in mixed $\mathrm{HNO}_{3}+\mathrm{HF}$ systems for various $\mathrm{HNO}_{3}$ concentrations and temperatures. 
Corrosion behavior in $\mathrm{HF}+\mathrm{HNO}_{3}$ mixtures is substantially different from that in $\mathrm{HF}+$ $\mathrm{H}_{2} \mathrm{SO}_{4}$ mixtures. This is illustrated in Figures 14 and 15 for alloys 22 and 276, respectively. In the presence of $\mathrm{HNO}_{3}$, the corrosion potential is substantially increased due to the oxidative properties of $\mathrm{HNO}_{3}$. Then, corrosion in $\mathrm{HNO}_{3}$ solutions proceeds primarily in the passive state and is controlled by the dissolution of the oxide in acidic environments. This results in relatively moderate corrosion rates in pure $\mathrm{HNO}_{3}$ solutions. In the presence of HF, the dissolution of the oxide is strongly accelerated. This results in a very strong increase in the corrosion rate as shown in Figures 14 and 15. In all cases, the model is in close agreement with experimental data.

As the final example of general corrosion calculations, Figure 16 shows the effect of oxygen on the corrosion potential of alloy 22 is shown. In this case, the solutions were aerated at various temperatures and the effect of $\mathrm{pH}$ was investigated. As shown in Figure $16, \mathrm{pH}$ and temperature are the primary variables that determine the corrosion potential in this case. The $\mathrm{pH}$ effect is particularly pronounced in acidic solutions. On the other hand, the effect of chlorides is negligible. These effects are accurately represented by the model. The prediction of the corrosion potential in aerated solutions as a function of $\mathrm{pH}$ is of particular importance for predicting localized corrosion.

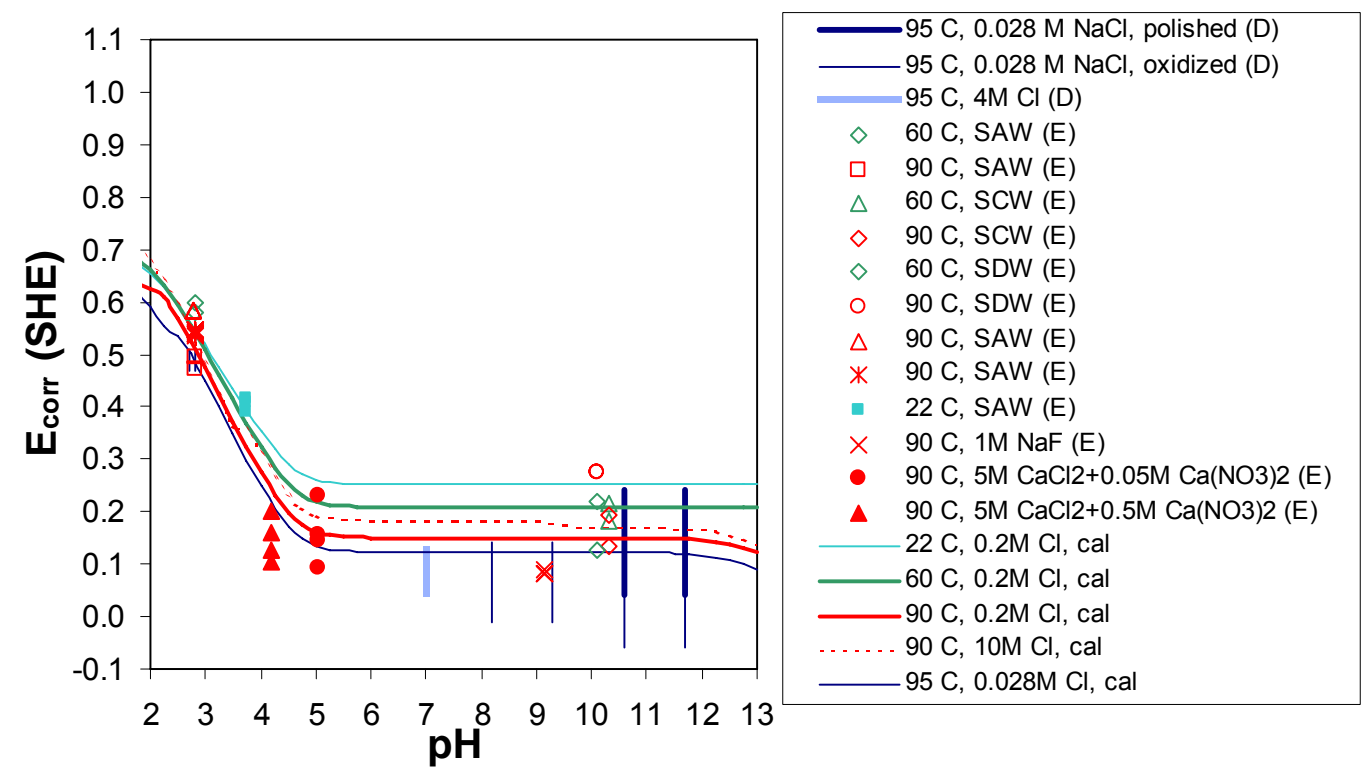

Figure 16. Calculated and experimental corrosion potentials for alloy C-22 in aerated waters as a function of $\mathrm{pH}$. The symbols SAW, SCW and SDW denote simulated acidified water, simulated concentrated water and simulated dilute water, respectively. The vertical lines show the ranges of data reported by Dunn et al. (2003) for $0.028 \mathrm{M}$ and $4 \mathrm{M} \mathrm{NaCl}$ solutions at $95^{\circ} \mathrm{C}$. 


\section{Development of a model for the repassivation potential}

The key to the practical application of this predictive approach is the accurate computation of the repassivation potential as a function of solution chemistry and temperature. For this purpose, a mechanistic model was developed in a previous study (Anderko et al., 2004). An important feature of this model is its capability of relating the key parameters that determine localized corrosion to the chemistry of aqueous environments, including aggressive, non-aggressive and inhibitive species.

Here, we generalize the model by focusing on systems containing various inorganic oxyanions in addition to chlorides. This is important in view of the fact that most industrially important systems are multicomponent. Several studies have shown that various inorganic anions such as nitrate, sulfate or carbonate can inhibit localized corrosion of Fe-Ni-Cr-Mo alloys (Szklarska-Smialowska, 1986, Strehblow and Titze, 1977, Jallerat et al., 1984, McCafferty, 1990, Kehler et al., 2001, Dunn et al., 2005a,b, Yang and Macdonald, 2007). In general, the effectiveness of the inhibition is a complex function of the concentrations of both aggressive and inhibitive ions, temperature, and the chemical nature of the anion. Previously, it has been shown that the repassivation potential shows an abrupt transition as a function of inhibitor concentration. This transition, which can be reproduced by the $\mathrm{E}_{\mathrm{rp}}$ model, can be identified with the threshold condition for inhibition. Thus, it is of great interest to investigate the interplay of aggressive and inhibitive species in a systematic way to develop a methodology for predicting the conditions at which localized corrosion is possible and those at which it cannot occur. The objective of this part of the research program is to develop such a methodology for Fe-Cr-Ni-Mo-W-N alloys in the presence of common inhibiting oxyanions, i.e., hydroxides, molybdates, vanadates, sulfates, nitrates, and nitrites.

In a previous paper (Anderko et al., 2004), a mechanistic model was developed for calculating the repassivation potential as a function of solution chemistry and temperature. The model was shown to reproduce experimental $\mathrm{E}_{\mathrm{rp}}$ data for alloys in contact with aggressive, non-aggressive and inhibitive ions. Also, it was shown to provide an estimate of the maximum propagation rate of individual pits. The model has been validated using laboratory $\mathrm{E}_{\mathrm{rp}}$ measurements for well-defined corrosive environments (Anderko et al., 2004), standard corrosion tests such as critical crevice temperature (Anderko et al., 2005a) and plant monitoring data in industrial streams (Anderko et al., 2005b).

The model has been derived by considering the dissolution of a metal in a localized corrosion environment in the limit of repassivation. According to the model, the metal (M) undergoes dissolution underneath a layer of concentrated metal halide solution MX. The concentrated solution may or may not be saturated with respect to a hydrous solid metal halide. In the process of repassivation, a thin layer of oxide is assumed to form at the interface between the metal and the hydrous metal halide. The model assumes that, at a given instant, the oxide layer covers a certain fraction of the metal surface. This fraction increases as repassivation is approached. Further, the model includes the effects of multiple aggressive and non-aggressive or inhibitive species, which are taken into account through a competitive adsorption scheme. The aggressive species form metal complexes, which dissolve in the active state. On the other hand, the inhibitive species 
and water contribute to the formation of oxides, which induce passivity. In general, the equations that describe these processes are complex and can be solved only numerically. However, a closed-form equation has been found in the limit of repassivation, i.e., when the current density reaches a predetermined low value $i_{r p}$ (assumed to be $i_{r p}=10^{-2} \mathrm{~A} / \mathrm{m}^{2}$ ) and the fluxes of metal ion become small and comparable to those for passive dissolution. Since the objective of this study is to apply this model to calculating $E_{r p}$ of Fe-Ni-Cr-Mo$\mathrm{W}-\mathrm{N}$ alloys in various aqueous chloride-oxyanion systems, we summarize here the parameters that need to be determined to apply the model in practice. These parameters will be evaluated on the basis of the experimentally obtained matrix of $E_{r p}$ data. Further, they will be generalized in terms of alloy composition.

The repassivation potential model yields a closed-form expression, which can be solved numerically to calculate $E_{r p}$ if the model parameters are known. For a system containing $N A$ aggressive ions and $N I$ inhibitive ions, this equation is given in a general form by:

$$
1+\sum_{k}^{N I}\left[\left(\frac{i_{r p}}{i_{p}}-1\right) \frac{l_{k}{ }^{\prime \prime}}{i_{r p}}\right] \theta_{k}^{n_{k}} \exp \left(\frac{\xi_{k} F E_{r p}}{R T}\right)=\sum_{j}^{N A} \frac{k_{j}{ }^{\prime \prime}}{i_{r p}} \theta_{j}^{n_{j}} \exp \left(\frac{\alpha_{j} F E_{r p}}{R T}\right)
$$

where $i_{p}$ is the passive current density, $i_{r p}$ is the experimental current density that defines repassivation $\left(i_{r p}=10^{-2} \mathrm{~A} / \mathrm{m}^{2}\right), \theta_{j}$ is the partial surface coverage fraction by solution species $j, T$ is the temperature, $R$ is the gas constant, $F$ is the Faraday constant and $k_{j}{ }^{\prime \prime}$, $l_{k}{ }^{\prime \prime}, n_{j}, n_{k}, \alpha_{j}$, and $\xi_{k}$ are electrochemical kinetic parameters as defined below. The summation on the right-hand side of eq. (1) is performed over all aggressive species $(j=$ $1, \ldots, N A)$ and the summation on the left-hand side pertains to inhibitive species $(k=1$, ..., NI). It should be noted that $\mathrm{H}_{2} \mathrm{O}$ molecules are treated as inhibitive species because they contribute to the formation of an oxide layer. The electrochemical parameters of the model are defined as follows:

(i) The quantity $k_{j}{ }^{\prime \prime}$ is the reaction rate constant for alloy dissolution mediated by the adsorption of aggressive species $j$. This constant is used in a scaled form (i.e., as $\left.k_{j}=k_{j}{ }^{\prime \prime} / i_{r p}\right)$ and is expressed using a scaled Gibbs energy of activation $\Delta g^{\neq}{ }_{A, j}$ :

$$
k_{j}=\frac{k_{j}^{\prime \prime}}{i_{r p}}=\exp \left(-\frac{\Delta g_{A, j}^{\neq}}{R T}\right)
$$

The quantity $\Delta g_{A, j}^{\neq}$is introduced in order to express the temperature dependence of the rate constant in a convenient thermodynamic form.

(ii) The quantity $l_{k}{ }^{\prime \prime}$ is the reaction rate constant for the formation of oxide mediated by the adsorption of inhibitive species $k$. As with the $k_{j}{ }^{\prime \prime}$ constant, it is used in a scaled form (i.e., as $\left.l_{k}=\left(i_{r p} / i_{p}-1\right) l_{k}{ }^{\prime \prime} / i_{r p}\right)$ and is expressed using a scaled Gibbs energy of activation $\Delta g^{\neq} I k$ : 


$$
l_{k}=\left(\frac{i_{r p}}{i_{p}}-1\right) \frac{l_{k}^{\prime \prime}}{i_{r p}}=\exp \left(-\frac{\Delta g_{I, k}^{\neq}}{R T}\right)
$$

(iii) The quantities $n_{j}$ and $n_{k}$. are the reaction rate orders with respect to the aggressive species $j$ and inhibitive species $k$, respectively. It has been found in previous studies that $n_{k}$ can be assigned a default value of one in practical applications of the model.

(iv) The parameters $\alpha_{j}$ and $\xi_{k}$ are the electrochemical transfer coefficients for the reactions involving the aggressive species $j$ and inhibitive species $k$, respectively. The parameter $\alpha_{j}$ can are assumed to be equal to one for simplicity.

The partial coverage fraction of a species $j$ is related to the activity of this species in the bulk solution through an adsorption isotherm, i.e.,

$$
\theta_{j}=\frac{r_{j} a_{j}}{1+\sum_{k} r_{k} a_{k}}
$$

where the adsorption coefficient is defined using the Gibbs energy of adsorption $\Delta G_{a d s, i}$, i.e.,

$$
r_{j}=\exp \left(-\frac{\Delta G_{a d s, j}}{R T}\right)
$$

The latter property can be assigned a common default value for the majority of species although specific parameters may be needed for strongly adsorbing species. For $\mathrm{H}_{2} \mathrm{O}$ in aqueous solutions, $\theta_{\mathrm{H} 2 \mathrm{O}}$ is assumed to be equal to one for simplicity.

For calculating the temperature dependence of the kinetic parameters, the scaled Gibbs energies of activation may be further related to temperature as

$$
\frac{\Delta g_{A, j}^{\neq}}{T}=\frac{\Delta g_{A, j}^{\neq}\left(T_{r e f}\right)}{T_{r e f}}+\Delta h_{A, j}^{\neq}\left(\frac{1}{T}-\frac{1}{T_{r e f}}\right)
$$

for aggressive ions and

$$
\frac{\Delta g_{I, k}^{\neq}}{T}=\frac{\Delta g_{I, k}^{\neq}\left(T_{r e f}\right)}{T_{r e f}}+\Delta h_{I, k}^{\neq}\left(\frac{1}{T}-\frac{1}{T_{r e f}}\right)
$$

for water and inhibitive species. In eqs. (6) and (7), the parameters $\Delta g_{A, j}^{\neq}\left(T_{r e f}\right)$ and $\Delta g_{I, k}^{\neq}\left(T_{\text {ref }}\right)$ are the scaled Gibbs energies of activation at reference temperature $T_{\text {ref }}=$ $298.15 \mathrm{~K}$ for the reactions mediated by the adsorption of aggressive and inhibitive ions, 
respectively. The quantities $\Delta h_{A, j}^{\neq}$and $\Delta h^{\neq}{ }_{l, k}$ are the corresponding enthalpies of activation. In a practical implementation of the model, the parameters are typically determined as follows:

(1) Since $E_{r p}$ data are most abundant for chloride solutions, the scaled Gibbs energy of activation for chloride ions $\left(\Delta g_{A, C l}^{\neq}\right)$, the reaction order with respect to chlorides $\left(n_{C l}\right)$, the scaled Gibbs energy of activation for water $\left(\Delta g^{\neq}{ }_{I, H 2 O}\right)$, and the electrochemical transfer coefficient for water $\left(\xi_{H 2 O}\right)$ are determined based on data for chloride solutions. It will be later shown in this study that this procedure can be simplified by the fact that the $n_{C l}$ and $\xi_{H 2 O}$ parameters can be assigned nearly-universal values for Fe-Ni-Cr-Mo-W-N alloys and do not necessarily need to be individually determined. If the temperature range of the data is sufficient to establish the temperature dependence of the Gibbs energies of activation, the enthalpies of activation $\Delta h_{A, C l}^{\neq}$ and $\Delta h^{7}{ }_{1, H 2 O}$ may also be determined according to eqs. (6-7).

(2) If the system contains aggressive species other than chlorides (e.g., bromides), the $\Delta g_{A, j}^{\neq}$and, if necessary, $n_{j}$ parameters are determined for such species using $E_{r p}$ data for either pure or mixed solutions containing such ions. Such cases were examined in a previous study [Anderko et al., 2004] and will not be considered here.

(3) The $\Delta g_{I, k}^{\neq}$and $\xi_{k}$ parameters for inhibitive ions $k$ are determined on the basis of data for mixed solutions containing chlorides and inhibitors. Data for mixed systems are necessary because $E_{r p}$ is undefined in solutions containing only inhibitors. The parameter $\xi_{k}$ can be assigned a common default value for all the inhibiting ions studied here. If necessary, the activation enthalpy $\Delta h_{I, k}^{\neq}$is also determined to reproduce the temperature dependence of the inhibition effect.

In this project, the repassivation potentials have been obtained for $316 \mathrm{~L}$ stainless steel (UNS 31603), alloy 600 (UNS N06600), alloy 690 (UNS N06690), alloy 254SMO (UNS S31254), 2205 duplex stainless steel (UNS S32205) and super 13Cr stainless steel (UNS S41425) in mixed aqueous solutions containing chloride ions and oxyanions. As oxyanions, hydroxides, molybdates, sulfates, vanadates, nitrates and nitrites were studied. Also, repassivation potentials were used for alloys AL6XN (UNS N08367), 800 (UNS N08800), 625 (UNS N06625), and 276 (UNS N10276) in chloride-only solutions. In addition, literature data for alloys 22 (UNS N06022), 825 (UNS 08825) and type 304L stainless steels (UNS S30403) were also used in modeling.

To keep the scope of the experimental study within manageable limits, the matrix of six alloys and six oxyanions was not investigated in its entirety. The effect of five oxyanions (i.e., $\mathrm{OH}^{-}, \mathrm{MoO}_{4}{ }^{2-}, \mathrm{SO}_{4}{ }^{2-}, \mathrm{VO}_{3}{ }^{-}$, and $\mathrm{NO}_{3}^{-}$) was studied for alloys $316 \mathrm{~L}$ and 690 . The chloride concentration - oxyanion concentration - temperature space was sampled in particular detail for type 316L stainless steel. Thus, the results for 316L SS serve as a prototype data set to which the remaining data sets could be compared. Additionally, repassivation potentials of $316 \mathrm{~L}$ SS have been measured in nitrite solutions to compare the effect of nitrites with that of nitrates. For alloy $600, E_{r p}$ data were obtained for mixtures with the $\mathrm{OH}^{-}, \mathrm{MoO}_{4}{ }^{2-}, \mathrm{SO}_{4}{ }^{2-}$, and $\mathrm{VO}_{3}{ }^{-}$ions. For alloy $254 \mathrm{SMO}$, the $\mathrm{OH}^{-}$, 
$\mathrm{MoO}_{4}{ }^{2-}, \mathrm{SO}_{4}{ }^{2-}$, and $\mathrm{NO}_{3}{ }^{-}$ions were investigated. A more limited data set was obtained for alloy 2205 , for which the $\mathrm{OH}^{-}, \mathrm{MoO}_{4}{ }^{2-}, \mathrm{SO}_{4}{ }^{2-}$ ions were studied. For the super- $13 \mathrm{Cr}$ stainless steel, only the effect of the $\mathrm{NO}_{3}{ }^{-}$ions was investigated. Together with literature data for alloy 22 (Dunn et al., 2005a,b), this experimental matrix makes it possible to elucidate the overall trends in the behavior of alloys in chloride - oxyanion systems and to establish a generalized correlation.

\section{Application of the model to individual alloys in chloride - oxyanion environments}

To analyze the effect of chlorides and oxyanions on the repassivation potential, we focus first on type $316 \mathrm{~L}$ stainless steel because the $\mathrm{E}_{\mathrm{rp}}$ data are most comprehensive for this alloy. Figure 1 shows the repassivation potential of type $316 \mathrm{~L}$ stainless steel in chlorideonly solutions at three temperatures $\left(23^{\circ} \mathrm{C}, 60^{\circ} \mathrm{C}\right.$ and $\left.95^{\circ} \mathrm{C}\right)$. The model parameters that are necessary to reproduce the results shown in this figure are listed in Table 3 . As shown in Figure 1, the slope of the repassivation potential changes as a function of chloride activity. A steeper slope is observed at low chloride concentrations. This is a general phenomenon for alloys and becomes more pronounced for more corrosion-resistant alloys. The transition between the low-slope and high-slope segments of the curves strongly depends on the alloy and temperature. The less-steep portion of the curve at higher chloride activities is determined by the parameters that represent the dissolution of the metal through the formation of metal-chloride complexes (i.e., $\Delta g_{A, C l}^{\neq}$and $n_{C l}$ ). The steeper portion at lower chloride concentrations is additionally determined by the parameters that represent the formation of the oxide through a reaction with water molecules (i.e., $\Delta g_{I, H 2 O}^{\neq}$and $\xi_{H 2 O}$ ). The slope of this segment increases with an increase in the parameter $\xi_{H 2 O}$. Using these parameters, the model represents the data essentially within experimental uncertainty.

In Figure 1, the repassivation potential is plotted as a function of the activity of chloride ions in the solution. A dependence of $\mathrm{E}_{\mathrm{rp}}$ on the concentration of the solution, which is more directly measurable than activity, is essentially identical in the dilute solution range (up to ca. $0.1 \mathrm{~m}$ ) and qualitatively similar for more concentrated solutions. It should be noted that the dependence of $\mathrm{E}_{\mathrm{rp}}$ on species activity is obtained directly from the repassivation potential model outlined above. However, to calculate the dependence of $\mathrm{E}_{\mathrm{rp}}$ on concentration, it is necessary to utilize a thermodynamic model for electrolyte solutions. Such a model should relate the concentrations to activities and provide other information such as species distribution and phase equilibria. In this study, we use a previously developed comprehensive electrolyte model (Zemaitis [1980], Rafal et al. [1995]) for this purpose. The use of the thermodynamic model in conjunction with the $\mathrm{E}_{\mathrm{rp}}$ model was described in more detail in a previous paper [Anderko et al., 2004].

Figures 2-7 show the results of calculations for mixed systems containing chlorides as aggressive species and six different inhibiting ions, i.e., hydroxides, molybdates, vanadates, nitrates, sulfates, and nitrites. In all cases, the results are plotted as a function of inhibitor concentration for fixed chloride concentrations at fixed temperatures. For all inhibitors, calculations have been performed for $23^{\circ} \mathrm{C}$ and $60^{\circ} \mathrm{C}$ with some additional results for nitrates at $95^{\circ} \mathrm{C}$. In all figures, the experimental data points at higher potentials (above ca. $0.64 \mathrm{~V}$ vs. SHE) correspond to experiments in which no localized corrosion 
was obtained. Such data points may correspond to other phenomena such as transpassive dissolution. Therefore, the model is not expected to reproduce such high values exactly at each condition at which they have been obtained. Instead, the model should yield high (although not necessarily the same) values of the repassivation potential at such conditions, thus predicting the absence of localized corrosion. On the other hand, the model is expected to quantitatively reproduce the lower values of $\mathrm{E}_{\mathrm{rp}}$ (i.e., below ca. 0.64 $\mathrm{V} / \mathrm{SHE}$ ), which correspond to the actual occurrence of localized corrosion. The inhibitor effect can be accurately reproduced using only three parameters, i.e., $\Delta g_{I, k}^{\neq}\left(T_{r e f}\right), \Delta h_{I, k}^{\neq}$, and $\xi_{I, k}$. Of these, only the $\Delta g_{I, k}^{\neq}\left(T_{r e f}\right)$ and $\Delta h_{I, k}^{\neq}$parameters are adjusted to match experimental data and $\xi_{I_{1} k}$ is assigned a common value for all inhibitors.

Figure 2 shows the effect of adding $\mathrm{NaOH}$ to $\mathrm{NaCl}$ solutions. The $\mathrm{E}_{\mathrm{rp}} \mathrm{vs}^{\mathrm{O}} \mathrm{OH}^{-}$ concentration curves have a characteristic shape with two distinct slopes. As the concentration of $\mathrm{OH}^{-}$ions is increased, the slope of the $\mathrm{E}_{\mathrm{rp}} \mathrm{vs}$. $\mathrm{OH}^{-}$concentration curve initially slowly increases with a very low, almost negligible slope. At a certain concentration of $\mathrm{OH}^{-}$, the slope of the $\mathrm{E}_{\mathrm{rp}}$ curve rapidly increases and the repassivation potential attains a high value. At $\mathrm{OH}^{-}$concentrations that lie beyond the high-slope portion of the $\mathrm{E}_{\mathrm{rp}} \mathrm{vs}$. $\mathrm{OH}^{-}$curve, localized corrosion becomes impossible even in systems with a high corrosion potential. Thus, there is a fairly narrow range of $\mathrm{OH}^{-}$concentrations over which the $\mathrm{E}_{\mathrm{rp}}$ curve transitions from a low-slope region (in which localized corrosion is possible depending on the value of the corrosion potential) to a high-slope region that constitutes the upper limit of $\mathrm{OH}^{-}$concentrations for localized corrosion. The exact location of the transition region depends on the temperature and chloride concentration. As shown in Figure 2, an increase in $\mathrm{Cl}^{-}$concentration results in a shift in the transition region to higher $\mathrm{OH}^{-}$concentration. This is due to the fact that more $\mathrm{OH}^{-}$ ions are necessary to inhibit localized corrosion as the concentration of chlorides increases. Similarly, the transition region shifts to higher hydroxide concentrations as the temperature increases. In some cases, inhibition of localized corrosion is impossible because a sufficiently high concentration of inhibiting ions cannot be achieved because of solubility limitations. This is the case for a system containing $4 \mathrm{M} \mathrm{NaCl}$ at $23^{\circ} \mathrm{C}$ as shown in Figure 3. For this solution, the $\mathrm{E}_{\mathrm{rp}} \mathrm{vs}$. $\mathrm{OH}^{-}$concentration curve terminates at the solubility limit before a transition to a high-slope segment of the curve can be obtained.

Figure 3 shows the experimental data and results of calculations for mixed systems containing $\mathrm{NaCl}$ and $\mathrm{Na}_{2} \mathrm{MoO}_{4}$. The $\mathrm{E}_{\mathrm{rp}}$ vs. $\mathrm{MoO}_{4}{ }^{2-}$ concentration curves are qualitatively similar to the $\mathrm{E}_{\mathrm{rp}} \mathrm{vs}$. $\mathrm{OH}^{-}$curves in Figure 2. However, the transition to the localized corrosion inhibition region (i.e., to the steep segment of the curve) occurs at lower inhibitor concentrations. The difference between the $\mathrm{MoO}_{4}{ }^{2-}$ and $\mathrm{OH}^{-}$ions is quite small at $23^{\circ} \mathrm{C}$, but becomes more pronounced at $60^{\circ} \mathrm{C}$. For example, the transition to the inhibition region for $0.04 \mathrm{M} \mathrm{Cl}^{-}$solutions at $60^{\circ} \mathrm{C}_{\text {occurs }}$ at roughly $0.03 \mathrm{M} \mathrm{MoO}_{4}{ }^{2-}$ and $0.4 \mathrm{M} \mathrm{OH}^{-}$. This indicates that molybdate ions are more effective for the inhibition of localized corrosion than hydroxide ions. At some conditions, inhibition cannot be achieved because of solubility limitations. This is shown in Figure 3 for $4 \mathrm{M} \mathrm{Cl}^{-}$solutions at $23^{\circ} \mathrm{C}$ and $0.42 \mathrm{M} \mathrm{Cl}^{-}$solutions at $60^{\circ} \mathrm{C}$. For these solutions, the $\mathrm{E}_{\mathrm{rp}}$ vs. molybdate molarity curve terminates at a point at which the solution becomes saturated with respect to sodium molybdate. Then, the curve cannot transition to a steep segment that signifies inhibition. 
The results for vanadate ions are shown in Figure 4. The effect of vanadates is similar to that of molybdates. In particular, the transition to the inhibition region occurs at similar concentrations for molybdates and vanadates. Figure 5 shows the experimental data and calculated results for nitrate ions. As shown in Figure 5, nitrate ions are more effective as inhibitors of localized corrosion than either molybdate or vanadate ions. This is due to somewhat lower concentrations of nitrate ions that are necessary to achieve the transition to the inhibition region. Also, the relatively high solubility of solids in mixed chloridenitrate solutions makes it possible to achieve inhibition even for high chloride concentrations. This is illustrated in Figure 5 for $3 \mathrm{M} \mathrm{Cl}^{-}$solutions at $23{ }^{\circ} \mathrm{C}$, for which inhibition can be achieved at relatively high nitrate concentrations. However, for $4 \mathrm{M} \mathrm{Cl}^{-}$ solutions, a solubility limit appears just below the transition region to the high-slope segment of the $\mathrm{E}_{\mathrm{rp}}$ curve.

The Gibbs energy of adsorption $\left(\Delta G_{a d s, i}\right)$ is assigned a constant value for most oxyanions (cf. Table 3). However, the accuracy of representing the $\mathrm{E}_{\mathrm{rp}}$ data for nitrate solutions is improved if a specific $\Delta G_{a d s, N O 3}$ value is regressed in addition to the $\Delta g_{I, N O 3}^{\neq}\left(T_{r e f}\right)$ and $\Delta h_{I, N O 3}^{\neq}$values.

Figure 6 shows the effect of sulfate ions on the repassivation potential. It is evident that sulfates have an appreciably weaker inhibiting effect than the other ions investigated in this study. For example, the sulfate concentration that is necessary to inhibit localized corrosion in $0.04 \mathrm{M} \mathrm{Cl}^{-}$solutions at $60^{\circ} \mathrm{C}$ is approximately $0.4 \mathrm{M}$ and is about an order of magnitude higher than the necessary concentration of molybdates, vanadates or nitrates. Also, solubility limits are encountered at relatively low concentrations, e.g., $0.42 \mathrm{M} \mathrm{Cl}^{-}$ solutions cannot be inhibited at $23{ }^{\circ} \mathrm{C}$ due to a solubility limit.

Figure 7 illustrates the inhibiting behavior of nitrites. It is evident that nitrites have somewhat stronger inhibitive properties than nitrates. In particular, inhibition of $4 \mathrm{M} \mathrm{Cl}$ solutions can be achieved at $23{ }^{\circ} \mathrm{C}$ because the transition to the inhibition range is not prevented by solubility limits.

Figures $8-12$ show the repassivation potential of alloy 600 in various environments. Figure 8 compares the calculated $\mathrm{E}_{\mathrm{rp}}$ values with experimental data for chloride-only environments. The data are less comprehensive for alloy 600 than for $316 \mathrm{~L} \mathrm{SS}$, but they are sufficient to establish model parameters. Figures $9-12$ show the effect of hydroxide, molybdate, vanadate, and sulfate ions, respectively. The general patterns are similar to those observed for $316 \mathrm{~L} \mathrm{SS}$. In particular, the transition from the region in which localized corrosion is possible to the inhibition region occurs at similar oxyanion concentrations as long as the temperature and chloride concentration are the same. The critical oxyanion concentration for the transition differs by a factor of 2-4 between the two alloys. When compared with $316 \mathrm{~L} \mathrm{SS}$, the critical oxyanion concentrations are higher for alloy 600 in the case of the $\mathrm{OH}^{-}, \mathrm{MoO}_{4}{ }^{2-}$, and $\mathrm{VO}_{3}{ }^{-}$ions, but somewhat lower in the case of the $\mathrm{SO}_{4}{ }^{2-}$ ions.

It can be observed that some experimental $E_{\mathrm{rp}}$ values seem to be somewhat lower at higher oxyanion concentrations than in chloride-only solutions. This is the case for 316L 
SS in hydroxide solutions (Fig. 2) and for alloy 600 in sulfate solutions. The model does not reproduce this occasional depression in the $\mathrm{E}_{\mathrm{rp}}$ values. In principle, such behavior could be accounted for only by a very substantial increase in the activity coefficients of $\mathrm{Cl}^{-}$ions in chloride - oxyanion mixtures at high concentrations, which would increase the activity of chloride ions and, hence, depress the repassivation potential. However, it seems more plausible to attribute this observation to the scattering of experimental data because it occurs only for a few alloy - oxyanion combinations and does not have a general character.

Figures 13 - 18 summarize the calculated and experimental repassivation potentials for alloy 690. The $\mathrm{E}_{\mathrm{rp}}$ values for alloy 690 are somewhat higher than those for alloy 600 , especially at low chloride activities (cf. Fig. 13). This is due to the higher Cr content of alloy 690 , which can be expected to contribute to the resistance to localized corrosion. The transition from the localized corrosion to the inhibition region occurs at similar oxyanion concentrations as for alloy 600 . However, the somewhat higher resistance of alloy 690 to localized corrosion makes it possible to achieve inhibition at some conditions of high $\mathrm{Cl}^{-}$concentrations, at which no inhibition is possible for alloy 600 . This is illustrated in Figure 14, which shows a transition to inhibition in a $4 \mathrm{M} \mathrm{Cl}$ solution at high concentrations of $\mathrm{OH}^{-}$ions. In the case of alloy 600 , such a transition does not occur before the saturation limit is reached (cf. Fig. 9).

Figures $19-22$ illustrate the effect of chlorides and oxyanions on the repassivation potential of alloy 254SMO. As shown in Figure 19, the $\mathrm{E}_{\mathrm{rp}}$ values of alloy 254SMO are substantially higher at all chloride activities than those of alloys 600 and 690 or type 316L stainless steel. This is due to the Mo and N content of alloy 254SMO, which contributes to the resistance to localized corrosion. Also, the enhanced resistance to localized corrosion manifests itself in a more pronounced high-slope segment of the $\mathrm{E}_{\mathrm{rp}}$ vs. chloride activity curve at low chloride activities. Because of the higher resistance of alloy 254SMO to localized corrosion, lower concentrations of oxyanions are necessary for a transition to the inhibition range. For example, the critical concentration of $\mathrm{MoO}_{4}{ }^{2-}$ ions that is necessary to achieve inhibition is lower for $0.4 \mathrm{M} \mathrm{Cl}^{-}$solutions at $60{ }^{\circ} \mathrm{C} \mathrm{(cf.}$ Fig. 20) than that needed for alloy 690 in $0.04 \mathrm{M} \mathrm{Cl}^{-}$solutions at the same temperature.

Figures 23 - 25 summarize the repassivation potentials for the 2205 duplex stainless steel. Figure 23 indicates that the behavior of $\mathrm{E}_{\mathrm{rp}}$ as a function of chloride activity is substantially different from that observed for the other alloys. While the repassivation potential is fairly low and similar to that for alloys $316 \mathrm{~L}$ or 600 at higher $\mathrm{Cl}^{-}$activities, it is substantially higher in more dilute chloride solutions. This results in a very pronounced high-slope segment of the $\mathrm{E}_{\mathrm{rp}}$ plot against chloride activity. Figures 24 and 25 show the effect of molybdate and sulfate ions, respectively. The oxyanion concentration that is necessary for the transition to the inhibition range is similar to that observed for alloy 254SMO.

In the case of alloy 22, the analysis has been performed on the basis of previously published data (Dunn et al., 2005, Anderko et al. 2004). The experimental $\mathrm{E}_{\mathrm{rp}}$ data for this alloy are particularly comprehensive and cover the range from $313 \mathrm{~K}$ to $448 \mathrm{~K}$ as shown in Figure 26. Due to its high Mo and W content, alloy 22 has the highest resistance to localized corrosion among the alloys studied here. This manifests itself in 
substantially higher $E_{\mathrm{rp}}$ values, most of which lie on the high-slope segment of the $\mathrm{E}_{\mathrm{rp}} \mathrm{vs}$. chloride activity diagram. This is in contrast with the lower alloys, for which the lowslope segment covers most of the practically important chloride activity (or concentration) range and the high-slope segment extends only over dilute solutions. For this alloy, the experimental data on the effect of oxyanions are limited to nitrates. The effect of nitrates on the repassivation potential is shown in Figure 27 for temperatures ranging from $353 \mathrm{~K}$ to $383 \mathrm{~K}$. As a result of the high resistance of alloy 22 to localized corrosion, inhibition can be achieved even at elevated temperatures in concentrated chloride solutions (e.g., $4 \mathrm{M} \mathrm{NaCl}$ and $4 \mathrm{M} \mathrm{MgCl}_{2}$ in Figure 27).

Finally, Figures 28 - 29 show the repassivation potentials of s-13Cr stainless steel in chloride and chloride-nitrate solutions. This alloy has the lowest resistance to localized corrosion among the alloys studied here due to its relatively low Mo and $\mathrm{Cr}$ content. This is evident from the relatively low values of $\mathrm{E}_{\mathrm{rp}}$ in Figure 28, which are below those for 316L SS (Fig. 1) and alloy 600 (Fig. 8). As shown in Figure 29, nitrates inhibit localized corrosion of this alloy in relatively dilute chloride solutions.

For all the investigated alloy - chloride - oxyanion combinations, the model reproduces the experimental data essentially within experimental uncertainty. The strong regularities that are observed in the repassivation behavior of various alloys, coupled with the evident qualitative relationship between the $\mathrm{E}_{\mathrm{rp}}$ values and the amount of alloying elements, indicate that a generalized correlation can be established for calculating the repassivation potential as a function of alloy composition.

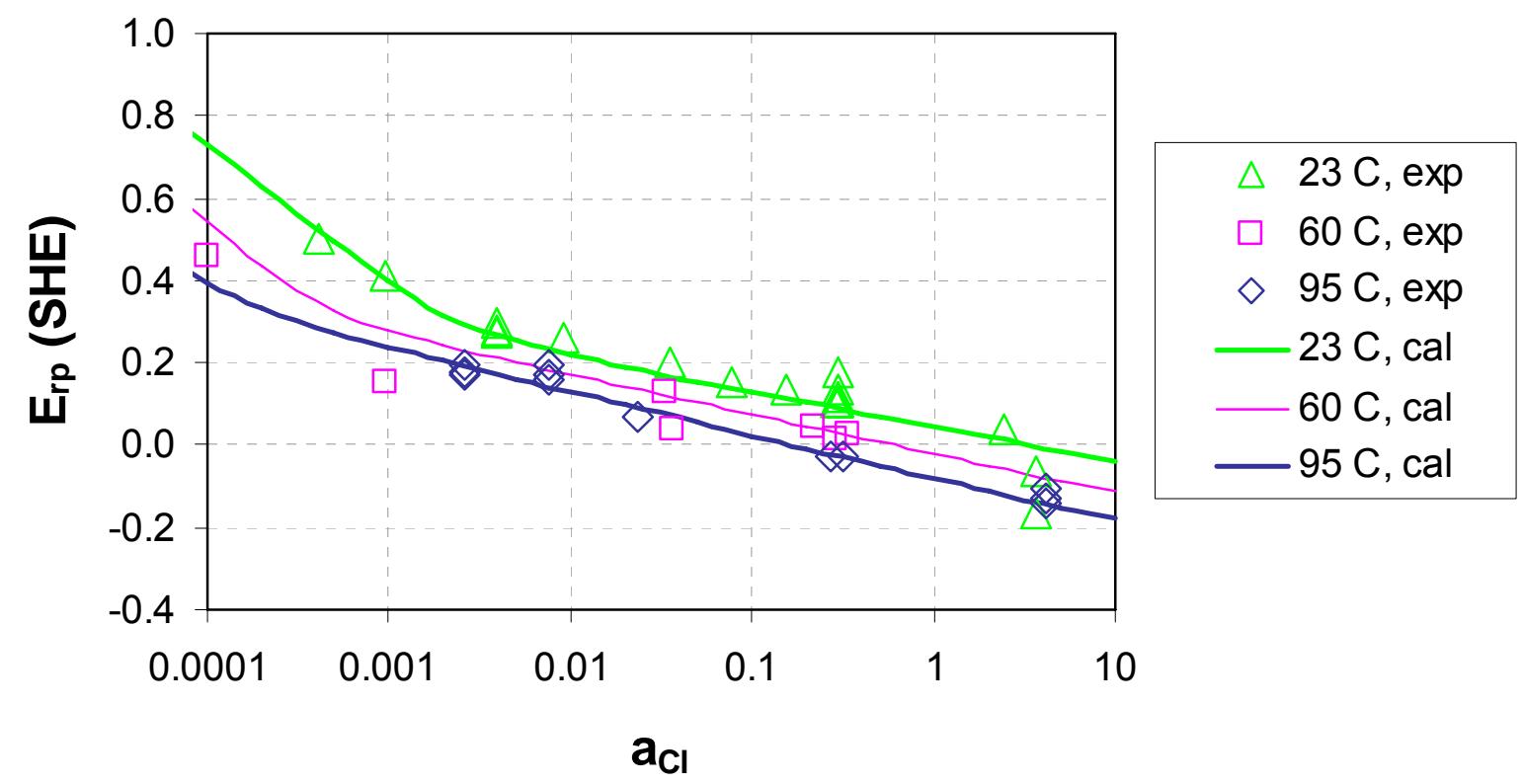

Figure 1. Repassivation potential of type $316 \mathrm{~L}$ stainless steel in chloride solutions as a function chloride ion activity at three temperatures. The symbols denote experimental data reported previously (Anderko et al., 2004) and in the present study. The lines have been obtained from the model. 


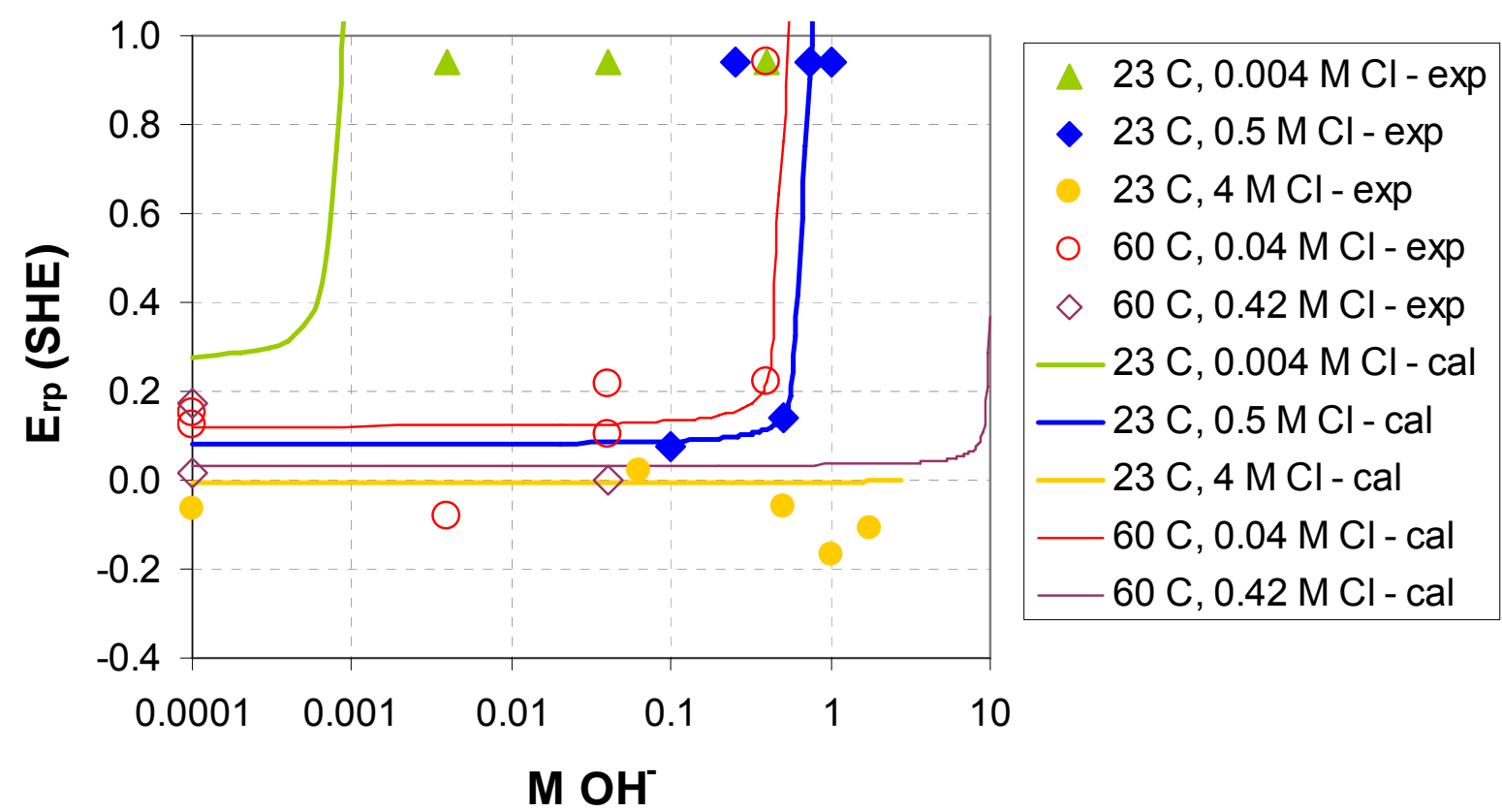

Figure 2. Calculated and experimental repassivation potentials of type 316 stainless steel in aqueous mixtures containing sodium chloride and hydroxide at $23^{\circ} \mathrm{C}$ and $60^{\circ} \mathrm{C}$.

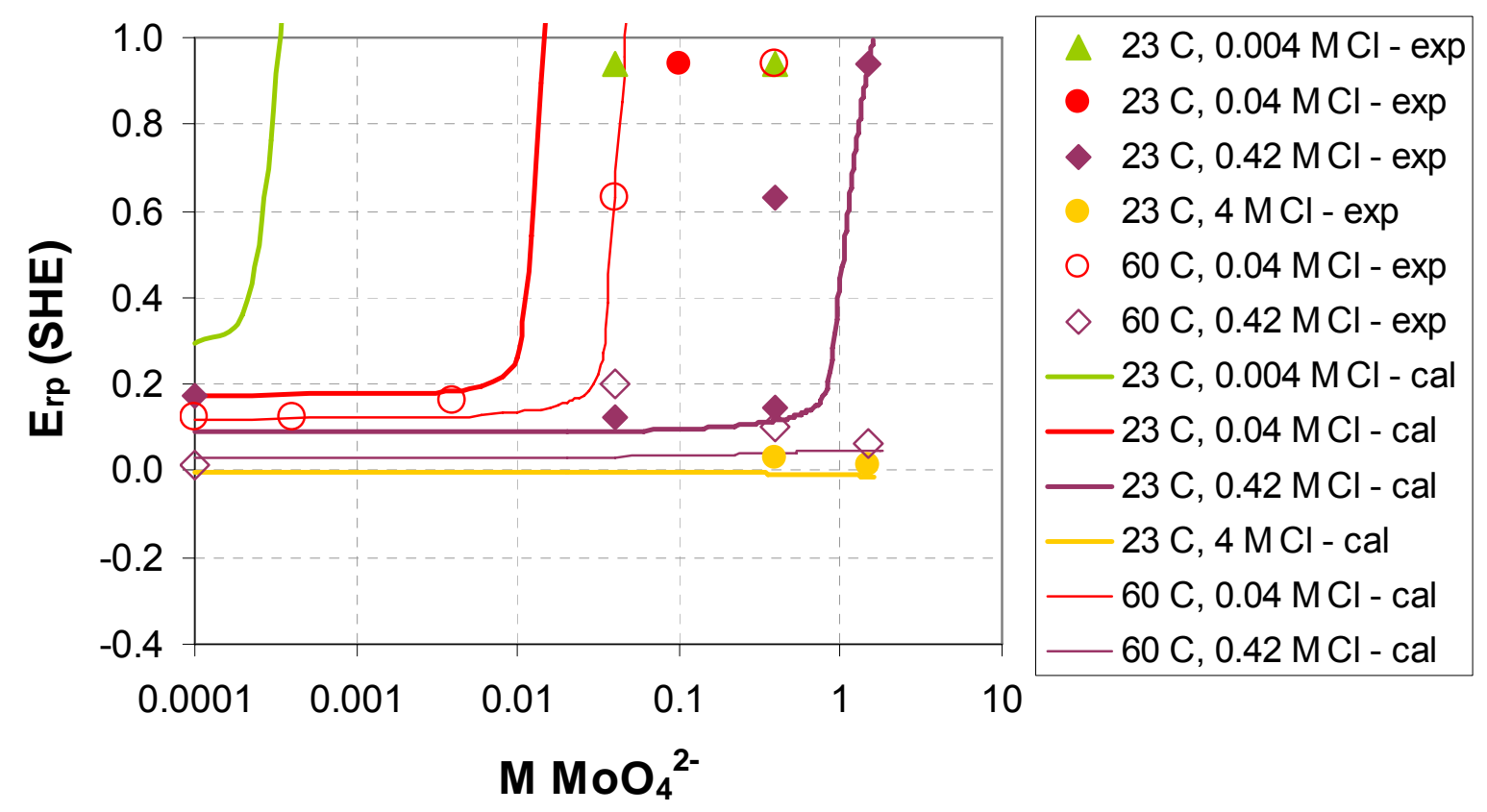

Figure 3. Calculated and experimental repassivation potentials of type 316 stainless steel in solutions containing sodium chloride and molybdate at $23^{\circ} \mathrm{C}$ and $60^{\circ} \mathrm{C}$. 


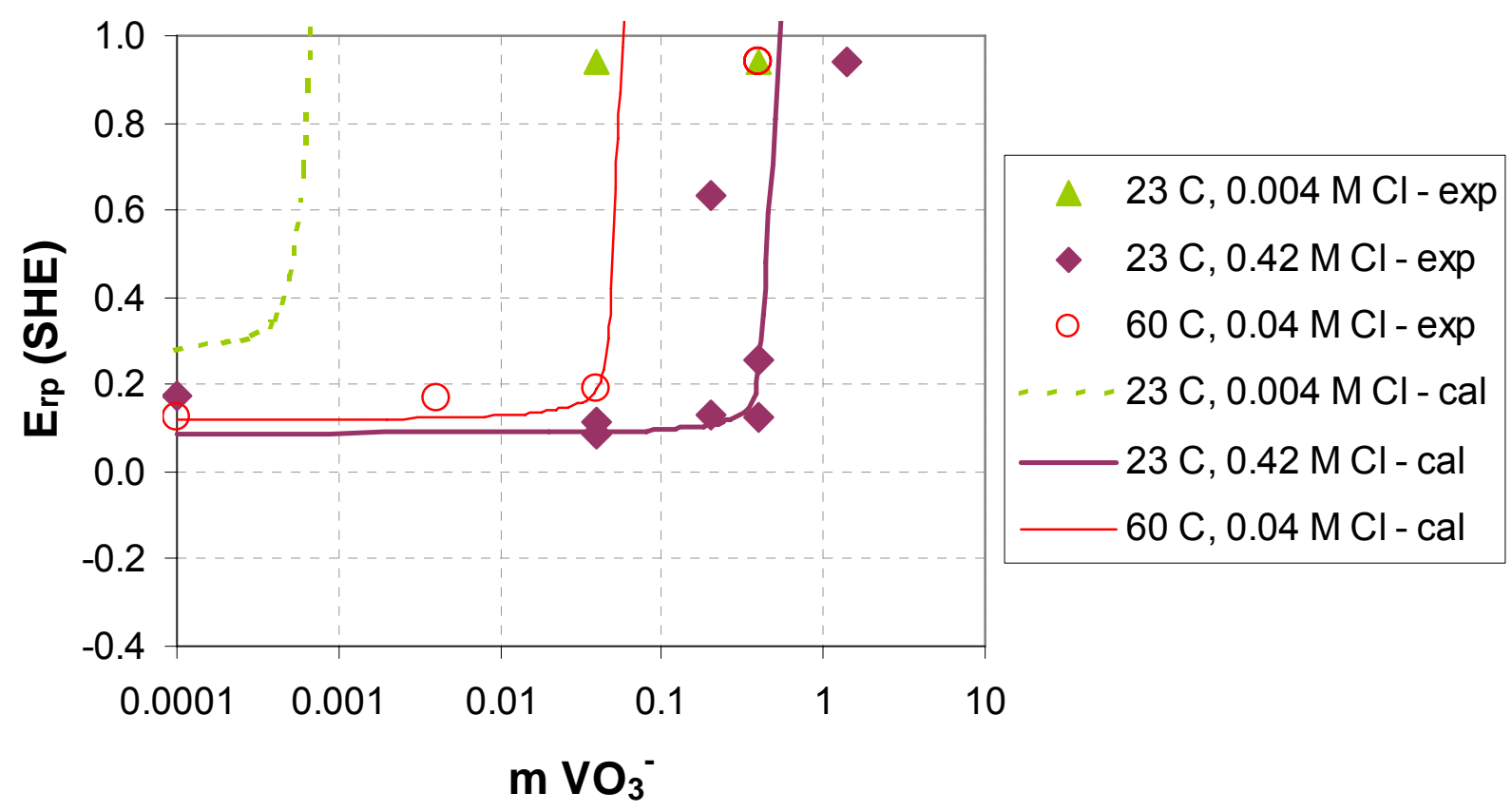

Figure 4. Calculated and experimental repassivation potentials of type $316 \mathrm{~L}$ stainless steel in solutions containing sodium chloride and vanadate at $23^{\circ} \mathrm{C}$ and $60^{\circ} \mathrm{C}$.

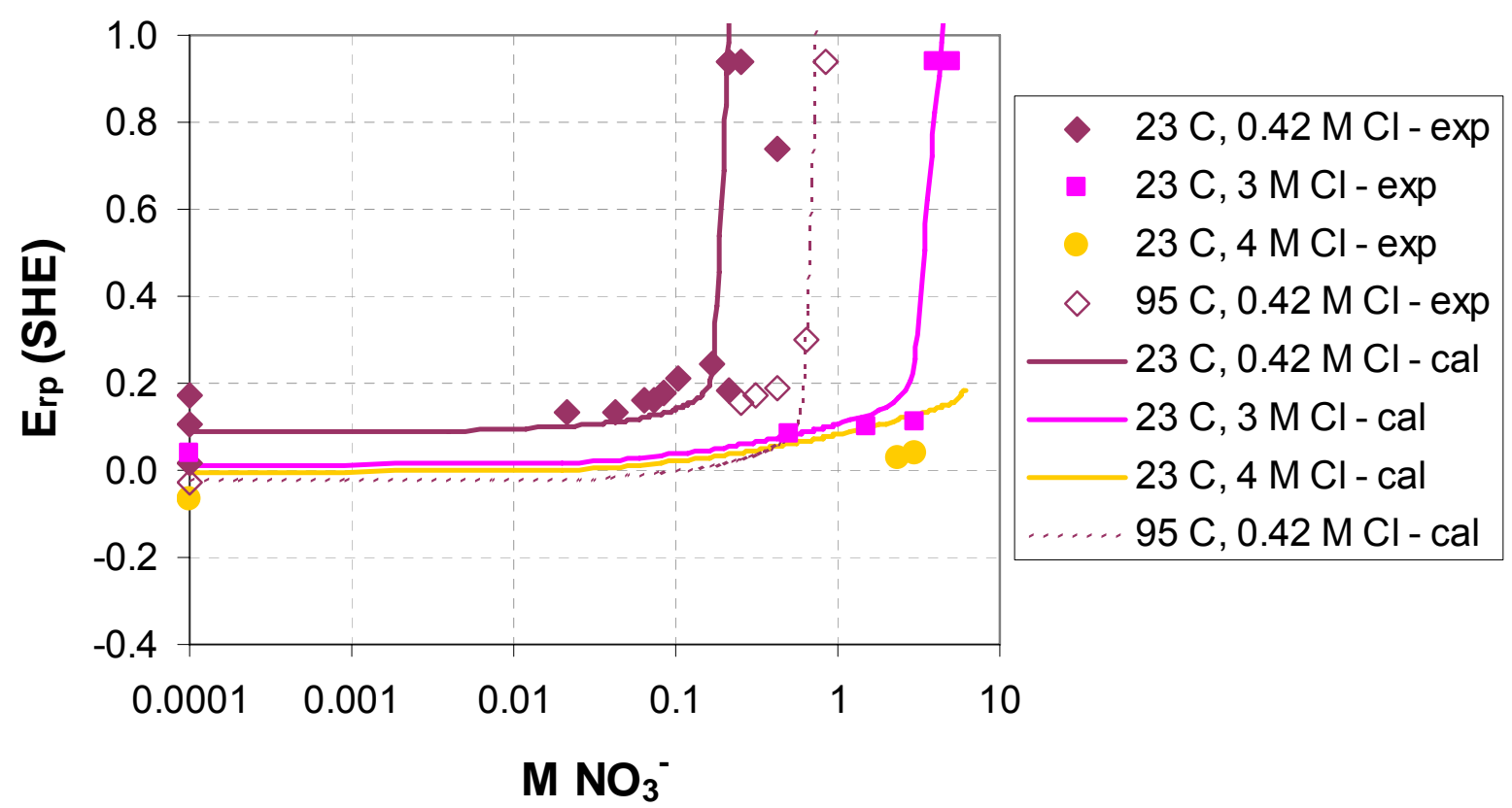

Figure 5. Calculated and experimental repassivation potentials of type $316 \mathrm{~L}$ stainless steel in solutions containing sodium chloride and nitrate at $23^{\circ} \mathrm{C}, 60^{\circ} \mathrm{C}$, and $95^{\circ} \mathrm{C}$. 


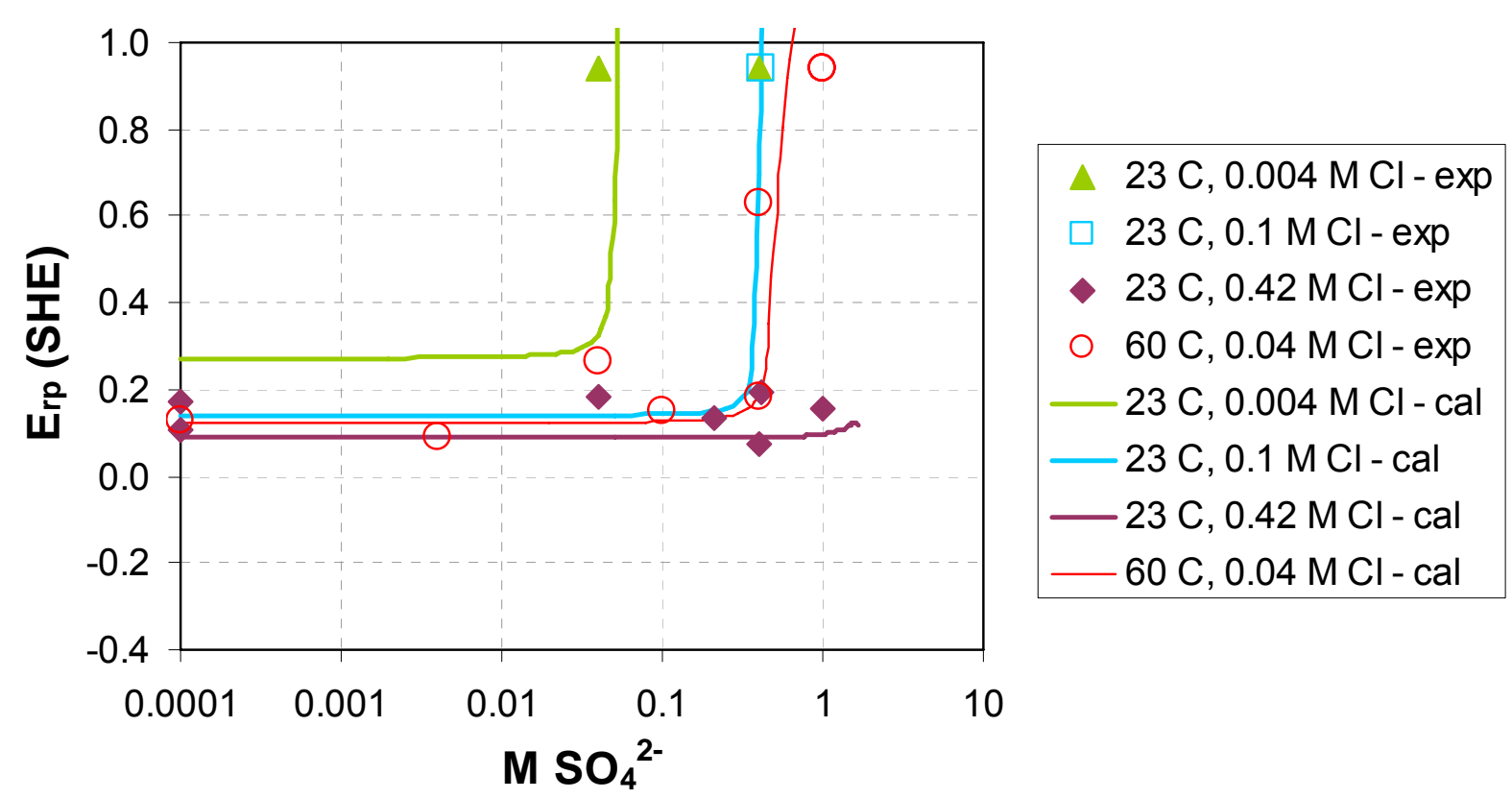

Figure 6. Calculated and experimental repassivation potentials of type $316 \mathrm{~L}$ stainless steel in solutions containing sodium chloride and sulfate at $23^{\circ} \mathrm{C}$ and $60^{\circ} \mathrm{C}$.

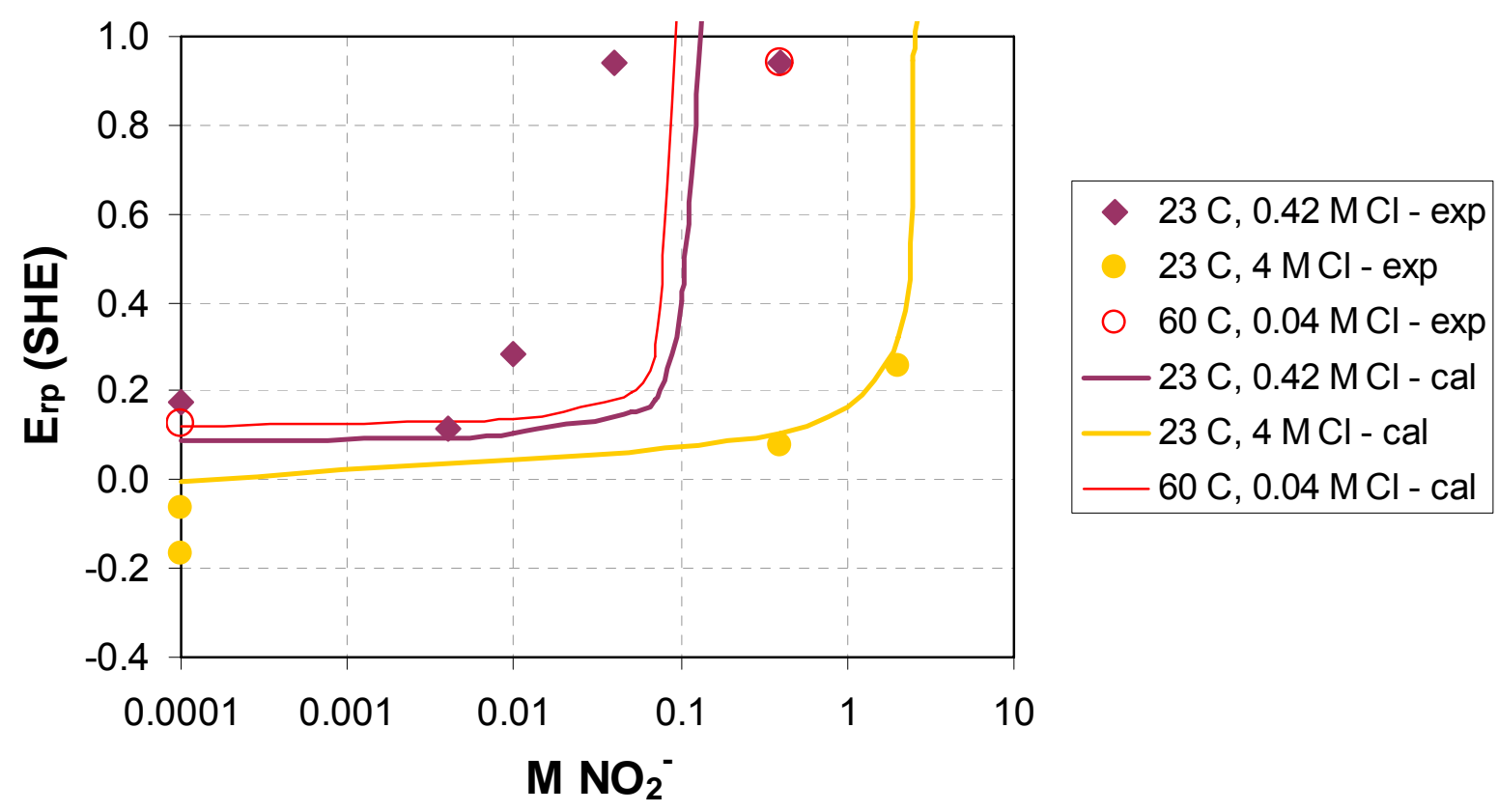

Figure 7. Calculated and experimental repassivation potentials of type $316 \mathrm{~L} \mathrm{SS}$ in solutions containing sodium chloride and nitrite at $23^{\circ} \mathrm{C}$ and $60^{\circ} \mathrm{C}$. 


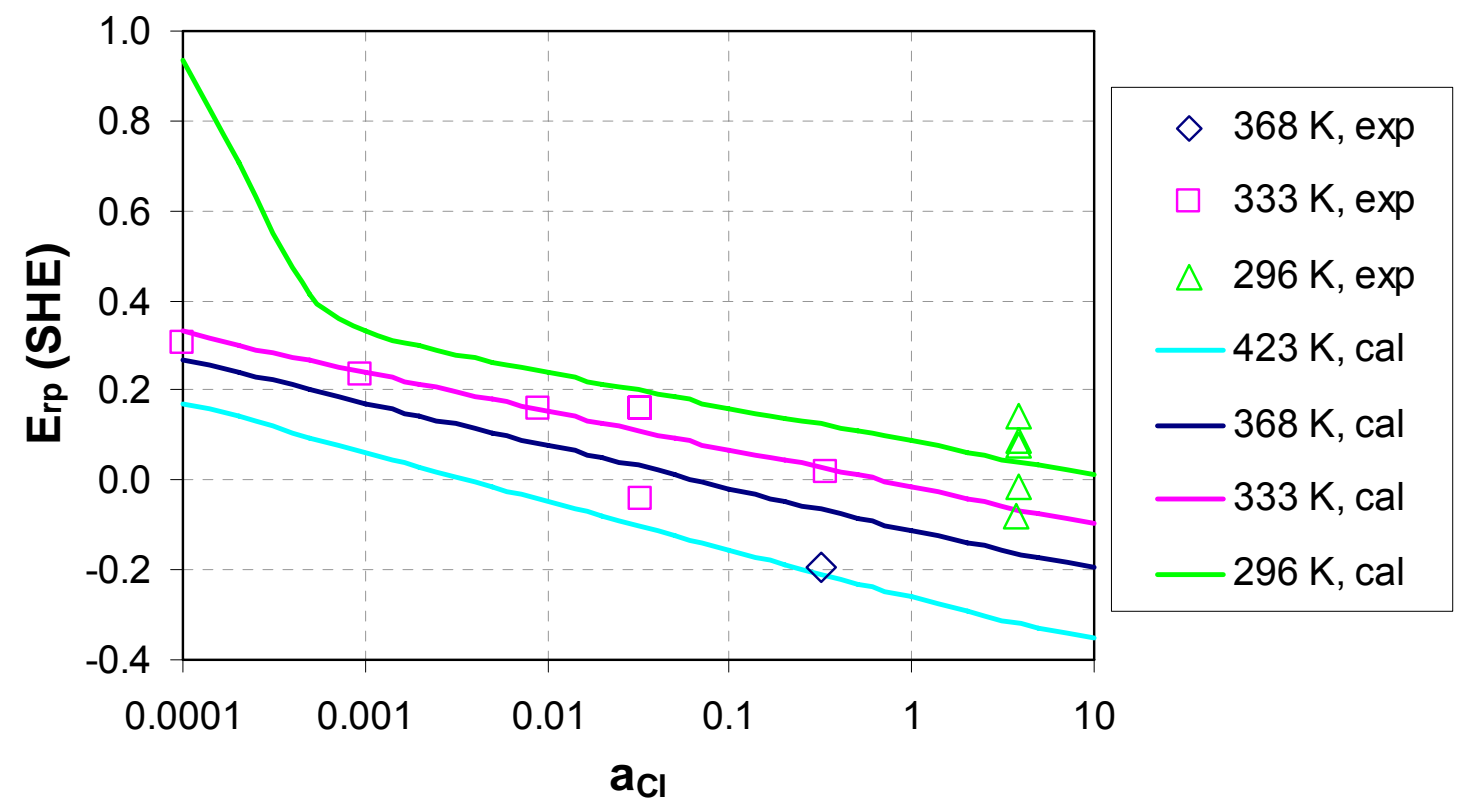

Figure 8. Repassivation potential of alloy 600 as a function of chloride activity at various temperatures.

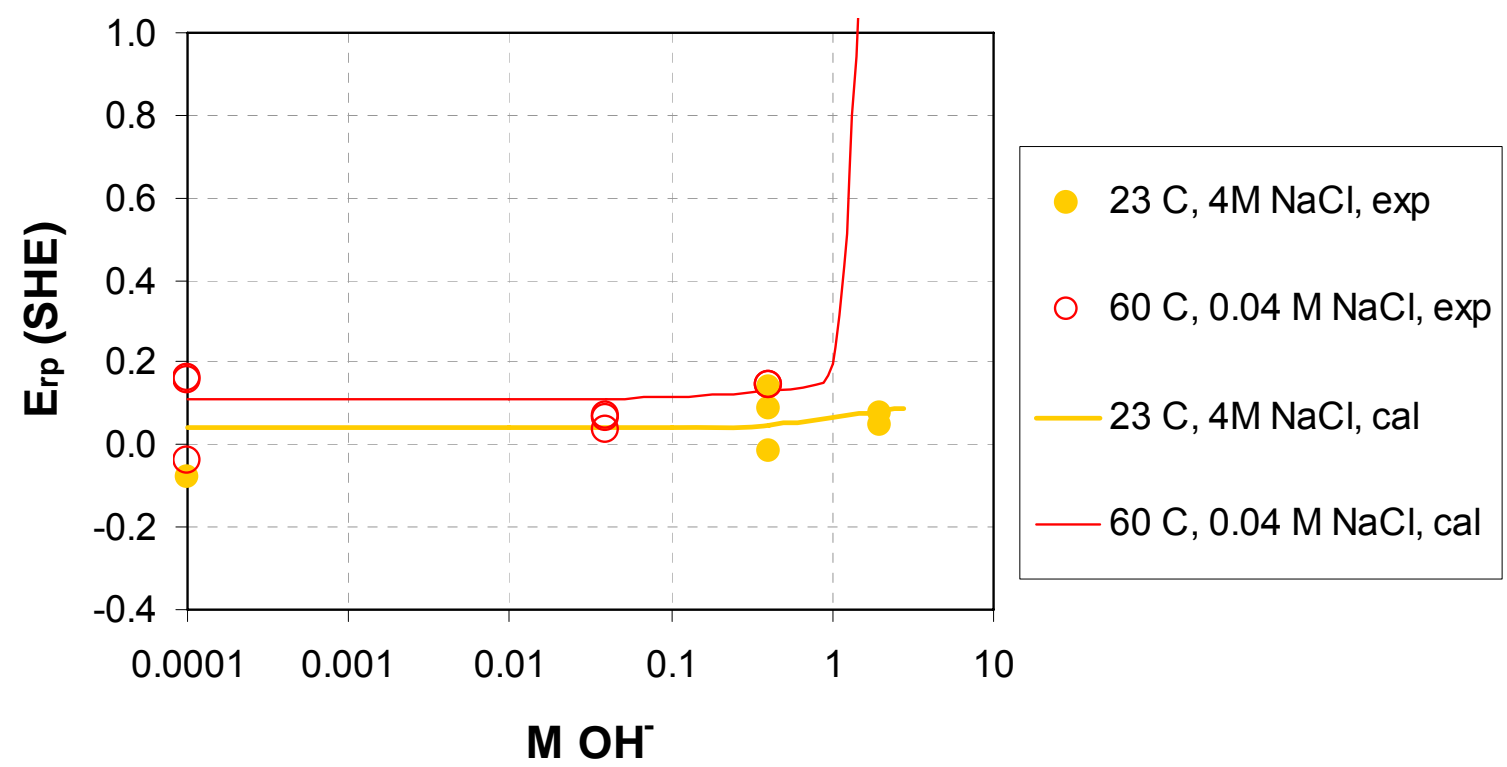

Figure 9. Calculated and experimental repassivation potentials of alloy 600 in mixed chloride - hydroxide solutions at $23^{\circ} \mathrm{C}$ and $60^{\circ} \mathrm{C}$. 


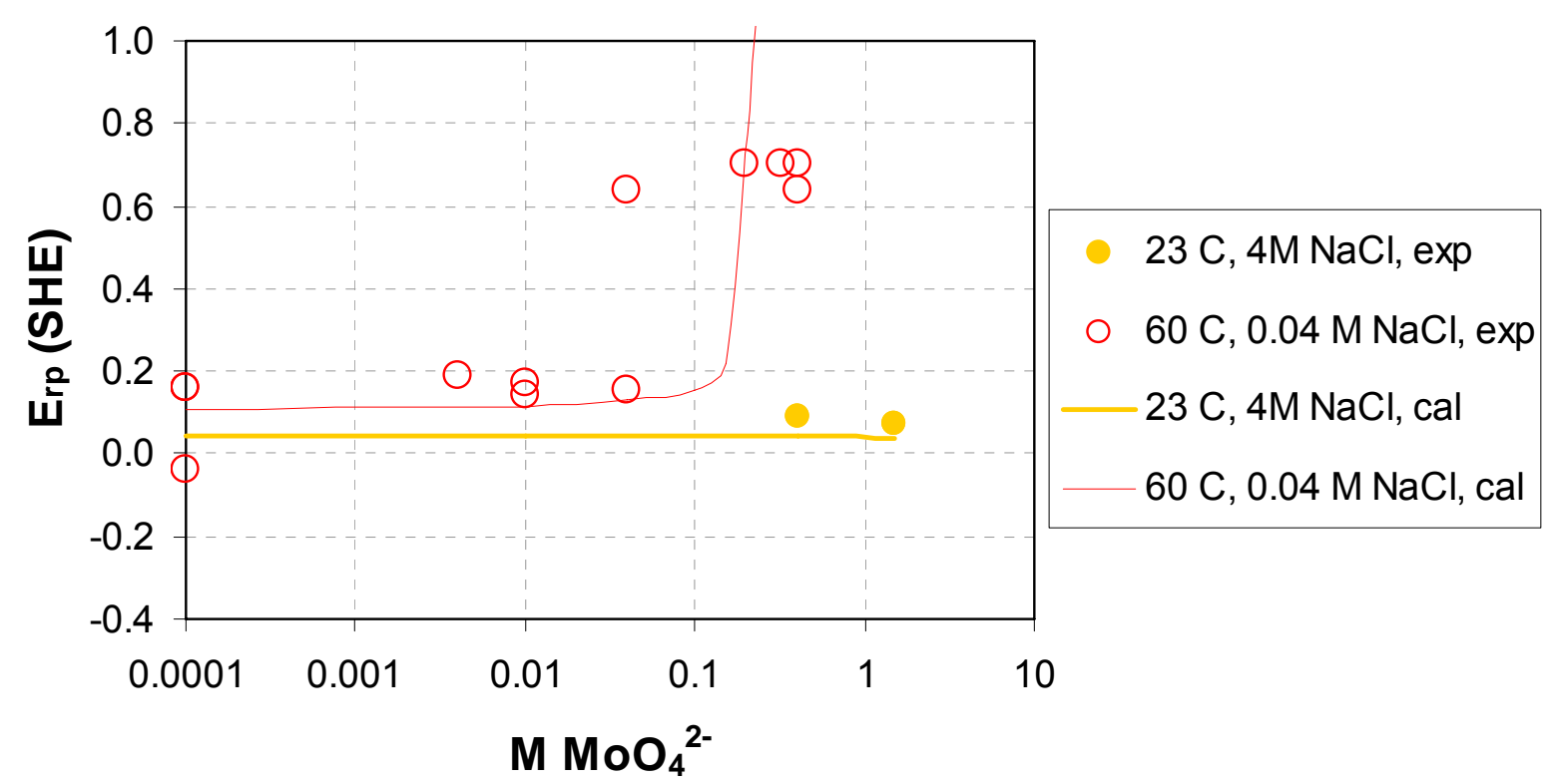

Figure 10. Calculated and experimental repassivation potentials of alloy 600 in mixed chloride - molybdate solutions at $23^{\circ} \mathrm{C}$ and $60^{\circ} \mathrm{C}$.

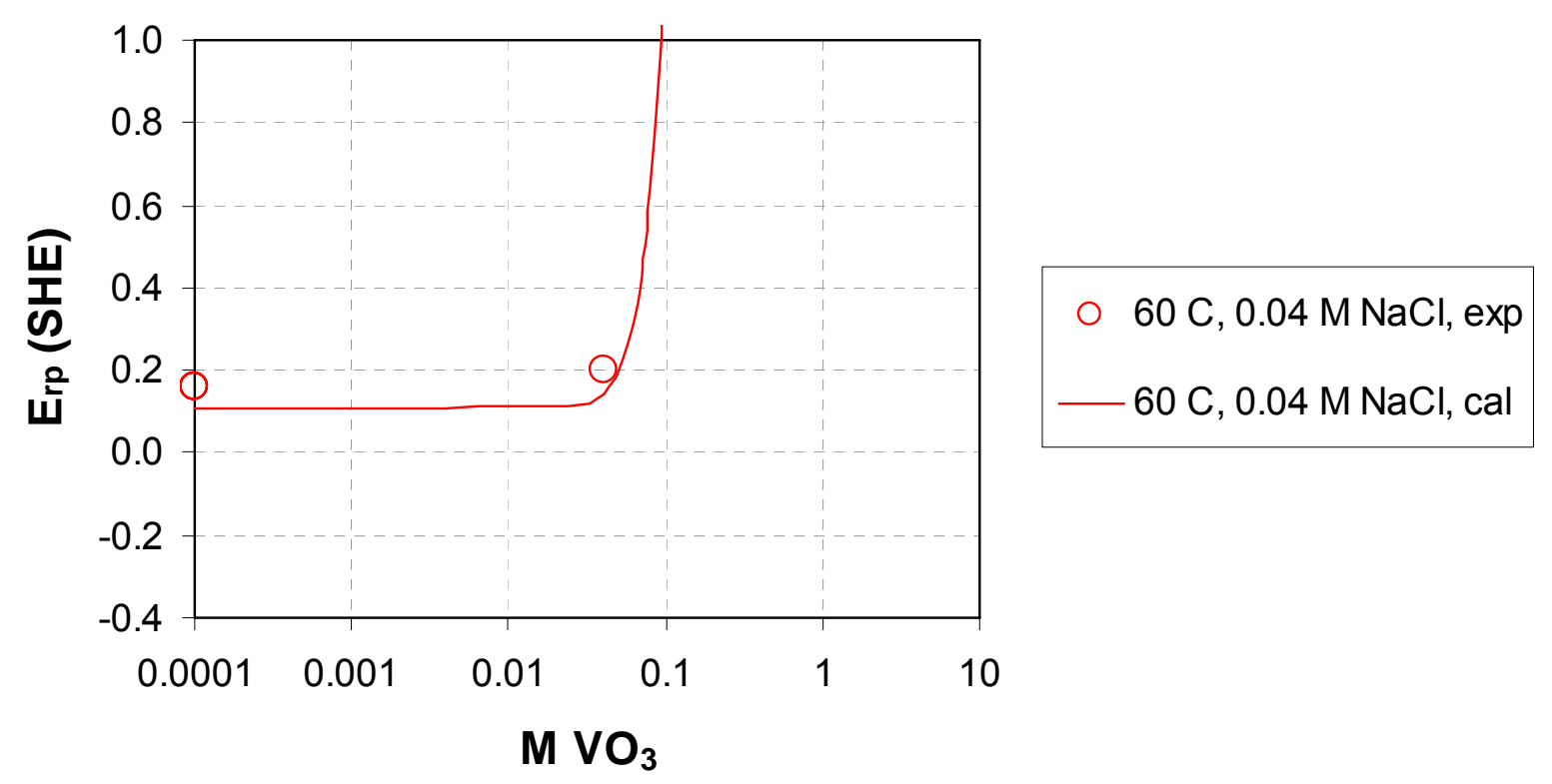

Figure 11. Calculated and experimental repassivation potentials of alloy 600 in mixed chloride - vanadate solutions at $60^{\circ} \mathrm{C}$. 


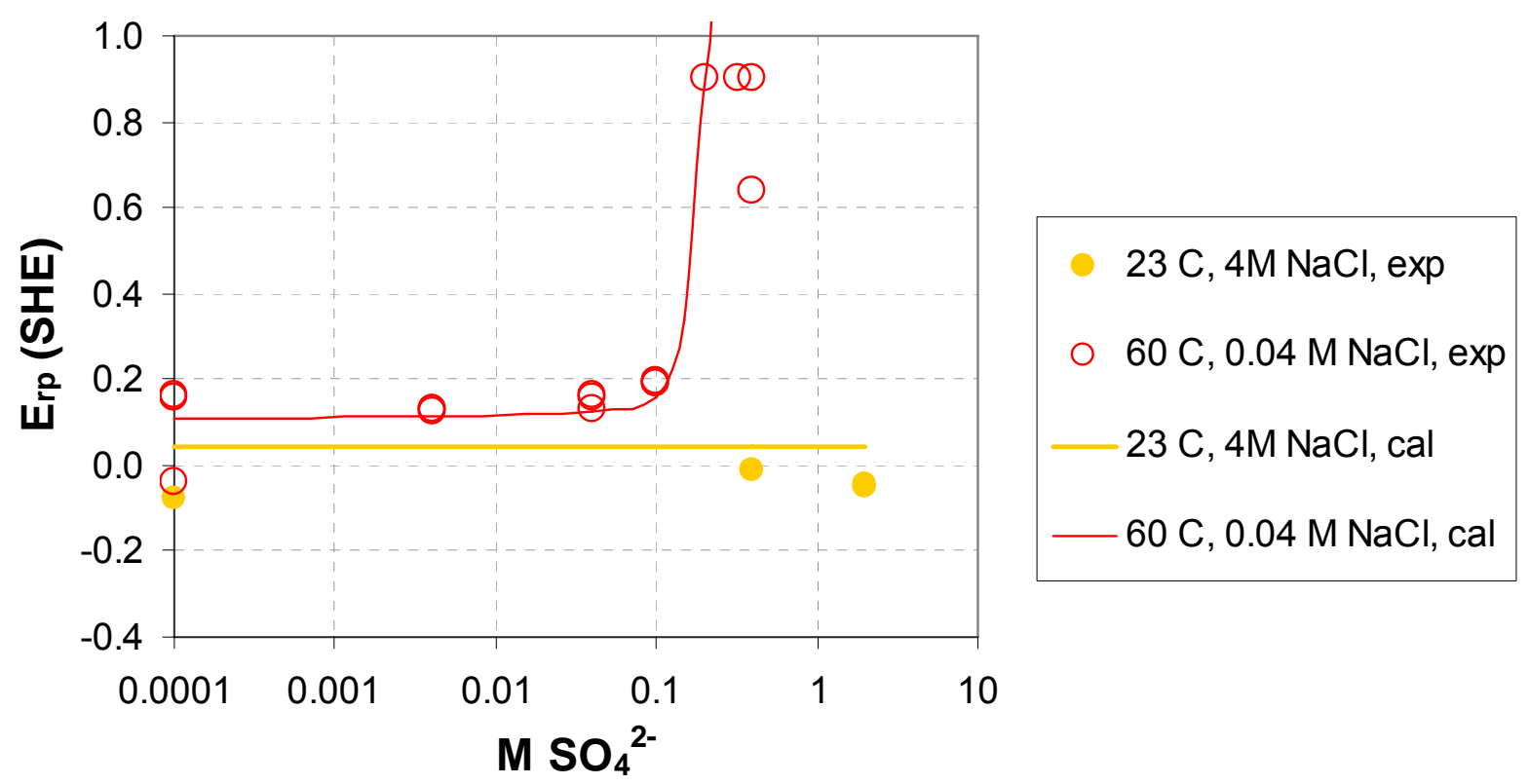

Figure 12. Calculated and experimental repassivation potentials of alloy 600 in mixed chloride-sulfate solutions at $23^{\circ} \mathrm{C}$ and $60^{\circ} \mathrm{C}$.

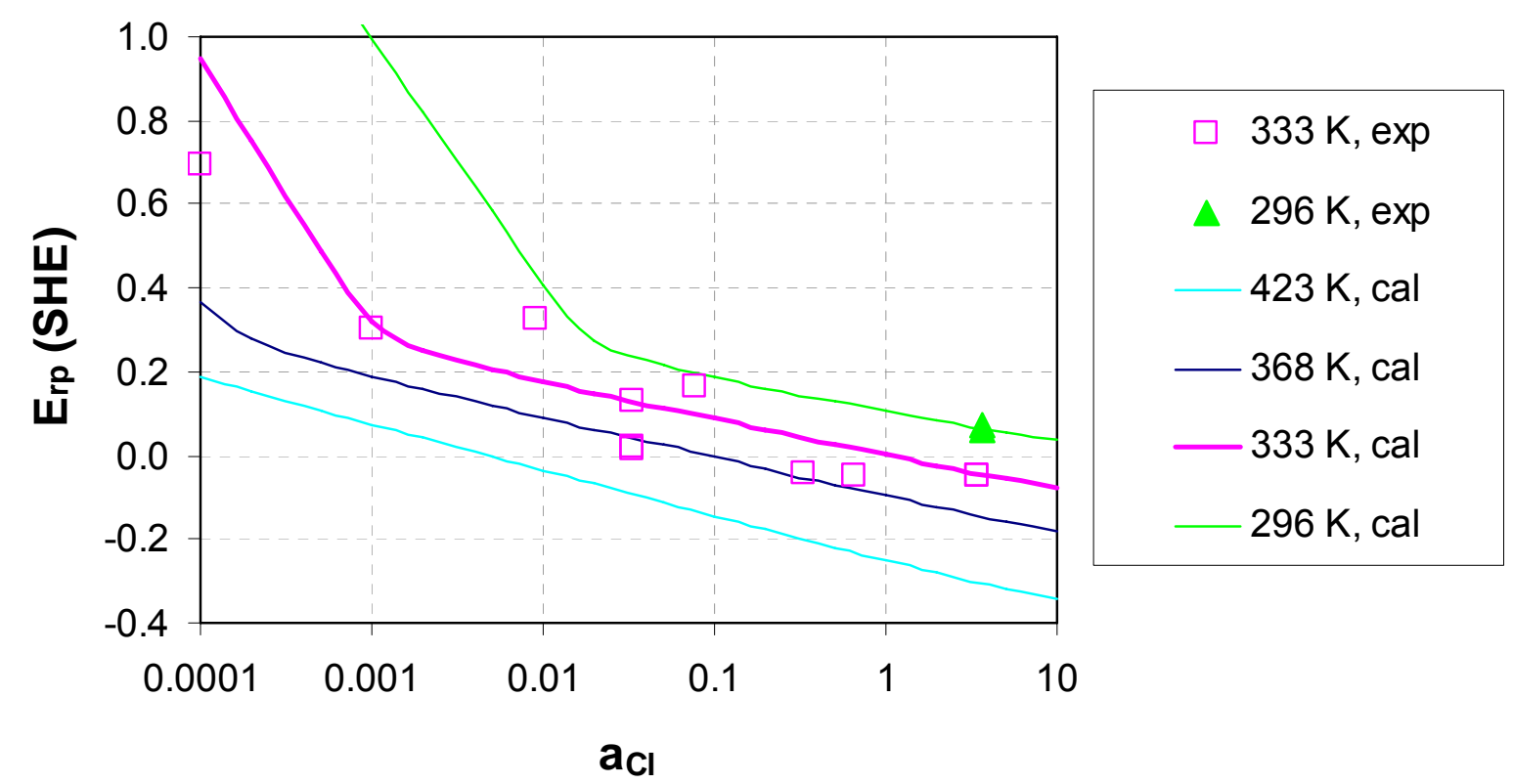

Figure 13. Repassivation potential of alloy 690 as a function of chloride activity and temperature. 


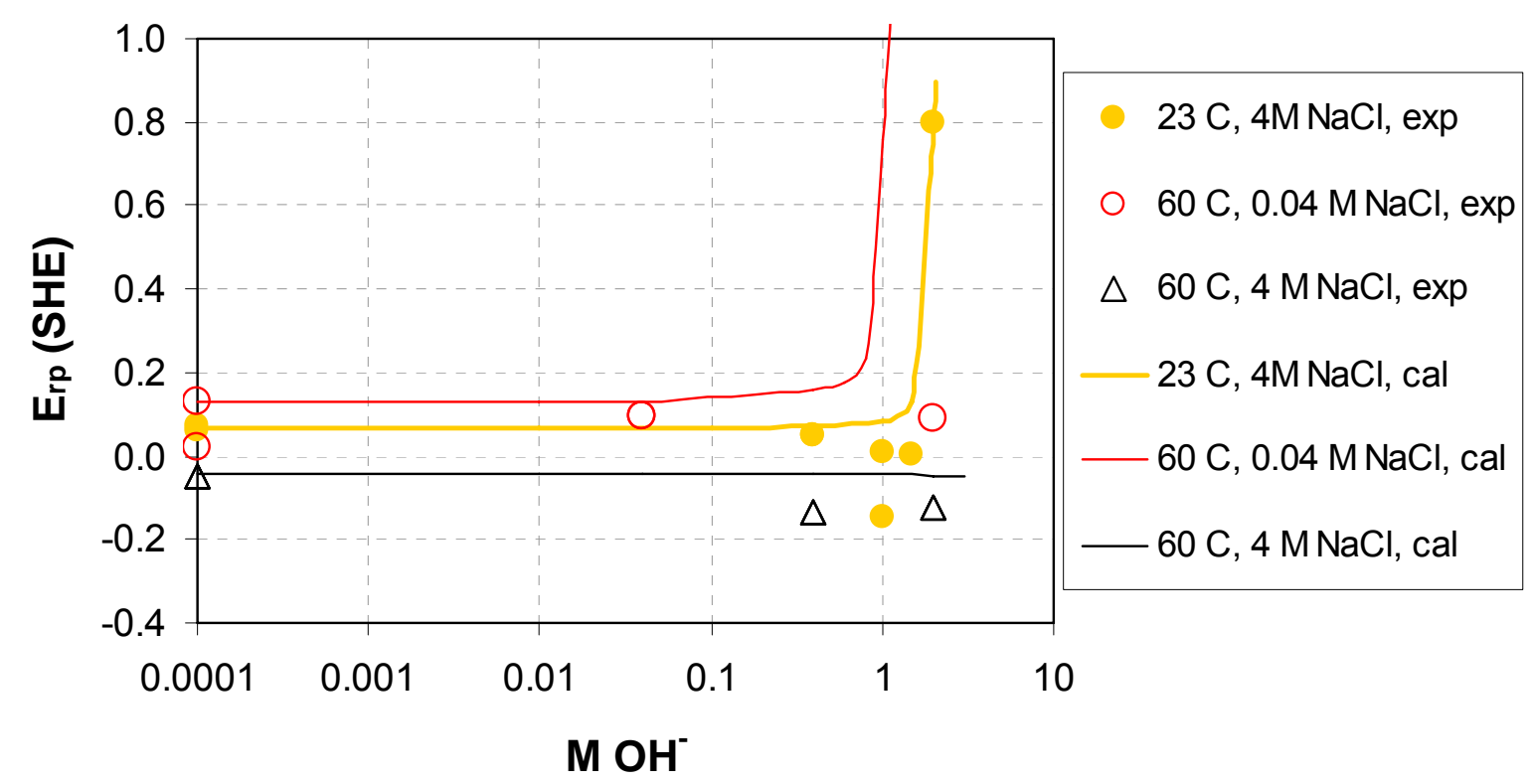

Figure 14. Calculated and experimental repassivation potentials of alloy 690 in mixed chloride - hydroxide solutions at $23^{\circ} \mathrm{C}$ and $60^{\circ} \mathrm{C}$.

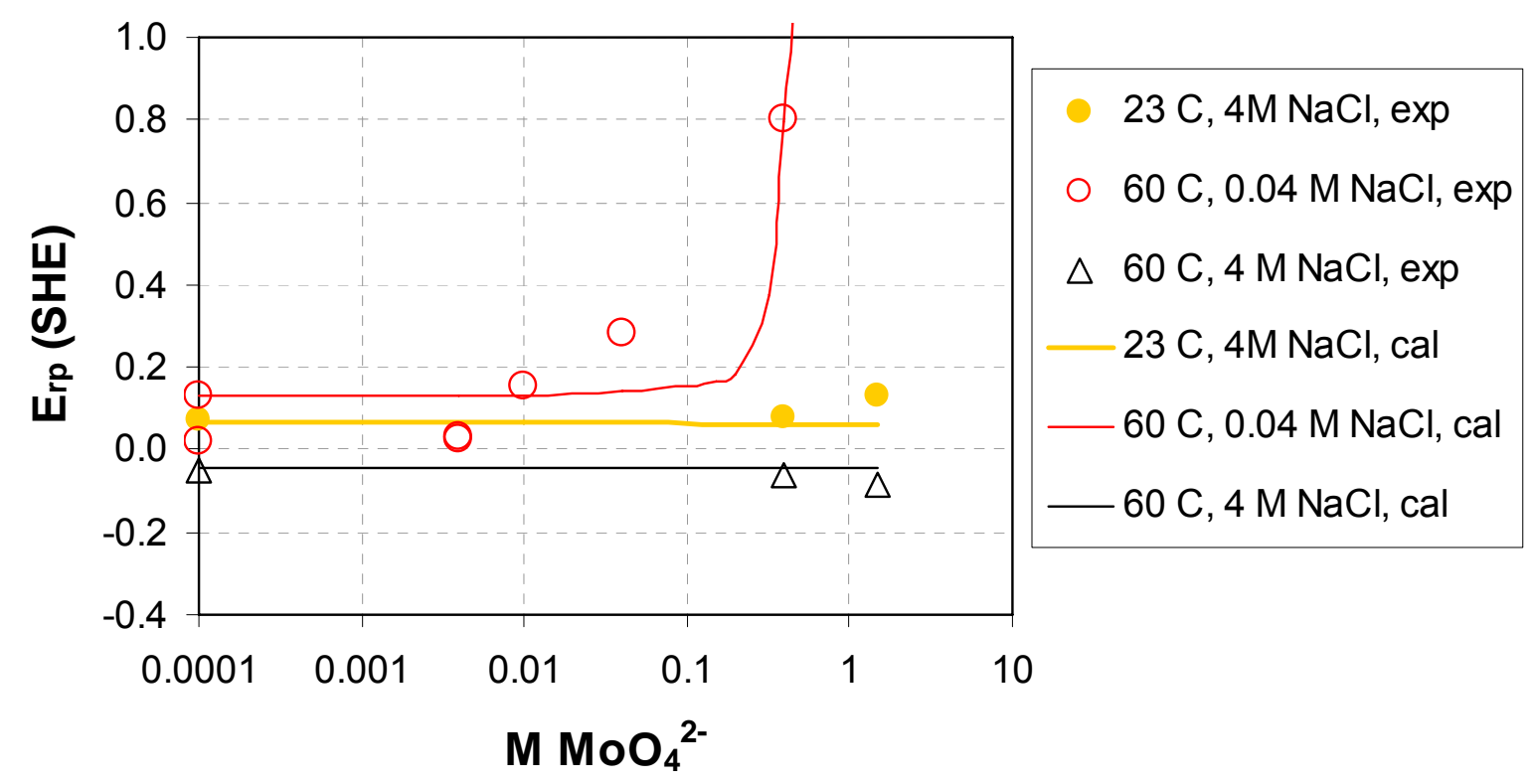

Figure 15. Calculated and experimental repassivation potentials of alloy 690 in mixed chloride - molybdate solutions at $23^{\circ} \mathrm{C}$ and $60^{\circ} \mathrm{C}$. 


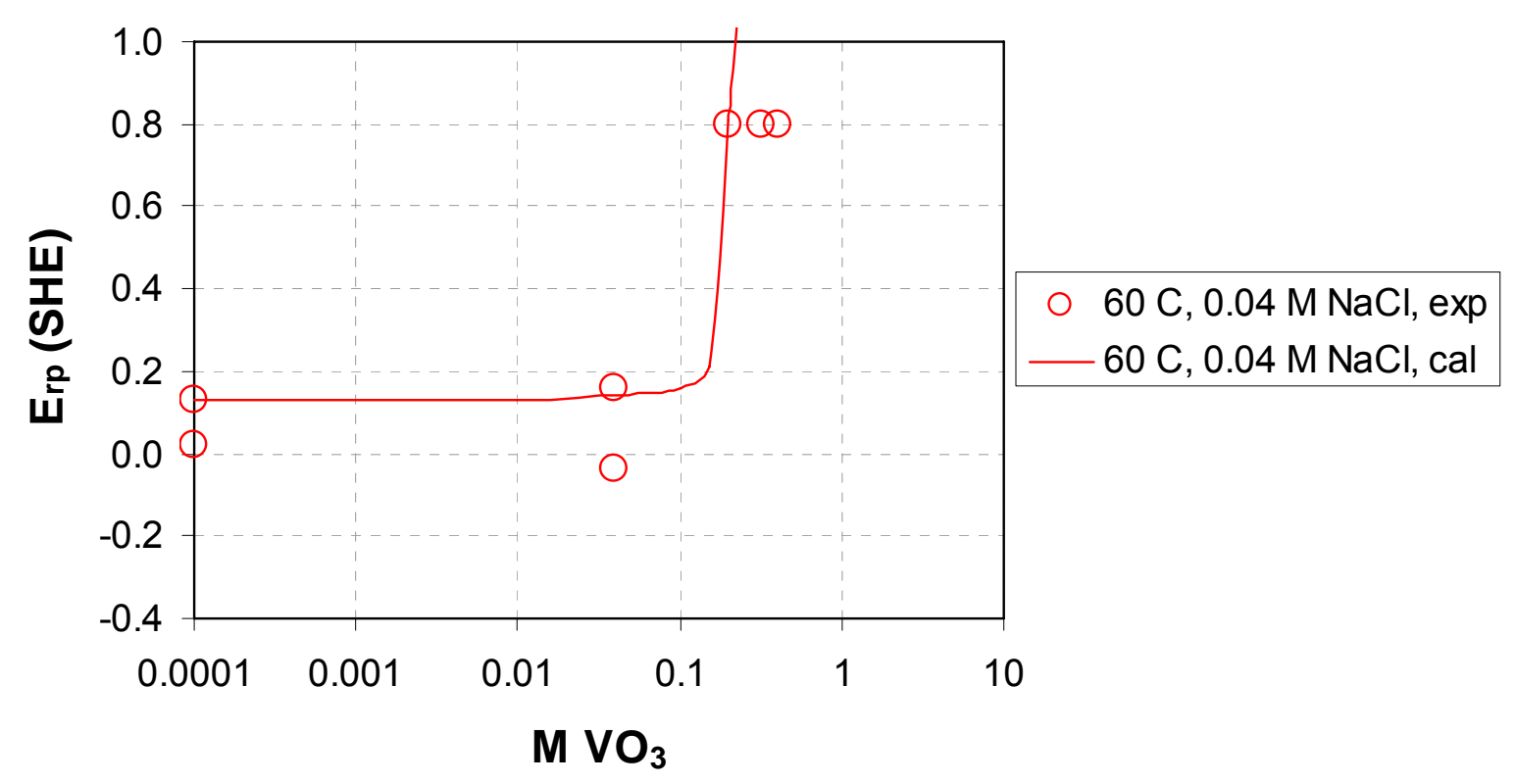

Figure 16. Calculated and experimental repassivation potentials of alloy 690 in mixed chloride - vanadate solutions at $23^{\circ} \mathrm{C}$ and $60^{\circ} \mathrm{C}$.

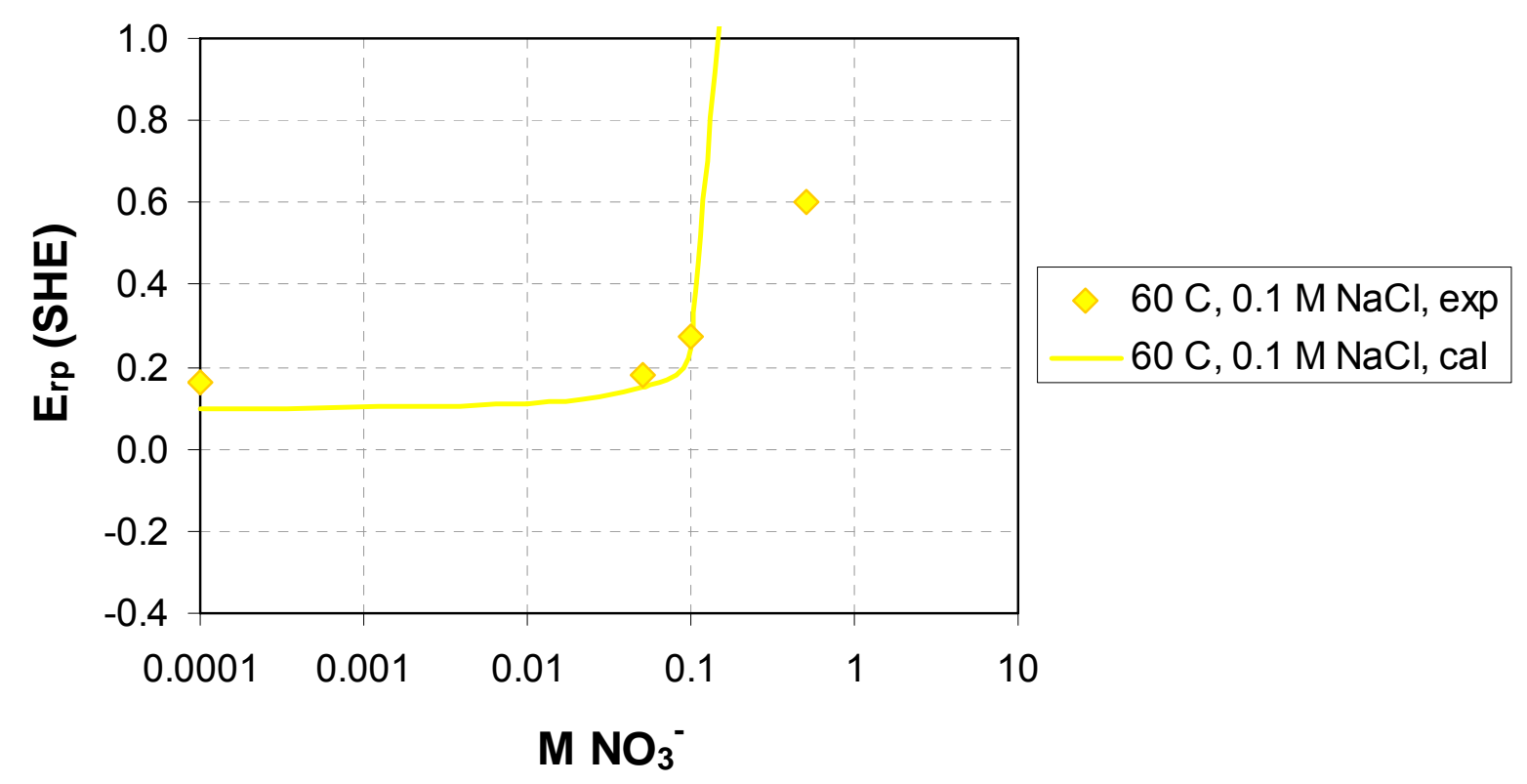

Figure 17. Calculated and experimental repassivation potentials of alloy 690 in mixed chloride - nitrate solutions at $60^{\circ} \mathrm{C}$. 


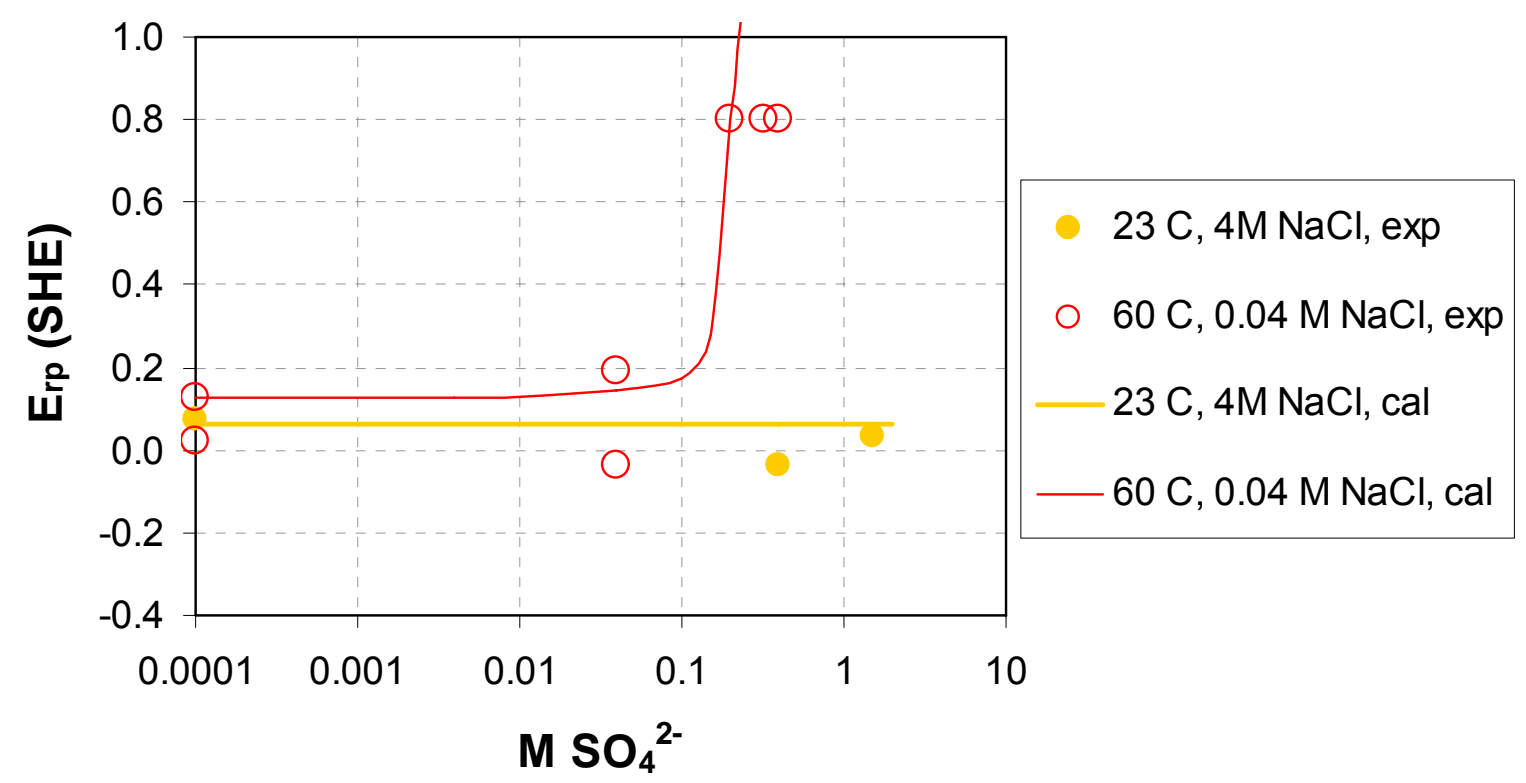

Figure 18. Calculated and experimental repassivation potentials of alloy 690 in mixed chloride - sulfate solutions at $23^{\circ} \mathrm{C}$ and $60^{\circ} \mathrm{C}$.

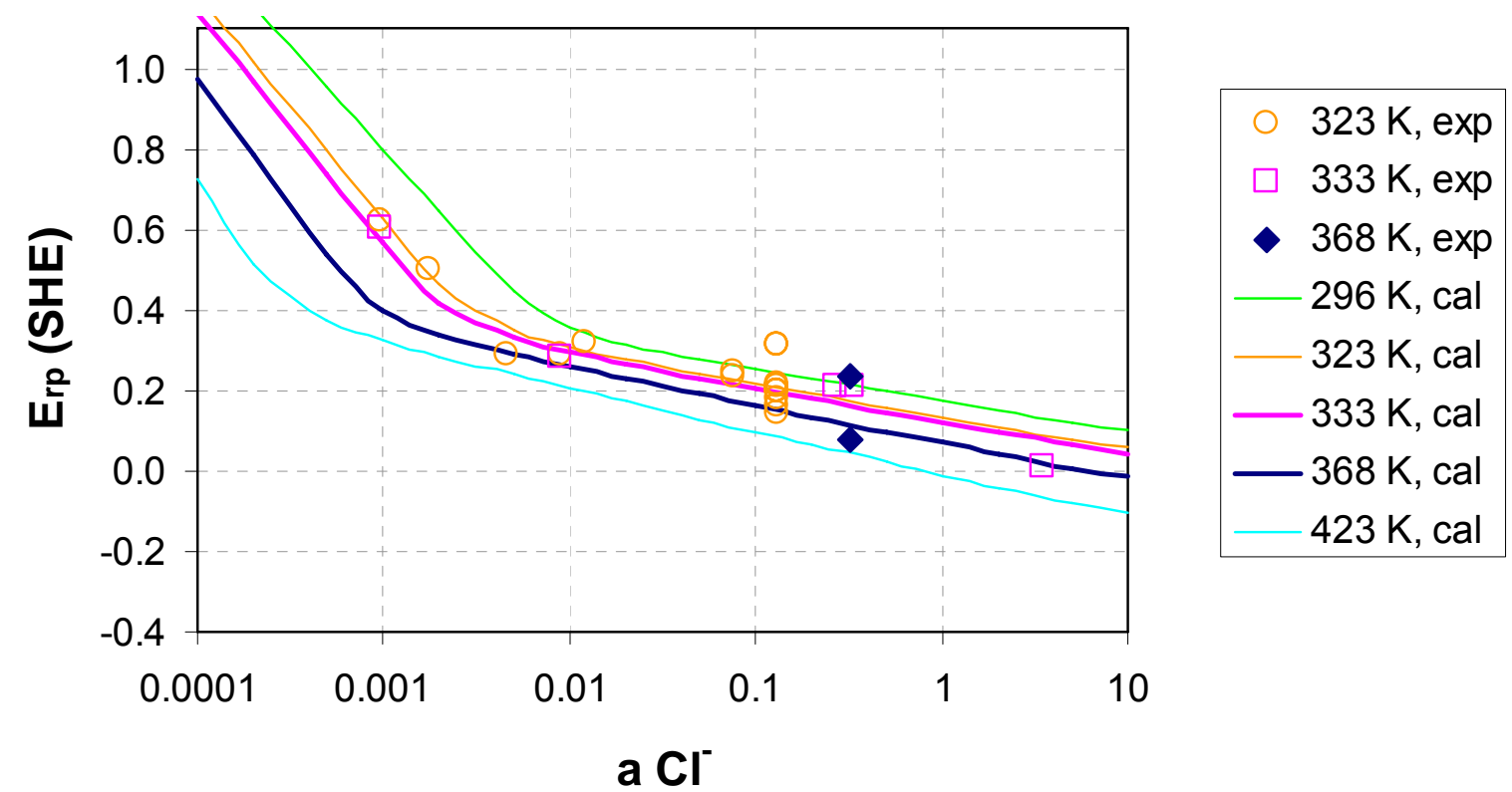

Figure 19. Repassivation potential of alloy 254SMO as a function of chloride activity and temperature. The experimental data are from this study and Sridhar et al. (2004). 


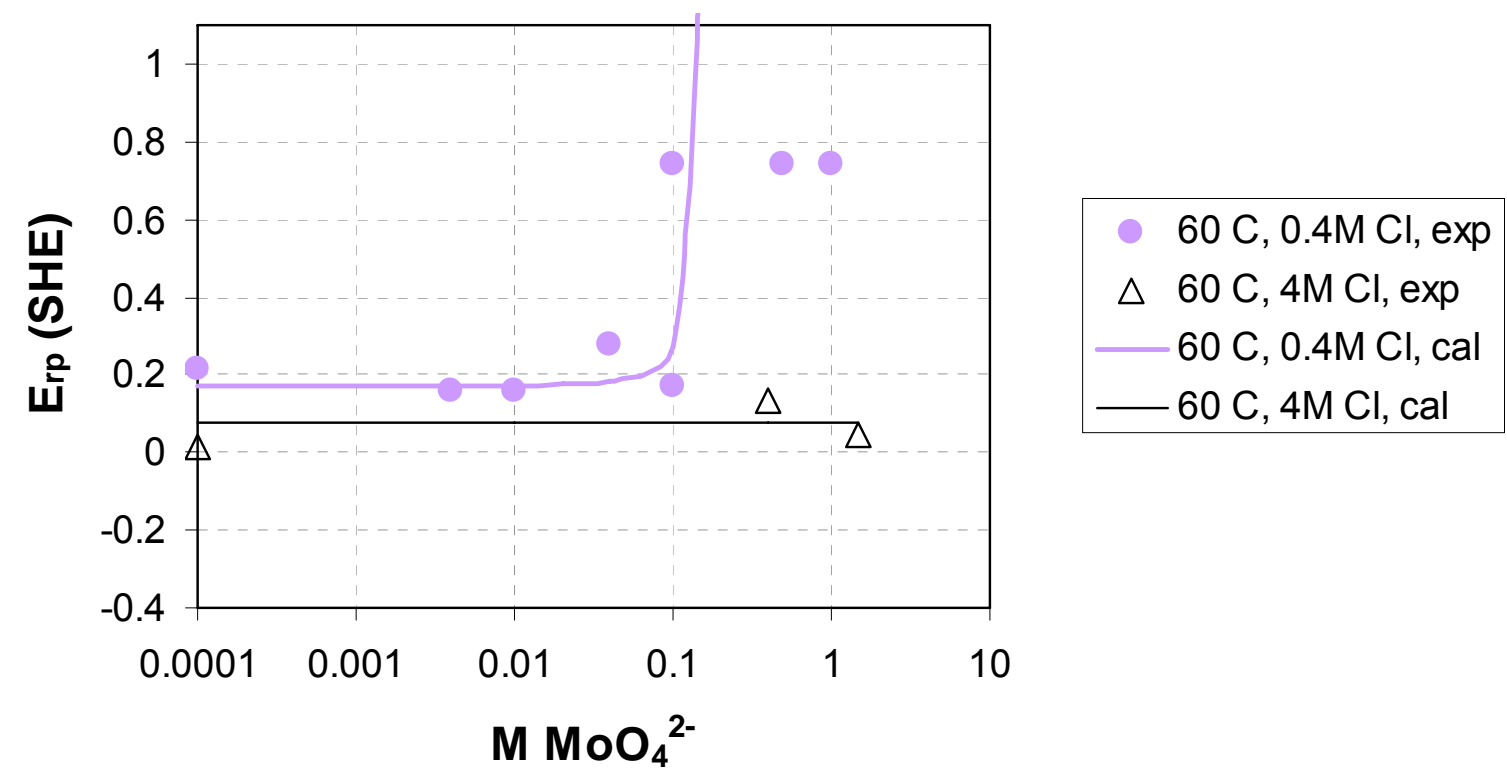

Figure 20. Calculated and experimental repassivation potentials of alloy 254SMO in mixed chloride - molybdate solutions at $60^{\circ} \mathrm{C}$.

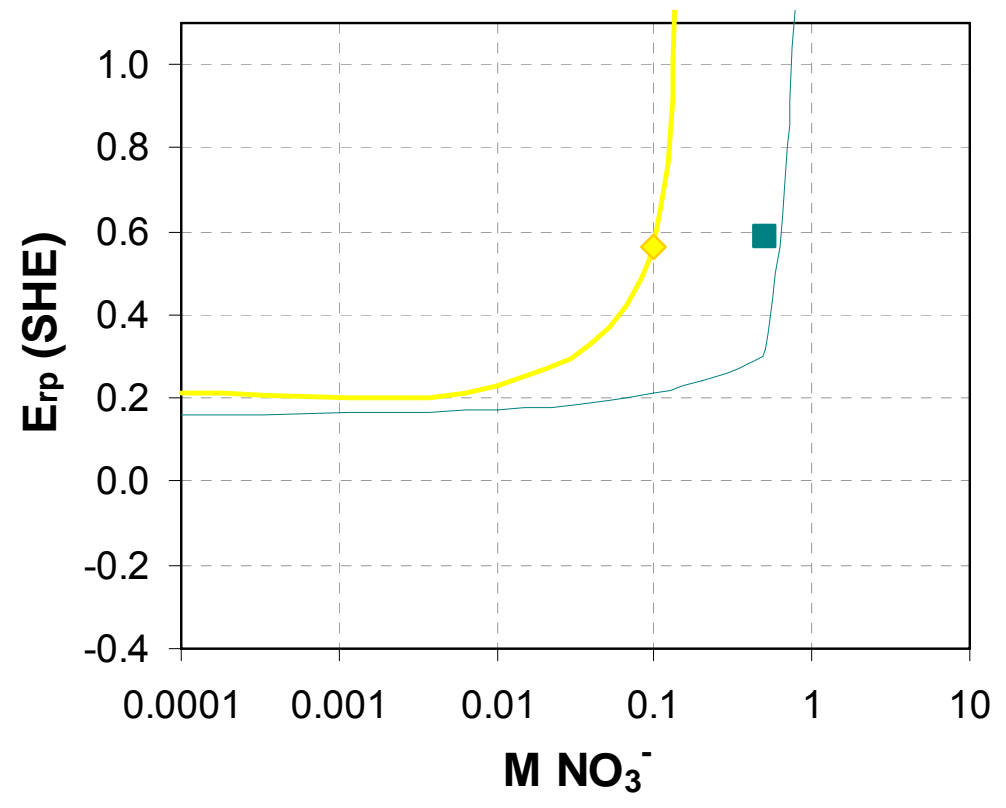

$60 \mathrm{C}, 0.1 \mathrm{M} \mathrm{NaCl}, \exp$

- $60 \mathrm{C}, 0.5 \mathrm{M} \mathrm{Cl}, \exp$ $60 \mathrm{C}, 0.1 \mathrm{M} \mathrm{NaCl}$, cal $60 \mathrm{C}, 0.5 \mathrm{M} \mathrm{Cl}$, cal

Figure 21. Calculated and experimental repassivation potentials of alloy 254SMO in mixed chloride - nitrate solutions at $60^{\circ} \mathrm{C}$. 


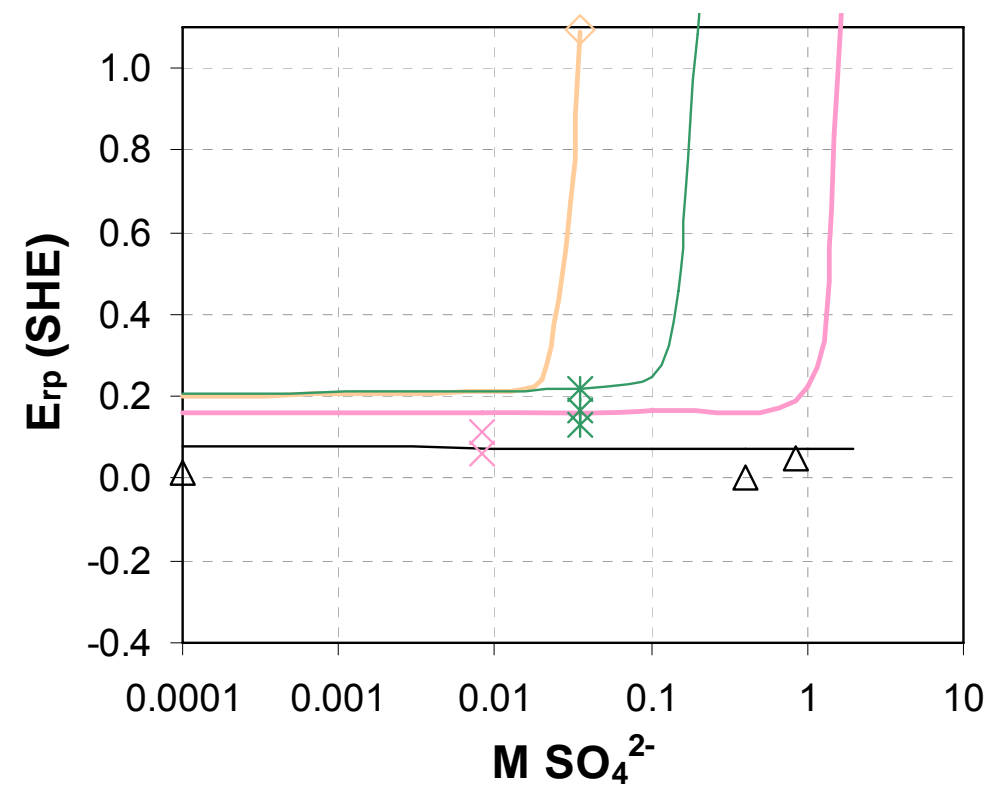

\begin{tabular}{|l}
\hline $23 \mathrm{C}, 0.677 \mathrm{M} \mathrm{Cl}, \exp$ \\
$* 50 \mathrm{C}, 0.169 \mathrm{M} \mathrm{Cl}, \exp$ \\
$\times 50 \mathrm{C}, 0.677 \mathrm{M} \mathrm{Cl}, \exp$ \\
$\triangle 60 \mathrm{C}, 4 \mathrm{M} \mathrm{Cl}, \exp$ \\
$23 \mathrm{C}, 0.677 \mathrm{M} \mathrm{Cl}$, cal \\
$-50 \mathrm{C}, 0.169 \mathrm{M} \mathrm{Cl}$, cal \\
$-50 \mathrm{C}, 0.677 \mathrm{M} \mathrm{Cl}$, cal \\
$-60 \mathrm{C}, 4 \mathrm{M} \mathrm{Cl}, \mathrm{cal}$
\end{tabular}

Figure 22. Calculated and experimental repassivation potentials of alloy 254SMO in mixed chloride - sulfate solutions.

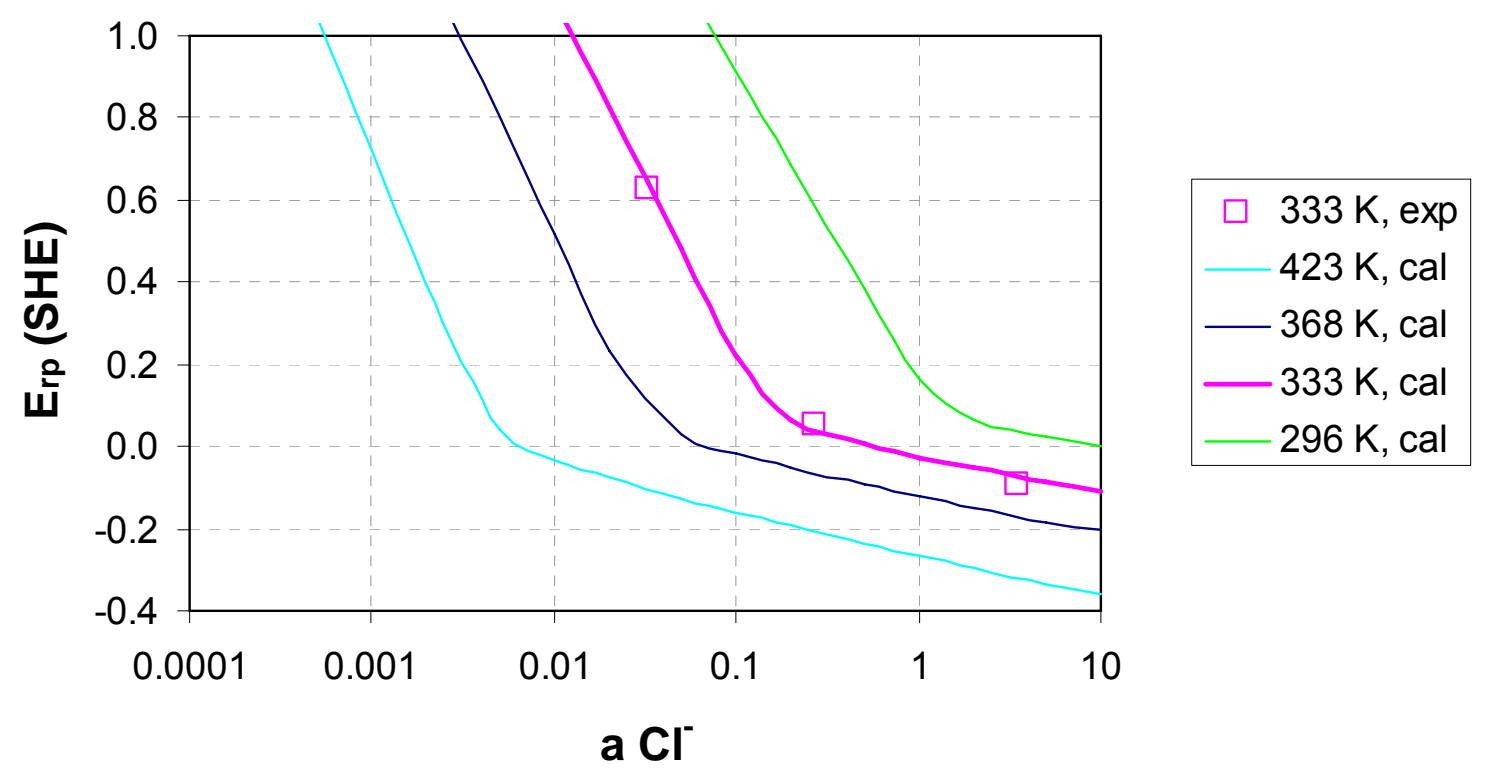

Figure 23. Repassivation potential of type 2205 duplex stainless steel as a function of chloride activity. 


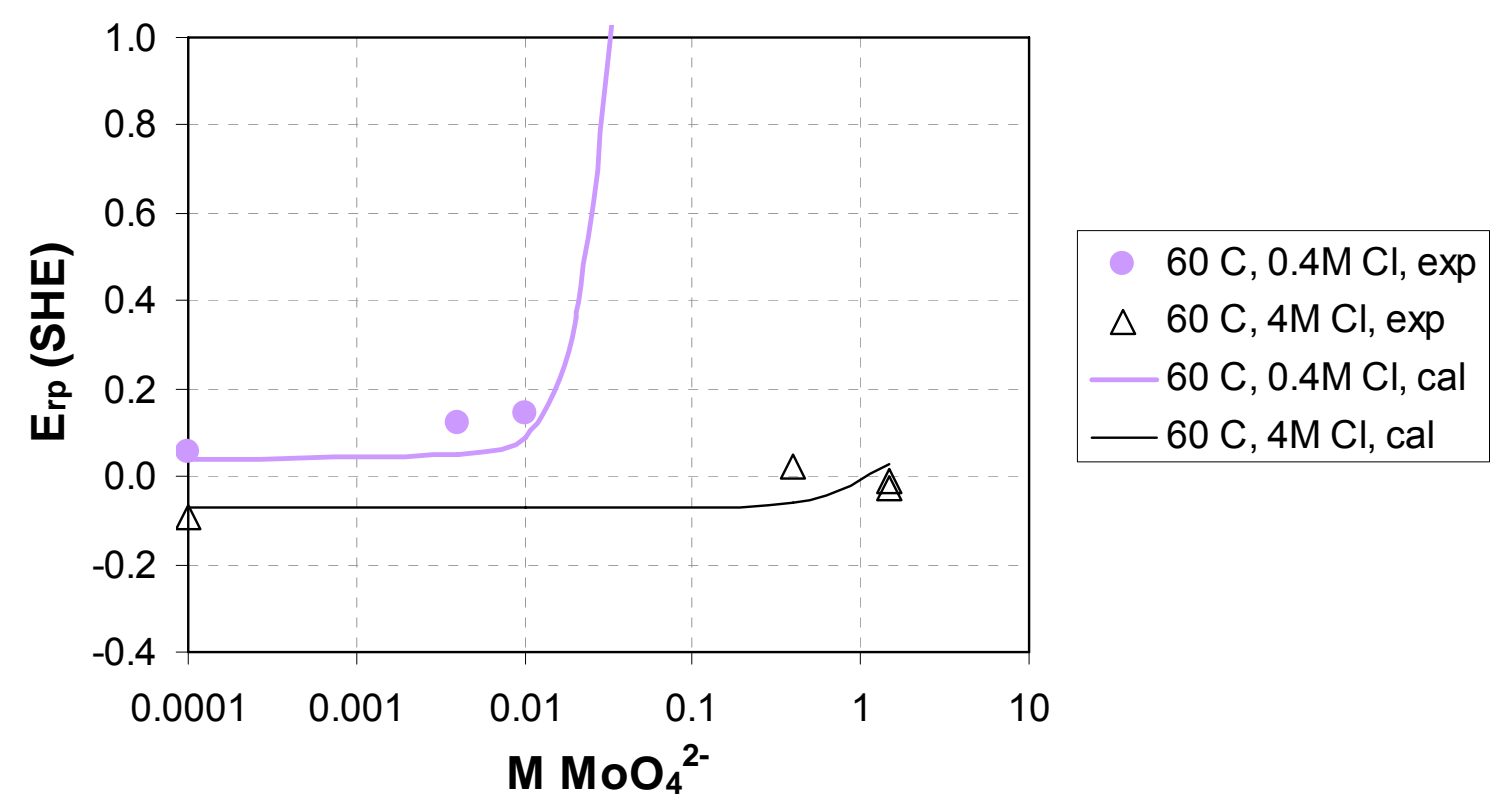

Figure 24. Calculated and experimental repassivation potentials of type 2205 stainless steel in mixed chloride - molybdate solutions.

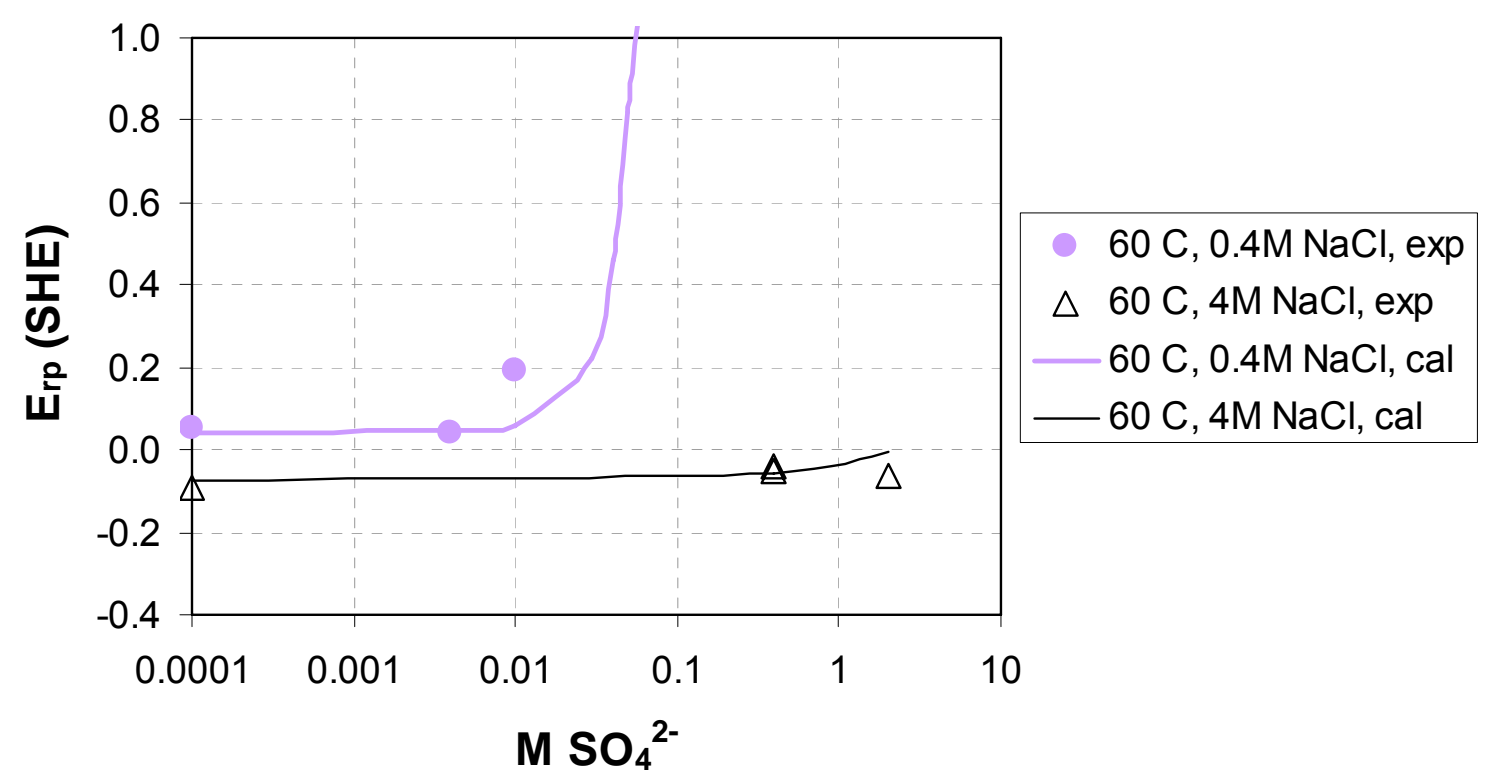

Figure 25. Calculated and experimental repassivation potentials of type 2205 stainless steel in mixed chloride - sulfate solutions. 

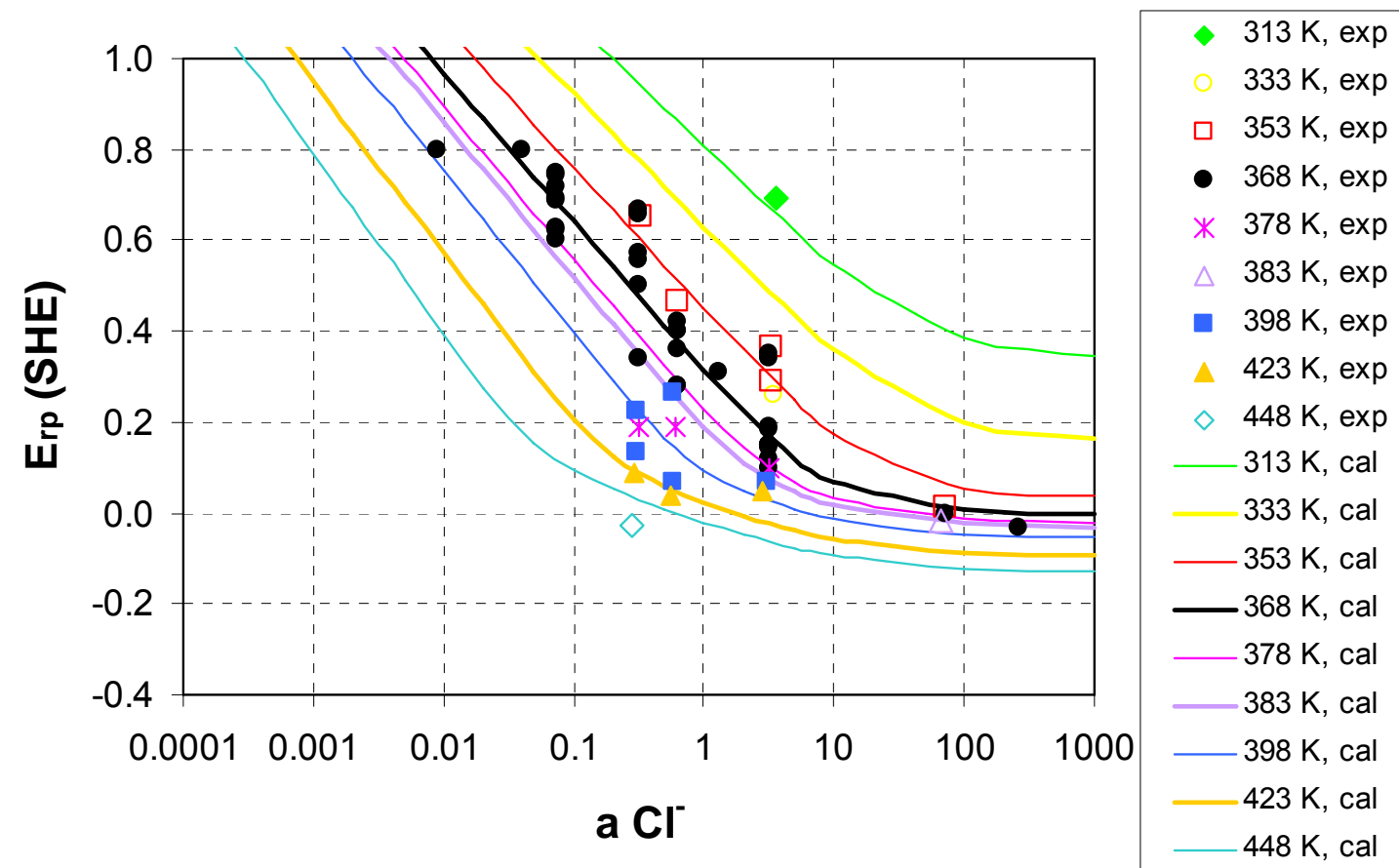

Figure 26. Repassivation potential of alloy 22 as a function of chloride activity and temperature. The experimental data are from Dunn et al. (2005) and Anderko et al. (2004).

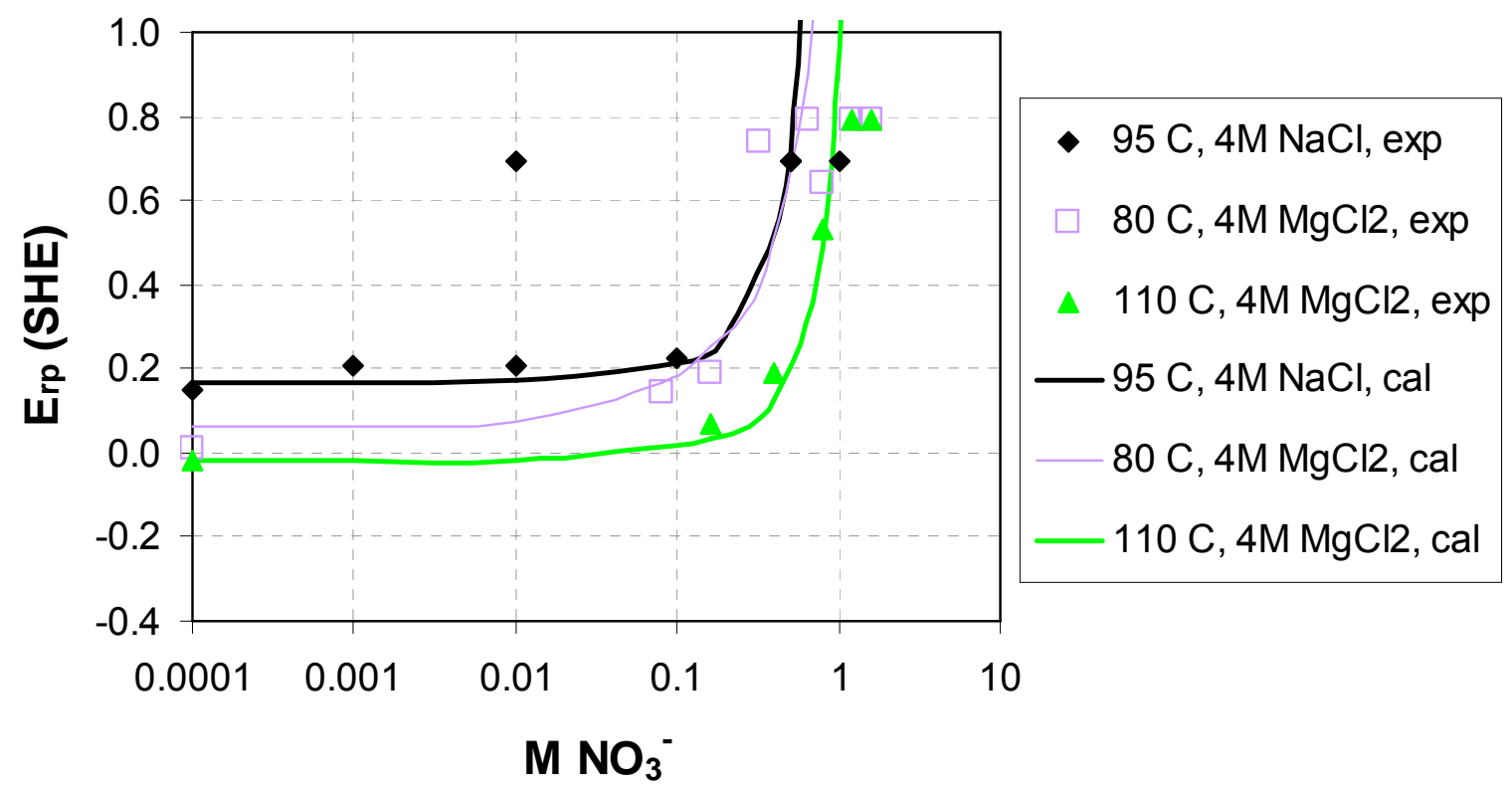

Figure 27. Calculated and experimental repassivation potential of alloy 22 in mixed chloride - nitrate solutions at $80^{\circ} \mathrm{C}, 95^{\circ} \mathrm{C}$, and $110^{\circ} \mathrm{C}$. The experimental data are from Dunn et al. (2005) 


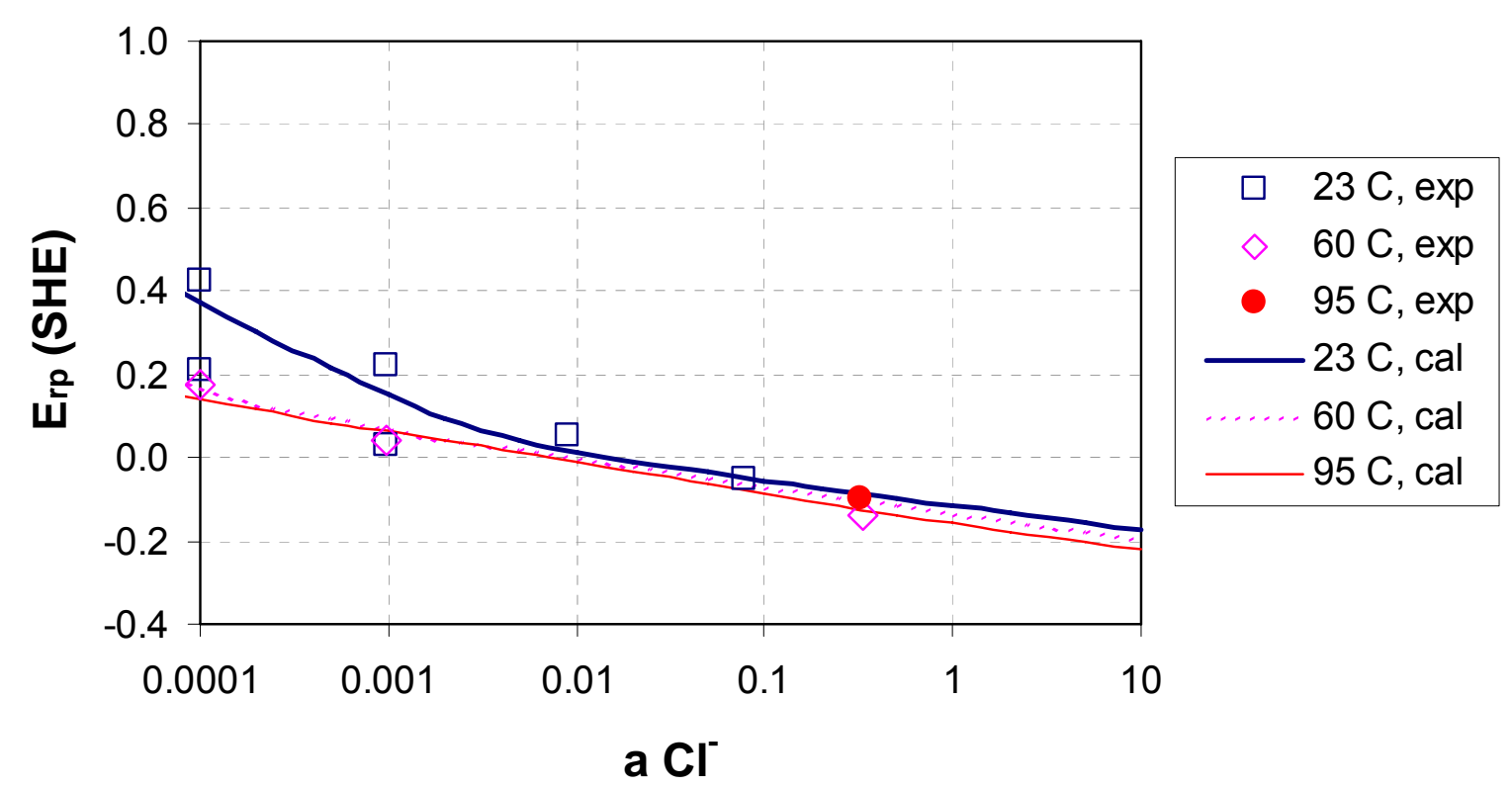

Figure 28. Repassivation potential of s-13Cr stainless steel (UNS 41425) as a function of chloride activity and temperature.

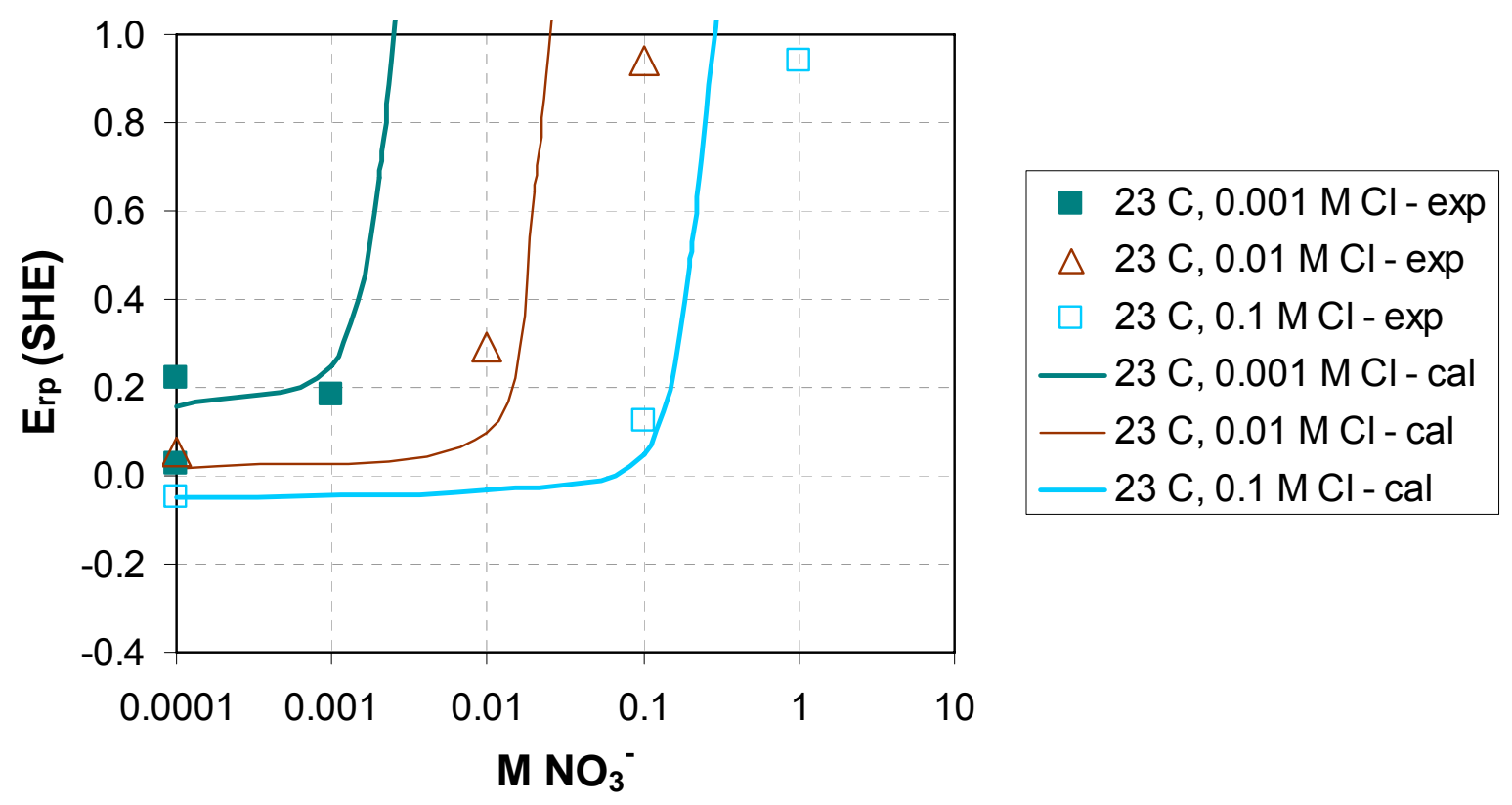

Figure 29. Calculated and experimental repassivation potentials of s-13Cr stainless steel (UNS 41425) in mixed chloride - nitrate solutions at $23^{\circ} \mathrm{C}$. 


\section{Generalization of the model as a function of alloy composition}

It is well known that the resistance of stainless steels and nickel-base alloys to localized corrosion can be correlated with the concentrations of $\mathrm{Cr}, \mathrm{Mo}, \mathrm{W}$, and $\mathrm{N}$ in the alloy. On the empirical level, the Pitting Resistance Equivalence (PRE) has been extensively used to rank the relative performance of alloys in aggressive environments. The PRE indices have been developed using a number of empirically derived equivalent compositions (Sridhar, 1990). These alloy equivalents are limited to the experimental conditions and the range of alloys considered (Hibner, 1987). The effect of alloying elements, especially chromium and molybdenum, has also been extensively studied from a mechanistic point of view (cf., Newman, 1985a,b, Lillard et al., 1994, Hayes et al., 2006). There is evidence that while chromium is responsible for passive behavior, molybdenum is responsible for repassivation after breakdown occurs. Repassivation potential increases with the amount of molybdenum in the alloy (Hayes et al., 2006), which can be attributed to the formation of molybdenum oxide in localized corrosion environments or to enrichment of molybdenum at the alloy surface. Tungsten can be expected to play a similar role. Also, it is generally accepted that the additions of nitrogen improve resistance to localized corrosion (cf. Newman and Shahrabi, 1987, Levey and van Bennekom, 1995, JargeliusPettersson, 1999). The dominant effect of nitrogen is associated with repassivation and may be due to the local formation of $\mathrm{NH}_{4}{ }^{+}$ions, which buffer the $\mathrm{pH}$ near the interface or to the accumulation of nitrogen on the surface, which alters the kinetics of the dissolution.

In this study, it is not our objective to examine the relationship between the repassivation potential and alloy composition from a mechanistic point of view. Rather, we use the available $\mathrm{E}_{\mathrm{rp}}$ database to establish an empirical correlation for calculating the repassivation potential as a function of alloy composition. The purpose of such a correlation is to predict the repassivation potential for alloys for which experimental data are not available or are dubious. At the same time, the relative numerical significance of terms associated with various alloying elements can contribute to our understanding of the importance of these elements in the repassivation process. In a previous study (Anderko et al., 2004a), a preliminary version of such a correlation was shown to be promising for a number of alloys in chloride solutions. Here, we develop a much more accurate and comprehensive correlation using a larger database. Further, we extend it to systems that contain oxyanions in addition to chlorides.

In the first step, a correlation has been established for Fe-Ni-Cr-Mo-W-N alloys in chloride-only solutions. This correlation is based on a database containing $\mathrm{E}_{\mathrm{rp}}$ values for 15 metals. In addition to the alloys discussed above (i.e., 316L, 600, 690, 254SMO, 2205, 22 , and s-13Cr), the database contains $\mathrm{E}_{\mathrm{rp}}$ data collected in Table 2 for alloys 625, 276, AL6XN, and 800 and previously published data for alloy 825 (Sridhar and Cragnolino, 1993, Anderko et al., 2004), 304L stainless steel (Yashiro et al., 1996), carbon steel (Brossia and Cragnolino, 2000) and nickel (Postlethwaite, 1967, Cragnolino, 1987).

As shown above, the repassivation potential of an alloy in an environment containing water and chloride ions is characterized, in the most general case, by seven parameters. This seemingly large number of parameters is not a hindrance to develop a general treatment because the parameters show significant regularities. In particular, three 
parameters can be assigned universal values without any appreciable loss in accuracy. Specifically, the Gibbs energy of adsorption of ions can be set equal to a common value, i.e.,

$\Delta G_{a d s, C l} /(k J / m o l)=10$

Further, analysis of experimental data reveals that the steeper portions of the plots of $\mathrm{E}_{\mathrm{rp}}$ versus chloride activity have similar slopes for various alloys. These slopes are controlled by the electrochemical transfer coefficient for the formation of passive oxide as a result of reaction with water $\left(\xi_{I, H_{2} O}\right)$. Thus, the $\xi_{I, H_{2} O}$ parameter can be assigned a common value, i.e.,

$\xi_{I, H_{2} O}=0.8$

Additionally, the slopes of the less-steep segments of the $\mathrm{E}_{\mathrm{rp}} \mathrm{Vs}^{-\mathrm{Cl}^{-}}$activity plots are also reasonably similar. These slopes are controlled by the $n_{A, C l}$ parameter, which can be thus given a constant value, i.e.,

$n_{A, C l}=1.1$

Further analysis reveals that the enthalpies of activation $\Delta h_{A, C l}^{\neq}$and $\Delta h_{I, H 2 O}^{\neq}$are linearly related to the respective Gibbs energies of activation $\Delta g_{A, C l}^{\neq}\left(T_{r e f}\right)$ and $\Delta g_{A, C l}^{\neq}\left(T_{r e f}\right)$. Such linear relations are not unexpected because analogous relationships are commonly observed for the enthalpies and Gibbs energies of formation of species that belong to homologous series. These relationships are given by:

$$
\begin{aligned}
& \Delta h_{A, C l}^{\neq}=0.055+0.002 \Delta g_{A, C l}^{\neq}\left(T_{r e f}\right) \\
& \Delta g_{I, H 2 O}^{\neq}=-0.015+0.032 \Delta g_{I, H 2 O}^{\neq}\left(T_{r e f}\right)
\end{aligned}
$$

This leaves only the two Gibbs energies of activation $\Delta g_{A, C l}^{\neq}\left(T_{r e f}\right)$ and $\Delta g_{I, H 2 O}^{\neq}\left(T_{\text {ref }}\right)$ to be determined explicitly in terms of alloy composition. Since the Gibbs energies of activation are thermodynamic quantities, their dependence on composition can be formally expressed by accounting for binary pair-wise contributions of components (cf. Pitzer, 1995):

$$
\Delta g^{\neq}=\sum_{i}^{N} \sum_{j}^{N} w_{i} w_{j} a_{i j}
$$

where $w_{i}(i=1, \ldots N)$ is the fraction of component $i$ and $a_{i j}$ are empirical binary parameters. Here, we define $w_{i}$ as the weight fractions. In practice, it is not feasible to account independently for all binary terms because the database would not be sufficiently large for such a purpose. Therefore, some terms need to be neglected while others are grouped and empirical exponents are introduced on an empirical basis. 
To calculate the Gibbs energy of activation for dissolution mediated by adsorption of aggressive species $\left(\Delta g_{A, C l}^{\neq}\left(T_{r e f}\right)\right)$, four contributions are needed, i.e.,

$$
\Delta g_{A, C l}^{\neq}\left(T_{r e f}\right)=\Delta g_{A, C l}^{\neq}(C r, F e, N i)+\Delta g_{A, C l}^{\neq}(M o, W)+\Delta g_{A, C l}^{\neq}(N)+\Delta g_{A, C l}^{\neq}(\text {misc })
$$

where $\Delta g_{A, C l}^{\neq}(\mathrm{Cr}, \mathrm{Fe}, \mathrm{Ni})$ is the baseline contribution for Fe-Ni-Cr alloys, $\Delta g_{A, C l}^{\neq}(M o, W)$ is an increment due to the effect of Mo and $\mathrm{W}, \Delta g_{A, C l}^{\neq}(N)$ is an increment due to $\mathrm{N}$ and $\Delta g_{A, C l}^{\neq}$(misc) is a miscellaneous contribution of other elements. The baseline contribution for Fe-Ni-Cr alloys reproduces the Gibbs energy of activation $\Delta g^{\neq}{ }_{A, C l}\left(T_{\text {ref }}\right)$ for alloys $600,690,800$ and $304 \mathrm{~L}$ as well as for carbon steel and nickel. It is given by:

$$
\Delta g_{A, C l}^{\neq}(\mathrm{Cr}, \mathrm{Fe}, \mathrm{Ni})=\Delta g_{A, C l}^{\neq}(\mathrm{Fe}) w_{F e}^{2}+\Delta g_{A, C l}^{\neq}(N i) w_{N i}^{2}-6.789 w_{C r} w_{N i}+132.3 w_{C r} w_{N i}
$$

where $\Delta g_{A, C l}^{\neq}(\mathrm{Fe})=-74.1$ and $\Delta g_{A, C l}^{\neq}(\mathrm{Ni})=-11.4$ are the Gibbs energies of activation for iron (or, for practical purposes, carbon steel) and nickel, respectively. The remaining contributions are calculated as

$$
\begin{aligned}
& \Delta g_{A, C l}^{\neq}(M o, W)=w_{C r}\left(w_{M o}+w_{W}\right)^{0.4}\left(488.55 x_{N i}^{1.3}+634.08 x_{F e}^{1.3}\right) \\
& \Delta g_{A, C l}^{\neq}(N)=w_{N} w_{C r}\left[1.967 e 6 w_{M o}-0.148 e 6\left(w_{F e}+2 w_{N i}\right)\right] \\
& \Delta g_{A, C l}^{\neq}(\text {misc })=-1542 w_{N b} w_{C r}
\end{aligned}
$$

With the current database, the $\Delta g_{A, C l}^{\neq}$(misc) term is limited to the effect of $\mathrm{Nb}$ and should be treated as tentative because it is based on data for a single alloy (i.e., alloy $625)$.

A similar scheme is adopted for the Gibbs energy of activation for the formation of oxide mediated by adsorption of $\mathrm{H}_{2} \mathrm{O}$, i.e.,

$$
\Delta g_{I, H 2 O}^{\neq}\left(T_{r e f}\right)=\Delta g_{I, H 2 O}^{\neq}(\mathrm{Cr}, \mathrm{Fe}, \mathrm{Ni})+\Delta g_{I, H 2 O}^{\neq}(\mathrm{Mo}, \mathrm{W})+\Delta g_{I, H 2 O}^{\neq}(N)+\Delta g_{I, H 2 O}^{\neq}(\text {misc })
$$

where

$$
\begin{gathered}
\Delta g_{I, H 2 O}^{\neq}(C r, F e, N i)=16.05 w_{F e}+169.5 w_{N i}+1967.9 w_{C r}^{1.1} \\
\Delta g_{I, H 2 O}^{\neq}(M o, W)=-2406.7\left[\left(w_{M o}+w_{W}\right)^{1.1}+w_{C r}^{1.1}\left(w_{F e}+1.4 w_{N i}\right)\right]+ \\
2013.1\left[\left(w_{M o}+w_{W}\right)^{1.1}\left(w_{F e}^{0.5}+w_{N i}^{0.5}\right)\right] \\
\Delta g_{I, H 2 O}^{\neq}(N)=w_{C r} w_{N}\left[-0.3491 e 6\left(w_{F e}+2 w_{N i}\right)+4.569 e 6 w_{M o}\right]
\end{gathered}
$$


$\Delta g_{I, H 2 O}^{ \pm}($misc $)=-4938 w_{N b} w_{C r}$

Thus, eqs. (8-12) and (14-23) constitute a generalized correlation for predicting the repassivation potential of Fe-Ni-Cr-Mo-W-N alloys as a function of composition. The repassivation potentials calculated from this correlation are shown in Figures 30 through 33 for 13 alloys in chloride solutions at $296 \mathrm{~K}, 333 \mathrm{~K}, 368 \mathrm{~K}$ and $423 \mathrm{~K}$, respectively. The calculated curves are in generally good agreement with experimental data. The overall average deviation between the calculated and experimental data for all alloys is $67 \mathrm{mV}$. This can be compared with the average deviation of $56 \mathrm{mV}$, which is obtained when repassivation potential data are fitted separately for each alloy. Thus, the generalized correlation increases the overall deviation only from 56 to $67 \mathrm{mV}$. Since Figures 30-33 compare the repassivation potentials of various alloys, they can also be used for ranking the alloys with respect to their resistance to localized corrosion as a function of chloride activity and temperature.

\section{Generalization of the model for mixed chloride - oxyanion environments}

The generalized correlation can be extended to mixed systems containing chlorides and oxyanions. For this purpose, we note that there is a relationship between the Gibbs energy of activation for the formation of oxide due to the adsorption of oxyanions $\Delta g^{7, k}\left(\mathrm{k}=\mathrm{OH}^{-}\right.$ , $\left.\mathrm{MoO}_{4}{ }^{2-}, \mathrm{VO}_{3}{ }^{-}, \mathrm{SO}_{4}{ }^{2-}, \mathrm{NO}_{3}{ }^{-}\right)$and that due to the adsorption of $\mathrm{H}_{2} \mathrm{O}\left(\Delta g^{7}{ }_{I, H 2 O}\right)$. This relationship is shown in Figure 34. The symbols in Figure 34 correspond to the seven alloys for which the anion effects were investigated (i.e., 316L, 600, 690, 254SMO, 2205, 22 , and $\mathrm{s}-13 \mathrm{Cr}$ ). The existence of such a relationship is understandable considering the fact that the tendency for repassivation in oxyanion-containing environments can be expected to be qualitatively related to that in oxyanion-free solutions. The relationship shown in Figure 34 can be expressed as

$$
\Delta g_{I, k}^{\neq}\left(T_{r e f}\right)=\min \left[\left(q_{1} \Delta g_{I, H_{2} O}^{\neq}\left(T_{r e f}\right)+q_{2}\right),\left(q_{3} \Delta g_{I, H_{2} O}^{\neq}\left(T_{r e f}\right)+q_{4}\right)\right]
$$

where the coefficients $q_{i}(\mathrm{i}=1, \ldots, 4)$ are specific to the five investigated anions. Also, the enthalpy of activation $\Delta h_{I, k}^{\neq}$and electrochemical transfer coefficient $\xi_{k}$ can be assigned constant values for various alloys. Once $\Delta g_{I, H 2 O}^{\neq}$is calculated from eqs. (19-23) as a function of alloy composition, eq. (24) can be used to predict the $\Delta g_{I, k}^{7}$ values for the anions. It is noteworthy that the $\Delta g_{I, k}^{\neq}$values are quite similar for the $\mathrm{OH}^{-}, \mathrm{MoO}_{4}{ }^{2-}, \mathrm{VO}_{3}{ }^{-}$, and $\mathrm{SO}_{4}{ }^{2-}$ anions. Thus, the main difference in the effect of these anions lies in their thermodynamic properties (as exemplified by their solubilities) and, once the thermodynamic effects are factored out, the contributions of these anions to repassivation are similar. On the other hand, the effect of nitrates is substantially different.

The correlation described above makes it possible to reproduce the repassivation potentials with essentially the same accuracy as that shown in Figures 1-29. Most importantly, it makes it possible to predict the repassivation potential for alloys that have not been experimentally investigated. 


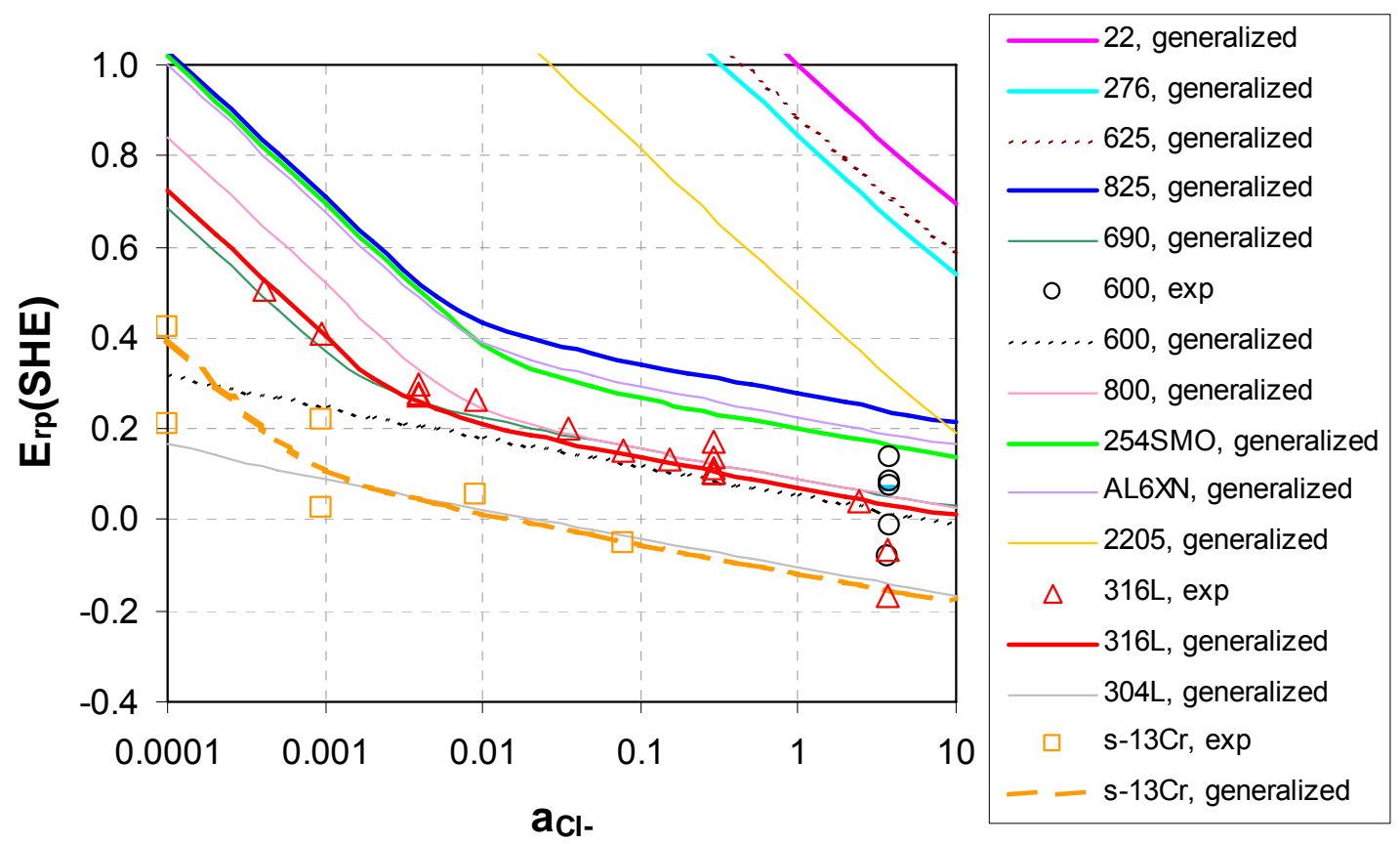

Figure 30. Comparison of repassivation potential values obtained from the generalized correlation with alloy composition (eqs. 8-12 and 14-23) with experimental data for various alloys at $296.15 \mathrm{~K}$.

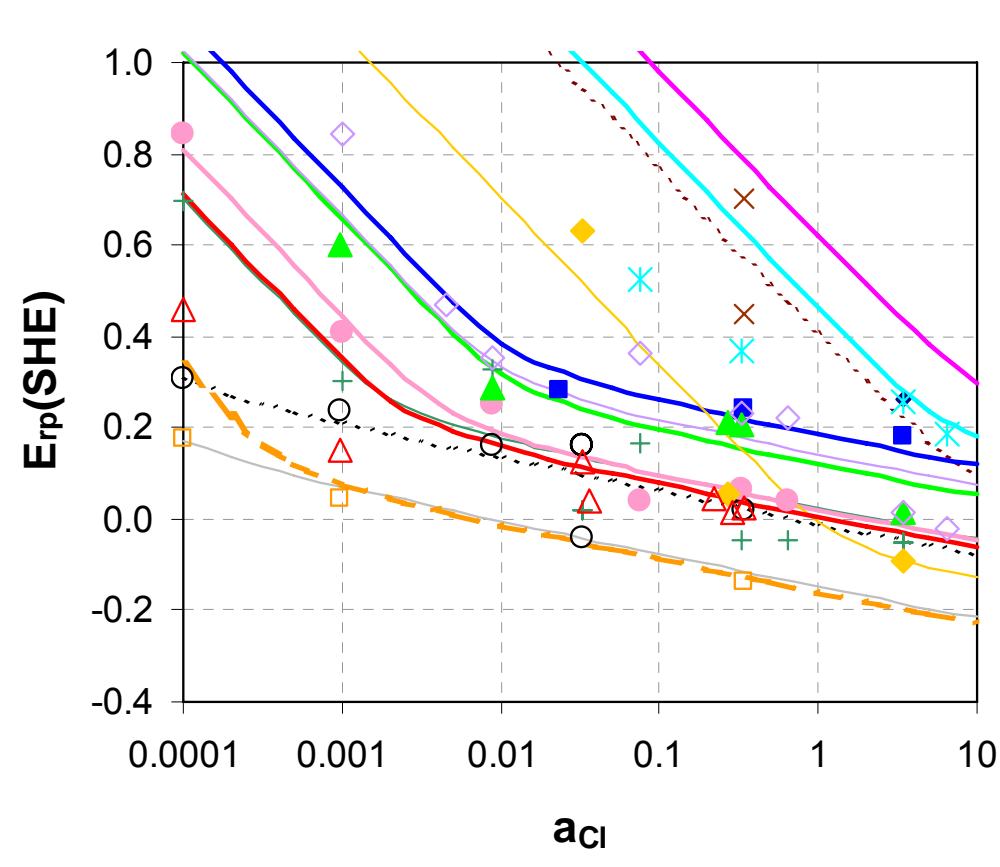

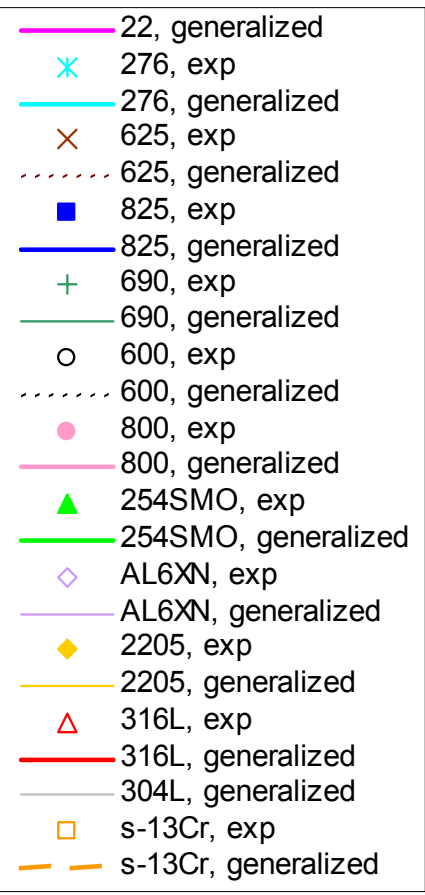

Figure 31. Comparison of $\mathrm{E}_{\mathrm{rp}}$ values obtained from the generalized correlation with alloy composition with experimental data for various alloys at $333.15 \mathrm{~K}$. 


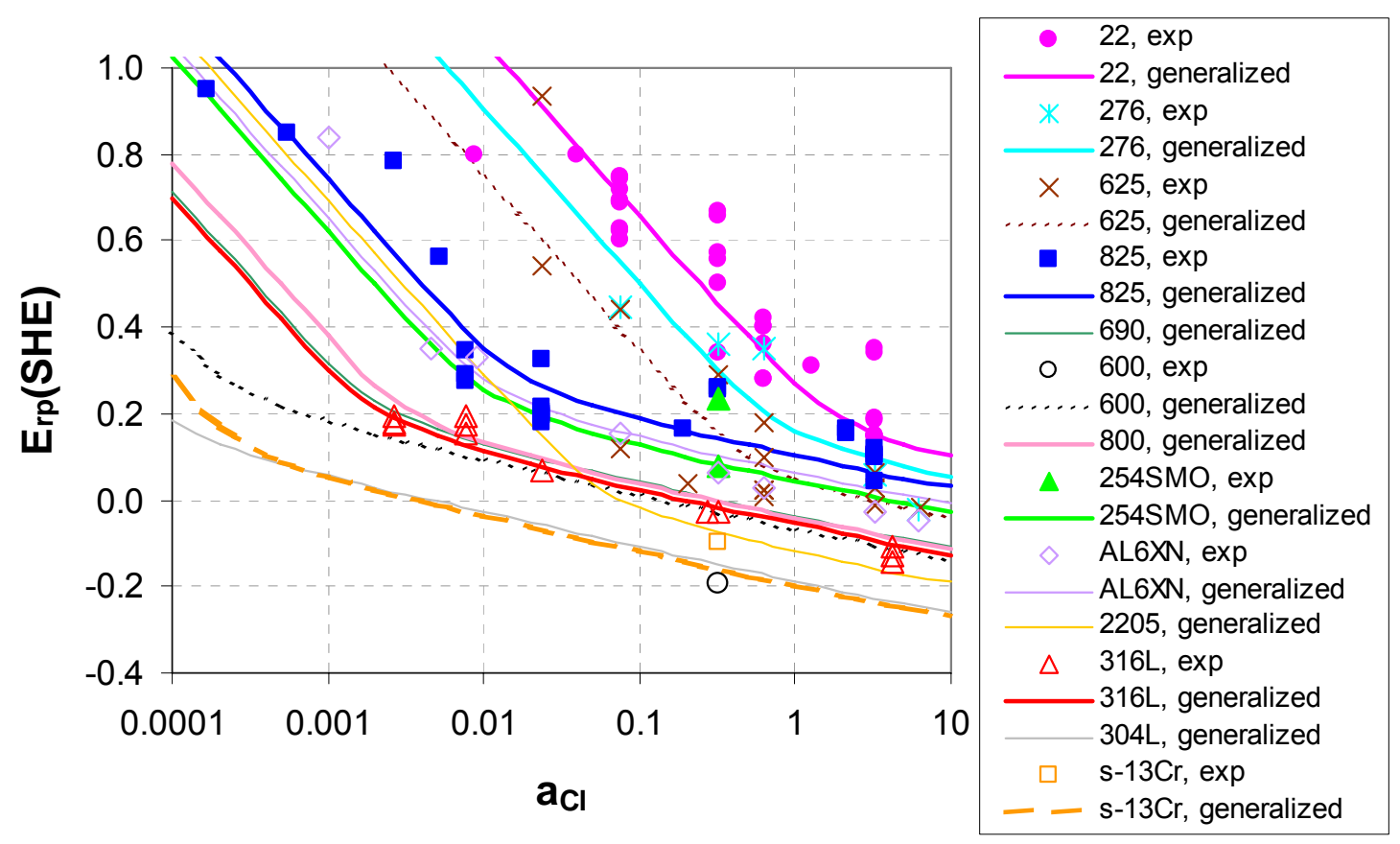

Figure 32. Comparison of $\mathrm{E}_{\mathrm{rp}}$ values obtained from the generalized correlation with alloy composition with experimental data for various alloys at $368.15 \mathrm{~K}$.
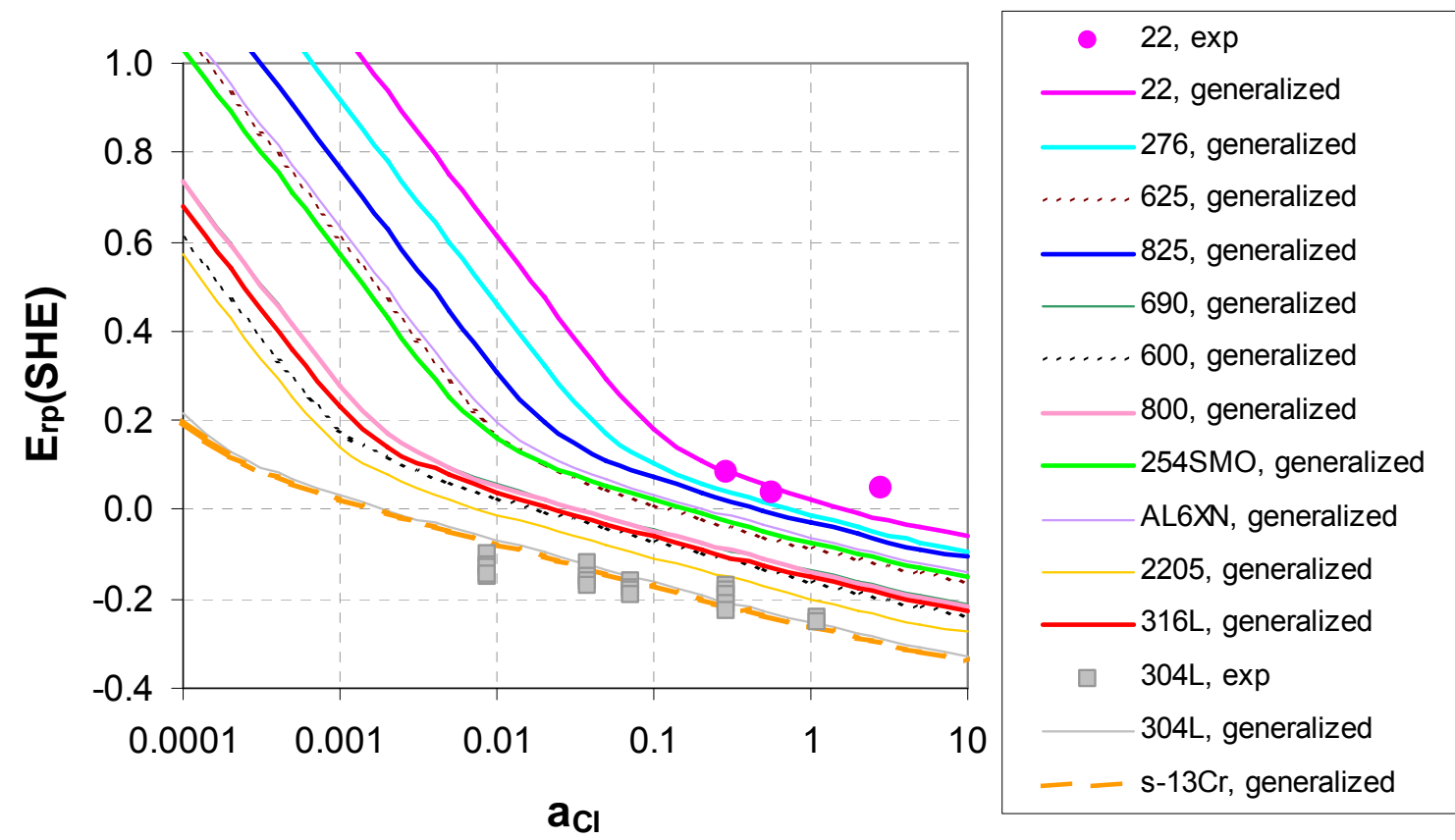

Figure 33. Comparison of $\mathrm{E}_{\mathrm{rp}}$ values obtained from the generalized correlation with alloy composition with experimental data for various alloys at $423.15 \mathrm{~K}$. 


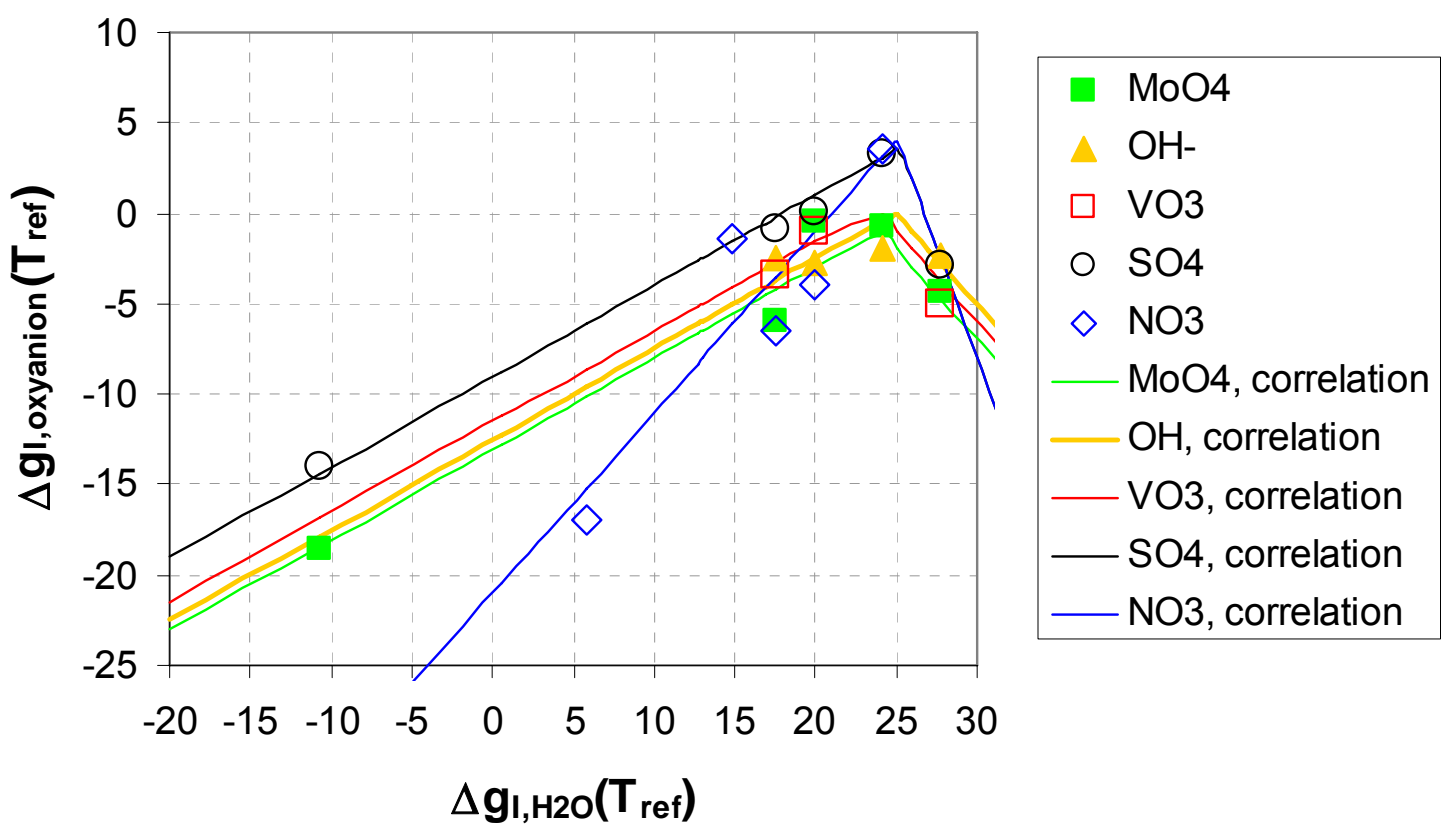

Figure 34. Correlation between the Gibbs energy of activation for formation of oxide mediated by adsorption of various oxyanions $\left[\Delta g_{\text {I,oxyanion }}^{\neq}\left(T_{\text {ref }}\right)\right]$ and that due to the adsorption of water $\left[\Delta g_{I, H 2 O}^{\neq}\left(T_{r e f}\right)\right]$ (eq. 24 and Table 4)

\section{Predicting the repassivation potential of heat-treated materials}

The fundamental methodology for calculating the effect of heat treatment on the repassivation potential consists of the following steps:

(1) Calculate the chromium and molybdenum depletion profiles as a function of the temperature, time of heat treatment and bulk alloy concentration.

(2) Calculate the dependence of the repassivation potential on the local concentration of $\mathrm{Cr}$ and Mo along the depletion profile. This can be readily accomplished using the generalized correlation that has been developed for relating $\mathrm{E}_{\mathrm{rp}}$ to the composition of Fe-Ni-Cr-Mo-W-N alloys.

(3) Averaging the local values of $\mathrm{E}_{\mathrm{rp}}$ along the depletion profile to obtain a value that corresponds to the repassivation of macroscopic pits or crevices on sensitized samples. Such a value can be quantitatively compared with the experimentally measurable repassivation potentials. 


\section{Predicting depletion profiles at grain boundaries}

To calculate the chromium and molybdenum depletion profiles, a comprehensive model of sensitization has been developed. This model quantitatively accounts for the following phenomena:

(a) Formation of carbides $\left(\mathrm{M}_{7} \mathrm{C}_{3}\right.$ or $\left.\mathrm{M}_{23} \mathrm{C}_{6}\right)$ at the grain boundaries in $\mathrm{Fe}-\mathrm{Cr}-\mathrm{Ni}-\mathrm{Mo}$ W-N-C alloys.

(b) Para-equilibrium between the carbide phase and the alloy matrix. In the paraequilibrium, the activity of carbon remains the same throughout the grain because of the rapid diffusion of interstitial carbon. At the same time, the activity of the chromium at the grain boundary is determined by the chemical equilibrium that governs the formation of the carbide. The boundary concentration of $\mathrm{Cr}$ is typically substantially lower than the $\mathrm{Cr}$ concentration in the matrix.

(c) Growth of the carbide phase as a function of time and simultaneous progressive healing of the $\mathrm{Cr}$-depleted zone. As the carbide phase grows, carbon rapidly diffuses from the grain matrix to enable the growth of the carbide. As the growth progresses, the concentration of carbon in the matrix may drop to a level that corresponds to the solubility of carbon. At the same time, chromium diffuses, much more slowly than carbon because of the $\mathrm{Cr}$ concentration gradient between the grain boundary and the matrix. The Cr diffusion results in the healing of the $\mathrm{Cr}$-depleted region. The diffusion of $\mathrm{Cr}$ and the growth of the carbide are linked through the para-equilibrium condition at carbide-matrix boundary because the para-equilibrium determines the minimum concentration of chromium at a given carbon concentration.

The sensitization model simulates these phenomena using only well-defined physical parameters, i.e., the Gibbs energy and enthalpy of formation of the carbide, diffusion coefficient of chromium and average grain size. Details of the mathematical treatment of the above phenomena are available from OLI Systems on request. To illustrate the performance of the sensitization model, we report the computation of chromium depletion profiles for alloys 600 and 825 .

Figures 35-37 compare the calculated and experimental chromium depletion profiles for alloy 600. The experimental data were taken from three sources, i.e., Was et al. (1981), Was and Kruger (1985) and Hall and Briant (1985). These sources are in a fairly reasonable, but not fully quantitative, agreement with each other. As shown in Figure 35, the model predictions are in excellent agreement with the data of Was and Kruger (1985). Also, the agreement with the data of Hall and Briant (1985) is good (cf. Fig. 37). Somewhat higher deviations are observed from the data of Was et al. (1981).

Figures 38-39 show the results of calculations for alloy 825. For this alloy, a fair amount of scattering is observed in the experimental data and some asymmetry in the profiles is noticeable (Pan et al., 2000). The model is in a reasonably good agreement with the data. 
The figures indicate that the model accurately accounts for the temperature and time dependence of sensitization. In particular, the flattening of the depletion curve, which is a manifestation of healing, is correctly predicted as a function of time.

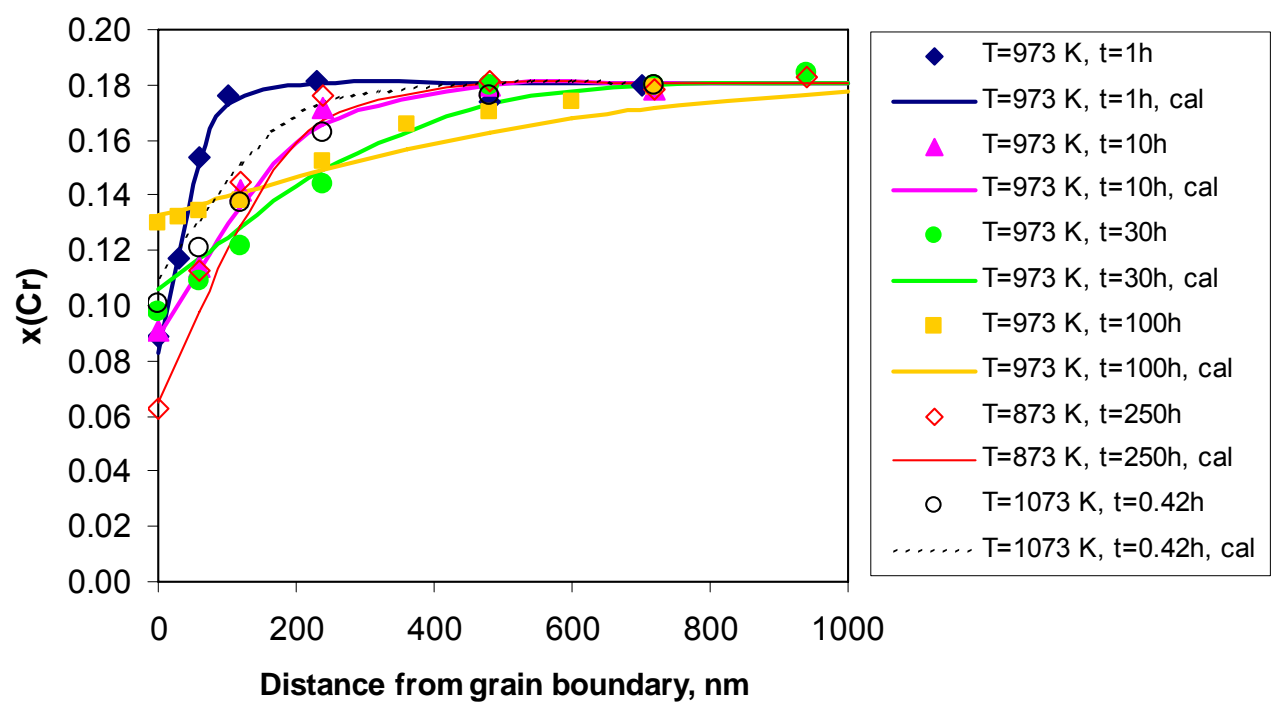

Figure 35. Calculated and experimental (Was and Kruger, 1985) chromium depletion profiles for alloy 600 sensitized at $973 \mathrm{~K}$ for varying amounts of time.

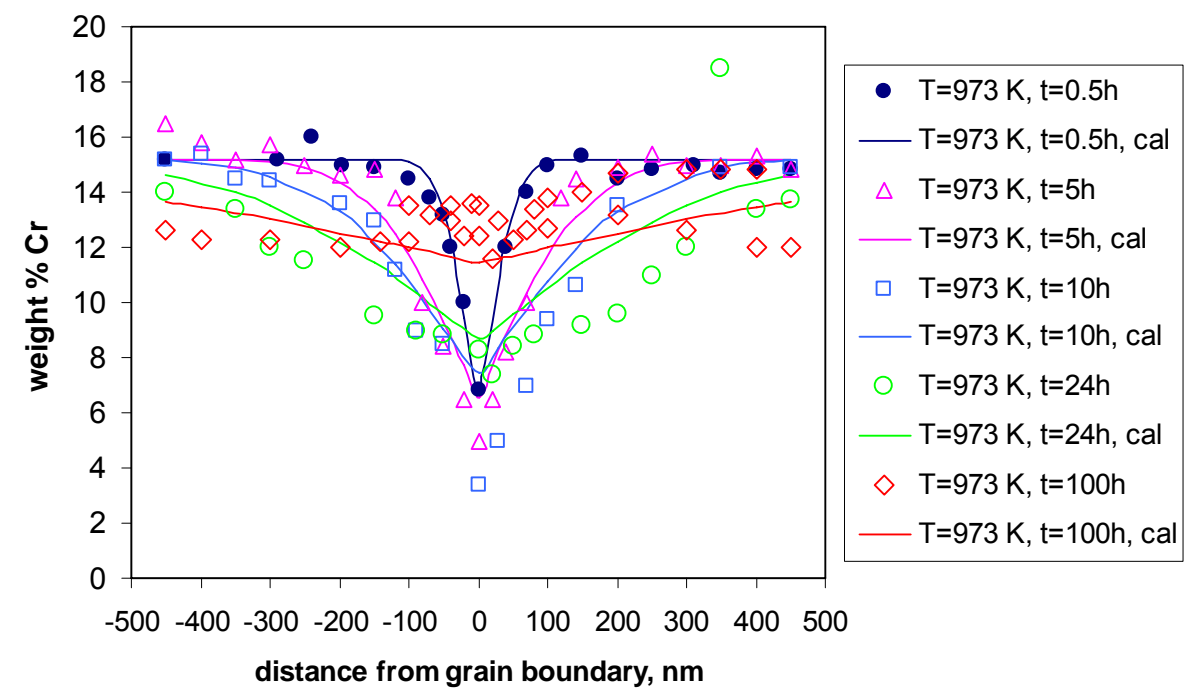

Figure 26. Calculated and experimental (Was et al., 1981) Cr depletion profiles for alloy 600 sensitized at $973 \mathrm{~K}$ for various amounts of time. 


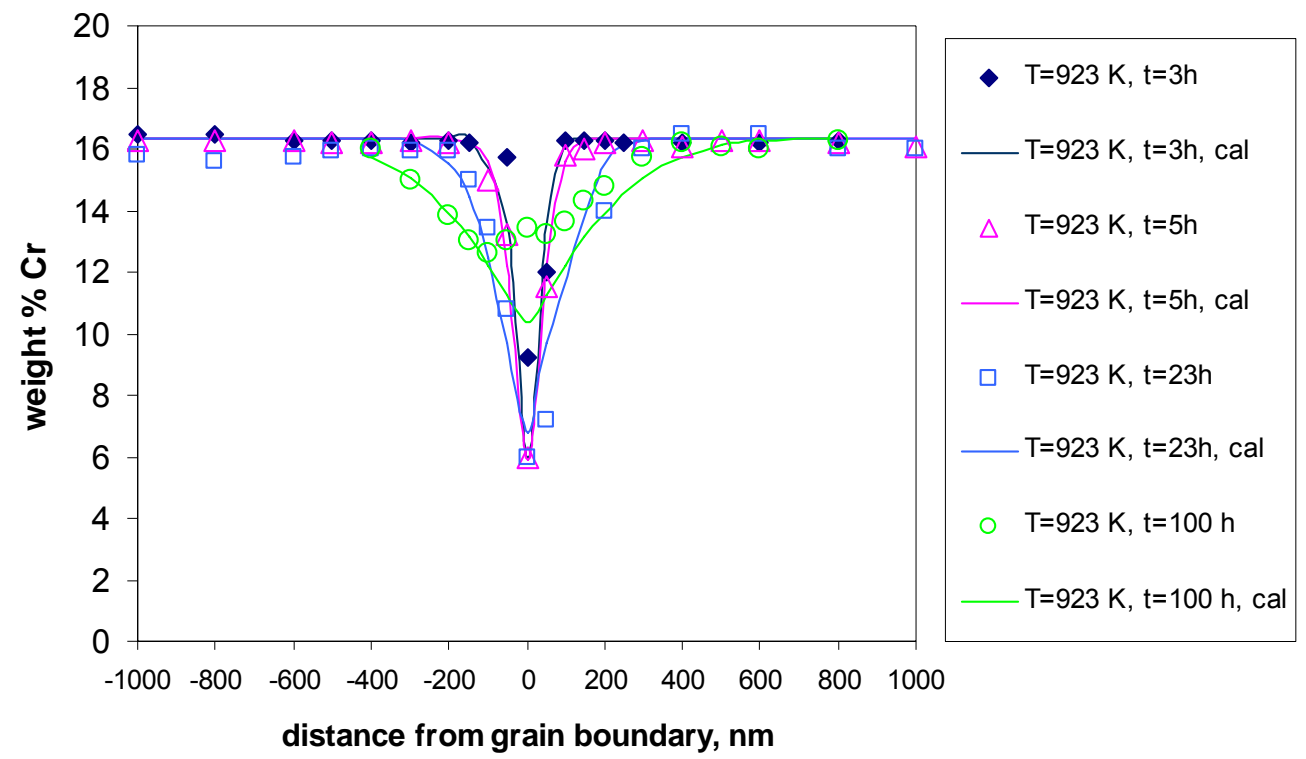

Figure 37. Calculated and experimental $\mathrm{Cr}$ depletion profiles for alloy 600 sensitized at $923 \mathrm{~K}$ for various amounts of time. The data are from Hall and Briant (1985).

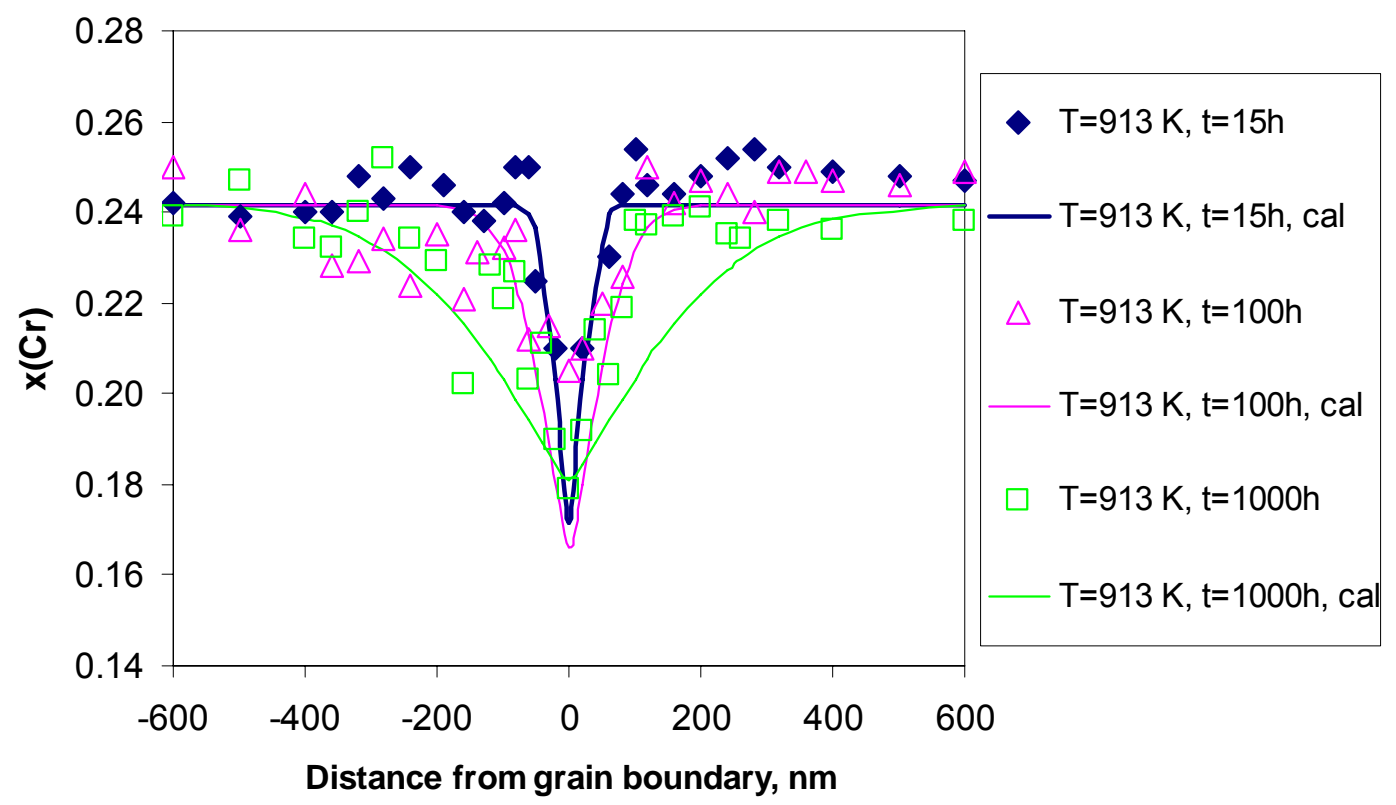

Figure 38. Calculated and experimental Cr depletion profiles for alloy 825 sensitized at $913 \mathrm{~K}$ for various times. The experimental data are from Pan et al. (2000). 


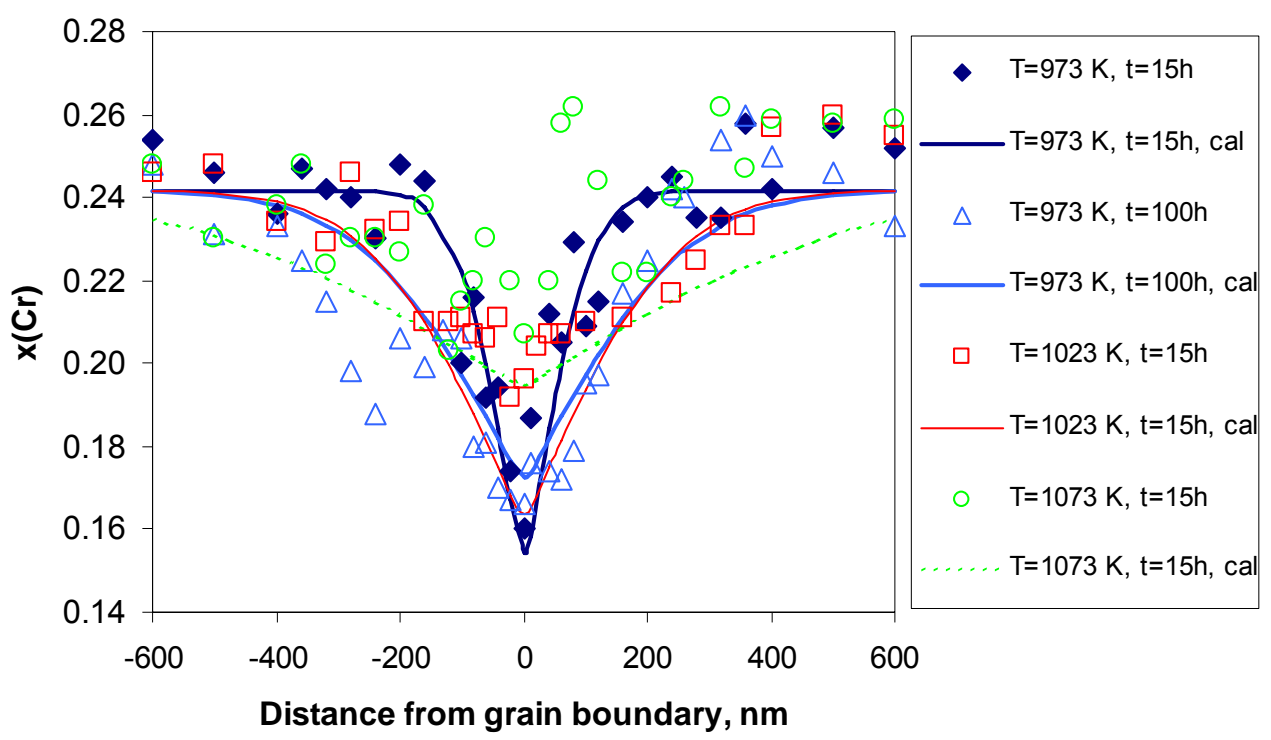

Figure 39. Calculated and experimental Cr depletion profiles for alloy 825 sensitized at 973, 1023, and $1073 \mathrm{~K}$. The experimental data are from Pan et al. (2000).

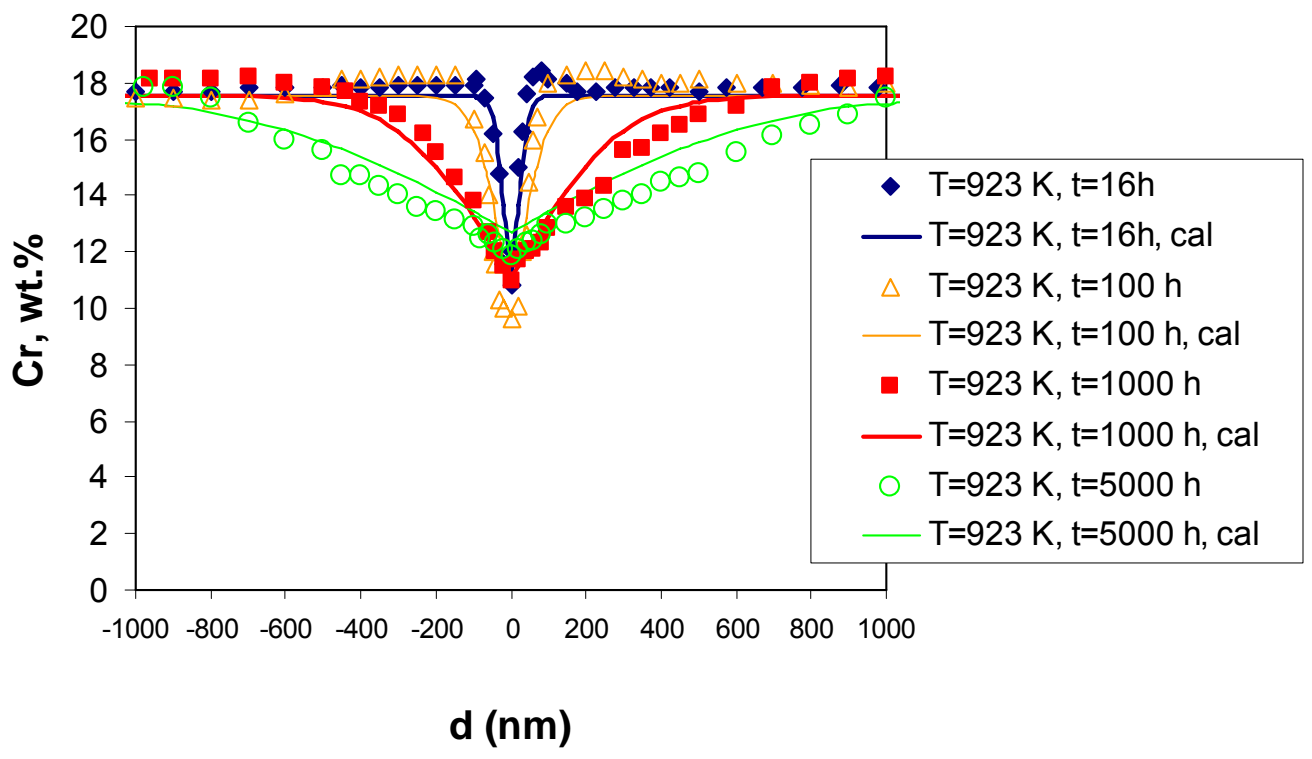

Figure 40. Calculated and experimental (Tekin et al., 1991) Cr depletion profilles for type 316L stainless steel (Krupp sample) sensitized at $923 \mathrm{~K}$ for various amounts of time.

The results of calculations for type 316L stainless steel are compared with experimental data in Figures 40-44. Depletion profiles for this alloy have been reported by Hall and Briant (1984), Tekin et al. (1991) and Sahlaoui et al. (2004) for various overlapping conditions of temperature and time of sensitization. These data are in fair, although imperfect agreement with each other. As shown in Figures 40-44, the model correctly 
reproduces the chromium depletion profiles. The moderate deviations from experimental data are primarily due to some discrepancies between the three sources of experimental data, which were used with equal weights in the regression of model parameters. Also, the observed deviations are partially due to some limited asymmetry of the experimental profiles, which cannot be explained by the model.

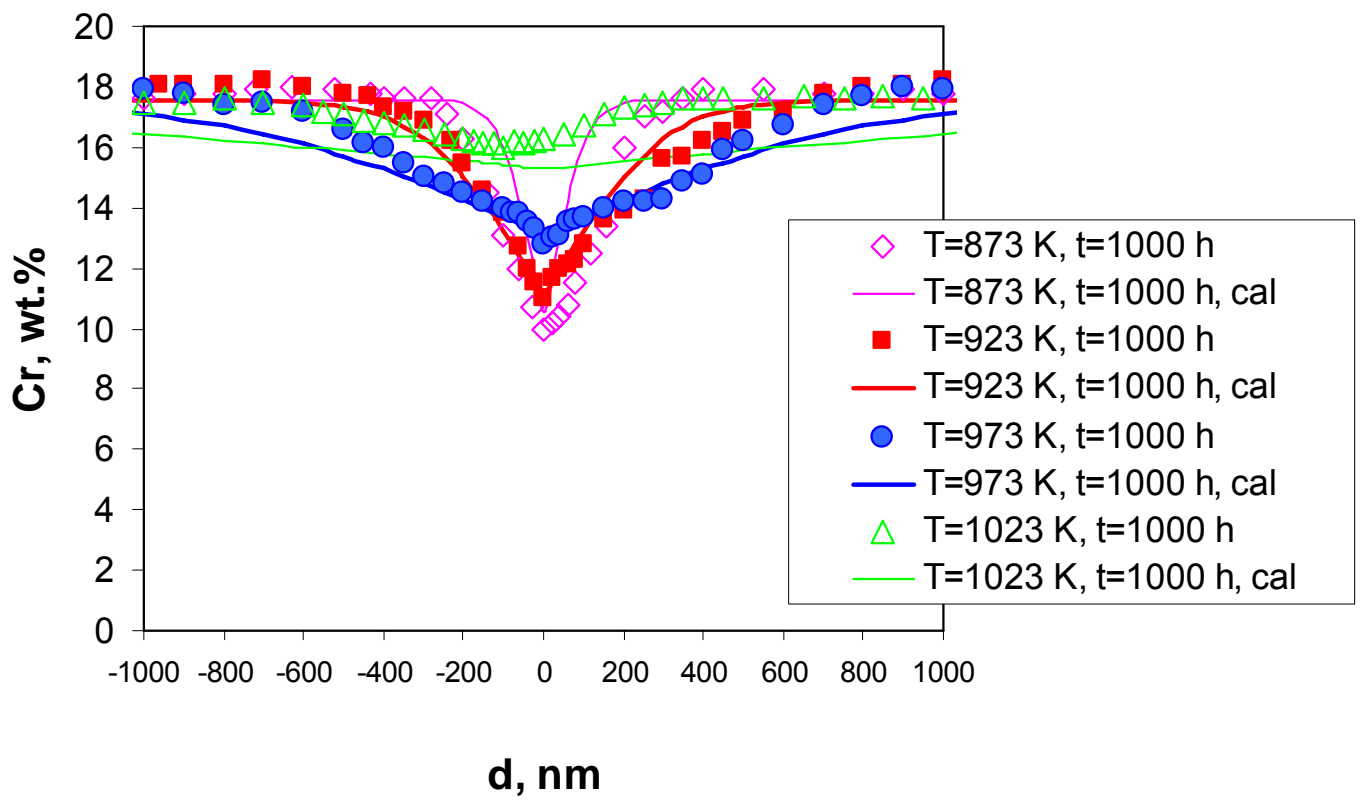

Figure 41. Calculated and experimental (Tekin et al., 1991) Cr depletion profiles for type 316L stainless steel (Krupp sample) sensitized for 1000 hours at various temperatures.

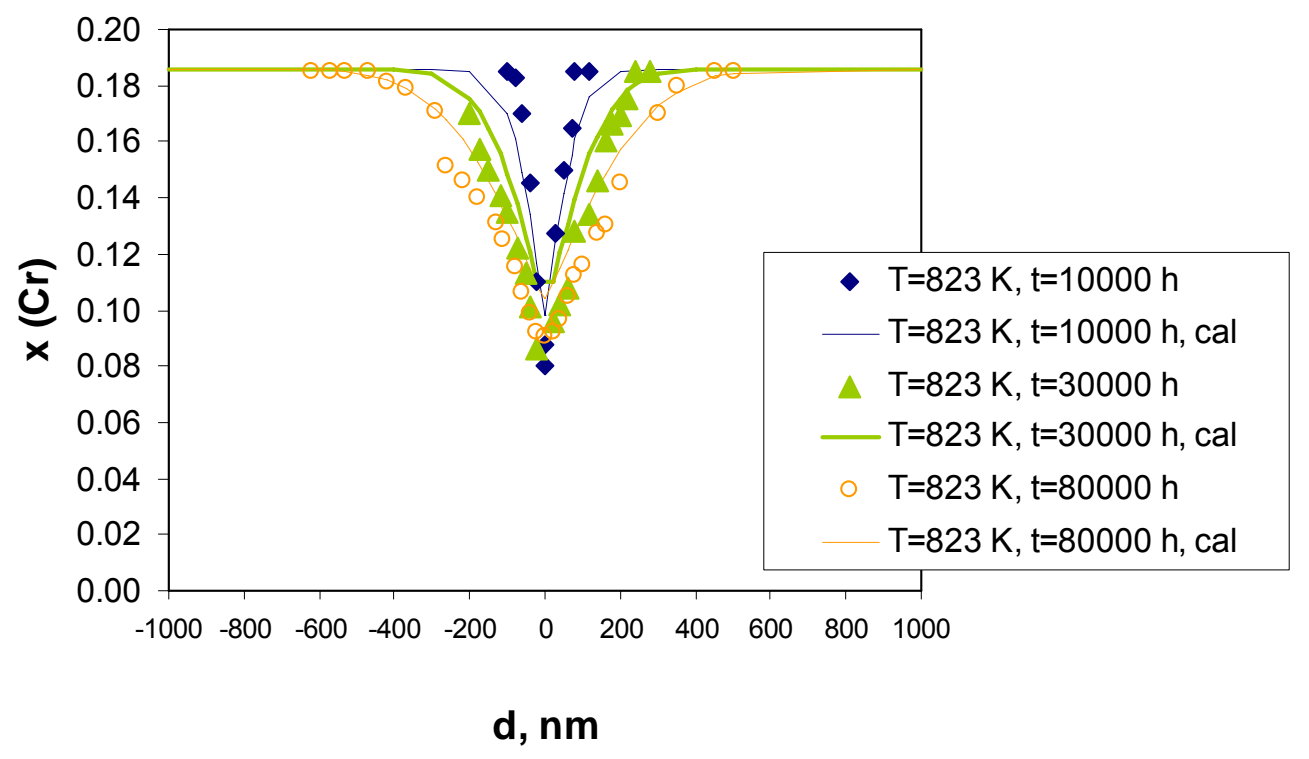

Figure 42. Calculated and experimental (Sahlaoui et al., 2004) Cr depletion profiles for type $316 \mathrm{~L}$ stainless steel sensitized at $823 \mathrm{~K}$ for various amounts of time. 
In contrast to the abundant data for $\mathrm{Cr}$ depletion, limited experimental information is available about molybdenum depletion. As shown in Figure 44, the model accurately predicts the Mo depletion profiles. It should be noted that $\mathrm{Cr}$ and Mo depletion are calculated simultaneously by the model using a uniform set of model parameters. Since the model parameters are transferable to similar alloys, Mo depletion can be predicted for a given alloy if no experimental data are available.

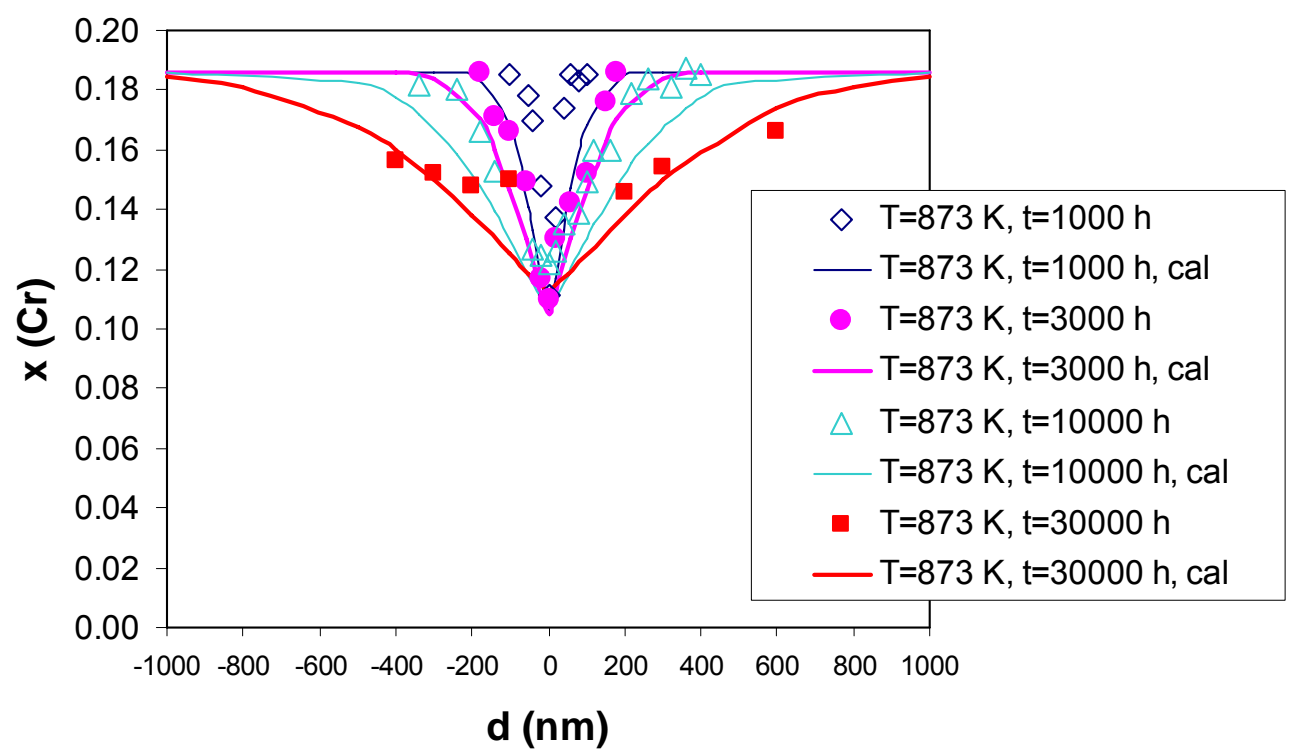

Figure 43. Calculated and experimental (Sahlaoui et al., 2004) Cr depletion profiles for type $316 \mathrm{~L}$ stainless steel sensitized at $873 \mathrm{~K}$ for various amounts of time.

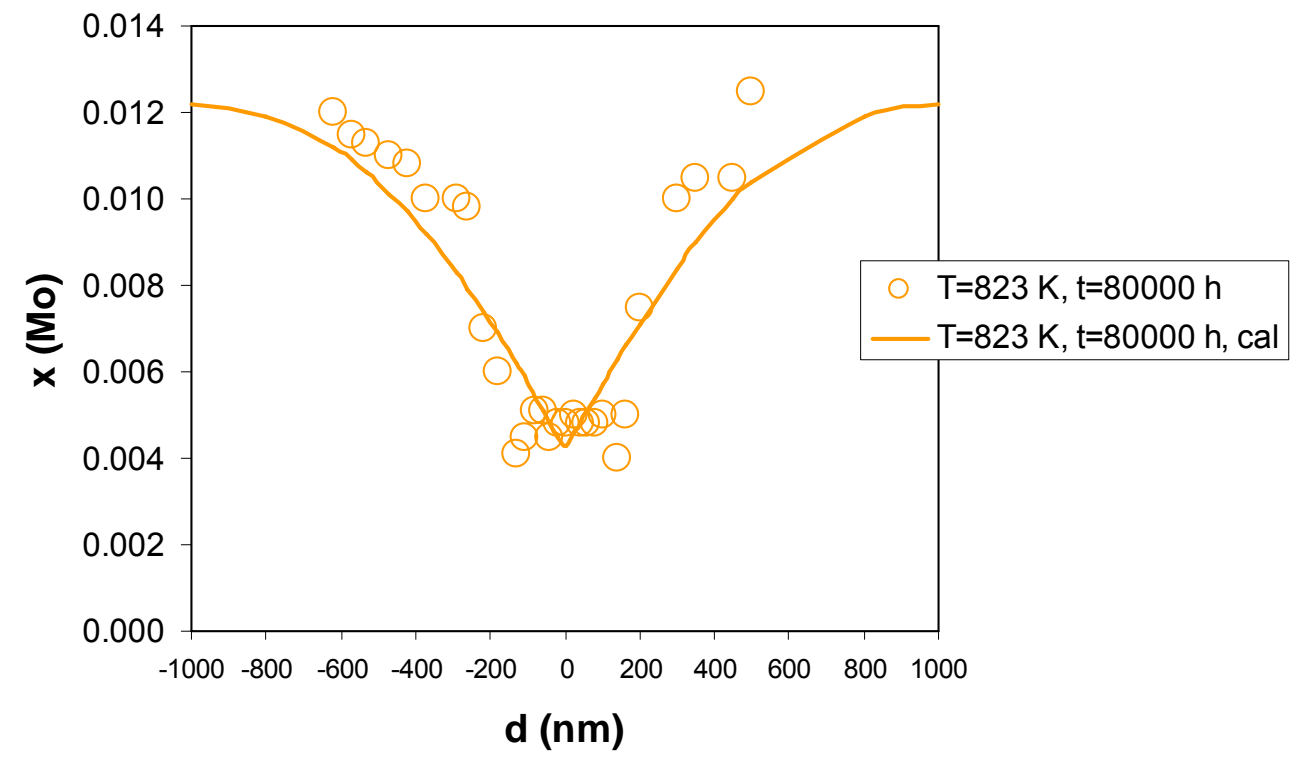

Figure 44. Calculated and experimental (Sahlaoui et al., 2004) Mo depletion profiles for type $316 \mathrm{~L}$ stainless steel sensitized at $823 \mathrm{~K}$ for $80000 \mathrm{~h}$. 


\section{Relating the repassivation potential to depletion profiles}

In a given chemical environment and at a given temperature, the repassivation potential is a function of the alloy chemistry. Specifically, it is determined by the chromium, molybdenum, tungsten and nitrogen content of the alloy and can be calculated using the correlation described above. The same correlation can be used to calculate the local values of the repassivation potential in the $\mathrm{Cr}$-depleted zones.

The local values of the repassivation potential depend on the local composition of the alloy as a function of the distance from the grain boundary. Figure 45 shows the difference between the local repassivation potential in alloy 825 and the $\mathrm{E}_{\mathrm{rp}}$ value of a homogeneous alloy. These calculations have been performed for alloy 825 sensitized for $15 \mathrm{~h}$ and $100 \mathrm{~h}$ at temperatures ranging from $873 \mathrm{~K}$ to $1073 \mathrm{~K}$. These sensitization conditions correspond to the chromium depletion profiles that have been experimentally obtained by Pan et al. (2000) and reproduced by the sensitization model described in the previous quarterly report. It should be noted that the reduction in the local $\mathrm{E}_{\mathrm{rp}}$ value qualitatively follows the chromium depletion profiles. This is understandable in view of the fact that the local concentration of $\mathrm{Cr}$ in the alloy is the primary determinant of the repassivation potential. The reduction in $\mathrm{E}_{\mathrm{rp}}$ is most pronounced at the grain boundary, where the local $\mathrm{Cr}$ concentration reaches a minimum. As shown in Figure 45, the predicted local $\mathrm{E}_{\mathrm{rp}}$ can drop by as much as $0.3 \mathrm{~V}$ at the grain boundary.

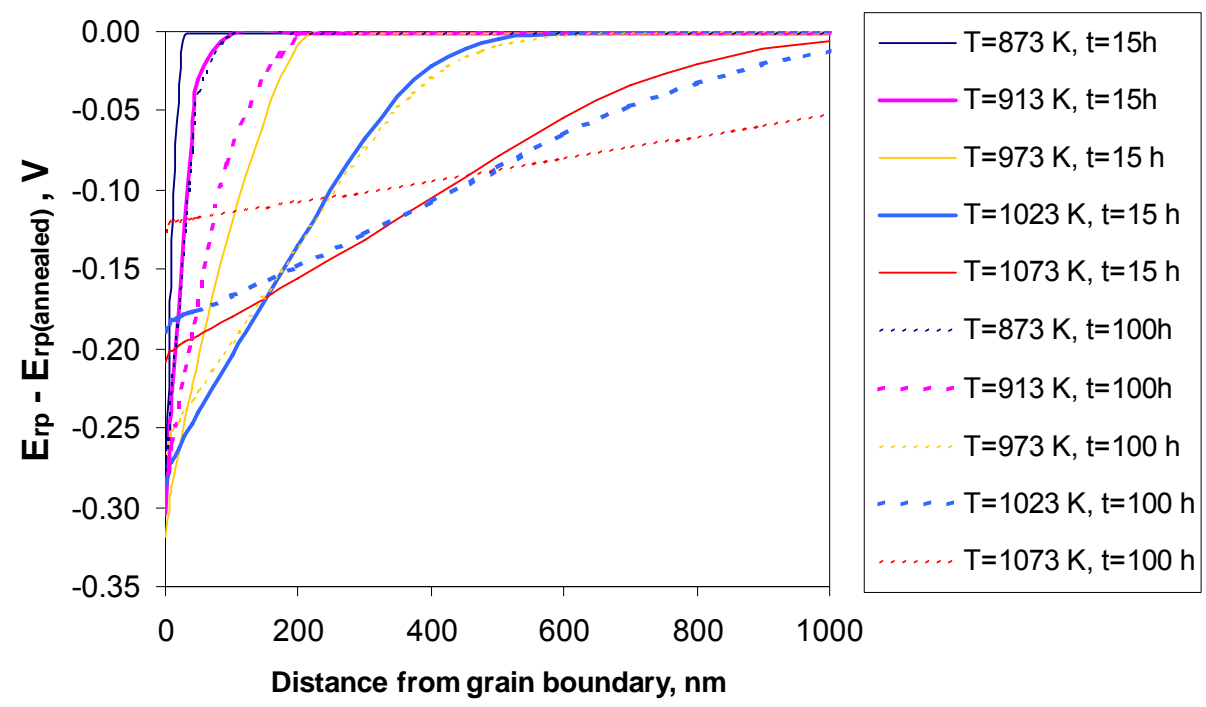

Figure 45. Reduction in the local value of the repassivation potential as a function of the distance from the grain boundary for alloy 825 samples sensitized for $15 \mathrm{~h}$ and $100 \mathrm{~h}$ at temperatures ranging from $873 \mathrm{~K}$ to $1073 \mathrm{~K}$.

However, the local value of $\mathrm{E}_{\mathrm{rp}}$ as a function of the distance from the grain boundary is not experimentally accessible. This is due to the fact that the measured repassivation potential is a macroscopic property, i.e., it reflects the repassivation of a pit with macroscopic dimensions. A macroscopic pit covers a certain finite surface of the alloy. The chromium concentration varies over the surface area that is exposed to the pit 
environment. Thus, the measurable repassivation potential can be expected to be an average of the local repassivation potentials over the alloy surface area that is exposed to the pit. In principle, it would be possible to calculate the averaged repassivation potential if the geometry of the pit was exactly known and the composition of the alloy that is exposed to the pit environment could be exactly ascertained. However, such information is not available in practice and, even if it were available, prediction of $E_{\mathrm{rp}}$ based on detailed measurements of individual pits would be of little predictive value. Instead, it is necessary to establish a procedure for calculating an estimate of the average repassivation potential for statistically distributed pits. For this purpose, it is reasonable to make the following assumptions:

(1) The measured $E_{\mathrm{rp}}$ primarily reflects the localized corrosion of the Cr-depleted regions rather than the surfaces whose $\mathrm{Cr}$ concentration is given by the nominal alloy composition. This is due to the fact that a pit stabilizes more easily in an area that is more susceptible to localized corrosion due to chromium (or molybdenum) depletion. Thus, the average repassivation potential should be calculated by integrating over the depleted zone.

(2) A pit needs to achieve a certain minimum size to be stabilized in an $\mathrm{E}_{\mathrm{rp}}$ measurement. Therefore, in the case of a narrow $\mathrm{Cr}$ depletion zones, the averaging may extend beyond the depletion zone to ensure that a certain minimum area of the alloy contributes to the measurable $\mathrm{E}_{\mathrm{rp}}$.

Following assumption (1), the average repassivation potential, $\left\langle E_{r p}\right\rangle$, is obtained by integration of the local repassivation potential, $E_{r p}$, as follows:

$$
\left\langle E_{r p}\right\rangle=\int_{0}^{L} E_{r p}[\underline{x}(z)] d z
$$

where $z$ is the distance from the grain boundary, $\underline{x}(z)$ is the alloy composition vector at a distance $z$, and the integration is performed from the grain boundary $(\mathrm{z}=0)$ to cover the extent of the depleted zone.

The definition of $L$ is unavoidably somewhat arbitrary, but a reasonable estimate can be obtained on the basis of the expression for the chromium depletion profile. The mole fraction of $\mathrm{Cr}$ in the depleted zone is given as a function of $z$ by

$$
x_{C r}^{\gamma}=x_{C r}^{\gamma \beta}+\left(x_{C r}^{0}-x_{C r}^{\gamma \beta}\right) \operatorname{erf}\left(\frac{z}{2 \sqrt{D t}}\right)
$$

where the grain boundary concentration, $x_{C r}^{\gamma \beta}$, is calculated from the combined thermodynamic-kinetic model as described before. We can introduce the effective thickness of the depleted zone, $Z_{\text {eff. }}$ For this purpose, we approximate the Cr profile by a straight line (in analogy with the classical treatment of Stawström and Hillert, 1969) by requiring that the total $\mathrm{Cr}$ depletion calculated from the straight-line approximation be equal to that obtained from the more rigorous eq. (2). The total $\mathrm{Cr}$ depletion (in moles $\mathrm{Cr}$ ) 
that results from eq. (2) is obtained by integration of the difference between the $\mathrm{Cr}$ concentration in the bulk, $C_{C r}^{0}$, and the local concentration, $C_{C r}^{\gamma}$, i.e.,

$$
\Delta n_{C r}^{\gamma}=S \int_{0}^{\infty}\left(C_{C r}^{0}-C_{C r}^{\gamma}\right) d z=\frac{S}{V_{m}^{\gamma}} \int_{0}^{\infty}\left(x_{C r}^{0}-x_{C r}^{\gamma}\right) d z
$$

where $\mathrm{S}$ is the grain surface area and $V_{m}^{\gamma}$ is the molar volume. Substitution of eq. (26) into eq. (27) and analytical integration yields:

$$
\Delta n_{C r}^{\gamma}=\frac{S\left(x_{C r}^{0}-x_{C r}^{\gamma \beta}\right)}{V_{m}^{\gamma}} \frac{2 \sqrt{D t}}{\sqrt{\pi}}
$$

With the straight-line approximation, the cross-section of the depletion zone is given by a right triangle with a surface area of $\left(x_{C r}^{0}-x_{C r}^{\gamma \beta}\right) Z_{e f f} / 2$ and, hence, the total $\mathrm{Cr}$ depletion is approximated as

$$
\Delta n_{C r}^{\gamma}=\frac{S}{V_{m}^{\gamma}} \frac{\left(x_{C r}^{0}-x_{C r}^{\gamma \beta}\right) Z_{e f f}}{2}
$$

Comparison of eq. (28) and eq. (29) yields a simple formula, i.e.,

$$
Z_{\text {eff }}=\frac{4 \sqrt{D t}}{\sqrt{\pi}}
$$

In view of assumption (2), the range over which the local $E_{\mathrm{rp}}$ values should be integrated is approximated by a sum of the effective size of the depletion zone $\left(Z_{e f f}\right)$ and a minimum size over which a pit can be stabilized $\left(L_{0}\right)$ :

$$
L=Z_{e f f}+L_{0}
$$

Thus, the averaged repassivation potential is calculated from equations (25), (30) and (31). The value of $L_{0}$ is assumed to be $20 \mathrm{~nm}$. This value plays a role only for very narrow depletion zones (i.e., for low sensitization temperatures or short times).

Figure 46 shows the results that have been obtained using this procedure for alloy 825 . In Figure 46, the reduction in the measured repassivation potential for sensitized samples is plotted as a function of sensitization temperature for two sensitization times $(15 \mathrm{~h}$ and $100 \mathrm{~h}$ ). It should be noted that the sensitization effect on the averaged (or experimentally observable) repassivation potentials is much weaker than on the local $\mathrm{E}_{\mathrm{rp}}$ values close to the grain boundary (cf. Figure 45). Thus, the averaging process (both in the experimental and computational sense) results in a relatively muted effect on sensitization on $\mathrm{E}_{\mathrm{rp}}$. Considering that no parameters were fitted to the data points shown in Figure 46, the prediction is in a good agreement with the experiment. The deviations between the 
calculated and experimental are essentially within experimental uncertainty. The minimum in the repassivation potential as a function of sensitization temperature is correctly predicted for the samples that were sensitized for $100 \mathrm{~h}$ and is somewhat off for the samples sensitized at $15 \mathrm{~h}$.

Figure 46 compares the calculated and experimental reduction in the repassivation potential for alloy 600 . In this case, the recent experimental data for samples sensitized at 973 have been used. Unlike Figure 45, Figure 46 illustrates the sensitization effect for three different chloride concentrations (i.e., $0.001,0.005$ and $0.04 \mathrm{~m}$ at $333 \mathrm{~K}$ ). On average, the sensitization effect is somewhat weaker than that observed for alloy 825 . The agreement between the experimental and predicted values is generally satisfactory although the predicted curves are more flat than the experimental data. As shown in the lower diagram of Figure 46, the predicted minimum in Erp is very flat, but it is reasonably consistent with the data. However, the predicted reduction in $\mathrm{E}_{\mathrm{rp}}$ is almost independent of the chloride concentration even though the absolute $\mathrm{E}_{\mathrm{rp}}$ values are a strong function of chloride. This unexpected finding is not a fundamental feature of the model, but results mostly from the adopted procedure for averaging the repassivation potential. Because of this effect, the agreement with the data is better for $0.001 \mathrm{~m}$ and $0.005 \mathrm{~m}$ solutions than for $0.04 \mathrm{~m}$ solutions, for which the experimentally observed effect is negligible.

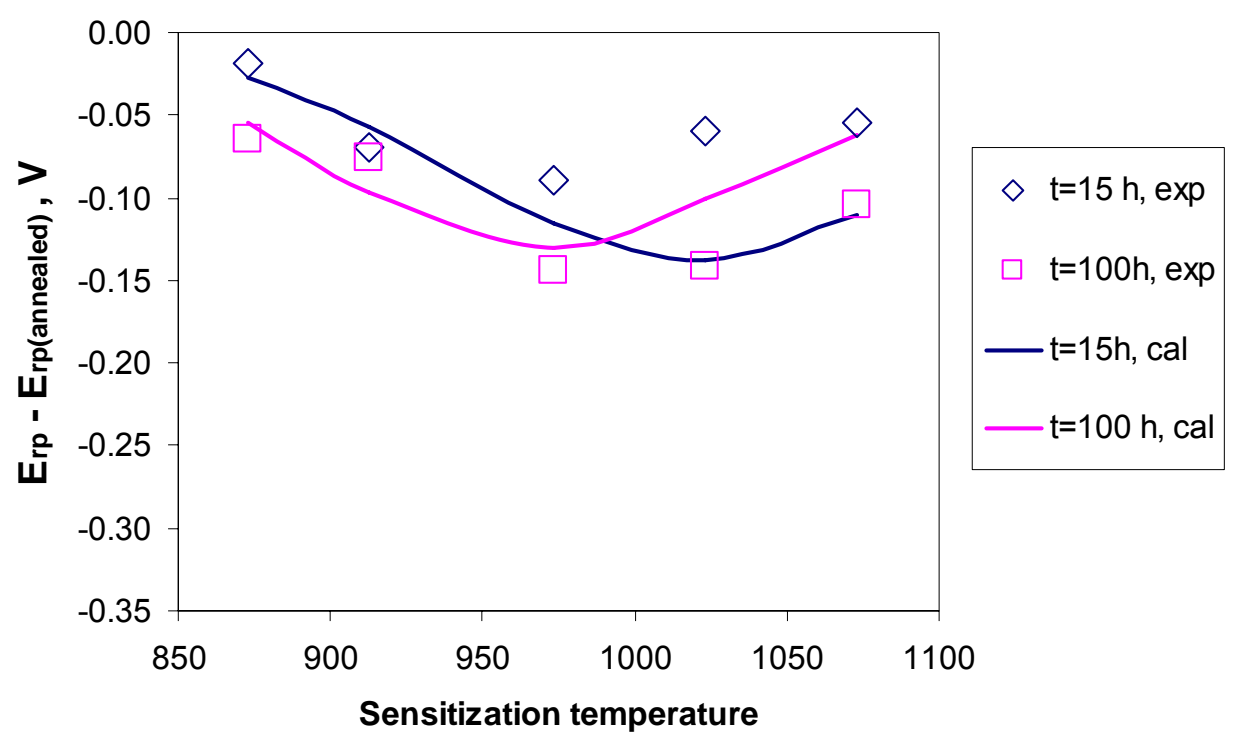

Figure 45. Comparison of predicted and experimental reduction in the repassivation potential of sensitized alloy 825 in $0.00266 \mathrm{~m}$ chloride solution at $368 \mathrm{~K}$. 

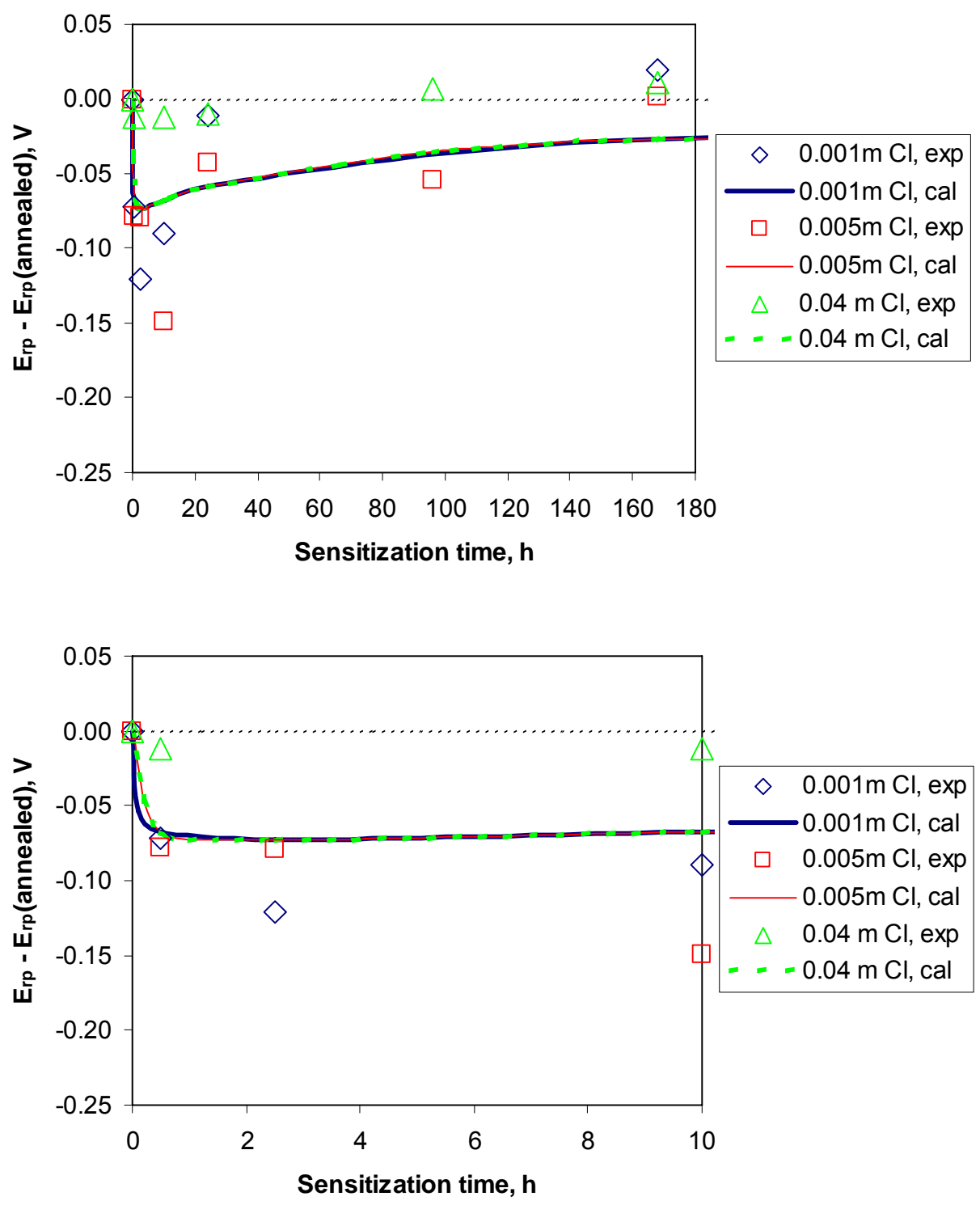

Figure 46. Comparison of predicted and experimental reduction in the repassivation potential of alloy 600 sensitized at $973 \mathrm{~K}$. The repassivation potentials were obtained at $333 \mathrm{~K}$ at various chloride concentrations. The upper diagram shows the full range of sensitization times (up to $168 \mathrm{~h}$ ) and the lower diagram presents a subset of the data for times up to $10 \mathrm{~h}$. 


\section{Repassivation potential of weldments}

As shown above, the $\mathrm{E}_{\mathrm{rp}}$ model can accurately predict the repassivation potential of heattreated samples. The same model is applicable to welded samples as long as the variation in alloy composition can be estimated.

Nickel-base alloys and superaustentic stainless steel welds may exhibit segregation of alloying elements (Cieslak et al., 1986). Segregation results in a pattern of Ni depletion and solute (i.e., Cr, Mo and W) enrichment in interdendritic volumes. At the same time, solute depletion occurs in dendrite cores. Cieslak et al. (1986) determined the distribution of alloying elements as a function of distance from the dendrite core. The solute depletion is typically most pronounced for molybdenum in nickel-base alloys.

As discussed in the previous report, localized corrosion is most likely to stabilize in the most susceptible regions, i.e., those with the lowest solute concentrations. Thus, the repassivation potential calculated in such a region should provide the lowest (i.e., most conservative) estimate of the measurable $\mathrm{E}_{\mathrm{rp}}$. Such calculations have been performed for alloys 276 and 22.

Figure 47 compares the calculated and experimental depression of the repassivation potential for welded samples of alloy 276 (i.e., the difference between $\mathrm{E}_{\mathrm{rp}}$ of the welded and annealed material). The calculated line illustrates the predicted worst-case $\mathrm{E}_{\mathrm{rp}}$ depression. As shown in Figure 47, there is a substantial scattering of the experimental results. Nevertheless, the predicted minimum in $\mathrm{E}_{\mathrm{rp}}$ is in a reasonable agreement with experimental data.

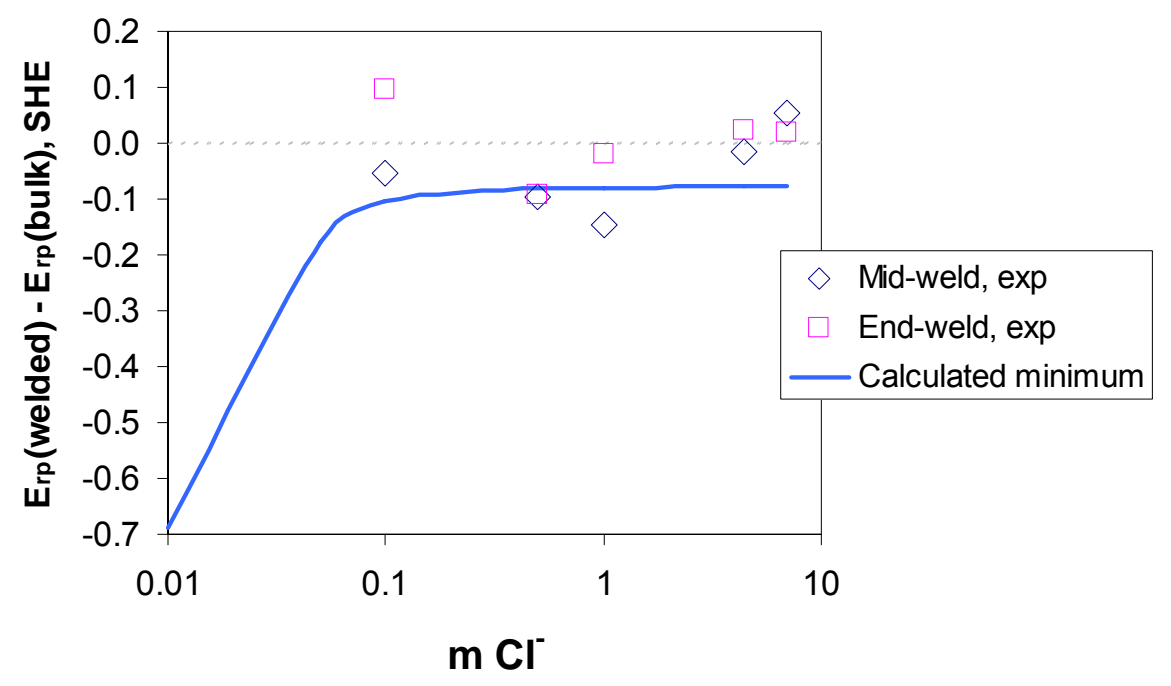

Figure 47. Calculated and experimental depression of the repassivation potential for welded samples of alloy $\mathrm{C}-276$ at $95^{\circ} \mathrm{C}$ at varying chloride concentrations. 
Figure 48 shows the calculated and experimental repassivation potentials for millannealed and welded alloy 22. In this case, the figure shows the actual, calculated and experimental, values of the repassivation potential rather than the depression of $E_{r p}$ due to welding. The model reasonably predicts the repassivation potentials for both the base alloy and welded samples. It should be noted that the data for welded samples were not used to adjust the model parameters in any way and, thus, Figure 48 represents a pure prediction. The depression of $\mathrm{E}_{\mathrm{rp}}$ due to welding is correctly predicted by the model.

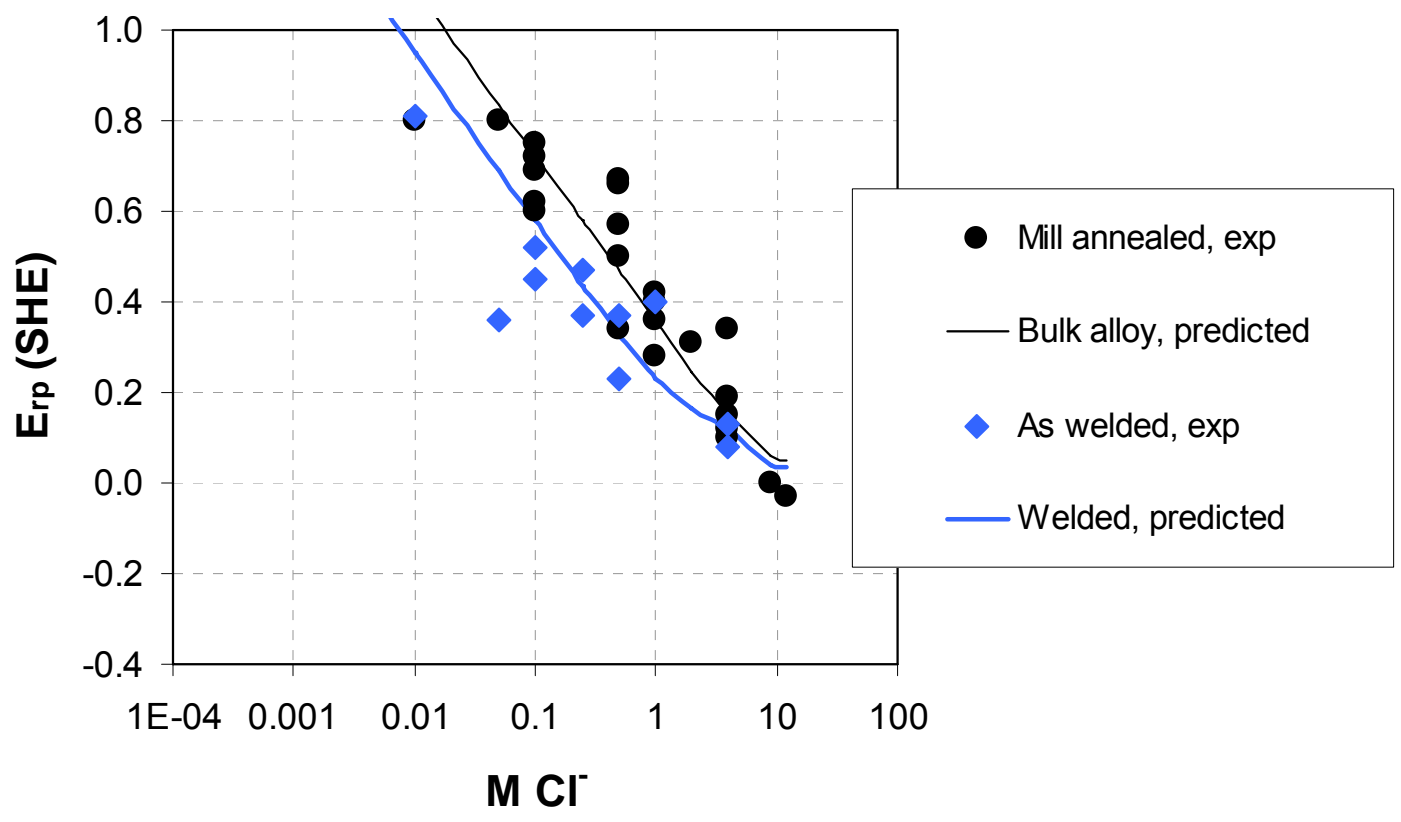

Figure 48. Calculated and experimental repassivation potentials of mill-annealed and welded alloy 22 at $95^{\circ} \mathrm{C}$ as a function of chloride ion concentration.

As shown in the preceding sections, the electrochemical model of corrosion predicts the repassivation potential for both base alloys and fabricated (i.e., heat treated or welded) specimens. When coupled with the corrosion potential calculated from the general corrosion model, it can be used to assess whether a given alloy is susceptible to localized corrosion.

A particularly stringent test of the reliability of the proposed model is the prediction of the critical crevice temperature. For example, Figure 49 shows the computation of the critical crevice temperature for alloy $\mathrm{C}-276$. The critical crevice temperature (CCT) can be identified as the temperature threshold above which crevice corrosion is observed. At temperatures below CCT, the corrosion potential ( $\left.\mathrm{E}_{\text {corr }}\right)$ should lie below the repassivation potential $\left(\mathrm{E}_{\mathrm{rp}}\right)$ whereas it should exceed $\mathrm{E}_{\mathrm{rp}}$ above CCT. Thus, the intersection of the $E_{\text {corr }}$ and $E_{\mathrm{rp}}$ curves versus temperature should provide an estimate of CCT. Figure 49 illustrates such calculations for alloy $\mathrm{C}-276$ in $6 \% \mathrm{FeCl}_{3}$ solutions. As shown in Figure 49, the $\mathrm{E}_{\mathrm{rp}}$ and $\mathrm{E}_{\text {corr }}$ curves intersect at a temperature that is in a good agreement with experimental critical crevice temperature data. Another example of prediction of CCT is shown in Figure 50 for alloy 625. 


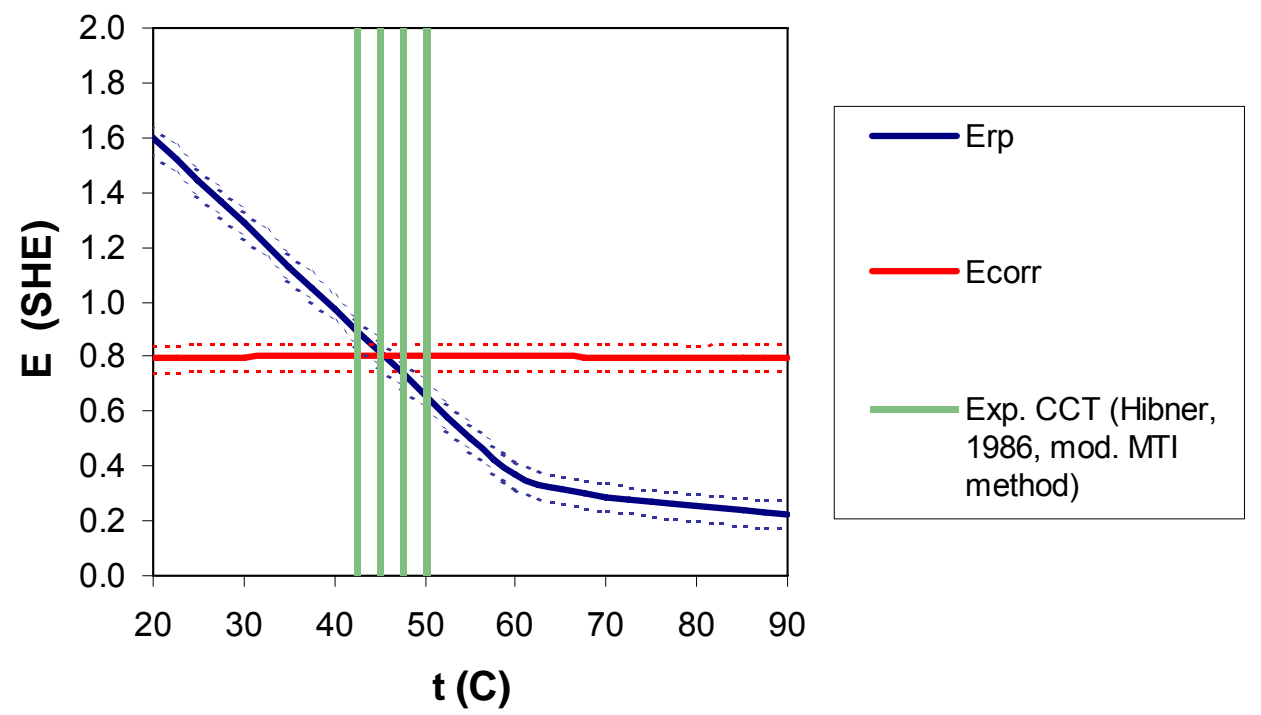

Figure 49. Prediction of the critical crevice temperature for alloy $\mathrm{C}-276$ in a $6 \% \mathrm{FeCl}_{3}$ solution. The intersection of the calculated corrosion potential and repassivation potential lines shows the predicted critical crevice temperature

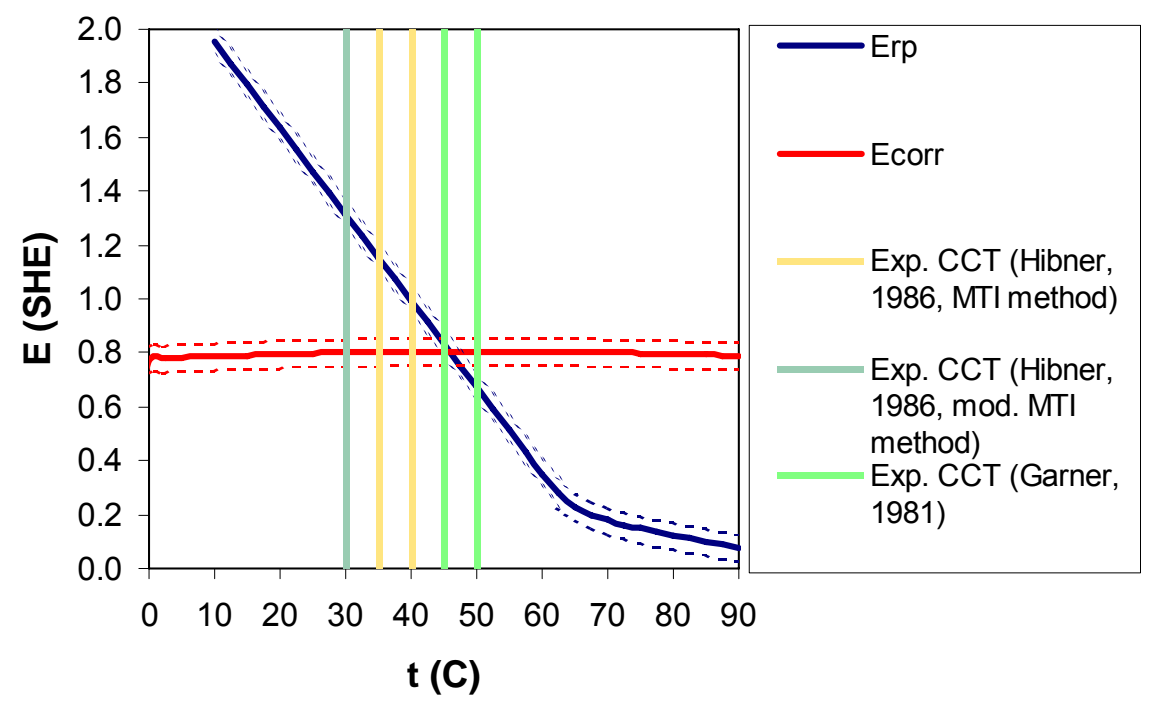

Figure 50. Prediction of the critical crevice temperature for alloy 625 in a $6 \% \mathrm{FeCl}_{3}$ solution.

While predicting whether or not localized corrosion occurs in a given chemical environment, the electrochemical models described so far do not predict the time evolution of corrosion damage nor do they account for the distributed, probabilistic nature of localized corrosion events. These topics will be described in the next section. 


\section{Prediction of corrosion damage}

Localized corrosion damage in an arbitrary system is completely defined if we know how many pits or other corrosion events (per $\left.\mathrm{cm}^{2}\right)$ have depths between $\mathrm{x}_{1}$ and $\mathrm{x}_{2}\left(\mathrm{x}_{1}<\mathrm{x}_{2}\right)$ for a given observation time, $\mathrm{t}$. Let us denote this number by $\Delta \mathrm{N}_{\mathrm{k}}\left(\mathrm{x}_{1}, \mathrm{x}_{2}, \mathrm{t}\right)$. Here, the index $\mathrm{k}$ denotes different types of corrosion events (e.g., pits or cracks). Instead of employing a function with three variables, $\Delta \mathrm{N}_{\mathrm{k}}$, it is more convenient to use a function of two variables - the integral damage function (IDF), $\mathrm{F}_{\mathrm{k}}(\mathrm{x}, \mathrm{t})$. This function is defined as the number $\left(\right.$ per $\mathrm{cm}^{2}$ ) of corrosion events with depths larger than $\mathrm{x}$ for a given observation time, $\mathrm{t}$. It is evident that

$$
\Delta \mathrm{N}_{\mathrm{k}}\left(\mathrm{x}_{1}, \mathrm{x}_{2}, \mathrm{t}\right)=\mathrm{F}_{\mathrm{k}}\left(\mathrm{x}_{1}, \mathrm{t}\right)-\mathrm{F}_{\mathrm{k}}\left(\mathrm{x}_{2}, \mathrm{t}\right)
$$

In turn, it is convenient to express the integral DF, $F_{k}(x, t)$, via the differential DF, $f_{k}(x, t)$, using the relation

$$
F_{k}(x, t)=\int_{x}^{\infty} f_{k}\left(x^{\prime}, t\right) d x^{\prime} \quad \text { or } \quad f_{k}(x, t)=-\frac{\partial F_{k}(x, t)}{\partial x}
$$

The differential DF for defects of type $k, f_{k}$, is defined by the condition that $f_{k}(x, t) d x$ is the number of defects $\mathrm{k}$ (per $\mathrm{cm}^{2}$ ) having a depth between $\mathrm{x}$ and $\mathrm{x}+\mathrm{dx}$ for a given observation time, $t$. It is evident that the set of functions $f_{k}$ for all types of defects yields complete information about damage in the system. The advantage of using the differential DF lies in the fact that it obeys a simple differential equation (see below) and, accordingly, can be calculated for any given set of conditions. Of course, all of the functions $\Delta \mathrm{N}_{\mathrm{k}}\left(\mathrm{x}_{1}, \mathrm{x}_{2}, \mathrm{t}\right), \mathrm{F}_{\mathrm{k}}(\mathrm{x}, \mathrm{t})$, and $\mathrm{f}_{\mathrm{k}}(\mathrm{x}, \mathrm{t})$ may depend, in a general case, on the position on the metal surface, but in this analysis we will assume that all sites belong to a given population.

The function $\mathrm{f}_{\mathrm{k}}$ has the dimension of $\# /\left(\mathrm{cm}^{2} \mathrm{~cm}\right)=\# / \mathrm{cm}^{3}$ (analogous to the concentration of a particle). Accordingly, it is very convenient to regard each defect as a "particle" that moves in the $\mathrm{x}$ direction (perpendicular to the surface, with $\mathrm{x}=0$ being at the metal surface). The coordinate of this particle, $x$, coincides with the depth of penetration of the defect. Accordingly, $\mathrm{f}_{\mathrm{k}}$ can be regarded as the concentration of particles and hence must obey the law of mass conservation,

$$
\frac{\partial \mathrm{f}_{\mathrm{k}}}{\partial \mathrm{t}}+\frac{\partial \mathrm{j}_{\mathrm{k}}}{\partial \mathrm{x}}=\mathrm{R}_{\mathrm{k}}, \quad \mathrm{k}=1,2, \ldots, \mathrm{K}
$$

where $j_{k}$ and $R_{k}$ are the flux density and the bulk source (sink) of the "particles" $k$, respectively. Thus, the subscript " $k$ " enumerates the corrosion defect and " $K$ " is the total number of different corrosion defects in the system. By definition $R_{k}(x, t) d x d t$ yields the number of defects $\mathrm{k}$ (per $\mathrm{cm}^{2}$ ) with depths between $\mathrm{x}$ and $\mathrm{x}+\mathrm{dx}$ that arise (or disappear) during the period of time between $t$ and $t+d t$, due to the transformation (repassivation, in the case of pits). 
The system of Equations (3) can be solved with the corresponding boundary and initial conditions.

and

$$
\mathrm{j}_{\mathrm{k}}=\mathrm{n}_{\mathrm{k}}(\mathrm{t}) \text { at } \mathrm{x}=0, \mathrm{t}>0
$$

$$
\mathrm{f}_{\mathrm{k}}=\mathrm{f}_{\mathrm{k} 0}(\mathrm{x}) \text { at } \mathrm{x}>0, \mathrm{t}=0
$$

where $\mathrm{f}_{\mathrm{k} 0}(\mathrm{x})$ is the initial distribution of defect $\mathrm{k}$ [usually we can assume that $\mathrm{f}_{\mathrm{k} 0}(\mathrm{x})=0$ ), i.e., no damage exists at zero time] and $n_{k}(t)$ is the nucleation rate of the same defect [i.e, $\mathrm{n}_{\mathrm{k}}(\mathrm{t}) \mathrm{dt}$ is the number of stable defects $\left(\right.$ per $\left.\mathrm{cm}^{2}\right)$ that nucleate in the induction time interval between $\mathrm{t}$ and $\mathrm{t}+\mathrm{dt}]$.

According to the theory developed above, calculation of the damage functions requires the determination of three independent functions for each kind of corrosion defect, $\mathrm{k}$ : The rate of defect nucleation, $\mathrm{n}_{\mathrm{k}}$, the flux density (growth rate) of the defect, $\mathrm{j}_{\mathrm{k}}$, and the rate of transition of one kind of defect to another, $\mathrm{R}_{\mathrm{k}}$, (for example, the transition of an active pit into a passive pit or the transition of a pit into a crack). In other words we need to have quantitative models for describing each stage of corrosion damage as indicated on Figure 1. Below, we will discuss briefly the feasibility of calculating each of these three functions from first principles.

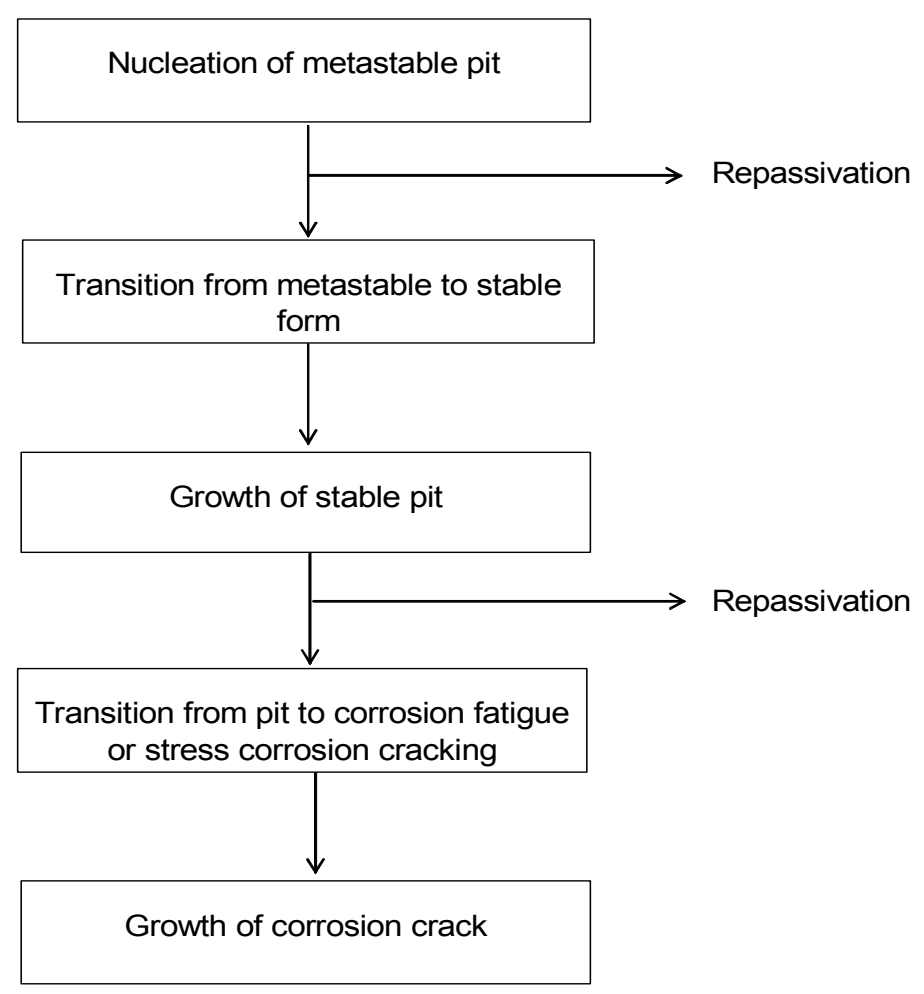

Figure 1. Schematic history of the nucleation and propagation of corrosion damage. 


\section{Rate of pit nucleation}

In many practical cases, it is possible to assume that all pits on a given surface nucleate during an initial period of time that is much less than the observation time, $t$, or the service life of the system, $\mathrm{t}_{\mathrm{s}}$ (instantaneous nucleation). For example, for the case of the pitting corrosion of aluminum in tap water, practically all of the pits were found to nucleate within the first two weeks [Aziz, 1956].

If pit nucleation cannot be regarded as being "instantaneous", the simplest assumption concerning the pit nucleation rate, $\mathrm{n}(\mathrm{t})=\mathrm{dN} / \mathrm{dt}$, [N is the number of stable pits (per $\mathrm{cm}^{2}$ ) that nucleate in the time interval between 0 and $t$.] that $n(t)$ is proportional to the number of available sites, $\mathrm{N}_{0}-\mathrm{N}(\mathrm{t})$ [Pistorius and Burstein, 1992], which yields.

$$
\mathrm{N}(\mathrm{t})=\mathrm{N}_{0}\left[1-\exp \left(-\mathrm{t} / \mathrm{t}_{0}\right)\right]
$$

where $\mathrm{N}_{0}$ is the maximum number of stable pits (per $\mathrm{cm}^{2}$ ) that can exist on the metal surface and $t_{0}$ is some characteristic time that depends on the corrosion potential, temperature, and electrolyte composition.

A more general and sophisticated calculation of the pit nucleation rate can be made on the basis of the Point Defect Model (PDM) [Lin et al, 1981, Macdonald et al. 1986, 1987, $1989,1992]$. In accordance with this model, it can be shown that the total number of nucleated pits can be described by the following expression [Engelhardt and Macdonald, 1998]

$$
\mathrm{N}(\mathrm{t})=\mathrm{N}_{0} \operatorname{erfc}\left(\frac{\mathrm{a}}{\mathrm{t}}+\mathrm{b}\right) / \operatorname{erfc}(\mathrm{b})
$$

The parameters a and $\mathrm{b}$ specifically depend on temperature, $\mathrm{pH}$, activity of halide ions, and the metal potential, but do not depend on the induction time. These dependencies can be found in the original works. However, it is also important to note that the original PDM describes pit nucleation for the case when the external conditions do not depend on time. This restriction can be a serious impediment in predicting the pit nucleation rate under practical conditions, for example, when seasonal changes in temperature and wetness are observed for a system that is subject to atmospheric corrosion. The generalization of PDM is also easy for the case of variable external conditions [Engelhardt and Macdonald, 2004, a].

\section{Rate of pit propagation}

The quantitative description of pit (or crack) growth can be regarded as one of the key problems in predicting corrosion damage in many practical systems. This follows from the fact that the calculated corrosion damage that is based only on this (growth) stage can be compared with experiment, in many limiting cases. For example when all pits nucleate "instantaneously", or when the induction time for pit nucleation is much smaller than the observation time, it is possible to ignore the initial stage of pit nucleation when estimating the damage. In addition, if the probability of survival of a corrosion defect is 
sufficiently high, we must take into account the possibility that a stable corrosion defect (pit or crack) nucleates immediately after the start of operation and propagates without repassivation. In any case, calculations based only on the growth stage yield the most conservative estimate of the service life, $\mathrm{t}_{\mathrm{s}, \mathrm{min}}$, of the system. We can be sure that, if calculation of the service life is based on growth alone, the real service life, $t_{\mathrm{s}}$, will at least be not less than $t_{s, \min }$.

In the simplest case, it can be assumed that the pit propagation rate, $\mathrm{V}$ depends only on the depth of the pit, and accordingly the flux density of the active pits can be represented in the form

$$
\mathrm{j}_{\mathrm{a}}(\mathrm{x}, \mathrm{t})=\mathrm{f}_{\mathrm{a}}(\mathrm{x}, \mathrm{t}) \mathrm{V}(\mathrm{x})
$$

where $f_{a}$ is the damage function of the active pits.

It is well known from both experiment [Szklarska-Smialowska, 1998] and theory [Engelhardt et al. 1999] that the dependence of the characteristic dimension of a corrosion cavity (for example, cavity depth, $\mathrm{x}$ ) on time, $\mathrm{t}$, can be expressed by a simple equation of the following form

$$
\mathrm{x}=\mathrm{kt}^{\mathrm{m}}
$$

where $\mathrm{k}$ and $\mathrm{m}$ are empirical constants, and, usually, $\mathrm{m} \leq 1$. However, this dependence of $\mathrm{L}$ on $\mathrm{t}$ cannot be used directly in mathematical calculations for small times, because of the non-physical limit

$$
\mathrm{V}=\frac{\mathrm{dx}}{\mathrm{dt}}=\mathrm{kmt}^{\mathrm{m}-1} \rightarrow \infty, \quad \text { at } \mathrm{t} \rightarrow 0 \text { and } \mathrm{m}<1
$$

This is why, instead of Equation (9), we use the following interpolation equation for pit propagation rate

$$
\mathrm{V}=\frac{\mathrm{dx}}{\mathrm{dt}}=\mathrm{V}_{0}\left(1+\mathrm{t} / \mathrm{t}_{0}\right)^{\mathrm{m}}
$$

where $\mathrm{n}=\mathrm{m}-1$ and $\mathrm{t}_{0}$ are constants, and $\mathrm{V}_{0}$ is the initial, finite rate of pit propagation. Equation (11) yields $\mathrm{V}=\mathrm{V}_{0}$ at $\mathrm{t} / \mathrm{t}_{0}<<0$ and $\mathrm{V}=\mathrm{V}\left(\mathrm{t} / \mathrm{t}_{0}\right)^{\mathrm{n}}$ at $\mathrm{t}>>\mathrm{t}_{0}$. In some cases it is necessary to present pit propagation rate, $\mathrm{V}$, as a function of the pit penetration depth, $\mathrm{x}$.

We will describe the changes of pit (crevice) propagation rate, $\mathrm{v}$, with its depth, $\mathrm{x}$, by the relation

$$
\mathrm{V}(\mathrm{x})=\frac{\mathrm{dx}}{\mathrm{dt}}=\mathrm{V}_{0} \varsigma(\mathrm{x})
$$

where 


$$
\varsigma(\mathrm{x})=\frac{1}{\left(1+\mathrm{x} / \mathrm{x}_{0}\right)^{(1-\mathrm{m}) / \mathrm{m}}}
$$

where the parameter, $\mathrm{x}_{0}$, has the dimension of length. It is evident that function $\zeta(\mathrm{x})$ satisfies the required boundary condition $\zeta(\mathrm{x}) \rightarrow 1$ at $\mathrm{x} \rightarrow 0$.

It is important to note that, in many cases, the period of time over which the approximation

$$
\mathrm{V}(\mathrm{x}) \approx \mathrm{V}_{0}=\text { constant }
$$

is valid can be comparable with the observation time (or even with the service life of the system). The reason is that corrosion is, generally speaking, a slow process and under real, practical conditions, values of the critical pit depth of the system, $\mathrm{x}_{\mathrm{cr}}$, (e.g., wall thickness of a pipe) and typical service life, $t_{s}$, impose significant restrictions on the values of the initial and average corrosion current densities and, thus, on the potential and concentration drops that might be observed in a corrosion cavity [Engelhardt and Macdonald, 2004, b]. Thus, as follows from Faraday's law, if $\mathrm{x}_{\mathrm{cr}}$ does not exceed the order of $1-10 \mathrm{~mm}$, and if the order of $\mathrm{t}_{\mathrm{s}}$ is not less than 1 year, the initial corrosion current densities in real pits cannot exceed values of $10^{-4}-10^{-3} \mathrm{~A} / \mathrm{cm}^{2}$, with the understanding that the polarization curve (corrosion current density vs. potential) does not change as the pit propagates [Engelhardt and Macdonald, 2004, b]. Such low current densities can arise only from relatively low values of the potential and concentration drops in open pits. In particular, it was shown that if localized corrosion takes place in an electrolyte having a conductivity of the order of that of sea water, it is possible to neglect the potential drop in an open corrosion cavity and, hence, it is possible to regard the rate of pit propagation as being constant under constant environmental conditions. The same conclusion holds for the pitting of $316 \mathrm{~L}$ stainless steel for practically any composition of the external electrolyte. This issue is discussed in greater depth in [Engelhardt and Macdonald, 2004, b].

However, in a general case, the concentration of electrolyte in practical systems can be very low and the potential and concentration drops inside pit cavities must be taken into account by estimating the pit growth rates. Thus, for example, the concentration of electrolyte (e.g., chloride) in steam turbines can be less than $1 \mathrm{ppm}$ and corrosion often takes place in practically pure water. It has been shown experimentally that potential drops in corrosion cavities can be of order of $0.1 \mathrm{~V}$ [Turnbull et al, 2004] in such systems. Accordingly, it becomes necessary to generalize the DFA and EVS methods for the case of corrosion in dilute electrolytes when pit (cavity) propagation rates depend on the pit (cavity) depth. It is important to note that the parameters $\mathrm{m}$, and $\mathrm{x}_{0}$ can be estimated from first principles by solving an appropriate system of mass and charge conservation equations for the species in the solution. A general mathematical model and corresponding computer code for calculating the potential and concentrations distributions in corrosion cavities (pits and cracks) has been developed. Calculation procedures reduce to solving the relevant system of mass conservation equations for the species in the solution. It can be shown that, if the width of the cavity, w, is much 
smaller than the crack depth, L, then averaging between the walls of the crack yields transport equations of the form:

$$
\frac{\partial\left(\mathrm{wC}_{\mathrm{k}}\right)}{\partial \mathrm{t}}=-\frac{\partial\left(\mathrm{wN}_{\mathrm{k}}\right)}{\partial \mathrm{x}}+\mathrm{wR}_{\mathrm{Vk}}+2 \mathrm{~N}_{\mathrm{sk}}, \quad \mathrm{k}=1, \ldots, \mathrm{K}
$$

where $\mathrm{N}_{\mathrm{k}}$ is the flux density, $\mathrm{R}_{\mathrm{Vk}}$ is the rate of creation of ionic species, $k$, per unit volume, $\mathrm{N}_{\mathrm{sk}}$ is the flux of species $\mathrm{k}$ through the metal-solution interface on the side walls, and $\mathrm{K}$ is the total number of species. Mass transfer by diffusion, migration, and convection, due to the movement of the crack walls, is considered by writing, according to the dilute solution theory, an equation for the flux of species, $k$, according to the Nernst- Planck equation:

$$
\mathrm{N}_{\mathrm{k}}=-\mathrm{D}_{\mathrm{k}}\left(\frac{\mathrm{dc}_{\mathrm{k}}}{\mathrm{dx}}+\frac{\mathrm{z}_{\mathrm{k}} \mathrm{F}}{\mathrm{RT}} \mathrm{c}_{\mathrm{k}} \frac{\mathrm{d} \varphi}{\mathrm{dx}}\right)
$$

where $c_{k}$ is the concentration of species $k, D_{k}$ is the diffusion coefficient, $z_{k}$ is the charge, $\mathrm{T}$ is the temperature, $\mathrm{R}$ is the gas constant, $\mathrm{x}$ is the distance down the crevice, and $\varphi$ is the electrostatic potential. The solution within the crevice is taken to be electrically neutral, so that

$$
\sum_{\mathrm{k}} \mathrm{z}_{\mathrm{k}} \mathrm{C}_{\mathrm{k}}=0
$$

After solving Equations (4) -(6) with corresponding boundary conditions, quantitative estimates for the parameters $m$ and $x_{0}$ can be obtained. However, in many practical cases, even analytical expressions for parameters $\mathrm{m}$ and $\mathrm{x}_{0}$ can be obtained. Thus, it can be shown that the parameter $\mathrm{m}$ can be expressed as

$$
\mathrm{m}=\frac{\alpha_{\text {eff }}+1}{2 \alpha_{\text {eff }}+1}
$$

where $\alpha_{\mathrm{eff}}$ is the effective anodic transfer coefficient for the metal or alloy (for the case of diffusion limitations $m=1 / 2$ ). The value of $\alpha_{\text {eff }}$, can be ascertained as follows. Usually, the electrodissolution reaction occurring in the cavity, due to oxidation of the metal, is described in terms of the Tafel equation as

$$
\mathrm{i}_{\text {corr }}=\mathrm{i}_{0} \exp \left[\frac{\alpha \mathrm{F}\left(\mathrm{E}-\mathrm{U}_{0}-\varphi_{\mathrm{s}}\right)}{\mathrm{RT}}\right]=\mathrm{i}^{*} \exp \left[-\frac{\alpha \mathrm{F} \varphi_{\mathrm{s}}}{\mathrm{RT}}\right]
$$

Here, $i_{0}$ is the exchange current density, $\alpha$ is the anodic transfer coefficient, $\mathrm{U}_{0}$ is the open-circuit potential, and $\mathrm{i}^{*}=\mathrm{i}_{0} \exp \left[\frac{\alpha \mathrm{F}\left(\mathrm{E}-\mathrm{U}_{0}\right)}{\mathrm{RT}}\right]$ is the current density calculated in the absence of a potential drop in the cell. All potentials $\mathrm{E}, \mathrm{U}_{0}$, and $\varphi_{\mathrm{s}}$, are referred to the same reference electrode at infinity. It is convenient to define 


$$
i^{*}=i_{0} f\left(C_{1 s}, C_{2 s}, \ldots, C_{N s}\right)
$$

where $i_{0}^{*}$ is the corrosion current density under the conditions when there are no concentration and potential drops in the solution and $\mathrm{C}_{\mathrm{ks}}$ is the surface concentration of species $\mathrm{k}$. We will assume that $\mathrm{i}_{0}^{*}$ is the initial corrosion current density that is realized in the system after depassivation of the surface. Usually, it is supposed that $i_{\text {corr }}$ does not depend on species concentration and $\mathrm{f} \equiv 1$ [Harb 1991]. However, in some cases, a power dependence has been assumed, i.e.

$$
\mathrm{f}\left(\mathrm{C}_{1 \mathrm{~s}}, \mathrm{C}_{2 \mathrm{~s}}, \ldots, \mathrm{C}_{\mathrm{Ns}}\right)=\prod_{\mathrm{k}=2}^{\mathrm{N}}\left(\frac{\mathrm{C}_{\mathrm{k}, \mathrm{s}}}{\mathrm{C}_{\mathrm{k}, \infty}}\right)^{\lambda_{\mathrm{k}}}
$$

where $\mathrm{C}_{\mathrm{k} \infty}$ is the bulk concentration of species $\mathrm{k}$. If ionic species that influence the kinetics of corrosion do not participate in any chemical or electrochemical reactions, their concentrations are described by the Boltzmann distribution law and we have for the corrosion current density:

$$
\mathrm{i}_{\text {corr }}=\mathrm{i}_{0}^{*} \exp \left[-\frac{\alpha_{\text {eff }} \mathrm{F} \varphi_{\mathrm{s}}}{\mathrm{RT}}\right]
$$

where

$$
\alpha_{\text {eff }}=\alpha+\sum_{\mathrm{k}=2}^{\mathrm{N}} \mathrm{z}_{\mathrm{k}} \lambda_{\mathrm{k}}
$$

is the effective transfer coefficient. In many practical cases, the corrosion current density depends only on the concentration of $\mathrm{Cl}^{-}$, in which case Equation (32) reduces to

$$
\alpha_{\mathrm{eff}}=\alpha-\lambda
$$

where $\lambda$ is the effective kinetic order of the metal dissolution reaction with respect to the $\mathrm{Cl}^{-}$concentration. Three different cases can occur under these conditions:

a) $\alpha>\lambda$, i.e. $\alpha_{\text {eff }}>0$. This is the usual case. Since the value of the electric potential at the bottom of the pit increases as the pit propagates, the dissolution rate at the bottom decreases as a function of pit depth (note that $\phi_{\mathrm{s}}$ is the potential in the solution with respect to a reference electrode at infinity).

b) $\alpha=\lambda$, i.e. $\alpha_{\text {eff }}=0$. In this case, the accelerating action of anions on the electrode reaction completely compensates for the increasing potential drop in the solution during pit growth. The dissolution rate does not change with pit length or time and equals its initial value.

c) $\alpha<\lambda$, i.e. $\alpha_{\text {eff }}<0$. In this last case, the accelerating action of anions on the electrode reaction outweighs the inhibiting effect that arises from the increase in the potential drop in the cavity environment, as the pit grows. Acceleration of the pit growth rate with time has been noted in the literature [Macdonald, Corrosion, 50, 761 (1985)]. 
The parameter $\mathrm{x}_{0}$ depends on $\alpha_{\text {eff }}$, electrolyte composition and the width of the electrolyte film. Thus, for the case of pitting corrosion in $\mathrm{NaCl}$ this parameter can be expressed as

$$
\mathrm{x}_{0}=\frac{\left(\mathrm{z}_{\mathrm{eff}}+1\right) \mathrm{FD}_{1}\left[\mathrm{Cl}^{-}\right]}{\mathrm{i}_{0}}
$$

where $z_{\text {eff }}$ is the effective valence of the metal or alloy, $D_{1}$ is the diffusion coefficient of metal ions, end $i_{0}$ is the initial corrosion current density. General expressions for the parameter $\mathrm{x}_{0}$ for many different conditions have also been derived but are not given here for the sake of brevity.

It has been tacitly assumed above that the rate of pit propagation is unequivocally determined by its depth and by the external conditions, i.e. there is no distribution in pit propagation rate for pits with equivalent depth. However, it is well known that the morphology of pits on any given surface can vary significantly, with some shapes favoring more rapid mass and charge transfer, and hence greater propagation rate [Marsh et al., 1988]. In addition, some pits will initiate at metallurgical features that may favor more rapid propagation, e.g. MnS inclusions [Marsh et al., 1988]. The distribution in pit propagation rate might also be explained, for example, by the spatial distribution in electrochemical activity of the anodic and cathodic sites on the corroding surface [Strutt et al., 1985].

In this report, we will assume, for simplicity, that the pit propagation rate does not change significantly during the propagation stage. This assumption can be justified for many real systems [Engelhardt and Macdonald, 2004]. In generalizing DFA for this case, we assume that the pits that propagate at a constant rate, $v$, nucleate in accordance with the equation.

$$
\mathrm{n}(\mathrm{t})=\int_{0}^{\infty} \lambda(\mathrm{t}, \mathrm{v}) \mathrm{dv}
$$

Here, the function $\lambda(\mathrm{t}, \mathrm{v})$ yields the number of pits with propagation rates between $\mathrm{v}$ and $\mathrm{v}+\mathrm{dv}$, that nucleate in the period of time between $\mathrm{t}$ and $\mathrm{t}+\mathrm{dt}\left(\right.$ per $\left.\mathrm{cm}^{2}\right)$.

It can be shown that, in this case, the expression for the flux of pits can be generalized as

$$
\mathrm{j}_{\mathrm{a}}(\mathrm{x}, \mathrm{t})=\int_{0}^{\infty} \exp (-\gamma \mathrm{x} / \mathrm{v}) \lambda(\mathrm{t}-\mathrm{x} / \mathrm{v}, \mathrm{v}) \mathrm{dv}
$$

Let us assume that the distribution in pit propagation rate does not depend on time, i.e.

$$
\lambda(\mathrm{t}, \mathrm{v})=\mathrm{n}(\mathrm{t}) \psi(\mathrm{v})
$$

where the function, $\psi(v)$, satisfies the evident normalization condition 


$$
\int_{0}^{\infty} \psi(v) d v=1
$$

To move further, we must assume a distribution function, $\psi(v)$, for the pit growth rate. For our purposes, it is most convenient to approximate $\psi(\mathrm{v})$, by Laplace's distribution function [Korn and Korn, 1968]

$$
\psi(\mathrm{v})=\frac{\exp (-|\mathrm{v}-\mathrm{V}| / \beta)}{2 \beta}
$$

with the mean pit propagation rate, $\mathrm{V}$, and dispersion $\sigma^{2}=2 \beta^{2}$.

\section{Rate of pit repassivation}

As noted above, we assume that the repassivation process obeys a first-order decay law

$$
R_{a}(x, t)=-\gamma f_{a}(x, t)
$$

where $\gamma$ is the delayed repassivation (“death") constant (i.e., the rate constant for repassivation of stable pits). The repassivation constant, $\gamma$, is, in general, a function of the external conditions, including the corrosion potential, temperature, and electrolyte composition. Generally speaking, $\gamma$ is also a function of the depth of the pit, $x$, because the local potential in the solution at the cavity surface depends on $x$, i.e. $\gamma$ might be a function of both the spatial coordinates and time. Of course, if the potential and concentration drops inside the corrosion cavity are insignificant during pit propagation, it is possible to neglect changes in parameter $\gamma$ (see above). However, the value of this constant still depends on the external conditions, such as potential, $\mathrm{pH}$, and concentration of aggressive species in the bulk electrolyte. We can also imagine the situation when the potential and concentration drops inside the pit are significant and time-dependent (for example, in extremely dilute solutions or in closed pits); in which case the probability of repassivation will be a function of pit depth and hence pit age. It also can be that active pits cannot exist if the potential, E, at the pit internal surface is less then some critical value, $\mathrm{E}_{\mathrm{cr}}$. Accordingly, if the value of $\mathrm{E}_{\mathrm{cr}}$ is reached at some pit depth, $\mathrm{x}_{\mathrm{cr}}$, active pits passivate and cannot penetrate further into the metal.

\section{Transition of a pit into a crack}

Regarding the transition of a pit into a crack, we assume that a pit immediately transforms into a crack if its depth exceeds some critical value $\mathrm{x}_{\text {nuc. }}$ According to Chen et. al. (1996), two conditions must be satisfied for crack nucleation to take place; namely,

$$
\mathrm{K}_{\mathrm{I}}>\mathrm{K}_{\mathrm{ISCC}}\left(\text { for SCC) or } \Delta \mathrm{K}_{\mathrm{I}}>\Delta \mathrm{K}_{\mathrm{I}, \text { th }}(\text { for } \mathrm{CF})\right.
$$

and 


$$
\mathrm{V}_{\mathrm{cr}}>\mathrm{V}_{\mathrm{pit}}
$$

( $\mathrm{V}_{\mathrm{cr}}$ and $\mathrm{V}_{\mathrm{pit}}$ are crack and pit propagation rates, respectively). The first requirement defines the mechanical (fracture mechanics) condition that must be met for the prevailing stress and geometry, while the second simply says that the nucleating crack must be able to "outrun" the pit.

It is important to emphasize that the value of parameter $\mathrm{x}_{\text {nuc }}$ can be crucial for calculating of the service life of the system, $t_{s}$. First of all, it is evident that $x_{\text {nuc }}$ influences the time of propagation of corrosion damage in the form of a pit (and in many if not in most cases this time can be comparable with $\mathrm{t}_{\mathrm{s}}$ ). But it can be also shown that $\mathrm{x}_{\text {nuc }}$ can also influence the propagation of corrosion damage in the form of crack in spite of the fact that usually $\mathrm{x}_{\mathrm{nuc}}<<\mathrm{x}_{\mathrm{cr}}$, where $\mathrm{x}_{\mathrm{cr}}$ is the critical depth of the system (for example, the depth of the wall of the construction).

\section{Rate of crack propagation}

From the electrochemical point of view, it has been suggested that pitting and crevice corrosion are identical but crevice corrosion involves longer ionic diffusion path (Galvele, 1977). On the other hand, the rate of corrosion crack propagation, $\mathrm{V}$, can be considered as a sum:

$$
\mathrm{V}=\mathrm{V}_{\mathrm{mec}}+\mathrm{V}_{\mathrm{el}}
$$

where $\mathrm{V}_{\text {mec }}$ and $\mathrm{V}_{\mathrm{el}}$ are the rates of crack propagation due to mechanical and the electrochemical reasons, correspondingly. The estimation of $\mathrm{V}_{\mathrm{mec}}$ is out of the scope of this project. On the other hand, there is no principal difference in estimating $\mathrm{V}_{\mathrm{el}}$ for the cases of crevices or cracks. Accordingly, we will regard cracks or crevices as particular pits that have a parallel slot or trapezoidal form with a depth $\mathrm{L}$ that is much greater than the width, w.

In a symmetrical crevice under steady state conditions, the average mass transfer equations are of the form [see Equation (15)]:

$$
\frac{\mathrm{d}\left(\mathrm{wN}_{\mathrm{k}}\right)}{\mathrm{dx}}=\mathrm{wR}_{\mathrm{Vk}}+2 \mathrm{~N}_{\mathrm{sk}}, \quad \mathrm{k}=1, \ldots, \mathrm{K}
$$

The difference between Equation (35) and the usual one-dimensional mass transfer equation is only due to the $\mathrm{N}_{\mathrm{sk}}$ term. In the majority of literature models, it is simply assumed that $\mathrm{N}_{\mathrm{sk}}=0$ (see, for example, reviews by Sharland, 1987 and Turnbull 1993). This simplification is based on the following assumptions. It can be shown that oxygen is consumed relatively quickly on the side walls and the cavity volume can be considered oxygen free (except for the thin layer near the crevice mouth). Accordingly, if oxygen reduction is the main cathodic reaction we can assume that there are no cathodic processes on the crevice walls. On the other hand, it is assumed that passive corrosion current density, $i_{p}$, is much smaller that the active anodic current density at the tip of the 
crevice, $\mathrm{i}_{\mathrm{t}}$. Accordingly, it is assumed that we can also neglect anodic processes on the passive surface, i.e. the crevice walls are considered to be isolated.

A clear criterion can be obtained to evaluate when it is possible to neglect cathodic current on the walls of the crevice. Thus, it can be shown that a potential drop down the crevice in the absence of concentration gradients (Ohm's approximation) in a parallel slot $(\mathrm{w}=$ const $)$ has the form:

$$
\varphi=-\frac{\mathrm{i}_{\mathrm{p}}}{\kappa \mathrm{w}} \mathrm{x}^{2}+\left(\frac{2 \mathrm{i}_{\mathrm{p}} \mathrm{L}}{\kappa \mathrm{w}}+\frac{\mathrm{i}_{\mathrm{t}}}{\mathrm{k}}\right) \mathrm{x}
$$

On the other hand, potential distribution for a parallel slot with passive walls has the simple form

$$
\varphi=\frac{\mathrm{i}_{\mathrm{t}} \mathrm{x}}{\kappa}
$$

As follows from Equations (36) and (37), we can neglect the passive current on the crevice walls if the dimensionless parameter

$$
\mathrm{R}=\frac{\mathrm{i}_{\mathrm{p}} \mathrm{L}}{\mathrm{i}_{\mathrm{t}} \mathrm{W}}
$$

is much less than 1. The physical meaning of this criterion is clear. It is possible to neglect corrosion current on the crevice walls if the total passive current that flows from the crevice walls is much less than the total active dissolution current from the crevice bottom. Usually, the ratio $i_{t} / i_{p}$ is of the order of $10-10^{3}$, but for long crevices $(\mathrm{L} \sim 1 \mathrm{~cm})$ the ratio $\mathrm{L} / \mathrm{w}$ can be the of the order of $10^{4}$ (when $\mathrm{w}$ is of the order of $1 \mu \mathrm{m}$ ). Accordingly, under normal conditions, $\mathrm{R}>>1$ and it does not make sense to describe quantitatively transport processes in the crevice without taking into account electrochemical processes on the walls. Accordingly, computer code for the numerical solution of Equations (16), (17) and (36) for the cases of specific systems has been developed.

The methods that have been developed previously for pitting corrosion can be generalized for the case of crevice (and crack) corrosion in the following way. The solution to the coupled transport equations governing species concentrations and potential for steady-state, nonconvective electrolytic systems can be represented as a function of a single variable, the quasipotential, q, [Pillay and Newman, 1993]. The quasipotential is a harmonic function, i.e. it satisfies Laplace's equation, and satisfies the following boundary conditions: $\mathrm{q}=0$ far away from the electrode surface, $\partial \mathrm{q} / \partial \mathrm{n}=0$ at an insulating surface, and $\partial \mathrm{q} / \partial \mathrm{n}=\mathrm{i}$ at the electrode surface. It is evident that $\mathrm{i}=-\operatorname{grad} \varphi$.

The distribution of $\mathrm{q}$ can be found from the law of charge conservation:

$$
\frac{d(w i)}{d x}=-\frac{d}{d x} w(x) \frac{d q}{d x}=2 i_{p}
$$


with the solution

$$
q=-2 i_{p} \int_{0}^{x} \frac{y}{w(y)} d y+\left[i_{t} w(L)+2 i_{p} L\right] \int_{0}^{x} \frac{d y}{w(y)}
$$

For the case of a deep one-dimensional pit, Equation (45) reduces to

$$
\mathrm{q}=\mathrm{i}_{\mathrm{t}} \mathrm{w}(\mathrm{L}) \int_{0}^{\mathrm{x}} \frac{\mathrm{dy}}{\mathrm{w}(\mathrm{y})}
$$

Now, if we want to calculate the concentration or potential distribution at the point $\mathrm{x}$ for the case of a deep crevice, we have to calculate the quasi-potential q by using Equation (40) (instead of using Equation (41) for a deep one-dimensional pit) and then, for the determined value of $\mathrm{q}$, calculate the concentrations and potential by using previously developed methods and software.

A case in which it is necessary to take into account electrochemical reactions on the walls of the crevice is corrosion in acidic solutions when the main cathodic reaction on the walls is hydrogen evolution. Under such conditions, the anodic current that is produced at the tip of the crevice can be simply consumed on the walls in the vicinity of the crevice, i.e. the current does not flow outside the crevice. It has been shown that in such a case the potential at the crack tip is close to the corrosion potential under normal conditions, i.e. the corrosion current density can be calculated via the Tafel relation

$$
\mathrm{i}=\operatorname{Aexp}\left(\frac{\alpha \mathrm{FE}}{\mathrm{RT}}\right)
$$

where $\mathrm{E}$ is the metal potential, $\alpha$ is the transfer coefficient for active metal dissolution and $\mathrm{A}$ is constant. It is then possible to substitute the corrosion potential $\mathrm{E}_{\text {corr }}$ for $\mathrm{E}$. However, under some circumstances (extremely high corrosion rates) it can be necessary to introduced a correction (i.e., potential drop in the solution, $\varphi$,) i.e. to write $\mathrm{E}=\mathrm{E}_{\mathrm{corr}}-$ $\varphi$. It has been shown that this correction can be found as a solution of the following equation

$$
\kappa \sqrt{\frac{\alpha_{\mathrm{c}} \mathrm{i}_{\mathrm{p}}}{\mathrm{RT} \kappa \mathrm{T}}} \varphi_{\mathrm{s}}=\operatorname{Aexp}\left(\frac{\alpha\left(\mathrm{E}_{\text {corr }}-\varphi_{\mathrm{s}}\right.}{\mathrm{RT}}\right)
$$

where $\alpha_{c}$ is the transfer coefficient for the cathodic reaction.

The third case in which electrochemical reactions on the walls of deep crevices can influence the rate of corrosion is the corrosion of metals in dilute solutions at high temperatures, when hydrogen ions, $\mathrm{H}^{+}$, that arise due to hydrolysis reaction, e.g.

$$
\mathrm{Fe}^{2+}+\mathrm{H}_{2} \mathrm{O}=\mathrm{Fe}(\mathrm{OH})^{+}+\mathrm{H}^{+}
$$


can discharge on the crevice walls.

Calculations show that in this case the following corrosion scheme can be suggested. The anodic current that is produced at the crack tip is consumed on the crevice walls near the crack tip. At a larger distance from the crack tip, a "balanced charge transport" region, with zero net current density in the solution, occurs. Finally, near the crevice mouth, there exists a region of non-zero net current density that is compensated for outside of the cavity (see Figure 2).

The last case is of practical importance for the corrosion in boiling water reactor (BWR) cooling environments. It is important to note the fact that an electrolyte in the crevice can be regarded as binary (this fact is a consequence of the very low solubilities of metalcontaining species in BWR environments and of the high value of the hydrolysis and dissociation constantans). This results in a great simplification of the quantitative description of transfer processes in the crevice. Moreover, it has been shown that, in practical cases, the potential at the crack tip in a BWR environment does not increase significantly from the value of the plateau potential (see Figure 13). In turn, the value of the potential drop between the pit mouth and the plateau can be found from the condition $i_{p}=i_{c}$, where $i_{c}$ is the cathodic current (hydrogen evolution in our case) even without solving the system of transport equations. However, it is important to note that in a general case the metal potential at the crack mouth, $\mathrm{E}_{\text {mouth }}$, does not coincide with the metal potential far away from the crack, $\mathrm{E}_{\text {corr }}$. To find a relation between $\mathrm{E}_{\text {corr }}$ and $E_{\text {mouth, }}$, it is necessary to solve Laplace's equation with respect to the electrical potential, $\varphi$, in the external environment (outside the crevice). An appropriate program for numerical solution of Laplace's equation has been written and it was possible to describe the final results even by approximate analytical expressions. Figure 3 compares selected results with experimental data of Ford et al. (1987)

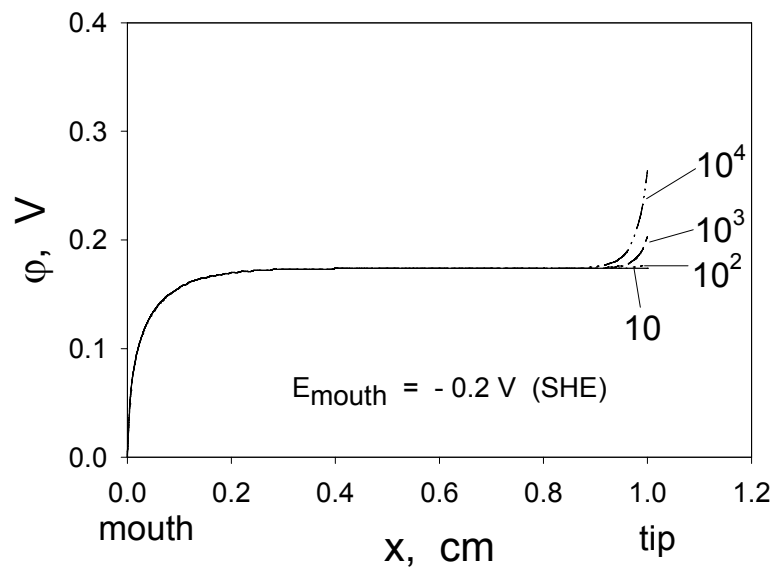

Figure 2. Potential drop down a crack for different values of the ratio of the current density at the crack tip, $i_{t}$, to the passive current density, $i_{\mathrm{p}}$, for corrosion of iron in $1.9 \times 10^{-6} \mathrm{NaCl}$ solution at $561 \mathrm{~K}$. E mouth $_{\text {is }}$ the metal potential at the crack mouth. 


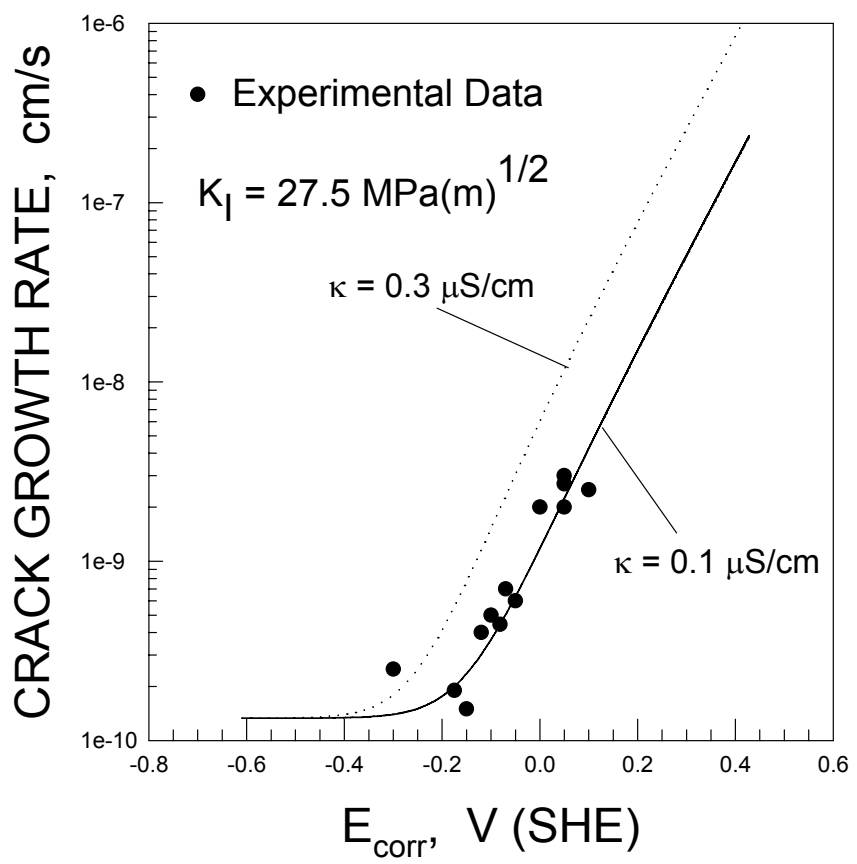

Figure 3. Measured and analytically calculated crack growth rates of sensitized Type 304 stainless steel as a function of the corrosion potential. $\mathrm{K}_{\mathrm{i}}$ is the applied stress intensity.

It must be noted that direct application of the methods described above to simulate the rates of crack propagation in real systems can be time consuming (because these methods reduce to the solution of rather complicated balance and ion transfer equations) and, in general, would be unsuitable for commercial software. On the other hand, experimental data for $\mathrm{V}_{\mathrm{el}}$ as a function of applied stress intensity, $\mathrm{K}$, can be represented in a very simple form (see, for example, Jones and Simonen, 1993) as:

$$
\mathrm{V}_{\mathrm{el}}=\mathrm{BK}^{\mathrm{p}}
$$

where the parameters $B$ and $p>0$ depend on the nature of the metal and external conditions. It would be remarkable if various models that have been proposed could rationalize the simplicity of the empirical crack propagation laws in spite of the complexity of the mathematical modeling process.

In this report, we demonstrate that it is possible to represent the crack growth law in the form of Equation (1). For simplicity, we will demonstrate this possibility for the case when the potential distribution along the crack is described in the framework of the Doig and Flewitt model [Doig and Flewitt, 1977, 1978, 1981, 1984], which is widely used in the theory of stress corrosion cracking (SCC). The results for more complicated cases (from a mathematical point of view) will be described later. The Doig and Flewitt model assumes that 
1. No concentration gradients are present in the crack (Ohm' law is satisfied).

2. The crack tip is anodically active (pure bare surface).

3. A cathodic current flows from the sides of the crack to complement the active anodic current at the crack tip and passive corrosion current from crack sides.

4. A steady state is reached when the electrode potential at the crack tip produces an anodic current that is balanced by the cathodic current on the crack surfaces.

5. The crack is regarded as a parallel slot.

We will accept all these assumption. However, for generality, we will assume that in accordance with the slip dissolution model of cracking (i.e., the most popular model for describing crack advance, Turnbull 1993) the crack tip is only partially open, i.e. the current density on the crack tip, $\mathrm{i}_{\mathrm{a}}$, can be represented as:

$$
\mathrm{i}_{\mathrm{a}}=\mathrm{i}_{0} \Gamma
$$

where $i_{0}$ is the current density on the bare surface, and the parameter $\Gamma$ is the ratio of the area of the bare surface to the total geometrical area (if the crack tip is totally bare, $\Gamma=1$ ).

After solving Laplace's equation for the electric potential with corresponding boundary conditions, it can be found that the electrode potential $\mathrm{E}_{\mathrm{s}}$, at the tip of the crack is given by the following relation:

$$
\Gamma \mathrm{wi}_{\mathrm{F}} \exp \left[\left(\mathrm{E}_{\mathrm{s}}-\mathrm{E}_{\mathrm{F}}\right) / \alpha\right]=\left[4 \mathrm{i}_{\mathrm{c}} \kappa \mathrm{w}\left(\mathrm{E}_{\mathrm{s}}-\mathrm{E}_{\mathrm{c}}\right)+\beta\left\{\exp \left[\left(\mathrm{E}_{\mathrm{s}}-\mathrm{E}_{\mathrm{c}}\right) / \beta-1\right\}\right]^{1 / 2}\right.
$$

where $i_{F}$ is the anodic dissolution current density at the crack tip at the potential $E_{F}$ and $\alpha$ is the Tafel slope for this reaction; $i_{c}$ and $E_{c}$ are, respectively, the constant corrosion current density (passive) and the corrosion potential on the crack surface; $\beta$ is the Tafel slope for the cathodic reaction on the crack surface, $w$ is the width of the crack, and $\kappa$ is the ionic conductivity of the solution (which is assumed constant). The crack width for the parallel slot is given by (Galvele, 1995):

$$
w=0.5 \frac{K^{2}}{\sigma_{y} E_{y}}
$$

where $\mathrm{K}$ is the applied stress intensity, $\sigma_{\mathrm{y}}$ is the material yield strength, and $\mathrm{E}_{\mathrm{y}}$ is Young's modulus of elasticity. Except for $E_{s}$, which is evaluated by Equation (3), the other variables are obtained experimentally. Once the value is calculated, the crack velocity, $\mathrm{V}_{\mathrm{el}}$, can be predicted by the Faraday's law:

$$
\mathrm{V}_{\mathrm{el}}=\mathrm{K}_{\mathrm{V}} \Gamma \mathrm{i}_{\mathrm{F}} \exp \left[\left(\mathrm{E}_{\mathrm{s}}-\mathrm{E}_{\mathrm{F}}\right) / \alpha\right] \mathrm{M} /(\delta \mathrm{Fn})
$$

where $\mathrm{K}_{\mathrm{V}}$ is the electrochemical equivalent of the metal that converts the corrosion current into the corrosion rate for the corroding surface. A table of parameters for the cases of steels in $8 \mathrm{M} \mathrm{NaOH}$ at $373 \mathrm{~K}$ and aluminum base alloys in $1 \mathrm{M} \mathrm{NaCl}, \mathrm{pH}=1.1$, at $298 \mathrm{~K}$ can be found, for example, in Galvele (1995). 
For analysis of Equation (47) it is convenient to introduce the following dimensionless variables and parameters:

$$
\psi_{\mathrm{s}}=\frac{\mathrm{E}_{\mathrm{c}}-\mathrm{E}_{\mathrm{s}}}{\beta}, \gamma=\frac{\beta}{\alpha}, \mathrm{A}=\frac{\Gamma \mathrm{i}_{\mathrm{F}, \max }}{2}\left(\frac{\mathrm{w}}{\beta \mathrm{Ci} \mathrm{i}_{\mathrm{c}}}\right)^{1 / 2}
$$

where $i_{F, \max }=i_{F} \exp \left[\left(E_{c}-E_{F}\right) / \alpha\right]$. This value is the current density calculated in the absence of potential drop in the cell (the maximum possible current density on the bare crack tip). The value $\psi=\left(\mathrm{E}_{\mathrm{c}}-\mathrm{E}\right) / \beta$ can be considered as a dimensionless potential. With the new variables, Equation (47) has the form:

$$
\operatorname{Aexp}\left(-\gamma \psi_{\mathrm{s}}\right)=\left[\exp \left(\psi_{\mathrm{s}}\right)-\psi_{\mathrm{s}}-1\right]^{1 / 2}
$$

This equation has no analytical solution for an arbitrary value of parameter $\mathrm{A}$, but it is easy to solve it for small and large values of $\mathrm{A}$. For $\mathrm{A}<<1$ the expression in brackets in Equation (51) approximately equals 0 , i.e. $\psi_{\mathrm{s}} \approx 0$. For $\mathrm{A}>>1$, the value of $\psi_{\mathrm{s}}$ must be large [i.e. $\left.\exp \left(\psi_{\mathrm{s}}\right)-\psi_{\mathrm{s}}-1 \approx \exp \left(\psi_{\mathrm{s}}\right)\right]$ and we have $\psi_{\mathrm{s}} \approx \ln (\mathrm{A}) /(\gamma+0.5)$. Accordingly, the factor $\mathrm{i}_{\mathrm{F}} / \mathrm{i}_{\mathrm{F}, \max }=\exp \left(-\psi_{\mathrm{s}}\right)$ approximately equals 1 for $\mathrm{A}<<1$ and $1 / \mathrm{A}^{1 /(\gamma+0.5)}$ for $\mathrm{A}>>$ 1. It can be suggested that the simplest interpolation formula that can be used for an arbitrary value of the parameter $\mathrm{A}$ is:

$$
\frac{\mathrm{i}_{\mathrm{F}}}{\mathrm{i}_{\mathrm{F}, \max }}=\exp \left(-\gamma \psi_{\mathrm{s}}\right)=\frac{1}{(1+\mathrm{A})^{1 /(\gamma+0.5)}}
$$

Figure 4 illustrates the accuracy of Equation (52).

A general equation for the open fraction of the surface of the crack tip, $\Gamma$, can be given in the form [Macdonald 1996]

$$
\Gamma=\frac{\mathrm{t}_{0}^{\mathrm{n}}}{(1-\mathrm{n}) \varepsilon_{\mathrm{f}}^{\mathrm{n}}}\left(\dot{\varepsilon}_{c t}\right)^{n}
$$

where $\varepsilon_{\mathrm{f}}$ is the fracture strain of passive film at the crack apex, $\dot{\varepsilon}_{c t}$ is the crack tip strain rate, and $t_{0}$ and $n$ are constants. It can be shown that $\Gamma$ can be approximated by the following expression:

$$
\Gamma=\mathrm{CK}^{4 \mathrm{n}}
$$

were $\mathrm{C}$ is the material constant and the value $\mathrm{n} \approx 1 / 2$ is often accepted. 


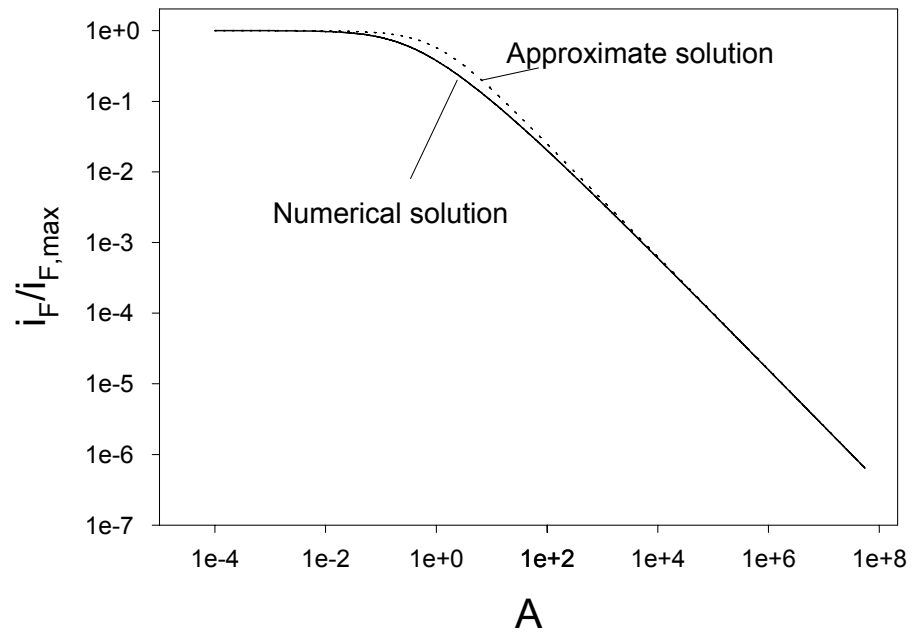

Figure 4. Comparison between numerical and approximate solution of Eq. (8).

It follows from Equations (52) and (54) that

$$
\mathrm{V}_{\mathrm{el}}=\frac{\mathrm{K}_{\mathrm{V}} \Gamma \mathrm{i}_{\mathrm{F}, \max }}{(1+\mathrm{A})^{1 /(\gamma+0.5)}}=\frac{\mathrm{QK}^{2}}{\left(1+\mathrm{YK}^{3}\right)^{1 /(\gamma+0.5)}}
$$

where the parameters

$\mathrm{Q}=\mathrm{K}_{\mathrm{V}} \mathrm{i}_{\mathrm{F}, \max } \mathrm{C} \quad$ and $\quad \mathrm{Y}=\frac{\mathrm{C} \mathrm{i}_{\mathrm{F}, \max }}{2}\left(\frac{2}{\sigma_{\mathrm{y}} \mathrm{E}_{\mathrm{y}}}\right)^{1 / 2}$

do not depend on $\mathrm{K}$. For sufficiently deep crevices, $\mathrm{YK}^{3}>>1$, and $\mathrm{V}_{\mathrm{el}}$ can be given in the form of Equation (45) with $\mathrm{p}=2(\gamma-1) /(\gamma+0.5)$ and $\mathrm{B}=\mathrm{Q} / \mathrm{Y}$. For the accepted values of parameters, i.e., for $\gamma=2$ for steels and $\gamma=1.8$ for aluminum the condition $p>0$ is satisfied.

\section{Rate of corrosion fatigue propagation}

Let us consider the difference between the quantitative description of stress corrosion cracking (SCC) and corrosion fatigue $(\mathrm{CF})$. This difference can be defined by the differences in boundary conditions and mass transfer conditions. It is evident that in both cases the total cavity propagation rate, $\mathrm{V}$, can be presented as a sum of two parts: mechanical component, $\mathrm{V}_{\text {mec }}$, (crack advance associated with mechanical fatigue/creep), and electrochemical, $\mathrm{V}_{\mathrm{el}}$, (environmental) component, which is determined by Faraday' law [see Equation (34)]. Of course, the values of $\mathrm{V}_{\text {mec }}$ are different for SCC and CF. For the case of corrosion fatigue 


$$
\mathrm{V}_{\mathrm{mec}}=C \dot{\varepsilon}_{\mathrm{ct}}
$$

where $\dot{\varepsilon}_{c t}$ is the crack tip strain rate, and $C$ is the is a material constant [Ford et al. 1987]. In the case of harmonic load, when

$$
\mathrm{K}(\mathrm{t})=\mathrm{K}_{\mathrm{m}}+\frac{1}{2} \Delta \mathrm{K} \sin (2 \pi \mathrm{ft})
$$

where $\mathrm{K}_{\mathrm{m}}$ is the mean value of stress intensity, $\mathrm{K}$, and $\Delta \mathrm{K}$ is the range of $\mathrm{K}$, and $\mathrm{f}$ is the cyclic frequency, $\mathrm{V}_{\text {mec }}$ can be presented in a standard power form:

$$
\mathrm{V}_{\mathrm{mec}}=\mathrm{Cf} \Delta \mathrm{K}^{\mathrm{n}}
$$

where $\mathrm{C}$ and $\mathrm{n}$ are material constants.

In the case of stress cracking, $V_{\text {mec }}$ can be associated with the creep velocity and can be expressed as a function of applied yield strength. For example, for $3.5 \mathrm{NiCrMoV}$ steel $\mathrm{V}_{\text {mec }}$ can be calculated by the following expression (Nuclear Regulatory Commission, 1980)

$$
\operatorname{Ln} R=-4.968-7302 / T+0.027 \sigma_{y s}
$$

where $\mathrm{R}$ is the crack growth rate (in units of $\mathrm{in} / \mathrm{h}$ ), $\mathrm{T}$ is the disk temperature (degree Rankine-F+460), and $\sigma_{\mathrm{ys}}$ is the room temperature disk yield strength. However, detailed investigation of the mechanical factors in SCC and CF are outside the scope of this project. Here, we considered only on the effects on $\mathrm{V}_{\mathrm{el}}$.

In accordance with Faraday's law, $\mathrm{V}_{\mathrm{el}}$ can be given in the form

$$
\mathrm{V}_{0}=\mathrm{K}_{\mathrm{V}} \Gamma \mathrm{i}_{0}
$$

where $\mathrm{K}_{\mathrm{v}}$ is the electrochemical equivalent volume of the metal or alloy, $\mathrm{i}_{0}$ is the corrosion current density on the bare surface and $\Gamma$ is the averaged ratio of the bare surface to the total geometrical area of the dissolving crevice tip. For pitting corrosion $\Gamma=1$, and for SCC or corrosion fatigue $\Gamma$ can be estimated from [Macdonald, 1996]

$$
\Gamma=\frac{\mathrm{t}_{0}^{\mathrm{n}} \dot{\varepsilon}_{\mathrm{ct}}^{\mathrm{n}}}{(1-\mathrm{n}) \varepsilon_{\mathrm{f}}^{\mathrm{n}}}
$$

where $t_{0}$ is the time of exposure of the bare surface prior to refilling, $n$ is the current decay constant, $\varepsilon_{\mathrm{f}}$ is the fracture strain of the passive film at the crack apex. The value of the crack tip strain rate, $\dot{\varepsilon}_{c t}$, can be found from Congleton's correlation [Congleton, 1985]. In the case of corrosion fatigue, $\dot{\varepsilon}_{c t}$ can be found from the comparing Equations (56) and (58) (power law). 
The principal question that arises in simplifying the model for corrosion fatigue is the following: Does the advection effect (the hydrodynamic fluid effect caused by moving walls) influence the average (over a long period of time) flux density of electrochemically active species at the crack tip? It can be shown that in the most important case of periodic applied stress, the answer depends on the value of parameter

$\varepsilon=\frac{\Delta \sigma}{\sigma_{\mathrm{m}}}=\frac{\Delta \mathrm{K}}{\mathrm{K}_{\mathrm{m}}}$

where $\sigma_{\mathrm{m}}$ is the mean value of applied stress, $\sigma, \Delta \sigma$ is the range of $\sigma$, and $\mathrm{f}$ is the cyclic frequency, within certain limits on the value of frequency. Usually, the dimensionless parameter, $\varepsilon$, can be considered to be small. To answer this question, the system of balance equations in a one-dimension approximation takes the form Equations (15). However, an additional convective term appears in the equation for the flux density. I.e. Equation (16) must be rewritten in the form

$$
N_{k}=-D_{k}\left(\frac{d c_{k}}{d x}+\frac{z_{k} F}{R T} c_{k} \frac{d \varphi}{d x}\right)+c v
$$

where $\mathrm{v}$ is the hydrodynamic velocity.

The hydrodynamic velocity, $\mathrm{v}$, can be found from the continuity equation for incompressible fluid

$$
\mathrm{v}=-\frac{1}{\mathrm{w}} \int_{0}^{\mathrm{x}} \frac{\partial \mathrm{w}}{\partial \mathrm{t}} \mathrm{dx}
$$

A general computer code for solving this system of equation has been developed.

However, in the simplest case, i.e., for the mass transfer of a single species (a metal ion) in the absence of migration in the crevice with passive walls, an approximate analytical solution can be obtained. For simplicity, we will also assume that the crack is a parallel slot, so that the crack width, w, at any moment equals to the crack opening displacement and, hence, is given by [Knot, 1987]

$$
w=\frac{K^{2}}{2 \sigma_{y} E_{y}}
$$

Here $\sigma_{\mathrm{y}}$ is material yield stress and $\mathrm{E}_{\mathrm{y}}$ is the Young's modulus of elasticity. It can be shown that, in this case, mass transfer is described by the following equation:

$\frac{\partial C}{\partial \tau}-\frac{\varepsilon \mathrm{X} \cos (\tau)}{1+0.5 \varepsilon \sin (\tau)} \frac{\partial C}{\partial X}=\frac{\partial^{2} C}{\partial X^{2}}$

with the boundary conditions 
$\mathrm{C}=1 \quad$ at $\mathrm{X}=0$ and $\mathrm{C}=0$ at $\mathrm{X}=\mathrm{L}$

where the following dimensionless variables are introduced:

$$
\mathrm{C}=\frac{\mathrm{c}}{\mathrm{c}_{\mathrm{s}}}, \quad \tau=\omega \mathrm{t}, \quad \mathrm{X}=\frac{\mathrm{x}}{\mathrm{L}_{0}}, \mathrm{~L}=1 / \mathrm{L}_{0}, \mathrm{~L}_{0}=\sqrt{\frac{\mathrm{D}}{\omega}},
$$

Here, 1 is the depth of the cavity, $c_{s}$ is the concentration of metal ions near the crack tip, which is assumed to be constant, $\mathrm{D}$ is the diffusion coefficient of metal ions, which is assumed to be constant and $\omega=2 \pi f$. Let us try to find solution of Equation (66) as an expansion:

$\mathrm{C}=\mathrm{C}_{0}+\varepsilon \mathrm{C}_{1}+\varepsilon^{2} \mathrm{C}_{2}+\ldots$

It is evident that in the zero-th approximation (in the absence of advection) we have

$\mathrm{C}_{0}=1-\mathrm{X} / \mathrm{L}$

And for the dimensionless flux density in the absence of advection, $\mathrm{J}_{0}$ we have

$\mathrm{J}_{0}=-(\mathrm{dC} / \mathrm{dX})_{\mathrm{X}=0}=1 / \mathrm{L}$

In the first approximation we have the equation

$$
\frac{\partial \mathrm{C}_{1}}{\partial \tau}+\varepsilon \mathrm{X} \cos (\tau) / \mathrm{L}=\frac{\partial^{2} \mathrm{C}_{1}}{\partial \mathrm{X}^{2}}
$$

with the boundary conditions

$\mathrm{C}=0$ at $\mathrm{X}=0$ and $\mathrm{C}=0$ at $\mathrm{X}=\mathrm{L}$

The periodic solution of this equation can be written as

$$
\mathrm{C}_{1}=-\mathrm{X} \sin (\tau) / \mathrm{L}+\mathrm{A} \sin (\tau+\theta)
$$

where

$$
\begin{aligned}
& A=\left|\frac{\sinh X(1+i) / \sqrt{2}}{\sinh L(1+i) / \sqrt{2}}\right|=\left[\frac{\cosh \sqrt{2} X-\cos \sqrt{2} X}{\cosh \sqrt{2} L-\cos \sqrt{2} L}\right]^{1 / 2} \\
& \theta=\arg \left[\frac{\sinh X(1+i) / \sqrt{2}}{\sinh L(1+i) / \sqrt{2}}\right]
\end{aligned}
$$


It is important to note that under normal conditions the value of the dimensionless depth $\mathrm{L}$ is very large in comparison with 1 . Thus for $\mathrm{l}=1 \mathrm{~cm}, \mathrm{D}=10^{-5} \mathrm{~cm}^{2} \mathrm{~s}^{-1}$ and $v=1 \mathrm{~Hz}, \mathrm{~L}=$ $1 /(\mathrm{D} / \omega)^{1 / 2}=792$ (for $v=600 \mathrm{~Hz}, \mathrm{~L}=19616$, and for $v=10^{-4} \mathrm{~Hz}, \mathrm{~L}=7.92$ ). It means that by calculating derivative of $\mathrm{C}_{1}$ at the crack tip (at $\mathrm{X}=0$ ) it is sufficient to take into account only the first term in the Equation (74). Accordingly, in the first approximation, we have

$\mathrm{J}=-(\mathrm{dC} / \mathrm{dX})_{\mathrm{X}=0}=1 / \mathrm{L}+\varepsilon \sin (\tau) / \mathrm{L}$

Finally, in accordance with Equation (71) and (76) we have a very simple expression for the ratio $\mathrm{J} / \mathrm{J}_{0}$

$\mathrm{J} / \mathrm{J}_{0}=1+\varepsilon \sin (\tau)$

Figure 5 shows that Equation (77) describes the oscillation quite accurately for a small value of the parameter $\varepsilon=0.05$. Of course, for larger values of $\varepsilon$ the coincidence between analytical and numerical solution is not so good (see Figure 6).

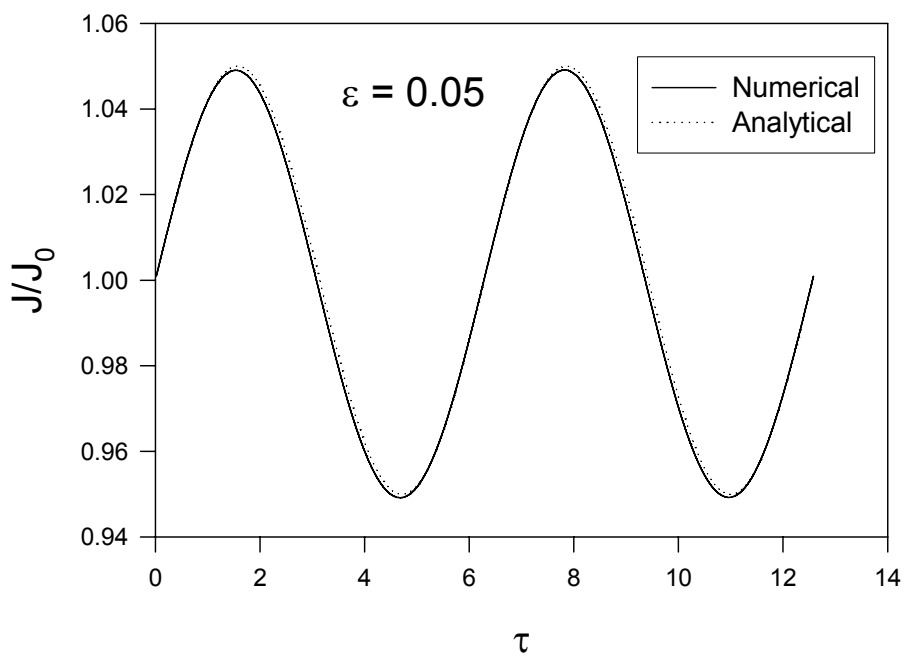

Figure 5. Ratio of the corrosion flux at the crack tip, J, to the corrosion flux in the absence of convection, $\mathrm{J}_{0}$, as a function of dimensionless time at $\varepsilon=0.05$.

The influence of advection on the corrosion rate can be characterized by the ratio $\mathrm{J} / \mathrm{J}_{0}$ averaged for a long period of time. It follows from Equation (77) that for small values of $\varepsilon,\left(\mathrm{J} / \mathrm{J}_{0}\right)_{\text {av }}$ equals 1 , i.e. there is no advection effect on the average corrosion rate. However, for large values of the parameter $\varepsilon$ some effect is observed (see Figure 6). It follows from Eqs. (66)-(68) that the value of $\left(\mathrm{J} / \mathrm{J}_{0}\right)_{\text {av }}$ depends only on $\varepsilon=\Delta \sigma / \sigma_{\mathrm{m}}$ and the dimensionless crack depth $\mathrm{L}=1 /(\mathrm{D} / \omega)^{1 / 2}$ The numbers in Figure 7 correspond to the value of $\mathrm{L}$ (Figures 5 and 6 are calculated at $\mathrm{L}=1000)$. There is a low frequency limit $(\mathrm{L} \rightarrow 0$ or $v \rightarrow 0$ ) and it equals 1 (no advection effects). Also, there is a high frequency limit (L $\rightarrow \infty$ or $v \rightarrow \infty$ ). It is reached when $\mathrm{L}$ approximately equals 100 . But no matter what 
value $\mathrm{L}$ has for sufficiently low $\varepsilon$ values ( $\varepsilon \leq 0.2$ ), it is possible to neglect the advection effect.

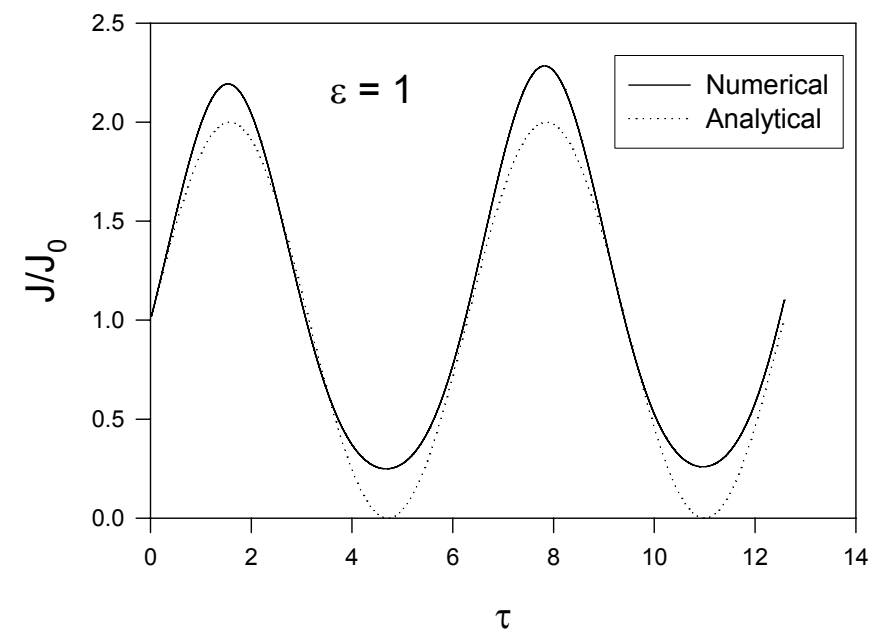

Figure 6. Ratio of the corrosion flux at the crack tip, J, to the corrosion flux in the absence of convection, $\mathrm{J}_{0}$, as a function of dimensionless time at $\varepsilon=1$.

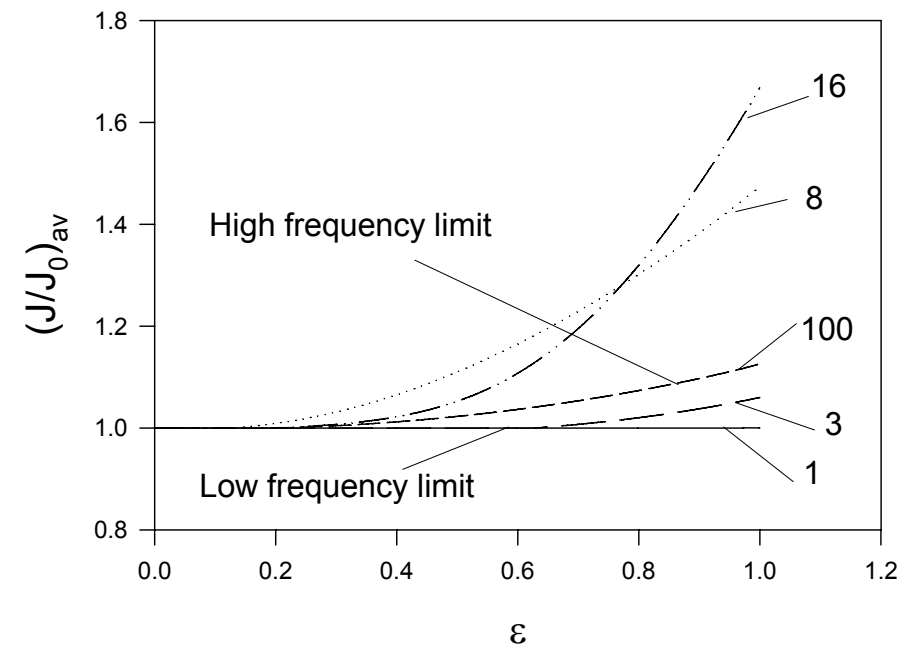

Figure 7. Ratio of the average corrosion flux at the crack tip, $\mathrm{J}$, to the corrosion flux in the absence of convection, $\mathrm{J}_{0}$, as a function of $\varepsilon$ for different values of dimensionless depth L.

Finally, we can conclude that it is possible to consider a corrosion fatigue crevice as a particular case of a motionless crack and calculate its propagation rate by using, for example, approximate methods for SCC. The only difference between the calculated environmental components of propagation rates in the case of corrosion cracking and corrosion fatigue is caused by different expressions for the crack tip strain rate. 


\section{Statistical properties of the damage function}

There is a close correspondence between the Damage Function Analysis (DFA), which has been described at some length above and Extreme Value Statistics (EVS). The latter technique has been used extensively to extrapolate damage (maximum pit or crack depth) from small samples in the laboratory to larger area samples in the field. Furthermore, DFA provides a means of calculating the central and scale parameters and their timedependencies in EVS from first principles and hence represents a unification of the two philosophies.

From a statistical point of view, all distributed properties of the system are completely determined by a Cumulative Distribution Function (CDF), $\Phi(\mathrm{x})$. By definition, $\Phi(\mathrm{x})$ is the probability that the depth of a randomly selected pit is $\leq \mathrm{x}$. We will postulate that the pit distribution on the metal surface is uniform. Accordingly, the total number of nucleated pit in the whole system is $\mathrm{SN}(\mathrm{t})$, where $\mathrm{S}$ is the area of the system and, from the definition of the integral damage function, $F$, the number of pits that have the depth $\leq$ $\mathrm{x}$, is $\mathrm{S}[\mathrm{N}(\mathrm{t})-\mathrm{F}(\mathrm{x}, \mathrm{t})]$. Accordingly, by definition of probability we have

$$
\Phi(\mathrm{x}, \mathrm{t})=\frac{\mathrm{S}[\mathrm{N}(\mathrm{t})-\mathrm{F}(\mathrm{x}, \mathrm{t})]}{\mathrm{SN}(\mathrm{t})}=1-\frac{\mathrm{F}(\mathrm{x}, \mathrm{t})}{\mathrm{N}(\mathrm{t})}
$$

We see that the cumulative distribution function for a given observation time, $\Phi(\mathrm{x}, \mathrm{t})$, can be calculated if we know (can calculate) the integral damage function of the system [note that the number of nucleated stable pits, $N(t)$ simply equals $F(0, t)]$. This relation can be regarded as being the bridge between the statistical and deterministic approaches for estimating the accumulation of localized corrosion damage on a surface.

Let us calculate, for example, the failure probability, $\mathrm{P}_{\mathrm{f}}$, of a system. By definition, $\mathrm{P}_{\mathrm{f}}$, is the probability that at least one corrosion event in any form (pit, crevice, stress corrosion crack, or fatigue crack) reaches a depth, $\mathrm{x}$, at a given observation time, $\mathrm{t}$, where $\mathrm{x}$, in this case, is the critical dimension. It is evident that the probability of a corrosion event not achieving the depth $\mathrm{x}$ at the tine, $\mathrm{t}$, is $\Phi(\mathrm{x}, \mathrm{t})$. Accordingly, the probability that none of the corrosion events will reach the depth of $\mathrm{x}$ is, $\Phi(\mathrm{x}, \mathrm{t})^{\mathrm{SN}(\mathrm{t})}$ where $\mathrm{S}$ is the surface area of the system and, finally, the probability of failure is

$$
\mathrm{P}_{\mathrm{f}}(\mathrm{x}, \mathrm{t})=1-\{1-\mathrm{F}(\mathrm{x}, \mathrm{t}) / \mathrm{N}(\mathrm{t})\}^{\mathrm{SN}(\mathrm{t})}
$$

Using the well known limit relation, $\lim (1+\mathrm{a} / \mathrm{x})^{\mathrm{x}} \rightarrow \exp (\mathrm{a})$ as $\mathrm{x} \rightarrow \infty$, and by assuming that $\mathrm{F}(\mathrm{x}, \mathrm{t}) / \mathrm{N}(\mathrm{t})<<1$ and $\mathrm{SN}(\mathrm{t})$ is a large number, we can rewrite Equation (20) in the form

$$
\mathrm{P}_{\mathrm{f}}(\mathrm{x}, \mathrm{t})=1-\exp \{-\mathrm{SF}(\mathrm{x}, \mathrm{t})\}
$$

As has been shown experimentally, in many practical cases, the asymptotic behavior (for large values of $x$ ) of the CDF can be described by the exponential relationship [Turnbull, 1993, Marsh 1988]: 


$$
\Phi(\mathrm{x}, \mathrm{t})=1-\exp [-(\mathrm{x}-\mathrm{u}) / \alpha]
$$

where $\mathrm{u}$ is the central parameter (the most frequent value) and $\alpha$ is the scale parameter, which defines the width of the distribution. Accordingly, as follows from Equation (81), the extreme value distribution (EVD), $\Psi(\mathrm{x}, \mathrm{t})$ (the probability that the largest value of pit depth $\leq \mathrm{x}$ ) is described by a double exponent (Gumbel Type I extreme value distribution) in the form [Gumbel, 1957]:

$$
\Psi(\mathrm{x}, \mathrm{t})=1-\mathrm{P}_{\mathrm{f}}=\exp [-\exp (-\mathrm{y})]
$$

where

$$
\mathrm{y}=(\mathrm{x}-\mathrm{h}) / \alpha
$$

and $\mathrm{h}=\mathrm{u}+\alpha \ln \mathrm{S}$.

Accordingly, we have for the integral damage function and the cumulative damage function the following expressions

$$
F(x, t)=\int_{0}^{\infty} N(t-x / v) \exp (-\gamma x / v) \psi(v) d v
$$

and

$$
\Phi(\mathrm{x}, \mathrm{t})=1-\int_{0}^{\infty} \mathrm{N}(\mathrm{t}-\mathrm{x} / \mathrm{v}) \exp (-\gamma \mathrm{x} / \mathrm{v}) \psi(\mathrm{v}) \mathrm{dv} / \mathrm{N}(\mathrm{t})
$$

respectively. In particular, for the case of instantaneous nucleation, we have

$$
\Phi(\mathrm{x}, \mathrm{t})=1-\int_{\mathrm{x} / \mathrm{V}}^{\infty} \exp (-\gamma \mathrm{x} / \mathrm{v}) \psi(\mathrm{v}) \mathrm{dv}
$$

If, in addition, the function $\psi(\mathrm{v})$ can be described by Laplace's distribution, it can be shown that the EVD function can be described by Equations (82) and (83) (Gumbel Type I extreme value distribution) and parameters $\alpha$ and $h$ can be expressed as

$$
\alpha=\frac{\beta \mathrm{t}}{1+\gamma \beta \mathrm{t} / \mathrm{V}}, \text { and } \mathrm{h}=\frac{\left[\mathrm{V}+\beta \operatorname{Ln}\left(0.5 \mathrm{SN}_{0}\right)\right] \mathrm{t}}{1+\gamma \beta \mathrm{t} / \mathrm{V}}
$$

We see that, for small values of $t$, the scale and central parameters can be described by

$$
\alpha=\beta \mathrm{t} \text { and } \mathrm{h}=\left[\mathrm{V}+\beta \ln \left(0.5 \mathrm{SN}_{0}\right)\right] \mathrm{t}
$$


i.e. they are proportional to time. However, for large observation times, the parameters $\alpha$ and $\mathrm{h}$ approach the following limits

$$
\alpha=\mathrm{V} / \gamma \quad \text { and } \mathrm{h}=\left[\mathrm{V}+\beta \ln \left(0.5 \mathrm{SN}_{0}\right)\right] \mathrm{V} /(\gamma \beta)
$$

that are independent of time. This fact can be regarded as being physically evident, because at sufficiently large times all pits become passive (the damage function becomes "frozen") and further propagation of damage cannot occur, provided that $\gamma>0$. This conclusion concerning the achievement of limiting pitting depth also follows from a formal statistical treatment of experimental data for underground carbon steel pipelines [Freiman, 1985]. The "freezing" of damage functions can also be seen in the propagation of corrosion damage on aluminum in tap water [Aziz, 1956].

As mentioned above, it is very important to establish relations between the physical parameters $\beta, \mathrm{V}, \gamma$ and $\mathrm{N}_{0}$ (where the surface area of the sample, $\mathrm{S}$, is assumed to be known) and the fitting parameters $\mathrm{a}_{\mathrm{i}}(\mathrm{i}=1,2,3)$. If, for example, the parameter $\mathrm{N}_{0}$ (maximum number of stable pit that can nucleate per $\mathrm{cm}^{2}$ ) is known from independent experiments, values of $\beta, \mathrm{V}, \gamma$ can be immediately found via fitting parameters $\mathrm{a}_{\mathrm{i}}$ (from the experimental data about depths of the deepest pits).

$$
\beta=a_{1}, V=a_{2}-\beta \operatorname{Ln}\left(0.5 \mathrm{SN}_{0}\right) \text { and } \gamma=a_{3} V / \beta
$$

By analogy, if we know the average pit propagation rate, $\mathrm{V}$, (and we know it if we know the polarization curve for active metal dissolution), we can calculate the parameters $\beta, \gamma$, and $\mathrm{N}_{0}$ from the experimental data for depths of the deepest pits. In the particular case of a very small sample it can be assumed that $\mathrm{V}+\beta \operatorname{Ln}\left(0.5 \mathrm{SN}_{0}\right) \approx \mathrm{V}$, and the parameters $\beta$, $\mathrm{V}$, and $\gamma$ can be found from experimental data on the depth of the deepest pits.

In this case, instead of Equations (87), we have

$$
\alpha=\frac{\beta \mathrm{t}}{1+\gamma \beta \mathrm{t} / \mathrm{V}} \text {, and } \mathrm{h}=\frac{\mathrm{V} \mathrm{t}}{1+\gamma \beta \mathrm{t} / \mathrm{V}}
$$

Equations (91) yield the lower estimate for damage propagation. They can be suitable in some cases of progressive nucleation if we assume that the pits that were formed first determine the corrosion damage (it always occurs at constant external conditions).

It is important to note that

$$
\mathrm{V}+\beta \approx \mathrm{V}_{\max }
$$

where $\mathrm{V}_{\max }$ is approximately the maximum possible pit growth rate. This value can be estimated via Faraday's law and the value of anodic dissolution current on the bare surface, $i_{a n}$. The last value for many practical systems can be estimated by using OLI models and software. Under these conditions (when $\mathrm{V}_{\max }$ can be estimated), Equation (92) can be considered as an additional condition, and unknown values of $\beta, \mathrm{V}, \gamma$ and $\mathrm{N}_{0}$ can be fitted without information on the number of nucleated pits. 
Some important conclusions follow from Equations (29). The ratio

$$
\alpha / \mathrm{h}=\beta /\left[\mathrm{V}+\beta \operatorname{Ln}\left(0.5 \mathrm{SN}_{0}\right)\right]=\mathrm{const}
$$

does not depend on time. It also follows from Equation (87) that $\alpha / \mathrm{h}<1$. Both these facts are mentioned in the literature (Strutt, 1985).

Criteria can also be obtained when repassivation phenomena influence the depth of the deepest pits. As follows from Equations (87), if the value of the dimensionless complex

$$
\mathrm{M}=\gamma \beta \mathrm{t} / \mathrm{V}
$$

is much less than 1, repassivation phenomena do not influence the depth of the deepest pits. In the opposite case, at $\mathrm{M}>>1$, the further propagation of the deepest pit cannot be observed.

At first glance, the influence of the repassivation phenomena on the pit propagation must depend on the dimensionless value

$$
\mathrm{M}_{1}=\gamma \mathrm{t}
$$

Really, if repassivation of pits obeys the first-order law, in the case of instantaneous nucleation the number of active pits $\mathrm{N}_{\mathrm{a}}$ can be estimated from the equation

$$
\mathrm{N}_{\mathrm{a}}=\mathrm{N}_{0}[1-\exp (-\gamma \mathrm{t})]
$$

Accordingly, at $\mathrm{M}_{1}=\gamma \mathrm{t} \gg>1$ practically all pits are repassivated and we can expect that corrosion damage is stopped.

The explanation why the time of damage propagation must depend on the parameter $\beta$ is as follows. At $\beta=0$, Equations (87) have the form

$$
\alpha=0, \mathrm{~h}=\mathrm{Vt}
$$

This means that, at $\beta=0$, in spite of the fact that the damage function depends on $\gamma$, the depth of the deepest pit, $\mathrm{L}_{\max }$, can be always found from the simple relation

$$
\mathrm{L}_{\max }=\mathrm{Vt}
$$

i.e. the probability of failure, $\mathrm{P}_{\mathrm{f}}$, is described by

$$
\mathrm{P}_{\mathrm{f}}=0 \text { at } \mathrm{t}<\mathrm{x} / \mathrm{V} \text { and } \mathrm{P}_{\mathrm{f}}=1 \text { at } \mathrm{t}>\mathrm{x} / \mathrm{V}
$$

It is clear that such a situation is not observed experimentally and the propagation of damage for a long period of time must depend not only on the parameter $\gamma$ but also on the parameters $\beta$ (and V). It is important to note that the difference between the values $\mathrm{M}$ and 
$\mathrm{M}_{1}$ (and accordingly between times of damage propagation) can be of one order of magnitude.

\section{Example of application of DFA. Transition of pits into cracks.}

Regarding the transition of a pit into a crack, we assume that a pit immediately transforms into a crack if its depth exceeds some critical value $\mathrm{x}_{\text {nuc. }}$ According to Chen et. al. (1996), two conditions that are described by Equations (32) and (33) must be satisfied for crack nucleation to take place.

It is important to emphasize that the value of parameter $\mathrm{x}_{\mathrm{nuc}}$ can be crucial for calculating the service life of the system, $t_{\mathrm{s}}$. First of all, it is evident that $\mathrm{x}_{\mathrm{nuc}}$ influences the time of propagation of corrosion damage in the form of a pit (and in many if not in most cases this time can be comparable with $t_{\mathrm{s}}$ ). But it can be also shown that $\mathrm{x}_{\text {nuc }}$ can also influence the propagation of corrosion damage in the form of a crack in spite of the fact that usually $\mathrm{x}_{\mathrm{nuc}}<<\mathrm{x}_{\mathrm{cr}}$, where $\mathrm{x}_{\mathrm{cr}}$ is the critical depth of the system (for example, the depth of the wall of the construction).

Actually, in many cases the crack propagation rate can be deduced for the mechanical component. Thus, for the case of corrosion fatigue, when the sinusoidal stress,

$$
\sigma=\sigma_{\mathrm{m}}+\Delta \sigma \sin (2 \pi \nu t)
$$

is applied ( $\sigma_{\mathrm{m}}$ and $\Delta \sigma$ are the mean stress and stress range correspondingly and $v$ is the frequency) the cavity propagation rate can be written in the form

$$
\frac{\mathrm{dx}}{\mathrm{dt}}=v C(\Delta K)^{\mathrm{n}}
$$

where $\Delta \mathrm{K}$ is the stress intensity range and $\mathrm{C}$ and $\mathrm{n}$ are empirical constants that depend on the alloy [Chen et al, 1996, McCloskey et al., 1999]. In turn the relation between stress intensity range, $\Delta \mathrm{K}$ and the stress range $\Delta \sigma$ is given by the relation

$$
\Delta \mathrm{K}=\mathrm{Q} \Delta \sigma \sqrt{\pi \mathrm{x}}
$$

where $\mathrm{Q}$ is a dimensionless parameter dependent on the shape of the crevice. Usually, the value $\mathrm{Q} \approx 1.1$ is accepted. The solution of the differential Equation (101) (at $\mathrm{n} \neq 2$ ) yields the time that is required for a crack to increase its depth from the nucleation stage $(\mathrm{x}=$ $\left.\mathrm{x}_{\mathrm{nuc}}\right)$ to a critical value $\left(\mathrm{x}=\mathrm{x}_{\mathrm{cr}}\right)$ :

$$
\mathrm{t}=\frac{\mathrm{n}-2}{2(v \mathrm{Q} \Delta \sigma \sqrt{\pi})^{\mathrm{n}}}\left(\frac{1}{\mathrm{x}_{\mathrm{nuc}}^{(\mathrm{n}-2) / 2}}-\frac{1}{\mathrm{x}_{\mathrm{cr}}^{(\mathrm{n}-2) / 2}}\right)
$$

Under normal conditions, $\mathrm{x}_{\mathrm{nuc}}$ is of the order of $100 \mathrm{~m} \mu$ whereas $\mathrm{x}_{\mathrm{cr}}$ is of the order of 1 $\mathrm{cm}$. Accordingly, the second term in the brackets in Equation (103) can be omitted and we can conclude that $\mathrm{t} \sim 1 / \mathrm{x}_{\text {nuc }}^{(\mathrm{n}-2) / 2}$ and does not depend on $\mathrm{x}_{\text {cr. }}$. Usually, the parameter $\mathrm{n}$ is 
of the order of 4 , i.e. $\mathrm{t} \sim 1 / \mathrm{x}_{\text {nuc. }}$ This strong dependence clearly shows the importance of reliable determination of the parameter $\mathrm{x}_{\mathrm{nuc}}$ and, particularly, the importance of having reliable criteria for the transition of pits into cracks.

However, there are points of view in the literature that a simple application of the principles of fracture mechanics based on the pit acting as an effective crack of the same depth [see Criterion (32) and (33)] would not be pertinent in many cases. This point of view is based on the experimentally observed fact that, whilst the crack depth usually exceeds the pit depth, there were examples where the pit depth extended significantly beyond the crack. Thus Figure 8 shows the percentage of pits with cracks measured on $3 \mathrm{NiCrMoV}$ steam turbine disk steel employing self loaded specimens to $90 \%$ of $\sigma_{0.2}$ for aerated pure water and aerated water containing $1.5 \mathrm{ppm}$ of chloride ions at $90{ }^{\circ} \mathrm{C}$ as a function of the depth of the pit [Turnbull and Zhou, 2004]. This figure clearly shows that cracks exist with a depth that exceeds the depth of some pits. The authors of this work assume that the crack may not have initiated from the base of the pit. This assumption cannot be explained from the point of view of fracture mechanics because the largest stress must occur at the bottom of the pit. The authors of this work also mention, as a very strange fact, that a remarkable similarity exists between the percentage of pits with cracks at specific pit depths, despite changes in exposure time and presence or absence of chloride.

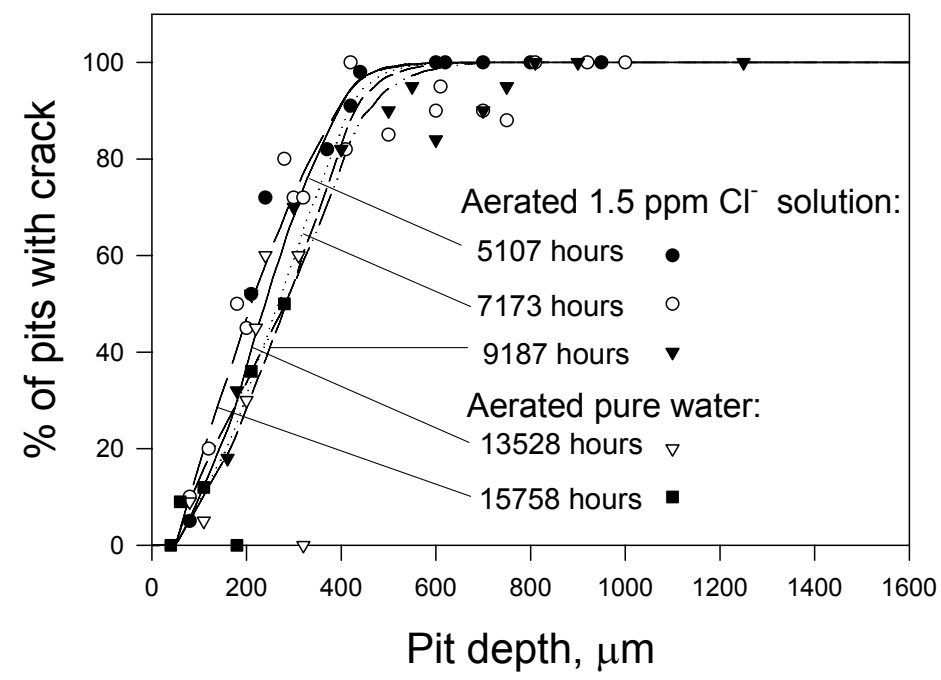

Figure 8. Likelihood of cracks developing from pits as a function of depth for $3 \mathrm{NiCrMoV}$ disk steel. The lines are calculated using Equations (104) - (107). The experimental data are taken from [Turnbull and Zhou, 2004].

We have found that the damage function analysis can explain these experimental facts within the framework of fracture mechanics. The analytical solution of balance equations for the differential damage functions (see our previous reports) for active pits, $f_{a}$, passive pits, $f_{p}$, and cracks, $f_{c r}$, is found as (albeit in a rather complicated form): 


$$
\begin{aligned}
& \mathrm{f}_{\mathrm{a}}=\int_{0}^{\infty}\left\{\frac{\exp \left[-\gamma \mathrm{g}(\mathrm{x}) / \mathrm{v}_{0}\right] \mathrm{n}\left(\mathrm{t}-\mathrm{g}(\mathrm{x}) / \mathrm{v}_{0}\right)}{\mathrm{v}_{0} \varsigma(\mathrm{x})} \mathrm{U}\left[\left(\max \left(\mathrm{x}_{\mathrm{tr}}, \mathrm{x}_{\mathrm{v} 0}\right)-\mathrm{x}\right]\right\} \psi\left(\mathrm{v}_{0}\right) d \mathrm{v}_{0}\right. \\
& \mathrm{f}_{\mathrm{p}}=\gamma \mathrm{U}\left(\mathrm{x}_{\mathrm{tr}}-\mathrm{x}\right) \times \int_{0}^{\infty} \frac{\gamma \exp \left[-\gamma \mathrm{g}(\mathrm{x}) / \mathrm{v}_{0}\right) \mathrm{N}\left(\mathrm{t}-\mathrm{g}(\mathrm{x}) / \mathrm{v}_{0}\right)}{\mathrm{v}_{0} \varsigma(\mathrm{x})} \psi\left(\mathrm{v}_{0}\right) \mathrm{dv}_{0} \\
& \mathrm{f}_{\mathrm{cr}}=\mathrm{U}\left(\mathrm{x}-\mathrm{x}_{\mathrm{tr}}\right) \times \int_{0}^{\infty}\left\{\begin{array}{l}
\mathrm{U}\left(\mathrm{x}_{\mathrm{tr}}-\mathrm{x}_{\mathrm{v} 0}\right) \mathrm{A}\left(\mathrm{x}, \mathrm{x}_{\mathrm{tr}}, \mathrm{t}\right)+ \\
+\mathrm{U}\left(\mathrm{x}_{\mathrm{tr}}-\mathrm{x}_{\mathrm{v} 0}\right) \mathrm{U}\left(\mathrm{x}_{\mathrm{v} 0}-\mathrm{x}\right) \mathrm{B}(\mathrm{x}, \mathrm{t})+ \\
+\mathrm{U}\left(\mathrm{x}_{\mathrm{tr}}-\mathrm{x}_{\mathrm{v} 0}\right) \mathrm{U}\left(\mathrm{x}-\mathrm{x}_{\mathrm{v} 0}\right) \times \\
\times\left[\mathrm{B}\left(\mathrm{x}_{\mathrm{v} 0}, \mathrm{t}-\theta\left(\mathrm{x}, \mathrm{x}_{\mathrm{v} 0}\right)\right)+\mathrm{A}\left(\mathrm{x}, \mathrm{x}_{\mathrm{v} 0}, \mathrm{t}\right)\right]
\end{array}\right\} \psi\left(\mathrm{v}_{0}\right) \mathrm{dv}_{0}
\end{aligned}
$$

where

$$
\mathrm{A}(\mathrm{x}, \mathrm{y}, \mathrm{t})=\frac{\exp \left[-\gamma \mathrm{g}(\mathrm{y}) / \mathrm{v}_{0}\right] \mathrm{n}\left[\mathrm{t}-\mathrm{g}(\mathrm{y}) / \mathrm{v}_{0}-\theta_{\mathrm{cr}}(\mathrm{x}, \mathrm{y})\right]}{\mathrm{V}_{\mathrm{cr}}(\mathrm{x})}
$$

and

$$
\mathrm{B}(\mathrm{x}, \mathrm{t})=\frac{\gamma}{\mathrm{V}_{\mathrm{cr}}(\mathrm{x})} \times \int_{\mathrm{x}_{\mathrm{tr}}}^{x} \frac{\exp \left[-\gamma \mathrm{g}\left(\mathrm{x}^{\prime}\right) / \mathrm{v}_{0}\right] \mathrm{n}\left[\mathrm{t}-\mathrm{g}\left(\mathrm{x}^{\prime}\right) / \mathrm{v}_{0}-\theta_{\mathrm{cr}}\left(\mathrm{x}, \mathrm{x}^{\prime}\right)\right]}{\mathrm{v}_{0} \varsigma\left(\mathrm{x}^{\prime}\right)} \mathrm{dx} \mathrm{x}^{\prime}
$$

were $\mathrm{U}(\mathrm{x})$ is the unit function $[\mathrm{U}(\mathrm{x})=0$ at $\mathrm{x} \leq 1$ and $\mathrm{U}(\mathrm{x})=1$ at $\mathrm{x}>0], \max (\mathrm{a}, \mathrm{b})=\mathrm{a}$ for $\mathrm{a} \geq \mathrm{b}$ and $\max (\mathrm{a}, \mathrm{b})=\mathrm{b}$ for $\mathrm{a}<\mathrm{b}$. Here, $\mathrm{x}_{\text {tr }}$ denotes the depth of a pit at which the condition of $\mathrm{K}_{\mathrm{I}}$ $=\mathrm{K}_{\mathrm{ISCC}}$ (for SCC) or $\Delta \mathrm{K}_{\mathrm{I}}=\Delta \mathrm{K}_{\mathrm{I} \text {,th }}$ (corrosion fatigue, CF) is satisfied and $\mathrm{x}_{\mathrm{V} 0}$ denotes the depth of the pit at which the condition $\mathrm{V}_{\mathrm{cr}}=\mathrm{V}_{\text {pit }}$ is satisfied for a pit that was born with an initial propagation rate $\mathrm{v}_{0}$. We also assume that the crack propagation rate, $\mathrm{V}_{\mathrm{cr}}(\mathrm{x})$, depends only on the crack depth, $x$. Accordingly, the function

$$
\theta_{\mathrm{cr}}=\int_{\mathrm{x}}^{\mathrm{x}} \frac{\mathrm{dy}}{\mathrm{V}_{\mathrm{cr}}(\mathrm{y})}
$$

is the age of a crack with depth $\mathrm{x}$, which was born at a distance $\mathrm{x}^{\prime}$ from the metal surface (i.e., at the bottom of a pit). All other symbols are introduced in our previous reports. It is important to note that the obtained solution recognizes the fact that, if the depth of the pit increases to $\mathrm{x}_{\mathrm{tr}}$, and after that pit is passivated, it must immediately transition into a crack, because the condition $\mathrm{V}_{\mathrm{cr}}>\mathrm{V}_{\text {pit }}$ is fulfilled.

Using the obtained solutions, the percentage of pits with cracks at specific pit depths, $\varepsilon$, is readily calculated from the relation

$$
\varepsilon=\frac{\mathrm{f}_{\mathrm{cr}}}{\mathrm{f}} \times 100 \%
$$

where $f=f_{a}+f_{p}+f_{c r}$ is the total differential damage function for corrosion defects. 
It can be shown that, for the same values of the kinetic parameters, Equations (104) (107) can satisfactorily explain the observed experimental data. Thus, in accordance with the experimental data, we note that $\mathrm{x}_{\mathrm{tr}}$ is of the order of $50 \mu \mathrm{m}$, and $\mathrm{V}_{\mathrm{cr}} \approx 10^{-10} \mathrm{~m} / \mathrm{s}$ for corrosion in aerated, $1.5 \mathrm{ppm} \mathrm{Cl}^{-}$solution (in the case of pure aerated water, the crack growth rate is lower by factor of 2). In addition, we assume that the distribution in the pit propagation rate is described by Laplaces's distribution with $\mathrm{V}_{0} \approx 3 \mathrm{~V}_{\mathrm{cr}}$ and $\beta \approx 0.1 \mathrm{~V}_{0}$ (a very sharp distribution), $\mathrm{x}_{0} \approx \mathrm{x}_{\mathrm{tr}}$ and $\gamma \approx 1 /(1000 \mathrm{~h})$ (see our previous reports). Finally, we assume that instantaneous nucleation of pits occurs in the system.

Figure 11 shows that satisfactory agreement is observed between the calculated and measured values of $\varepsilon$. Figure 11 only shows that DFA allows us to explain satisfactorily the principal experimental data for the transition of pits into cracks during the stress corrosion cracking of steam turbine disk steel on the basis of the proposed mechanical conditions [Turnbull and Zhou, 2004]. Practically, we fitted all parameters by using experimental data for the percent of pits with cracks measured on disk steel in a $1.5 \mathrm{ppm}$ $\mathrm{Cl}$ solution after 5107 hours for predicting the percent of pits with cracks in a $1.5 \mathrm{ppm} \mathrm{Cl}$ solution after 7173 hours and 9187 hours and for the percent of pits with cracks on disk steel in aerated pure water at 13528 hours and 15758 hours, i.e. for different times and external conditions.

\section{Example of application of DFA. Extrapolation of corrosion damage in space and time}

In this section, a general method for extrapolating corrosion damage in space and time is described. We also demonstrate the application of this method to pitting corrosion, crevice corrosion and stress corrosion cracking (SCC), which may be the most dangerous forms of localized corrosion of fabricated materials.

As shown above, the extreme value distribution function (EVD), $\Psi(x, t)$, i.e. the probability that the largest value of corrosion depth is less than or equal to $\mathrm{x}$ for a given observation time, $t$., can be expressed via the integral damage function, $F(x, t)$, through the relation

$$
\Psi=\exp (-\mathrm{SF})
$$

where $\mathrm{S}$ is the total area of the system. Accordingly, the EVD density function

$$
\psi=\frac{\partial \Psi}{\partial \mathrm{x}}
$$

yields the probability that the depth of the deepest corrosion event will be within the interval $\mathrm{x}+\mathrm{dx}$ for a given observation time $\mathrm{t}$. In our previous reports, numerical and analytical calculations of differential damage function, $f(x, t)$ and integral damage function $\mathrm{F}(\mathrm{x}, \mathrm{t})$ were described. However, in the majority of instances, we do not know all the kinetic parameters that determine localized corrosion in a system (very often, we have no information about any of these parameters). Accordingly, in a general case, we cannot calculate $\psi$ directly from Equations (109) and (110). We will denote $\psi=\psi\left(\mathrm{x}, \mathrm{t} ; \mathrm{a}_{\mathrm{k}}\right)$ where $\mathrm{a}_{\mathrm{k}}(\mathrm{k}=1,2, \ldots, \mathrm{m})$ are unknown parameters and $\mathrm{m}$ is a total number of these parameters. 
Let us imagine that a user has a data set $\left(\mathrm{x}_{\mathrm{i}}, \mathrm{t}_{\mathrm{i}}, \mathrm{s}_{\mathrm{i}}\right), \mathrm{i}=1, \ldots, \mathrm{n}$, where $\mathrm{x}_{\mathrm{i}}$ is the depth of the deepest corrosion event over a sample with the area $s_{i}$, of a metal exposed to a corrosion environment for time $t_{i}$ and $n$ is the number of available experimental points. The areas $s_{i}$ could pertain to either distinct coupons from a design experiment, or else to random samples taken at various times from various regions of metal thought to be representative of the whole system with area $\mathrm{S}$. The method can be used for a relatively small total number of experimental points, $\mathrm{n}$.

It is evident that the probability, $\mathrm{P}$, to yield such a set of $\mathrm{n}$ experimental points (within intervals $\left.x_{i}+d x, t_{i}+d t, i=1,2, \ldots, n\right)$ is

$$
\mathrm{P}=\left(\prod_{\mathrm{i}=1}^{\mathrm{n}} \psi\left(\mathrm{x}_{\mathrm{i}}, \mathrm{t}_{\mathrm{i}}, \mathrm{s}_{\mathrm{i}} ; \mathrm{a}_{\mathrm{k}}\right)\right) \mathrm{dx}^{\mathrm{n}} \mathrm{dt}^{\mathrm{n}}
$$

The most probable values of these parameters can be estimated as those that yield the maximum $\mathrm{P}$ value. It is convenient to use the logarithm of $\mathrm{P}$ instead of $\mathrm{P}$. Accordingly, the problem of finding the maximum of the function $\mathrm{P}$ is equivalent to finding the minimum of the function

$$
\mathrm{L}=-\sum_{\mathrm{i}=1}^{\mathrm{n}} \operatorname{Ln}\left(\psi_{\mathrm{i}}\right)=\sum_{\mathrm{i}=1}^{\mathrm{n}} \operatorname{Ln}\left(\mathrm{s}_{\mathrm{i}}\right)+\sum_{\mathrm{i}=1}^{\mathrm{n}} \operatorname{Ln}\left[\mathrm{f}\left(\mathrm{x}_{\mathrm{i}}, \mathrm{t}_{\mathrm{i}} ; \mathrm{a}_{\mathrm{k}}\right)\right]+\sum_{\mathrm{i}=1}^{\mathrm{n}} \mathrm{s}_{\mathrm{i}} \mathrm{F}\left(\mathrm{x}_{\mathrm{i}}, \mathrm{t}_{\mathrm{i}} ; \mathrm{a}_{\mathrm{k}}\right)
$$

where

$$
f\left(x, t ; a_{k}\right)=-\frac{\partial F\left(x, t ; a_{k}\right)}{\partial x}
$$

is the differential damage function.

The unknown values of the parameters, $a_{k}$, yielding the minimum value of $L$, can be determined by solving the set of equations

$$
\frac{\partial \mathrm{L}}{\partial \mathrm{a}_{\mathrm{k}}}=0, \quad \mathrm{k}=1,2, \ldots, \mathrm{m}
$$

It is well known that there are no general methods for solving systems of more than one nonlinear equation [Press et al. 1999]. This is why, along with the solution of the equation system (114), we are also considering the direct minimization of the function L. In many cases, such minimization can be made relatively easier than the direct solution of the System (114). In the current version of the code, a "brute-force" procedure is used for small values of unknown parameters $(\mathrm{m} \leq 3)$. In this procedure, the permissible range of each parameter $\mathrm{a}_{\mathrm{k}}$, is divided into $\mathrm{q}_{\mathrm{k}}$ equal increments $\Delta \mathrm{a}_{\mathrm{k}}$ so that the m-parameter space is divided into $\prod_{k=1}^{m} q_{k}$ hypercubes. The value of $L$ is calculated at the vertices of each hypercube. This procedure assures that the global minimum of the function $\mathrm{L}$ will be found with the desired accuracy $\Delta \mathrm{a}_{\mathrm{k}}$ for unknown parameters. As an alternative, a Monte Carlo simulation has been implemented. However, this method becomes time consuming for $m>4$. We have also implemented such direct methods as Powell's method and Grid- 
Search method. The latter two methods are very fast and acceptable results for all applications have been obtained. However, in some cases, problems with the starting point for calculations arose (instead of obtaining the global minimum of the function $\mathrm{L}$, the solution converges to a local one). In the current OLI Systems code we use "bruteforce" method for $m \leq 3$ and Powell's method for $m>3$ (in combination with the Monte Carlo method for determining the starting point).

It is important to note that no assumption has been made that the extreme value distribution function obeys extreme value statistics (EVS). If this is the case, the procedure can be substantially simplified. Let us assume, for example, that EVD obeys the Gumbel distribution, i.e.

$$
\Psi(\mathrm{x}, \mathrm{t})=\exp [-\exp (-\mathrm{y})]
$$

where

$$
\mathrm{y}=(\mathrm{x}-\mathrm{h}) / \alpha
$$

and $h$ and $\alpha$ are central and scale parameters, respectively. It can be shown that the mean depth of the deepest corrosion event, $d$, can be expressed via $h$ and $\alpha$ as

$$
\mathrm{d}=\mathrm{h}+\gamma \alpha
$$

where $\gamma=0.5772157 \ldots$ is Euler's constant. In turn, the standard deviation of the value $\mathrm{d}$ is

$$
\sigma=\frac{\pi \alpha}{\sqrt{6}}
$$

Our numerical calculations and experimental data show that pitting corrosion really obeys the Gumbel distribution. And it has been shown that in this case the dependences of parameters $h$ and $\alpha$ on time can be described via rectangular hyperbolic functions as a result of repassivation phenomena.

As mentioned in our previous report, the extreme value statistics methodology for predicting the time evolution of localized corrosion has been implemented in the CorrosionAnalyzer, OLI Systems' software for the chemical process and related industries. This methodology can be used under conditions when not all, or even none, of the kinetic parameters that determine the pit nucleation rate, pit propagation rate, and pit repassivation rate, are known. The unknown parameters are determined by comparing the results of analytical or numerical calculations of the depths of the deepest pits (crevices) with the experimentally observed corresponding values for short-term experiments. After determining values for the unknown parameters, the depths of the deepest pit (crevice) for the total system (i.e. for the system with arbitrary surface area) for long-term exposure are predicted.

Particularly for the case of instantaneous nucleation, it has been shown that the location parameter, $h$, and scale parameter, $\alpha$, in extreme value cumulative distribution functions are described by hyperbolic relations: 


$$
h=\frac{a_{1} t}{1+a_{2} t}, \quad \alpha=a_{3} h
$$

Figure 9 illustrates the illustrates the applicability of hyperbolic dependence for predicting the results of classical experiments for measuring the depth of the deepest pits in the corrosion of aluminum alloy 2S-O in Kingston tap water (Aziz, 1955).

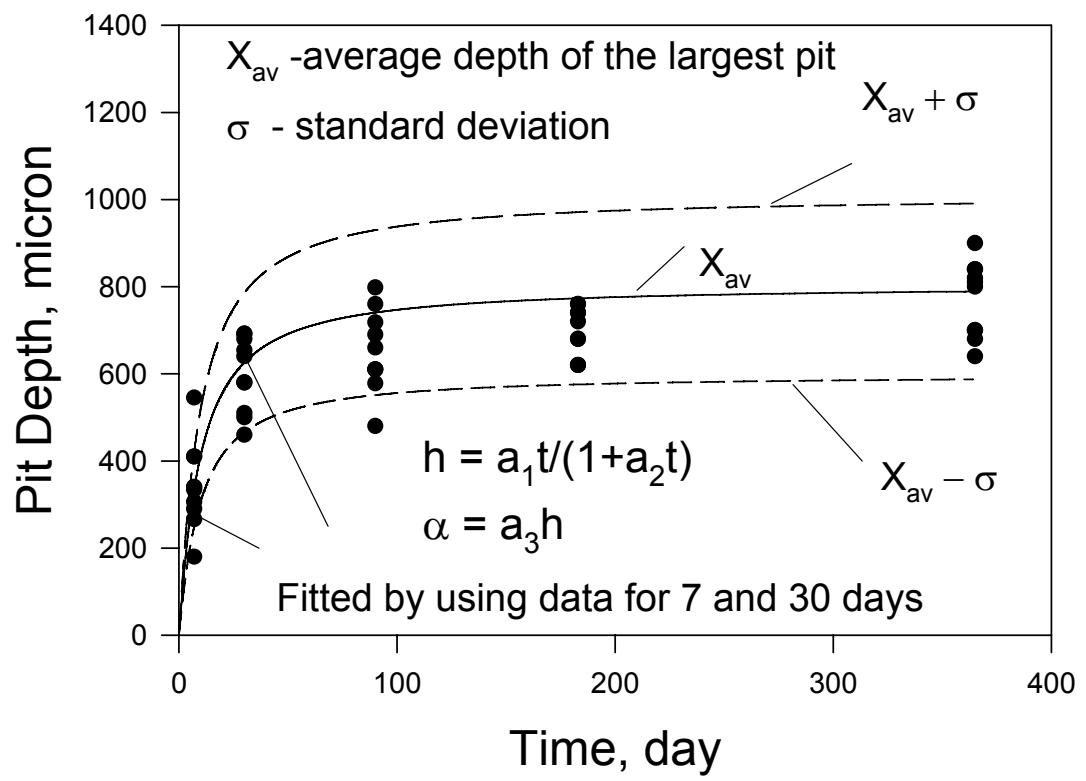

Figure 9. Fitting experimental data (black circles) with the help of logarithmic Distributions (Equation. 119).

We see that applicability can be considered as absolutely satisfactory. Note that only the data for $\mathrm{t}=1$ week and 1 month were used for prediction for a period of up to 1 year.

However, as mentioned by Kowaka (1994) the typical time-relations that are usually used for estimating the location and scale parameters in extreme value distributions are of power law type:

$$
h=a_{1} t^{a_{2}}, \quad \alpha=a_{3} h
$$

or a logarithmic law type:

$$
h=a_{1} \log (t)+a_{2}, \quad \alpha=a_{3} h
$$

We generalized our computer codes to allow users to apply the power and logarithmic functions along with the hyperbolic one. Figures 10 and 11 illustrates the applicability of power and logarithmic dependencies for predicting the depth of the deepest pits in the corrosion of aluminum alloy 2S-O in Kingston tap water (Aziz, 1955). Note that only the data for $\mathrm{t}=1$ week and 1 month were used for prediction for a period of up to 1 year. 
We see that the application of power law yields unacceptable results for the given case. The applicability of power law is usually explained by the fact that the growth law for an individual pit can be usually described by the power function (Laycock et al., 1990), i.e.

$$
L=a t^{b}
$$

It is clear that the power Law (122) does not take into account the repassivation of pits that explains the failure of prediction in Figure 10.

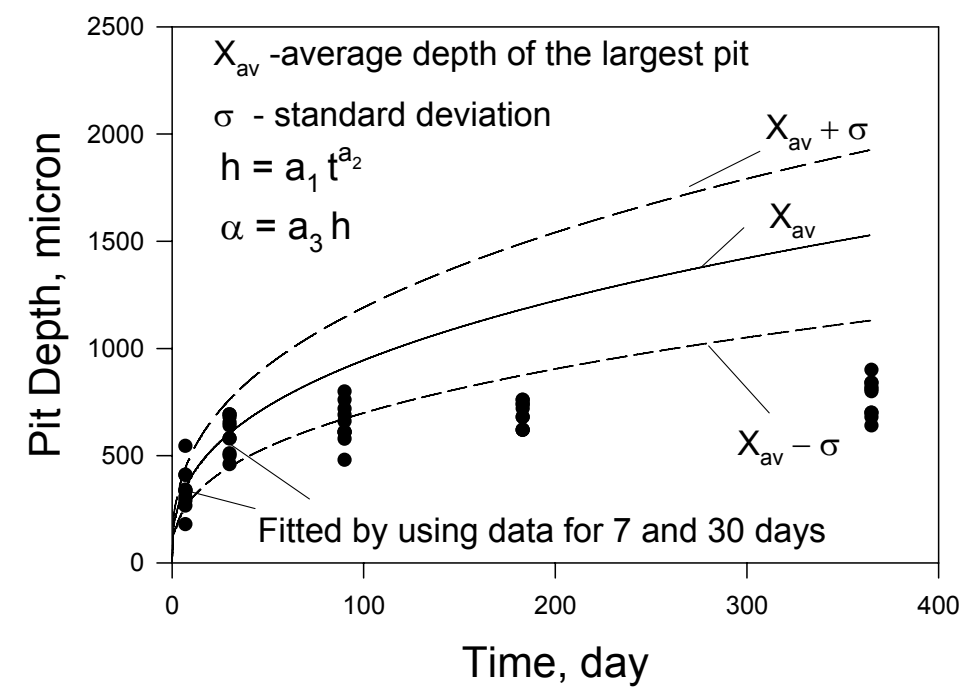

Figure 10. Fitting experimental data (black circles) with the help of power distributions (eq. 120).

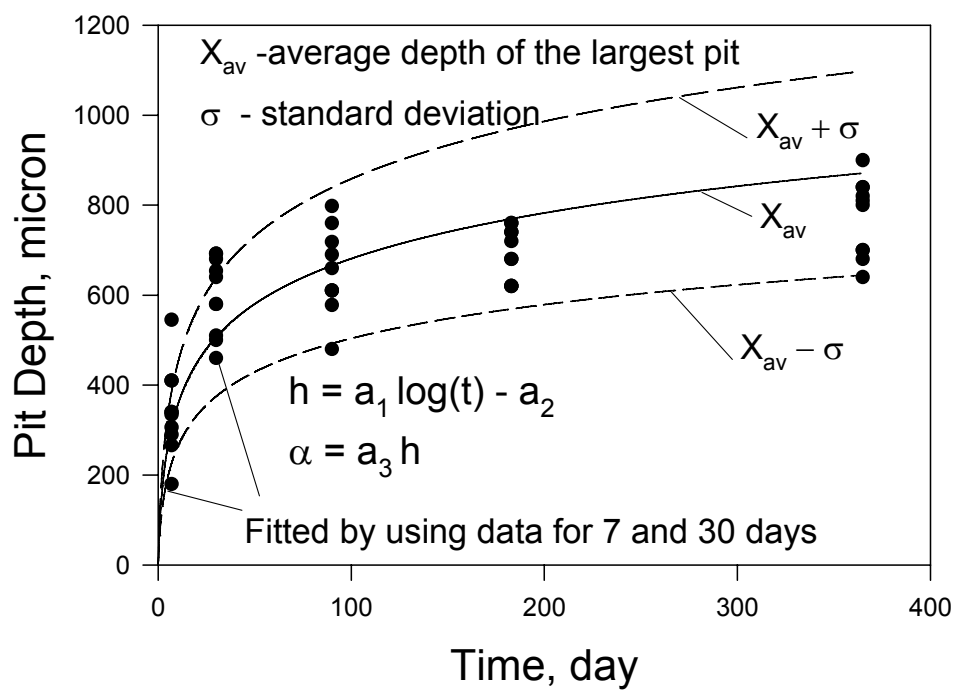

Figure 11. Fitting experimental data (black circles) with the help of logarithmic Distributions (eq. 121).

On the other hand, the application of the logarithmic law yields acceptable (but maybe imperfect) results (see Figure 11). However, at present, there is no physical model that 
could explain a logarithmic law of pit growth. Really, if we assume that the growth law of individual pits can be described by a logarithmic function, i.e,

$$
L=a \operatorname{Ln}(t)+b
$$

it can be easily shown that this leads to an exponential decrease of the pit propagation rate with pit depth:

$$
\frac{d L}{d t}=\frac{a}{e^{(L=a) / b}}
$$

This dependence is substantially stronger than the maximum possible decrease of the rate of open pit growth under diffusion control when $d L / d t \sim 1 / L$. Accordingly, we can conclude that the logarithmic dependence of pit growth law is formally introduced for the effective description of pit propagation in the presence of the repassivation phenomena. We have suggested (and implemented) in the code a generalization of the hyperbolic functions (1) in the form

$$
h=\frac{a_{1} t^{a_{4}}}{1+a_{2} t^{a_{4}}}, \quad \alpha=a_{3} h
$$

The advantage of the general hyperbolic dependence (125) is that it coincides with the power law (2) at short times and yields the accurate transition:

$$
h \rightarrow a_{1} / a_{2}=\text { constant at } \mathrm{t} \rightarrow \infty
$$

as it must be due to the repassivation. Of course, if the repassivation phenomena are not essential (which may be, for example, the case for stress corrosion cracking or corrosion fatigue), the parameter $\mathrm{a}_{2} \approx 0$ and the power law is obtained at arbitrary times. It is interesting to mention that the calculations show that the parameter $\mathrm{a}_{4}=1.0093 \approx 1$, i.e. fitting by using general hyperbolic dependences yields, for the given case, practically the same results as the simple hyperbolic dependence (as described in our previous reports). There is experimental evidence that crevice corrosion, stress corrosion cracking (SCC) and corrosion fatigue also obey the Gumbel distribution [Kowaka, 1994]. However, in the case of crevice corrosion and SCC, we cannot expect, in general, that repassivation phenomena play an essential role in crevice propagation. Experimental evidence and theoretical estimations (see previous reports) show that the propagation of crevices can be represented as power functions with respect to time (at least for sufficiently deep crevices).

Figure 12 shows the results of fitting unknown parameters to the experimental data on crevice corrosion under ethylene-propylenediene monomer rubber (EPDM) on 2024 T3 aluminum after salt spray testing for 2, 4, 610 and 20 days (Vajo et al., 2003). After applying the procedure described above, we obtained the following values of the fitting parameters: $\mathrm{a}_{1}=0.778, \mathrm{a}_{2}=0.384$ and $\mathrm{a}_{3}=0.280$. If $\mathrm{t}$ is measured in days, Equation (120) yields results in $\mathrm{mm}$. We see that, by using the obtained parameters, we can really 
reproduce the experimental data. For comparison purposes, Figure 12 also shows the predictive power of our method when fitting has been performed by using data for only 2 , 4 and 6 days. We can see that even for 20 days (or for the period of time that is 3 times longer than the period of time for which experimental data are available), the prediction yields acceptable results.

In some cases, instead of relation (120), it is more convenient to use a relation of the type

$$
\mathrm{h}=\mathrm{h}_{0}\left[\left(1+\mathrm{t} / \mathrm{t}_{0}\right)^{\mathrm{b}}-1\right] \text {. }
$$

Such dependencies describe crevice propagation with a constant rate for short times (when diffusion limitations do not play a role) and, for sufficiently large times, they coincide with Equation (120). The latter approach can yield a better agreement with experiment for crevice corrosion under a silicon adhesive on a 380 cast aluminum seal (Vajo et al., 2003).

2024 -T3 aluminum seals after salt spay

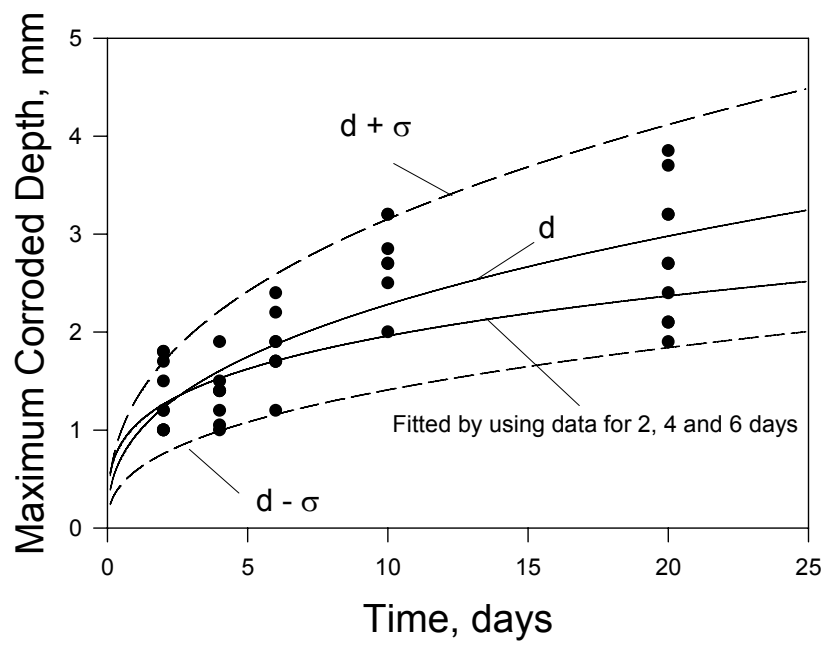

Figure 12. Mean maximum corroded depth for a crevice formed by ethylenepropylenediene monomer rubber on 2024-T3 aluminum seal.

In the case of stress corrosion cracking, it is convenient to rewrite Equations (120) in the form)

$$
\mathrm{h}=\mathrm{h}_{0}+\mathrm{a}_{1}\left(\mathrm{t}-\mathrm{t}_{0}\right)^{\mathrm{a}_{2}} \quad \text { and } \quad \alpha=\mathrm{a}_{3}\left(\mathrm{t}-\mathrm{t}_{0}\right)^{\mathrm{a}_{2}}
$$

Here, $\mathrm{h}_{0}$ and $\mathrm{t}_{0}$ are additional parameters. The physical meaning of these parameters is as follows: $h_{0}$ is the threshold depth and $t_{0}$ is the incubation period prior to steady crack propagation.

Figure 12 shows the results of calculations for stress corrosion cracking in sensitized 304 stainless steel in $250{ }^{\circ} \mathrm{C}$ water with $20 \mathrm{ppm}$ dissolved oxygen (Akashi and Kawamoto, 1983). The obtained values of the $h_{0}$ and $t_{0}$ parameters are $h_{0}=50.5 \mu \mathrm{m}$ and $t_{0}=90 \mathrm{~h}$. It 
is important to note that this value of $\mathrm{h}_{0}$ is very close to the empirically known value of the threshold crack depth in $304 \mathrm{SS}$, which is around $50 \mu \mathrm{m}$ (Akashi and Kawamoto, 1983).

It is also important to note that the parameter $\mathrm{a}_{2}$ [the power in Equation (128)] is found to be 1.16, i.e $\mathrm{a}_{2}>1$. Such values (i.e., greater than 1) cannot be obtained in principle by using the rectangular hyperbola functions as it was done in the case of pitting corrosion. This observation clearly shows that a mechanical component must be taken into account in the case of SCC.

For comparison purposes, Figure 10 also shows the predictive power of our method when parameter fitting is performed by using data for only 96 and 144 hours. The obtained value of threshold depth for this case is $59.5 \mu \mathrm{m}$.

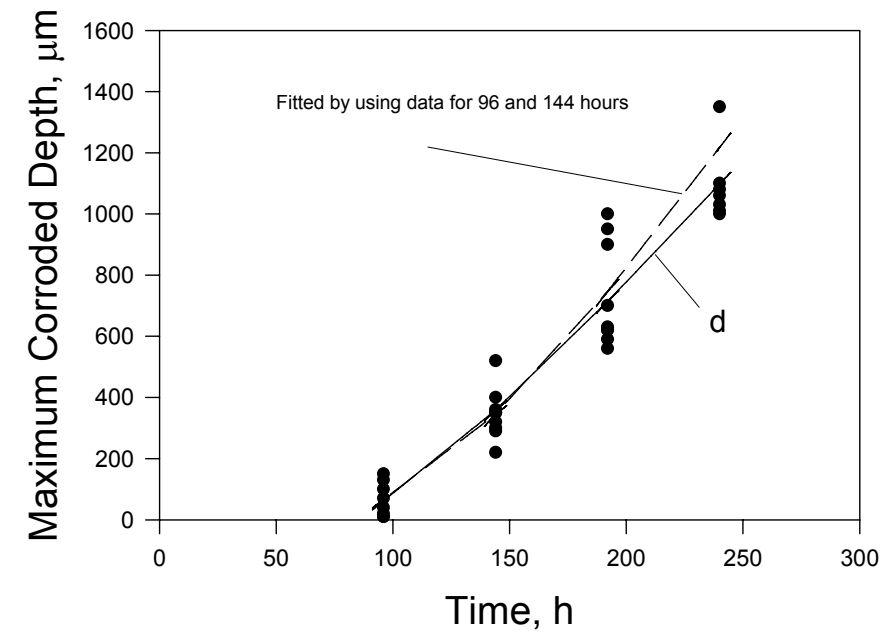

Figure 13. Maximum SCC crack depth distribution for sensitized 304 SS.

The above results indicate that the previously developed methods for extrapolating experimentally measured corrosion damage into the future have been successfully generalized to crevice corrosion and stress corrosion cracking. The applicability of this method has been validated against experimental data.

\section{Application of DFA to the r largest order statistics}

It is evident that, since only the maximum pit depth on each coupon is used in this method, we need to have a relatively large number of coupons used in short-term experiments in order to assure a reliable prediction. As an alternative approach, the socalled $\mathrm{r}$ largest order statistics can be used (see, for example, Weisman, 1978, Smith, 1986). It is based, in our case, on the measurement of the depths of the fist $r$ deepest pits. Because $r$ is a relatively small number (2-10), such measurements can be performed with little extra effort in comparison with the measurement of the single deepest pit. The data for the depth of the $r$ deepest pits are available in corrosion literature, However, as it was 
noted by Scarf (1993), "even when the $r$ largest order statistics have been available, they have often been discarded leaving just the maxima for estimation purposes".

Accordingly, we decided to generalize our method to the case of $r$ largest order statistics. Below only the final results are outlined. For the case of $r$ largest order statistics the set of experimental data is organized in the following way. Let us assume that the index $i$ $(1=1,2, . ., n)$ enumerates the different coupons with the surface $s_{i}$ at the observation time $t_{i}$. Here, $\mathrm{n}$ is the total number of coupons that were investigated at all observation times. Of course, we can use several coupons for a given time, i.e., not all $t_{i}$ values are different. We also denote by $\mathrm{x}_{\mathrm{i}, \mathrm{j}}\left(\mathrm{j}=1,2, \ldots, \mathrm{r}_{\mathrm{i}}\right)$ the depth of the $\mathrm{j}^{\text {th }}$ deepest pit $x_{i, 1} \geq x_{i, 2} \geq \ldots \geq x_{i, r_{i}}$ where $r_{i}$ is the number of the measured deepest pits on the $i^{\text {th }}$ coupon.

It is evident that the probability, $\mathrm{P}$, to observe such a set of data experimentally is:

$$
P=\left(\prod_{i=1}^{n} \psi\left(x_{i j}, t_{i}, s_{i} ; a_{k}\right)\right) d x^{N} d t^{n}
$$

where $N=n \sum_{i=1}^{n} r_{i}, \psi$ is the joint distribution function, i.e. the probability that $\mathrm{r}_{\mathrm{i}}$ deepest pits on the $\mathrm{i}$-th coupon are within the ranges $\left(x_{i 1}, x_{i 1}+d x\right), \ldots,\left(x_{i r_{i}}, x_{i r_{i}}+d x\right)$ for the period of time between $t_{i}$ and $t_{i}+d t$., and $a_{k}$ is the set of unknown parameters that must be fitted to the results of short term experiments.

It has been found that the joint distribution function, $\psi$, can be presented in the form

$$
\psi\left(\mathrm{x}_{\mathrm{ij}}, \mathrm{t}_{\mathrm{i}}, \mathrm{s}_{\mathrm{i}} ; \mathrm{a}_{\mathrm{k}}\right)=\exp \left\{-\exp \left(-y_{i r}\right)-\sum_{j=1}^{r_{i}} y_{i j}\right\} / \alpha^{r_{i}}
$$

where

$$
y_{i j}=\frac{x_{i j}-h}{\alpha}-\operatorname{Ln}\left(s_{i} / s_{0}\right)
$$

Here, $\mathrm{s}_{0}$ is the area of some particular coupon or simply some unit area. The central parameter, $h$, and the scale parameters, $\alpha$, are functions of time only. As it was shown in our previous reports they can be described by hyperbolic functions [see Equation 119). It is evident that the most suitable values of the unknown parameters are those that yield the maximum value of the probability, $\mathrm{P}$, or the minimum value for its negative logarithm. These expressions can be considered as a generalization of corresponding expressions of Scarf (1993) to the case when different coupons can have different areas.

The corresponding code for the minimization of the required function has been developed on the basis of the "brute-force" and Powell's methods. Figure 14 shows an example of the application of the developed method. The experimental data have been extracted from the work of Pierpoline et al. (1987). Here, we used data for 3 stainless steal coupons $(2 \mathrm{x}$ $2 \times 1 / 2$ in) exposed for various times in ferric chloride solution ( 1 coupon at $49.5 \mathrm{hrs}$ and 2 coupons for $144.17 \mathrm{hrs}$ ). Four deepest pits were measured on each coupon. 
After fitting, the average maximum pit depth $\mathrm{X}_{\mathrm{m}, \mathrm{av}}$ and its standard deviation $\sigma$ have been calculated by using the relations (Laycock et al. 1990).

$$
\mathrm{X}_{m, a v}=\mathrm{h}+\gamma \alpha
$$

where $\gamma=0.5772157 \ldots$ is Euler's constant and

$$
\sigma=\frac{\pi \alpha}{\sqrt{6}}
$$

Figure 14 shows that we are able to satisfactorily describe the experimental data that were obtained at $\mathrm{t}=453.25 \mathrm{hrs}$, where four deepest pits on two coupons were measured (note that $98 \%$ of the maximum pit depth observation must be within $\left(X_{m, a v}-2 \sigma, X_{m, a v}+2 \sigma\right)$.

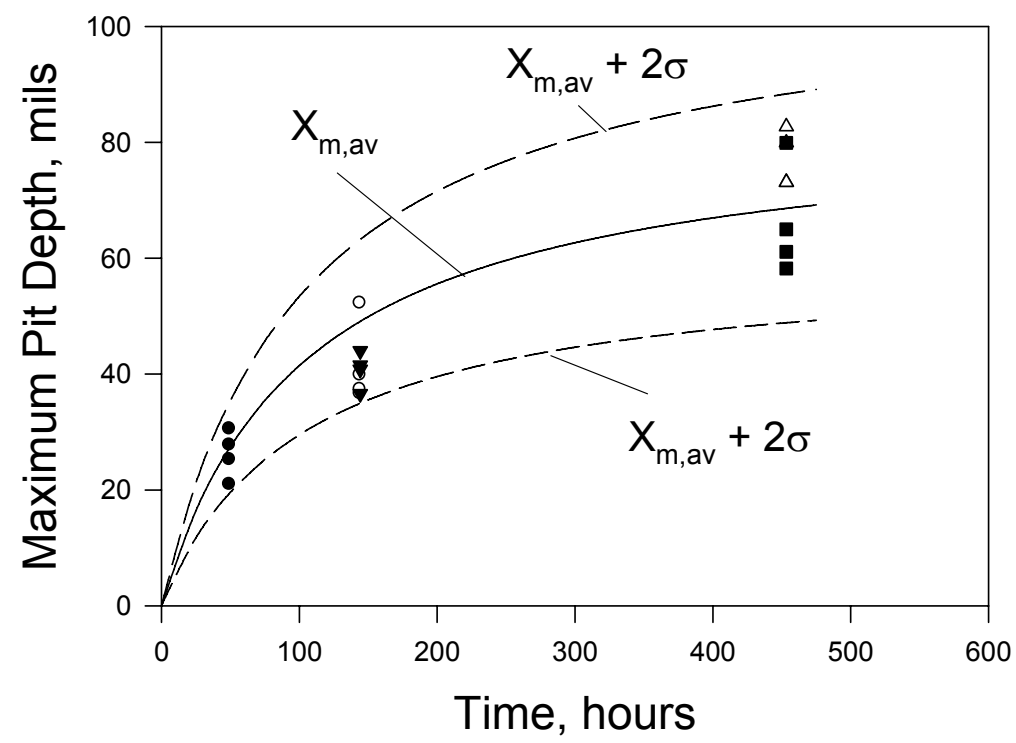

Figure 14. Extreme depths on 316L stainless steel

\section{Monte Carlo Simulation of Pit Propagation}

As described above, a general quantitative method for modeling the propagation of corrosion damage on the basis of damage function analysis (DFA) was developed by drawing an analogy between the growth of pits and movement of particles. The applicability of this method has been verified by comparing the predicted and measured corrosion damage (i.e., the depth of the deepest pit or cracks) for many practical systems. However, under real conditions, it can occur that only a few pits (cracks) or even a single pit (crack) can be alive (or propagate) on the corroding metal surface. In this case, the differential equations for the damage function, which are equivalent to a balance equation for particles in discontinuous media, lose their physical sense. Therefore, we decided to develop an alternative Monte Carlo simulation method for describing the propagation of 
corrosion damage. The main idea of this method is to keep track of each stable pit (crack) that can nucleate, propagate, and repassivate on the metal surface.

A great advantage of this method lies in the fact that this approach allows us to take into account the interactions between particular individual pits (cracks) in an explicit manner. By doing so, it becomes possible to reduce the number of unknown parameters that describe interaction between individual pits (cracks).

The main idea of the Monte Carlo method is to keep track of each stable pit (or crack) that nucleates, propagates and repassivates on the metal surface. Let us denote by $N_{0}$ the total number of stable pits that can nucleate on a metal surface having a total area of $S$. We enumerate these pits by the index $k=1,2, \ldots, N_{0}$ and we track each of these pits individually. Initially, we suggest that there are no stable pits on the metal surface. We proceed by calculating the probability that a pit will nucleate in a stable form during the time step $d t$ as

$$
P_{n u c l}=\frac{N(t+d t)-N(t)}{N_{0}-N(t)}
$$

where $N(t)$ is the number of stable pits that nucleate within the time interval between 0 and $t . P_{\text {nucl }}$ is defined as the ratio of the number of pits that nucleate in the time interval between $\mathrm{t}$ and $t+d t$ to the number of available sites at moment $t$.

For each pit, $k$, that has not yet been born, we generate a random number $0 \leq G_{k} \leq 1$. If $G_{k} \leq P_{n u c l}$, a pit is proclaimed to have been born with a depth of penetration $x=0$; otherwise, it is considered not to have been born and will be interrogated in the following step. In the case of instantaneous nucleation, all pits in the amount of $N_{0}$ are born during the first time step. In the more general, "progressive nucleation" case, the function $N(t)$ can be calculated by using, for example, the Point Defect Model (PDM). In accordance with this model, it can be shown that the total number of nucleated, stable pits can be described by the following expression [Engelhardt and Macdonald, 2004]

$$
N(t)=0 \text { at } t \leq \tau \quad \text { and } \quad N(t)=N_{0} \operatorname{erfc}\left(\frac{a}{t-\tau}+b\right) / \operatorname{erfc}(b) \quad \text { at } t>\tau
$$

Here, $\tau$ is the time of dissolution of the pit cap until rupture. Parameters $a$ and $b$ specifically depend on temperature, $\mathrm{pH}$, activity of halide ion, and the metal potential, but do not depend on the observation time. These dependencies can be found, for example, in [Engelhardt and Macdonald, 2004].

The Cartesian coordinates of the centers of the nucleated pits, $X_{k}$ and $Y_{k}$, are also established by using the random number generator, but this may be modified in the future to correspond to particular metallurgical, micro-structural, and micro-chemical features on the surface (e.g., emergent precipitates or second phase particles) that may not be randomly distributed (e.g., $\mathrm{Cr}_{23} \mathrm{C}_{7}$ precipitates on emergent grain boundaries in stainless steels). 
At each time step, the depth of the $j$-th stable, living pit, $a_{j}$, is calculated sequentially by using Faraday's law

$$
a_{j}(t+d t)=a_{j}(t)+K_{V} i_{j}(t) d t
$$

where $K_{V}$ is the electrochemical equivalent of the metal that transforms the corrosion current density at the pit internal surface into the rate of metal removal. We assume that $i_{j}$ is described by Tafel's law for the active metal dissolution current density as a function of potential, i.e.

$$
i_{j}=i_{0} \exp \left(-\frac{\alpha F \Delta \varphi_{j}}{R T}\right) \text { at } \Delta \varphi_{j}<\Delta \varphi_{c r} \text { and } i_{j}=0 \text { at } \Delta \varphi_{j} \geq \Delta \varphi_{c r}
$$

where $\Delta \varphi_{j}$ is the averaged potential drop on the active surface (relative to a point that is remote from the hemispherical pit of index $\mathrm{j}$ ), $\alpha$ is the transfer coefficient of the metal dissolution reaction, $i_{0}$ is the corrosion current density at the corrosion potential, $\mathrm{T}$ is the Kelvin temperature, $\mathrm{F}$ is Faraday's constant, and $\mathrm{R}$ is the gas constant. $\Delta \varphi_{c r}$ is the critical value of the potential drop at which the repassivation potential $E_{r p}=E_{c o r r}-\Delta \varphi_{c r}$ is reached inside the pit ( $E_{\text {corr }}$ is the corrosion potential of the metal).

It can be shown (see our previous report) that the average potential drop on the active surface of a hemispherical pit (relative to a point far away from it), $\Delta \varphi_{\mathrm{j}}$, can be estimated by the following relation

$$
\Delta \varphi_{j}=\frac{b a_{j} i_{j}}{\kappa}+\sum_{k \neq j} \frac{i_{k} a_{k}^{2}}{\kappa d_{k}}
$$

Here, the index $k$ denotes the pits on the surface (the pit of interest is denoted by the index $j), a_{k}$ is the radius of the hemispherical pit, $i_{k}$ is the average current density inside the pit, $\kappa$ is the conductivity, and $b \approx 2.14$ is a constant. The first term in Equation (138) describes the contribution of the central pit to the potential drop and the second term describes the contribution of all other pits on the corroding surface

Accordingly, $i_{j}$ is calculated by using Equation (137), where $\Delta \varphi_{\mathrm{j}}$ is determined by a numerical solution of the equation

$$
\Delta \varphi_{j}=\frac{b a_{j} i_{0}}{\kappa} \exp \left(-\frac{\alpha F \Delta \varphi_{j}}{R T}\right)+\sum_{k \neq j} \frac{i_{o} a_{k}^{2}}{\kappa} \exp \left(-\frac{\alpha F \Delta \varphi_{k}}{R T}\right)
$$

By solving this equation, we assume that all $\Delta \varphi_{k}$ in the second term on the right-hand side of Equation (139) are known and are equal to their previous (in the iteration sense) values.

After each time step, the repassivated (dead) pits are excluded from the population. A pit is considered dead if $\Delta \varphi_{j}>\Delta \varphi_{c r}$. In addition, if two pits touch each other, i.e. if 


$$
d_{i, j} \leq a_{i}+a_{j}
$$

where $d_{i, j}$ is the distance between the centers of the $i$-th and $j$-th pits, the smallest pit is declared repassivated (dead).

In addition, we consider the probability that pits can repassivate accidentally (by chance). It is assumed that the probability of pit repassivation during each time step is proportional to the magnitude of this step, i.e. $P_{\gamma}=\gamma d t$, where $\gamma$ is the delayed repassivation constant [Macdonald and Urquidi-Macdonald, 1992]. Practically, for the $j$-th living pit in each time step, we generate the random number $0 \leq G \leq 1$. If $G \leq P_{\gamma}$, the pit is declared to be dead (passivated) and is excluded from the further consideration, otherwise, the pit is considered to be alive on entering the next time step. We see that our Monte-Carlo simulation method describes all three stages the pit propagation damage - nucleation, propagation and repassivation of stable pits.

As an example of the application of this Monte Carlo simulation method within DFA, we consider the corrosion of aluminum alloy Alcan 2S-O in tap water [Aziz, 1956]. In this paper, for the purpose of numerically simulating the accumulation of pitting damage on the alloy surface, we will assume the values of various model parameters that are shown in the Table 1. The parameters for the $\operatorname{PDM}(\tau, a$, and $b)$ were chosen somewhat arbitrarily. The aim was only to ensure that, by the end of two weeks, practically all stable pits had nucleated, as indicated by the experimental data [Aziz, 1956]. The value of $K_{V}$ corresponds to that for aluminum and the value of $\kappa$ corresponds to that typically assumed for tap water. The value for the delayed repassivation constant, $\gamma$, was chosen to ensure that, by the end of two months, the bulk of the pits represented by the bell-shaped curve have ceased to grow [Aziz, 1956]. The value of $\alpha$ has been chosen as being typical for metal dissolution and only the value of $i_{0}$ has been fitted to the experimentally measured values of maximum pit depth at $t=1$ week after metal exposure [Aziz, 1956]. Finally, the sample is considered to be rectangular with the dimensions $7 \times 18 \mathrm{~cm}$ and $N_{0}$ $=450$. [Aziz, 1956].

Table 1. Parameter values for model calculations.

\begin{tabular}{|l|l|}
\hline $\mathrm{i}_{0}$ & $1.5 \times 10^{-2} \mathrm{~A} / \mathrm{cm}^{2}$ \\
\hline $\mathrm{K}_{\mathrm{V}}$ & $3.44 \times 10^{-5} \mathrm{~cm}^{3} / \mathrm{C}$ \\
\hline$\alpha$ & 1 \\
\hline$\kappa$ & $0.3 \times 10^{-3} \Omega^{-1} \mathrm{~cm}^{-1}$ \\
\hline$\Delta \varphi_{\mathrm{cr}}$ & $200 \mathrm{mV}$ \\
\hline $\mathrm{T}$ & $25^{0} \mathrm{C}$ \\
\hline$\tau$ & 3 days \\
\hline $\mathrm{a}$ & 3.65 days \\
\hline $\mathrm{b}$ & 1 \\
\hline$\gamma$ & 0.066 day $^{-1}$ \\
\hline
\end{tabular}

Figure 16 shows a comparison of results of the Monte Carlo simulation with experimental data. For a given observation time, $t$, we perform $M$ simulations as 
described above and, accordingly, receive $M$ values $x_{1}^{*}(t), x_{2}^{*}(t), \ldots, x_{M}^{*}(t)$ for the depth of the deepest pits. After that, we calculate the average (mean) value of the depth of the deepest pit as

$$
X_{a v}(t)=\frac{1}{M} \sum_{m=1}^{M} x_{m}^{*}(t)
$$

and the standard deviation as

$$
\sigma(t)=\sqrt{\frac{1}{M-1} \sum_{m=1}^{M}\left(X_{a v}(t)-x_{m}^{*}(t)\right)^{2}}
$$

For a sufficiently large value of $M(M \geq 40$, in our case), the results practically do not depend on the value of $M$. Because, usually, $95 \%$ of all experimental measurements lie in the interval $\left(X_{a v}-2 \sigma, X_{a v}+2 \sigma\right)$, we posit that excellent agreement is observed between the experimental and simulation results.

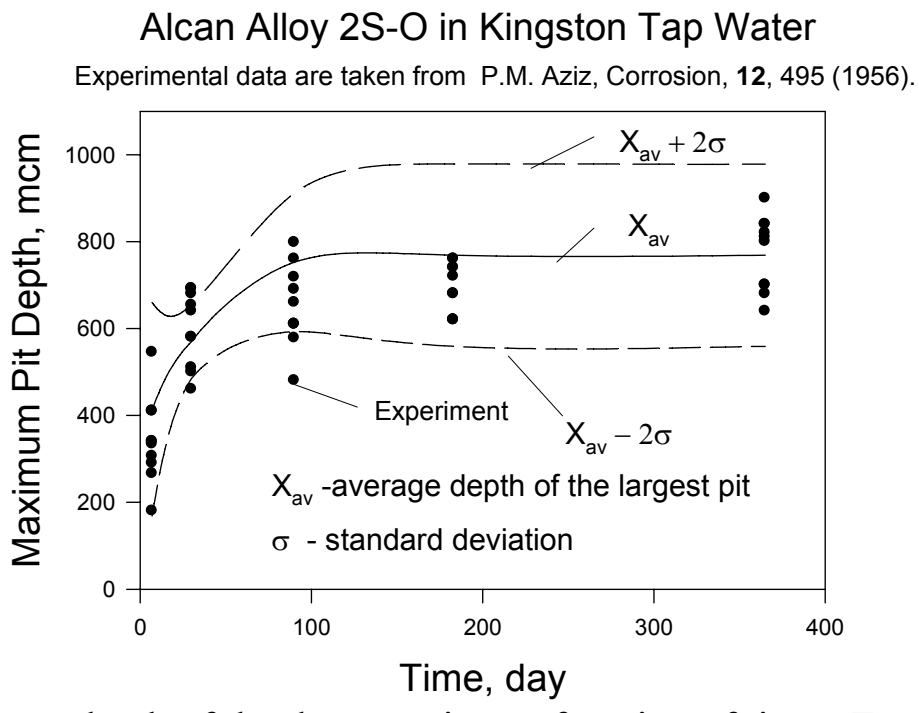

Figure 15 The mean depth of the deepest pit as a function of time. Experimental data are taken from Ref. [Aziz, 1956].

The main advantage of deterministic models over the statistically-based models lies in the fact that deterministic models allow us to make predictions for environmental conditions that lie beyond the available experimental data, because the predictions are analytic and based upon a sound physical model and because the prediction is constrained by the natural laws to that which is physically real. As an example, Figure 17 shows the influence of electrolyte conductivity on the mean depth of the deepest pits from multiple, identical sample areas on the surface as a function of time.

Finally, it is important to note that our current version of the Mont Carlo model describes only the propagation of pitting corrosion damage. In the future, we will include in our 
model the effects of the transition of pits into cracks, which will allow us to describe the accumulation of stress corrosion cracking and corrosion fatigue damage. In particular, we will include the interaction between multiple, but different propagating cracks [Kamaya and Totsuka, 2002].

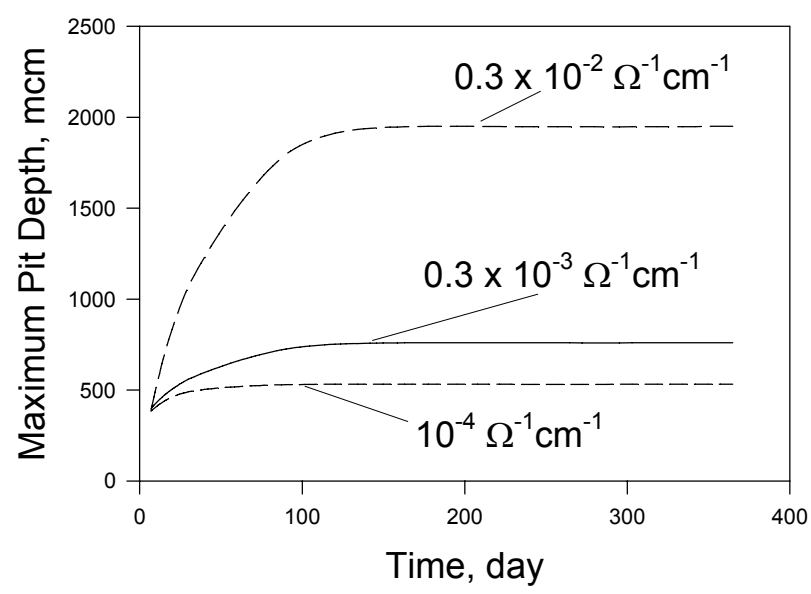

Figure 16. The mean depth of the deepest pit as a function of time for different conductivities of the electrolyte.

\section{Analytical method for estimating chloride concentrations inside the crevice}

It is well known that Monte Carlo simulation is very time consuming [i.e., this method requires numerous (thousands) repetitive calculations]. Accordingly, the acceleration of previously developed computer codes received primary emphasis. Particularly, we considered the accumulation of chloride or other aggressive anions inside the crevice due to the establishment of a differential aeration cell, where our aim was to develop a relatively simple method for predicting the chloride concentration and potential distribution inside an active crevice. This is because the current density inside the pits, $i_{\text {pit, }}$, (i.e. the rate of pitting corrosion) can be described in general terms by the equation:

$$
i_{p i t}=k_{A} C_{A^{-}}^{\lambda}
$$

where $C_{A^{-}}$is the concentration of the aggressive anions, $k_{a}$ is the rate constant for the reaction proceeding in the anodic direction (which depends on the potential and, in a general case, on $\mathrm{pH}$ ), and $\lambda$ is the effective kinetic order of the metal dissolution reaction with respect to the anion concentration. In many cases the value of $\lambda$ has a value of $0.5-$ 1, i.e this dependence can be significant [Freiman, 1985]. It is evident that the accumulation of aggressive anions in crevices is especially important in the cases of application of fabricated materials where corroding crevices in different junctions are very often observed. 
This problem has been considered on the basis of a simplified analytical method for estimating corrosion cavity propagation rates (Engelhardt et. al., 1997). It can be shown that the concentration of chloride ions can be estimated by assuming that chloride ions inside the crevice must compensate the increase of concentration of metal ions that takes place due to the passive corrosion inside the crevice (the concentration of all other species can be neglected to a good approximation under normal conditions).

Here, we report only the final results. It is convenient to characterize the amplifier properties of the crevice, $\mathrm{A}$, by the ratio [amplification factor $(\mathrm{AF})$ ] of the concentration of chloride at any position in the crevice $C_{C^{-}}(x)$ to the bulk concentration of chloride, $\mathrm{C}_{\mathrm{Cl}^{-}}^{0}$. It has been shown that

$$
A_{\mathrm{Cl}^{-}}(\mathrm{x})=\frac{\mathrm{C}_{\mathrm{Cl}^{-}}(x)}{\mathrm{C}_{\mathrm{Cl}}^{0}}=1+\frac{i_{p}\left(2 L x-x^{2}\right)}{F D_{1}(1+z) w C_{C l^{-}}^{0}}
$$

where, $\mathrm{i}_{\mathrm{p}}$ is the passive corrosion current density, $D_{l}$ and $z_{l}$ are the diffusion coefficient and the valence of corroding metal, respectively, $F$ is the Faraday number, and $x$ is the distance down the crevice. Here we assume that the crevice has the shape of a parallel slot with the depth $L$ and the width, $w$. It is important to note that the potential drop in the cavity can be found via the Boltzmann distribution as

$$
\varphi=\frac{R T}{F} \operatorname{Ln}\left(A_{C^{-}}\right)
$$

if the amplification factor is known.

It is also possible to characterize the amplifier properties of the crevice by the ratio of the average concentration of chloride inside the crevice, $\bar{C}_{\mathrm{Cl}^{-}}$to the bulk concentration of chloride. It can be shown that

$$
\bar{A}_{C l^{-}}=\frac{\bar{C}_{C l^{-}}}{C_{C l^{-}}^{0}}=\frac{i_{p} L^{2}}{3 F D_{1}(1+z) w C_{C l^{-}}^{0}}
$$

We see that the amplifier factor $\bar{A}_{C l^{\prime}}$ is proportional to the passive current density, $\mathrm{i}_{\mathrm{p}}$, square of the depth of the crevice, $L$, and is inverse proportional to the width of the crevice, $w$, and to the bulk concentration of chloride ion, $C_{\mathrm{Cl}^{-}}^{0}$.

We also investigate the case when the surface of the metal is covered by a thin electrolyte film with a thickness, $\mathrm{h}$, and the conductivity, $\kappa$. In this case the possible concentration and potential drops in the external environment outside the crevice must be taken into account. It has been shown that, in this case, 


$$
A_{C l^{-}}(x)=\left(\frac{i_{p} L^{2} F \alpha}{2 \kappa R T h}\right)^{1 / \alpha_{3}}+\frac{i_{p}\left(2 L x-x^{2}\right)}{F D_{1}(1+z) w C_{C l^{-}}^{0}}
$$

where $\alpha$ is the transport coefficient for oxygen reduction, $T$ is the temperature and $R$ is the gas constant.

It is evident that the first term in Equation (147) describes the influence of the external environment on the amplification factor, whereas the second term (describes the influence of the internal environment. It can be easily shown that

$$
\varepsilon=\frac{\left[A_{C l^{-}}\right]_{e x t}}{\left[\bar{A}_{C l^{-}}\right]_{\text {int } t}} \approx \frac{w}{h}
$$

We see that the relative error that is introduced by neglecting the influence of the external environment is described by the ratio of the width of the crevice to the thickness of electrolyte film and can be of the order of $100 \%$. In other words, the influence of the external environment must be taken into account, in the general case, if we would like to describe quantitatively the transport processes inside the crevice.

It is well known that the application of inhibitors can be a promising way for reducing corrosion damage in the system with fabricated materials. Accordingly, we developed a simplified (but rather accurate) analytical method for estimation times that required for an inhibitor to fill out the crevice.

For simplicity, we consider here the case of a narrow $(\mathrm{w}<<\mathrm{X}, \operatorname{tg} \beta \approx \beta)$ and sharp crevice (see Figure 17).

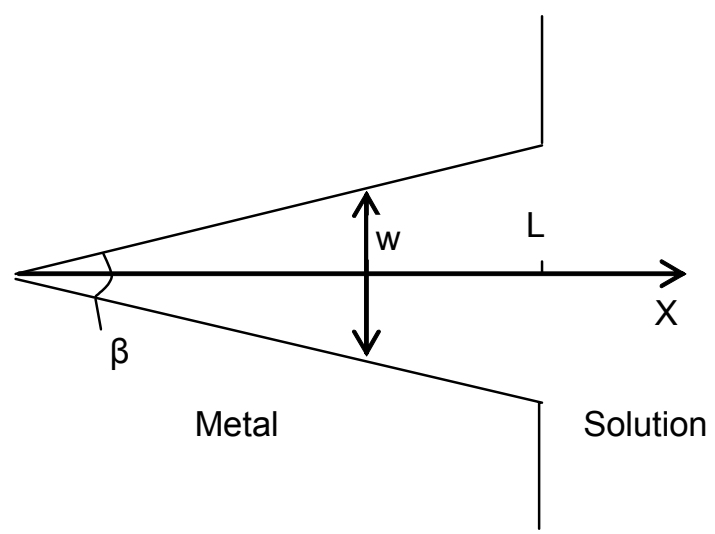

Figure 17. The scheme of the crevice.

The distribution of the inhibitor inside the crevice can be described by the following equation (Turnbull, 1985): 


$$
\frac{\partial C}{\partial t}=D\left(\frac{\partial^{2} C}{\partial X^{2}}+\frac{1}{X} \frac{\partial C}{\partial X}\right)+\frac{D}{X \beta} \frac{\partial C}{\partial n}
$$

where $C$ is the concentration of the inhibitor, $t$ is the time, $D$ is the diffusion coefficient. The derivative $\partial C / \partial n$ is taken along the direction normal to the crevice wall. The boundary and initial conditions have the evident form:

$$
\partial C / \partial X=0 \quad \text { at } \mathrm{X}=0 ; \quad C=C_{0} \quad \text { at } \mathrm{X}=\mathrm{L}
$$

where $C_{0}$ is the bulk concentration of the inhibitor, and

$$
C=0 \quad \text { at } \mathrm{t}=0
$$

Let us assume that the adsorption of the inhibitor is described by Henry's isotherm. It can be shown that in this case Equation (1) can be rewritten in the following form:

$$
\left(1+\frac{K}{X \beta}\right) \frac{\partial C}{\partial t}=D\left(\frac{\partial^{2} C}{\partial X^{2}}+\frac{1}{X} \frac{\partial C}{\partial X}\right)
$$

where $\mathrm{K}$ is the rate constant.

Let us consider two limiting two limiting cases:

The adsorption is a slow process $(\mathrm{K} \rightarrow 0)$. In this case the second term in the brackets on the left-hand side of Equation (152) can be omitted and the analytical solution of this equation yields the following expression for the flux of the inhibitor inside the crevice:

$$
Q(t)=2 \beta C_{0} \sum_{k}\left[1-\exp \left(-\lambda_{k}^{2} D t / L^{2}\right)\right] / \lambda_{k}^{2}
$$

Here $\lambda_{\mathrm{k}}$ is the root of the equation $\mathrm{J}_{0}\left(\lambda_{\mathrm{k}}\right)=0$, where $\mathrm{J}_{0}$ is the Bessel function. By using Equation (153) it is easy to show that for

$$
t_{0} \approx 0.46 L^{2} / D
$$

the average concentration of the inhibitor inside the crevice differs by less than $5 \%$ from the bulk concentration.

In the opposite case, when adsorption can be considered as a fast process $(\mathrm{K} \rightarrow \infty)$, the first term in the brackets on the left-hand side of Equation (4) can be omitted. By analogy with the first case it can be shown that the estimation

$$
t_{0} \approx 1.84(K L) /(D \beta)
$$


is valid for the case of the fast adsorption. The interpolation formula

$$
t_{0} \approx 0.46 L^{2} / D+1.84(K L) /(D \beta)
$$

describes satisfactorily the time that is required for the inhibitor to fill out the crevice for arbitrary values of $\mathrm{K}, \mathrm{L}$ and $\beta$.

\section{Example of application of DFA to pitting}

In the experimental section of this report, data are reported for the depth of several deepest pits measured on 316L SS pipe segments exposed to $\mathrm{NaCl} / \mathrm{FeCl}_{3} / \mathrm{FeCl}_{2}$ solution for different exposure times, $t$, at different temperatures. The data for $\mathrm{T}=40^{\circ} \mathrm{C}$ are shown in Figure 18.

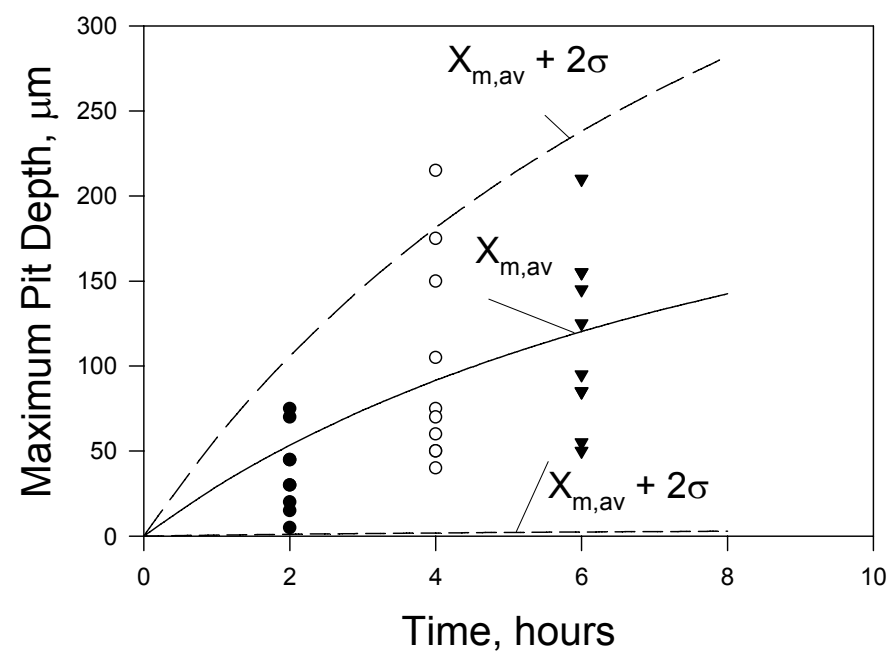

Figure 18. The mean depth of the deepest pit for $316 \mathrm{~L}$ SS pipe segments exposed to $\mathrm{NaCl} / \mathrm{FeCl}_{3} / \mathrm{FeCl}_{2}$ at $40{ }^{\circ} \mathrm{C}$.

We try to predict the results of the experiment for $t=6$ hours by using the data for 2 and 4 hours by using the $r$ largest order statistics as described above. We see that the result of the application of this method this method is satisfactory.

Let us try to use the obtained results for the prediction of the experiments at a different temperature, i.e., at $\mathrm{t}=20^{\circ} \mathrm{C}$. The corresponding experimental data are shown in Figure 19.

Considering that we do not know the temperature dependence of the kinetic parameters, we need data for a single moment of time from short-term experiments when we can neglect the repassivation of pits. By comparing results for $\mathrm{t}=2$ hours measured at different temperatures, we can conclude that $\mathrm{V}_{20} / \mathrm{V}_{40}=\beta_{20} / \beta_{40} \approx 1 / 3$ (see Equation 91). Then, assuming that repassivation constant depends slightly on temperature we can 
predict the results of measurements at $t=8$ hours. We can see that the results of the prediction are satisfactory in this case.

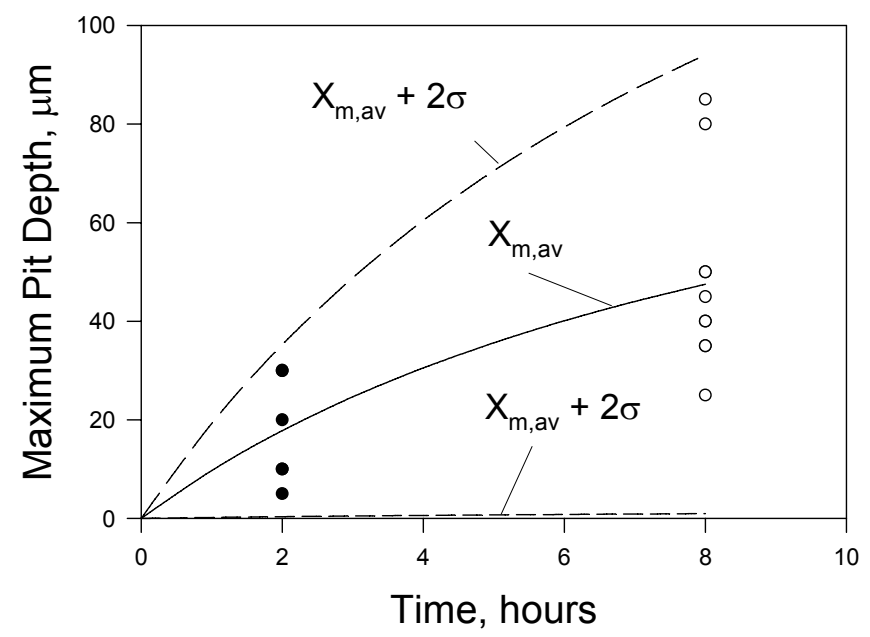

Figure 19. The mean depth of the deepest pit for welded 316L SS pipe segments exposed to $\mathrm{NaCl} / \mathrm{FeCl}_{3} / \mathrm{FeCl}_{2}$ at $20{ }^{\circ} \mathrm{C}$.

\section{Encapsulation of models in software}

The results of this research have been incorporated into OLI Systems' Corrosion Analyzer, a software tool that serves as the primary vehicle for the commercialization of this technology. This tool is already used by many companies in the chemical process industry. In process design, the Corrosion Analyzer provides the industry with (1) reliable prediction of the tendency of base alloys for localized corrosion as a function of environmental conditions and (2) understanding of how to select alloys for corrosive environments. In process operations, the software will help to predict the remaining useful life of equipment based on limited input data. Thus, users will also be able to identify process changes, corrosion inhibition strategies, and other control options before costly shutdowns, energy waste, and environmental releases occur. With the Corrosion Analyzer, various corrosion mitigation measures can be tested in a virtual laboratory. 


\section{Summary}

The experimental work performed at the Southwest Research Institute resulted in localized corrosion parameters that were used to further develop OLI System's electrochemical model. Fundamental studies of the electrochemical properties of advanced materials also led to important metallurgical and electrochemical findings and aided the understanding of the behavior of these materials under different conditions. The most important experimental findings are listed below.

Microstructural characterization of precipitated phases of 2205 was performed with STEM to gain an understanding into the effect of fabrication processes on the microstructure and microchemistry of the duplex stainless steels. Both ferrite-ferrite and ferrite-austenite boundary precipitates were found in case of 700 and $870^{\circ} \mathrm{C}$ thermal aging temperatures. At $700^{\circ} \mathrm{C}$, a eutectoid like transformation had occurred where the ferrite decomposed to sigma and secondary austenite phases. The composition of this secondary austenite was found to contain approximately half the chromium of the primary austenite, and caused the isothermally aged material to become susceptible to localized corrosion attack. At $870^{\circ} \mathrm{C}$, the precipitates were more globular and pervasive throughout the microstructure. Again, a Cr-rich precipitate phase was accompanied by a secondary austenite phase, whose composition was approximately ${ }^{2} / 3$ that of the primary austenite phase. This Cr-depleted phase made the specimen more susceptible to localized corrosive attack, but to a lesser extent than aging at $700^{\circ} \mathrm{C}$.

Corrosion potential measurements of 316L stainless steel, 2205 duplex stainless steel and alloy $\mathrm{C}-22$ showed that the presence of oxidizing species can affect the corrosion potential under acidic conditions. Long-term corrosion potential measurements and potentiodynamic tests of $\mathrm{Cu}-\mathrm{Ni}$ alloys in synthetic seawater in the presence of free chlorine showed indicated that higher than recommended (0.2-0.5 ppm) free chlorine concentrations can lead to more severe corrosion, while lower free chlorine concentrations may have a beneficial effect on their corrosion resistance. This effect is related to the effect of free chlorine on the anodic behavior of $\mathrm{Cu}-\mathrm{Ni}$ alloys, since their cathodic behavior was not affected by the presence of free chlorine in the tested concentration range ( $0-2 \mathrm{ppm})$.

Crevice repassivation tests of $\mathrm{Cu}-\mathrm{Ni}$ alloys in different environments, $\mathrm{E}_{\text {rcrev }}$ was determined as a function of several factors (i.e., $\mathrm{pH}, \mathrm{T}, \mathrm{c}_{\mathrm{Cl}^{-}}, \mathrm{c}_{\text {inhibitor }}$ ). Correlations between the crevice corrosion parameters and environmental conditions were established. Crevice repassivation tests utilizing a new test method, the THE test, provided correlations between $\mathrm{E}_{\text {rcrev }}$ and the torque as well as the charge density in case of highly corrosion resistant alloys (C-22, 825).

The effect of inhibitors on the crevice repassivation potential of several alloys, including 316L SS, 254SMO, 2205 duplex SS, alloy 600 and alloy 690, was measured at different chloride levels. A number of ions were identified as effective inhibitors of localized corrosion of these alloys depending on the environmental factors, e.g., temperature, chloride ion concentration, while others were found to act as aggressive ions accelerating 
the localized corrosion. These results were then used to develop parameters to be incorporated in the OLI corrosion software.

Metallurgical influences on $\mathrm{E}_{\text {rcrev }}$ for thermally aged alloys 600 and 690 were determined. Thermal aging of these alloys results in carbide precipitation at grain boundaries, and a susceptibility to intergranular corrosion is expected. A drop in measured $\mathrm{E}_{\text {rcrev }}$ was observed for initial aging times at $700^{\circ} \mathrm{C}$ for alloy 600 , followed by healing of $\mathrm{E}_{\text {rcrev }}$ within 24 hours of aging for all solutions tested. No metallurgical influences on $\mathrm{E}_{\text {rcrev }}$ for alloy 690 were determined due to the failure of chromium depleted regions in this alloy to drop below critical thresholds needed for sensitization in the solutions tested. EPR tests using a solution containing $0.05 \mathrm{M} \mathrm{H}_{2} \mathrm{SO}_{4}$ and $5 \times 10^{-5} \mathrm{M} \mathrm{KSCN}$ performed at room temperature were able to discern between various degrees of sensitization for alloy 600 , and tracked well with literature results for depletion volumes. Kinetics for evolution of susceptibility to intergranular attack (sensitization) apparent from both $\mathrm{E}_{\mathrm{rcrev}}$ and EPR tests did not correlate. It is believed the different corrosivity of the test solutions, as well as the different aims of each test, resulted in this discrepancy. While EPR is valuable in ranking materials with respect to IGA susceptibility, it is too aggressive to predict the lifetime expectancy of in-service real-world materials. $\mathrm{E}_{\text {rcrev }}$ was able to discern between different levels of sensitization, and has been shown previously to be a better predictor for lifetime expectancy. Localized corrosion susceptibility of 2205 duplex stainless steel was measured as a function of isothermal heat treatment using crevice repassivation potential tests in chloride solutions. It was found that at $700^{\circ} \mathrm{C}$ aging treatment, there was a non-recoverable drop of $\sim 450 \mathrm{mV}$ in $\mathrm{E}_{\text {rcrev }}$. A similar drop was noted at $870^{\circ} \mathrm{C}$, but this was partially recovered with prolonged isothermal aging.

Actual welds of C-276 alloy were tested to determine the effect of welding on the localized corrosion susceptibility. No significant difference between the base and welded materials were found in their $\mathrm{E}_{\mathrm{rcrev}}$ values. Literature review of the microstructural and microchemical changes revealed that no Cr segregation occurred after solidification, thus the matrix and TCP phases that formed during the solidification process had similar $\mathrm{Cr}$ contents.

Damage growth and distribution measurements were carried out to develop experimental parameters for damage function analysis. The ultimate goal of this part of the work was to predict the remaining lifetime of process equipment. Flat specimens made out of alloy 825 showed significant pit coalescence and preferential corrosion at the meniscus, therefore they did not indicate any trends of damage growth as a function of environmental variables. The use of cylindrical specimens eliminated both experimental artifacts and provided damage growths kinetics as a function of exposure time and temperature.

OLI Systems has developed a comprehensive model for predicting the occurrence of localized corrosion as a function of solution chemistry and temperature. This model relies on the computation of the corrosion potential and the repassivation potential. Localized corrosion may occur if the corrosion potential exceeds the repassivation potential in a given environment. It has been demonstrated that both models accurately account for the effects of environmental chemistry. In particular, the repassivation potential model has been shown to be accurate for mixtures containing both aggressive and inhibitive ions. 
The model considers competitive dissolution, adsorption, and oxide formation processes at the metal - salt film - solution interface. Using the database developed in this work and previously reported data, the parameters of the model have been established. The model quantitatively predicts the transition between concentrations at which localized corrosion is possible and those at which inhibition is expected. It is capable of predicting the repassivation potential over wide ranges of experimental conditions using parameters that can be generated from a limited number of experimental data. The parameters of the model have been generalized as a function of alloy composition, thus making it possible to predict the repassivation potential for alloys that have not been experimentally investigated.

Further, the repassivation potential model has been shown to work for heat-treated alloys and weldments as well as base alloys. This was made possible by the development of a methodology for calculating chromium a molybdenum depletion profiles and by the availability of the generalized correlation that makes it possible to predict $\mathrm{E}_{\mathrm{rp}}$ as a function of alloy composition.

An important part of the predictive methodology is the general corrosion model, which simultaneously predicts the corrosion potential and uniform corrosion rate. This model simulates electrochemical reactions at the metal-solution interface. The electrochemical model of general corrosion takes into account various partial reactions on the surface of the metal and transport processes for the species that participate in the reactions. The model includes passivation phenomena, which may be influenced by $\mathrm{pH}$ and the presence of aggressive or inhibitive species in the solution. Further, it combines the partial processes to compute corrosion rates in the framework of the mixed potential theory. The model has been extensively validated for various engineering alloys.

On the basis of the Damage Function Analysis, a method for extrapolating experimentally measured pitting corrosion damage to the future, within the realm of Extreme Value Statistics (EVS), has been developed. This method can be used under the conditions when not all, or even none, of the kinetic parameters that determine the pit nucleation rate, pit propagation rate, and pit repassivation rate, are known. The unknown parameters are determined by comparing results of analytical or numerical calculation of the Integral Damage Functions or Extreme Value Distribution Functions with the experimentally observed functions for short-term experiments. After determining the values of the unknown parameters, damage functions for long-term exposure are predicted. Combining DFA and the results of periodic inspections has significant advantages over a purely statistical approach. Thus, DFA allows us to express the fitting parameters for the extreme value distribution in terms of the values for physical parameters in the deterministic models contained within DFA (e.g. pit nucleation and propagation rates, repassivation constants, etc.) or in terms of parameter values determined from independent experiments. Accordingly, it is possible to find appropriate forms for the time dependencies of empirical coefficients for traditional, statistical analysis. Moreover, it becomes possible to predict the changes of the statistical fitting parameters contained within the extreme value distribution with variations in the external conditions (corrosion potential, temperature, bulk composition of the electrolyte), because the connections between the statistical and physical parameters have been 
established. Criteria for the influence of repassivation phenomena on the propagation of localized corrosion damage have been obtained.

This method for predicting pitting corrosion damage has been generalized for the cases of crevice corrosion, stress corrosion cracking and corrosion fatigue and also for the cases when different corrosion events (for example, pits and cracks) are simultaneously present in the system. The method also alloys us to explain the main experimental data for the transition of a pit to a crack on the basis of generally accepted mechanical conditions. We also generalized DFA method to the case of $r$ largest order statistics

As an alternative to the DFA method the deterministic Monte Carlo simulation method has been developed. The main idea of the Monte Carlo method is to keep track of each stable pit (or crack) that nucleates, propagates and repassivates on the metal surface. This method is based on the existing deterministic models describing nucleation, propagation, and repassivation of localized corrosion processes. It is possible to apply the Monte Carlo method to the case when only a few pits (or cracks), or even only a single pit (or crack), may be alive (i.e., propagating) on the corroding metal surface. A great advantage of this method lies in the fact that this approach allows us to take into account the interactions between particular individual pits (cracks) in an explicit manner. By doing so, it becomes possible to reduce the number of unknown parameters that describe the interaction between individual pits (cracks).

The methods have been implemented in the CorrosionAnalyzer, OLI's software product that encapsulates corrosion technology in a user-friendly form. A Windows interface has been designed for this purpose. With this interface, users will be able to input inspection data (primarily, depth of the deepest pit as a function of time) and obtain a prediction of the evolution of corrosion damage in the future.

\section{Awards}

1. Our recent paper:

A. Anderko, N. Sridhar, L.T. Yang, S.L. Grise, B.J. Saldanha and M.H. Dorsey, "Validation of a Localized Corrosion Model Using Real-Time Corrosion Monitoring in a Chemical Plant”, Corrosion Engineering, Science and Technology, 40 (2005) 3342.

has been selected for the $\mathbf{2 0 0 6}$ Bengough Award of the Institute of Materials, Minerals and Mining for a paper published by the Institute that makes an outstanding contribution to the subject of corrosion and degradation of all types of materials and their control

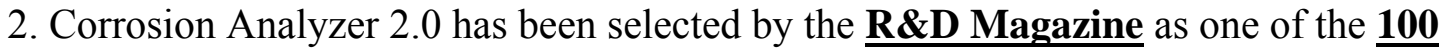
most technologically significant products introduced into the marketplace over the past year. The award ceremony will take place on October 18, 2007 in Chicago. 


\section{Publications and Presentations}

A. Anderko, N. Sridhar, L.T. Yang, S.L. Grise, B.J. Saldanha and M.H. Dorsey, "Validation of a Localized Corrosion Model Using Real-Time Corrosion Monitoring in a Chemical Plant”, Corrosion Engineering, Science and Technology, 40 (2005) 33-42

A. Anderko, "Thermodynamic and Electrochemical Models for Predicting General and Localized Corrosion", Advanced Modeling of Corrosion Damage Evolution, ONR Workshop, Airlie Center, Warrenton, VA, June 14-15, 2005.

A. Anderko, N. Sridhar and C.S. Brossia, "Prediction of Corrosion of Nickel-Base Alloys and Stainless Steels in Oxidizing Environments Using Thermodynamic and Electrochemical Models", paper no. 05053, CORROSION/2005, Houston, TX, 2005.

A. Anderko, N. Sridhar, G. Tormoen and C.S. Brossia, "Modeling Localized Corrosion in Complex Process Environments in the Presence of Inhibitors", paper no. 06215, CORROSION/2006, San Diego, CA, March 12-16, 2006.

G. Engelhardt, Biswas R., Zaki A., Lvov S., Macdonald D., "The use of channel flow cells for electrochemical kinetic studies in high temperature aqueous solutions", Corros. Sci., 52, pp. 4124-4131, (2007).

G. Engelhardt and D.D. Macdonald, "Deterministic Prediction of Corrosion Damage in Power Plant Heat Transfer Circuits Along Realistic Corrosion Evolutionary Paths," NIST Mini-Symposium on Corrosion, Gaithersburg, MD, April 27, 2005

G. Engelhardt, and D.D. Macdonald, "The Use of Channel Flow Cells for Electrochemical Kinetic Studies in High Temperature Aqueous Solutions", presented at the Electrochemical Society 2006 Joint International Meeting, 10/29/06 - 11/03/06, Cancun, Mexico.

G. R. Engelhardt, D.D. Macdonald, L. G. McMillion, "Deterministic Monte Carlo Simulation of Localized Corrosion Damage," Invited Paper, Corrosion Modeling Workshop sponsored by Office of Naval Research Global Under the Auspices of University of Milan, Cernobbio, Lake Como, Italy, 29-31 July 2006.

M.A. Jakab, N. Sridhar and A. Anderko, "Localized Corrosion Susceptibility of Cu-Ni Alloys in Chloride Containing Environments", paper no. 07243, CORROSION/2007, Nashville, TN, March 11-15, 2007

D.D. Macdonald, and G. Engelhardt, "Challenges in Predicting the Accumulation of Localized Corrosion Damage-A Review of Critical Issues", Egyptian Corrosion Soc., 23rd Conf. Corrosion Problems in Industry, Ras Sedr, Egypt, Dec. 6-9, 2004.

D.D. Macdonald, B. Marx and G. Engelhardt, "Passivity and Passivity Breakdown on Iron and Steel," NIST Mini-Symposium on Corrosion, Gaithersburg, MD, April 27, 2005 
D.D. Macdonald, and G. Engelhardt, Unification of the Deterministic and Statistical Approaches for Predicting Localized Corrosion Damage in Aircraft Aluminum Alloys, 9th Joint FAA/DoD/NASA Conference on Aging Aircraft, March 6-9, 2006, Atlanta, GA.

D. D. Macdonald, S. Colominas, J.N. Tokash, J. McLafferty, J. Nollinger, and G. Engelhardt, "Electrochemical Hydrogen Storage Systems," Argonne National Laboratory, Argonne, IL, Sept. 10-12, 2007. (Invited).

D.D. Macdonald, G. R. Engelhardt, L. G. McMillion, "Determinism in the Prediction of Corrosion Damage," Corrosion Modeling Workshop sponsored by Office of Naval Research Global Under the Auspices of University of Milan, Cernobbio, Lake Como, Italy, 29-31 July 2006, (Invited).

L.G. McMillion, D.D. Macdonald, and G. Engelhardt, "Highly Accurate Electrochemical Data for Corrosion Modeling and Damage Prediction," Corrosion Modeling Workshop sponsored by Office of Naval Research Global Under the Auspices of University of Milan, Cernobbio, Lake Como, Italy, 29-31 July 2006 (invited).

C.S. Brossia, A. Anderko and N. Sridhar, "Predicting the Long-Term Localized Corrosion of Alloys in Complex Industrial Environments", paper no. 172, EUROCORR 2004, Nice, France.

N. Sridhar, C.S. Brossia, G. Tormoen and A. Anderko, "Life Prediction of Systems Subject to Localized Corrosion from a Limited Experimental Data Set", Research in Progress Symposium, CORROSION/2005, Houston, TX, 2005.

N. Sridhar, "Continuum and Mesoscale Modeling of Localized Corrosion - Status and Future", Advanced Modeling of Corrosion Damage Evolution, ONR Workshop, Airlie Center, Warrenton, VA, June 14-15, 2005.

Y. Zhang, D. D. Macdonald, M. Urquidi-Macdonald, G. R. Engelhardt, R. B. Dooley, "Prediction for Pitting Corrosion of AISI Type 403 Stainless steel in ChlorideContaining, Borate Buffer Solution," EPRI $8^{\text {th }}$ Intl. Conf. on Cycle Chemistry in Fossil and Combined Cycle Plants with Heat Recovery Steam Generators, Calgary, Alberta, Canada, June 20-23, 2006. 


\section{References}

Airey, G. P. (1979). Corrosion 35(3): 129-136.

Airey, G. P. and F. W. Pement (1983). Corrosion 39(2): 46-55.

Airey, G. P., A. R. Vaia, et al. (1981). Journal of Metals: 28-34.

Akashi M. and Kawamoto T. Boshoku Gijutsu (Corrosion Engineering), 32, 9 (1983).

Ali, A. J. (1994). Corrosion Science 36(4): 773-783.

Ali, A. J. and J. R. Ambrose (1992). Corrosion Science 33(7): 1147-1159.

Amadou, T., C. Braham, et al. (2004). Metallurgical and Materials Transactions 35A: 3499-3513.

Anderko, A. and R.D. Young, Corrosion, 56 (2000) 543

Anderko, A., P. McKenzie and R.D. Young, Corrosion, 57 (2001) 202

Anderko, A., N. Sridhar, D.S. Dunn, Corrosion Sci., 46 (2004) 1583.

Anderko, A., N. Sridhar, C.S. Brossia, D.S. Dunn, paper no. 04061, CORROSION/2004, NACE International, New Orleans, LA (2004)

Anderko, A., N. Sridhar, C.S. Brossia, paper no. 05053, CORROSION/2005, NACE International, Houston, TX (2005).

Anderko, A., N. Sridhar, L.T. Yang, S.L. Grise, B.J. Saldanha, M.H. Dorsey, Corrosion Eng. Sci. Tech., 40 (2005) 33.

ASTM (2003). D1141-98 "Standard Practice for the Preparation of Substitute Ocean Water", ASTM International.

ASTM (2004). G108-94(2004) $)^{\varepsilon 1}$ "Standard Test Method for Electrochemical Reactivation (EPR) for Detecting Sensitization of AISI Type 304 and 304L Stainless Steels", ASTM International.

Aziz P. M ., Corrosion, 12, 495 (1956).

Badji, R., M. Bouabdallah, et al. (2007). Materials Characterization article in press.

Bailey, G. L. (1951). Journal of Institue of Metals 79(5): 243-291.

Bandy, R. and R. Van Rooyen (1984). Corrosion 40(6): 281-289.

Beccaria, A. M., G. Poggi, et al. (1991). Corrosion Science 32(11): 1263-1275.

Beccaria, A. M., G. Poggi, et al. (1994). Werkstoffe und Korrosion 45: 562-569. 
Bernard, F., V. Shankar Rao, et al. (2005). Journal of the Electrochemical Society 152(10): B415B420.

Bianchi, G., G. Fiori, et al. (1978). Corrosion 34(11): 396-406.

Brossia, C.S., G.A. Cragnolino, Corrosion, 56 (2000) 505.

Brossia, C. S., N. Sridhar, et al. (2004). Predicting the Long-Term Localized Corrosion of Alloys in Complex Environments. Eurocorr 2004. Nice, France, NACE.

Brown, M. H. (1969). Corrosion 25(10): 438-443.

Calliari, I., M. Zanesco, et al. (2006). Journal of Materials Science 41: 7643-7649.

Casales, M., V. M. Salinas-Brave, et al. (2002). Materials Science and Engineering A 332: 223230.

Chen G.S., Wan K.-C., Gao M., Wei R. P., and Flournoy T. N., Mat. Sci. Eng., A219, 126 (1996).

Chen, T. H., K. L. Weng, et al. (2002). Materials Science and Engineering A338: 259-270.

Chen, T. H. and J. R. Yang (2001). Materials Science and Engineering A311: 28-41.

Chen, T. H. and J. R. Yang (2002). Materials Science and Engineering A338: 166-181.

Cieslak, M. J., T. J. Haeadley, et al. (1986). Metallurgical Transactions 17A: 2035-2047.

Cieslak, M.J., G.A. Knorovsky, T.J. Headley and A.D. Romig, Jr., Metall. Trans. A, 17 A (1986) 2107

Congleton J., Shoji T., Parkins R. N., Corros. Sci., 26, 163 (1985).

Cragnolino, G.A. in Advances in Localized Corrosion, Proceedings of the Second Conference on Localized Corrosion, H.S. Isaacs (ed.) Orlando, FL (1987).

Devine, T. M. (1979). Journal of the Electrochemical Society 126(3): 374-385.

Devine, T. M. (1980). Metallurgical Transactions 11A: 791-800.

Devine, T. M. (1988). Acta Metallurgica 36(6): 1491-1501.

Doig, P. and P.E. Flewitt P.E., Proc. R. Soc. Lond., A357A, 439-452 (1977).

Doig, P. and Flewitt P.E., Metal. Trans, 9A, 357-362 (1978).

Doig, P. and Flewitt P.E., Metal. Trans., 12A, 923-931 (1981).

Doig, P. and Flewitt P.E, in Corrosion in Power Generating Equipment, Ed. By M.O. Speidel and A. Atrens, Plenum Press, New York, 1984, p. 139. 
Doig, P. and Flewitt P.E., in Embrittlement by the Localizes Crack Environment, Ed. By R.P. Ganglof, The Metallurgical Society of AIME, Warredale, PA, 1984, P.305.

Duffaut, F., J.-P. Pouzet, et al. (1966). Corrosion Science 6: 83-85.

Dunn, D.S., N. Sridhar, and G.A. Cragnolino, Corrosion, 52 (1996) 115.

Dunn, D.S., G.A. Cragnolino, N. Sridhar, Corrosion, 56 (2000) 90-104.

Dunn, D.S., L. Yang, Y.M. Pan, G.A. Cragnolino, CORROSION/2003, paper 3697, NACE International (2003).

Dunn, D. S., D. Darwalla, et al. (2003). Effect of Fabrication Processes in Materials Stability Characterization and Corrosion, Center for Nuclear Waste Regulatory Analyses, SwRI, San Antonio, TX.

Dunn, D.S., Y.-M. Pan, L. Yang, G.A. Cragnolino, Corrosion 61 (2005) 1078.

Dunn, D.S., O. Pensado, Y.-M. Pan, R.T. Pabalan, L. Yang, X. He, K.T. Chiang, "Passive and Localized Corrosion of Alloy 22 - Modeling and Experiments", Report CNWRA 2005-02, Southwest Research Institute, 2005.

Duthil, J. P., G. Mankowski, et al. (1996). "The Synergetic Effect of Chloride and Sulphate on Pitting Corrosion of Copper." Corrosion Science 38(10): 1839-1849.

Efird, K. D. (1975). "Potential-pH Diagrams for 90-10 and 70-30 Cu-Ni in Seawater." Corrosion 31(3): 77-83.

Efird, K. D. (1977). "The Synergistic Effect of Ni and Fe on the Sea Water Corrosion of Copper Alloys." Corrosion 33(10): 347-350.

Efird, K. D. and J. Verink, E. D. (1977). "The Crevice Protection Potential for 90-10 Copper Nickel." Corrosion 33(9): 328-331.

El Koussy, M. R., I. S. El Mahallawi, et al. (2004). Materials Science and Technology 20: 375381.

Elmer, J. W., T. A. Palmer, et al. (2007). Materials Science and Engineering A311: 28-41.

Engelhardt G, and Macdonald D. D., Corrosion, 54, 469 (1998).

Engelhardt G, and Macdonald D. D., Corr Sci., 46, 2735 (2004),

Engelhardt G, and Macdonald D. D., Corr Sci., 46, 1159 (2004),

Engelhardt G., Macdonald D. D., and Urquidi-Macdonald M., Corros. Sci., 41, 2267 (1999).

Engelhardt G., Urquidi-Macdonald M Macdonald D. D., and Urquidi-Macdonald M., Corros. Sci., 39, 419 (1997).

Fang, Z., Y. S. Wu, et al. (1998). Corrosion 54(5): 339-346. 
Ford, F.P., D.F. Taylor, P.L. Andresen and R.G. Ballinger, Report NP-5064M, Electric Power Research Institute, Palo Alto, CA (1987).

Freiman L.I . Progress in Science and Technology. Corrosion and Corrosion Protection [in Russian], 11, VINITI, p. 3, (1985).

Galvele, J., Proc. $4^{\text {th }}$ Int. Symp. Passivity, Airlie, West Virginia, p. 285.

Galvele, J., "Electrochemical Aspects of Stress Corrosion Cracking" in: Modern Aspects of Electrochemistry', Ed.: R. E. White, Plenum Press, New York, 27, 1995, pp 233-358.

Gouda, V. K., A. A. Khedr, et al. (2000). Bulletin of Electrochemistry 16(7): 289-295.

Gumbel E. J., Statistics of Extremes, Columbia University Press, NY, (1957).

Hall, E.L., C.L. Briant, Metallurg. Trans. A. 1984, 15A, 793-811

Hall, E. L. and C. L. Briant (1985). Metallurgical and Materials Transactions 16A: 1225-1235.

Harb J.N. and Alkire R. C., J.Elecrochem. Soc., 138, 2594 (1991).

Hayes, J.R., J.J. Gray, A.W. Szmodis, C.A. Orme, Corrosion 62 (2006) 491.

Herbsleb, G. and P. Schwaab (1991). Precipitation of Intermetallic Compounds, Nitrides and Carbides in AF 22 Duplex Steel and Their Influence on Corrosion Behavior in Acids. Duplex Stainless Steels '91, American Society for Metals: Metals Park, OH.

Hettiarachchi, S. and T. P. Hoar (1979). Corrosion Science 19: 1059-1067.

Hibner, E.L. Materials Performance, 26 (3) (1987) 37.

Hoffmeister, H. and G. Lothongkum (1994). Welding in the World 33(2): 91-96.

Isaacs, H.S., U. Bertocci, J. Kruger and Z. Smialowska (eds.), Advances in Localized Corrosion, NACE-9, Houston, TX: NACE International, 1990

Ismail, K. M., A. M. Fathi, et al. (2006). Corrosion Science 48(8): 1912-1925.

Jallerat, F., L. Pari, F. Bourelier, K. Quang, Proc. $9^{\text {th }}$ Intern. Congress on Metallic Corrosion, National Research Council, Ottawa, Canada, 1984.

Jargelius-Pettersson, R.F.A., Corrosion Sci. 41 (1999) 1639.

Jones, D. (1996). Principles and Prevention of Corrosion, Prentice Hall.

Jones, R.H. Simonen E.P. Mater. Sci. Eng, A160, 127-136 (1993).

Josefsson, B., J.-O. Nilsson, et al. (1991). Phase Transformation in Duplex Steels and the Relation Between Continuous Cooling and Isothermal Heat Treatment. Duplex Stainless Steels. Bourgogne, France. 
Kacar, R. and M. Acarer (2003). Materials Science and Engineering A338: 259-270.

Kamaya M. and Totsuka N., Corros. Sci., 44, 2333 (2002).

Kato, C., B. G. Ateya, et al. (1980). Journal of the Electrochemical Society 127(9): 1890-1896.

Kato, C., J. E. Castle, et al. (1980). Journal of the Electrochemical Society 127(9): 1897-1903.

Kay, J. J., G. P. Yu, et al. (1989). Metallurgical Transactions A 20A(10): 2057-2067.

Kehler, B.A., G.O. Ilevbare, J.R. Scully, Corrosion 57 (2001) 1042.

Kim, J.-S. and H.-S. Kwon (1999). Corrosion 55(5): 512-521.

Knot J., J. Strain Anal, 10, 201 (1975).

Kordatos, J. D., G. Fourlaris, et al. (2001). Scripta Materiala 44: 401-408.

Korn A. and M. Korn M., “Mathematical Handbook”, McGraw-Hill, NY, (1968).

Kowaka M., "Introduction to Life Prediction of Industrial Plant Materials", Allerton Press, New York, 1994.

Kruger, R. M., G. S. Was, et al. (1988). Acta Metallurgica 36(12): 3163-3176.

LaQue, F. L. and J. F. Mason (1950). Proceedings of American Petroleum Industry 30M(3): 103113.

Laycock P.A., Cottis R.A., and Scarf P.A. J.Electrochem. Soc., 137, 64 (1990).

Lee, R. N., M. K. Norr, et al. (1991). Corrosion 47(8): 645-652.

Levey, P.R., A. van Bennekom, Corrosion 51 (1995) 911.

Lillard, R.S., M.P. Jurinski, J.R. Scully, Corrosion 50 (1994) 251.

Lin L.F., Chao C. Y., and Macdonald D. D., J. Electrochem. Soc., 128, 1194 (1981).

Liou, H.-Y., R.-I. Hsieh, et al. (2002). Corrosion Science 44: 2841-2856.

Lo, I.-H. and W.-T. Tsai (2007). Corrosion Science 49: 1847-1861.

MacDonald, D. D., B. C. Syrett, et al. (1978). Corrosion 34(9): 289-301.

Macdonald D. D. and M. Urquidi-Macdonald M., Electrochim. Acta, 31, 1079 (1986).

Macdonald D. D., Corrosion, 50, 761 (1985).

Macdonald D, Corr. Sci., 38, 1003-1010 (1996).

Macdonald D. D. and Urquidi-Macdonald, J. Electrochem. Soc., 134, 41 (1987). 
Macdonald D. D. and Urquidi-Macdonald M, J. Electrochem. Soc., 136, 961 (1989).

Macdonald D. D. and Urquidi-Macdonald M, J. Electrochem. Soc., 139, 3434 (1992).

McCafferty, E., J. Electrochem. Soc. 137 (1990) 3731.

Mankowski, G., J. P. Duthil, et al. (1997). Corrosion Science 39(1): 27-42.

Marsh G. P, Bland I.D. and Tailor K. J., Br. Corr. J., 23, 157 (1988).

McCloskey T. H, Dooley R. B., and McNaughton W. P., "Turbine Steam Path Damage: Theory and Practice, Vols 1 and 2", Electric Power Research Institute, Palo Alto, CA, 1999.

McGuire, G. E., A. L. Bacarella, et al. (1978). Journal of the Electrochemical Society 125(11): 1801-1804.

McIlree, A. R. and H. T. Michels (1977). Corrosion 33: 60-67.

Merino, P., X. R. Novoa, et al. (1993). Materials Science and Technology 9: 168-171.

Metikos-Hukovic, M. and I. Milosev (1992). Journal of Applied Electrochemistry 22: 448-455.

Michalska, J. and M. Sozanska (2006). Materials Characterization 56: 355-362.

Mignone, A., A. Borello, et al. (1982). Corrosion 38(7): 390-402.

Milosev, I. and M. Metikos-Hukovic (1991). Journal of the Electrochemical Society 138(1): 6167.

Milosev, I. and M. Metikos-Hukovic (1992). Corrosion 48(3): 185-193.

Milosev, I., M. Metikos-Hukovic, et al. (1992). Journal of the Electrochemical Society 139(9): 2409-2418.

Natishan, P.M., R.G. Kelly, G.S. Frankel and R.C. Newman (eds.), Critical Factors in Localized Corrosion, Pennington, NJ: The Electrochemical Society, 95-15, 1996

P.M. Natishan, H.S. Isaacs, M. Janik-Czachor, V.A. Macagno, P. Marcus and M. Seo (eds.), Passivity and Its Breakdown, Pennington, NJ: The Electrochemical Society, 97-26, 1998

Newman, R.C., Corrosion Sci. 25 (1985) 331; ibid., 25 (1985) 341.

Newman, R.C., T. Shahrabi, Corrosion Sci. 27 (1987) 827.

Nilsson, J.-O. and P. Liu (1991). Materials Science and Technology 7: 853-862.

North, R. F. and M. J. Pryor (1970). Corrosion Science 10: 297-311.

Nuclear Regulatory Commission (NRC) 1979/1980, Docket Nos. 50-3380L and 50-3390L.

Palmer, T. A., J. W. Elmer, et al. (2004). Materials Science and Engineering A 374: 307-321. 
Pan, Y.-M., D.S. Dunn, G.A. Cragnolino, N.S. Sridhar, Metall. Trans. 31A (2000) 1163

Park, C. J., V. S. Rao, et al. (2005). Corrosion 61(1): 76-83.

Parvizi, M. S., A. Aladjem, et al. (1988). International Materials Reviews 33(4): 169-200.

Pierpoline R., White J., Wong C., Cornell L and Griffin R. 'The depth distribution og pits in 316L stainless steel in ferric chloride', In H. Isaacs and U. Bertocci (eds), Advances in Localized Corrosion, NACE-9, 1987, pp.109-116.

Pilay, B. and Newman J., J. Electrochem. Soc., 140, 414 (1993).

Pistorius P. S. and G.T. Burstein G. T., Phil. Trans. R. Soc. Lond. A, 341, 531 (1992).

Pitzer, K.S., Thermodynamics, $3^{\text {rd }}$ edition, McGraw-Hill: New York, NY, 1995.

Postlethwaite, J., Electrochim. Acta 12 (1967) 333.

Press W., Teukolsky S., Vetterling W., and Flannery B., "Numerical Recipes in FORTRAN 77. The Art of Scientific Computing". Cambridge University Press. 1999.

M. Rafal, J. W. Berthold, N. C. Scrivner, S. L. Grise, Models for electrolyte solutions, in S. I. Sandler, ed., Models for Thermodynamic and Phase Equilibria Calculations, p. 601-670 (New York, NY: M. Dekker, 1995).

Ravindranath, K. and S. N. Malhotra (1994). Corrosion 50(4): 318-328.

Scarberry, R. C., S. C. Pearman, et al. (1976). Corrosion 32(10): 401-406.

Sahlaoui, H., K. Makhlouf, H. Sidhom, J. Philibert, Mat.Sci. Eng. A 372 (2004) 98-108

Scarf P.A., Appl. Stoch. Models Data Anal., 35, 135 (1993).

Schleich, W. (2005). Application of Copper-Nickel Alloy UNS C70600 for Seawater Service, paper No. 05222. CORROSION/2005, NACE.

Seo, M., B. Macdougall, H. Takahashi, and R.G. Kelly (eds.), Passivity and Its Breakdown, Pennington, NJ: The Electrochemical Society, 99-27, 1999

Sieurin, H. and R. Sandstrom (2006). Materials Science and Engineering A 418: 250-256.

Sieurin, H. and R. Sandstrom (2007). Materials Science and Engineering A 444: 271-276.

Sharland, S.M. Corrosion Sci. 27, 289 (1987).

Singh, V. B. and A. Gupta (2001). Journal of Materials Science 36: 1433-1442.

Sridhar, N. (1990). Effect of Alloying Elements on Localized Corrosion Resistance of NickelBase Alloys. Advances in Localized Corrosion H.-S. Isaacs, U. Bertocci, J. Kruger and S. Smialowska. Houston, TX, NACE. 
Sridhar, N. and G. A. Cragnolino (1993). Corrosion 49(11): 885-894.

Sridhar, N. in Advances in Localized Corrosion, H.S. Isaacs, U. Bertocci, J. Kruger, and S.

Smialowska (editors), Houston, TX: NACE International, p.263, (1990)

Sridhar, N., C.S. Brossia, D.S. Dunn, A. Anderko, Corrosion, 60 (2004) 915.

Sridhar, N., G.A. Cragnolino, Corrosion 49 (1993) 885.

Smith R. L., J. Hydrol., 86, 27 (1986).

Staehle, R.W., B.F. Brown, J. Kruger, A. Agarwal (eds.), U.R. Evans Conference on Localized Corrosion, NACE-3, Houston, TX: NACE International, 1974

Stawström, C. and M. Hillert, J. Iron Steel Inst., January 1969, 77-85.

Strehblow, H.H., B. Titze, Corrosion Sci. 17 (1977) 461.

Strutt J. E., Nicholls J. R. and Barbier B., Corros. Sci., 25, 305 (1985).

Syrett, B. C. (1981). Corrosion Science 21(3): 187-209.

Syrett, B. C. and S. S. Wing (1980). Corrosion 36(2): 73-85.

Szklarska-Smialowska Z., Pitting Corrosion of Metals, NACE-International, Houston, 1986.

Tekin, A., J.W. Martin, B.A. Senior, J. Materials Sci. 1991, 26:2458-2466

Theus, G. J. (1977). Corrosion 33(1): 20-26.

Thomas, J. G. N. and A. K. Tiller (1972). British Corrosion Journal 7(11): 256-262.

Thomas, J. G. N. and A. K. Tiller (1972). British Corrosion Journal 7(11): 263-267.

Turnbull, A. Meter. Sci. Technol, 1, ,700 (1985).

Turnbull A., Br. Corros. J., 28, 297 (1993).

Turnbull A, Zhou S., Hinds G., Corros. Sci., 46, 193 (2004).

Vajo J. et al. Corr. Sci., 45, 497, (2003).

Valilappan, M., M. Natesan, et al. (1990). Bulletin of Electrochemistry 6(2): 213-214.

Verink, J., E. D. and M. Pourbaix (1971). Corrosion 27(12): 495-505.

Was, G. S. (1990). Corrosion 46(4): 319-330.

Was, G. S. and R. M. Kruger (1985). Acta Metallurgica 33(5): 841-854. 
Was, G. S., H. H. Tischner, R.M. Latanision (1981). Metallurgical and Materials Transactions A 12A: $1397-1408$.

Weisman I., J. Amer. Statist. Assoc, 73, 812 (1978)

Weeks, J. R. (1974). Corrosion of Steam Generator Tubing in Operating Pressurized Water Reactors. Corrosion Problems in Energy Conversion and Generation. J. C. S. Tedmon. Princeton, NJ, The Electrochemical Society.

Wilson, I. L. W. and R. G. Aspden (1976). Corrosion 32: 193-201.

Woods, R. J. K., S. P. Hutton, et al. (1990). Corrosion Science 30(12): 1177-1201.

Yang, S., D.D. Macdonald, Electrochim. Acta 52 (2007) 1871.

Yashiro, H., K. Tanno, S. Koshiyama, K. Akashi, Corrosion, 52 (1996) 109.

Yukitoshi, T., K. Yoshikawa, et al. (1979). Unpublished Research. Was et al, Metallurgical and Materials Transactions A, 12A, p. 1397-1408, 1981, Sumitomo Metal Industries Ltd. .

Zaky, A. M. and F. H. Assaf (2002). British Corrosion Journal 37(1): 48-55.

Zemaitis, J.F. Jr. ACS Symp. Series 1980, 133, 227-246.

Zhou S., Turnbull A, Corros. Eng., 38, 97 (2003). 